Frontier Tibet 


\section{Asian Borderlands}

Asian Borderlands presents the latest research on borderlands in Asia as well as on the borderlands of Asia - the regions linking Asia with Africa, Europe and Oceania. Its approach is broad: it covers the entire range of the social sciences and humanities. The series explores the social, cultural, geographic, economic and historical dimensions of border-making by states, local communities and flows of goods, people and ideas. It considers territorial borderlands at various scales (national as well as supra- and sub-national) and in various forms (land borders, maritime borders), but also presents research on social borderlands resulting from border-making that may not be territorially fixed, for example linguistic or diasporic communities.

\section{Series Editors}

Tina Harris, University of Amsterdam

Willem van Schendel, University of Amsterdam

\section{Editorial Board Members}

Franck Billé, University of Cambridge

Duncan McDuie-Ra, University of New South Wales

Eric Tagliacozzo, Cornell University

Yuk Wah Chan, City University Hong Kong 


\section{Frontier Tibet}

Patterns of Change in the Sino-Tibetan Borderlands

Edited by

Stéphane Gros 
Cover illustration: Pelpung Monastery

Photograph by Rémi Chaix, 2004

Cover design: Coördesign, Leiden

Lay-out: Crius Group, Hulshout

$\begin{array}{ll}\text { ISBN } & 9789463728713 \\ \text { e-ISBN } & 9789048544905 \text { (pdf) } \\ \text { DOI } & 10.5117 / 9789463728713 \\ \text { NUR } & 740\end{array}$

\section{(c) (1) $\Theta \Theta$}

Creative Commons License CC BY NC ND (http://creativecommons.org/licenses/by-nc-nd/3.o)

(c) All authors / Amsterdam University Press B.V., Amsterdam 2019

Some rights reserved. Without limiting the rights under copyright reserved above, any part of this book may be reproduced, stored in or introduced into a retrieval system, or transmitted, in any form or by any means (electronic, mechanical, photocopying, recording or otherwise). 


\section{Table of Contents}

Foreword and Acknowledgements

Stéphane Gros

Chronology of Major Events

Stéphane Gros

\section{Part I Borders inside out}

Introduction

1 Frontier (of) Experience

Introduction and Prolegomenon

Stéphane Gros

2 The Increasing Visibility of the Tibetan 'Borderlands'

Katia Buffetrille

3 Boundaries of the Borderlands

Mapping Gyelthang

Eric D. Mortensen

\section{Part II Modes of Expansion and Forms of Control}

Introduction

4 Trade, Territory, and Missionary Connections in the SinoTibetan Borderlands

John Bray

5 Settling Authority

Sichuanese Farmers in Early Twentieth-Century Eastern Tibet Scott Relyea 
6 Wheat Dreams

Scientific Interventions at Chinese Model Farms in Kham, 1937-1949

Mark E. Frank

7 The Origins of Disempowered Development in the Tibetan

Borderlands

C. Patterson Giersch

8 Pastoralists by Choice

281

Adaptations in Contemporary Pastoralism in Eastern Kham

Gillian G. Tan

\section{Part III Strategic Belongings}

Introduction

9 Money, Politics, and Local Identity

An Inside Look at the 'Diary' of a Twentieth-Century Khampa Trader Lucia Galli

10 The Dispute between Sichuan and Xikang over the Tibetan Kingdom of Trokyap (1930s-1940s)

Fabienne Jagou

11 The Rise of a Political Strongman in Dergé in the Early

Twentieth Century

The Story of Jagö Topden

Yudru Tsomu

12 Harnessing the Power of the Khampa Elites

Political Persuasion and the Consolidation of Communist Party Rule in Gyelthang

Dáša Pejchar Mortensen

13 Return of the Good King

Kingship and Identity among Yushu Tibetans since 1951

Maria Turek 
14 Yachen as Process

Encampments, Nuns, and Spatial Politics in Post-Mao Kham Yasmin Cho

Afterword

Chinese Settler Colonialism: Empire and Life in the Tibetan

Borderlands

Carole McGranahan

Index

541

List of Maps, Figures and Tables

Maps

$\begin{array}{lll}\text { Map } 1 \text { General map of the study area } & 18\end{array}$

Map 1.1 Situating Kham 43

Map 1.2 'Inner Tibet' and the limits of Central Tibet Government according to McMahon's line (Simla Convention) $\quad 49$

Map 1.3 The borders of Xikang province as defined in 1933 and $1939 \quad 50$

Map 1.4 The Great Shangri-La Eco-Tourism Zone 66

Map 3.1 Gyelthang (Xianggelila) and its surrondings 120

Map 4.1 The principal M.E.P. mission stations in the SinoTibetan borderlands, c. $1900 \quad 156$

Map 5.1 Map showing 1727 stele and the main trade road through Kham. Inset: Location of Kham within the Qing Empire

182

Map 5.2 Full extent of Zhao Erfeng's bureaucratization and location of main farming settlements, with indication of Tibetan and Chinese claims at Simla Convention (1913-1914) 200

Map 6.1 Map of Xikang territory showing the locations of the Simaqiao and Taining experimental stations 233

Map 10.1 Localization of the Kingdom of Trokyap, c. $1940 \quad 345$

Map 11.1 Dergé at the time of Jagö Topden 369 
Figures

Figure 1.1 The Continuum of Boundary Dynamics, from Parker (2006)

61

Figure 1.2 A detail of Qiu Zhijie's 'Map of the World' series

49

Figure 1.3 The Möbius strip: from frontier zone to topological space $\quad 71$

Figure 2.1 Lung Ngön monastery: Jarung Kashor stûpa (Bodnath) 97

$\begin{array}{lll}\text { Figure 2.2 Kawakarpo range } & 102\end{array}$

Figure 2.3 Gesar statue, Machen (Golok Tibetan Autonomous Prefecture)

102

Figure 4.1 Chinese coolies carrying tea to Dartsedo $\quad 156$

$\begin{array}{lll}\text { Figure 4.2 Tibetan Inn in Dartsedo } & 167\end{array}$

$\begin{array}{lll}\text { Figure 4.3 Bathang, early twentieth century } & 171\end{array}$

Figure 6.1 B.A.I. staff member (name unknown) standing in front of an entrance to the headquarters of the Xikang Provincial Taining Pastures in 1939 238

Figure 13.1 The last ruling Nangchen king, Trashi Tséwang (Topgyel) Dorjé (1910-1961)

457

Figure 13.2 Sketch map of Nangchen based on a narrative land record composed by one of the gyelpo 472

Figure 14.1 The nuns' residential sector in Yachen in $2010 \quad 491$

Figure 14.2 The hut construction next door to Drölma's hut 496

Figure 14.3 The maze-like pathways in the nuns' residential sector $\quad 500$

Figure 14.4 The nuns' residential sector in Yachen in $2016 \quad 508$

Figure 14.5 The complex of prefabricated metal quarters 509

\section{Tables}

Table 8.1 Overview of selected government policies in Kham, 1990s-present 286

Table 8.2 Detail of pastoral movements $\quad 291$ 


\section{Foreword and Acknowledgements}

This book stems from a research project funded by the European Research Council (Starting Grant 283870) entitled 'Territories, Communities and Exchanges in the Kham Sino-Tibetan Borderlands'. The project called for an understanding of the Sino-Tibetan borderlands in their historical, geographical, and multi-ethnic complexities, and in a relational sense of boundaries of identity re-construction between neighbouring Tibetans and Chinese. The two worlds (Tibetan and Chinese) have mingled to some extent, while the cultural and ethnic divide have been maintained, and the process has involved at different levels many diverse local communities who may at varying degrees have recognized themselves - or not - in either of these two large categories of identity. In exploring the extent to which the region of eastern Tibet called Kham can be said to be 'Sino-Tibetan', we thought it worthwhile to highlight its connected features, its relational nature as a nexus of power. This volume aims to explore the intertwined questions of place-making, identity, and socio-political transformations that constitute Kham's convoluted historical trajectory and influenced its becoming as a regional formation.

A first outcome of the research project was the edited volume entitled 'Worlds in the Making: Interethnicity and the Processes of Generating Difference in Southwest China' (Gros, ed. 2014). It set out to compare a variety of visions and conceptualizations of people and places located at the crossroads between the conventional cultural areas of Southwest China, Southeast Asia, and Tibet and we addressed, among other topics, issues of Otherness and identity building. Contributors thereby sought to go beyond the pervasive dichotomy that often leads to a depiction of encounters in terms of acculturation, absorption by the other, or resistance to the other. While at different historical moments particular categories of identity have certainly been mobilized and the boundaries between them hardened, the volume explores various ways in which identity results from evolving relations and transactions.

A second edited volume, 'Frontier Tibet: Trade and Boundaries of Authority' (Gros, ed. 2016), derived from the realization that within the field of Sino-Tibetan frontier studies, there was still little in-depth scholarly discussion about commerce, trade, and the people who facilitated these activities. Examining such activities was also of primary importance for the period of transition between the Qing dynasty (1644-1911) and the Republic of China (1912-1949), when eastern Tibet became an exemplary case of 
frontier expansion and state building, a process during which this region underwent state-led political integration. The present volume builds on these earlier efforts and achievements, and takes as its challenge what C. Patterson Giersch (2016) called for in his Afterword: 'using local Kham history to push the boundaries of global borderlands studies'. We do so with contributions from both historians and anthropologists.

A growing literature now offers a healthy critique of traditional historiographies of China's frontier zones by approaching them as liminal or interstitial areas where economic and cultural exchanges take place along processes of ethnic formation. These are not marginal places; borderlands have their own logics and integrity - not only in relation to a centre as an expression of a spatial dichotomy but also in relation to particular histories. Scholarship has been increasingly challenging centrist views and their peripheralizing gaze to uncover the borderlands's own centrality. Such studies have prompted a reconsideration of the centre-periphery paradigm as a historical construct.

Particularly relevant to the time-frame of this volume is the substantial revision of the history of the Qing Empire in China and Inner Asia that falls under the heading 'new Qing history' (e.g. Waley-Cohen 2004) which, by reconsidering the Manchu's contribution and relationship to Chinese culture, challenges the received wisdom of the Sino-centric model of Confucian cultural unity (Crossley 1999, Dunnell and Millward 2004, Di Cosmo and Wyatt 2003, Elliot 2001, Perdue 2005, Rawski 1996). This body of literature has productively enacted the necessary dialogue between history and anthropology with greater attention to the intricacies of the local and effective use of the notion of ethnicity. Influential volumes have also combined historical and anthropological perspectives and have highlighted (dis)continuities in the political and cultural processes of articulating territorial integration and multicultural rule (e.g. Brown 1996, Faure and Ho 2013, Harrell 1995, Lary 2007, Rossabi 2004).

Comparable approaches have informed more nuanced views of Tibetan diversity across the plateau, challenging a unitary history of the Tibetan people. Several authors have shown how premodern Tibet developed its own Buddhist civilizing mission at the frontier of the state (Samuel 1993, Goldstein 1998, Huber 2011, Tuttle 2011), and that the Tibetan world is also characterized by internal diversity and the related dynamics of ethnicity (Kolås and Thowsend 2005, Shneiderman 2006, Klieger 2006). Some approach 'borders as liminal spaces' that are intrinsically ambivalent and unstable (Tenzin 2014, xiv), or focus on barely visible 'interstitial populations' (Roche 2014) in the context of porous and labile ethnic, linguistic, and territorial 
boundaries (see Gros 2014). Increasingly, and across the disciplinary divide of Sinology and Tibetology, our understanding of the Sino-Tibetan borderlands in their diversity and connections with larger dynamics, is being reshaped.

Some of the first studies about Kham were for some time dominated by an interest in the history of religious institutions and charismatic figures (Smith 1968, 1969, 1970). As many have pointed out with due reason, religious history is of primary importance for understanding Kham's history in its cultural, political, and economic dimensions. The religious diversity and the contemporary forms of religious revival are essential local dynamics in Kham (see Germano 1998). Following in the footsteps of Elliot Sperling's (1976) seminal article on Zhao Erfeng's (Chao Er-feng) role in late Qing China's colonial expansion, many historians have examined the policies aimed at taking control of this increasingly contested space, focusing on particular locales and time periods of the late nineteenth and early twentieth centuries. Along the same lines, Western language publications have focused on questions such as: imperial expansion and Sichuan leaders' shifting strategies of colonization (Coleman 2014; Dai 2009; Ho 2008; Relyea 2015a, 2015b, 2016, 2017; Wang 2011); Sino-Tibetan relations during the Guomindang rule and the provincialization of the frontier (Jagou 2001, 2006; Lawson 2013; Leibold 2005; Lin 2006; Rodriguez 2011; Tuttle 2005); or development of self-rule and resistance in Kham (Angdrugtsang 1973; Norbu 1986; Peng 2002; McGranahan 2006, 2007). This Foreword cannot do justice to all contributions that would fall within 'Kham studies': this expanding literature is discussed in the introductory chapter and by each author according to their thematic focus.

Since the 1990s, under the leadership of Tibetan researchers in China and in exile, several series of publications on the history and cultural traditions of Kham have appeared, most notably the important set of publications from the project initiated by Tashi Tsering of the Amnyen Machen Institute. Contributions in both Tibetan and Chinese languages regarding Kham's history, culture, and contemporary economic development are now extremely numerous in China where there is a growing interest in local histories, from individual monasteries or former chieftains to specific regions. Two edited volumes of the proceedings of the International Association of Tibetan Studies have laid the ground for the development of studies of eastern Tibet and Kham in particular (Epstein 2002, van Spengen and Jabb 2009), and many have been published in China (e.g. Ze Po and Ge Lei 2004, Luobu and Zhao 2008, among others) where emphasis is often laid on the period of transition from empire to nation (see Shi 2011). In the Chinese academic context 'Kham(pa) studies' (Ch. Kang(ba) xue) has emerged as a 
new disciplinary field. Its development can hardly be totally neutral and calls for attention to its ethico-political implications.

One key development in recent studies of Kham or other locales of the Sino-Tibetan borderlands is the emphasis on a history from below and increased attention to alternative histories that are not to be found in official records (see Hayes 2014, Holmes-Tagchungdarpa 2014, Kang and Sutton 2016, Tsomu 2015, Ptáčková and Zenz 2017). This volume contributes to this new trend, while also acknowledging the continuous relevance of an in-depth analysis and a critique of processes of expansion that progressively led to the integration of 'Tibet' into the People's Republic of China. For this reason, there is still a strong Chinese studies component in this book and its title can also be understood as a provocation. For it is clear that if this edge of the Tibetan plateau remains a frontier from a Sino-centric perspective, many of the chapters attest to the different ways some places have kept their own centrality in the eyes of their inhabitants, albeit with new parameters. These are part of the patterns of change explored in these pages.

The reader no doubt understands that this book does not attempt to sum up our knowledge of Kham and this particular part of the Sino-Tibetan borderlands. Contributors were invited to reflect, through their own historical or ethnographic material, on the relevance of Kham for borderland studies and no theoretical framework was imposed. There still are, of course, many gaps to be filled. Needless to say, none of us speaks on behalf of the Khampa. In fact, Kham is used as a heuristic to explore collective and individual trajectories at crucial historical conjunctures and to demonstrate that Kham is highly relevant for the study of Asian borderlands and our understanding of 'Tibet' in its relationship to 'China', both understood as contingent entities with shifting territorial imprints. This book calls for a regional approach across the divide between history and anthropology, while not taking for granted the character of the region. Indeed, the challenge is to write a regional history that speaks to the complexity of the lived experiences of place, territory, sovereignty, and agency.

As with all projects, especially when they are collaborative in nature, many debts have been accumulated over the years. First of all, my deep gratitude goes to Yudru Tsomu for the meaningful discussions and exchanges we had during the preparation of this manuscript, and for the comments she offered on the other chapters including my introduction. Most contributions to this volume were presented during the international conference 'Territories, Communities, and Exchanges in the Sino-Tibetan Borderlands' that took place on 18-20 February 2016, at the Cité Universitaire Internationale de Paris. My thanks go to Rémi Chaix, Lara Maconi, and Kunsang 
Namgyal-Lama who helped co-organize the event. In the run-up to this conference and the present volume, there was the pleasure of exchanging ideas with David Atwill, Chen Bo, Paddy Booz, Keila Diehl, Dawa Drolma, Isabelle Henrion-Dourcy, Hue-Tam Ho Tai, Tenzin Jinba, Tom Mullaney, Peter Perdue, Benno Weiner, Kären Wigen, Wen-hsin Yeh, Zhang Yuan, and Tang Yun, to name a few.

I wish to express my gratitude to all contributors for staying on board this publishing project, for their patience and intellectual involvement. Sincere thanks go to Remi Chaix for the wonderful maps that are included in this volume, and to Bernadette Sellers for her language editing of several of the chapters including mine. The final phase of the preparation for this volume took place during my time at the University of California, Berkeley, where the Institute for South Asia Studies welcomed me as a visiting scholar in the framework of their recent Himalayan Studies Initiative; I am very grateful to Alexander von Rospatt, Lawrence Cohen, Munis Faruqui, and Puneeta Kala for the opportunity and the space it provided me to bring this project to completion. My stay was made possible thanks to support from the InSHS-CNRS in the framework of its programme 'soutien à la mobilité internationale'. While at Berkeley, exchanges with Khashayar Beigi, Franck Billé, Kamala Russell, and William F. Stafford Jr were particularly stimulating and helped me shape my introductory chapter.

Last but not least, my heartfelt thanks go to all members of the Centre for Himalayan Studies at CNRS for their support and friendship.

\section{Stéphane Gros}

Berkeley, 12 September 2018

\section{References}

Andrugtsang Gonpo Tashi. 1973. Four Rivers, Six Ranges: A True Account of Khampa Resistance to Chinese in Tibet. Dharamsala: Information Office of His Holiness the Dalai Lama.

Brown, Melissa J., ed. 1996. Negotiating Ethnicities in China and Taiwan. Berkeley: University of California Press.

Coleman, William M., IV. 2014. Making the State on the Sino-Tibetan Frontier: Chinese Expansion and Local Power in Batang, 1842-1939. Unpublished PhD dissertation, Columbia University.

Crossley Pamela K. 1999. A Translucent Mirror: History and Identity in Qing Imperial Ideology. Berkeley: University of California Press. 
Dai, Yingcong. 2009. The Sichuan Frontier and Tibet: Imperial Strategy in the Early Qing. Seattle: University of Washington Press.

Di Cosmo N. and D. J. Wyatt, eds. 2003. Political Frontiers, Ethnic Boundaries, and Human Geographies in Chinese History. London: RoutledgeCurzon.

Dunnell, Ruth W. and James A. Millward. 2004. 'Introduction'. In New Qing Imperial History: The Making of the Inner Asian Empire at Qing Chengde, edited by James A. Millward, Ruth W. Dunnell, Mark C. Elliot, and Philippe Forêt, 1-12. London: RoutledgeCurzon.

Elliot, Mark C. 2001. The Manchu Way: The Eight Banners and Ethnic Identity in Late Imperial China. Stanford, CA: Stanford University Press.

Faure, David, and Ho Ts'ui-p'ing, eds. 2013. Chieftains into Ancestors: Imperial Expansion and Indigenous Society in Southwest China. Vancouver: University of British Columbia Press.

Germano, David. 1998. 'Re-membering the Dismembered Body of Tibet: Contemporary Tibetan Visionary Movements in the People's Republic of China'. In Buddhism in Contemporary Tibet: Religious Revival and Cultural Identity, edited by Melvyn Goldstein and Matthew Kapstein, 53-94. Berkeley: University of California Press.

Giersch, C. Patterson. 2016. 'Afterword: Why Kham? Why Borderlands? Coordinating New Research Programs for Asia'. Cross-Currents: East Asian History and Culture Review 19 (E-journal); print journal 5 (2): 440-452.

Gros, Stéphane. 2014. 'Devenirs identitaires dans les confins sino-tibétains: contextes et transformations'. Cahiers d'Extrême-Asie 24: 63-102.

Gros, Stéphane, ed. 2014. 'Worlds in the Making: Interethnicity and the Processes of Generating Difference in Southwest China'. Special issue, Cahiers d'Extrême-Asie 24.

Gros, Stéphane, ed. 2016. 'Frontier Tibet: Trade and Boundaries of Authority in Kham'. Special issue, Cross-Currents: East Asian History and Culture Review 19 (E-journal); print journal 5 (2).

Goldstein, Melvyn C. 1998. 'Introduction'. In Buddhism and Contemporary Tibet: Religious Revival and Cultural Identity, edited by Melvyn Goldstein and Matthew Kapstein, 1-14. Berkeley: University of California Press.

Harrell, Stevan, ed. 1995. Cultural Encounters on China's Ethnic Frontiers. Seattle: University of Washington Press.

Hayes, Jack Patrick. 2014. A Change in Worlds on the Sino-Tibetan Borderlands: Politics, Economies, and Environments in Northern Sichuan. Lanham, MD: Lexington.

Ho, Dahpon David. 2008. 'The Men Who Would Not Be Amban and the One Who Would: Four Frontline Officials and Qing Tibet Policy, 1905-1911'. Modern China $34(2): 210-246$. 
Holmes-Tagchungdarpa, Amy. 2014. The Social Life of Tibetan Biography: Textuality, Community, and Authority in the Lineage of Tokden Shakya Shri. Lanham, MD: Lexington.

Huber, Toni. 2011. 'Pushing South: Tibetan Economic and Political Activities in the Far Eastern Himalaya, ca. 1900-1950'. In Buddhist Himalaya: Studies in Religion, History and Culture, Proceedings of the Golden Jubilee Conference of the Namgyal Institute of Tibetology, 2008, vol. 1, edited by Alex McKay and A. Balicki-Denjongpa, 259-276. Gangtok: Namgyal Institute of Tibetology.

Jagou Fabienne, 2001. 'Le contrôle des marches sino-tibétaines à l'époque de la Chine républicaine'. Géographie et cultures 34: 5-24.

Jagou, Fabienne. 2006. 'Vers une nouvelle définition de la frontière sino-tibétaine: la Conférence de Simla (1913-1914) et le projet de création de la province de Xikang'. Extrême-Orient, Extrême-Occident 28:147-167.

Kang, Xiaofei and Donald Sutton. 2016. Contesting the Yellow Dragon: Ethnicity, Religion, and the State in the Sino-Tibetan Borderland. Leiden: Brill.

Klieger, P. Christiaan, ed. 20o6. Tibetan Borderlands. Leiden: Brill.

Kolås, Åshild and Monika P. Thowsend. 2005. On the Margins of Tibet: Cultural Survival on the Sino-Tibetan Frontier. Seattle: University of Washington Press.

Lary, Diana. 2007. 'Introduction'. In The Chinese State at the Borders, edited by Diana Lary, 1-10. Vancouver: University of British Columbia Press.

Lawson, Joseph D. 2013. 'Warlord Colonialism: State Fragmentation and Chinese Rule in Kham, 1911-1949'. The Journal of Asian Studies 72 (2): 299-318.

Leibold, James. 2005. 'Un-mapping Republican China's Tibetan Frontier: Politics, Militarism and Ethnicity along the Kham/Xikang Border'. The Chinese Historical Review 12 (2): 191-227.

Lin, Hsiao-ting. 2006. Tibet and Nationalist China's Frontier: Intrigues and Ethnopolitics, 1928-49. Vancouver: University of British Columbia Press.

Luobu Jiangcun and Zhao Xinyu, eds. 2008. Kang-Zang yanjiu xin silu:wenhua, lishiyu jingjifazhan (New Directions in Tibeto-Kham Studies: Culture, History, and Economic Development). Beijing: Minzu chubanshe.

McGranahan, Carole. 2006. 'Tibet's Cold War. The CIA and the Chushi Gangdrug Resistance, 1956-1974'. Journal of Cold War Studies 8 (3): 102-130.

McGranahan, Carole. 2007. 'Empire Out of Bonds: Tibet in the Era of Decolonization'. In Imperial Formations, edited by Ann Laura Stoler, Carole McGranahan, and Peter C. Perdue, 173-209. Santa Fe, NM: School for Advanced Research Press. Norbu, Jamyang. 1986. Warriors of Tibet: the Story of Aten and the Khambas Fight for the Freedom of Their Country. London: Wisdom Publications.

Peng, Wenbin. 2002. 'Frontier Process, Provincial Politics and Movements for Khampa Autonomy During the Republican Period'. In Khams pa Histories: Visions of People, Place, and Authority, edited by L. Epstein, 57-84. Leiden: Brill. 
Perdue, Peter C. 2005. China Marches West: The Qing Conquest of Central Eurasia. Cambridge, Mass.: The Belknap Press of Harvard University Press.

Ptáčková, Jarmila and Adrian, Zenz, eds. 2017. 'Mapping Amdo: Dynamics of Change'. Special Issue, Archiv Orientální:Journal of African and Asian Studies, supplementa $\mathrm{x}$.

Rawski, Evelyn. 1996. 'Presidential Address: Reenvisioning the Qing: The Significance of the Qing Period in Chinese History'. The Journal of Asian Studies 55 (4): $829-850$.

Relyea, Scott. 2015a. 'Conceiving the 'West': Early Twentieth-Century Visions of Kham'. Modern China 4 (3): 181-200.

Relyea, Scott. 2015b. 'Yokes of Gold and Threads of Silk: Sino-Tibetan Competition for Authority in Early Twentieth-Century Kham'. Modern Asian Studies 49 (4): 963-1009.

Relyea, Scott. 2016. 'Victorianizing Guangxu: Arresting Flows, Minting Coins, and Establishing Authority in Early Twentieth Century Kham'. Cross-Currents: East Asian History and Culture Review 19 (E-journal); print journal 5 (2): 350-377.

Relyea, Scott. 2017. 'Indigenizing International Law in Early Twentieth-Century China: Territorial Sovereignty in the Sino-Tibetan Borderland'. Late Imperial China $_{3} 8$ (2): 1-6o.

Roche, Gerald. 2014. 'Flows and Frontiers: Landscape and Cultural Dynamics on the Northeast Tibetan Plateau'. The Asia Pacific Journal of Anthropology 15 (1): 1-25.

Rodriguez, Andres. 2011. 'Building the Nation, Serving the Frontier: Mobilizing and Reconstructing China's Borderlands during the War of Resistance (1937-1945)'. Modern Asian Studies 45 (2): 350-351.

Rossabi, Morris, ed. 2004. Governing China's Multiethnic Frontiers. Seattle: University of Washington Press.

Samuel, Geoffrey. 1993. Civilized Shamans: Buddhism in Tibetan Societies. Washington: Smithsonian Institution Press.

Shi Shuo. 2011. 'Jin jinian dalu xuezhe dui Kangqu de yanjiu ji jueshi' (New Directions in the Study of Kham Among Mainland Researchers in the Last Decade). Xinnan Minzu Daxue Xuebao 12: 1-6.

Shneiderman, Sara. 2006. 'Barbarians at the Border and Civilising Projects: Analaysing Ethnic and National Identities in the Tibetan Context'. In Tibetan Borderlands, edited by P. Christiaan Klieger, 9-34. Leiden: Brill.

Smith, E. Gene. 1968. 'Introduction'. In The Autobiography and Diaries of Si-tu Pan-chen, 1-23. New Delhi, Lokesh Chandra IAIC.

Smith, E. Gene. 1969. 'Preface'. In The Autobiographical Reminiscences of NgagdBang-dPal-bZang, Late Abbot of Kah-Thog Monastery, edited by Sonam T. Kazi, 1-20. Gangtok: Sonam T. Kazi. 
Smith, E. Gene. 1970. 'Introduction'. In Kongtrul's Encyclopaedia of Indo-Tibetan Culture, Parts 1-3, 1-87. New Delhi: Lokesh Chandra IAIC.

Sperling, Elliot. 1976. 'The Chinese Venture in K'am, 1904-1911, and the Role of Chao Erh-feng'. The Tibet Journal 1 (2): 10-36.

Tenzin, Jinba. 2014. In the Land of the Eastern Queendom: The Politics of Gender and Ethnicity on the Sino-Tibetan Border. Seattle: University of Washington Press.

Tsomu, Yudru. 2015. The Rise of Gönpo Namgyel in Kham: The Blind Warrior of Nyarong. Lanham, MD: Lexington Books.

Tuttle, Gray. 2005. Tibetan Buddhists in the Making of Modern China. New York: Columbia University Press.

Tuttle, Gray. 2011. 'Challenging Central Tibet's Dominance of History: The Oceanic Book, a Nineteenth Century Politico-Religious Geographic History'. In The Rise of the Modern in Tibet, Proceedings of the Eleventh Seminar of the International Association for Tibetan Studies, Königswinter, Germany 2006, edited by Gray Tuttle, 135-172. Andiast, Switzerland: International Institute for Tibetan and Buddhist Studies GmbH.

Waley-Cohen, Joanna. 2004. 'The New Qing History'. The Radical History Review 88: 193-206.

Wang, Xiuyu. 2011. China's Last Imperial Frontier: Late Qing Expansion in Sichuan's Tibetan Borderlands. Lanham, MD: Lexington Books.

Ze, Po and Ge Lei, eds. 2004. Hengduanshan minzu wenhua zoulang. Kangba wenhua mingren luntan wenji (The Cultural and Ethnic Corridor of the Hengduan Mountains: Miscellany Forum of Personalities about Khampa Culture). Beijing: Zhongguo zangxue chubanshe. 
Map 1

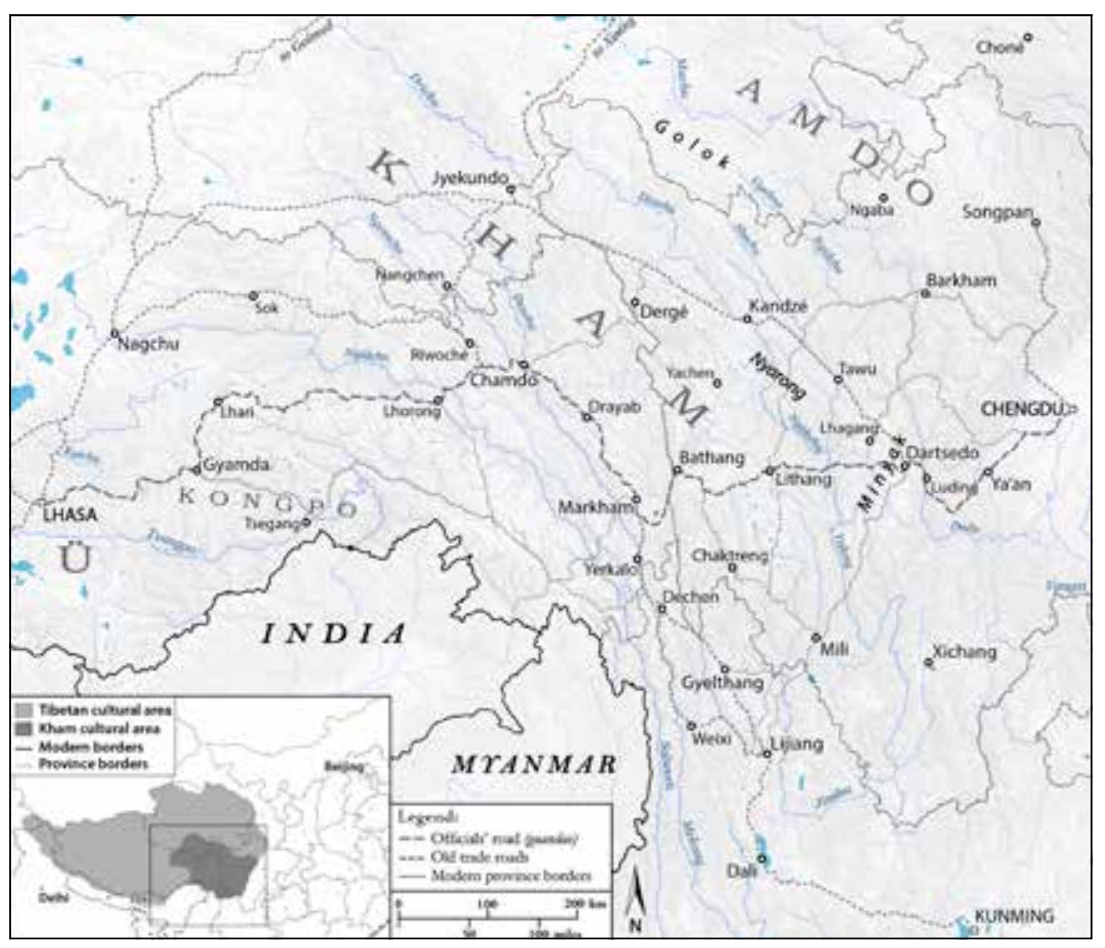




\title{
Chronology of Major Events
}

\author{
With Particular Attention to the Sino-Tibetan Borderlands
}

\author{
Stéphane Gros
}

This chronology provides a selection of major events of global and local significance: it foregrounds some key historical events to convey a sense of how eastern Tibet, and Kham in particular, has been shaped by various actors in conjunction with fluctuating political, economic, and cultural forces of different scales and intensity. It focuses on the period from the mid-nineteenth century, during which Kham became a contentious zone, to the present. The first section of the chronology, however, starts in the seventeenth century because of the historical importance of this period and its relevance for later events.

\section{The Unification of Tibet, and the Manchu Protectorate (c. 1642-1911)}

In the early seventeenth century, the Fifth Dalai Lama with Mongolian military assistance unified a vast territory and institutionalized a political system forged from a union of temporal and spiritual powers. From 1642 until $195^{2}$ (or 1959, when the Dalai Lama left definitively for India), the central part of the Tibetan plateau and most of its western areas were ruled by the Dalai Lamas or their regents and an ecclesiastic-nobiliary government, the Ganden Phodrang, based in the city of Lhasa. Central Tibet's relative independence from external influence came to an end in the early eighteenth

\footnotetext{
1 This chronology aims to supplement existing chronologies with a focus on eastern Tibet and draws on Blondeau and Buffetrille (2002); Snellgrove and Richardson (1986); Tuttle and Schaeffer (2013); Travers (2009). For a general survey of Kham over history and the sources for such a history, Alexander Gardner's (2003) substantial commentary on the volume edited by Lawrence Epstein (2002) is a vital contribution. The realization of this chronology would not have been possible without Yudru Tsomu's collaboration and the many critical and constructive suggestions offered by David Atwill, Rémi Chaix, Carole McGranahan, and Scott Relyea. I alone am responsible for all remaining approximations, errors, and shortcomings.
}

Gros, Stéphane (ed.), Frontier Tibet: Patterns of Change in the Sino-Tibetan Borderlands. Amsterdam, Amsterdam University Press 2019

DOI: $10.5117 / 9789463728713$ _CHRON 
century with the rise of the Qing dynasty (1644-1911) which in 1720 established a protectorate. Qing influence on the Tibetan plateau peaked under the reign of the Qianlong emperor and gradually dwindled over the nineteenth century. Amdo and much of Kham were not consistently ruled by Lhasa during this period. In fact, starting in the eighteenth century, most of the multiple polities (kingdoms, chiefdoms) and localities within Kham and Amdo, though often claimed by both Beijing and Lhasa governments, paid only loose and sometimes shifting allegiance to these centres of power.

In 1720, Qing forces first entered and garrisoned troops on the Tibetan plateau in response to Zunghar Mongol invasion and occupation of Lhasa. Soon afterwards, in 1727, a simple stone stele was erected at Bumla mountain pass along the main official road from China proper into Tibet. Geographically, the stele marked the watershed between the Drichu (Upper Yangtze) and Dzachu (Mekong) Rivers, and politically marked the divide between Central Tibet and China proper, with much of Kham falling on the Sichuan side of the border (see Map 1). The erection of the stele signalled the Qing's political dominance with the establishment of a loose protectorate over Tibet manifested by the imperial envoys (ambans) in Lhasa.

The delimitation of the border by no means signified full territorial integration of the ethnically Tibetan lands to the east under direct Qing political rule. In 1729, only the border town of Dartsedo (Dajianlu) was accorded the administrative status of a sub-prefecture and with it nominal jurisdiction over some fifty local rulers. Most of Kham remained a complex patchwork of relatively independent polities in the hands of local kings, princes, monasteries, and other lay rulers. Even when they had been granted tusi (indigenous chieftain) titles that implied a form of allegiance to the emperor, they remained beyond the direct administrative reach of Qing officials in either Chengdu or Beijing, and equally beyond Lhasa's direct control.

In Kham, the Gyelrong (Ch. Jiarong) region in northwestern Sichuan province became the theatre of major military intervention. Local Qing officials in Sichuan fuelled a local conflict between some of the eighteen Gyelrong chieftains to such an extent that it turned into a major frontier war. The two so-called Jinchuan campaigns (1747-1749 and 1771-1776) became the most costly of all Qing military campaigns. In their aftermath the policy of 'substituting chieftains with state-appointed civilian officials' (gaitu guiliu, often glossed as 'bureaucratization') was introduced in the area. These Qing interventions, combined with infrastructure work such as road building, brought about limited Qing authority in certain parts of Kham. During this period the religious influence of Central Tibet over the eastern region led to a large number of monasteries being built or converted to the Geluk school. 
1578 Sönam Gyatso (1543-1588) receives the title of Dalai Lama from Mongol leader Altan Khan.

1612 The king of Tsang, Karma Püntsok Namgyel reigns over Central Tibet. 1617 Death of the Fourth Dalai Lama, Yönten Gyatso (b. 1589), a Tümed Mongol.

1630s-1756 Zunghar Khanate rules over much of central Eurasia, embracing Tibetan Buddhism.

1636-1724 Qoshot Khanate, under Gushri Khan (1582-1655) and his sons, rules over most of Amdo.

1639-1641 Gushri Khan defeats the Beri king Dönyö Dörjé, and places parts of Kham, including the easternmost kingdom of Chakla, under his authority.

1642 Gushri Khan defeats the king of Tsang. Beginning of the Fifth Dalai Lama's rule, Ngawang Lobzang Gyatso, and the regency of Sönam Rapten. Beginning of the Ganden Phodrang regime which lasted until 1959.

The Tenth Karmapa, who was supported by the king of Tsang, flees the fighting. He finds shelter in Lijiang (Jang Satam) and Gyelthang (1647) and remains in Kham until 1672 .

1644-1911 Qing (Manchu) dynasty rules over China.

1644-1661 Reign of Emperor Shunzhi (b. 1638).

1645 Construction of the Potala Palace begins.

1647 End of the domination of the Naxi King of Lijiang (Jang Satam) over the territory of Muli (Mili).

1648 Treaty of Westphalia. European powers increasingly rely on border treaties to define the territorial sovereignty of individual states. 1652-1653 Journey of the Fifth Dalai Lama to Beijing; meets Emperor Shunzhi. 1652 The Fifth Dalai Lama supports the expansion of the monastery of Bathang, renamed 'Ganden Pendeling'.

1656 Rapjampa Samten Zangpo patronizes the building of one of the three main monasteries in Muli, then Muli Gönchen, marking the early days of Geluk presence in Muli.

1661-1722 Reign of Qing Emperor Kangxi.

1666 The Qing Dynasty grants the title of Xuanwei shisi (Pacification commissioner) to the Chakla king (Mingzheng tusi), placing him under the jurisdiction of the Sichuan Imperial Government.

1667 The Qoshot Mongol forces make their way into Gyelthang, conquering the area on behalf of the Fifth Dalai Lama. Döndrupling monastery is built there and adherents of the Karmapa and Nyingmapa schools are forced to convert to the Gelukpa school. 
1674 The Naxi king of Lijiang supports an armed revolt in reaction to Geluk influence; it is quelled by Mongolian forces and results in the handing over of Gyelthang to the Dalai Lama.

1679 Construction of the large monastery of Ganden Sumtseling in Gyelthang on the advice of the Fifth Dalai Lama.

1682 Death of the Fifth Dalai Lama, concealed by Regent Sanggyé Gyatso until 1696 to consolidate the Ganden Phodrang's rule. 1684 War with Ladakh.

1684-1692 Publication of the Kangxi edition of the Tibetan Buddhist canon (kangyür).

1697-1700 Lhazang Khan becomes chief of Mongol (Qoshot) forces in Tibet. 1699 Tsangsé Trinlé, the garpön/dzongpön (commissioner/magistrate) dispatched by the Tibetan government in Lhasa, kills the Chakla king and seizes areas to the east of Gyelrong Gyelmo Ngülchu (Dadu he). 1700 The Sichuan governor Tang Xishun leads troops on a punitive expedition against Tsangsé Trinlé and re-captures areas to the east of Gyelrong Gyelmo Ngülchu (Dadu he). Trokyap (one of the Gyelrong kingdoms) submits to the Qing.

1702 The Qing dispatches civil officials to supervise trade between China and Tibet, and establishes a customs office in Dartsedo.

1703 The Tibetan government in Lhasa sends two depas (governors) to rule Bathang.

1705 Lhazang Khan, with the approval of the Manchu Emperor Kangxi (r. 1662-1722), attacks Lhasa and kidnaps the Regent Sanggyé Gyatso (b. 1653) who dies in captivity. Lhazang rules Central Tibet until his death in 1717. 1706 Death of the Sixth Dalai Lama (b. 1683) following his dethronement by Lhazang Khan.

1706 The iron bridge in Chakzamkha (Luding) is completed.

1707 Capuchin missionaries in Lhasa.

1709 Foundation of Labrang monastery in Gansu by Jamyang Zhepa (1648-1721).

1716 Jesuit priest Ippolito Desideri in Lhasa.

1717 Invasion of Tibet by Zunghar Mongols and assassination of Lhazang. 1720 Tibetan and Manchu forces repel Zunghars; Seventh Dalai Lama,

Kelzang Gyatso (1708-1757), settles at the Potala Palace. 1722-1735 Reign of Qing Emperor Yongzheng. 1722 Dechen and Lijiang areas fall under the jurisdiction of Yunnan Province but are still religiously led by the Dalai Lama. Most of the Kagyu and Nyingma school monasteries in those areas are forced to convert to the Geluk school. 
1723-1724 Civil war follows the withdrawal of Manchu forces in Lhasa.

Mongols and Tibetans in Amdo rebel against Manchus but are harshly suppressed, and Amdo is integrated in the Manchu empire.

1727-1747 Polhané (1689-1747), a Tibetan aristocrat, rules Tibet with Manchu support.

1727-1735 The Seventh Dalai Lama is exiled to Kham.

1727 Erection of the Bumla (Ningjing shan) stele on the mountain pass marking the eastern territorial limit of Central Tibet.

1728 The Qing court establishes amban as a resident envoy in Lhasa; this posting lasts until 1911.

1729 Dajianlu (Dartsedo) sub-prefecture is created, and the Qing dispatches a sub-prefect in charge of transporting provisions and funds for troops stationed in Tibet, who is to be stationed in Dartsedo with a battalion of 200.

1729 Dergé king Tenpa Tsering builds the Dergé Printing House.

1736-1796 Reign of Qing Emperor Qianlong.

1744 Foundation of Yonghegong Gelukpa monastic university in Beijing.

1745 End of Christian mission in Lhasa.

1747-1749 First Jinchuan campaign in northwestern Sichuan's Tibetan region of Gyelrong to quell internal feuds.

1747 Death of Polhané, succeeded by his son Gyurmé Namgyel. Last lay ruler in Tibet.

$175^{\circ}$ Gyurmé Namgyel is assassinated; murder of ambans and further

Manchu military expedition. Seventh Dalai Lama becomes head of state. 1757-1777 Death of Seventh Dalai Lama (1757). An ecclesiastical regent is appointed to ensure interregnum until the next Dalai Lama's majority. First of an almost continuous series of monk regents until the 1950s. 1757-1858 British East India Company rule in India. 1771-1776 Second Jinchuan campaign; Manchu most costly military intervention on its borderlands. 1788-1791 Nepalese (Gurkha) invasion of Tibet; Tibetan army defeated.

Nepalese are pushed back by Qing army. 1792 Qianlong emperor enacts reforms of Tibetan administration and sets rules for selecting the Dalai Lamas. The Qing administration implements the policy of 'substituting chieftains with state-appointed civilian officials' (gaitu guiliu) in the Sino-Tibetan borderlands. Beginning of a policy of excluding foreigners from Tibet.

1794 Publication of the Qianlong edition of the Manchu translation of Tibetan Kangyür. 1796-1820 Reign of Qing Emperor Jiaqing. 
1804 Death of the eighth Dalai Lama, Jampel Gyatso (b. 1758) who reigned only briefly (1787-1790). Over the next seventy years, the following Dalai Lamas, Lungtok Gyatso (1805-1815), Tsültrim Gyatso (1816-1837), Khedrup Gyatso (1838-1857), up to the twelfth Dalai Lama, Trinlé Gyatso (18561875), never exercise power which remains in the hands of monk regents supported by the Manchu emperors.

1814-1816 Anglo-Nepal War.

\section{From Gönpo Namgyel's Attempted Unification to Zhao Erfeng's Forceful Integration (1860-1911)}

As the situation in Gyelrong had shown, the independence of most of the Kham polities from the two distant centres, in spite of continuous commercial, political, and religious ties, created a state of instability. The threat became even greater with the rise of Gönpo Namgyel in the 186os. This local charismatic leader and fierce warrior attempted a forced political unification of Kham's polities from his stronghold in Nyarong, not far from Dartsedo. Because Gönpo Namgyel's expanding rule over neighbouring polities, including the powerful kingdom of Dergé, posed a challenge to both the Lhasa government and the Chinese provincial authority of Sichuan, they endeavoured to strengthen their grip on Kham. The Qing court's reluctance to make any military intervention during a period of financial crisis and of Western imperialist threats gave Tibetan central authorities the opportunity to send in troops who successfully defeated Gönpo Namgyel (1865) and allowed them to extend their administrative rule over parts of Kham by appointing a high commissioner (chikhyap).

Until the end of the nineteenth century, the presence of Manchu civil servants and soldiers in the border zone, especially along the main communication arteries, was intended to provide logistical support to representatives of the Qing government stationed in Tibet. These Manchu officials did not exercise authority over local rulers. However, Qing bureaucracy or military colonies were progressively taking over the frontier territories to be in a position to administer them directly. Not only were political structures and local hierarchies being dismantled but religious institutions were also challenged at times if not abolished, with the Qing often supporting the Geluk school of Buddhism (that of the Dalai Lama) and favouring it over other schools. Concurrently, the beginning of the twentieth century saw the growing interests of various Western powers in Tibet - notably the British in India who sent a military expedition into Lhasa (1903-1904) and forced a trading agreement. 
While in Bathang, Fengquan (?-1905), who was appointed to the office of Assistant Amban residing in Tibet in 1904, took steps towards reducing the power of the local chiefs and reclaiming wastelands. Violent rioting broke out and Fengquan was killed with some of his troops, as well as two of the French missionaries residing in Bathang. A punitive expedition was then led by Ma Weiqi (1846-1910), the commander-in-chief of Sichuan's provincial troops. The Han Bannerman Zhao Erfeng (Chao Er-feng) completed the campaign against the city of Bathang, followed by a wave of military conquests and the destruction of monasteries. After his conquests, Zhao Erfeng became in late 1906 the first Sichuan-Yunnan Frontier Commissioner (duban Chuan Dian bianwu dachen). In the following months, Zhao took measures to train soldiers and to clear land; replacing local chiefs by appointed officials; opening mines; developing trade; and founding new schools.

1837-1865 Nyarong wars in Kham led by Gönpo Namgyel, ending with Manchu and Central Tibetan intervention. 1839-1842 Opium War (Nanking Treaty signed in 1842). 1844 The Qing emperor relaxes rules against the presence of Catholics. Western missionaries enter Tibetan areas.

1846 The Vatican establishes a parish centred around Lhasa and entrusts the 'Tibet Mission' to the Foreign Missions Society of Paris. It is renamed 'Dajianlu Mission' as missionaries settle primarily in Kham.

1849 The Qing court dispatches Qi Shan to lead the Qing troops and indigenous soldiers of fifteen indigenous leaders, including the Chakla king, Dergé king and others to fight against Gönpo Namgyel in Nyaké (Middle Nyarong). 1850-1864 Taiping Rebellion.

1850-1851 Gönpo Namgyel attacks Drango and Kandzé, and occupies both regions.

1855 Gönpo Namgyel attacks Lithang but is defeated.

1855 Nepal-Tibet War.

1856 Gönpo Namgyel occupies Lithang, and soon attacks Bathang. Defeated

in Bathang, he begins to invade the territory under the jurisdiction of the Chakla king.

1861 The Chakla king recalls his subjects from postal stations and refuses

to perform ulag (corvée labor) to transport Qing officials. Jing Wen, the newly appointed amban, is consequently unable to continue his journey through Chakla in the latter half of the year. 1861 British annexation of Sikkim. 1865 Tibetan military intervention to quell Gönpo Namgyel. 
During the second half of the nineteenth century, access to Central Tibet is forbidden to foreigners. European Christian missionaries, of whom there have been many in Tibetan areas since the beginning of the seventeenth century, are forced to settle in peripheral regions.

1866 To secure authority over the region, the Office of the Tibetan High Commissioner (Nyarong chikhyap) is established in Nyarong. 1866-1867 The imposition of Lhasa's authority directly over Nyarong soon leads to local discontent. Dagé Sepo, a local headman, incites several hundred local people to besiege the commissioner's house, arguing that the Tibetan commissioner is collecting exorbitant taxes and levies.

1875 The Tibetan commissioner's forceful seizure of local households in Lithang creates resistance. Sichuan provincial authorities dispatch officials to lead troops to attack the protestors. The Tibetan commissioner is dismissed from his post on the grounds that he has caused unrest in the region.

1889 Large-scale revolt against the Tibetan commissioner's rule in Nyarong led by the people of Nyarong, under the leadership of Sala Yungdrung, a minor headman.

1874-1908 reign of Qing Emperor Guangxu. 1876 Birth of the Thirteenth Dalai Lama, Tupten Gyatso.

1883 Anti-Nepalese riots in Lhasa.

1884-19o8 Qing Empire governed by Empress Dowager Cixi (b. 1835). 1886-1895 Regency of Demo Khutughtu Lobzang Trinlé.

1888 Tension between Tibet and Britain in Sikkim, and first British invasion of Tibet.

1894-1895 First Sino-Japanese War.

1895 The Thirteenth Dalai Lama, Tupten Gyatso, becomes head of state. The regent attempts an assassination.

1896 Hostility escalates between the Lhasa government and Qing frontier officials. Qing troops take over Nyarong, and the Tibetan commissioner and his subordinates all flee to Central Tibet.

Sichuan Governor Lu Chuanlin proposes to introduce bureaucratization (gailiu) in Nyarong.

1904 Fengquan is appointed Assistant Amban to Tibet. Posted in Chamdo, he remains in Bathang.

The Younghusband Expedition invades Central Tibet. Military defeat of the Tibetans who sign an Anglo-Tibetan treaty and agree to concede commercial advantages to the British, and open three trade stations at Yatung (Tib. Dromo), Gyantsé and Gartok. The Thirteenth Dalai Lama flees to Mongolia. 
Tibet is increasingly forced to give in to pressure from competing British and Russian commercial and political interests. 1905 Assassination of Fengquan, the assistant amban, in Bathang. 1905 Ma Weiqi launches a punitive expedition, and Zhao Erfeng leads deadly military campaigns and the destruction of monasteries in southern Kham to bring Kham and neighbouring Tibetan regions under Qing control. 1906 Anglo-Chinese Convention excludes Tibet. Britain recognizes Qing suzerainty over Tibet.

1906 Zhao Erfeng becomes the first Sichuan-Yunnan Frontier Commissioner

(Chuan Dian bianwu dachen) and proceeds to promote development programs.

1908 The Thirteenth Dalai Lama, still in exile, visits Beijing for an imperial audience. 1908-1911 Reign of infant Emperor Pu Yi (1906-1967). 1909 The Thirteenth Dalai Lama returns to Tibet. 1910 Zhao Erfeng's troops occupy Lhasa; the Thirteenth Dalai Lama flees to India.

1911 Frontier Commissioner Fu Songmu (1869-1929) prepares a memorial proposing the creation of Xikang Province.

1911 Republican revolution and end of the Manchu Qing Dynasty. The Manchu garrison of Lhasa surrenders.

\section{The Simla Convention and Its Aftermath: The Birth of a Border (1912-1926)}

The collapse of the Qing Empire in the early twentieth century signalled the end of China's imperial order and the advent of a republic. It also marked the loss of Outer Mongolia, which broke away in 1921 to become an independent political entity, and its geopolitical dislocation was accentuated further by Japanese military intervention in Manchuria. The first part of the twentieth century was clearly a dangerous moment of territorial dismemberment for China. Irreversible power struggles in the name of sovereignty, nationalism, and modernization took place with a direct impact on the becoming of the Sino-Tibetan frontier. In spite of some continuities with imperial practices, the advent of the nation-state introduced some irrevocable changes that affected territories and ethnic groupings in the way they are now conceived and lived. Since then these have led to competing narratives of belonging and to historicizing statecraft that supports claims of identity and sovereignty. It is not only that China at the time did not have a modern 
concept of Westphalian sovereignty, but also that other indigenous notions of sovereignty intermingled with newer forms of governmentality - an intermingling that continues today.

The wave of local uprisings followed by territorial conquests and reforms led by the Frontier Commissioner Zhao Erfeng at the end of the Qing dynasty, and the geopolitical tension that led to the Simla Convention (1913-1914) between Republican China, British India, and Tibet supposedly to settle the status of Tibet and border issues, all constituted a decisive turning point for the future of the Sino-Tibetan frontier.

1912 Return of Thirteenth Dalai Lama. 1912 Foundation of the Chinese Republic.

1913 Declaration of independence by the Thirteenth Dalai Lama. Tibeto-

Mongol Treaty that asserts the independence of both nations. Tibet acquires a flag, a currency, and national stamps.

1914 Creation of the Sichuan Frontier Special Administrative Region (Chuanbian tebie xingzheng quyu).

1914 Tripartite Convention in Simla. Agreement reached but China refuses to sign the final document. 1916 Creation of the Chuanbian dao (The Circuit of the Sichuan Border). 1918 Tibetan troops progress eastwards and approach Nyarong and Bathang.

British consul Teichman helps to negotiate a ceasefire. The Chamdo and Rongpatsa agreements divide Kham along the Jinsha River (Dri chu). 1920-1921 Sir Charles Bell's mission to Lhasa to foster better relations between

Tibet and Britain. British active aid in terms of equipment and training of the Tibetan army.

1924 Ninth Panchen Lama (1883-1937) goes into exile in China. 1924 Foundation of the Mongolian People's Republic.

1924 The Sichuan Frontier Special Administrative Region becomes the 'Xikang Special Administrative Region' (Xikang tebie xingzhengqu). 1927 No. 24 army commander Liu Wenhui is appointed Chief Commander of Chuankang Frontier Defence and concurrently Chairman of Sichuan Provincial Government.

\section{Kham as Xikang Province (1928-1955)}

Following the failure of the Simla Convention, each of the protagonists sought to increase its control of the eastern regions of Kham. The Lhasa government created new civil and military positions and placed governors 
in each of the major border towns, such as Chamdo and Dergé. Nationalist China developed its project to create Xikang province, which built on the early proposal made by Zhao Erfeng following his efforts to administratively incorporate the territory he had 'pacified'. In September 1928, warlord Liu Wenhui established an administrative committee for the 'Special region of Xikang'. A government was set up and the western Sichuan highlands finally became Xikang Province in 1939, still under the control of the militarist Liu Wenhui and his supporters in Sichuan. The Xikang regional administration relied heavily on outside subsidies and the export of opium. Finally, the idea of a separate province was abandoned in 1955 by the government of the People's Republic of China, and Xikang's territory was divided up between the Tibet Autonomous Region (T.A.R., created in 1965), Sichuan, and Yunnan. The shifting boundary between Sichuan and Lhasa-controlled Tibet during the Qing dating back to the early seventeenth century became fixed, and the Drichu (Jinsha River) became the border between the T.A.R. and Sichuan on the new administrative map.

1928-1937 The Guomindang government of Chiang Kai-shek takes power. Establishment of the Nanjing Government (the first centralized government since 1911 in China) and the Tibetan and Mongolian Affairs Commission. 1928 Chinese warlord Liu Wenhui sets up the 'Administrative Committee of the Special Region of Xikang' (Xikang tequ zhengwu weiyuanhui) in Kangding. He occupies the Kham borderlands and his troops are pushed back into Sichuan.

1928 Qinghai province is created by the Guomindang and ruled by Chinese Muslim warlords (Ma family). 1930s Start of the 'Khampa rule for Kham' self-rule movement by Kelzang Tsering. $193^{2}$ Warlord Liu Wenhui again invades the Kham borderlands, breaking the armistice agreed to by Nationalists. Within five months Chinese troops push Tibetans back to the Jinsha river (Drichu) and threaten Chamdo. 1933 Death of the Thirteenth Dalai Lama, Tupten Gyatso. 1934 Radreng (Reting) Rinpoché (1911-1947) is made regent. 1934 Chinese Communist Long March enters parts of eastern Tibet. 1935 Creation of the 'Xikang Administrative Inspection District' (Xikang xingzheng ducha qu); Liu Wenhui heads the 'Committee for the Edification of Xikang Province' (Xikangjiansheng weiyuanhui).

1935 The Gara Lama (Nörla Hutuktu) launches the second 'Khampa rule of Kham' movement. 1935 Chinese and British missions in Lhasa. 
1937 The Fourteenth Dalai Lama Tenzin Gyatso is discovered by a search party, in Qinghai. A Muslim warlord demands a ransom to allow the party to return to Lhasa.

1937-1945 Second Sino-Japanese War.

1937 Chinese central government moves to Chongqing (Sichuan) to escape Japanese invasion.

1939 Creation of Xikang province, to be dismantled in 1955.

1939 Foundation of the Tibetan Communist Party in Sichuan by students originally from annexed Kham, under the aegis of Bapa Püntsok Wangyel. This nationalist party aims to set up an independent and revolutionary Tibet. Bapa Püntsok Wangyel is banished from Tibet in 1949.

The Khangsar family, together with the Panchen Lama's camp, launches the third 'Khampa rule of Kham' movement, also known as the 'Kandzé Incident'.

Foundation in Kalimpong (India) of a party inspired by the republican ideal, the Tibetan Progressive Party, dismantled in 1946.

1940 Enthronement of the Fourteenth Dalai Lama.

1941 End of the Reting Regency, forced to resign in favour of the conservative monk Taktra (1874-1952).

1942 The Tibetan government establishes a Ministry of Foreign Affairs.

1945 The government of Xikang issues an ordinance against opium.

1947 The Tibetan government represses a revolt in Lhasa led by Reting and his supporters.

194715 August, India becomes independent, marking the end of the British Indian Empire. End of British interests in Tibet, the British mission becomes an Indian mission.

1948 Tibetan trade mission visits China, the United States, and the United Kingdom.

1949 Fall of the Guomindang, closure of the Chinese mission in Lhasa and expulsion of all the Chinese from Tibet.

19491 October, Establishment of the People's Republic of China.

1950 The Fourteenth Dalai Lama is made head of state at the age of fifteen.

\section{China's Tibet (1951-2018)}

Tibet's incorporation into P.R.C. took place gradually in the 1950s. The 'Seventeen-Point Agreement' granted Tibet internal autonomy but the radical intervention of communists in eastern Kham (1956) and Amdo (1958) highlighted their desire to impose their policies and reforms on Central 
Tibet as well. The repression of the Lhasa uprising in March 1959 and the flight of the Dalai Lama to India marked the end of the traditional Tibetan government. Tibetan territories became autonomous administrative units, such as the Tibet Autonomous Region, and several prefecture- or county-level units in Sichuan and Yunnan. The policy of liberalization and openness launched by Deng Xiaoping in 1978 allowed a cultural and religious renewal in Tibet. However, the demonstrations and pro-independence protests that took place in Lhasa between 1987 and 1989 reflected the persistence of a cultural divide and strong identity claims in spite of continuous efforts from the Chinese government regarding economic development in the Tibet Autonomous Region. The wave of demonstrations that occurred in spring 2008 in all regions of Tibetan culture in P.R.C. seemed to call into question the politics of differential inclusion implemented in Tibetan regions.

195124 October, Central Tibet is incorporated into the People's Republic of China by the 'Seventeen-Point Agreement', in which representatives of the Tibetan government accept integration in exchange for internal autonomy.

1952 Beginning of the creation of Tibetan autonomous administrative units in eastern areas of the Tibetan plateau.

1954 The Dalai Lama and the Panchen Lama go to Beijing to meet Mao Zedong.

1955 Dissolution of Xikang province and incorporation of the region under its jurisdiction into Sichuan province. Uprisings following forced collectivization, bombing of monasteries in Kham (1956). An influx of refugees from eastern Kham and from Amdo to Lhasa begins. Creation of the Voluntary National Army, a Khampa resistance organization.

Eastern Kham becomes Ganzi (Kandzé) autonomous prefecture. 1956 The Chinese government sets up the Preparatory Committee for the Tibet Autonomous Region to replace the Tibetan government.

Dalai Lama and Panchen Lama travel to India for the Buddha Jayanti celebrations $(2,500$ th anniversary of the birth of Buddha).

1956 Beginning of Khampa resistance and coordinated fighting. Start of C.I.A. aid to the resistance fighters.

1957 Southernmost Tibetan region of Kham becomes Diqing (Dechen) Tibetan Autonomous prefecture which is integrated in Yunnan province. 195816 June, Creation of the resistance movement chushi gangdruk ('four rivers, six mountains') by Khampa of various fringes of society. 1958 Great Leap Forward and creation of the people's communes. Massive rebellion in Amdo, strongly repressed. 
195910 March, Uprising in Lhasa and repression. The Fourteenth Dalai Lama flees to India, followed by about 80,00o Tibetans.

Premier Zhou Enlai announces the abolition of the former Tibetan government.

On the road to exile, the Dalai Lama founds a government and denounces the Seventeen-point Agreement.

The United Nations adopts a first resolution on Tibet calling for respect for human rights and rights to cultural and religious specificity.

1962 War between China and India over the Sino-Indian border, the so-

called 'McMahon Line' decided at the Simla Convention in 1914 but not recognized by China. The border issue is still not resolved in 2019.

${ }_{1965}$ Creation of Tibetan Autonomous Region (T.A.R.) which includes western and Central Tibet and parts of western Kham.

1966-1976 Cultural Revolution leads to massive destruction of religious

and civilian buildings. Prohibition of monastic life, re-education and imprisonment of a large number of lay and religious Tibetans.

1970 Creation of the Tibetan Youth Congress, the largest non-government political organization in exile, based in Dharamsala.

1971-1972 The visits to China by Kissinger and Nixon mark the Sino-American rapprochement and the shifting of U.S. C.I.A. and Department of State policy regarding aid to Tibetan resistance fighters.

1976 Death of Mao Zedong.

1978 Period of relative liberalization under Deng Xiaoping and the 'Four Modernizations' policy. Release of a large number of former public servants of the traditional Tibetan government who have been imprisoned since 1959 or during the Cultural Revolution.

1979 Visit of the first delegation of the Tibetan government in exile in Tibet. 1980 Hu Yaobang visits Tibet and initiates reforms.

1988 The Dalai Lama presents his 'Strasbourg Proposal' to the European

Parliament: the three Tibetan regions (Central Tibet, Kham, and Amdo) would be united into a 'Greater Tibet', in exchange for which he would accept autonomy within P.R.C., renouncing independence. While this position alienates Tibetans, the first condition remains unacceptable to the Chinese government.

1987-1989 Uprising in Lhasa and Martial Law imposed.

1989 The Dalai Lama is awarded the Nobel Peace Prize.

1989 Tiananmen Square events and repression.

1989 Death of the tenth Panchen Lama.

1991 Dalai Lama meets with U.S. President George H.W. Bush in Washington, D.C. 
1993 The Chinese government breaks off official relations with Dharamsala. 1995 Dispute between the Dalai Lama and Chinese authorities over the choice of the eleventh Panchen Lama.

1996 Large-scale campaign of patriotic re-education and denunciation of the Dalai Lama in T.A.R. Uprisings in Lhasa.

1997 Death of Deng Xiaoping. 2001 Zhongdian (Gyelthang) County in Yunnan officially renamed Shangri-

La (Xianggelila) County.

2001 Start of construction of the Golmud-Lhasa (Qinghai-Tibet) railroad $(1142 \mathrm{~km})$.

2002 P.R.C. and the exiled government of Dharamsala resume relations interrupted since 1993 .

2006 Official opening of the Golmud-Lhasa railroad. 2008 Tibetan riots against Chinese civilians in Lhasa. 2008 March-May Manifestations and riots of unprecedented scale in all regions of Tibetan culture in P.R.C. Sporadic demonstrations continue, as well as arrests and intensive political re-education sessions.

8 May, the Olympic flame is carried to the top of Everest.

12 May, a violent earthquake strikes Sichuan's Wenchuan County, in Aba (Ngawa) Tibetan and Qiang Autonomous Prefecture.

21 June, the Olympic flame passes through Lhasa.

2009 Beginning of a long series of self-immolation protests in Kham and Amdo (153 as of December 2018).

\section{References}

Blondeau, Anne-Marie and Katia Buffetrille, eds. 2002. Authenticating Tibet:Answers to China's 100 Questions. With a Foreword by Donald Lopez. Berkeley: University of California Press.

Snellgrove, David and Hugh Richardson. 1986. A Cultural History of Tibet. Boston: Shambala.

Travers, Alice. 2009. 'Chronologie de l'histoire du Tibet'. Outre-Terre 21 (1): 109-128. Tuttle, Gray and Kurtis R. Schaeffer. 2013. The Tibetan History Reader. New York: Columbia University Press. 



\section{Part I}

Borders inside out 



\title{
Introduction
}

\author{
The Editor
}

It is quite common to conceive of China and Tibet as two distinct culturally bounded entities in spite of the fact that the 'Tibet' we generally have in mind is territorially part of the People's Republic of China (P.R.C.). Only an internal administrative border separates the Tibet Autonomous Region (T.A.R.) from adjacent provinces, like Sichuan to the east, where today we find a significant number of Tibetans who make up the majority of inhabitants of other administrative units, such as the Ganzi (Kandzé) Tibetan Autonomous Prefecture. These current administrative divisions represent the modern ordering and territorialization of the so-called Sino-Tibetan borderlands, and the region called Kham.

On the one hand, the administrative border separating T.A.R. from Sichuan province does not correspond to a particularly conspicuous social boundary, yet the border introduces a separation that creates new differentiations. On the other hand, older regional distinctions such as the one between Central Tibet (Ü) and Kham or Amdo on the eastern edge of the plateau are nowadays fragmented by administrative borders that cut through them according to a different logic from a local sense of belonging and attachment. In other words, throughout China's Tibetan regions, current administrative divisions have implications regarding variations in policies and their implementations and, when combined with places' geographical and historical specificities, they have led to a high degree of diversity in local Tibetan societies and economies (see Hillman 2010).

The three chapters that follow take stock of the implications of this layered complexity of boundary-making in the Sino-Tibetan borderlands and offer complementary perspectives on how to conceptualize borderland space in relation to neighbouring historical power centres but also in its own terms via a necessary re-centring. This first section offers an opening onto the volume's exploration of the intertwined questions of place-making, identity, and socio-political transformations that have made up Kham's convoluted historical trajectory and that have contributed to the emergence of its internal diversity. The three chapters therefore problematize the boundaries of Kham, its 'plural unity' across time and its characteristics as a cultural nexus.

The introductory chapter by Stéphane Gros provides both a historical and anthropological discussion and a conceptual framework to suggest 
ways of understanding the production of place in a dynamic fashion. Such a perspective, he argues, forces us to look at Kham, within the Sino-Tibetan borderlands, as exemplifying a frontier situation at different historical junctures. There are specific processes that relate to imaginaries about civilization and progress, the emergence of institutional order, and the use of resources, which are characteristic of the frontier as a particular political project and an epistemological distinction (see Tsing 2005). This introductory chapter firmly identifies the relevance of Kham in the field of borderland studies and reflects on the topographies of power that have contributed to shaping the future of this intermediary zone between China and Tibet. As 'borderland' or 'frontier' are existing categories for both China and Tibet as expansive political and civilizational centres, Kham must be thought of as a third space, and not exclusively as 'Tibetan' in a simplistic binary opposition to 'Chinese'.

In her chapter, Katia Buffetrille explores the relevance of the notion of 'borderlands' in the context of Tibetan history by reviewing the vernacular terminology. She posits the 'Sino-Tibetan' borderlands as being 'between power centers' (Zartman 2010, 2) that exert their influence in a civilizational, politico-economic, or more generally cultural sense, but her chapter particularly emphasizes the dynamic relationship between Kham (and Amdo) and Lhasa. As Buffetrille shows, the current administrative structure has channelled differentiated socio-economic developments, which have fundamentally reconfigured the relationship between Kham and the traditional centre, Lhasa and Central Tibet. These changes have nurtured a cultural dynamism that has now given Kham a new centrality. As she demonstrates, the massive changes that have taken place over the last decades not only reveal the vitality of the borderlands but also challenge our conventional perception of the centre and upset established hierarchies. In the contemporary period, the in-betweenness of Kham further blurs the boundaries of distinction and the sense of belonging, lending it increased prominence.

Some places in particular have gained more visibility, and newer understandings of identity prompt us to question older and emerging conceptualizations of place. This is certainly the case with Gyelthang in southern Kham, as discussed by Eric D. Mortensen, a place that has retained its own centrality in the eyes of its inhabitants but has also undergone earthshattering transformations because it has been re-branded 'Shangri-La' for the sake of tourism development. Mortensen offers a multifaceted account of the sense of place inhabitants have forged in their interactions with other Tibetans but also with the numerous groups that surround them such as 
the Yi, the Naxi, the Lisu, or the Bai further south. In doing so, Mortensen navigates along and across the various boundaries of Gyelthang, alerting us to their malleable character while at the same time foregrounding the variability of the conceptualization of place and sense of belonging. In his case, it is not so much the centrality of place that matters - although it seriously unsettles our understanding of such a place as a 'borderland' - but more crucially the issue of categorization and ordering, and of attempting to map the unmappable.

These inquiries force us to rethink our conventional categories and methodologies, and remind us that territory is not a given. The question of regional formation and identity raises the problem of defining boundaries, or borders, which makes the theorist run the risk 'of going round in circles, as the very representation of the border is the precondition for any definition', as political theorist Etienne Balibar $(2002,76)$ puts it. There are dynamics that cannot be contained by scaled spatial entities in any straightforward way. As Gros emphasizes in his introductory chapter, the dynamic process of interaction that animates Kham as a zone of contact is a 'field of relations' that is both at the edge and in the middle of territories. This, he argues, is the result of the constitutive role of the frontier, which creates evolving patterns of connection and division.

\section{References}

Balibar, Etienne. 2002. 'What is a Border?' In Politics and the Other Scene, 75-86. Translations by Christine Jones, James Swenson, and Chris Turner. London: Verso. Hillman, Ben. 2010. 'China's Many Tibets: Diqing as a Model for 'Development with Tibetan Characteristics?' Asian Ethnicity 11 (2): 269-277.

Tsing, Anna L. 2005. Friction: An Ethnography of Global Connection. Princeton: Princeton University Press.

Zartman, William I. 2010. Understanding Life in the Borderlands: Boundaries in Depth and Motions. Athens: The University of Georgia Press. 



\title{
1 Frontier (of) Experience
}

\author{
Introduction and Prolegomenon
}

Stéphane Gros

\begin{abstract}
This introductory chapter lays out the historical background and the conceptual framework that underlie the volume's collective effort to problematize the Kham region of eastern Tibet, and, more broadly, the Sino-Tibetan borderlands. It discusses conventional depictions of political, economic, and ideological topographies of these borderlands, and brings to the fore frontier dynamics that lead to a topological reconfiguration in which Kham appears neither simply distant nor proximate and neither outside nor inside, and where the distance between core/periphery and Sino/Tibetan, become distorted.
\end{abstract}

Keywords: border, boundary, frontier, Kham, space, topology

\section{Introduction}

Places are singular concretions made up of plural experiences. They accumulate sediments of time, layers of meaning linked to the evolution of landscape and the multiple histories of human activities that have contributed to shaping them. They are also contested spaces subjected to internal and external forces that often work against each other and contribute to variegated place-making processes.

This book focuses on one such place that defies a straightforward characterization: the eastern region of the Tibetan plateau that Tibetans call Kham. This name is one of several conventional divisions of the Tibetosphere, and seems to imply a form of regional unity. However, this eastern fringe of the plateau, a rugged mountainous region that has long been a frontier for both China-based regimes and Lhasa-based regimes, is not easily described as

Gros, Stéphane (ed.), Frontier Tibet: Patterns of Change in the Sino-Tibetan Borderlands. Amsterdam, Amsterdam University Press 2019

DOI: 10.5117/9789463728713_CHO1 
a whole and the question of what makes the region cohere is left hanging. In this book we use Kham as a heuristic category to explore the various implications of the designation of this region as a Sino-Tibetan borderland.

More than half of the six million Tibetans currently residing in the People's Republic of China (P.R.C.) live in the eastern borderlands of the Tibetan plateau that span across several of the current administrative divisions: the Tibetan Autonomous Region, Yunnan, Sichuan, Gansu and Qinghai provinces. Within this larger area, Kham is of undeniable demographic importance and we can estimate that nearly thirty per cent of all Tibetans in the P.R.C. live in what is known as Kham (see Ryavec 2015, 178-180) (see Map 1.1).

Kham is an area about three times the size of France. Until the 1950s it consisted of a plethora of agricultural and pastoralist societies of different scales, with their own sense of locality, each differentiated by variations in traditions and modes of authority. Politically speaking, Kham has been a very fragmented region where numerous principalities, chiefdoms, or tribal areas have coexisted, ruled by semi-independent chiefs, local kings or lamas, who rubbed shoulders with one another and occasionally with Tibetan or Chinese armies, heralding the presence of distant centres of power. Kham exhibits great internal diversity - whether in terms of language, culture, ethnicities, or historical trajectories - and it is difficult to disentangle the region from external influences, from both Central Tibet and China proper, which are themselves far from self-evident historical entities. Our goal is not to delimit an 'identity' or to inscribe Kham in some kind of regional 'naturalness' that would take for granted the existence of bounded geographical-cum-cultural territories. On the contrary, by combining approaches that shed light on variegated processes of transformation, we emphasize change and becoming, and dynamic processes of place-making.

There are several reasons for focusing on the region within the SinoTibetan borderlands that Tibetans call Kham. First and foremost, as a vernacular name for a place to which its current inhabitants, the Khampas, have a strong sense of belonging, it constitutes a meaningful category and a logical entry point into its diverse on-the-ground realities. A second reason is that by using Kham as a starting point for our enquiries we may be in a better position to recognize Kham's own centrality and specificity - one that is not strictly limited to or defined by political polarities. A third reason for considering Kham as a significant spatial unit is precisely its pivotal role in the history of Tibetan and Chinese expansions and resistance to them, and how these encounters and experiences have contributed to the becoming of places and peoples, whether Tibetan or not. Finally, it also 


\section{Map 1.1 Situating Kham}

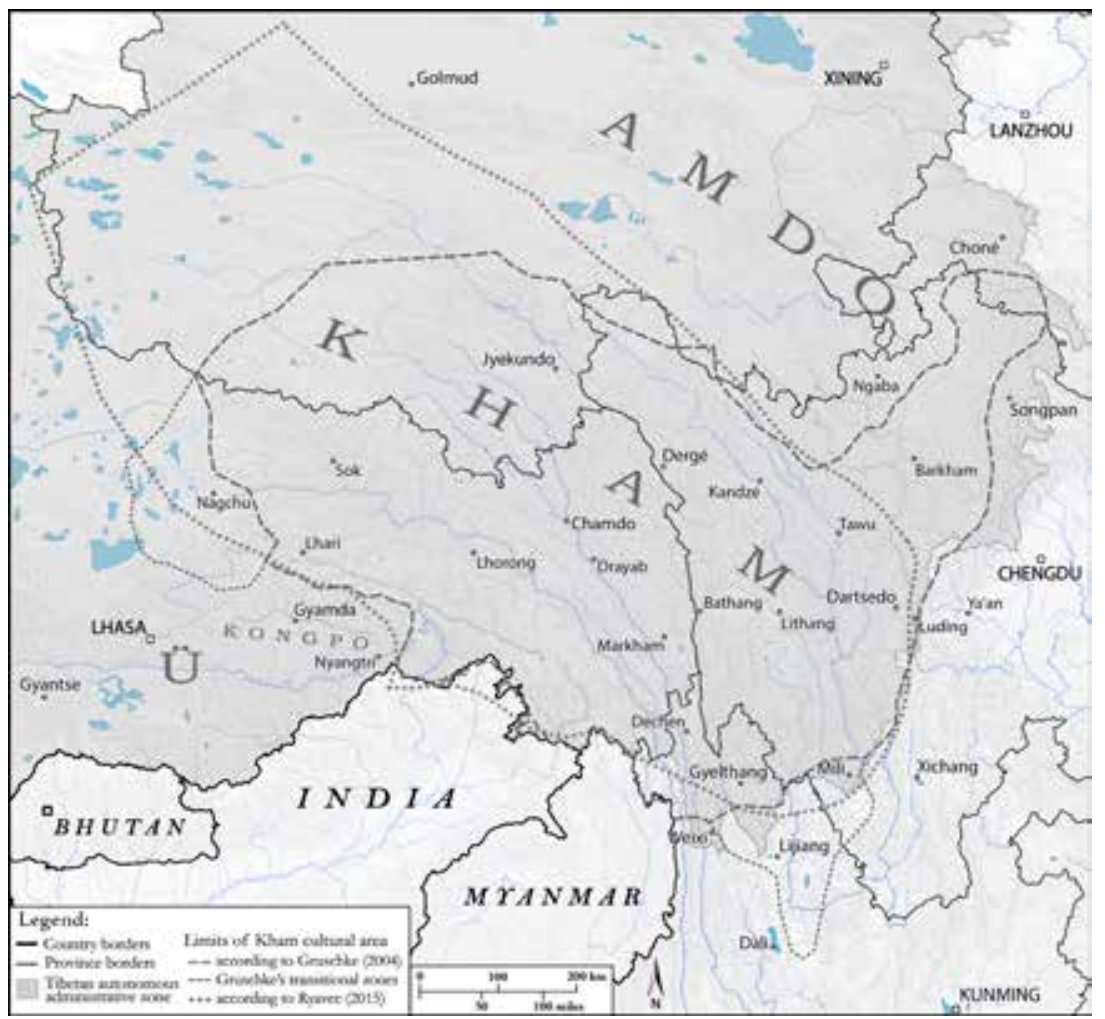

Sources: Based on SRTM (NASA) and modern administrative borders extracted from GADM database (www.gadm.org, v.2.5 July 2015)

Author: Rémi Chaix

seems methodologically sound to delve into the particularities of a place before we launch into any comparison on a regional or global scale. ${ }^{1}$

In this volume, we scrutinize Kham through a sense of spatial anchoring and through the nexus of relations that contributes to its vibrant life. The various representations and perceptions of these lands are all equally valuable for our scholarly endeavour, for it is at the intersection of these that even a partial understanding of Kham can be reached. The contributions to

1 The emergence of a field of 'Kham studies' is to be linked to the gradual 'regionalization' of research on the Tibetan cultural area since the 1980 s. The construction of these new poles of regional studies ('Ladakh Studies', followed by 'Bhutan Studies', and 'Amdo Studies') should not distract us from a multipolar and integrated approach to the Tibetan world. About the development of Amdo studies, see the recent volume edited by Ptáčková and Zenz (2017), and in particular the Introduction by Emilia Róża Sułek and Jarmila Ptáčková (2017). 
this endeavour bridge historical investigations with contemporary ethnographies of Kham, focusing on a period of major transformations on various scales that started in the mid-nineteenth century. Given the involvement of external powers and the degree of these transformations, the notion of frontier dynamics seems particularly fitting and equally applicable to past and present patterns of change without ruling out Kham as a place in its own right. As anthropologists Lars Rodseth and Bradley Parker (2005, 9) pointed out, 'frontiers are the quintessential matrices of change'. We understand change as multidirectional and inherently dependent on forms of agency that generate hybridity as well as acculturation, social mobility as well as marginalization. The events and individual stories that several of the chapters recount are lived experiences of people who made history at their own level. They reveal the dynamics of exchange and interaction that influenced their trajectories in the complex entanglements of life at the frontier. As we try to capture these stories and these actors' perceptions of the events as they unfold, we unavoidably encounter the frontiers of our own experience, the limits and complexities of knowledge production. There is no typical frontier pattern and no reason to consider the American West as the model against which to assess other frontier experiences - or to discard the term altogether (see Klein 1996, Imamura 2015). The 'frontier' is very much part of the political imagination of China for example and, as Tim Oakes (2007, 243; also 2012) puts it bluntly, ' $t$ t]he western frontier has been a defining aspect of Chinese identity for several thousand years, making the U.S. version a mere blip in history by comparison'. Here, the common narrative of the frontier as a place facing expansive forces meets the metaphorical use of the term that discursively projects political imaginary onto the space characterized as a frontier.

This introductory chapter provides a framework for this approach to Kham by examining the literature and the conventional political, economic, and ideological topographies of the 'Sino-Tibetan borderlands'. I particularly bring to the fore frontier dynamics that lead to a topological reconfiguration in which the distance between binaries such as core/periphery and Sino/ Tibetan become distorted. Kham as a frontier is neither simply distant nor proximate and neither outside nor inside. From a Chinese perspective, the 'Tibetan' Other remains a vital but not absolute 'outside': it is intricately entangled, across differences, with a Chinese 'self'. From a Tibetan perspective, Kham is part of 'Greater Tibet' through a sense of a naturalized link between identity and territory, even though the exiled community itself constitutes a deterritorialized appendix. How has Kham managed to survive in spite of its spatial, administrative, economic, and political 
reconfigurations that led to the very transformation of its conditions of existence and forms of renewed vitality?

\section{Topographic Meanderings}

We often use 'Tibet' in various ways as a macro-regional category to refer to three overlapping layers: the geological expanse of the Tibetan Plateau, the 'Land of snow' (gang jong); the ethno-cultural entity that is conventionally called 'ethnographic Tibet'; and finally the political entity. All three layers encompass different places and societies, and there is generally no single term to describe them collectively. Before the idea of a 'Greater Tibet' made up of 'three regions' (chölkha sum), Ü-Tsang, Amdo, and Kham, gained prominence over recent years, Tibet was spatially divided into the 'upper region' of Ngari to the west, the 'middle region' of Ü-Tsang centred around Lhasa, and the 'lower region' of Dokham to the east (see Mills 2014, Ryavec 2015, Weiner 2016, Yang 2016). The issue, to which I will return, is that this ethno-cultural complexity questions where exactly an ethnographic Tibet starts and ends (see Weiner 2016), and the eastern edges of the plateau exemplify the problem of the crisscrossing of various ecological, cultural, and political zones. As a matter of fact, 'Tibet', like 'China', are changing historical entities with evolving contours, deeply influenced and shaped by successive political regimes.

The overarching toponym for the so-called Sino-Tibetan borderlands is Dokham, meaning the 'confluence (do) on the frontier (kham)', and can be further subdivided into Amdo and Kham. ${ }^{2}$ In other words, as Katia Buffetrille explores in her chapter, Kham can be understood as the frontier/ border that lies on the eastern edge of Central Tibet (Ü). The central part of the plateau, with its capital Lhasa, is generically called Bö (Bod), which often stands for our 'Tibet'. It is roughly speaking this area that corresponds historically to what in Chinese is referred to as Xizang (see among others Gruschke 2004a and b, Jagou 2010, Ren and Rdo rje 1991).

The strongly felt divide between Bö, Kham, and Amdo as spaces of respective regional attachment and belonging is key to understanding Tibetan diversity. Within each of these categories, it is common for the inhabitants

2 According to the White Annals (Deb ther dkar po) by the Tibetan scholar Gedun Chopel, 'Kham-Amdo' meant 'frontier' or 'border' in Tibetan, while the term 'Amdo', as a separate geographical designation, is a fairly recent invention. It is generally assumed that Kham and Amdo are equivalent to Dotö and Domé respectively. 
to identify themselves in reference to local toponyms or to the valley (yül) as a form of localized identity. This results in a fragmented landscape of 'homelands' (phayül, 'fatherland'), as Eric Mortensen discusses in his chapter about Gyelthang. In fact, Emily Yeh (2007) rightly points out that the sense of nativeness, to be 'born of this soil and rocks' (sakyé dokyé), is typically used to indicate one's belonging to a particular village or neighbourhood, not on a level of a broader collective identity.

Reference to the landscape when describing Kham as a whole is, however, evident in the designations 'the four rivers and six ranges' (chushi gang$d r u k$ ) and 'the four great valleys' (rong chenshi). These are the deep valleys formed by the Yalung, the Yangtze, the Mekong, and the Salween, running almost parallel to each other, which over the course of history have been important migratory corridors and have constituted pathways allowing for significant trade and cultural links. Exchanges and communication were sustained eastwards and westwards, and gave birth to major routes that connect China and Tibet. However, they have remained constrained by the high elevation ranges that separate them and the disjointed landscape of a tortuous crisscross of mountains. ${ }^{3}$

In Chinese, the mountainous barrier that made up the marches leading to the plateau has generally been referred to as a border or frontier (bian), and the name Kang, derived from the name in Tibetan (Kham), appeared relatively recently. ${ }^{4}$ Viewed from the east, the high-altitude passes of this mountain range are both limits and connecting points. Here, like elsewhere on the Empire's periphery, 'inner lands' (neidi) were clearly demarcated from lands that lay 'beyond the pass' (guanwai). In Kham, the town of Dartsedo (Dajianlu, today's Kangding) became the gateway to Tibet from China proper. It constituted a 'frontier portal' (Millward 1998, 153) and, for many people, it represented the border itself; it was the main node on the communication channels that linked both sides. Situated within larger networks of roads that developed in the course of the centuries, starting mainly in the Ming dynasty (1368-1644), it developed as a principal site for trade and commercial activity. Even today, 'the Chinese still refer to travel

3 I use conventional English names for these rivers which in Tibetan and Chinese are respectively called, from east to west: Nyak chu / Yalongjiang; Dri chu / Jinshajiang; Dza chu / Lancangjiang; and Ngül chu / Nujiang. These great rivers, to which the Dadu River next to the Minyak region further east should be added, drain the area which is made up of six highland ranges. The mountain ranges themselves are key elements in the delimitation of the Kham region. 4 Before the Chinese term Kang came into usage, one of the first mentions of Kham is to be found, for example, in the form of 'Kanma' in the Yuzhi pingding Xizang bei (1724). I thank Yudru Tsomu for bringing this to my attention. 
beyond Dartsedo as "going beyond the pass" (dao guanwai qu), implying that the other side of the mountain is a totally different world' (Tsomu $2015,3)$. This evokes the stereotypical vision of the 'frontier' as a contact zone between formerly separate populations deeply confined within their cultural attributes and various ecological determinisms.

These depictions still fail to render the texture of the lived space with all the layers and facets of the experience of place the inhabitants of these lands have accumulated. For various boundaries-ethnic, linguistic, religious, or cultural-crisscross the region and are often obliterated by the overriding binary of the Sino-Tibetan encounter. Regional boundaries are porous and therefore political and social processes move across these boundaries. A much needed ethno-history of toponyms would be revealing of the several topo-graphies: ways that people have been 'writing the earth' in their mutually constitutive relationships with the environment. These are stories of landscapes in their relation to human occupation, of pocketed communities and their sense of place, of a constellation of sacred 'powerful places', but also stories of various political reconfigurations, or expansions and their renaming practices. ${ }^{5}$

\section{Frontiers, Boundaries, Border(land)s}

Despite the permanence of the sense of identity Kham continues to portray, it is not a stable entity. It is made up of a constellation of places where encounters between various actors have produced a complex interweaving of various belongings and a nested sense of place. Given the diversity of local realities rendered even more complex by the contemporary context and by integration into the Chinese State, resulting in Kham being parcelled out between the Tibet Autonomous Region (T.A.R.) and several autonomous administrative units within Qinghai, Sichuan, and Yunnan provinces, it is unproductive to search for the unity of this region in a 'cultural core' subtracted from the centripetal and centrifugal forces that have been at work here. It is the combination of both its 'relative location' (van Spengen and Jabb 2009, 7) vis-à-vis China proper and Central Tibet and its own

5 Little in-depth research on toponymy has been undertaken yet it is certainly a long-awaited contribution. See, however, the work carried out through the Tibetan and Himalayan Digital Library (THDL). For the name of 'Tibet', see Jagou (2010), and for toponymy in the Gesar epic, see Chayet (2003). Several bilingual (Tibetan and Chinese) volumes providing lists of place names (diming lu) have been published in China since the mid-1980s, but they are often problematic and seldom reliable. 
multifaceted internal composition that contribute to making Kham a locale where specific identity, territorial, economic, and social processes take place. Can the terms 'frontier', 'boundary', or 'borderland' capture some of these processes?

Let us briefly synthesize the spatio-temporal variation of Kham as an inbetween place surrounded by two power centres and highlight its changing political geography (see Maps 1.2 and 1.3). As mentioned in the historical account provided with the chronology of events, Chinese imperial expansion led to the first materialization of the border between China and Tibet in the form of a stele (1727), a single anchorage point in the mountainous landscape of Kham that was meant to symbolize a linear frontier of territorial engulfment. It was a visual marker on one of the two major trade routes, which was also the so-called 'official's road' (Ch. guan dao, Tib. gyalam, 'wide road') connecting Sichuan to Central Tibet. It was to take two centuries for this stele to turn into a more clearly demarcated extended frontier zone on the map for the purpose of specifying, according to Western standards of sovereignty, the territorial distinction between China and Tibet. This led to drawing several borderlines, each according to competing claims put forth by Tibetan and Chinese authorities and mediated by the British at the Simla Convention (1913-1914) (see Map 1.2; see also Relyea, this volume). China's claim over this transitional zone that Kham had long constituted resulted in the border zone ('Sichuan border', Chuanbian) being reconfigured as an administrative unit with shifting borders (redrawn in 1926 and 1939), which became the short-lived province of Xikang (1939-1955) (see Map 1.3). Here we have a good example of how China's territorial expansion relied on 'imperial machineries' that aimed at transforming these frontiers, 'plastic intermediate zones' (Crossley, Siu, and Sutton 2006, 3, 17) into 'legible state spaces' (Scott 2009). Finally, after the founding of the People's Republic of China (1949), Xikang province disappeared from the map, and Kham was divided between several provinces, mostly outside the Tibet Autonomous Region. The administrative boundary between T.A.R. and the province of Sichuan has since played a critical role in the becoming of places and the people it separates (see Buffetrille, E. Mortensen, and Cho, this volume).

The changes outlined above remind us of the organic metaphor that historian Michel Baud and Willem van Schendel $(1997,223-225)$ put forth as a developmental model of the borderlands corresponding to a five-stage life-cycle, from infancy to adolescence and adulthood, then decline and disappearance. However, this depiction tells us far less about the borderlands themselves than about the Chinese perspective and the explicit claim since the early twentieth century that this borderline was in fact an internal one; 


\section{Map 1.2 'Inner Tibet' and the limits of Central Tibet Government according to McMahon's line (Simla Convention)}

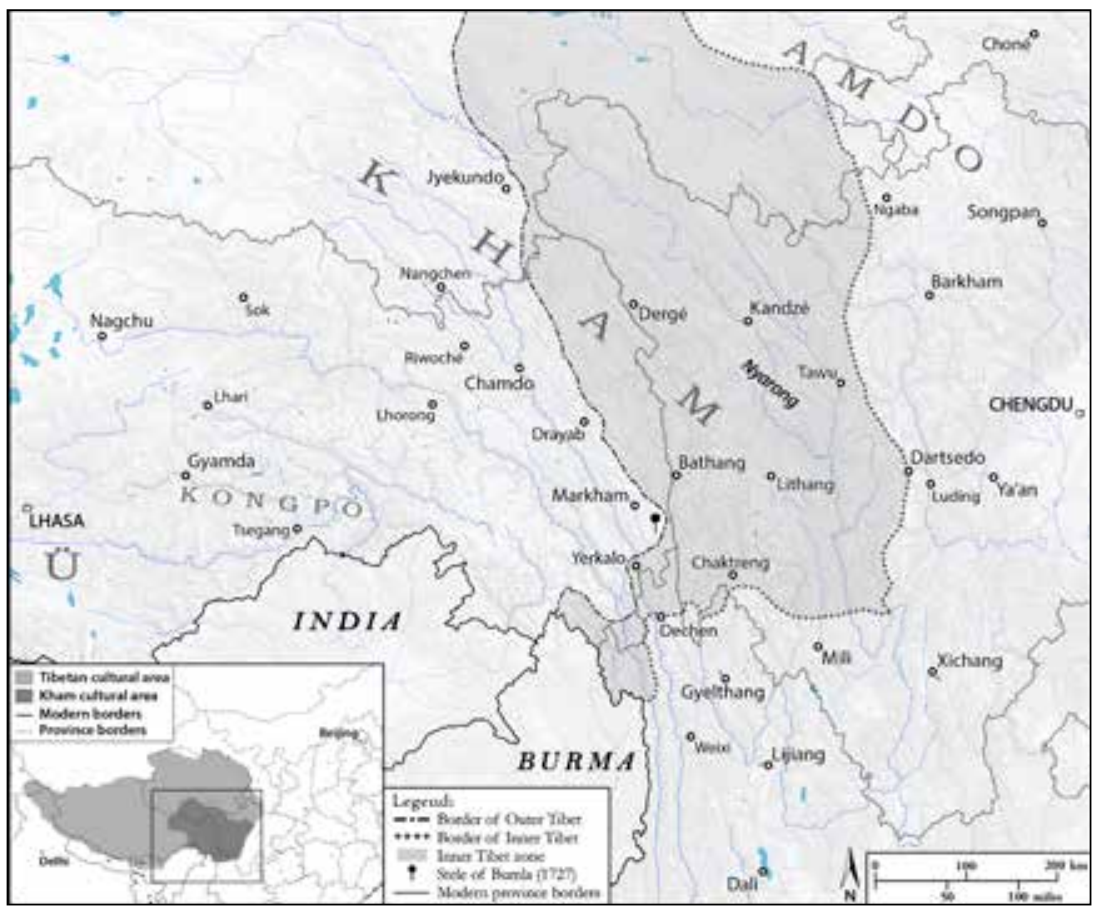

Sources: Based on Richardson (1945); SRTM (NASA) and modern administrative borders extracted from GADM database (www.gadm.org, v.2.5 July 2015) Author: Rémi Chaix

a claim highly contested by the Tibetan government, but 'officialized' by the Simla Convention's use of the artificial labels of 'Outer Tibet' and 'Inner Tibet'. From both perspectives, on the other side of the disputed borderline that cut through Kham there was not an outside but an integral part of their respective 'geo-body' (Winichakul 1994). Yet, these two perspectives ultimately erased other indigenous knowledge of political space. The two frontiers clashed with each other and the borderland itself remained 'embryonic' (Baud and Van Schendel 1997). In fact, Kham became one of these 'inner frontiers' of China, discussed by Owen Lattimore (1951, 234), a quality it has retained to this day. The administrative border that separates the Tibet Autonomous Region from its adjacent Tibetan administrative units in Qinghai, Sichuan, or Yunnan has created a strong dichotomy in terms of both policies and cultural dynamism. In light of these spatio-temporal changes, we are now better equipped to clarify how the terms 'borderland', 
Map 1.3 The borders of Xikang province as defined in 1933 and 1939

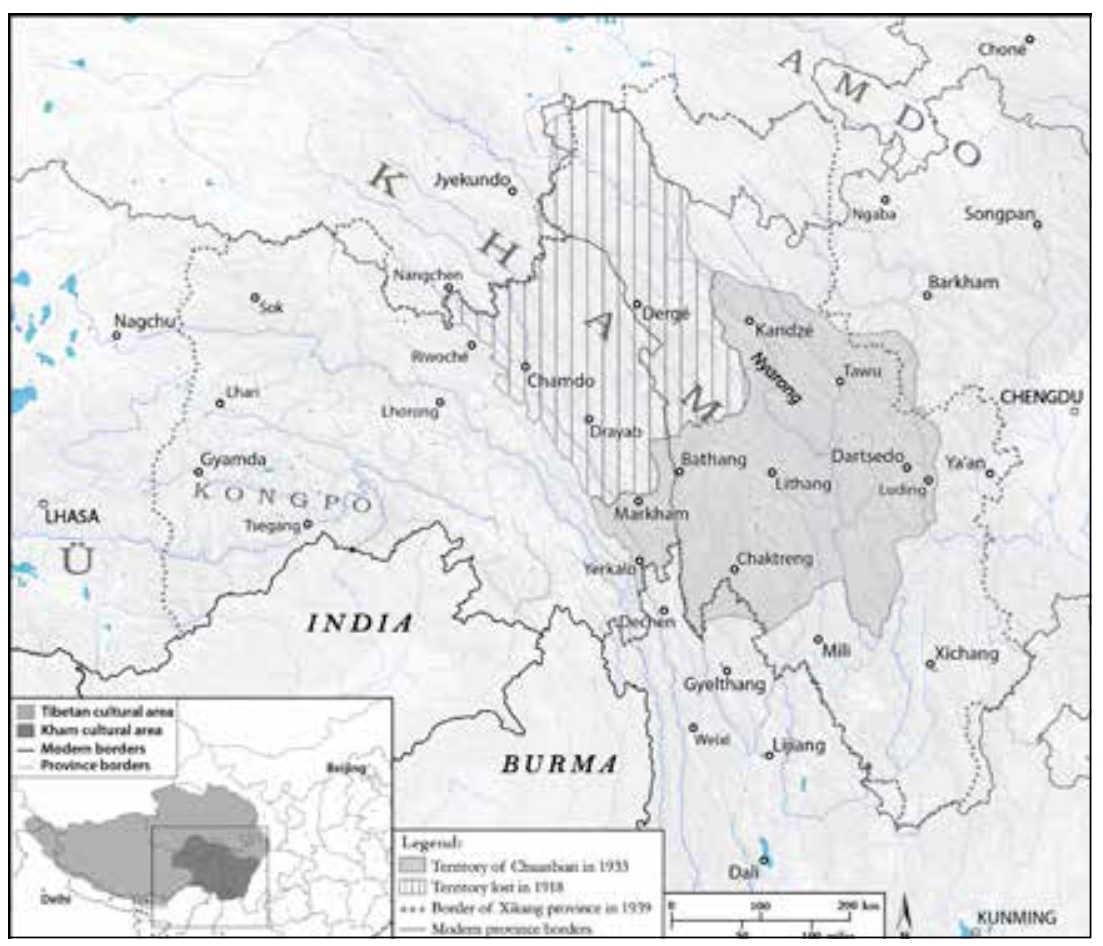

Sources: Based on Ren Naiqiang (1933), SRTM (NASA) and modern administrative borders extracted from GADM database (www.gadm.org, v.2.5 July 2015) Author: Rémi Chaix

'boundary', and 'frontier' equally apply to the case of Kham as they each refer to different specificities. Let us clarify our lexicon in this context. ${ }^{6}$

While the word 'borderland' has been widely applied to various regions and contexts similar to frontier zones, it is, however, defined by the presence of an actual border. If border designates an international boundary line, we have seen how the drawing of such a line between 'Tibet' and 'China'

6 The approaches are just as diverse as the definitions of these terms, and here I can only clarify my use of them for the purpose of the present discussion. Twenty years ago, two books discussed the by then already extensive literature and diversity of approaches to borders, frontiers, and boundaries, i.e. Donnan and Wilson (1999); Rösler and Wendl (1999); and the same year Adelman and Aron's (1999) seminal article was published. See also Hall (2005) and Parker (2006) in particular for a discussion of the terminology. Much has therefore been written since then in the fields of 'border studies', 'frontier studies', and 'borderland studies' and it is beyond the scope of this section to do justice to this very extensive literature. 
through Kham was attempted but ultimately failed - and transformed into an internal one within the administrative division of the P.R.C. The boundary did not disappear because of the impossibility of such a border in the given geopolitical context at the time. This boundary not only indicates in spatial terms a division imposed by the topography but also refers to a more dynamic sociological one through processes of exclusion or incorporation that take place on the edges of socio-political units or between ethnicities for example, as the interactional approach introduced by Barth (1969) has long demonstrated regarding ethnic formations.

Seen from the distant centres, Kham was a frontier, a meaning that the name in Tibetan is said to convey. It was not a static frontier, nor was it reducible to a fluctuating colonization front but it was a dynamic, permeable, and shifting space; in other words, a 'frontier zone' similar to other spaces of imperial expansion such as those depicted by Peter Perdue in his seminal study China Marches West (2005). Frontiers and borderlands function in tandem. The Chinese word bianjiang, or the French word frontière, both conflate the two meanings. Katia Buffetrille (this volume) shows that in Tibetan the vernacular terminology 'defines the borderlands as places to be defended or to be made civilized'?

The notions of borderland and frontier clearly overlap when understood as zones of contact (e.g. Pratt 1991) and of intense interactions, composed of various types of boundaries (i.e. geographic, political, demographic, cultural, and economic), and which can rapidly change according to local circumstances. This locally variable volatility is a special characteristic of frontiers and borderlands alike, where the transboundary solidarities and alliances that take place, often motivated by economic interest or livelihood strategies, become invisible if we look through an exclusively territorial lens of the border defined as the 'end of the state', subsumed to the one-dimensional issue of national sovereignty. Looking at Kham as a

7 As Mark Elliot (2014) recently discussed, the distinction between the terms in English can hardly be portrayed by translation into other languages, whether it be French and Chinese, or Manchu for that matter. It should, however, be noted that because of the nuances in the English terms, a coinage like jiequ is now often used in Chinese to refer to 'borderlands'. For a very detailed survey of the terminology related to frontiers, borders and boundaries in Chinese historical texts, see Calanca and Wildt (2006). Etymologically, the French frontière originally refers to a military front and the extension of civilization; its different levels of meaning are more complex however. See for example Febvre (1928) and the constructive discussion in Jeanpierre (2010). I hope it is clear for the reader that my use of 'frontier' here is distinct from that of Frederick Jackson Turner (1861-1932), whose frontier thesis and Anglo-American centric definition of the frontier as the 'meeting point between savagery and civilization' (Turner [1893] 1994, 32) has led many to abandon the use of the word altogether. 
frontier or a borderland should not limit us to a state-centric view: there are many places in Kham that could be considered as having been central in many different ways because of their economic, political, cultural, or religious role. After all, Kham saw the emergence of multiple independent polities, such as the powerful kingdom of Dergé that could rival with religious centres in Central Tibet, or that of Chakla, with its capital at Dartsedo that made it the gateway to Tibet from China. There were four main kingdoms (Dergé, Chakla, Bathang, and Lithang) in Kham, which declared allegiance to the Qing emperor and for this reason became known in Chinese as the 'four big indigenous chieftains' (si da tusi). ${ }^{8}$

A multidimensional and relational approach to Kham is indeed necessary if a thorough examination of the range of connections constitutive of the social fabric is to be made. Our collective investigation in this volume considers historically specific geographies of social relations and forms of interconnection that denote the different dimensions of space and scale, territory and network (see Jessop et al. 2008; also Rumford 2012; Giersch 2016). As Lawrence Epstein pointed out in his Introduction to the seminal volume Khams pa Histories (2002), frontier processes are both political and discursive. There is a wide array of voices to be taken into account depending on whose perspective we adopt. We can only offer a polyphonic assemblage, furthermore limited by the range of archival or ethnographic sources. Thus, the fragmentary politico-religious landscape and complex cultural matrix of Kham necessarily results in 'multivocality'. I would argue that it also requires us to pay due attention to its constitutive 'multilocality' which we can address, according to the anthropologist Margaret Rodman (1992, $641)$, as the 'politicized, culturally relative, historically specific, local and multiple constructions' of places affected by influences of imperial history, modernity, and contemporary contexts. The chapters in this volume set out to explore these dimensions by considering diverse spatial entanglements and historical (dis)continuities.

\section{Relational Spaces}

Some regions, particularly contested frontiers, continuously defy categorization in conventional terms altogether. The historians Mark Lewis and

8 There were, however, many other smaller polities in Kham. The Qing Empire's indirect rule relied on 'indigenous chieftains' (tusi) to levy taxes and other duties, such as quelling 'rebellions' for which they received military titles. 
Kären Wigen (1997) have provocatively challenged the limits of our spatial lexicons for anthropogeographical analysis and in so doing have drawn up four particularly productive models: the middle ground, the archipelago, the diaspora, and the matrix (ibid., 142-156). Each helps to grasp how cultural territories are increasingly being cross-cut and redefined by networks and mobility, as growing diasporas of merchants, migrants, and refugees around the world lead to mutations of conceptions of place and identity on different scales. But before I return to the notions of 'middle-ground' and 'matrix' in the context of the Sino-Tibetan borderlands and in relation to 'frontier dynamics', it is necessary to further clarify the implications of an approach to Kham not as a regionally confined space but as a process-oriented spatial formation.

In the context of a re-evaluation of area studies and borderland studies, Willem van Schendel's (2002) proposal to design an unconventional regional area as a heuristic was a particularly powerful intervention: 'Zomia' (the land of highlanders) not only created an arena of alternative thinking about borderland areas where Central, South, Southeast, and East Asia meet but also started a new narrative of place inspired by process geographies. This toponymic invention has since taken on a life of its own, especially following the publication seven years later of James Scott's (2009) depiction of Zomia as an area where people strategically keep the state at a distance, helped by the 'friction of terrain'.

Much debated, Scott's (2009) book helped shed some light on a vast territory that was overlooked by various 'center-centric' gazes that kept reproducing a centre-periphery paradigm without renewing an understanding of these peripheral zones. For all the productive discussion it triggered, Scott's Zomia is, however, only one way of looking at a more general methodological and conceptual challenge that the region offers us, as Jean Michaud (2000, 2006, 2010,2017 ) has been particularly apt at showing. As geographical and cultural concepts, however, we may still wonder, as Michaud queries (2010, 212), whether 'notions such as Zomia, the Southeast Asian Massif, the Himalayan Massif, or Haute-Asie, have [ever] been needed by the subjects themselves'. In our case, doesn't Kham already stand as a categorical challenge of a kind - without us having to coin another Zomia-like term?

This volume complements recent interventions which for a large part engage the now quite inescapable notion of Zomia and take borderlands as an entry point into issues of agency, sovereignty, and transnational connections. Yet the problem remains: how can we productively think about Zomia as a place if it is after all a kind of borderland-cum-frontier zone, which should be addressed as a process? In this regard, Kham is not 
posited in this volume as a prescribed geophysical regional framework but as a fragmentalized space of interconnected and interdependent locales and people. By looking at Kham through diverse lenses and approaching it on varied scales, and combining history and anthropology, the chapters take into account different forms of conjunctions and territorial belongings conceived as heterogeneous, discontinuous, and relational (e.g. Cartier 2002, Jessop et al. 2008).

In other words, Kham is a good-to-think-with category. As we move away from a purely spatial definition, there is one important question that 'Zomiathinking' (Shneiderman 2010, 293) forces us to address: by operating a kind of topological reversal by which the borderlands (the in-between) of culture areas and political centres come to the foreground, it raises the question of self-determination and sovereignty. As the etymology of the term region conveys, a region is a form of spatialization of sovereignty, a spatial entity (regio, 'direction, district') where a form of control is exercised (regere, 'to rule, direct'). The region as a place of otherness destabilizes and complicates the claims of powerful centres (Rafael 1999). Kham offers a rich historical and ethnographic challenge to those who want to articulate the parts and the whole of a regional category, and what it 'is' and 'does' (see Paasi and Metzger 2016) as I will further analyse in the last part of this Introduction.

Historical and contextual specificity should certainly inform the way we think about regional formations. Whatever the scale, regions are not timeless entities but are shaped by diverse historical forces and often reorganized economically and politically through multiple cross-cutting influences. At the same time, we need not assume that any of these regions are discrete, continuous blocks, even when they are named and seem on the surface to constitute the basis of some kind of unity - whether cultural or otherwise. At the heart of our inquiries lies the apparent paradox of Kham as a named regional category and at the same time a heterogeneous frontier zone and nexus of power.

\section{Archaeologies of Sovereignty}

The history of Kham when regarded as a frontier zone has to be set against the background of geopolitical tensions between Lhasa-based regimes and China-based regimes, and the growing presence of Western powers. ${ }^{9}$ Tensions arose mainly during the mid-nineteenth and early twentieth 
centuries and revolved around issues of territorial integrity, sovereignty, and nationhood. The issue at stake was the definition of where the eastern border of the Central Tibetan polity should be in relation to the Chinese polity and therefore the determination of the respective territorial reach of the interlocutors, as alluded to above (see Maps 1.2 and 1.3). This was at the very least an ambiguous issue, given that imperial formations do not end at their geographic boundaries, and that the expansive states of Tibet and China similarly contributed to creating zones with overlapping forms of authority at their peripheries (see Lattimore 1962, McGranahan 2003a, 2003b, 2007, Perdue 2001). But the adoption of standards derived from international law and the notion of sovereignty in a modern sense, as Scott Relyea discusses in his chapter, carried implicit recognition that the outside of the nation is another nation's inside.

It should first be emphasized that several 'sovereignty regimes' (Agnew 2005) have to be taken into account. The confrontation of the two centres that contributed to making Kham a site of overlapping and fragmented sovereignties, a 'Sino-Tibetan' borderland tied to larger geopolitical issues, is the result of the emergence in the nineteenth century of the nation-state as the primary vehicle of sovereign power. As Benedict Anderson (1991) demonstrated, this Western-born notion that was to become an international standard created a new spatialization of authority, which implied that boundaries were part of what define the state and its sovereign rule over a homogenous territory. ${ }^{10}$ At the turn of the twentieth century in the case of Tibet in its relation to China and British India, there was no clearly marked boundary. The imperative to map the territory and to identify its borders clearly with respect to a bounded sense of statehood became most pressing.

There were various attempts to draw a borderline in Kham, and today the linear demarcation is internal to the Chinese nationscape between T.A.R. and other provinces such as Sichuan and Yunnan. These arbitrary territorial and administrative divisions have been acquiring greater salience and verisimilitude, but as Charlene Makley has argued for Amdo further north, in Kham too 'these modern boundaries are just the most recent in a long history of contending "maps of power" over the region' (2003, 599).

We know of at least one attempt at an alternative geography of Kham that was formulated in the late nineteenth century by the polymath Jamgon

10 European powers increasingly relied on border treaties to define the territorial sovereignty of individual states following the 1648 Treaty of Westphalia. In its political dealings with European nation-states, China was forced to clarify its borders and what remained of its frontiers. European colonial powers forced upon China the Western concept of treaty-defined territorial sovereignty. 
Kongtrul (see Gardner 2006, 2009; Zangpo 2001). In a text entitled the 'Twenty-five holy sites of Dokham' (Dokham né chen nyer nga), a selection of religious sites are drawn together to elaborate what Alexander Gardner $(2009,98)$ calls a 'narrative map'. As Gardner shows, it was a symbolic rather than scientific and political attempt to establish the geographic existence of Kham through the grouping of meaningful and powerful places in the landscape. Significantly, this grouping was inclusive of Kham's religious diversity - the region saw the blossoming of diverse religious sects in the eighteenth century - but exclusive of Geluk sites. Therefore, the spatial and religious unity of Kham represented by Jamgon Kongtrul's 'map' was a reaction to the 'looming annexation of his homeland' by Central Tibet, which in 1868 he perceived as the 'invader' (100), even if in the end it was China that appropriated Kham.

If the Ganden Phodrang and Geluk domination was what constituted a threat to Kham's identity in the eyes of Kongtrul, it was also at this particular time in history that Gönpo Namgyel strived towards a political unification of Kham and 'dared to defy the authority of both centers of power' (Tsomu 2015, 132) until his expansion was halted by the Lhasa government. An insider's perspective thus shows that external territorial threats and claims came from both Central Tibet and China; it also shows, perhaps more importantly, that there was a diverse but nevertheless resilient sense of centrality. As Amy Holmes-Tagchungdarpa $(2011,8)$ has argued, the main polities (kingdoms) in eastern Tibet 'ultimately conceived of themselves as their own centres, even as other centres tried to define them as the periphery' (see also Turek, this volume).

Kham never displayed a stable religious or political unity. However, the 'self-rule' movements of the 1930s exemplify how new visions for political action were taking shape in response to Tibetan and Chinese nation-building projects, and how forms of regional autonomy were strategically devised (Peng 2002). ${ }^{11}$ For many eastern Tibetans the potentiality of unity resurfaced when invasion and military enforcement of Chinese rule made it necessary to have recourse to a form of national cohesion; resistance was strong in Kham and the rebel army (significantly named the Chushi Gangdruk) joined

11 See in particular Duara (2003) for a discussion of imperialism and nationalism in China in the twentieth century. While nation-building has often been approached in terms of the influence of Western concepts, Tuttle (2007) makes an important contribution to the reconsideration of the Sino-Tibetan interface on Tibetan terms, by underlining the role that Buddhism played in China's transition to a nation-state, thereby portraying the Chinese nationalist narrative as not purely secular. On the role of Buddhism during the national construction of the republican period, see also Bulag $(2007,33-40)$. 
forces with Tibetans in Lhasa. Kham has since become closely associated with its 'warrior' spirit and is regarded as a place of resistance (McGranahan 2010, 61; Norbu 1986). Resistance then became a national project and it is in this context that the 'three regions of Tibet' (chölkha sum) are referred to as 'provinces' and have been given an aura of political unity (Mills 2014; Weiner 2016).

The Sino-Tibetan frontier was clearly not a no man's land and there existed former politico-religious arrangements which, according to Geoffrey Samuel's (1993) overview of Tibet's political history, were part of a continuous field of a wide variety of political and social formations. In her discussion about the critical intervention of British diplomacy in the frontier dispute, Carole McGranahan (2003b) points out that in Tibet, 'state organization operated under different principle and organizational strategies' compared to the nation-state; therefore, different understandings of statehood and authority made the delineation of the eastern border between Tibet and China 'the one issue that consistently impeded the passing of any treaty' between China, Tibet, and Britain (2003b, 40; also 2010, $42 \mathrm{ff})$. That such a clear boundary did not exist exemplifies the fact that there remained a contested area with overlapping zones between the two centres' claim to sovereignty and territorial integrity on the one hand, and the constellation of polities themselves in Kham on the other hand.

This fragmented political landscape with its local models of jurisdiction and often competing allegiances was also made up of an intricate network of religious institutions belonging to different Buddhist sects. In the context of Tibetan areas, therefore, while it has often been pointed out that rule was more a matter of control over people than land, such rule also involved some ritualistic components linked to local territorial deities, and could rely heavily on monastic institutions that exercised authority over agricultural and nomadic land and levied taxes. In other words, access to land for subsistence farming and for subsequent taxation was an important factor in territorial demarcations and in the political systems or patterns of relations within or between communities. ${ }^{12}$ One aspect that certainly complicates our understanding of the variations of configurations that existed and the diversity of indigenous notions they mobilized is the importance of the multi-ethnic make-up of the region and the various religious traditions.

12 See Huber (2004, 142-143) about ritual practices (ri-khrims or ri-rgya) that entail a claim or control over a territory, at local community or state level, with reference to Amdo and Kham. Macdonald (1987) laid the ground for a comparison across the extended Himalayas of indigenous notions of authority that can be linked to the emergence of the state. 
Cults to mountain deities that control particular territories can, for example, contribute to the inhabitants' sense of identity (Karmay 1994). Spiritual landscapes animate local identities and territorial deities have long played an important role in local notions of authority and sovereignty.

What is conventionally referred to as 'ethnographic Tibet' or 'historical Tibet' ${ }^{\prime 3}$ is often presented as corresponding to a complex mixture of societies loosely connected together, each of which represented a peculiar type of political institution and system of authority. Among the various political entities in Kham under religious or secular rulers, there is also evidence of the limited degree to which an aristocratic or monastic estate could exercise its authority over its peasant tenants or nomadic clients. Some of these polities, however, were fairly centralized states, generally kingdoms, with recognized figures of authority (kings, gyelpo) such as in Dergé or Chakla, estates ruled by chieftains or lords (pon), or territories headed by hereditary lords (depa), such as Bathang and Lithang, designated by the Lhasa government (the Ganden Phodrang).

One of the challenges when writing about these political formations is the use of Western terminology, such as 'nation-state' in relation to forms of centralized political authority and control, or more generally the application of notions of sovereignty or nationalism to socio-cultural realities that are not entirely fitted to our conceptual tools. Even more challenging and important, however, is to re-think notions such as (territorial) sovereignty and its foundational assumptions in a comparative perspective that would take full account of indigenous notions beyond those that come from the two main centres. ${ }^{14}$ When the anthropologist Edmund Leach $(1960,49-50)$ was writing about the 'frontiers of Burma', he rightly alerted us to the 'dogma' of sovereignty as 'a by-product of the clash of European Imperialist interests'. He pointed out that in the case of Burma and adjacent regions, the political systems interpenetrated and that in this context their delimitation should not be equated with the hard line of the border between sovereign nationstates but should be considered as 'zones of mutual interest'. This formulation is also reminiscent of the work of Owen Lattimore, a prominent figure in

13 Historical or ethnographic Tibet encompasses both the predominantly Tibetan areas located in today's Sichuan, Yunnan, Qinghai, and Gansu provinces and the Tibet Autonomous Region. In some works, the latter is also referred to as 'political Tibet', see for example Goldstein (1998, 4), and the discussion in McGranahan (2010, 48-52).

14 While the need to revisit the notion of sovereignty is even greater for the contemporary period, the conventional understanding of sovereignty as a state's unlimited and indivisible rule over a territory and its population has been increasingly examined and challenged (see Biersteker and Weber 1996; Benite, Geroulanos, and Jerr 2017). 
the history of 'Inner Asian frontiers', who stated that 'the linear Frontier never existed [in China] except in concept. The depth of the trans-Frontier, beyond the recognized linear Frontier, made possible a historical structure of zones, which varied from time to time' $(1962,115)$.

Kham exemplified several of these 'zones of mutual interest' where overlapping forms of authority sometimes led to multiple allegiances, and as Thomas Hansen and Finn Stepputat $(2006,295)$ presented in their discussion about sovereignty, in such places and societies 'sovereign power historically was distributed among many forms of local authority'. Places where borders have indeed crystallized at various historical moments were subjected to influences of varying intensity emanating from multiple centres. And so much so that belonging and allegiance themselves could be variable and multiple, favouring specific forms of sovereignty, anchored in the liminality of these zones.

\section{Frontier Dynamics}

Recent scholarship has overall significantly contributed to a multipolar social history of Chinese and Tibetan worlds and their internal diversity. In such works, conventional unitarian visions of 'China' and 'Tibet' are unsettled, opening up to the different forms of relations that existed between the centres of power and the various groups under their rule or influence, and foregrounding the diversity of frontiers themselves, away from the highly polarized antagonism and with closer attention to local agency.

There is now growing literature on the borderlands of China that emphasizes the need to include indigenous conceptions and actors in historical narratives of place-making. ${ }^{15}$ Most of the recent contributions about the histories of specific locales within the Sino-Tibetan borderlands have offered a thicker description of events and people in the making of these histories. In this endeavour, the 'middle ground' approach developed by Richard White (2011 [1991]) in his study of the processes of mutual accommodation and creative misunderstandings between Algonquian-speaking Indians and French, British, and Americans in the Great Lakes region between 1650-1815 has proven particularly inspiring. As histories of China's Southwest started to highlight border transformation mechanisms, resistance movements,

15 Most notably all the contributions that fall within the so-called 'New Qing history' (see for an overview Waley-Cohen 2004; and more recently Wu 2016), as alluded to in the Foreword to this volume. 
identity processes and ethnic entanglements (e.g. Atwill 2005; Herman 2007), C. Patterson Giersch $(2001,2006)$ applied the 'middle ground' model to his analysis of the negotiations between Tai polities and Qing officials across Southern Yunnan province. This approach has opened avenues for a deeper understanding of historical agency in other parts of Southwest China. There is now greater attention to indigenous agency beyond the role of elites and more in-depth analysis of the dynamics of colonial expansion and the need to break out of the centre-local typology (e.g. Faure and Ho 2013, Weinstein 2014, Lawson 2017).

Bridging studies of China's Southwest with those of eastern Tibet, Yudru Tsomu (2009) distinguishes an 'official' and an 'unofficial' middle ground in her study of the Chakla kingdom of Dartsedo, notions she equally applies to describe the situation of other polities in Kham (Tsomu 2015). The 'official' middle ground corresponds to the negotiations of forms of accommodation, albeit limited, that took place in the political and administrative dealings between local Tibetan leaders and the Qing administration. The 'unofficial' middle ground corresponds to the social interactions, cultural contacts, and exchanges that developed through trade and economic activities, involving merchants and immigrants. Similarly, Patrick Hayes (2014) draws on this distinction in his environmental and social history of the Songpan (Zunchu) region of northern Kham, and shows how adaptation to ecological conditions is an important factor in the formation of the 'middle ground' at these two levels.

These depictions point to the diversity of experiences on the ground and to the need to acknowledge the reality of a felt sense of centrality of some of Kham's communities at different times in their history (see also Jinba 2014; Holmes-Tagchungdarpa 2014; Kang and Sutton 2016). In other words, they raise the questions: how is our understanding of local history reconfigured if we 'see like a border' (Jinba 2017; Jonhson et al. 2011, 67; Rumford 2012, 896) and fully acknowledge the agency of local inhabitants in processes of change? How can we centre the narrative more on local people's role in socio-political and environmental transformations?

If Kham makes for a comparable case of continuous frontier engagement, like the one studied by C. Patterson Giersch in the Sino-Southeast Asian borderlands, it is not only for its 'middle ground' specificity but also for its maintenance as a 'persistent frontier' (Giersch 2006, 9). One of the reasons for this persistence is precisely, as we have seen, because the border never materialized. It is also because the frontier remained the locus of historical dynamism, modulated by change. The comparative model proposed by Bradley Parker (2006) of a 'continuum of boundary dynamics' that 
Figure 1.1 The Continuum of Boundary Dynamics, from Parker (2006) ${ }^{16}$

\section{BORDERLANDS}

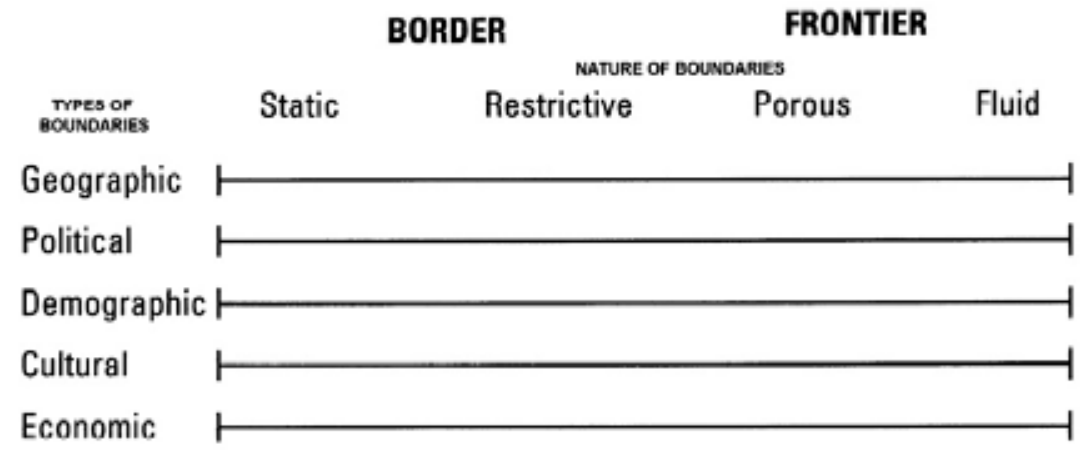

forms what he calls the 'borderland matrix' is helpful here in tracing this 'persistence'. For the purpose of this model, Parker defines borderlands as 'regions around or between political or cultural entities where geographic, political, demographic, cultural, and economic circumstances or processes may interact to create borders or frontiers' (81). The variations among these processes are conceived on a continuum from the more static and limiting border situation to that of the fluid and less constrained frontier situation (see Figure 1.1).

In Kham, the geographic (topographic, climatic) boundary was fairly restrictive, marking a clear border as one entered the Tibetan world. The political boundary similarly became an increasingly constricting one as attempts were made to delimit a border. The demographic and cultural boundaries remained porous, even if the numeric importance of immigration was not very significant until recently. But when this is set against a longer time period, we can see both a tendency to maintain cultural and ethnic distinctions and forms of 'merger' or 'fragmentations' (see Rodseth 2005, Gros 2014b). The economic boundary was probably the most fluid, and a crucial aspect of Kham's economic dynamism, and relative political and cultural importance throughout history.

Overall, one interesting thing regarding this model is that it confirms that the different boundaries are not congruent. This way of conceptualizing the

16 The five major categories of boundaries (boundary sets) are further subdivided and, for example, the 'Demographic boundary' in the figure encompasses population density and ethnic composition, and the 'Cultural boundary' includes religious as well as linguistic boundaries. 
borderland is not without similitudes with what was proposed under the label 'Tibetan-Yi corridor' (Ch. Zang-Yizoulang), a designation originally coined by the famous Chinese anthropologist Fei Xiaotong (1910-2005). Over the last two decades this corridor, running along the eastern edge of Kham but extending further north and south, has been a lively field of study across disciplines (see Li 2008, Shi 2005). However, this 'ethnic corridor', as it is also called, has never been clearly defined (see Gros 2014a, b) but serves as a moniker for an approach to the linguistic, ethnic, or cultural variability set against the historical longue durée. In areas that could be regarded as the edges of Kham, the borderlands are less clearly Sino-Tibetan and more Naxi-Tibetan or Yi-Tibetan or, as Eric Mortensen discusses in his chapter, not even borderlands at all.

\section{Knowledge, Imagination, and Utopia}

Now what's going to happen to us without barbarians? Those people were a kind of solution. - C.P. Cavafy, 'Waiting for the Barbarians' ([1975] 1992)

As we consider various approaches to the Sino-Tibetan borderlands, it is worth reminding ourselves that ethnology as a discipline developed in China in close connection with frontier studies. Consider the year 1926: the famous educator and reformist Cai Yuanpei (1868-1940) published a seminal article that officialized the term minzu xue to designate the ethnological discipline; the same year Wu Wenzao (1901-1985), then still a sociology student at Columbia University, promoted bianzheng xue, the 'study of frontier affairs', framed as an inclusive approach to the cultures of peripheral peoples that in turn influenced the development of field anthropology. ${ }^{17}$ During this same period, the scholar Li Anzhai (1900-1985) who became

17 See Cai (1962 [1926]) and Wu (1990 [1926]). Professor at Yanjing University, Wu Wenzao moved to Kunming where he founded the Department of Sociology at Yunnan University as well as the Yunnan Ethnology Society (Yunnan minzu xuehui). He became the mentor of a generation of ethnologists in the 1930s, including Fei Xiaotong and Lin Yaohua (1910-2000). About Wu Wenzao, see in particular Wang $(1999,2000)$. While Wu Wenzao's approach to development in border regions was inspired by the methods developed for colonial administration in the United States, Ling Chunsheng, a student of Marcel Mauss and Marcel Granet in Paris became one of the main actors in the promotion and institutionalization of ethnology as applied to frontier issues (Brown 2008, 56-90). Field research had proven to be a necessary tool for colonial powers to manage and control their empires, and as Chen Zhihong (2017) recently demonstrated, a similar methodological shift happened in China in disciplines such as anthropology, sociology, geology, 
one of the founding members of the study of Sino-Tibetan borderlands, advocated 'social work' and 'frontier service' at the borders as a project to modernize and promote the development of minority societies (Chen 2010, 106-130; Rodriguez 2011; Yen 2012).

The republican period was dominated by the experience of a 'frontier crisis' (bianjiang weiji) and the question regarding the place that ethnic and cultural diversity could hold in nation-building. A plethora of diverse frontier study societies sprang up that proposed ways of developing the frontiers. 'Go to the frontier' (dao bianjiang qu) was a dominant slogan of the intellectual and political life of the republican era that encouraged the study and ethnography of these frontiers, where migrants had settled and new cultivated lands had been established, where agents were charged with carrying out cartographic and topographical surveys, and new natural resources had been identified. ${ }^{18}$ While the 'frontier' was reinterpreted and naturalized as a quintessentially national space it was also the site of ambivalent attitudes; 'frontier reconstruction' remained 'work in progress' and contested ground between both scholars and officials. The new provincial entity of 'Xikang' is a case in point. During the Sino-Japanese war, it appeared in official propaganda as an example of frontier provinces contributing to a national united war effort, promoted by the rising power of the warlord Liu Wenhui (1895-1976) who held the reins of Xikang's construction. To extend their influence, Chiang Kai-shek and the Guomingdang (G.M.D.) pursued a policy of economic reconstruction involving large investments in transportation and communications, which allowed for effective penetration of the region and ensured the central government's role in its development. ${ }^{19}$

After being resettled in the provinces of Yunnan and Sichuan where universities were displaced during the war, Chinese ethnologists or anthropologists, many of whom had returned from study visits abroad, conducted the first field surveys on ethnic groups in border regions. In short, this period was a golden age for the development of the discipline, and the southwestern borders an ethnographic paradise. During this period Kham became an important locale for new imaginings of the nation's geo-body. The border

and modern geography, and 'field research was linked to scientific spirit, and was regarded as an important symbol of new-style intellectuals' (217-218).

18 See in particular Chen Zhihong's (2008) study which rightly places this movement during the republican era in the broader context of modern 'territoriality'. James Leibold $(2007,51-79)$ has demonstrated that at the political level, 'border administration' (bianzheng) was based on a genuine willingness to establish minority allegiance.

19 For example, by creating the Sichuan and Xikang economic development committee in March 1939. See Lin Hsiao-ting (2006). 
zone was raised to province status: a 'New Xikang' open for travel, discovery, and dreams of growth and progress (see Frank, this volume).

The promotion and idealization of these regions whose inhabitants could no longer be portrayed as barbarians because they were now regarded as co-nationals was an important component of the 'frontier reconstruction' spirit. Travellers and ethnographers were often motivated by a nationalist impulse, a 'crusade to reaffirm Chinese sovereignty' over the border regions, so Mo Yajun $(2013,130)$ writes about the ethnographer-photographer Zhuang Xueben (1909-1984) whose work represents, she argues, a kind of objectification of his Khampa subjects, even though his work also leaves behind more multi-dimensional legacies (see Holmes-Tagchugdarpa 2015). Scholarly circles did not break free from these stereotypes, as Yudru Tsomu (2013) underlines with regard to the ethnologist Ren Naiqiang (1894-1989) and his paternalistic, erotic and exotic view of the Khampa. However, not all past or present descriptions of peripheral groups were derived from paternalism, or cultural judgment. In the 1930s Shen Congwen (1902-1988) was already portraying 'barbarians' in positive terms and exerted significant influence over a younger generation of artists and aspiring ethnographers, as Lara Maconi (2014) recently affirmed. Today border regions inhabited by minorities are increasingly becoming places of spiritual renewal in the national discourse (Oakes 2007, 253; Ying 2014, 29).

The historically shifting boundaries of Kham's entangled forms of allegiance and belonging certainly resonate in its situation today: Kham's contemporary cultural politics, complicated by new factors linked to the global economy, tourism, and heritage discourses and practices, all converge to create alternative restructurings. In the words of Charlene Makley (2003, 598), such borderlands have been and remain 'creative grounds for the making and unmaking of often-competing sociocultural worlds'. Since the period of reform and liberalization of the late 1980 s in particular, places have been undergoing profound changes. Pasts are being reinvented, full of potentialities for the present. A case in point is the town of Gyelthang (Ch. Zhongdian) in Yunnan province which changed its name in 2001 to the myth-laden Shangri-La (Ch. Xianggelila). This process of branding epitomizes the merging of Western and Chinese imaginings, supposedly infused with local culture, in order to create a new paradise for tourism (Hillman 2003, Kolås 2008; see Buffetrille and E. Mortensen, this volume). Myth turns into capital.

More recently, a much larger zone designated as the 'Great Shangri-La economic zone' (Zhongguo da Xianggelila jingji quan) was drawn on the map by the combined efforts of the Tibet Autonomous Region, Sichuan, and 
Yunnan provinces - a zone whose boundaries more or less match Kham's and which blurs the physical space and the representational space (Map 1.4). In a similar fashion to what happened in Northwest Yunnan with the 'Great rivers project' led by The Nature Conservancy (T.N.C.) in collaboration with the provincial government, the idea is to convert protected areas into sources of revenue. As Zinda $(2014,109)$ points out, the issue at stake is the designation of 'a special conservation zone in the spirit of the special economic zones that have had a famous role in coastal China's economic ascent; this would complement its unofficial designation as a special ethnic zone, a location of authentic Tibetan difference'. ${ }^{20}$ To paraphrase Tim Oakes $(2000,683)$ who commented on how place-based cultural traditions were being 'traded in' and replaced with provincially defined regions, an ideology of 'zone' culture is a necessary enabling device for the trade. The very idea of a 'zone' speaks directly to our concern here as a re-branding of the frontier. As Carolyn Cartier $(2018,468)$ argues, by such designations 'the party-state re-maps urban and regional futures at large through targeted changes to subnational territory'. This is a different kind of 'provincialization' from the transformation of the borderland into Xikang province that took place in republican times. This time the western frontier is being turned into a commercial utopia (Oakes 2007, 2012) and the Shangrilaization process is escalating (see Yeh and Coggins 2014). It is a renewed vision of the region's imagined wilderness (that of the 'frontier') and pristine landscape, where nature and culture should be preserved selectively, once again deprived of their agency and creativity.

As Tim Oakes $(2007,258)$ astutely notes, 'the frontiers of China and America meet and converge in Shangri-La, and it is the commercial dimension of the frontier idea that has enabled this'. This convergence brings to mind the work of the artist Qiu Zhijie whose project 'Mapping the world' (Ch. shijie ditu jihua) involves creating imaginary maps by drawing inspiration from various geopolitical contexts. Qiu's maps depict geographical and conceptual territories placed according to his own categorization of knowledge and ideologies, and cartography is used as a tool to reflect on the naturalization of knowledge and power. On one of these maps (see Figure 1.2) we can find an area where the fifth-century poet Tao Yuanming's Peach Blossom Spring encounters the Shangri-La of James Hilton's Lost Horizon, a proximity that alerts us to some continuities across time and space, and the dynamic reconfiguring of sites enacted by the convergence noted by

20 On 'special economic zones' (S.E.Z.) as ‘special ethnic zones' see also Vasantkumar (2014, $54-56)$. 


\section{Map 1.4 The Great Shangri-La Eco-Tourism Zone}

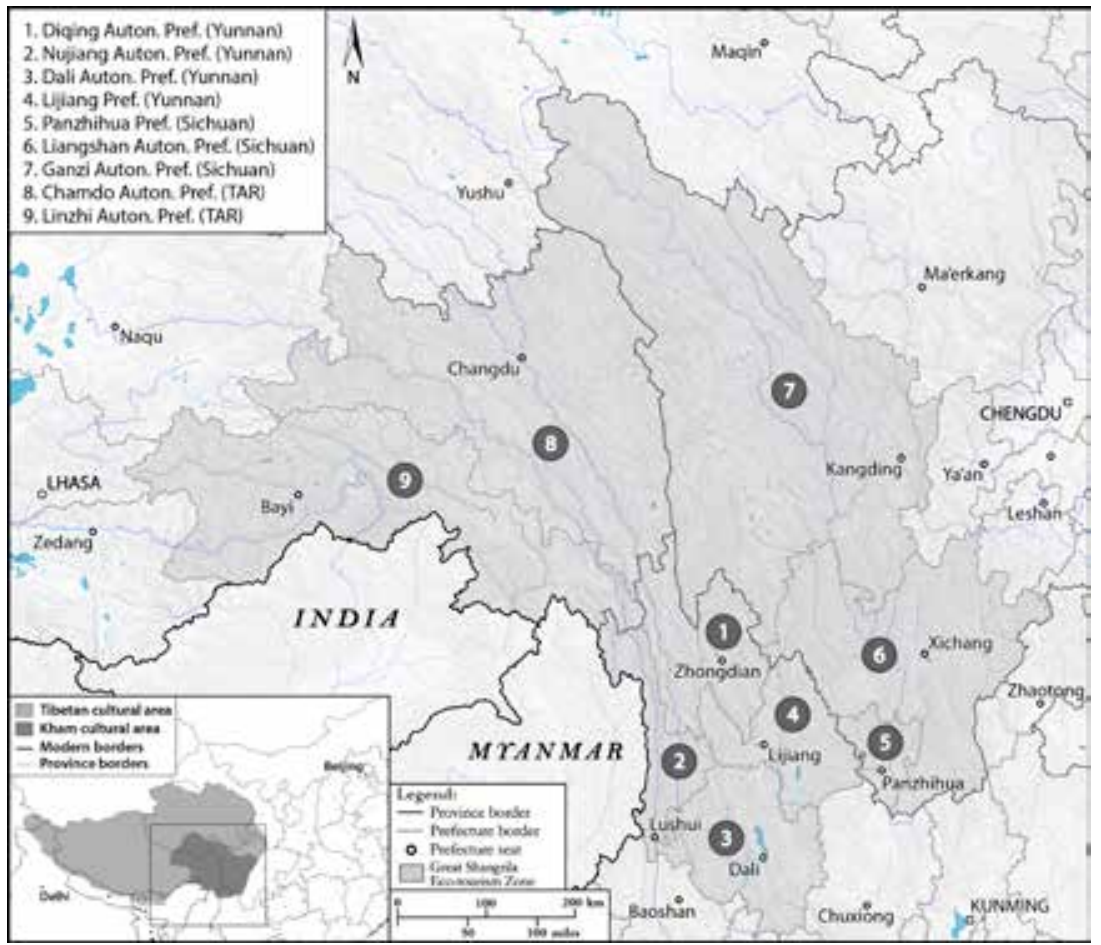

Sources: Based on SRTM (NASA) and modern administrative borders extracted from GADM database (www.gadm.org, v.2.5 July 2015)

Author: Rémi Chaix

Tim Oakes. Not far from these utopian sites is the 'city on the border', an allusion to an influential novel by Shen Congwen that humanizes, if not romanticizes, ethnic folk of China's southwestern frontier. In this 'Pure land' is also to be found the 'country of women' and the famous Lugu lake (nowadays a major tourist destination in Yunnan), right next to Thoreau's Walden pond. This kind of cross-cultural coming together on Qiu's very large maps produces a recasting of place 'in its gathering and collusion of othernesses and spatiotemporal elsewheres', to borrow Robert Oppenheim's $(2007,486)$ formulation; they also create a visual overflow with perhaps irreconcilable meanings.

Beyond the 'commercial dimension' that contributes to the emergence of these new geographical formations, there is also some interplay between the dimensions of tradition, tourism, and politics. A site like Shangri-La the town, the region, the 'zone' - becomes what Michel Foucault called a 
Figure 1.2 A detail of Qiu Zhijie's 'Map of the World' series

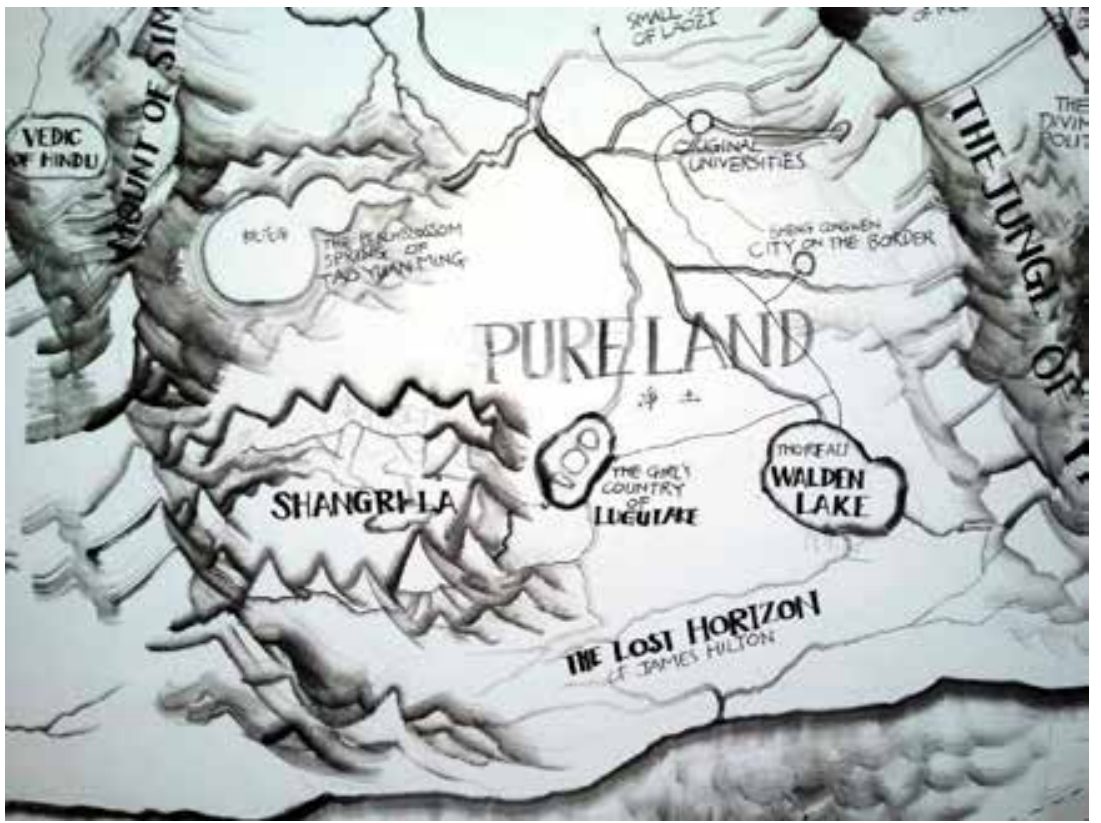

heterotopia, an 'effectively enacted utopia', both an alternative place and a place of alternatives, a place that 'is capable of juxtaposing in a single real place several spaces, several sites that are in themselves incompatible' (1986, $24,25)$. On a larger scale, as Peter Bishop (2001, 204) argues, Tibet itself can be designated as a heterotopia, because it has become 'a plurality of often contradictory, competing, and mutually exclusive places simultaneously positioned on a single geographical location'. ${ }^{21}$

\section{Patterns of Change and Topological Figures}

Growing scholarship in the field of Chinese studies has been tracing the continuities between periods, from the late Qing to the founding of the P.R.C., that were often considered as radical ruptures. We must be careful when talking of change regarding borderland narratives that focus on the centrist view of radical turns, such as from Empire to nation-state. These

21 Bishop (1999, 381) also applied the Foucauldian notion of heterotopia more specifically to Lhasa and to the Potala Palace. 
turning points should be assessed in light of locally rooted continuities even when some political, economic, and environmental transformations are indeed perceived as a 'change in worlds' (Hayes 2014). Just as historians of borderlands Pekka Hämäläinen and Samuel Truett $(2011,357)$ alert us to the fact that '[f]inding new centers for borderlands history means also plotting change differently'.

Speaking of borderlands necessarily implies looking at politics and its entanglement with other fields of social activity, and how they evolve through time and across cultures. Continuities and changes are articulated around a dynamic and heterogeneous process of intervention. Such interventions of necessity rely on new forms of thought, new ideas, and new thinkers but they do not exclusively refer to a contingent or exterior character that would be the source of change: they may be internally engendered or externally produced. The chapters here explore some of these interventions and how places are products of local histories and practices as well as relations with the broader environment. These interventions are, I would argue, 'frontier moments' that through a process of territorialization also become 'spatial moments' (van Schendel 2015), which can be used to examine the 'clashes, negotiations, compromises, and adjustments as people construct places out of a range of resources, human as well as non-human, and material as well as discursive' (see Siu, Tagliacozzo, and Perdue 2015, 10). These historical and cultural conjunctures, the issues of interpenetration, hybridity, convergence, and the sense of exclusion and inclusion are addressed through different lenses, sketching different patterns of change that have affected and continue to affect people and places in Kham.

The picture of Kham I have endeavoured to draw in this Introduction is a kaleidoscopic view of its historical trajectories and changing territorial imprint, shifts that alter and shape how people are located. It points to the importance of taking into consideration the relations between the whole and its parts with their own autonomy and histories, and the merging of the material, the emotional, and the discursive in processes of place-making in order to grasp Kham's multiplicity. This multiplicity not only raises questions about the 'relations of interiority' (properties) that are attributed to Kham as a category of identity, as a culture area, or even as a newly crafted 'zone'. It also poses the question of the 'relations of exteriority' (capacities) in which the outside/inside divide becomes blurred and can hardly be disentangled from both 'Tibet' and 'China' - themselves contingent historical entities. In Kham, where does one end and the other start?

At the meso-level of a regional entity, Kham as a heuristic illustrates the complexity of experiences of commonalities and connectedness, and 
the conundrum that multiplicity poses regarding concepts of identity and belonging especially in a highly politicized context (Mills 2014). ${ }^{22}$ The notion of 'belonging' is helpful here to emphasize boundary dynamics and 'the shifting character of borders and frontiers, imagined and real, as well as the possibilities of boundary-crossing, boundary-shifting, and boundaryblurring' (Pfaff-Czarnecka and Toffin 2011, xiv). Kham is a reminder that 'there are several places in the same territorial extension' (Feuchtwang 2004, 10). The 'frontier situation' is less about reactively stressing an identity than crossing imposed boundaries; the 'frontier' is a variable-geometry notion.

By recognizing that Kham is in both Tibet and China we can perhaps complexify the exclusion and inclusion binary (and the domination vs. resistance binary) and productively complement discussions that have so far relied on notions of hybridity, or more recently of symbiosis (Smyer Yu 2017) and of convergence (Jinba 2017). An apt reformulation of the implication for thinking about Kham and the Sino-Tibetan borderlands in this fashion is to move away from the constraints of topography and territory towards a more topological imagination, whereby the gap between the here and there is not so much a matter of actual distance than social relations, exchange, and interactions.

A topological imagination can be applied to frontiers and borders alike, seen as porous membranes (Slatta 1997, 32, 53), which not only constitute what distinguishes the inside and the outside (of a political, cultural, ethnic unit) but also the encounter between them. In other words, borders are not so much containers than 'outer membranes' of state territoriality, with varied thickness and permeability (Billé 2017). The idea of the thickness of the boundary conjures images of the border or frontier zone as an interface that mediates relations, an 'in-between' quality that has direct implications on its internal non-homogenous composition, made up of a constellation of diverse social formations with variable spatial imprints.

There have been many attempts to reflect on these issues using more unfamiliar forms of spatialization such as archipelagos or hollow rings, lattices, meshwork, and patchwork, fuelled by an increased need to move away from spatial containers (such as the nation-state) and to explore process geographies (see van Schendel 2002). Since John Agnew's (1994) influential article about the 'territorial trap' the traditional vision of the topography 
of power has been shattered and has led to questions about the existence of clear 'insides' and 'outsides' of spatial authority.

The vision of a social landscape where the centre's reach is limited in the remote periphery, and according to which horizontal relations and vertical hierarchies determine the equation of various topographies of power, is a vision anchored in Euclidean geometry. As anthropologist Hjorleifur Jonsson $(2010,200)$ has already pointedly proposed in criticizing the underpinnings of the Zomia concept, 'it is imperative to rethink the assumptions that sustain this particular production of knowledge'. In order to deconstruct the centre/ periphery binary it is useful to think along the lines of what Edwin Ardener $\left(2012,5^{23}\right)$ suggests in the case of 'remote areas' that 'the actual geography is not the overriding feature - it is obviously necessary that "remoteness" has a position in topographical space, but it is defined within a topological space whose features are expressed in a cultural vocabulary'.

Because frontier zones, like 'remote areas', are both geographical spaces and social constructs, one satisfying characteristic about the notion of 'middle ground' as a spatial metaphor is that it conflates the process of accommodation characteristic of the frontier and the actual space where the process unfolds; but it does not qualify that space. The matrix, as discussed above, as a 'boundary-blurring cultural formation' (Lewis and Wigen 1997, 151), can perhaps better capture a process through which cultures interpenetrate each other's core spaces; as a result, in the 'borderland matrix' the internal exclusions and the external inclusions constitute a topological conundrum. We are faced with the shaping of a topology of belonging whereby the merging between the internal and the external creates possibilities for emerging social forms and events. We then inescapably face the challenge, as scholars, of renewing our vocabulary for an accurate rendering of these processes and of what emerges.

Therefore, to consider that Kham is in both Tibet and China results in rethinking the analysis of the Sino-Tibetan borderlands as a space and the very meaning of the hyphen (see Gros 2016, 220). The Möbius strip is a good metaphor to think with and can perhaps help provide a topology-inspired new conceptual grammar (see Figure 1.3).

The Möbius strip and its a priori paradoxical two-sidedness displays characteristics that are congruent with processes that take place in the frontier zone: 1) the inside and outside are part of a single continuous space, yet can nonetheless be identified as distinct sides at any one point or location; 2) there is a continuous exchange between what happens internally and what takes place outside; 3) sources of change, as stressed above, are both internal and external and produce transformations that allow relationships to be 
Figure 1.3 The Möbius strip: from frontier zone to topological space

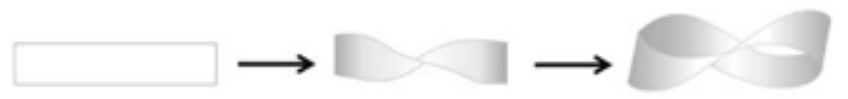

Source: Allen $(2016,42)$

reproduced differently. For social topology, these continuities undergoing transformations are what is of interest here (see Allen 2016, Martin and Secor 2014). In the case of the Sino-Tibetan borderlands, topology can capture the non-linear characteristic of this zone, and perhaps how the colonial process with its constant 're-mapping' can be effectively addressed as spatial history. Furthermore, the trope of the Möbius strip also conveys the malleability of Kham as an analytic and heuristic concept.

According to a recent discussion about topology in social and cultural theory, a topological surface such as the Möbius strip can be described as 'a relational field of emergence' (Lury, Parisi, and Terranova, 2012, 8). This is a particularly fitting formulation for Kham if we are to challenge its givenness and fixity as a spatial entity that would exist 'out there' prior to the relations and the world they create. Places and territories are continuously produced in a relational manner. The description provided in the previous sections of the spatio-temporal variation of Kham as an in-between place substantiate the claim that the multiplicity of its constitutive relations 'does not simply happen in the in-between' of power centres 'but rather operates a topological continuum of the in-between' (Lury, Parisi, and Terranova, 2012, 13, emphasis added). The Möbius strip, as a continuous surface with only one side, also aptly evokes the historical process by which frontier dynamics tends to cycle through, producing new forms of territorialization and re-ordering. If one starts on one side and follows the loop of the Möbius strip, one ends up on the other side without having crossed a border.

This brings us back to our original question: what about Kham then as a 'regional entity' in this complex lattice of relational networks and non-Euclidean geometry? As I have tried to emphasize in this Introduction and as the following chapters further illustrate, it is important to recognize that Kham is a composite entity. According to Ansi Paasi and Jonathan Metzger's recent discussion about regional formations, multiple actors are involved in these processes: local actors but also more or less distant 'others' who "lie topologically and topographically both "inside" and "outside" the everlastingly reconstructing, material and discursive socio-spatial process that becomes labelled as "the region", and where variegated actors contribute 
to producing (often contested) accounts and narratives of such regions as to some degree constituting coherent and definable entities' $(2016,8)$. To promote the notion of frontier is to go beyond regarding Kham as a straightforward and unproblematic regional category. To push for a vision of Kham as a topological space is another step towards formulating aspects of co-presence that acknowledge the continuity of relationship of power in a process of transformation that shapes forms of inclusion and exclusion.

\section{Glossary of Tibetan terms}

chölkha sum

chushigangdruk

Dokham

Domé

Dotö

Dza chu

depa

Dokham né chen nyer nga

Dri chu

Ganden Phodrang

Gedun Chopel

gangjong

gyalam

gyalpo

Ngül chu

Nyak chu

phayül

pon

rong chenshi

sakyé dokyé chol khagsum

chu bzhi sgang drug

Mdo khams

Mdo smad

Mdo stod

Rdza chu

sde pa

Mdo khams gnas chen nyer lnga

'Bri chu

Dga' ldan pho brang

Dge 'dun chos 'phel

gang ljongs

rgya lam

rgyal po

Rngul chu

Nyag chu

phayul

dpon

rong chen bzhi

sa skye rdo rkyes

\section{Glossary of Chinese terms}

bian

bianjiang weiji

bianzheng

Chuanbian

Daduhe
邊

邊疆危機

邊政

川邊

大渡河 


$\begin{array}{ll}\text { dao bianjiang qu } & \text { 到邊疆去 } \\ \text { dao guanwaiqu } & \text { 到關外去 } \\ \text { guan dao } & \text { 官道 } \\ \text { guanwai } & \text { 關外 } \\ \text { jiequ } & \text { 界區 } \\ \text { Jinshajiang } & \text { 金沙江 } \\ \text { Lancangjiang } & \text { 瀾滄江 } \\ \text { neidi } & \text { 內地 } \\ \text { Nujiang } & \text { 怒江 } \\ \text { Shen Congwen } & \text { 沈從文 } \\ \text { shijie ditujihua } & \text { 世界地圖計劃 } \\ \text { si da tusi } & \text { 四大土司 } \\ \text { Xianggelila } & \text { 香格里拉 } \\ \text { Yalongjiang } & \text { 雅龍江 } \\ \text { Zang-Yi zoulang } & \text { 藏彝走廊 } \\ \text { Zhongguo da Xianggelila jingji quan } & \text { 中国大香格里拉經濟圈 }\end{array}$

\section{References}

Adelman, Jeremy, and Stephen Aron. 1999. 'From Borderlands to Borders: Empires, Nation-States, and the Peoples in Between in North American History'. American Historical Review 104 (3): 814-41.

Agnew, John. 1994. 'The Territorial Trap: The Geographical Assumptions of International Relations Theory'. Review of International Political Economy 1: 53-80.

Agnew, John. 2005. 'Sovereignty Regimes: Territoriality and State Authority in Contemporary World Politics'. Annals of the Association of American Geographers 95 (2): 437-461.

Allen, John. 2016. Topologies of Power: Beyond Territory and Network. London: Routledge.

Anderson, Benedict. 1991. Imagined Communities: Reflections on the Origins and Spread of Nationalism, revised ed. London: Verso.

Ardener, Edwin. 2012. 'Remote Areas: Some Theoretical Considerations'. HAU: Journal of Ethnographic Theory 2 (1): 519-533.

Atwill, David. 2005. The Chinese Sultanate: Islam, Ethnicity, and the Panthay Rebellion in Southwest China, 1856-1873. Stanford, CA: Stanford University Press.

Barth, Fredrik. 1969. 'Introduction'. In Ethnic Groups and Boundaries: The Social Organization of Culture Difference, 9-38. Boston: Little, Brown.

Baud, Michel, and Willem van Schendel. 1997. 'Towards a Comparative History of Borderlands'. Journal of World History 8 (2): 211-242. 
Benite, Zvi Ben-Dor, Stephanos Geroulanos, and Nicole Jerr, eds. 2017. The Scaffolding of Sovereignty: Global and Aesthetic Considerations in the History of a Concept. New York: Columbia University Press.

Biersteker, Thomas J., and Cynthia Weber, eds. 1996. State Sovereignty as Social Construct. Cambridge: Cambridge University Press.

Billé, Franck. 2018. 'Skinworlds: Borders, Haptics, Topologies'. Environment and Planning D: Society and Space 36 (1): 60-77.

Bishop, Peter. 1999. 'Reading the Potala'. In Sacred Spaces and Powerful Places in Tibetan Culture, edited by Toni Huber, 367-385. Dharamsala: Library of Tibetan Works and Archives.

Bishop, Peter. 2001. 'Not Only a Shangri-la: Images of Tibet in Western Literature'. In Imagining Tibet: Perceptions, Projections and Fantasies, edited by Thierry Dodin and Heinz Räther, 200-222. Boston: Wisdom Publications.

Brown, Clayton. 2008. Making the Majority: Defining Han Identity in the Chinese Ethnology and Archeology. Unpublished PhD dissertation, University of Pittsburgh.

Bulag, Uradyn. 2002. The Mongols at China's Edge: History and the Politics of National Unity. Lanham: Rowman and Littlefield.

Bulag, Uradyn. 2007. 'From Empire to Nation: The Demise of Buddhism in Mongolia'. In The Mongolia-Tibet Inferface: Opening New Research Terrains in Inner Asia, edited by Uradyn Bulag and Hildegard Diemberger, 19-58. Leiden: Brill.

Cai Yuanpei. 1962 (1926). 'Shuo minzu xue' (On Ethnology). In Cai Yuanpeiminzuxue lunzhu (Ethnological Writings of Cai Yuanpei), edited by Zhongguo minzu xuehui, 1-11. Taipei: Zhonghua Book Co.

Calanca, Paola and François Wildt. 2006. 'Les frontières: quelques termes-clés'. Extrême-Orient, Extrême-Occident 28: 17-56.

Cartier, Carolyn. 2002. 'Origins and Evolution of a Geographical Idea: The Macroregion in China'. Modern China 28 (1): 79-142.

Cartier, Carolyn. 2018. 'Zone Analog: The State-Market Problematic and Territorial Economies in China'. Critical Sociology 44 (3): 455-470.

Cavafy, C. P. 1992 (1975). 'Waiting for the Barbarians'. In C.P. Cavafy: Collected Poems. Translated by Edmund Keeley and Philip Sherrard. Princeton: Princeton University Press.

Chayet, Anne. 2003. 'A propos des toponymes de l'épopée de Gesar'. Revue d'études tibétaines 3: 4-29.

Chen, Zhihong. 2008. Stretching the Skin of the Nation: Chinese Intellectuals, the State, and the Frontiers in the Nanjing Decade (1927-1937). Unpublished PhD dissertation, University of Oregon.

Chen, Zhihong. 2017. 'Romance with the Periphery: Chinese Travel Writing About the "Frontier" During the Nanjing Decade (1927-1937)'.Journal of Tourism History 8 (3): $215^{-223}$. 
Crossley, Pamela Kyle, Helen F. Siu, and Donald S. Sutton, eds. 2006. Empire at the Margins: Culture, Ethnicity, and Frontier in Early Modern China. Berkeley: University of California Press.

Donnan, Hasting, and Thomas M. Wilson. 1999. Borders: Frontiers of Identity, Nation and State. London: Berg.

Duara, Prasenjit. 2003. Sovereignty and Authenticity: Manchukuo and the East Asian Modern. Lanham: Rowman and Littlefield.

Epstein, Lawrence, ed. 2002. Khams pa Histories: Visions of People, Place and Authority. Leiden: Brill.

Faure, David, and Ts'ui-p'ing Ho, eds. 2013. Chieftains into Ancestors: Imperial Expansion and Indigenous Society in Southwest China. Vancouver: University of British Columbia Press.

Faure, David. 2013. 'Introduction'. In Chieftains into Ancestors: Imperial Expansion and Indigenous Society in Southwest China, edited by David Faure and Ho Ts'uip'ing, 1-21. Vancouver: University of British Columbia Press.

Febvre, Lucien. 1962 (1928). 'Frontière: le mot et la notion'. In Pour une histoire à part entière. Paris: SEVPEN.

Feuchtwang, Stephan. 2004. 'Introduction: Making Place'. In Making Place: State Projects, Globalisation and Local Responses in China, edited by S. Feuchtwang, 3-31. London: UCL Press.

Foucault, Michel. 1986. 'Of Other Spaces' (J. Miskowiec trans.). Diacritics 16 (1): 22-26.

Gardner, Alexander. 2003. 'Review article - Khams pa histories: Visions of people, place and authority'. The Tibet Journal 28 (3): 61-96.

Gardner, Alexander. 2006. The Twenty-five Great Sites of Khams: Religious Geography, Revelation, and Nonsectarianism in Nineteenth-Century Eastern Tibet. Unpublished PhD dissertation, The University of Michigan.

Gardner, Alexander. 2009. 'The Twenty-five Great Sites of Khams: A Narrative Map of an Imperiled Place'. In Studies in the History of Eastern Tibet, edited by Wim van Spengen and Lama Jabb, 97-132. Leiden: Brill.

Gellner, David N. 2013. 'Introduction'. In Borderland Lives in Northern South Asia, edited by D. Gellner, 1-23. Durham, NC: Duke University Press.

Giersch, C. Patterson. 2001. 'A Motley Throng: Social Change on Southwest China's Early Modern Frontier, 1700-1880'. The Journal of Asian Studies 6o (1): 67-94.

Giersch, C. Patterson. 2006. Asian Borderlands: The Transformation of Qing China's Yunnan Frontier. Cambridge, MA: Harvard University Press.

Giersch, C. Patterson. 2010. 'Across Zomia with Merchants, Monks, and Musk: Process Geographies, Trade Networks, and the Inner-East-Southeast Asian Borderlands'. Journal of Global History 5: 215-239. 
Giersch, C. Patterson. 2011. 'Cotton, Copper, and Caravans: Trade and the Transformation of Southwest China'. In Chinese Circulations: Capital, Commodities and Networks in Southeast Asia, edited by Wen-Chin Chang and Eric Tagliacozzo, 37-61. Durham, NC: Duke University Press.

Giersch, C. Patterson. 2014. 'Commerce and Empire in the Borderlands: How Do Merchants and Trade Fit into Qing Frontier History?' Frontier of History in China 9 (3): $361-383$.

Giersch, C. Patterson. 2016. 'Afterword: Why Kham? Why Borderlands? Coordinating New Research Programs for Asia'. Cross-Currents: East Asian History and Culture Review 19 (E-journal); print journal 5 (2): 440-452.

Goldstein, Melvyn C. 1998. 'Introduction'. In Buddhism and Contemporary Tibet: Religious Revival and Cultural Identity, edited by Melvyn Goldstein and Matthew Kapstein, 1-14. Berkeley: University of California Press.

Gros, Stéphane. 2014a. 'Introduction'. Special issue 'Worlds in the Making: Interethnicity and the Processes of Generating Difference in Southwest China'. Cahiers d'Extrême-Asie 24: 1-30.

Gros, Stéphane. 2014b. 'Devenirs identitaires dans les confıns sino-tibétains: contextes et transformations'. Cahiers d'Extrême-Asie 24: 63-102.

Gros, Stéphane, ed. 2016. 'Frontier Tibet: Trade and the Boundaries of Authority in Kham'. Special issue, Cross-Currents: East Asian History and Culture Review 19 (E-journal); print journal, 5 (2).

Gruschke, Andreas. 2004a. The Cultural Monuments of Tibet's Outer Provinces. Kham - Volume 1. The TAR Part of Kham (Tibet Autonomous Region). Bangkok: White Lotus Press.

Gruschke, Andreas. 2004b. The Cultural Monuments of Tibet's Outer Provinces. Kham - Volume 2. The Qinghai Part of Kham. Bangkok: White Lotus Press.

Hall, Thomas D. 2005. 'Borders, Borderland, and Frontiers, Global'. In New Dictionary of the History of Ideas, Vol. 1, edited by Maryanne Cline Horowitz, 238-242. Detroit: Charles Scribner's Sons.

Hämäläinen, Pekka, and Samuel Truett. 2011. 'On Borderlands'. The Journal of American History 98 (2): 338-361.

Hansen, Thomas Blom, and Finn Stepputat. 2006. 'Sovereignty Revisited'. Annual Review of Anthropology 35: 295-315.

Harrell, Stevan, ed. 1995. Cultural Encounters on China's Ethnic Frontiers. Seattle: University of Washington Press.

Harrell, Stevan. 1995. 'Introduction: Civilizing Projects and Reaction to Them'. In CulturalEncounters on China's Ethnic Frontiers, edited by Stevan Harrell, 3-36. Seattle: University of Washington Press. 
Hayes, Jack Patrick. 2014. A Change in Worlds on the Sino-Tibetan Borderlands: Politics, Economies, and Environments in Northern Sichuan. Lanham, MD: Lexington.

Herman, John E. 2007. Amid the Clouds and Mist: China's Colonization of Guizhou, 1200-1700. Cambridge, MA: Harvard University Asia Center, Harvard University Press.

Hillman, Ben. 2003. 'The Poor in Paradise: Tourism Development and Rural Poverty in China's Shangri-la'. In Landscapes of Diversity: Indigenous Knowledge, Sustainable Livelihoods and Resource Governance in Montane Mainland Southeast Asia. Proceedings of the $3^{\text {rd }}$ Symposium on MMSEA 25-28 August 2002, Lijiang, P.R. China, edited by Xu Jianchu and Stephen Mikesell, 545-553. Kunming: Yunnan Science and Technology Press.

Holmes-Tagchungdarpa, Amy. 2011. 'Defining Peripheral Power: Writing the History of the Kingdom of Lhathog, Eastern Tibet'. In New Views of Tibetan Culture, edited by David Templeman, 7-19. Caulfield, Australia: Monash University Press.

Holmes-Tagchungdarpa, Amy. 2014. The Social Life of Tibetan Biography: Textuality, Community, and Authority in the Lineage of Tokden Shakya Shri. Lanham, MD: Lexington.

Holmes-Tagchungdarpa, Amy. 2015. 'Depicting Life in the Twentieth-Century Sino-Tibetan Borderlands: Local Histories and Modernities in the Career and Photography of Zhuang Xueben (1909-1984)'. In China's Encounters on the South and Southwest: Reforging the Fiery Frontier over Two Millenia, edited by James A. Anderson and John K. Whitmore, 339-369. Leiden: Brill.

Huber, Toni. 2004. 'Territorial Control by “Sealing” (rgya sdom-pa): A Religio-Political Practice in Tibet'. Zentralasiatische Studien 33: 127-152.

Imamura, Masao. 2015. 'Guest Editorial: Rethinking Frontier and Frontier Studies'. Political Geography 45: 96-97.

Jagou, Fabienne. 2010. 'Étude des toponymes utilisés par les Mandchous pour définir le territoire tibétain'. In Études tibétaines en l'honneur d'Anne Chayet, edited by J.-L. Achard, 127-146. Genève: Droz.

Jeanpierre, Laurent. 2010. 'Frontière'. In Dictionnaire des concepts nomades en sciences humaines, edited by Olivier Christin, 157-169. Paris: Métailié.

Jessop, Bob, Neil Brener, and Martin Jones. 2008. 'Theorizing Sociospatial Relations'. Environment and Planning D: Society and Space 26: 389-401.

Jinba, Tenzin. 2014. In the Land of the Eastern Queendom: The Politics of Gender and Ethnicity on the Sino-Tibetan Border. Seattle: University of Washington Press.

Jinba, Tenzin. 2017. 'Seeing Like Borders: Convergence Zone as a Post-Zomian Model'. Current Anthropology 58 (5): 551-575.

Jonhson, Corey et al. 2011. 'Interventions on Rethinking 'the Border' in Border Studies'. Political Geography 3o: 61V69. 
Jonsson, Hjorleifur. 2010. 'Above and Beyond: Zomia and the Ethnographic Challenge of/for Regional History'. History and Anthropology 21(2): 191-212.

Kang, Xiaofei and Donald Sutton. 2016. Contesting the Yellow Dragon: Ethnicity, Religion, and the State in the Sino-Tibetan Borderland. Leiden: Brill.

Klein, Kerwin Lee. 1996. 'Reclaiming the " $F$ " Word, or Being and Becoming Postwestern'. The Pacific Historical Review 65 (2): 179-215.

Kolås, Åshild. 2008. Tourism and Tibetan Culture in Transition: A Place Called Shangrila. London: Routledge.

Lattimore, Owen. 1962. Studies in Frontier History: Collected Papers 1928-1958. London: Oxford University Press.

Lattimore, Owen. 1951 (1940). Inner Asian Frontiers of China. New York: Capitol Publishing and American Geographical Society.

Lawson, Joseph. 2017. A Frontier Made Lawless: Violence in Upland Southwest China, 180o-1956. Vancouver: University of British Columbia Press.

Leach, Edmund. 1960. 'The Frontiers of “Burma”. Comparative Studies in Society and History 3 (1): 49-68.

Leibold, James. 2007. Reconfiguring Chinese Nationalism: How the Qing Frontier and its Indigenes Became Chinese. New York: Palgrave Macmillan.

Lewis, Martin W. and Kären E. Wigen. 1997. The Myth of Continents: A Critique of Metageography. Berkeley: University of California Press.

Li Shaoming. 2008. Zang-Yi zoulang minzu lishi wenhua (History and Culture of the Tibeto-Yi Corridor). Beijing: Minzu chubanshe.

Lin, Hsiao-ting. 2006. Tibet and Nationalist China's Frontier: Intrigues and Ethnopolitics, 1928-49. Vancouver: University of British Columbia Press.

Lury, Celia, Luciana Parisi, and Tiziana Terranova. 2012. 'Introduction: The Becoming Topological of Culture'. Theory Culture Society 29 (4/5): 3-35.

Macdonald, Alexander. 1987. 'Remarks on the Manipulation of Power and Authority in the High Himalaya'. The Tibet Journal 12 (1): 3-16.

Maconi, Lara. 2014. 'Dans les yeux des artistes: Visions chinoises de Muli et du Kham pendant la seconde guerre sino-japonaise (1937-1945)'. Cahiers d'Extrême-Asie 23: 163-199.

Makley, Charlene E. 2003. 'Gendered Boundaries in Motion: Space and Identity on the Sino-Tibetan Frontier'. American Ethnologist 30 (4): 597-619.

Martin, Lauren and Anna J. Secor. 2014. 'Towards a Post-Mathematical Topology'. Progress in Human Geography 38 (3): 420-438.

McGranahan, Carole. 2002. 'Sa spang mda' gnam spang mda': Murder, History, and Social Politics in 1920s Lhasa'. In Khams pa Voices: Visions of People, Place, and Authority, edited by L. Epstein, 103-126. Leiden: Brill.

McGranahan, Carole. 2003a. 'Empire and the Status of Tibet: British, Chinese, and Tibetan Negotiations, 1913-1934'. In The History of Tibet, Vol. 3: The Tibetan 
Encounter with Modernity, edited by Alex McKay, 267-295. Richmond, UK: Curzon Press.

McGranahan, Carole. 2003b. 'From Simla to Rongbatsa: The British and the "Modern" Boundaries of Tibet'. The Tibet Journal 28 (4): 39-6o.

McGranahan, Carole. 2006. 'Tibet's Cold War: The CIA and the Chushi Gangdrug Resistance, 1956-1974'. Journal of Cold War Studies 8 (3): 102-130.

McGranahan, Carole. 2007. 'Empire Out of Bonds: Tibet in the Era of Decolonization'. In Imperial Formations, edited by Ann Laura Stoler, Carole McGranahan, and Peter C. Perdue, 173-209. Santa Fe, NM: School for Advanced Research Press.

McGranahan, Carole. 2010. Arrested Histories: Tibet, the CIA, and Memories of a Forgotten War. Durham: Duke University Press.

Michaud, Jean, ed. 200o. Turbulent Times and Enduring People: Mountain Minorities in the Southeast Asian Massif. Richmond: Curzon Press.

Michaud, Jean. 2010. 'Editorial: Zomia and beyond'. Special Issue 'Zomia and beyond', edited by Jean Michaud, Journal of Global History 5 (2): 187-214.

Michaud, Jean. 2017. 'What's (written) History For? On James C. Scott's Zomia and Especially Chapter $6^{1 / 2}$. Anthropology Today 33 (1): 6-10.

Mills, Martin A. 2014. 'Who Belongs to Tibet? Governmental Narratives of State in the Ganden Podrang'. In Facing Globalization in the Himalayas: Belonging and the Politics of the Self, edited by G. Toffin and J. Pfaff-Czarnecka, 397-419. New Dehli: Sage.

Millward, James A. 1998. Beyond the Pass: Economy, Ethnicity, and Empire in Qing Central Asia, 1759-1864. Stanford: Stanford University Press.

Mo Yajun. 2013. 'The New Frontier: Zhuang Xueben and Xikang Province'. In Chinese History in Geographical Perspective, edited by Jefff Kyong-McClain and Du Yongtao, 121-139.Lanham: Lexington Books.

Norbu, Jamyang. 1986. Warriors of Tibet: the Story of Aten and the Khambas Fight for the Freedom of Their Country. London: Wisdom Publications.

Oakes, Tim. 2000. 'China's Provincial Identities: Reviving Regionalism and Reinventing Chineseness'. The Journal of Asian Studies 59 (3): 667-692.

Oakes, Tim. 2007. 'Welcome to Paradise! A Sino-U.S. Joint-Venture Project'. In China's Transformations: The Stories beyond the Headlines, edited by L. Jessen and T. Weston, 240-264. Lanham, MD: Rowman and Littlefield.

Oakes, Tim. 2012. 'Looking Out to Look In: The Use of the Periphery in China's Geopolitical Narratives'. Eurasian Geography and Economics 53 (3):315-326.

Oppenheim, Robert. 2007. 'Actor-Network Theory and Anthropology after Science, Technology, and Society'. Anthropological Theory 7(4): 471-493.

Paasi, Ansi and Jonathan Metzger. 2016. 'Foregrounding the Region'. Regional Studies 51 (1): 19-30. 
Parker, Bradley J. 2006. 'Toward an Understanding of Borderland Processes'. American Antiquity 71 (1): 77-100.

Peng, Wenbin. 2002. 'Frontier Process, Provincial Politics and Movements for Khampa Autonomy During the Republican Period'. In Khams pa Histories: Visions of People, Place, and Authority, edited by L. Epstein, 57-84. Leiden: Brill. Perdue, Peter C. 2001. 'Empire and Nation in Comparative Perspective: Frontier Administration in Eighteenth-Century China'.JEMH 5 (4): 282-304.

Perdue, Peter C. 2005. China Marches West: The Qing Conquest of Central Eurasia. Cambridge, MA: The Belknap Press of Harvard University Press.

Pfaff-Czarnecka, Joanna, and Gérard Toffin. 2011. 'Introduction: Belonging and Multiple Attachments in Contemporary Himalayan Societies'. In The Politics of Belonging in the Himalayas: Local Attachments and Boundary Dynamics, edited by J. Pfaff-Czarnecka and G. Toffin, xi-xxxviii. New Dehli: Sage.

Pratt, Mary Louise. 1991. 'Arts of the Contact Zone'. Profession: 33-40.

Ptáčková, Jarmila and Adrian, Zenz, eds. 2017. 'Mapping Amdo: Dynamics of Change'. Special Issue, Archiv Orientální:Journal of African and Asian Studies, supplementa $\mathrm{x}$.

Rafael, Vicente L. 1999. 'Regionalism, Area Studies, and the Accidents of Agency'. American Historical Review 104 (4): 1208-1220.

Ren, Naiqiang and Tshe-dbang Rdo-rje. 1991. 'A Toponymic and Administrative Study of Mdo-Khams'. In Theses in Tibetology in China, compiled by $\mathrm{Hu}$ Tan, 30-66. Beijing: China Tibetology Publishing House.

Richardson, Hugh E. 1945. Tibetan Precis. Calcutta: Government of India Press.

Roche, Gerald. 2014. 'Flows and Frontiers: Landscape and Cultural Dynamics on the Northeast Tibetan Plateau'. The Asia Pacific Journal of Anthropology 15 (1): 1-25. Rodman, Margaret C. 1992. 'Empowering Place: Multilocality and Multivocality'. American Anthropologist (NS) 94 (3): 640-656.

Rodriguez, Andres. 2011. 'Building the Nation, Serving the Frontier: Mobilizing and Reconstructing China's Borderlands during the War of Resistance (1937-1945)'. Modern Asian Studies 45 (2): 350-351.

Rodseth, Lars and Bradley J. Parker. 2005. 'Introduction: Theoretical Considerations in the Study of Frontiers'. In Untaming the Frontier in Anthropology, Archaeology, and History, edited by Bradley J. Parker and Lars Rodseth, 3-21. Tucson: University of Arizona Press.

Rodseth, Lars. 2005. 'The Fragmentary Frontier: Expansion and Ethnogenesis in the Himalayas'. In Untaming the Frontier in Anthropology, Archaeology, and History, edited by Bradley J. Parker and Lars Rodseth, 83-109. Tucson: University of Arizona Press.

Rösler, Michael and Tobias, Wendl, eds. 1999. Frontiers and Borders: Anthropological Perspectives. Frankfurt: Peter Lang. 
Rumford, Chris. 2012. 'Towards a Multiperspectival Study of Borders'. Geopolitics 17: 887-902.

Ryavec, Karl E. 2015. A Historical Atlas of Tibet. Chicago: The University of Chicago Press.

Samuel, Geoffrey. 1993. Civilized Shamans: Buddhism in Tibetan Societies. Washington: Smithsonian Institution Press.

Scott, James C. 2009. The Art of Not Being Governed: An Anarchist History of Upland Southeast Asia. New Haven, CT: Yale University Press.

Shi Shuo, ed. 2005. Zang-Yi zoulang: Lishi yu wenhua (The Tibeto-Yi Corridor: History and Culture). Chengdu: Sichuan Renmin Chubanshe.

Shi Shuo. 2011. 'Jin jinian dalu xuezhe dui Kangqu de Yanjiu ji jueshi' (New Directions in the Study of Kham among Mainland Researchers in the Last Decade).Xinnan Minzu Daxue Xuebao 12: 1-6.

Shneiderman, Sara. 2010. 'Are the Central Himalayas in Zomia? Some Scholarly and Political Considerations across Time and Space'. In 'Zomia and beyond', special issue, Journal of Global History 5(2): 289-312.

Siu, Helen F., Eric Tagliacozzo, Peter C. Perdue. 2015. 'Introduction: Spatial Assemblage'. In Asia Inside Out: Connected Places, edited by E. Tagliacozzo, H. F. Siu, and P. C. Perdue, 1-30. Cambridge: Harvard University Press.

Slatta, Richard W. 1997. Comparing Cowboys and Frontiers. Norman: University of Oklahoma Press.

Smyer Yü, Dan. 2017. 'Introduction: Trans-Himalayas as Multistate Margins'. In Trans-Himalayan Borderlands: Livelihoods, Territorialities, Modernities, edited by D. Smyer Yü and J. Michaud, 11-41. Amsterdam: Amsterdam University Press.

Sperling, Elliot. 1976. 'The Chinese Venture in K'am, 1904-1911, and the Role of Chao Erh-feng'. The Tibet Journal 1 (2): 10-36.

Sułek, Emilia Róża and Jarmila Ptáčková. 2017. 'Mapping Amdo: People and Places in an On-going Transition'. In 'Mapping Amdo: Dynamics of Change'. Special Issue, edited by J. Ptáčková and A. Zenz, Archiv Orientální:Journal of African and Asian Studies, supplementa x: 1-14.

Tsering, Tashi. 1985. 'Ñag-ron் Mgon-po Rnam-rgyal: A 19th Century Khams-pa Warrior'. In Soundings in Tibetan Civilization, edited by B. N. Aziz and M. Kapstein, 196-214. New Delhi: Manohar.

Tsomu, Yudru. 2009. 'Political and Territorial Survival in the Sino-Tibetan Borderland: A Case Study of the Lcags La Kingdom During the Qing Dynasty'. In Studies in the History of Eastern Tibet, edited by Wim van Spengen and Lama Jabb, 55-96. Verlag: International Institute for Tibetan and Buddhist Studies.

Tsomu, Yudru. 2013. 'Taming the Khampas: The Republican Construction of Eastern Tibet'. Modern China 39 (3): 319-344.

Tsomu, Yudru. 2015. The Rise of Gönpo Namgyel in Kham: The Blind Warrior of Nyarong. Lanham, MD: Lexington Books. 
Turner, Frederick J. 1994 (1893). 'The Significance of the Frontier in American History'. In 'The Frontier in American History'. In Rereading FrederickJackson Turner: 'The Significance of the Frontier in American History' and Other Essays, edited by John Mack Faragher, 31-6o. New Haven, CT: Yale University Press.

Tuttle, Gray. 2007. Tibetan Buddhists in the Making of Modern China. New York: Columbia University Press.

Van Schendel, Willem. 2002. 'Geographies of Knowing, Geographies of Ignorance: Jumping Scale in Southeast Asia'. Environment and Planning D: Society and Space 20: 647-668.

Van Schendel, Willem. 2015. 'Spatial Moments: Chittagong in Four Scenes'. In Asia Inside Out: Connected Places, edited by Eric Tagliacozzo, Helen S. Hsiu, and Peter Perdue, 98-127. Cambridge, MA: Harvard University Press.

Van Spengen, Wim and Lama Jabb. 20o9. 'Introduction'. In Studies in the History of Eastern Tibet, edited by Wim van Spengen and Lama Jabb, 7-17. Verlag: International Institute for Tibetan and Buddhist Studies.

Vasantkumar, Chris. 2014. 'Dreamworld, Shambala, Gannan: The Shangrilazation of China's "Little Tibet". In Mapping Shangrila: Contested Landscapes in the Sino-Tibetan Borderlands, edited by Emily T. Yeh and Chris Coggins, 51-74. Seattle: University of Washington Press.

Vasantkumar, Chris. 2017. 'Tibetan Diaspora, Mobility and Place: "Exiles in Their Own Homeland"'. Theory, Culture \& Society 34 (1):115-136.

Wang Mingming, 1999-200o. 'Minzu yu Guojia. Cong Wu Wenzao de zaoqi lunshu chufa' (Nationality and State: From the First Works of Wu Wenzao), Yunnan minzu xueyuan xuebao 16 (1/6) (1999): 19-25; 17 (6/1) (2000): 20-26.

Weinstein, Jodi L. 2014. Empire and Identity in Guizhou: Local Resistance to Qing Expansion. Seattle, WA: University of Washington Press.

Weiner, Benno R. 2016. 'Tibet in China? China in Tibet'. In Handbook on Ethnic Minorities in China, edited by Zang Xiaowei, 83-110. Cheltenham: Edward Elgar.

White, Richard. 2011 (1991). The Middle Ground: Indians, Empires, and Republics in the Great Lakes Region, 1650-1815. Cambridge: Cambridge University Press.

Wilson, Thomas M., and Hastings Donnan. 2012. 'Borders and Border Studies'. In A Companion to Border Studies, edited by T. M. Wilson and H. Donnan, 1-25. Malden MA: Blackwell.

Winichakul, Thongchai. 1994. Siam Mapped: A History of the Geo-Body of a Nation. Honolulu: University of Hawai'i Press.

Wu Wenzao. 1990 (1926). 'Minzu yu guojia'. Liumei Xuesheng Jibao (A Quaterly Journal for Chinese Students America) 11 (3). Reprinted in Wu Wenzao, Renleixue shehuixueyanjiu wenji (Studies in Anthropology and Sociology). Beijing: Minzu chubanshe, 19-36. 
Yang, Evelyne. 2016. 'Tracing the Chol kha gsum: Reexamining a Sa skya-Yuan Period Administrative Geography'. Revue d'Études Tibétaines 37: 551-568.

Yeh, Emily T. 2007. 'Exile Meets Homeland: Politics, Performance, and Authenticity in the Tibetan Diaspora'. Environment and Planning D: Society and Space 25: 648-667.

Yeh, Emily T., and Chris Coggins, eds. 2014. Mapping Shangrila: Contested Landscapes in the Sino-Tibetan Borderlands. Seattle: University of Washington Press.

Yen, Hsiao-pei, 2012. Constructing the Chinese: Paleoanthropology and Anthropology in the Chinese Frontier, 1920-1950. Unpublished PhD dissertation, Harvard University. Ying, Li-hua. 2014. 'Vital Margins: Frontier Poetics and Landscapes of Ethnic Identity'. In Mapping Shangrila: Contested Landscapes in the Sino-Tibetan Borderlands, edited by Emily T. Yeh and Chris Coggins, 27-50. Seattle: University of Washington Press.

Zangpo, Ngawang. 2001. Sacred Ground:Jamgon Khongtrul on 'Pilgrimage and Sacred Geography'. Ithaca, NY: Snow Lion Publications.

Zartman, William I. 2010. Understanding Life in the Borderlands: Boundaries in Depth and Motions. Athens: The University of Georgia Press.

Ze Po and Ge Lei, eds. 2004. Hengduanshan minzu wenhua zoulang. Kangba wenhua mingren luntan wenji (The Cultural and Ethnic Corridor of the Hengduan Mountains: Miscellany Forum of Personalities about Khampa Culture). Beijing: Zhongguo zangxue chubanshe.

Zinda, John Aloyysius. 2014. 'Making National Parks in Yunnan: Shifts and Struggles within the Ecological State', in Mapping Shangrila: Contested Landscapes in the Sino-Tibetan Borderlands, edited by Emily T. Yeh and Chris Coggins, 105-128. Seattle: University of Washington Press.

\section{About the Author}

StÉPHANE GRos is a researcher at the Centre for Himalayan Studies, Centre National de la Recherche Scientifique (C.N.R.S., France). A social anthropologist by training (PhD Paris-Nanterre University, 2005), he has published a monograph entitled La Part Manquante (Société d'ethnologie, 2012) about the Drung (Dulong), a long-deprived minority of swidden agriculturalists of Yunnan province (China). He is the author of numerous articles and book chapters on issues of interethnic relations and ethnic classification, representations of ethnic minorities, poverty and categorization, as well as rituals and cosmology. He has edited or co-edited four collections of relevance to ethnographic theory, Chinese studies, and area studies. He was Principal Investigator for the European-Research-Council-funded project (Starting Grant No. 283870, 2012-2016) entitled 'Territories, Communities, and Exchanges in the Kham Sino-Tibetan Borderlands' (http://kham.cnrs.fr). 



\title{
2 The Increasing Visibility of the Tibetan 'Borderlands'
}

\author{
Katia Buffetrille
}

\begin{abstract}
This article discusses the expression 'Tibetan Borderlands', a designation commonly used in Tibetan scholarly works when dealing with Kham and Amdo areas. It also reconsiders the centre-periphery dynamics between Central Tibet and the eastern regions, especially in the contemporary context. Contrary to most studies that focus on the relations between the eastern Tibetan regions and China, this paper questions their relation to the traditional centre: Lhasa and Central Tibet. In view of the current decline of Lhasa and its prevalence as a centre, is it still relevant today to speak of the eastern Tibetan regions as borderlands, and all the more so when they appear to have taken over from Lhasa as the new Tibetan centre?
\end{abstract}

Keywords: Buddhism, cultural life, identities, Kham, politics, tourism

To Elliot Sperling ${ }^{1}$

With the collapse of Lhasa as the center of its cultural world, the Tibetan periphery has had to devise means of survival in order to preserve its identity. - Tsering Shakya, 'Whither the Tsampa Eaters?' (1993, 8).

1 While writing this article, I learned of the death of a very dear and close friend, Elliot Sperling. As a tribute to his total dedication to the Tibetan cause, I would like to offer him this article.

This article has benefited greatly from comments made by participants at the symposium 'Territories, Communities, and Exchanges in the Sino-Tibetan Borderlands', especially from those of Stéphane Gros and Pat Giersch to whom I am very grateful. I thank Bernadette Sellers who edited my English. All remaining errors are mine.

Gros, Stéphane (ed.), Frontier Tibet: Patterns of Change in the Sino-Tibetan Borderlands. Amsterdam, Amsterdam University Press 2019

DOI: 10.5117/9789463728713_CHO2 


\section{Introduction}

The eastern edge of the Tibetan plateau has long been the meeting ground and the politico-cultural interface between Mongols, Manchus, and Chinese rulers on one side, and Central Tibet rulers on the other. Nevertheless, this chapter focuses exclusively on the regions of Kham and Amdo as borderlands or margins of Central Tibet and Lhasa (Ü) in contemporary times. Two reasons go to explain this choice: on the one hand, these regions (especially Kham) have been the focus of growing attention in recent scholarship which details their relations with China from various perspectives - political, commercial, religious, cultural, etc. - (among others, Sperling 1976, 10-36; Nietupski 1999, 2011; Van Spengen 2000, 2006, 209-230; Epstein, ed. 2002; Rigzin Thargyal 2007; Mackley 2007; Van Spengen and Lama Jabb, eds. 2009; Gros, ed. 2016). Much less attention has been given to how these two regions, often qualified as 'eastern Tibet', can be understood and characterized in relation to Central Tibet. Among the few contributions on this topic, Pommaret (1999) and Huber (2011) discuss the Central Tibetan attitude towards some highland communities in the south (Mönpa-Lhopa), and Shneiderman (2006) focuses chiefly on the issue of ethnicity.

The expression 'Tibetan borderlands' appears quite commonly in Tibetan scholarly works, but the implications of its use on the areas it applies to are seldom explained. Among the earliest is Aris's (1992) edited volume and introduction to photographs by the famous botanist-explorer Joseph Rock. As is often the case with works that deal with Kham and Amdo (see for example Wellens 2010; Yeh and Coggins 2014), Aris focuses only on the Chinese side of the borderland, as if Amdo or Kham were not also a borderland with Central Tibet. This is true of another conventional expression: 'Sino-Tibetan Border(lands)' (see Jinba 2014) which furthermore renders invisible the other ethnicities of these borderlands (Roche 2014). By contrast, the eponymous volume edited by Klieger (2006) offers a much broader coverage of Tibetan Borderlands in which he encompasses Nepal, Ladakh, Sikkim, Baltistan, Gyelrong, and Amdo. These few references, among many others, suffice to point out that while the Tibetan borderlands have been the focus of growing attention, further work has yet to be done not only to grasp a better understanding of these diverse areas but mainly to reconsider the centre-periphery dynamics between Central Tibet and the eastern regions, especially in the contemporary context.

To shed some light on these dynamics, in this chapter I propose to first explore the Tibetan terminology used for borderlands and borders, and then to outline the characteristics of the relations between the traditional centre 
of the Tibetan world (Lhasa and Central Tibet) and its eastern periphery. Against this background and underlying the changes that have taken place over several decades in Kham and Amdo, I argue that at present we observe a process whose dynamics no longer radiate from the centre to the periphery but, on the contrary, from the periphery to the centre. This de-centering process, as I see it, is the result of a complex combination of factors that I detail by paying particular attention to the fields of religion, politics, culture, and tourism.

Through this endeavour I rely on an understanding of 'borderlands' akin to Zartman's definition (2010, 2): 'Borderlands are inhabited territories located on the margins of a power center, or between power centers, with power understood in the civilizational as well as the politico-economic sense. But like the sea at the edge of land (and the reverse), they are continually in movement, both fast and slow and any static depiction of the moment contains within it the elements of its change'. This type of definition, however, gives prominence to power relations and centrifugal forces that need to be counterbalanced with proper acknowledgement of the dynamics alluded to above and the forms of agency that also contribute to shaping change. The contemporary period seems to be characteristic of a 'frontier moment', following Gros' coinage in his Introduction, as a particular political and cultural conjuncture; it unsettles the conventional prism of centre-periphery relations.

Here I emphasize the relation to one centre (Lhasa) as opposed to the other (Beijing), which should not be understood as underestimating the latter's role and influence on the changes I depict, because this particular lens seems appropriate for questioning whether the term borderlands is still appropriate to describe the two eastern regions, Kham and Amdo. In a more provocative manner, this chapter raises the question: since the prevalence of the centre that led these eastern regions to be called borderlands is no longer what it used to be, is it still relevant to speak of borderlands when the centre is in decline and the periphery has somehow dethroned the centre?

\section{Vernacular terminology ${ }^{2}$}

It would seem worthwhile to start our examination by reviewing the vernacular terminology in the context of Tibetan history for what we conventionally

2 In this section based on Tibetan terminology, the Wylie system of transliteration is given in parenthesis after the simplified transcription. 
call borderlands, borders, frontiers, or margins. This brief outline will show significant overlaps with the modern concept of borderland.

In ancient documents and inscriptions, one finds so, or sokha (so kha), for 'frontier' and so lönpo (so blon po ${ }^{3}$ for 'frontier minister' (Richardson 1985, 112-113). The great scholar and artist Gendün Chömpel (1903-1951) reminds us that 'the minister who maintained vigilance (so) against external enemies was known as phyi so and the minister who maintained vigilance within the state was known as nang so. The latter term is still used as a title. ${ }^{4}$ The term so blon is an offshoot of the above term and is often encountered in the inscriptions of $r$ do ring (stone monuments)' (Gedun Choephel 1978, 27-28). According to this author, the notion of 'border' is implicit in the toponym Kham, which derives from the expression khamkyi gyeltren (khams kyi rgyal phran), 'the small principality on the border [...], denoting the "border" of the land' (ibid., 24).

Still in use today, sokha has the meaning of 'a place to be on the watch for enemies; a watchtower' (Tshig mdzod chen $m o)^{5}$ and is thus related to borders. A common expression in the literature is takhop ( $m$ tha' 'khob), an expression that comes from the Sanskrit pratyanta meaning: ${ }^{6}$ bordering on, adjacent or contiguous; a bordering country, i.e. a country occupied by barbarians'. The Tshig mdzod chen mo $(1986,1201)$ defines takhop as 'a land where civilisation [Dharma] has not spread', ' 'the country where the fourfold retinue $^{8}$ of the Buddha have not come'; 'a border region of a country or a kingdom. ${ }^{9}$ It is not surprising that this expression, which can be glossed as referring to bad, rough, remote, and barbarous areas, is generally used in Buddhist historiography with the meaning 'uncivilized country'. It is significantly applied, for example, to Tibet, the Land of Snow, before the latter was civilized or 'tamed' by Buddhism. ${ }^{10}$ Takhop is also sometimes

3 See also the Dba'bzhed (folio 5b; Pasang Wangdu-Diemberger 2000, 39) where we can read that Dba' gsal snang was sent to Mang yul as so blon.

4 On nang so, see also Yangdon Dhondup (2011, 33-59).

5 Dgra la sol ta sa; so kha'i mgar (1986, 2952).

6 Monier-Williams $(1993,664)$. I would like to thank Daniel Berounsky for this information.

$7 \quad$ Riggzhung ma dar pa'iyul.

8 Sangs rgyas kyi 'khor rnam bzhi mi rgyu ba'i yul; the four types of followers of the Buddha are male and female laypersons, fully ordained male and female persons [including monks, nuns, and male and female novices].

9 Rgyal khams sam yul gru bzhigi mtha' mtshams sa khul.

10 There are plenty of examples in the Mani bka' 'bum, a 'treasure-text' (gter ma) which is a collection of teachings and practices centred on Avalokiteśvara as well as in the Rgyal rabs gsal ba'i me long (Mirror Illuminating the Royal Genealogies), a fourteenth-century Buddhist historiography. As for example in the Rgyal rabs gsal ba'i me long translated by Sørensen (1994), 
understood as the periphery populated by 'barbarians'. ${ }^{11} \mathrm{Ta}\left(m t h a^{\prime}\right)$ with the meaning of 'remote, borders' is still in use in modern times. In the $1940 \mathrm{~s}$ the Khampa Communist Bapa Püntsok Wangyel and his friends used it in the name of the organization they founded, the Khambö takhül ledönuyön lenkhang (Khams bod mtha'khul las don u yon lhan khang), the 'Communist Party Work Committee of the Kham-Tibetan Border Area' (Goldstein et al. 2004, 129). This expression is used today in the media to describe a remote area. ${ }^{12}$ In addition, one can say tatsam (mtha'mtshams) (lit. demarcation of the margins) or satsam (sa mtshams) (lit. demarcation of land) for borders, and satsam kyimi (sa mtshams kyi mi), for 'people of the border' or satsamsu dökhen (sa mtshams su sdod mkhan), 'those who inhabit the border.'. ${ }^{13}$

To sum up, we can say that the vernacular terminology defines the borderlands as places to be defended or to be made civilized. But do people from Central Tibet regard Kham and Amdo as places to be defended or civilized? And what about the perception Tibetans from eastern areas have of $\ddot{U}$, the traditional centre?

\section{Borderlands versus Centre}

For centuries, Central Tibet and its capital Lhasa were considered to be the centre - as expressed in the very name of the region, Ü, 'Centre' - of the historical, religious, economic, and cultural life of the Tibetan world,

$m$ tha' 'khob, pp. 26 and 38 of the Tibetan text, is translated as 'barbarous borderland' (Sørensen 1994, 97 and 112), and kha ba can ni mtha' 'khob kla klo'i yul is translated as 'The Snow-capped [country], a barbarous and savage borderland' (Sørensen 1994, 205).

11 This is the case in a Tibetan encyclopedia compiled in the fifteenth century by Döndam Mawe Senge (Don dam smra ba'i seng ge), the Bshad mdzod yid bzhin nor bu (A Treasure of Explanation, the Jewel that Fulfills One's Desires) (Smith 2001, 221). See also: $m$ tha' 'khob kyi kla klo rnams, 'People Inhabiting the Outlying Territories' http://rywiki.tsadra.org/index.php/ mtha\%27_\%27khob_kyi_kla_klo (accessed 4 September 2017); and kla klo mtha' khob kyizhal lce, 'The Law of the Barbarian Borderlands' http://www.tbrc.org/\#!rid=Oo1ACI124|Oo1ACI1240 1ACI168\$12165 (accessed 4 September 2017). The Tibetan and Himalayan Library's dictionary gives 'outlying district, border, outskirts, barbarian, primitive [border]land without learning. Border regions. A wild and savage land; borderland; primitive borderland', http://www.thlib. org/reference/dictionaries/tibetan-dictionary/translate.php (accessed 8 September 2017).

12 http://tb.tibet.cn/2010news/xzxw/whjy/201404/t20140410_1987488.html (accessed 4 September 2017).

Samten Karmay told me that in the eulogy (bstod pa) to Shugden, it is written: gshen rab lugs ngan 'dzin pa' imtha' 'khob tu: here $m$ tha' 'khob designates the Dromo valley, in southern Tibet, on the eastern border of Sikkim (personal communication 17 February 2015).

13 Information given orally by Chung Tsering (17 January 2016). 
the civilizing centre where all Tibetans aspired to go, at least once in their lifetime. A saying expresses this feeling very clearly: 'They who have not seen Lhasa live only half [a life]. ${ }^{14}$ 'Until 1950, all Tibetan-speaking people regarded Lhasa as the centre of their universe', writes Tsering Shakya (1993, 10). The same applied to Tibetans from all over Tibet, as shown for example in Tibetan biographical literature translated into English. Aten, a 'Khampa warrior', claims that 'for our people in eastern Tibet it was the culminative [sic] experience of a lifetime to see Lhasa, at least once before we died. The city was not only the capital of our country but also the centre of our culture and our religion' (Jamyang Norbu 1979, 45). Rinchen Lhamo ([1926] 1985, 165), also a Khampa and the first Tibetan woman to marry a European, Sherap from Kham (Combe 1975, 56), noble ladies such as Jamyang Sakya from Kham (Jamyang Sakya and Emery 1990, 43), or Dorje Yudon Yuthok from Lhasa (1990, 73), and Bapa Püntsok Wangyel (Goldstein et al. 2004, 69), among others, all speak about Lhasa in the same terms. As for the great Amdowa yogi Shabkar, 'he portrays the city of Lhasa as being the "center of Tibet"' (Pang 2018, 44).

Amdowas emphasized even further the centrality of the city when going on a pilgrimage to Lhasa, saying that 'they were going to Ü, to the [spiritual] centre'. They even called themselves Ü-pas, literally 'those of the centre', understood as 'those going to the [spiritual] centre' (Naktsang Nulo 2014, 75), and the road the pilgrims took when going to Lhasa on a pilgrimage was called ülam, 'The road to the [spiritual] centre', that is to say Lhasa.

One may wonder why people from Ü do not call themselves Ü-pas in the same way that people from Kham are called Khampas or those from Amdo, Amdowas. Could it be because they do not have the same sense of unity, or because they travel less than people from the eastern regions who often have to explain their origin (it is a fact that Khampas and Amdowas often went to Central Tibet for religious or commercial purposes, while it was not usual for people from Central Tibet to travel to the east); or rather because, being from the centre, they represent the place in relation to which others define themselves. ${ }^{15}$

As for monks from the eastern regions, going to Lhasa to study at the famous Gelukpa monasteries, even if they were Bönpos, was extremely important since the monasteries at the periphery were 'unable to compete

14 Lha sa ma mjal mi lus phyed pa.

15 Generally speaking, this parallels a 'majority' (those at the centre) as the by-default category. This is true of Han in the context of China. See Mullaney et al. (2012), a collection of essays exploring what it means to be Han in China. 
with the great scholastic centres' in Lhasa (Dreyfus 2003, 47). For these monks, Drepung was the most prestigious centre of philosophical studies since it had been the seat of the Ganden Phodrang, the Tibetan government in former times, thus lending importance to a government of which they otherwise considered themselves independent.

The feeling of not even belonging to the same country (namely Tibet) was manifest in the use of the term Bö, 'Tibet', to designate Lhasa and Central Tibet. ${ }^{16}$ The biography of Bapa Püntsok Wangyel (2004) clearly shows how the idea of a pan-Tibetan nationality was often badly looked upon because many Khampas regarded the 'Böpas', Tibetans from Central Tibet, as 'different nationalities or ethnic groups' (Goldstein et al. 2004, 55 ) - a perception confirmed by a Khampa from Lithang who describes his trips to Lhasa before 1959 as going to 'Tibet' (Bö), ${ }^{17}$ implying that he was going to another country. But Böpa does not have the same meaning throughout Tibet and the people from the high plateau of Changthang, the Northern Plain, only use it to designate the people of Lhasa (Tsering Shakya 1993, 8). ${ }^{18}$

Another striking example of this sense of not belonging to Tibet - nor to China - can be found in a Golok song recorded by Namkhai Norbu $(1997,3)$ :

I rebel (nolok) against those up there/ I rebel against Tibet/ I rebel/ Against the orders of the Dharma King of Tibet I rebel/ I rebel and the sky is with $\mathrm{me} /$ The blue sky is with the rebellion/ I rebel against those down there. I rebel/ Against China I rebel $[\ldots]^{19}$

As this song clearly shows, relations between the Ganden Phodrang government and the peripheral areas were not of the peaceful neighbourly sort. There were numerous conflicts and exchanges of fire could often be heard. In the 1930s the Khampas regarded the 'Tibetan army', the army of the Lhasa government, as an enemy army. In a book written by a certain Orgyan Nyima (2016) containing a collection of interviews by Khampas describing their lives between the 1930s and the Chinese occupation of

16 A lot of work still has to be done on the terms pha yul, lung pa, rgyal khab, mes rgyal (This last term is a new one which appeared after 1950. Information Bugang from Chamdo, May 2016). The question of when Tibetans use these words depends on the region they belong to, on the context, and on who their interlocutor is.

17 McGranahan $(2010,120)$. See also Goldstein et al. $(2004,54)$.

18 Here I will not discuss the situation among the diaspora since it is beyond the scope of this paper.

19 Namkhai Norbu doesn't provide the Tibetan version of the song. 
the 1950s, those interviewed recount the 'invasion of the Tibet Army' in the 1930s (ibid., 22, 29, 36, etc.). Khampas were even members of a militia which, alongside the Muslim warlord Ma Bufang (1903-1975), fought against the Tibetan Army (ibid., 27), and the militia in Drawu (place of the narrator's native community ${ }^{20}$ joined the Chinese soldiers to defeat the Dergé troops (ibid. 4). During those years, the Khampas considered that they were in 'Tibet proper' when they were on the other side of the Drichu or Yangtze (Goldstein et al. 2004, 57), which marked the frontier between 'Inner Tibet' (Kham) under Qing authority and 'Outer Tibet' (Bö) under the Ganden Phodrang, thus following and respecting the Simla Convention of $1914 .{ }^{21}$ It was only with the advent of the People's Liberation Army that 'the hatred between Drawu and Dege faded' (ibid., 44) since they had to fight side by side against the same enemy. Nevertheless, relations between them were still tense: in 1956, following the numerous battles between Khampas and the soldiers of the People's Liberation Army, Khampa traders appealed to the Lhasa government for help and were 'amazed' not to receive an answer (Tsering Shakya 1999, 141). In fact, following the implementation in 1955-1956 of so-called 'democratic reforms' in Kham, widespread revolts erupted and were brutally repressed; the main monastery in Lithang was bombed on 28 March 1956. Many Khampas fled and took refuge in Lhasa ${ }^{22}$ where they had to face the inhabitants of the city who, at the outset, did not believe their stories about the exactions. On the contrary, 'they tended to stereotype them as unruly and troublesome' (Tsering Shakya 1999, 142), all the more so since the Khampas themselves conceived their own country as 'a lawless and uncertain land' in which 'a rifle was an essential part of man's life. It was not only the fear of bandits [...] but also due to prevalence of bloody and interminable feuds' (Jamyang Norbu 1979, 24). ${ }^{23}$ Relations between Lhasapas and Khampas were problematic: even though Lhasapas did not refer to Khampas and Amdowas by the same pejorative names they used for communities on the southern margins, they nevertheless considered themselves much more 'civilised' (Pommaret 1999, 53; Schneiderman 2006, 15; Huber 2011, 260).

20 Drawu (Gra 'u) was a place under the jurisdiction of Drawu cenurion (Tib. brgya dpon; Ch, baihu) in Jyekundo (I thank Yudru Tsomu for this information).

21 On the Simla Convention regarding Kham, see Goldstein (1989, 67-74 and 832-841).

22 According to Kapstein $(2004,237)$ about 55,000 Amdowas and Khampas camped in and around Lhasa at the beginning of 1959.

23 There is an old saying: A blow on the nose of a hated enemy / Is surely more satisfying / Than to listen to the advice / Of benevolent parties (Jamyang Norbu 1979, 25). 
For their part, Khampas perceived themselves as 'straightforward and honest' while they regarded Lhasapas as affected and slick (McGranahan 2010, 121). When in Lhasa on a pilgrimage or for trade, Khampas and Amdowas were faced with new customs, new laws, and new habits, which often accentuated this feeling of otherness they felt in relation to Lhasapas. In 1954-1955, when Naktsang Nulo $(2014,108)$, a young Amdowa, went on a pilgrimage to Lhasa with his father and some companions, he was struck by the spectacle he witnessed of criminals with shackles around their ankles and a yoke around their necks. This reminded him of a saying he had often heard: 'If you want to see the sufferings of hell, you must go to Lhasa'. ${ }^{24}$ Moreover, one of his companions was arrested by Tibetan soldiers, and the Amdowa pilgrims refused to abide by the laws laid down by the Ganden Phodrang, laws which they did not consider themselves to be concerned by. They therefore disarmed the soldiers, released the prisoner, and handed him over to their own chief (ibid. 117), the only person who, according to them, represented the law.

\section{Local and national identities}

Relations between the centre and the eastern borderlands were not devoid of ambivalence. But after Chinese communists entered Central Tibet in the 1950s, regional identities that were traditionally strongly bound to local territory, religious school, and master were then eclipsed by a pan-Tibetan identity, more secularized (through the influence of intellectuals) and politicized. ${ }^{25}$

The emergence of a feeling of Tibetan national identity is a recent phenomenon linked to political events in the recent past (occupation of Tibet, national policies, and ethnic categorization system introduced by the Communists) (Tsering Shakya 2012, 24) - even if regional identity is still sometimes stronger than national identity (Kolås 2008, 83). Indeed, there were grounds for a shared identity: Tibetan Buddhism, a specific culture, a common mythology, a common written language, a common history, shared memories, customs, and territory gave the population of the vast Tibetan plateau a sense of belonging to a specific group, sharing a large number of identity features distinct from other countries.

24 dmyal khams sdug bsngal ni blta dgos na; lha sa'i grong du 'gro dgos ni red (Naktsang Nulo [Nags tshang nus blo] 2008, 190).

25 For the transformation from a feeling of regional identity to a much more secular feeling of national identity, see Tsering Shakya (1993) and Jia Mang (2015). 
At the root of this sense of common belonging also lies the fact that Tibetans consider themselves insiders, that is to say Buddhists (nangpa) as opposed to outsiders, non-Buddhists (chipa). This strong feeling was expressed, for instance, through the name given to Chinese Communists who were described as 'enemies of the doctrine' (tendra), while the 'Four Rivers, Six Ranges' resistance army, the Chushi Gangdruk, was also called 'The Tibetan Volunteer Army to Defend Buddhism' (Bökyi tensung dang langmak).

The first time the whole Tibetan population was united in a 'common purpose and shared values' (Tsering Shakya 1999, 165) was in 1957 when Khampa traders from Lhasa organized groups of people to collect, from all Tibetan regions, contributions towards offering a golden throne to the Dalai Lama in order to preserve Tibet and Tibetans from any obstacles and calamities that might arise. ${ }^{26}$ This was offered to the hierarch on 4 July during a ceremony called Tenshuk shabten, which, for Dreyfus $(2005,12)$, marked 'the birth of Tibetan nationalism, the awareness that Tibetans have of belonging to a single country'.

The creation of the resistance army in 1958 was also an important step in nurturing the feeling of national identity. Although the Khampas organized it to combat the Chinese and made up the majority of the fighters, some Amdowas and Lhasapas joined its ranks, thus creating a national movement (Nima Chodon 2012, 35-45). ${ }^{27}$

Between 1959, the year of the Lhasa uprising, until 1980 Tibet suffered a series of dreadful events: 'democratic' reforms, the destruction of the religious and cultural heritage, and the Great Leap Forward and Cultural Revolution that swept through China. But following the visit to Central Tibet in 1980 by Hu Yaobang, the then Secretary of the Chinese Communist Party, a movement of 'liberalization' emerged which led to a religious and cultural revival. Amdo and Kham then underwent a 'revitalization of the local identity and the reconstitution of scarred sites, with this revival of religion and traditional practices heightening local identity' (Tsering Shakya $2012,24)$. As we shall see, however, this revitalization of the local identity does not preclude the feeling of national identity from (re)appearing as soon as Tibetans confront the 'Others', the Chinese.

26 This ceremony expressed the people's loyalty and confidence in the Dalai Lama's leadership and confirmed his earthly sovereign powers (Andrugtsang 1973, 51).

27 It is important to underline that many Amdowas had already been killed or jailed. '[In 1958] some nomadic areas of Amdo were reported to have been virtually emptied of men, all having fled or been killed or imprisoned. Most of the population of the Sokpo (Mongol) areas east of the Ma chu were reportedly massacred' (Smith 1997, 442). 


\section{Religious revival}

Religious revitalization led to the (re)construction of religious buildings in the eastern borderlands just like in Central Tibet. Yet these areas stand out from others by the fact that replicas of monuments from Central Tibet, India and Nepal were (re)built. I have already shown elsewhere (Buffetrille 2015, 133-152) that the choice of duplicate edifices bears witness to the glory of a politically and religiously prestigious Tibetan past, referring to a time of Imperial Greatness, to the introduction of Buddhism in the Land of Snow, and to India, the holy country from where Buddhism came. They also constitute substitutes to famous pilgrimage sites where Tibetans are not allowed or are unable to go since these replicas are said to bring the same amount of merit.

Lung Ngön monastery in Golok Tibetan Autonomous Prefecture is a perfect example of a place where many replicas have been erected (Figure 2.1): the main temple of Samyé (the first monastery built in Central Tibet in the eighth century), and Sekhar Gutog, Milarepa's tower originally located in Lhodrag (southern Tibet) (see Akester 2016, 305-328; 464-469), as well as the Bodh Gaya Mahabodhi temple and the Jarung Kashor stūpa (Bodnath), which is even bigger than its original in Nepal. Dzogchen monastery, in Kandzé Autonomous Prefecture, also has its own replica of the Jarung Kashor stūpa whose consecration took place on Guru Rinpoche's day, 13 August 2016. Moreover, in several monasteries, such as Sershül or Dzogchen, Aśoka pillars and statues of elephants covered in gold leaves - a clear reference to India - have been built in the front courtyard. Furthermore, a private Tibetan company intends to build a new Yumbu Lagang in Amdo. ${ }^{28}$

One building in particular has been duplicated in many places: Milarepa's tower, perhaps because Milarepa is considered the Tibetan yogi par excellence - contrary, for instance, to Padmasambhava who came from India (another sign of the emphasis on Tibetan identity). One was built in the seventeenth century in the city of Tsö in Amdo, then rebuilt after its destruction during the Cultural Revolution. Another one is to be found in Kham, in Sangkar (Gyelrong region), ${ }^{29}$ and yet another one in Kyodrag gönpa (Nangchen region). $3^{0}$

28 Françoise Robin, personal communication, 17 February 2015. She saw the plans of the building in 2014. Yumbu lhagang is said to have been the oldest building in Tibet. It was the palace of King Lhathotho Rinyentsen, the 28 th mythical king. According to tradition, various Buddhist items - text about Avalokiteśvara as a stūpa - fell onto the roof one day. Not understanding the content of these objects yet aware of their value, he treasured them.

29 http://www.alamy.com/stock-photo-china-tibet-kham-sangkar-gyarong-gorges-novicesin-front-of-milarepa-70376412.html (accessed 15 November 2017)

30 I thank Cécile Ducher for this information. The monastery belongs to the Barom Kagyü School. 
While Lhasa has long been the main destination for pilgrimages, eastern areas now appear to be more and more attractive on a religious level to the overall Tibetan population, and this is not only because of the replicas. Another phenomenon specific to Amdo and Kham is the presence of charismatic religious figures who have created new semi-monastic Buddhist encampments (chö gar) where several thousands of lay and religious devotees gather or have founded mountain hermitages (ritrö). Among them we find four prominent masters: Jigme Püntsok (1934-2004), founder of Larung Gar; ${ }^{31}$ Drubwang Lüntog Gyeltsen (1927-2011), known as Khempo Achung, who created Yachen Samten Ling (also simply called Yachen), which houses nuns as well as monks (see Cho, this volume); Kusum Lingpa (1934-2009), who set up Lung Ngön in Golok (see Buffetrille 2009, 523-554); and Dechen Ösel Dorjé (b. 1921), founder of five mountain hermitages in Nangchen (Terrone 2010). The setting-up of monastic camps is nothing new. Religious encampments already existed in the fourteenth century and were generally associated with the Karma Kagyü School (Terrone 2008, 763; 2009, 87). What is new though is the presence of lay and religious practitioners and the size of these encampments, which can house more than 10,00o practitioners, exceeding the number of monks in monasteries such as Drepung or Sera prior to the 195 os. $^{32}$

These masters largely contributed to the revitalization of Buddhism in contemporary Tibet. Not only did they attract Tibetan disciples from all parts of Tibet and from all schools of Tibetan Buddhism, but also many Chinese practitioners. They were famous treasure-revealers (tertön) of the Nyingma school of Buddhism who upheld an ecumenical approach (rimé, lit. 'impartial'). Their endeavour has been perpetuated by their disciples. This is no mere anecdote because, as Dreyfus has shown, 'memories as they are contained in the "treasures" act as a focus of identity for Tibetans' (1994, 209).

A new religious phenomenon that was inspired by Jigme Püntsok and systematized during the years 2008-2010 by his main disciples continues today through other great masters and gives new visibility to these regions: a

31 See Germano (1998, 53-94) and Terrone (2008, 747-779 and 2009, 73-110).

32 Since July 2016 the Chinese authorities have started the demolition of monastic dwellings in Larung gar and the eviction of nuns and monks with the aim of cutting the number back to 5000 . See Shadow of Dust across the Sun: How Tourism is Used to Counter Tibetan Culture Resilience. ICT Report 13 March 2017. https://www.savetibet.org/shadow-of-dust-across-the-sun-how-tourismis-used-to-counter-tibetan-cultural-resilience/ (accessed 8 September 2017). Yachen underwent the same fate in the summer of 2017, see http://www.phayul.com/news/article.aspx?id=39431 $\&$ article $=$ After+Larung + Gar\%2c+Yarchen + Gar+demolition+underway (accessed 8 September 2017). 
Figure 2.1 Lung Ngön monastery: Jarung Kashor stûpa (Bodnath)

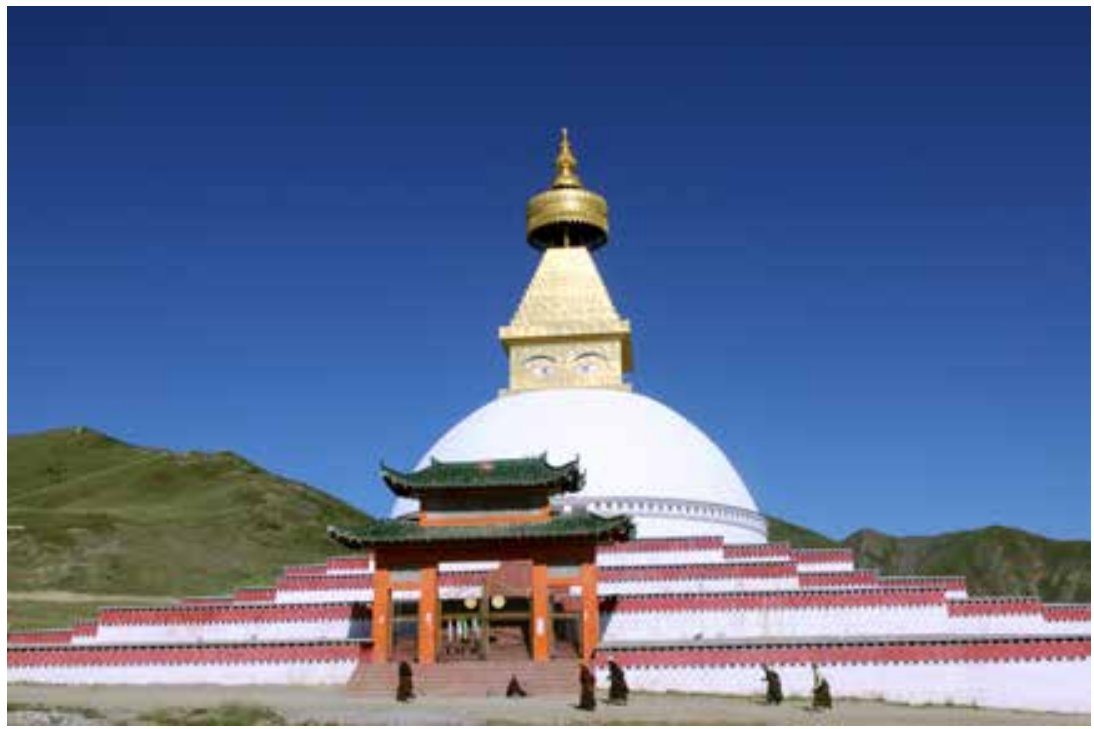

Photograph by Katia Buffetrille 2011

movement based on a new set of 'Ten Virtues'33 - with a focus on the ban on killing animals. Vegetarianism, which is not listed as one of the ten virtues, is also strongly advocated (see Tan, this volume). This new phenomenon, much discussed on blogs and supported by high-ranking lamas mostly from the eastern 'borderlands', is gaining strength throughout the country. ${ }^{34}$ In Amdo and Kham, for instance, most monasteries no longer serve meat but, while some of them allow their monks to eat meat outside (like Rongwo gönchen in Rebgong), others have totally banned its consumption inside and outside the monastery (such as Tashi Dargyeling in Kham). This movement, which has not received the support of all Tibetan people, has spread to the Tibet Autonomous Region (T.A.R.).

It may happen that the religious sphere is sometimes conflated with the political sphere. It is a well-known fact that the most important sacred mountains are located in border areas (as are beyül, valleys hidden by Padmasambhava

33 The ten new virtues are: 1) not to butcher and sell meat, 2) not to steal or rob, 3) not to fight with weapons, 4) not to prostitute one's body, 5) not to sell guns and opium, 6) not to smoke opium or cigarettes, 7) not to drink alcohol, 8) not to gamble, 9) not to hunt, and 10) not to wear animal skin and fur.

34 See Galley (2011, 2013, 2016); Gaerrang (2011, 2012); Barstow (2013); Buffetrille (2015, 2016). 
where Tibetans could seek refuge when dangers threatened the country). ${ }^{35}$ These mountains, which were traditionally perceived as territorial gods (yül lha), a non-Buddhist concept, mainly attracted populations from the surrounding areas who, through their worship, expected various mundane benefits (see Buffetrille 1998, 18-34). But this has changed. The year 2015 was the year of the sheep according to the Tibetan duodenary calendar and the most important year for the pilgrimage to Mount Kawakarpo, located in northwest Yunnan province. Pilgrims from all over the Tibetan plateau came to circumambulate the mountain in growing numbers thanks to new modern means of transportation, to the rise in income, and to the increasing Buddhicization of these sacred mountains. In fact, these mountain territorial gods are more and more integrated in the Buddhist pantheon through a process of Buddhicization, which has led to their transformation into Buddhist sacred mountains. The growing number of pilgrims who come from all Tibetan regions to circumambulate Mount Kawakarpo (Figure 2.2) is also a consequence of the Chinese authorities' religious policies that have prevented Tibetans from going to Kailash, the most sacred mountain in the T.A.R., for the great pilgrimage in the year of the horse (2014). Consequently, quite a few Lhasapas and people from Central Tibet have replaced it with the Kawakarpo pilgrimage, taking advantage of the greater political openness in eastern regions. This exemplifies the fact that the political situation can vary greatly across the Tibetan Plateau.

\section{Political situation}

As previously mentioned, following the Chinese occupation in the 1950s, the Land of Snow underwent a series of dramatic events that contributed to the decline of the Holy City. Moreover, in 1965 the territory that had been governed by the Ganden Phodrang since the seventeenth century was transformed into the so-called Tibet Autonomous Region which, for the Chinese authorities, corresponds to what they consider to be 'Tibet'. For decades and up until today they regard it as an 'autonomous' area that had to be kept under strict control. This tighter control contrasts with the situation in Kham and Amdo - with the exception of parts of western Kham that are included in the T.A.R. - which have been fragmented into various autonomous administrative entities within Chinese provinces. There, the control exercised by the authorities has always been looser than it was in the T.A.R., providing more opportunities and relatively greater freedom to partake in various cultural and religious practices. 
Figure 2.2 Kawakarpo range

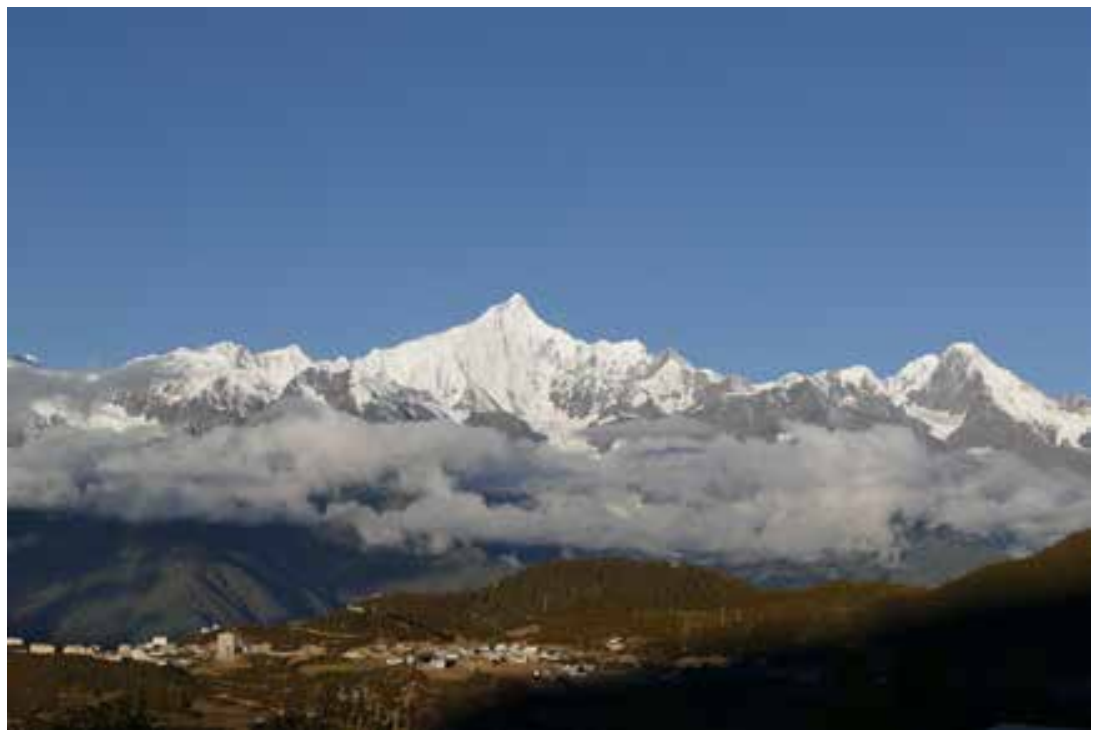

Photograph by Katia Buffetrille 2014

At a political level, the demonstrations in 2008, which started in Lhasa and were led by monks, spread throughout the entire plateau. The feeling of national identity was clearly expressed by Khampas and Amdowas who brandished the Tibetan flag during their demonstrations. From then on Tibetans in the eastern areas once again became agents of resistance, destroying the common perception of Tibetans in Tibet as powerless victims of the Chinese state (see also Shneiderman 2006, 61-63). Even though Lhasa had been a place of considerable contestation in the 1980 os and in subsequent years, the Tibetan diaspora was usually considered to be the main centre of resistance and the promoter of nationalism. After 2008, however, the eastern margins became the centre of numerous peaceful protests: refusal to celebrate the New Year or to harvest; sit-ins by students or monks; desertion of monasteries by nuns and monks to escape the new restrictive rules; celebration of 'White Wednesdays' (Lhakar) that has spread through the diaspora, etc..$^{6}$ One retaliatory measure imposed on Khampas and Amdowas was the ban on travelling freely to the T.A.R., demanding that they possess

36 On this day which is said to be the day the Dalai Lama was born, Tibetans 'eat Tibetan food, wear Tibetan clothing, speak [the] Tibetan language and celebrate the Tibetan identity'. See https://lhakardiaries.com/about/ (accessed 1o February 2019). 
a special permit, that they stay in designated hotels - new regulations that have contributed to altering a little more the role that Lhasa has played in Tibetan life for more than a millennium.

Following on from the 2008 demonstrations, a movement of selfimmolations that was launched in Amdo Ngawa in 2009 has significantly strengthened the sense of identity of all Tibetans in the Land of snow and beyond. ${ }^{37}$ To this day (15 March 2019), 153 Tibetans have self-immolated in Tibet and, with only six exceptions - in the years 2011 and 2012 - all the immolators hailed from Kham or Amdo (including two young men who self-immolated outside Jokhang temple in Lhasa on 27 May 2012 and a woman in Beijing on 12 September 2012). Following the system of 'punishment by association' established by the Chinese authorities, which entitles them to imprison all the relatives of the self-immolator, the movement has dwindled dramatically. ${ }^{38}$ Nevertheless, despite a step-up in spot-checks, Tibetans from the borderlands are still mobilized, and as of 2015 a succession of lone protests started to take place in Kham and Amdo.39

\section{Cultural revival}

One might think that this political tension in the borderlands would hinder the development of cultural life, which on the contrary is thriving. The literary scene has moved from Central Tibet to Amdo, particularly from the mid-1990s onwards, as shown by numerous scholars (Venturino 2007, Hartley and Schiaffini 2008, Lama Jabb 2015, among others). Almost all writers who publish work in Tibetan (Döndrup Gyal, Tsering Döndrup, Shogdung, Jangbu, Sangdor, to name just a few) are from Amdo, as are several others who write in Chinese (Yidam Tsering, or Jamphel Gyatso i.e. Jiangbian Jiacuo), without forgetting Alai, from Gyelrong. Starting in 1993, quite a few of them set up literary groups, a phenomenon which apparently

37 On self-immolations, see the Hot Spot in Cultural Anthropology (online), 11 April 2012; Buffetrille and Robin, eds. 2012; Buffetrille 2016, 343-36o. The first immolation by a Tibetan took place in Delhi (India) on 27 April 1998. The self-immolator was Thupten Ngodrup, a sixty-year-old ex-Buddhist monk from Tashilhunpo monastery (Central Tibet) and a former soldier (in exile). See Buffetrille (2012, 1-18). See also the Afterword by Carole McGranahan, this volume.

38 There have been a total of 153 immolations in Tibetan areas: 1 in 2009, 12 in 2011, 84 in 2012, 26 in 2013, 11 in 2014, 7 in 2015, 3 in 2016, 6 in 2017, and 3 in 2018.

39 http://tchrd.org/lone-tibetan-protester-holding-dalai-lamas-portrait-detained-incommunicado/ (accessed 10 February 2019).

http://www.rfa.org/english/news/tibet/critical-03212017154647.html (accessed 1o February 2019). 
does not exist in Lhasa. ${ }^{40}$ The publishing sector is also booming in eastern areas along with websites and independent online forums, though none come from the T.A.R. (Tsering Shakya 2012, 27).

Moreover, the support that Chinese authorities have manifested over the decades for the recording and study of the Gesar Epic has prompted a revival in Kham and in Amdo of the Gesar religious cult and of the dances and cham dedicated to him. Statues of Gesar are being erected everywhere and museums dedicated to him are being opened (Figure 2.3). This revitalization of the Gesar tradition, which is used by the Chinese authorities as a means of propaganda, has nevertheless created an arena where Tibetans can assert their identity. ${ }^{41}$

In Amdo the preservation of a pure Tibetan language is taken very seriously, and changes have been observed over the years with the gradual disappearance of Chinese loan words from the language. The importance accorded to language, a very strong medium for asserting the Tibetan identity, is often expressed on small pieces of paper that are put in shops requesting that Tibetans speak a pure Tibetan. Since 2010 Tibetans from Amdo have manifested through peaceful demonstrations their attachment to their language and its teaching in schools, a movement that has recently spread to Chengdu where a Chinese People's Political Consultative Congress regional committee member and professor at Sichuan Teachers University has appealed for a real bilingual education. ${ }^{42}$ Since 2012 Tibetans have even succeeded in organizing in Nangchen a week-long competition to test Tibetan language skills. ${ }^{43}$

Amdo is also the cradle of new forms of expression with filmmakers such as Padma Tseten, Sonthar Gyal, Jangbu, or Kashem Gyal. They generally focus on their native land, shooting in rural or nomadic environments and in the Tibetan language. Their films give insight into contemporary eastern Tibet, far from old stereotypes, exoticism, and Western fantasies. The spectator is confronted with today's situation: the difficulties, frustrations, and marginalization the Tibetan population encounters when faced with modernization and globalization whose impact on their traditional world is often brutal and destructive. Thanks to their success, their films are now

40 Sangye Gyatso (Gangzhün) 20o8, 263-279, in particular pp. 268, 272-278.

41 Buffetrille (2010, 523-554), Henrion-Dourcy (2017, 191-214).

42 http://www.rfa.org/english/news/tibet/education-01192017151624.html (accessed 1o February 2019).

43 http://www.rfa.org/english/news/tibet/awards-02012016143320.html (accessed 1o February 2019). 
Figure 2.3 Gesar statue, Machen (Golok Tibetan Autonomous Prefecture)

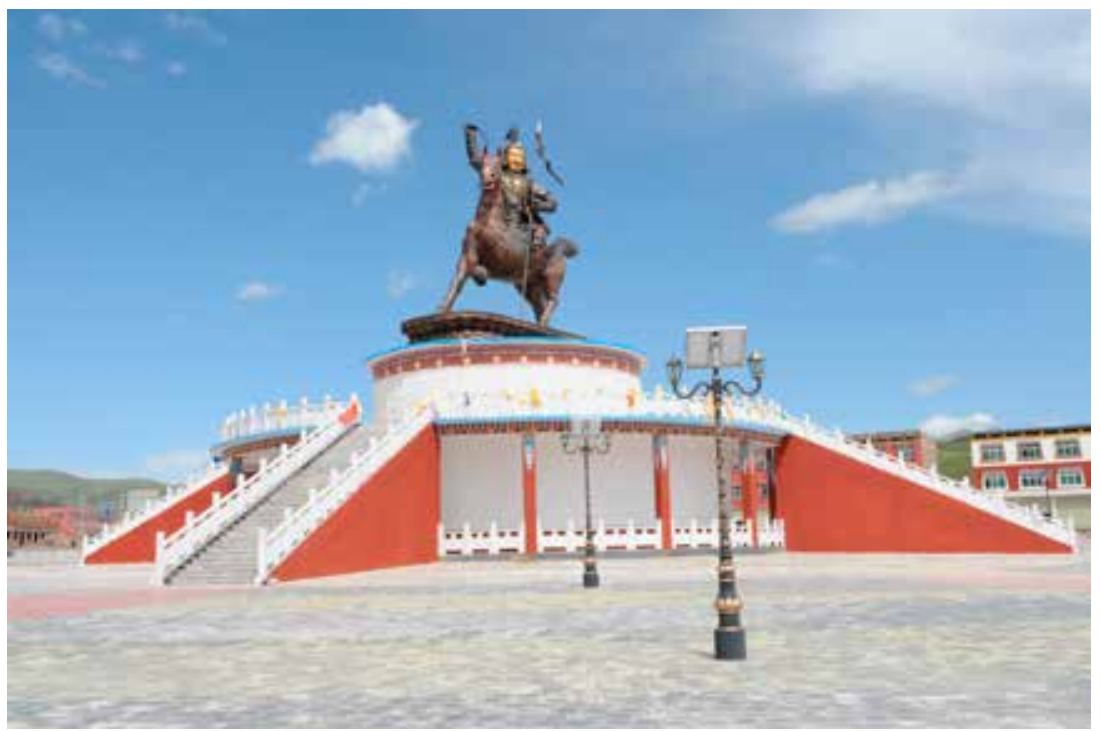

Photograph by Katia Buffetrille 2011

competing at national and international levels and have brought to mainland China, and even beyond, images of the Tibetan world of the margins.

Though writers and filmmakers are mainly Amdowas, most celebrated popular singers such as Yadong, Tsewang Lhamo, Dekyi Tsering, or Kunga Tsering are Khampas. They are recognized all over Tibet regardless of the language in which they sing: the Lhasa dialect, the Khampa dialect, or even Chinese. Their songs, which often deal with the beauty of the Tibetan landscape, religion, and the importance of expressing one's Tibetanness through language, for instance, contribute to strengthening the sense of a Tibetan identity. The Chinese authorities are not altogether mistaken about the hidden messages of these artists, some of whom end up in jail. ${ }^{44}$

Local N.G.O.s also play a role in the cultural sphere and often hold an emphatic discourse on Tibetanness. A number of foreign N.G.O.s were expelled after the 2008 protests and many local ones forced to suspend their activities. Nevertheless, some are still active in the eastern borderlands and

44 See among others: https://www.freetibet.org/about/human-rights/case-studies/musicians (accessed 10 September 2017). http://www.rfa.org/english/news/tibet/singers-11292014130459. html (accessed 10 September 2017). http://www.guchusum.in/popular-tibetan-singer-jailedfor-political-songs-released/ (accessed 10 September 2017). 
continue to provide services after changing their status to 'social enterprise' to escape the tighter controls in place today. In Kham, for instance, the Kawakarpo Institute in Dechen is highly involved in promoting local culture. Not only does it organize classes of spoken and written Tibetan, but it also publishes local writers (poetry and essays) and old songs heard in villages in a magazine entitled Return (Logs phebs). ${ }^{45}$ Though first published only in Chinese, it was decided in 2013 to publish it also in Tibetan. For some, this may appear to be a symbolic move since Tibetans in this area read more Chinese than Tibetan. It perhaps announces the beginning of a revival in Tibetan scripture in Dechen region, a revival that can be seen as the 'protection of one's own ethnic identity and culture from cultural assimilation, and resistance to the Chinese cultural and political domination in Tibet' (Jia Mang 2015, 20). In fact, whereas in the years 2003-2005 there were practically no Tibetan-language books in Gyelthang, since 2014 bookshops have boasted a growing Tibetan section.

\section{Boom in tourism}

At the beginning of the 1980 s, especially from 1984 with the opening of the Tibetan Autonomous Region to individual travellers, foreigners fascinated by Tibet poured into the T.A.R. But the Lhasa demonstrations in 1987, 1988, and 1989, the imposition of martial law from April 1989 to May 1990, and the restriction imposed on Westerners in the 1990s to travel only in groups organized through big-budget travel agencies all led to a relatively small number of Western visitors to the T.A.R. (compared to Nepal for example). The decision to promote tourism in the T.A.R. was taken in 2001 at the Fourth Tibet Work Forum in Beijing, but it was oriented mainly towards Chinese tourists.

For their part, officials and locals in the eastern borderlands realized the economic potential of tourism and launched several projects to promote their region's landscapes and culture. A Khampa Art Festival was organized as early as 1994. It is now held every four years on a rota basis in Jyekundo (Qinghai), Gyelthang (Yunnan), Chamdo (T.A.R.) and Dartsedo (Sichuan), therefore calling upon a Khampa city from each of the four Chinese provinces into which Kham has been divided, thus recreating a sort of Khampa territory. This festival is aimed at showing through various performances how

45 The title itself is interesting and may give rise to various interpretations: return to the past? to the old world? to the old culture? to the Dalai Lama? etc. 
Tibetan culture is protected and developed in the framework of the People's Republic of China (P.R.C.). It attracts innumerable tourists, both Chinese and Tibetan, from every part of the country. It receives strong support from the Chinese authorities, which have thereby become one of the instigators of the emergence of a new Khampa identity - this in no way undermines the large voluntary participation on the part of Tibetans.

Gyelthang is another example of a successful touristic destination. The boom started in 2001 after the city was renamed Shangrila. ${ }^{46}$ The place attracts mostly Chinese tourists, but more and more Tibetans from Lhasa and Central Tibet come to the city thanks to the airport which offers flights to and from Lhasa. This explosion of tourism (six million visitors in 2013 from April to September alone, according to a Tourist Office official) has drawn most of the local population into the tourist industry. Many Khampas from the area who were living in India have come back. The boom in tourism has attracted many Tibetans from other areas who are looking for a job and in addition like being in a place where police control is not as strict as elsewhere in the Tibetan areas. They settle here and often intermarry with local people. Quite a few are from Amdo or from Central Tibet. Most of them have been educated in India and often know each other from their period of exile. Their presence is far from being merely anecdotal: on the one hand, these are people who read and write Tibetan, contrary to the majority of Gyelthangpas; and on the other hand, and in spite of a strong sense of local identity and a tendency to keep company with people who are originally from the same region, their shared experience of living together reinforces a sense of national identity.

\section{Conclusion}

Although the civilizational centre of the Tibetan world was traditionally Lhasa and Central Tibet, the so-called Tibetan eastern borderlands, that is to say Kham and Amdo, are seen to be benefiting from increasing visibility and to be becoming today a seat both of resistance and of civilizational development. The dynamics of this shift are driven by the political situation: a centre crushed by a wall of silence and a periphery subjected to weaker control for several decades. As they watch Sinicization steamroller everything in its path, Khampas and Amdowas reveal their tenacity in claiming their Tibetanness in every way possible, as long as the latter is of a pacific nature, thus in keeping with the request of the Dalaï-Lama. In a way, the demise of

Among others, see Hillman (2003, 177-190; 2010, 269-277), Kolås (2008). 
Lhasa as the centre of the Tibetan cultural world has prompted people of the border areas to find new ways to assert their own culture and identity. Though Khampas or Amdowas still fight to preserve their identity, their sense of belonging to the Tibetan nation is also present and expressed as soon as they are confronted with a denial of their right to express their identity.

As this chapter has demonstrated, and casting back to Zartman's definition $(2010,2)$, '[borderlands] are continually in movement, both fast and slow and any static depiction of the moment contains within it the elements of its change'. Going beyond a simplistic portrayal of these borderlands as passive victims of distant power centres, this chapter has brought to the fore some of their internal dynamics. Today, the eastern margins of the Tibetan plateau no longer appear as a boundary between what in the past was considered the centre of the Tibetan world (Lhasa and Central Tibet) and the present dominant centre, the P.R.C. In spite of the centrally imposed diktat, people from these areas are active players in religious, political, cultural, and tourist realms. They take part in many ways in the dynamics that shape the Tibetan identity today, even when State institutions are involved, as in the Khampa art festival. This process of (re)construction of cultural forms and sense of belonging further blurs the centre-periphery divide and is exemplary of the kind of entanglements discussed by Gros in his Introduction. As he points out, the 'in-betweenness' of the borderlands gives rise to new proximities and distances alike; it attests to the multiplicity of the constitutive relations of the borderlands, which generate both continuity and transformations.

It is not the first time in Tibetan history that a territory on the margins has managed to maintain its own identity despite pressure exerted by the two centres of power that surround it. As is clearly shown by Yudru Tsomu (2009, 67), under the Qing, the kingdom of Chakla in Kham, 'managed to [...] survive by relying on a nascent Qing China to resist the encroachment of the newly founded Dalai Lama's government of Lhasa'. The new centres that are Kham and Amdo, however, do more than just survive as Tibetan cultural, religious, political, and touristic centres: in the contemporary context, they constitute new poles of attraction for Tibetans and Chinese alike.

\section{Glossary of Tibetan Terms}

Amdo

Barom Kagyü school

beyül

Bö
A mdo

'ba' rom bka' brgyud school.

sbas yul

Bod 
Bökyi Tensung dang langmak

Bönpo

Böpa

Chakla

cham

Chamdo

chipa

chögar

Chushi Gangdruk

Dartsedo

Dechen

Dechen Ösel Dorjé

Dekyi Tsering

Dergé

Döndrup Gyal

Drepung

Drichu

Drubwang Lüntok Gyeltsen

Dzogchen monastery

Gaden Phodrang

Gendün Chömpel

Gelukpa

Golok

Gyelrong

Gyelthang

Jampel Gyatso

Jangbu

Jarung Kashor

Jyekundo

Jigme Püntsok

Karma Kagyü

Kashem Gyal

Kawakarpo

Kham

Khempo Achung

Künga Tsering

Kyodrag gönpa

Kusum Lingpa

Larung gar

Lhathotho Rinyentsen
Bod kyi bstan srung dang blangs dmag

Bon po

Bod pa

Lcags la

'cham

Chab mdo

phyipa

chos sgar

Chu bzhi gangs drug

Dar rste mdo

Bde chen

Bde chen 'Od gsal rdo rje

Bde skyid Tshe ring

Sde dge

Don grub rgyal

'Bras spungs

'Bri chu

Grub dbang lung rtogs rgyal mtshan

Rdzogs chen dgon pa

Dga' ldan pho brang

Dge 'dun chos 'phel

Dge lugs pa

Mgo log

Rgyal rong

Rgyal thang

'Jam dpal rgya mtsho

Ljang bu

Bya rung kha shor

Skye dgu mdo

'Jigs med phun tshogs

Kar ma bka' brgyud

Mkha' byams rgyal

Kha ba dkar po

Khams

Mkhan po A khyug

Kun dga' tshe ring

Skyo brag dgon pa

Sku gsum gling pa

Bla rung gar

Lha tho tho ri gnyan btsan 


\begin{tabular}{ll} 
Lhodrag & Lho brag \\
Lung Ngön monastery & Lung sngon dgon pa \\
Nangchen & Nang chen \\
nangpa & nang pa \\
Ngawa & Nga ba \\
Nyingma & Rnying ma \\
Padma Tseten & Pema Tshe brtan \\
Rebgong & Reb gong \\
ritrö & rikhrod \\
rimé & ris med \\
Rongwo gönchen & Rong bo dgon chen \\
Samyé tsuglakhang & Bsam yas gtsug lag khang \\
Sengdor & Seng rdor \\
Sangkar & Zangs dkar (?) \\
Sekhar Gutok & Sras mkhar dgu thog \\
Shabkar & Zhabs dkar \\
Sonthar Gyal & Zon thar rgyal \\
Sershül & Ser shul dgon pa \\
Shogdung & Zhogs gdung \\
Tashi Dargyeling & Bkra shis dar rgyas gling \\
Tendra & Bstan dgra \\
Tenshuk shabten & brtan bzhugs zhabs brten \\
tertön & gter ston \\
Tsering Döndrup & Tshe ring don grub \\
Tsewang Lhamo & Tshe dbang lha mo \\
Tsö & Gtsos \\
Ü & Dbus \\
ülam & dbus lam \\
Yachen Samten Ling & Ya chen bsam gtan gling \\
Yadong & Ya dong \\
Yidam Tsering & Yi dam Tshe ring \\
Yumbu Lagang & Yum bu bla sgang \\
Yül lha & yul lha \\
& \\
\hline &
\end{tabular}

\section{References}

Akester, Matthew. 2016. Four Rivers, Six Ranges: Reminiscences of the Resistance Movement in Tibet. Dharamsala: Information and Publicity Office of H.H. the Dalai Lama. 
Aris, Michael. 1992 Lamas, Princes and Brigands. Joseph Rock's Photographs of the Tibetan Borderlands of China. New York: China Institute in America.

Barstow, Geoff. 2013. 'Buddhism Between Abstinence and Indulgence: Vegetarianism in the Life and Works of Jigme Lingpa'. Journal of Buddhist Ethics 20: 73-104.

Bernbaum, Erdwin. 1980. The Way to Shambala. A Search for the Mythical Kingdom Beyond the Himalayas. New York: Anchor Press.

Buffetrille, Katia. 1998. 'Reflections on Pilgrimages to Sacred Mountains, Lakes and Caves'. In Pilgrimage in Tibet, edited by A. McKay, 18-34. Leiden: IIAS and Curzon Press.

Buffetrille, Katia. 2007. 'Pays caché' ou 'Avenir radieux'? Le choix de Shes rab rgya mtsho. In Pramanakirtih. Papers Dedicated to Ernst Steinkellner on the Occasion of his 7oth Birthday. Part 1, edited by B. Kellner, H. Krasser, H. Lasic, M.T. Much, H. Tauscher, 1-22. Vienna: Wiener Studien zur Tibetologie und Buddhismuskunde 70.1. Arbeitskreis für Tibetische und Buddhistische Studien Universität Wien.

Buffetrille, Katia. 2009-2010. "May the New Emerge From the Ancient! May the Ancient Serve the Present!” The Gesar Festival of Rma chen (A mdo 2002)'. Special Issue, 'The Earth Ox Papers. Proceedings of the International Seminar on Tibetan and Himalayan Studies. Dharamsala, September $3^{\text {rd }}-5^{\text {th }} 2009^{\prime}$, edited by Roberto Vitali. The TibetJournal 34 (3) / 35 (2): 523-554.

Buffetrille, Katia. 2012. 'Self-immolation in Tibet: Some Reflections on an Unfolding History'. Special Issue 'Tibet is Burning. Self-Immolations: Ritual or Political Protest?', edited by K. Buffetrille and F. Robin. Revues d'études tibétaines 25: 1-18. URL: http://himalaya.socanth.cam.ac.uk/collections/journals/ret/pdf/ ret_25_01.pdf. Accessed 7 June 2019.

Buffetrille, Katia. 2014. 'A controversy on vegetarianism'. In Trails of the Tibetan Tradition, Papers for Elliot Sperling, edited by Roberto Vitali, 113-128. Dharamsala: Amye Machen Institute. URL: http://himalaya.socanth.cam.ac.uk/collections/ journals/ret/pdf/ret_31.pdf. Accessed 7 June 2019.

Buffetrille, Katia. 2015. 'Some Remarks on Bya rung kha shor and Others Buddhist Replicas in Amdo'. In From Bhakti to Bon: Festschrift for Per Kvcrne, edited by H. Havnevick and C. Ramble, 133-152. Oslo: NOVUS.

Buffetrille, Katia. 2016. 'Corps sacrifiés, corps sanctifiés. Immolations, funérailles et martyre au Tibet'. In Mythes, rites et émotions : les funérailles le long de la Route de la soie. Actes du colloque Mythes, rites et émotions : les funérailles le long de la Route de la soie, Université Paris 7 Denis Diderot, 8 et 9 mars 2013, edited by A. Caiozzo, 343-36o. Paris: Honoré Champion.

Buffetrille, Katia. 2016. 'Les nomades tibétains et les 10 nouvelles vertus'. In Les Tibétains, edited by M. F. Bennes, 46-56. Paris: Ateliers Dougier.

Buffetrille, Katia and Françoise Robin, eds. 2012. Special issue 'Tibet is Burning: Self-Immolations: Ritual or Political Protest?'. Revues d'Etudes Tibétaines 25. 
Chodon, Nima. 2012. 'Le mouvement de résistance Choushi Gangdrouk contre l'occupation chinoise'. In L'histoire du Tibet du XVIIème au XXIème siècle, Compte-rendu de la journée de conférences du 3 mars 2012, Groupe d'information internationale sur le Tibet du Sénat (Rapport G1 104), edited by F. Robin and K. Buffetrille, 35-44. Paris: Sénat. (online version: URL: http://www.senat.fr/ notice-rapport/2011/ga104-notice.html. Accessed 12 February 2019.

Choephel, Gedun. 1978. The White Annals. Dharamsala: LTWA.

Combe, G. A. 1975. A Tibetan on Tibet. Kathmandu: Ratna Pustak Bhandar.

Dhondup, Yangdon. 2011. 'Reb kong: Religion, History and Identity of a Sino-Tibetan Borderland'. Revue d'études tibétaines 20: 33-59.

Dreyfus, Georges. 2003. The Sound of Two Hands Clapping: The Education of a Tibetan Buddhist Monk. Berkeley: University of California Press.

Dreyfus, Georges. 2005. 'Are We Prisoners of Shangrila? Tibetan Religious Nationalism'. Journal of the International Association of Tibetan Studies 1:1-21.

Epstein, Lawrence. ed. 2002. Khams pa Histories. Visions of People, Place and Authority. Proceeding of the gth Seminar of the IATS, Leiden 2000. Leiden: Brill.

Gaerrang (Kabzung). 2011. 'The Alternative to Development on the Tibetan Plateau: Preliminary Research on the Anti-Slaughter Movement'. Revues d'Etudes Tibétaines 2: 31-43.

Gaerrang (Kabzung). 2012. Alternative Development on the Tibetan Plateau: The Case of the Slaughter Renunciation Movement. Unpublished PhD dissertation.

Gayley, Holly. 2011. 'The Ethics of Cultural Survival: A Buddhist Vision of Progress in Mkhan po 'Jigs phun's Heart Advice to Tibetans for the 21st Century'. In Mapping the Modern in Tibet, edited by G. Tuttle, 435-502. International Institute for Tibetan and Buddhist Studies.

Gayley, Holly. 2013. 'Reimagining Buddhist Ethics on the Tibetan Plateau'.Journal of Buddhist Ethics 20: 247-284.

Gayley, Holly. 2016. 'Controversy over Buddhist Ethical Reform: A Secular Critique of Clerical Authority in the Tibetan Blogosphere'. Himalaya: The Journal of the Association for Nepal and Himalayan Studies 36 (1): 22-43.

Gros, Stéphane, ed. 2016. Special issue 'Frontier Tibet: Trade and Boundaries of Authority in Kham'. Cross Currents: East Asian History and Culture Review 19.

Germano, David. 1998. 'Re-membering the Dismembered Body of Tibet: Contemporary Tibetan Visionary Movements in the People's Republic of China'. In Buddhism in Contemporary Tibet. Religious Revival and Cultural Identity, edited by M. C. Goldstein and M. Kapstein, 53-94. Berkeley: University of California Press.

Giersch, C. Patterson 2016. 'Afterword: Why Kham? Why Borderlands? Coordinating New Research Programs for Asia'. Cross Currents: East Asian History and Culture Review 19: 1-12. 
Goldstein, Melwyn C. 1989. A History of Modern Tibet 1913-1951. The Demise of the Lamaist State. Berkeley: University of California Press.

Goldstein, Melwyn C. et al. 2004. A Tibetan Revolutionary: The Political Life and Times of Bapa Phüntso Wangye. Berkeley: University of California Press.

Gyatso, Sangye (Gangzhün). 20o8. 'Modern Tibetan Literature and the Rise of Writers Coteries'. In Modern Tibetan Literature and Social Change, edited by L. R. Hartley and P. Schiaffini-Vedani, 263-28o. Durham: Duke University Press. Hartley, Lauren and Patricia Schiaffini-Vedani, eds. 2008. Modern Tibetan Literature and Social Change. Durham: Duke University Press.

Henrion-Dourcy, Isabelle. 2017. 'La danse de Gesar au monastère de Dzogchen (Kham). Notes préliminaires'. In Musique et épopée en Haute-Asie. Mélanges offerts à Mireille Helffer à l'occasion de son $90^{e}$ anniversaire, edited by K. Buffetrille and I. Henrion-Dourcy, 191-213. Paris: L'Asiathèque.

Hillman, Ben. 2003. 'Paradise Under Construction: Minorities, Myths and Modernity in Northwest Yunnan'. Asian Ethnicity 4 (2): 177-190.

Hillman, Ben. 2010. 'China's Many Tibets: Regional Autonomy and Local Policy in Diqing'. Asian Ethnicity 11 (2): 269-277.

Huber, Toni. 2011. 'Pushing South: Tibetan Economic and Political Activities in the Far Eastern Himalaya, ca. 1900-1950'. In Buddhist Himalaya: Studies in Religion, History and Culture. Proceedings of the Golden Jubilee Conference of the Namgyal Institute of Tibetology, 2008, vol. 1, edited by A. McKay and A. Balicki-Denjongpa, 259-276. Gangtok: Namgyal Institute of Tibetology.

Jia, Mang. 2015. 'The Transformation of Tibetan Identity'. Senior Theses 11. URL: http:// digitalcommons.linfield.edu/soanstud_theses/11. Accessed 12 February 2019.

Jabb, Lama. 2015. Oral and Literary Continuities in Modern Tibetan Literature: The Inescapable Nation. Lanham: Lexington Books.

Jinba, Tenzin. 2014 In the Land of the Eastern Queendom: The Politics of Gender and Ethnicity on the Sino-Tibetan Border. Seattle: University of Washington Press.

Kapstein, Matthew. 'A Thorn in the Dragon's side'. In Governing China's Multiethnic Frontiers, edited by Morris Rossabi, 230-269. Seattle: University of Washington Press.

Klieger, P. Christiaan, ed. 20o6. Tibetan Borderlands. Leiden: Brill.

Kolås, Åshild. 2008. Tourism and Tibetan Culture in Transition: A Place Called Shangrila. London: Routledge.

Lhamo, Rinchen. 1985 [1926]. We Tibetans. New York: Potala Publications.

McGranahan, Carole. 2010. Arrested Histories: Tibet, the CIA, and Memories of a Forgotten War. Durham, NC: Duke University Press.

McGranahan, Carole and Ralf Litzinger, eds. 2012. Hot Spot Forum 'Self-immolation as Protest in Tibet', Cultural Anthropology Online (9 April 2012).

Mackley, Charlene. 2007. The Violence of Liberation: Gender and Tibetan Buddhist Revival in Post-Mao China. Berkeley: University of California Press. 
Mullaney, Thomas, James Liebold, Stéphane Gros, and Eric Vanden Bussche, eds. 2012. Critical Han Studies: The History, Representation, and Identity of China's Majority. Berkeley: University of California Press.

Nietupski, Paul. 1999. Labrang. A Tibetan Buddhist Monastery at the Crossroads of Four Civilizations. Ithaca: Snow Lion Publications.

Nietupski, Paul. 2011. Labrang Monastery: A Tibetan Buddhist Community on the Inner Asian Borderlands 1709-1958. Lanham: Lexington Books.

Norbu, Jamayang. 1979. Horseman in the Snow: The Story of Aten, an Old Khampa Warrior. Dharamsala: Information Office, Central Tibetan Secretariat.

Norbu, Namkhai. 1997.Journey Among the Tibetan Nomads: An Account of a Remote Civilization. Dharamsala: LTWA.

Nulo, Naktsang.[Nags tshang nus blo]. 2008. Nags tshang zhi lu'i skyid sdug. Dharamsala: Kha ba dkar po bod kyi rig gzhung sri zhu khang.

Nulo, Naktsang. 2014. My Tibetan Childhood: When Ice Shattered Stone, translated by A. Cargill and Sonam Lhamo. Durham, NC: Duke University Press.

Nyima, Orgyan. 2016. Living and Dying in Modern Tibet: The Time of Great Calamities. Internet Archive. URL: https://archive.org/details/LivingAndDyingInModernTibet. Accessed 12 February 2019.

Pang, Rachel H. 2018. 'The Singer of Tibet: Shabkar (1781-1851), the 'Inescapable Nation', and Buddhist Universalism'. Himalaya: The Journal of the Association for Nepal and Himalayan Studies 38 (1): 42-54. URL: http://digitalcommons. macalester.edu/himalaya/vol38/iss1/9. Accessed 12 February 2019.

Pommaret, Françoise. 1999. 'The Mon-pa Revisited: In Search of Mon'. In Sacred Spaces and Powerful Places in Tibetan Culture, edited by T. Huber T., 52-76. Dharamsala: LTWA.

Richardson, Hugh. 1985. A Corpus of Early Tibetan Inscriptions. Royal Asiatic Society. Roche, Gerald. 2014. 'Flows and Frontiers: Landscape and Cultural Dynamics on the Northeast Tibetan Plateau'. The Asia Pacific Journal of Anthropology 15 (1): $1-25$.

Sakya, Jamyang and Julie Emery. 1990. Princess in the Land of Snows: The Life of Jamyang Sakya in Tibet. Boston: Shambala.

Sa skya Bsod nams rgyal mtshan. 1981. Gyal ba gsal ba'I me long. Beijing: Mi rigs dpe skrun khang.

Sardar-Afkhami, Abdol-Hamid. 2001. The Buddha's Secret Gardens: End-times and Hidden-Lands in Tibetan Imagination. Unpublished PhD dissertation, Harvard University.

Shakya, Tsering. 1993. 'Whither the Tsampa Eaters?' HIMAL, Himalayan Magazine 6 (5): 8-11.

Shakya, Tsering. 1999. The Dragon in the Land of Snows. A History of Modern Tibet since 1947. London: Pimlico. 
Shakya, Tsering. 2012. 'Self-immolation: The Changing Language of Protest in Tibet'. In 'Tibet is Burning - Self-Immolations: Ritual or Political Protest?' Special issue, edited by K. Buffetrille and F. Robin. Revue d'études tibétaines 25: 19-40. Shneiderman, Sara. 2006. 'Barbarians at the Border and Civilising Projects: Analysing Ethnic and National Identities in the Tibetan Context'. In Tibetan Borderlands, edited by C. Kleiger, 9-34. Leiden: Brill.

Smith, Gene. 2001. Among Tibetan Texts: History and Literature of the Himalayan Plateau. Boston: Wisdom Publications.

Smith, Warren. 1996. Tibetan Nation: A History of Tibetan Nationalism and SinoTibetan Relations. New Delhi: HarperCollins Publishers.

Sørensen, Per K. 1994. Tibetan Buddhist Historiography: The Mirror Illuminating the Royal Genealogies: An Annotated Translation of the XIVth Century Tibetan Chronicle Rgyal rabs gsal ba'i me long. Wiesbaden: Harrassowitz Verlag.

Sperling, Elliot. 1976. 'The Chinese Venture in K'am, 1904-1911, and the Role of Chao Erh-feng'. The Tibet Journal 1 (2): 10-36.

Sulman, Wasif Khan Muslim. 2015. Trader, Nomad, Spy: China's Cold War and the People of the Tibetan Borderlands. Chapel Hill: University of North Carolina Press.

Terrone, Antonio. 2008. 'Tibetan Buddhism beyond the Monastery: Revelation and Identity in Rnying Ma Communities of Present-day Kham'. In Images of Tibet in the $19^{\text {th }}$ and $20^{\text {th }}$ Centuries, edited by Monica Esposito, 747-779. Paris: École Française d'Extrême-Orient.

Terrone, Antonio. 2009. 'Householders and Monks: A Study of Treasure Revealers and Their Role in Religious Revival in Contemporary Eastern Tibet'. In Buddhism beyond the Monastery. Tantric Practices and Their Performers in Tibet and the Himalayas, edited by S. Jacoby and A. Terrone, 73-110. Leiden: Brill.

Thargyal, Rinzin. 2007. Nomads of Eastern Tibet. Social Organization and Economy of a Pastoral Estate in the Kingdom of Dege. Leiden: Brill.

Tsomu, Yudru. 2009. 'Political and Territorial Survival in the Sino-Tibetan Borderland: A Case Study of the Lcags La Kingdom During the Qing Dynasty'. In Studies in the History of Eastern Tibet, edited by Wim van Spengen and Lama Jabb, 55-96. Verlag: International Institute for Tibetan and Buddhist Studies.

Van Spengen, Wim. 200o. Tibetan Border World: A Geohistorical Analysis of Trade and Traders. London: Kegan Paul International.

Van Spengen, Wim. 2006. 'Chone and Thewu: Territoriality, Local Power and Political Control on the Southern Gansu-Tibetan Frontier, 1880-1940'. In Tibetan Borderlands, edited by C. Klieger, 209-230. Leiden: Brill.

Van Spengen, Wim. and Lama Jabb, eds. 20o9. Studies in the History of Eastern Tibet. Verlag: International Institute for Tibetan and Buddhist Studies.

Venturino, Steven J. ed. 2007. Contemporary Tibetan Literary Studies. Leiden: Brill. 
Wangdu, Pasang. and Hildegard Diemberger (trad.). 2000. Dba' bzhed: The Royal Narrative Concerning the Bringing of the Buddha's Doctrine to Tibet. Vienna: Verlag der Österreichische Akademie der Wissenschaften.

Wellens, Koen. 2010. Religious Revival in the Tibetan Borderlands: The Premi of Southwest China. Seattle: University of Washington.

Yeh, Emily T. and Chris R. Coggins eds. 2014. Mapping Shangrila: Contested Landscapes in the Sino-Tibetan Borderlands. Seattle: University of Washington Press.

Yuthok, Dorje Yudon. 1990. The House of the Turquoise Roof. Ithaca: Snow Lion Publications.

Zartman, William I. 2010. Understanding Life in the Borderlands: Boundaries in Depth and in Motion. Athens: University of Georgia Press.

\section{About the Author}

KATia Buffetrille is a social anthropologist, specialist in Tibetan Studies, researcher at the École Pratique des Hautes Études, Sorbonne, Paris. Her research interests focus on Tibetan cultural and political issues in the context of the P.R.C., 'popular' rituals and their changes, issues on current Buddhist phenomena (vegetarianism, self-immolations, etc.). She has written numerous articles and books, and has edited several collected works, including Pèlerins, lamas et visionnaires. Sources orales et écrites sur les pèlerinages tibétains (Wien, 200o), Authenticating Tibet, Answers to China's 1oo questions (with A.M. Blondeau, University of California Press, 2008), Revisiting Rituals in a Changing Tibetan World (Brill, 2012), Musique et épopée en Haute-Asie (with I. Henrion-Dourcy, L'Asiathèque) and L'âge d'or du Tibet: XVII ${ }^{e}$ XVIII siècles (Les Belles Lettres, forthcoming). 



\title{
3 Boundaries of the Borderlands
}

\author{
Mapping Gyelthang
}

Eric D. Mortensen

\begin{abstract}
This project seeks to discern and problematize the physical and conceptual boundaries of the Tibetan region of Gyelthang, in southern Kham. At issue are questions about the relationships between older conceptualizations of place and newer understandings of identity vis place. How do the various peoples who live within its boundaries understand Gyelthang? I argue that the complex and dynamic webs of religious institutions and ethnic identities in the region neither conform to fixed physical or conceptual boundaries, nor situate Gyelthang as being in a 'borderland' between Tibet and China for local inhabitants. My work is based on an evaluation of historical sources coupled with ethnographic and folkloric data gathered during fieldwork conducted over the past twenty-five years in Gyelthang.
\end{abstract}

Keywords: folklore, Geza, Gyelthang, Shangri-La, Xianggelila, Yunnan

\section{Introduction}

This chapter seeks to discern and problematize the physical and conceptual boundaries of the Tibetan region of Gyelthang, in southern Kham. At issue are questions about the relationships between older conceptualizations of place and newer understandings of identity vis place in 21st-century Sino-Tibetan borderlands, and about what might constitute a borderland. I argue that the complex and dynamic webs of religious institutions and ethnic identities in the region neither conform to fixed physical or conceptual boundaries, nor situate Gyelthang as being in a 'borderland' between Tibet and China for local inhabitants.

Gros, Stéphane (ed.), Frontier Tibet: Patterns of Change in the Sino-Tibetan Borderlands. Amsterdam, Amsterdam University Press 2019

DOI: 10.5117/9789463728713_CHO3 
Today, Gyelthang is part of Northwest Yunnan Province of the People's Republic of China, roughly corresponding to the current administrative division of Shangri-La County (Ch. Xianggelila xian), although not, more expansively, the Diqing Tibetan Autonomous Prefecture (Ch. Diqing Zangzu zizhizhou). Gyelthangpa - the people of Gyelthang - speak several local Tibetic languages, ${ }^{1}$ and there are pockets within this territory where Tibetan inhabitants identify neither as Gyelthangpa nor Khampa. Gyelthang cannot be cleanly defined by the constellations of monastic power. With no specific historical political or religious demarcation of the boundaries of Gyelthang, and with no unified linguistic or ethnic identity, what then makes (or made) Gyelthang Gyelthang? How do the various peoples who live within its boundaries understand Gyelthang? Do Tibetans of Gyelthang understand themselves to be Khampa, or even Gyelthangpa?

As historians and anthropologists interested in Kham, many of us seek to understand the interface of the Tibetan and Chinese cultural, political, and religious 'borderlands', and recent works have ostensibly addressed the region, sometimes without adequately scrutinizing the way we employ the term - as Gros and Buffetrille also point out in this volume. ${ }^{2}$ The concept of a Sino-Tibetan 'borderland' also assumes a prioritization of the points of view of the large but historically distant power centres of 'Tibet' (whatever 'Tibet' might mean or might have meant historically to Gyelthangpa), and 'China', writ large (same issue). The borderlands are further problematized by the ethnic diversity of the interface. Not only are there many ethnic groups such as the Naxi, Yi, Primi, Drung, Nung, Lisu, Bai, and Malimasa who live within and between regions traditionally understood as Tibetan and (Han) Chinese in southern Kham, but the cultural identity of these peoples is differently understood depending on the perceiver (e.g. many Tibetans from areas further north in Kham think of the Naxi as being slightly wayward Tibetans, despite the Naxi understanding of themselves as distinct from Tibetans), and depending, bien sûr, on the imposed ethnic classificatory scheme devised by the Chinese state. Historically, and to a lesser degree still today, Gyelthang is positioned between other Tibetans to the north, and non-Han groups to the south, east, and west. So, in effect, Gyelthang might be better considered the Naxi-Tibetan borderlands or the Yi-Tibetan, rather

1 See Bartee (2007), and for a nuanced account of the 'Tibetic languages' of the region, see Suzuki (2015).

2 In her review of Emily T. Yeh and Chris Coggins's (2014) edited volume, Mapping Shangrila, Katia Buffetrille (2016) celebrates the scholarship inside the volume, while 'regretting the absence of a discussion about the definition of the term "Sino-Tibetan Borderlands"'. 
than the Sino-Tibetan borderlands. My point here is that there is a worry that the term 'borderlands' runs the risk of assuming a simple dichotomy between two important groups, but such is not necessarily the predominant way Gyelthangpa understand themselves; many Gyelthangpa neither think of their neighbours as two large clearly-defined identity centres, nor do they see themselves as living 'in between'.

In what follows, I will delve into two related tributaries that together contribute to the difficulties in fixing a clear definition of Gyelthang. First, in admittedly rough and broad brushstrokes, I will attempt to contextualize the roles of power and history in the demarcation of Gyelthang with an emphasis on the importance (or lack thereof) of Ganden Sumtseling monastery. ${ }^{3}$ While since the seventeenth century Ganden Sumtseling monastery constituted an important centre of identity-gravity in the region, the geographical extension of its control was not congruent with the region of Gyelthang. ${ }^{4}$ The monastery includes eight kangtsen, or monastic colleges. Importantly, some of the geographical areas controlled by the eight kangtsen fall outside of Gyelthang. ${ }^{5}$ Herein, I will bring us up to the present moment (2018) and

3 Although certainly not the only monastery in the region, Ganden Sumtseling was, since the late seventeenth century, the primary monastery of Gyelthang, representing the reach of influence of the Ganden Phodrang in Lhasa. However, the much smaller Geluk monastery of Ringa (Ch. Da Bao Si) is sometimes better known to Tibetans from other regions and remains a place of great spiritual import to locals.

4 By 'identity-gravity', here, I am highlighting the idea that for many Gyelthangpa, the monastery itself was an important part of their identity, and the monastery and its geographical location served as a crucial place indicator for one's homeland. When speaking with people about where one is from, monasteries not only serve as part of an answer, but people from farther afield often associate people with the religious and/or political affiliations of the most prominent local monastery or even monastic kangtsen. Of course, a monastery is much more than simply an identity marker.

5 Kangtsen are physical structures within the monastery, associated with geographical areas near to the monastery. In total, the areas associated with the kangtsen correspond to the full range of control of the monastery, and the Tibetan (and Naxi) inhabitants traditionally paid taxes to and sent their sons to be monks at their corresponding kangtsen. This is not to say that the entirety of the population represented by a kangtsen of Sumtseling Monastery were Gelukpa Buddhists. For example, while Dongwang kangtsen, one of the most important and economically powerful at Sumtseling, is the place Gelukpa families from Dongwang send their sons to be monks, the valley system of Dongwang includes many Nyingmapa families that do not support and are in no way affiliated with Sumtseling. When Gelukpa pilgrims from Dongwang visit Sumtseling, a stop at the Dongwang kangtsen is a central component of their visit, is the central place of their financial donations, and is the residence of the monks who would be asked to travel to Dongwang when there is a need for the performance of domestic ceremonies. More to the point of this chapter, though, Dongwang lies to the north of and is not considered to be part of the region of Gyelthang. The constellation of power of the most central and important monastery in Gyelthang - both in terms of constellation of monastic institutional power and 
illuminate how difficulties associated with the monastery contribute to a lack of clarity about Gyelthangpa identity. Second, attention will be turned to the theoretical work of scholar of comparative religious theory Jonathan Z. Smith. I employ Smith's claims and warnings about the relationship between 'map' and 'territory' in relation to dynamics of identity among Tibetans of Gyelthang. I do not think that the idea of Kham, the notion of being a borderland, and even the moniker of Gyelthang are particularly important to local inhabitants or central to their identity. Instead, far more value is placed on the very local, the very ground beneath very real feet. My work is based on an evaluation of historical sources coupled with ethnographic and folkloric data gathered during fieldwork conducted over the past twenty-five years in Gyelthang.

\section{Gyelthang as Territory: Power, the State, and the Monastery}

All told, Gyelthang is relatively small, and today one can drive across from east to west in three hours, and from south to north in about five. ${ }^{6}$ There are two common misconceptions about Gyelthang: first, that it is the Tibetan region of Yunnan Province. Rather, it is one of several Tibetan regions of Yunnan; the regions of Dechen and Tacheng are not part of Gyelthang, nor are other Tibetan areas of Yunnan such as Yagra, and Dongwang. ${ }^{7}$ Second,

the related power of the Geluk religious order - does not correspond to the physical landscape of the region of Gyelthang. See Schwieger (2010) and Kolås (2008), and for a detailed account of the power dynamics behind the founding of the monastery, see Schwieger (2011). For details about Ganden Sumtseling prior to its destruction, see Bstan-pa-rgyal-mtshan (1985). For an understanding of Sumtseling monastery's destruction during the early phases of the Cultural Revolution, see the chapter by Dáša Mortensen in this volume. For a glimpse into the role of the monastery vis the local community fifteen years ago, see Hillman (2005). For a sense of Gyelthangpas' understanding of and sentiments about Sumtseling, see Mortensen (2016).

6 Gyelthang is approximately 120 miles $(193 \mathrm{~km})$ north to south, and at its widest, 60 miles $(97 \mathrm{~km})$ east to west. However, due to the high mountains and steep river valleys running longitudinally more or less north to south, there are no direct east-west roads. Gyelthang is approximately $10,000 \mathrm{~km}^{2}$.

7 The edges of Gyelthang are, alas, difficult to define, and the definitions can depend on whom you ask. Inhabitants of Balagezong, for example, do not universally consider themselves to be Gyelthangpa, and their neighbours, the inhabitants of Nagara, do not think of Balagezong as part of Gyelthang. However, some people from Shangrila Town with whom I have spoken describe Balagezong as being part of Gyelthang. Part of this discrepancy can perhaps be attributed to the fact that while Balagezong does lie within Yunnan and to the (north)east of Benzilan, which is considered to be just outside the western edges of Gyelthang, the inhabitants of Balagezong are rumoured to be descendants of refugees from Bathang, in today's Sichuan Province, to the 
that it corresponds to Shangri-La County-Level City (Xianggelila County); it does not (see Map 3.1).

The idea of Gyelthang is bordered to the southwest by the (primarily Lisu, Tibetan, Naxi, and Han) Weixi Lisu Autonomous County (within Diqing Prefecture), including the Tibetan area of Tacheng, which is not part of Gyelthang. To the west, Gyelthang does not include areas west of the Nixi valley. Thus, Benzilan and Dechen fall outside of Gyelthang. Deqin County (Ch. Deqin xian) to the northwest, is not part of Gyelthang. The country of Myanmar and the Tibetan Autonomous Region (T.A.R.) lie not far to the west and northwest.

The Tibetan Autonomous Ganzi Prefecture of Sichuan and the proximate valley of Chaktreng (Xiangcheng), lie just beyond the northern boundary of Gyelthang, just north of the mountain Daxueshan (locally Jiarongya) and the valley system of Dongwang Township (Tib. Termarong). ${ }^{8}$

north. This suggests that for some, inclusion in the category of Gyelthangpa can sometimes include conceptions of historical homelands and dynamics of migration.

8 The Tibetans who live in or hail from the valleys of Dongwang do not consider themselves to be Gyelthangpa. Thus, the northern boundary or Gyelthang lies along the granite outthrusts of the earth's crust that form the Daxueshan (literally 'Big Snow Mountain'), and, to the west, form the watershed between the village system of Nagara and Dongwang. It is entirely possible that Dongwang is today considered by some to be part of Gyelthang in that it is part of ShangriLa County. However, most commonly, Dongwang and Gyelthang are discussed by locals as separate places. Today, people in Dongwang refer to people from Chaktreng (Ch. Xiangcheng) as Sichuan people (Sichuan ren). The etymology of the Tibetan name for Dongwang is a bit unclear. Most commonly, the Chinese name Dongwang is understood to be a rendering of the Tibetan Termarong, marking a relationship between the precipitous valley and the treasure (terma) revelation tradition (rong, in Tibetan, means 'gorge' or 'narrow ravine', which very accurately describes Dongwang). Another possible Tibetan root for Dongwang is the name Tongrong, with tong echoic of one of the six tribes of Yarlung. A third possibility for the Tibetan name for Dongwang is simply gtorma rong, as one prominent mountain peak in the region resembles a cone-shaped torma (ritual effigy). The possible etymologies of Tongrong and Torma rong were provided to me by Bai Linde, assistant director of the Foxueyuan (Buddhist Research Institute) in Shangri-La (personal interview 12 July 2017). See also Zhongdian xian renmin zhengfu, Zhongdian xian diming lingdao xiaozu (1984). Interestingly, Bai Linde also claimed that many of the current inhabitants of Dongwang trace their ancestry to the south, and that they were once Naxi. This would not be surprising, as Naxi communities can be found in Sichuan and the T.A.R., and the complex and syncretic relationship between Naxi and Tibetan religions is in evidence throughout the region, such as in the use of Naxi pictograph-painted wooden slats in Dorje phurba rituals in the Karma Kagyu monastery of Phangpu northeast of Chaktreng, and the huge overlap of local ritual practices and folklore; see, for example, Mortensen (2006). Today, the Nyingmapa maintain a strong presence in Dongwang, and there are notably no Nyingma monasteries in Gyelthang. About half the populace of Dongwang is Geluk, and Ganden Sumtseling monastery has a Dongwang kangtsen. Semantically and structurally, it is unclear whether Sumtseling has a kangtsen for Dongwang, or if, from a more grass-roots perspective, 


\section{Map 3.1 Gyelthang (Xianggelila) and its surroundings}

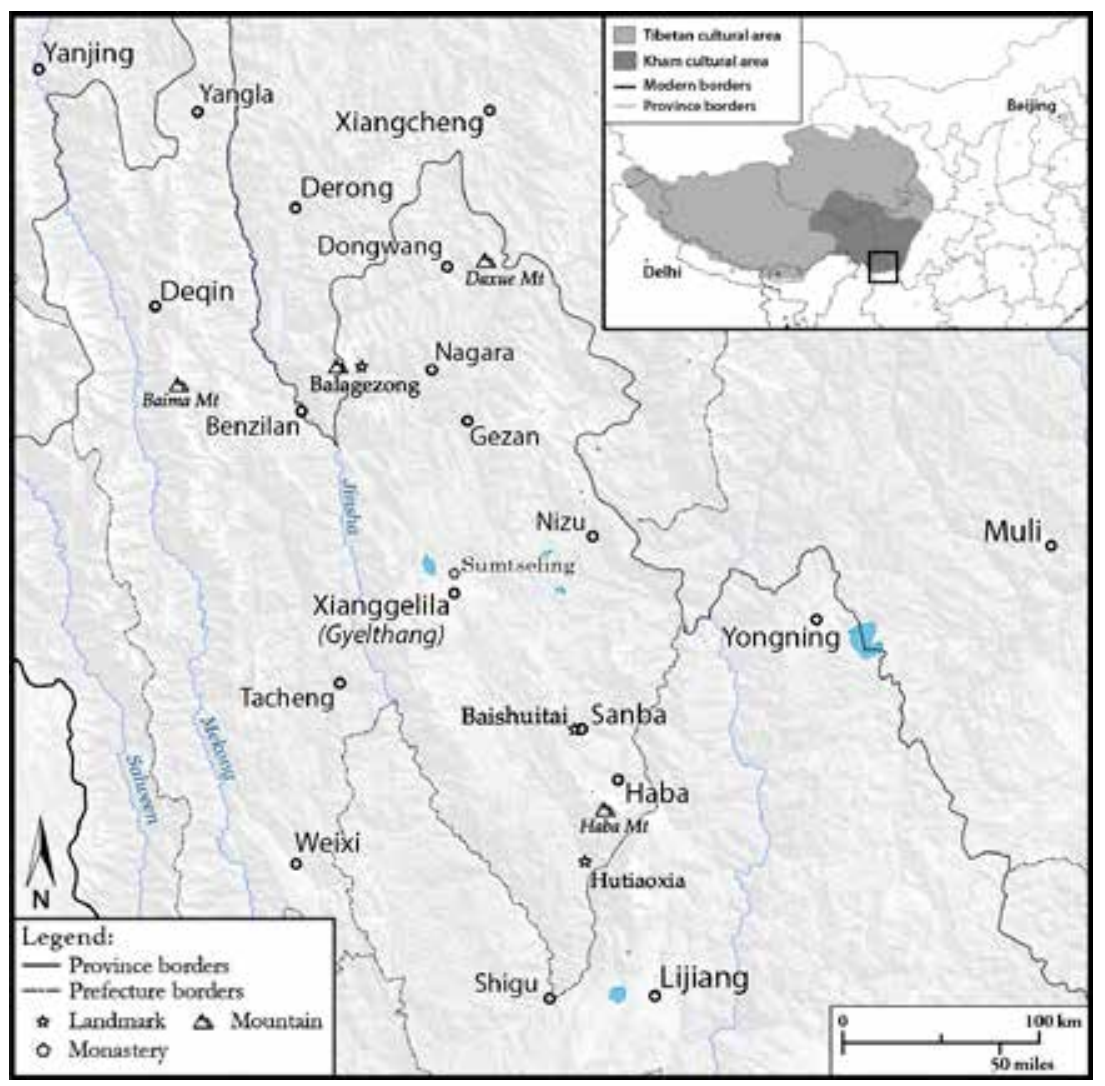

Sources: Based on SRTM (NASA) and modern administrative borders extracted from GADM database (www.gadm.org, v.2.5 July 2015)

Authors: Rémi Chaix and Stéphane Gros

Dongwang maintains a kangtsen at Sumtseling. Nevertheless, in terms of Geluk identity, the inhabitants of Dongwang, despite their kangtsen at Sumtseling to the south, have a stronger affinity with religious institutions to the north in Chaktreng, across the border in what is today Sichuan Province; see Thondup (1992). This affinity is in part related in recent decades to the religious affiliation with the tantric yidam Dorje Shugden; Shugden practice is strong among the Gelukpa of Dongwang, and Chaktreng remains one of the centres of Shugden practice in southern Kham. Geluk monasteries in Chaktreng, Bathang, and Gyelthang, for example, had strong bonds, although bandit raids from Chaktreng to Gyelthang were notorious; see D. Mortensen (2016) and Rock (1947). Chaktreng raids prior to the 1950s on the valleys of Yagra (just to the northwest of Gyelthang) were particularly devastating, as large percentages of the young men in Yagra villages were killed. While conducting folklore fieldwork in Yagra in 2013, I was told on several occasions that P.R.C. control in the region was welcomed largely because it brought an end to such raids and low-intensity internecine warfare. 
The (historically mostly Tibetan, Primi, and Nuosu Yi) Muli Tibetan Autonomous County of Sichuan, just east of the village of Nizu (Tib. Miksur), is the eastern border of Gyelthang, and the (primarily Naxi) Lijiang prefecture-level City lies to the south. ${ }^{9}$ The southern boundary of Gyelthang, in essence, is the Yangtze River (locally called the Jinshajiang, 'Golden Sands River'). Thus, predominantly Naxi areas such as Sanba and Baishuitai spring, the Hui reaches of upper Haba village, several Yi villages such as Jiulong, and the entirety of Haba Mountain (the north side of Tiger Leaping Gorge, Ch. Hutiaoxia), all lie within Gyelthang. The land across the river from Shigu town, as is evidenced by the territorial demarcation inscribed on the town's famous stone drum from which the town gets its moniker, marks the southernmost reaches of Gyelthang.

Historically, prior to P.R.C. control of the region, Gyelthang was only periodically under the political control of Tibetan powers (Gyaltsen 1971). Indeed, we should be careful to distinguish between 'political' and 'religious' Tibetan power, for although monasteries were and are often seats of political, economic, and military dominance (or perhaps 'centres of gravity', depending on one's perspective), even when the Gelukpa government of the Ganden Phodrang, based in Lhasa, exerted only limited control over Gyelthang, Ganden Sumtseling Monastery remained the most important institution in the minds of many Tibetans (and many Naxi) in the region. ${ }^{10}$ Gyelthang was not part of the large region controlled by (Nyagrong) Gönpo Nyamgyel during the height of his power between 1835-1865. Indeed, the areas of Jol (Dechen), ${ }^{11}$ the region of Lijiang and the Mu kingdom, Gyelthang, and Muli (in today's Sichuan), all lay to the south of his control (Tsering 1985, Tsomu 2015).

9 For early definitions of Gyelthang, see Schwieger (2017). See also Diqing zhou gaikuang bianxie zu (2007).

10 Historically (and in some small senses into the present), the Naxi were practitioners of Kagyu Buddhism. With the destruction of many Kagyu monasteries in the 1870 s during the Muslim Panthay Rebellion, many disenfranchised Naxi monks returned to their home villages to become ritual experts, syncretically blending Bön and Buddhist ritual cycles with local religious dynamics including elements of Yi religion. For more details, including the argument that this shift in the 1870 s led to the flourishing of Naxi $d t \hat{\text { - }}$-mbà pictographic script, see Jackson and Pan (1998); also Jackson (1979). For alternative perspective, see Mathieu (2003). Indeed, it is difficult to say who the Naxi were prior to their identification as such at the hands of the state in the 1950s, and their religious practices were not definitively separable, taxonomically, from the religious practices of their neighbours: the Moso, Gyelthangpa Geluk Tibetans, Nizupa, Primi, Yi, etc. See Mortensen (2009) for a discussion. In fact, boundaries of ethnicity were far more fluid and malleable prior to the 1950 s than they are today, when ethnic identity is more 'fixed' by institutional and state power structures.

11 Identifying Dechen as Jol is questionable here, as Jol is sometimes understood as the region stretching south into Yunnan, including Jang (Jang Satam), although whether Jol encompassed 
Gyelthang's centre is Jiantang Town, the county seat, generally known as Xianggelila, called Zhongdian throughout at least the second half of the twentieth century until 2002, and still sometimes called Zhongdian by locals who find the tourist-driven transformation of the name of their home to be somewhat surreal. The town and region have long been a Tibetan interface with neighbouring peoples, primarily the Naxi, and the 'Old Town' of Dukezong was around 30 percent Naxi until the tsunami of tourism shattered the traditional demography. Xianggelila has recently exploded into a bourgeoning small city, stretching across the entirety of the valley between the central village of Dukezong and the historically important Geluk monastery Ganden Sumtseling. Following the logging ban of 1998, the economy has largely transformed into a tourist service industry, with mining, song rong mushroom, and caterpillar fungus collection and sales providing a massive influx of capital in the past two decades.

In order to understand the geographic and perhaps cultural identities of the people who live in the region where southeastern Tibet interfaces with the rest of Yunnan Province, we must scrutinize and complicate any simplistic notions of what constitutes the 'state'. Studies of the role of the Chinese state have drawn valuable attention to the problem of historical blame and to complicity in the enactment of state policies in local non-Han contexts. ${ }^{12}$ If one's nominal identity is in formal ways created or established by a 'state', per se, then understanding who constitutes the 'state' becomes of increased importance. It is clear that local government actors enact policies that affect minority nationality (Ch. shaoshu minzu) communities in differing ways in different regions. It is simultaneously valuable to understand the construction and negotiation of ethno-political identity as being as much informed by interethnic and intra-ethnic relationships and perceptions as it is by the hitherto prioritized (and overly simplistic) binary model of assessing the identity of a given minority group in relationship to the Chinese state. In other words, the tensions, concerns, conflicts, and everyday grievances at the forefront of

the entirety of Jang is questionable. I am unsure about this point, and do not know how the Naxi under the Mu kings (and earlier) understood the boundaries or overlaps between Jol and Jang Satam, let alone how they understood Gyelthang.

12 See, for example, Mueggler (2011), Harrell (2007), and D. Mortensen (forthcoming). Mueggler's brilliant ethnography complicates the notion of simplistic blame for devastation suffered by a community that found the Chinese state both imaginatively distant and manifest as eager members of their own community. Harrell's point is similar, focusing on the examples of several individuals who, despite their local ethnic identity, represented the state. Both Mueggler's and Harrell's works address Yi peoples, geographically close to but culturally distinct from Gyelthangpa Tibetans. For an assessment of the dynamics between Gyelthangpa and 'the state', see also Mortensen (2016). 
the minds of locals in (for example) Gyelthang are as much shaped by their relationships with other local minority ethnic groups (such as the Naxi, Yi, and Hui) and non-local Tibetans as they are by relationships with the Han Chinese or the local or national governments. ${ }^{13}$ Local relationships with the state are only further complicated in Gyelthang when the local authorities and policy implementers (and sometimes makers) are themselves Naxi or Tibetan.

Part of the reason the identification of institutional agents of power (the 'state', monasteries, etc.) is so vital is that just as victors write history, those with power are the ideological if not the literal cartographers of identity in terms of the nomenclature of place. Any older model wherein Gyelthang marked the interface between Tibetan populations and various other peoples such as the Naxi, Yi, Lisu, Bai, etc. (but notably not Han Chinese population centres), is also rendered complex now that the government of the P.R.C. controls Gyelthang.

Most Tibetans of Gyelthang are Gelukpa Buddhists, ${ }^{14}$ although the decimation of institutional religion over the past sixty years has left the region with a precarious sense of its own Buddhist identity. Sumtseling monastery has been rebuilt from the utter devastation it underwent at the hands of locals in 1966, during the early tumult of the Cultural Revolution (D. Mortensen, forthcoming). Sumtseling, though, remains a complex and tense institution - a tension largely exacerbated by issues surrounding the divisive personage of the protection deity (yidam) Dorje Shugden. In essence, over the past two decades, the Chinese government has seized upon the Fourteenth Dalai Lama's dismissal of Dorje Shugden from the Geluk pantheon, and augmented the post Cultural Revolution ostensible rehabilitation of Buddhist practice with legitimation and amplified valuation of Dorje Shugden temples and monasteries, particularly in southern Kham. Thereby, a tense bifurcation has been exacerbated in Gyelthang (and elsewhere, such as in Dongwang) wherein monastery, kangtsen, temple, household, and individual loyalties to either the Dalai Lama or Dorje Shugden (and thus 'the state') have become polarized (Hillman 2005, E. Mortensen Taklung Kagyu monastery just outside of Jiantang Town, Nyagpel Monastery (sngags 'phel sdom gsum gling), and there are several other Kagyu monasteries in the broader region. For information about religions in Zhongdian county, see Zhondian xianzhi bianzuan weiyuanhui (1997, 227-230, 233-235), also for descriptions of the various monasteries in Zhongdian county. In addition, there are vital elements of Bön in the religiosity of the people of Nizu valley, although from the best I can discern, Nizu religion is a syncretic mix of Bön, local (non-Bön, mi chö) practices and beliefs, and some Geluk influences. 
2016). Entire village systems within Gyelthang, such as Xiao Zhongdian and Sanba, where Dorje Shugden practice is strong, are in the throes of something akin to what citizens of the U.S.A. call 'culture wars', vis-à-vis the anti-Shugden areas of Geza and Dukezong, which are loyal to the Dalai Lama. Stories in Jiantang town abound about family members who won't eat with one another, about village families whose member's funerals are shunned by other families from the same small village, and businesses refusing to hire employees who maintain religious loyalties on the other side of this sensitive divide. The tensions are very high, and the 'Shugden issue' is perhaps the most serious divisive force in Gyelthangpa society today.

Again, although the territory of the regions affiliated with Sumtseling's kangtsen does not match up with the map of Gyelthang, the tensions are perhaps most acute at Sumtseling itself, despite the outward gleam presented for the throngs of Han tourists. The 'pro-Shugden' kangtsen have the support of the abbot (Tib. khenpo), and the government, which, as the anti-Shugden people will tell you, provides a lot of funding for Shugden temples and monasteries precisely to aggravate and sew discord within the community. The 'Shugden issue' is prevalent beyond Gyelthang, of course, and throughout Kham there are push-pull tensions within Tibetan communities between those who are striving for cooperation and unity and those who are heated in their partisanship over the issue. In Gyelthang and Chaktreng, however, 'pro-Shugden' support is a vibrant, if minority voice. Döndrupling monastery (also Gelukpa) outside the town of Benzilan (and therefore also just outside of Gyelthang) does not suffer this same tension, as it eschews Shugden practice, and as a result many residents of Gyelthang have more respect for Döndrupling than they do for the more local and larger Ganden Sumtseling monastery. Clearly, one set of outlying and obvious questions that remains unanswered in this analysis includes why the boundaries of Gyelthang do not match with the territory associated with the eight kangtsen of Sumtseling. The strongest conclusion I can offer to this issue is that the idea of Gyelthang long predates the establishment of Ganden Sumtseling (1679). ${ }^{15}$

\section{A Sense of Place: Ambiance, Identity, and the 'Idea' of Gyelthang}

So, as we examine what Kham is, in other words where it is and who lives there, we must ask the same thing of its sub-regions, its southern plateau

15 The ruins of a Karma Kagyu monastery that predated Geluk hegemony in the valley can still be found in the forest east of Napa Hai on the road to Nixi. 
grasslands (Tib. thang), of its 'borderlands'. How close can we 'zoom in' to best understand place? Of course, in wondering such things, we note that political and religious control is not the only cartographer at work in defining Gyelthang or the identity of its inhabitants. Granted, in saying this I am making several assumptions. First, I am assuming that there is a marked difference, at times, between authoritative definitions of a region and the understandings of regional identity by local inhabitants. Second, I am assuming that a sense of place is not constituted entirely by places. When I imagine my own hometown, the ambiance of my memories of that place is constructed by more than just its physical setting, the land, and weather. The ambiance of place is often informed by one's friends, kin, experiences, by the languages used in the transmission and creation and negotiation of culture, and by such things as wildlife, cuisine, past events, jokes, and lullabies. Place is in vital ways a blending of the physical place and the people who live there, yet augmented by appositional definitions of who does not live there and what other 'places' are like.

Gyelthang, then, is a place wherein Tibetans live alongside and interspersed with Naxi, Nuosu Yi, Hui, Lisu, Bai, and other minority nationality (shaoshu minzu) peoples, as well as with increasing numbers of Han Chinese, many of whom have migrated from Sichuan. It is a place that has on the one hand seen its ethnic identity effaced in Mao-era campaigns, and on the other hand experienced reified state-narrated Tibetan identity-revivification in light of ethnic tourism in recent years. It is a place with a relatively weak sense of Tibetan nationalism and, correlatively, with a diluted and arguably insecure sense of pan-Tibetan identity, although the suppressed political uprising of 2008 in Kham has led to a slight augmentation of this pan-Tibetan identity. Gyelthangpa are often belittled or demeaned by Tibetans from Ü-Tsang and from farther north in Kham (e.g. Dergé and Kandzé) and Amdo, with sentiments ranging from 'Ah... that's China', to 'Shugden people'. The local Tibetic languages spoken in Gyelthang are unintelligible even to Tibetans from nearby places like Lithang or Dechen, let alone Lhasa, and indeed, Tibetan is spoken by less and less Gyelthangpa, and Chinese loanwords are increasingly common in local parlance. Tibetic languages within Gyelthang are also at times mutually unintelligible, and it is important to note that language is not a unifying characteristic of what makes Gyelthang Gyelthang. Tibetan language education is not robust in Gyelthang, and Tibetan literacy is rapidly declining, although it is questionable whether it was ever particularly strong.

Gyelthang is a place where many rural Tibetan women regularly sport communist Mao caps, in part because they do not adhere to the sentiment 
that communist policies constituted a bad change. Gyelthang is a place where many villagers in remote regions are thankful for the establishment of the P.R.C. rule. Gyelthang is a place where Chinese nomenclature for geographical features is employed on a regular basis and the Tibetan and Naxi names are often all but forgotten. It is a place where the local names for many gods are forgotten.

Gyelthangpa are sometimes seen as less Tibetan' by other Tibetans, and the Gyelthangpa know this. Coupled with a particularly ineffectual and politically compromised monastery, ${ }^{16}$ few Gyelthangpa know much about Buddhist philosophy, ethics, or practices. Indeed, many Gyelthangpa see themselves as peripheral to the rest of Tibet (although there are also peripheries within this peripheral place) and understand themselves as well-integrated with the rest of China. This is not, of course, to say that Gyelthangpa are in fact 'less' Tibetan than other Tibetans, as such a claim presupposes an ideal Tibetanness or a normative cultural authority. The sense of difference from other Tibetans, even their direct neighbours, contributes to a local sense of distinction. Although if asked 'are you Khampa', most Gyelthangpa would say 'yes', very few offer Kham as part of their identity unless asked. Instead, locals will say they are Gyelthangpa (typically with the Chinese pronunciation of Jiantang), or that they are from Shangri-La (Ch. Xianggelila).

For Gyelthangpa, despite the embarrassment or insecurity about having less religious or linguistic vitality or 'authenticity' as other Tibetans, there is never ever a sense for Tibetan Gyelthangpa that they are not Tibetan. The 'border' is to the east, south, and southwest. Gyelthangpa do not think of themselves as a border-land', per se, but instead as the southeastern reaches of Tibet, with the territory of other minority nationalities on the other side of an often-inexact boundary. That Gyelthang's location in Yunnan Province separates it politically and administratively from Sichuan and the Tibetan Autonomous Region (T.A.R.), and thus from the rest of Kham, is important, but Gyelthangpa don't think of themselves as thereby less Tibetan, regardless of what other Tibetans might think. They also don't see themselves as more a part of China than any other part of Tibet. One crucial and enormous caveat to this line of thinking is that it is foolish to generalize and thereby essentialize all Gyelthangpa as thinking or believing the same thing; just as it is wildly problematic to claim that 'Chinese people believe' any singular thing, Gyelthangpa are diverse in their perspectives, and certainly do not share identical senses of their own identities.

16 For details on the sentiments toward Ganden Sumtseling monastery, see E. Mortensen (2016). 
For most Gyelthangpa, the ambiance of daily life does not involve a heavy flavouring of the sense of being a 'borderland'. Sure, farmers in Geza (Tib. Ketsak) are influenced by their proximity to Han China in ways as varying as the effects of outside mining companies on clean water to the lament for the religious vacuum resulting from the spiritual impotence of the monastery, from the television they enjoy to their inability to procure a passport with ease, and from mandatory hospital childbirth to mandatory centralized boarding schools. And their view to the north and northwest, to Kham and the rest of the Tibetan world, is infinitely more profound and pervasive. In order to conceive of living in a 'borderland', in a place of liminality or 'between-ness' or even of interface, culturally or ethnically or even religiously, there needs to be a sense of belonging to both or to neither.

The 'idea' of Gyelthang remains relatively clear in the minds of most locals, regardless of changes in language, demography, institutional power, politics, or maps. Whereas much else has changed for locals in the way place is defined by power or authority, the idea of Gyelthang, perhaps because it is so local and old, has remained a more vital part of local identity than the idea of Kham, although that it remains does not mean that it has not changed.

Most Gyelthangpa consider themselves to be Khampa only secondarily, unlike, for example, in Lithang, where Khampa identity is central and primary. Gyelthang is an old idea and is potentially thereby more stable. ${ }^{17}$ There are also differences between Gyelthang and the rest of Kham worthy of note, such as the fact that there are relatively few Gyelthangpa nomads. In this, Gyelthang shares something with the Tibetans of Muli, Dechen, and other places that are technically (whatever that means) part of Kham. Key, here, is why any of this matters, and for whom? Obviously, identity matters deeply to more or less everyone, from the song rong hunters to the state, and a sense of homeland is central to Tibetan life. The Tibetan term phayül, 'homeland', is often one of the first things Tibetans from different regions ask of one another when they meet. Gyelthangpa visiting Lhasa do not answer this question with the word 'Kham', but with 'Gyelthang'. If asked for more specificity, most would follow-up with 'Xianggelila' (only in the last few years has the old name Zhongdian faded from use) or 'Yunnan'. Obviously, Gyelthangpa visiting Lithang (as it is also part of Kham) would never answer 'Kham'. And although where you say you are from is not the be all and end all of identity, the degree to which Gyelthangpa think of themselves as Khampa matters in important senses when it comes to issues of larger Tibetan regional 
identity and affiliation, which can have political and religious ramifications. However, locally, on a day-to-day level, the boundaries of what is and what is not Gyelthang, whether or not one is foremost Khampa or Gyelthangpa, and whether or not Shangri-La Town is a 'borderland', per se, matter little.

Yes, there are small pockets of Amdowa inside northern Kham and vice versa, and yes, people in Tibet generally identify, with great specificity, as being from a particular region (e.g. people are not simultaneously Khampa and Amdowa). This aspect of identity - that of the place you identify as being from, your phayül - is not edgeless; this aspect of Tibetan identity does not bleed like watercolours. But other aspects of identity, of culture, religion, and ethnicity, absolutely do. In Gyelthang, maps don't help much. Maps are not identity.

\section{Map, Territory, and the Cartographer's Guild}

Who are the cartographers, and why are they (we) making the maps they (we) make? What is at stake, and for whom? In his work 'Map Is Not Territory', Jonathan Z. Smith (1994, 291, and f.n. 115) worries about 'the insistence on the cognitive power of distortion, along with the concomitant choice of the map over the territory'. In the case of understanding Gyelthang, of attempting to see landforms through the mist, why is it we sometimes privilege the map? Who might want us to privilege the territory? Whose territory? Owned or controlled by whom? Territory how defined, how constituted? 'Borderlands' according to whom?

Jonathan Z. Smith continues: 'There are situational or relational categories, mobile boundaries which shift according to the map being employed' (ibid.). In his introductory chapter, Stéphane Gros describes the constant 're-mapping' that results from discursive socio-spatial processes and various knowledge economies. Similarly, here, there are Buddhist institutional maps (e.g. kangtsen territories), Chinese geopolitical taxonomic maps, ethnic maps, road maps, satellite maps, linguistic maps, and tourist maps all defining Gyelthang differently, and all with different sorts of agency and power. Yet they do not agree or conform when it comes to Gyelthang. A map, writes Smith $(2004,17)$, 'guarantees meaning and value through structures of congruity and conformity'.

Smith's concern is religion, and the problematic nature of discerning patterns in religiosity. Perhaps Smith's greatest contribution to the discipline of comparative religion has been to critique problematic methods of comparison, identifying quagmires and pitfalls for the comparativist. He writes (ibid.): 
Students of religion have been most successful in describing and interpreting this locative, imperial map of the world - especially within archaic, urban cultures. [...] Yet, the very success of these topographies should be a signal for caution. For they are largely based on documents from urban, agricultural, hierarchical cultures. The most persuasive witnesses to a locative, imperial world-view are the production of well organized, self-conscious scribal elites who had a deep vested interest in restricting mobility and valuing place. [...] In most cases one cannot escape the suspicion that, in the locative map of the world, we are encountering a self-serving ideology which ought not to be generalized into the universal pattern of religious experience and expression.

Smith's identification of a 'universal pattern' is 'intended to refer to Mircea Eliade's "archaic ontology", but the 'ideological element' was expanded to include 'a variety of approaches to religion which lay prime emphasis upon congruency and conformity, whether it be expressed through phenomenological descriptions of repetition [or] functionalist descriptions of feedback mechanisms' $(1994,229)$. Smith is concerned with what he sees as a pervasive tendency of scholars of the historical and comparative study of religion to seek out and identify patterns of similarity between religious phenomena. He famously identifies this tendency as methodologically problematic, noting that similarities in the eye of the beholder were importantly not constitutive of causal mechanisms. In other words, patterns of religious phenomena described by scholars led to associative conclusions about the relationships between religious phenomena based on such 'magical' causal criteria as mimesis, contiguity, or raw similarity. Smith expands his concerns with 'universal patterns' he saw in the work of Eliade to critique the broader field of comparative religion, and emphasizes the importance of scrutinizing difference instead of similarity when engaging in the methodology of comparison. In our creation of and wondering about maps and borderlands, how might we best avoid the error of generalizing our emphases on the production of locative classifications of the people who live in the mountains and grasslands and forests of the area called Gyelthang? Can we possibly, as Gros calls for in his Introduction, conceive of spaces as social constructs through more unfamiliar forms of spatialization?

When we identify 'the very success of these topographies' as being the historical forces and institutional agents of place naming for a place such as Gyelthang, we wonder about what 'self-serving' ideologies are being generalized. Who, in the case of Gyelthang, are the 'well organized, self-conscious 
scribal elites who [have] a deep vested interest in restricting mobility and valuing place'? Could the answer be the 'state', or perhaps the Tibetologists who perpetuate a focus on 'borderland', 'frontier', or 'territory' based on a hermeneutic that privileges the large, powerful, power centres of Tibet and China? ${ }^{18}$

One point here is that Smith's emphasis is on religion, and when we 'map' his point onto the lived ground of Gyelthang, we must wonder about the applicability of his larger question. What are the parallel 'ideologies' and patterns for our wonderings about the 'idea' of Gyelthang for the people who live therein? Identity for Gyelthangpa certainly includes religion, but religious identity for Gyelthangpa is not markedly different from other peoples in southern Kham, excepting perhaps that institutional Buddhist revival has been relatively stagnant in Gyelthang. To what degree can Smith's cautionary about the cartographers of a locative map help us to remove the boundaries of provinces and counties, the demarcated regions of Sumtseling's kangtsen, or even, if we expand the notion, the edges of 'minority nationality' groups, or the importance of sacred mountains (as decided by whom)?

What are the contexts being negotiated when the question of Gyelthang comes up in conversation? In scrutinizing Gyelthang, it is not so much that boundaries move as that different models are selectively employed based on the context of identity-negotiation. For example, even with the issue of phayül, whether or not a local will use the word or even think of the notion of Gyelthang depends on with whom they are speaking or interacting and why. Gyelthang is only used as an identifier of home-identity when someone from, say, Geza, is speaking with a Tibetan (only when speaking Tibetan) from the outside, or when the Geza person is themself outside of the region speaking with another Tibetan. Thus, while it is understood that Gyelthang is a placename known to Tibetans in general, the word is only used to locate one's homeland in the ears of an outside listener. While this is not too surprising - I do not harp on about being a North Carolinian when I am in North Carolina talking with other North Carolinians - the situation is distinct in that when inside Gyelthang 'territory' there is almost never any sense of a sufficient cohesion, or nationalism (or the equivalent), not much sense of local Gyelthangpa pride - because there is not really a strong sense of bounded place or importance of place or central notion of what Gyelthang even means. This is not to say that farmers in Geza in

18 Note that in China (and to some degree in other countries) it is difficult to disentangle Tibetology from the 'state'. 
Gyelthang, for example, are not proud of their valley, or even of the larger region, and this sense of awesomeness can include a sense that this southern reach of Kham is in fact different in qualitative important ways to locals. They feel a strong sense of 'Ah, home again in this beautiful land' when they come back.

I would argue that identity in Gyelthang is particularly local, tied to the land itself but not to any map of the land, similar to the ways in which religion is often very local in 'peripheral' areas (thus defining the periphery). Particularly in more rural parts of Gyelthang, the revivification of local non-Buddhist, pre-Buddhist (yet not Bön), 'folk religion' (Tib. mi chö) has been the result of the systematic deconstruction of institutional religion. The absence of numbers of charismatic or respected teachers at Sumtseling has left communities without religious teachers for decades. In conjunction with decreased literacy and a general state-imposed dismantling of the importance of religion, people in, for example, Geza or Nagara villages have replaced aspects of what were formerly more orthodox Buddhist valences with religious identity strands of story that are markedly and often beautifully folkloric. In this context, the cartographers are very local, and do not add to their recipes, at least not intentionally, emphases on notions such as 'periphery' or 'borderland'. The village community is a centre, and the mountains above the tree lines are full of monsters.

In Geza, for example, the animated landscape is instrumental in the construction of local identity, and people are concerned about mining and water, and about mushroom harvests. They re-perform stories about nowuninhabitable (and previously invisible) villages that were made visible and abandoned due to dangerous naknyi gö (wild people), transgressions having to do with the bounds of what it means to be human, or forced relocations of villages at the hands of representatives of the state due to the perceived remoteness of the high villages, or both. The border is something akin to everything out of sight over all the surrounding mountains.

Smith's topography employs three categories: 1 ) the 'here' of domestic religion, located primarily in the home and in burial sites; 2 ) the 'there' of public civic and state religions, largely based in temple constructions; and 3) the 'anywhere' of a rich diversity of religious formations that occupy an interstitial space between these other two loci, including a variety of religious entrepreneurs and ranging from groups we term 'associations' to activities we label 'magic' (Smith 2004, 325). Of the three, the people of Geza and Nagara, for example, are far more focused on the first, the local, the 'here' of domestic religion, though not merely relegated to the house. The extended family's local domestic religion is the category we see most 
manifest in Geza village life. ${ }^{19}$ With local domestic religiosity, displacement and forgetfulness become paramount concerns, alongside the worry about agency and who controls or creates memory (Smith 2004, 326-327; Mueggler 2001; E. Mortensen 2016). In the sphere of civic and national religion, the religion of 'there' is 'over there' in relation to one's home place and involves expressions of power. For the people of Geza, this is Buddhism, and the 'there' is, quite fundamentally, Ganden Sumtseling monastery. What does 'political legitimacy' mean for locals? To what degree are jurisdictions based on what local people care about?

For Gyelthangpa, seeing themselves as peripheral to Central Tibet or to the rest of Kham is a different thing, categorically, than seeing themselves as the borderlands, as the in-between people on competing guild maps. Larger questions of whether Tibet historically understood itself as a centre or peripheral world (vis Kalachakra or other cosmography, or in relation to powerful neighbours) are also worthy of deeper exploration. ${ }^{20}$

I'd like to argue here that Gyelthang is, in a sense, an idea of place, the definition and meaning of which is quite old, if vague, and the reasons for its territory no longer very important. Locals absolutely identify as Gyelthangpa, understand themselves to be Khampa even if this is only secondary, and many do deeply love where they live. Locally, the 'idea' of Gyelthang is stronger than the 'idea' of Kham, and while Gyelthangpa may understand Gyelthang to be peripheral to the rest of the Tibetan world, they don't really locate themselves when they think about their identity as being the borderland between two or more places. Proximity matters. Just because Gyelthang is peripheral to Tibetan cultural power centres does not make it the interface between Tibet and China. It is not adjacent, historically, to China, but to other minority regions. It is not the boundary, although it might be considered frontier for the Chinese, particularly in years long past.

'A theory, a model, a conceptual category cannot be simply the data writ large', pens Smith $(2004,31)$. Gyelthang, if it is an idea, cannot be constituted merely by a constellation of data points - unless we connect them differently, more topologically, as Gros suggests in his chapter. What would be the data points of Gyelthang? Tourist maps readily available in the Old Town do a fine job of offering a version of such a way of understanding places within a larger place, and their importance. Religious sites are writ large, with sketches of monasteries sized according to their 'importance' for the tourist (and for

19 For an example from China, see Granet (1929, 205; 1951, 21-25).

20 Regarding ways in which China and India have historically understood the other-ness of their neighbours, see White (1991). 
their entrance ticket sticker price). Roads between these sites are the only paths depicted, and the maps are printed on brown paper reminiscent of enticingly old and perhaps mysterious maps. Truly, the effect of tourism on Gyelthang in the past twenty years has been profound. Huge government money has revitalized the same buildings that the same government's policies razed half a century ago, and there are now nice roads, hundreds of hotels, an airport, and soon, a rail line. Opportunities to capitalize on the boom are myriad, and, like in much of China, the populace is far better off economically than they were a few decades ago. The tourism is, of course, managed by the state in conjunction with local entrepreneurs, etc., but the degree of agency locals have to determine how their own identities are marketed is questionable at best. The exotification and racism that has accompanied the creation and control of the narrative of 'authentic' Tibetanness has had an odious effect on Gyelthangpa identity, including religious identity.

In the performance of cultural identity, formative stories are dripping with the charisma of the suspension of (dis)belief. Just as the 'truth' and 'reality' of monsters in wild-forest-man tale performances is importantly unimportant, and just as accuracy (and sometimes even efficacy) in local non-Buddhist divination rituals is not (always) why they are performed, so too the 'authenticity' of Tibetan religio-cultural identity is not really why the tourists come to Shangri-La. The description of 'authenticity', after all, depends on whom you ask. Gyelthangpa agency is, at best, not of primary concern to the Cartographer's Guild of Shangri-La County.

\section{Epilogue}

In his wonderful essay 'Bible and Religion', Jonathan Z. Smith exhumes Jorge Luis Borges' parable about the perfectly congruent map that is, among other things, absolutely useless for 'finding one's way around' (2004, 209). Borges' passage is worth quoting in full:

In that Empire, the Art of Cartography attained such Perfection that the map of a single Province occupied the entirety of a City, and the map of the Empire, the entirety of a Province. In time, these Unconscionable Maps no longer satisfied, and the Cartographer's Guild struck a Map of the Empire whose size was that of the Empire, and which coincided point by point with it. The following generations, who were not so fond of the Study of Cartography, as their Forebears had been, saw that that 
vast Map was useless, and not without some Pitilessness was it, that they delivered it up to the Inclemencies of Sun and Winters. In the Deserts of the West, still today, there are Tattered Ruins of that Map, inhabited by Animals and Beggers; in all of the Land there is no other Relic of the Discipline of Geography. ${ }^{21}$

I ask you to envision Borges' empire (imperial power, cartographers?) as 'us', the practitioners and cartographers of Tibetology. Ever cognizant of China's imperial hegemony and goal of assimilation as a 'spectral state ${ }^{22}$ that looms over our need as historians to complicate, to problematize, and to emphasize the proportionality of even minute detail, we also care for emic assertions of identity, care about the local, and seek out stories that fill out and paint our map of Kham with bleeding watercolour. But as we seek to define, taxonomize, and render intelligible the nuances of Kham, we may be wise to push through to see the ramifications of Smith's claim that 'map is not territory'.

If territory, for Smith, equals data that needs to be processed and analysed in order to create a map (a model), then if maps are not territory it is because they are inevitably merely representative abstractions - phantom and inexact semiotic parole penned by power. How then might Tibetologists create useful maps to best represent, for example, Gyelthang? Only if the notion of 'borderlands' (or of Kham) is particularly helpful for a given purpose should it be employed. ${ }^{23}$ Importantly, not all 'maps' are contributions to cartographic knowledge. Some might be dreamscapes, others records of experience, some pathways of memory, and others intentionally misleading. When we consider Gyelthang, perhaps Smith is suggesting that if we wish to consider a map, we need to critically admit its quality of abstraction, but also that maps are nevertheless not things that we should not make at all, or that should exist only as tatters in western regions populated by animals and beggars. Focusing on the identity of Gyelthang as place, a multi-layered place with lived experiences and ambiances, is such a problematic abstraction, and one we should consider, perhaps, only for certain purposes. But mapping Gyelthang as a borderland, and even as part of a larger borderland, belies the local sense of place.

21 Borges, 'Exactitude in Science', as quoted in Smith $(2004,209)$.

22 Here taking out of context a phrase coined by Mueggler (2001).

23 I am indebted here to Stéphane Gros for his valuable comments on this section of this chapter, and for his suggestions about rethinking Smith's notions of maps, particularly in light of their possible 'utility'. Regarding the problem of what kind of knowledge can produce what kind of conceptualization of space and thus of 'map', see Mueggler (2011). 
We add as many details as we possibly can to our understanding of the histories (and who constructed them), of the religions (and how they make meaning in people's lives), and of the importance of place in each. With collective scholarship, isn't our map becoming increasingly detailed? Wouldn't it be more 'helpful' were we to highlight certain places of interest (to the reader, unless 'they' is really 'we', in which case the guild's map is intended for internal circulation only), perhaps by sketching them in relative size of value or importance across Kham? Are we the Cartographer's Guild, 'striking' a map, like minting currency, coinage we can exchange for contested histories? Is the utility of smaller maps more beneficial to us as we seek to define 'borderlands'? Why should we, or why should the Gyelthangpa, care whether or not the Central Tibetans, who don't give much of a flip about Gyelthangpa in the first place, see Gyelthang as a 'borderland'? How do other residents of northwest Yunnan and Gyelthang, many of whom are not Tibetan, see themselves?

Perhaps the Cartographer's Guild is comprised of pan-Tibetan advocates. Imagine zooming in on Google Earth ${ }^{24}$ but instead of the image getting closer to a particular locus, the borders of the map - the physical edges of the computer screen - grow wider with each click on the zoom function icon. And almost as an afterthought, if we as scholars are the Cartographer's Guild, then who are 'the following generations, who were not so fond of the Study of Cartography'? Smith writes: 'For Borges, when map is the territory, it lacks both utility and any cognitive advantage with the result that the discipline which produced it, deprived of its warrants, disappears' (Smith 2004, 209).

\section{Glossary of Chinese and Tibetan Terms}

$\begin{array}{ll}\text { Chaktreng } & \text { Phyag phreng } \\ \text { Deqin xian } & \text { 德钦县 } \\ \text { Diqing Zangzu zizhizhou } & \text { 迪庆藏族自治州 } \\ \text { Döndrupling } & \text { Don grub gling (Tib.), Dongzhulin si } \\ & \text { 东竹林寺 (Ch.) } \\ \text { Dorje Shugden } & \text { Rdo rje Shug ldan } \\ \text { Geza } & \text { Skad tshag } \\ \text { Gyelthang } & \text { Rgyal thang }\end{array}$

24 https://google.com/earth/ Ironically, this is not something easy to do inside China, where Google is currently blocked. 


$\begin{array}{ll}\text { Hutiaoxia } & \text { 虎跳峽 } \\ \text { Jinshajiang } & \text { 金沙江 } \\ \text { kangtsen } & \text { khang tshan } \\ \text { khenpo } & \text { mkhen po } \\ \text { mi chö } & \text { mi chos } \\ \text { Nagara } & \text { Nags rked rag } \\ \text { naknyigö } & \text { nags myi rgod } \\ \text { Nizu } & \text { Rmig zur } \\ \text { shaoshuminzu } & \text { 少數民族 } \\ \text { Termarong } & \text { Gter ma rong } \\ \text { Tongrong } & \text { Stong rong } \\ \text { Tormarong } & \text { Gtor ma } \\ \text { Xiangcheng } & \text { 乡城 } \\ \text { Xianggelilaxian } & \text { 香格里拉县 }\end{array}$

\section{References}

Bartee, Ellen. 2007. A Grammar of Dongwang Tibetan. Unpublished PhD Dissertation. University of California, Santa Barbara.

Borges, Jorge Luis. 1998 (1946). 'Exactitude in Science'. Collected Fictions. New York. Bstan-pa-rgyal-mtshan. 1985. Rgyal thangyul lung dgon gnas dang bcas pa'i byung ba mdo tsam brjod pa blo gsal mgul pa mdzes pa'i rgyan (A History of the Rgyalthang Dgon-pa Monastic Complex and its Environs). Dharamsala, H.P., India: Rgyal-thang Bya-'thab, Ngag-dbang Thabs-mkhas.

Buffetrille, Katia. 2016. 'Review: Mapping Shangrila'. Asian Highlands Perspectives 40: 527-533.

Diqing zhou gaikuang bianxie zu 迪庆州概况编写组 (Editing Division of the Survey of Diqing Prefecture). 2007. Diqing Zangzu Zizhizhou gaikuang 迪庆藏 族自治州概况 (Survey of the Diqing Tibetan Autonomous Prefecture). Beijing: Minzu chubanshe.

Granet, Marcel. 1929. La Civilisation chinoise: La vie publique et la vie privée. Paris: La Renaissance du livre.

Granet, Marcel. 1951. La Religion des Chinois, $2^{\text {nd }}$ ed. Paris: Presses Universitaires de France.

Gyaltsen, Lobsang. 1971.'Ba' kyi lo rgyus (History of Kham Ba-pa). Dehra Dun: Nyingmapa Lamah Press.

Harrell, Stevan. 2007. 'Létat, c'est nous, or We Have Met the Oppressor and He is Us: The Predicament of Minority Cadres in the PRC'. In The Chinese State at the Borders, edited by Diana Lary, 221-239. Vancouver: UBC Press. 
Hillman, Ben. 2005. 'Monastic Politics and the Local State in China: Authority and Autonomy in an Ethnically Tibetan Prefecture'. The China Journal 54: 29-51. Jackson, Anthony and Pan Anshi. 1998. 'The Authors of Naxi Ritual Books, Index Books and Books of Divination'. In Naxi and Moso Ethnography: Kin, Rites, Pictographs, edited by Michael Oppitz and Elizabeth Hsu, 237-274. Zürich: Völkerkundemuseum Zürich.

Jackson, Anthony. 1979. Na-khi Religion: An Analytical Appraisal of Na-khi Ritual Texts. The Hague: Mouton Publishers.

Kolås, Åshild. 2008. Tourism and Tibetan Culture in Transition: A Place Called Shangrila. New York: Routledge.

Mathieu, Christine. 2003. A History and Anthropological Study of the Ancient Kingdoms of the Sino-Tibetan Borderland - Naxi and Mosuo. Lewiston, NY: The Edwin Mellen Press.

Mortensen, Dáša Pejchar. 2016. The History of Gyalthang Under Chinese Rule: Memory, Identity, and Contested Control in a Tibetan Region of Northwest Yunnan. Unpublished PhD Dissertation. University of North Carolina Chapel Hill.

Mortensen, Dáša Pejchar. Forthcoming. 'Historical Amnesia in Gyalthang: The Legacy of Tibetan Participation in the Cultural Revolution in Yunnan Province'. In Conflicting Memories: Tibet under Mao Retold, edited by Benno Ryan Weiner, Françoise Robin, and Robbert Barnett. Leiden: Brill.

Mortensen, Eric D. 2006. 'Raven Augury from Tibet to Alaska: Dialects, Divine Agency, and the Bird's-Eye View'. In A Communion of Subjects: Animals in Religion, Science, \& Ethics, edited by Kimberley Patton and Paul Waldau, 423-436. New York: Columbia University Press.

Mortensen, Eric D. 2016. 'Prosperity, Identity, Intra-Tibetan Violence, and Harmony in Southwest China: The Case of Gyalthang'. In Ethnic Conflict and Protest in Tibet and Xinjiang: Unrest in China's West, edited by Ben Hillman and Gray Tuttle, 201-222. New York: Columbia University Press.

Mortensen, Eric D. 2009. 'Mosuo and Naxi Nationalities'. In Encyclopedia of Modern China. Volume 2, 613-614. Detroit: Charles Scribner's Sons.

Mueggler, Erik. 2001. The Age of Wild Ghosts: Memory, Violence, and Place in Southwest China. Berkeley: University of California Press.

Mueggler, Erik. 2011. The Paper Road: Archive and Experience in the Botanical Exploration of West China and Tibet. Berkeley: University of California Press.

Rock, Joseph. 1947. The Ancient Na-khi Kingdom of Southwest China. Cambridge: Harvard University Press.

Schwieger, Peter. 'Dynamic of Shangri-La: Or Turning the Prayer Wheel for the Protection of the Multiethnic Society'. In Études tibétaines en l'honneur d'Anne Chayet, edited by Jean-Luc Achard, 269-278. Genève: École Pratique des Hautes Études. 
Schwieger, Peter. 2011. 'The Long Arm of the Fifth Dalai Lama: Influence and Power of the Fifth Dalai Lama in Southeast Tibet'. In Buddhist Himalaya: Studies in Religion, History, and Culture. Volume I, edited by Alex McKay and Anna Balikci-Denjongpa, 239-258. Gangtok: Namgyal Institute of Tibetology.

Schwieger, Peter. 2017. 'On the Jurisdiction in South-East-Tibet after the Rise of the dGa' ldan pho brang Government'. In Social Regulation: Case Studies from Tibetan History, edited by Jeannine Bischoff and Saul Mullard, 126-15o. Leiden: Brill.

Smith, Jonathan Z. 1994 (1978). Map is not Territory: Studies in the History of Religions. Chicago: University of Chicago Press.

Smith, Jonathan Z. 2004. Relating Religion: Essays in the Study of Religion. Chicago: University of Chicago Press.

Suzuki, Hiroyuki 铃木博之. 2015. Dongfang Zang qu zhu yuyan yanjiu 东方藏区 诸语言研究 (A Study of the Various Languages of Eastern Tibet). Chengdu: Sichuan minzu chubanshe.

Thondup, Kargyal. 1992. Mdo khams cha phreng kyi lo rgyus gser gyi snye ma (The Golden Grain of Dokham Chaktreng's History). Dharmasala: Library of Tibetan Works and Archives.

Tsering, Tashi. 1985. 'Nag-ron Mgon-po Rnam-rgyal: A $19^{\text {th }}$ Century Khams-pa Warrior'. In Soundings in Tibetan Civilization, edited by Barbara Nimri Aziz and Matthew Kapstein, 196-214. New Delhi: Manohar Publications.

Tsomu, Yudru. 2015. The Rise of Gönpo Namgyel in Kham: The Blind Warrior of Nyarong. Lanham: Lexington Books.

White, David Gordon. 1991. Myths of the Dog Man. Chicago: The University of Chicago Press.

Yeh, Emily T. and Chris Coggins, eds. 2014. Mapping Shangrila: Contested Landscapes in the Sino-Tibetan Borderlands. Seattle: University of Washington Press.

Zhondian xianzhi bianzuan weiyuanhui 中甸县志编纂委员会 (Zhongdian County Gazetteer Compilation Committee). 1997. Zhongdian xianzhi 中甸县 志 (Zhongdian County Gazetteer). Kunming:Yunnan minzu chubanshe.

Zhongdian xian renmin zhengfu, Zhongdian xian diming lingdao xiaozu 中甸县 人民政府, 中甸县地名领导小组 (Zhongdian County People's Government, Zhongdian County Place Names Leadership Small Group). 1984. Yunnan sheng Diqing Zangzu Zizhizhou Zhongdian xian diming zhi 云南省迪庆藏族自治州 中甸县地名志 (The Gazetteer of Place Names in Zhongdian County, Diqing Tibetan Autonomous Prefecture, Yunnan Province). Chengdu: Xinan minzu yinshua chang. 


\section{About the Author}

ERIC D. Mortensen is Professor of Religious Studies at Guilford College, U.S.A. He teaches courses on Tibetan and Himalayan religions and comparative religious theory. His research and writing projects involve topics in the religion and folklore of Gyelthang, the relation of oral tradition to Naxi pictographic texts and ritual performances, and oral literature in the region of Geza. 



\section{Part II}

Modes of Expansion and Forms of Control 



\title{
Introduction
}

\author{
The Editor
}

Most of the recent research on the Sino-Tibetan borderlands, in history, anthropology, and related fields has focused on the dynamics of state incorporation and on the marginalization of the local population. Following the Manchu intervention in Tibet in the 1720s, there was a sustained effort to incorporate Kham into Sichuan province both administratively and economically. These moves were countered by attempts from the government of Central Tibet, the Ganden Phodrang, to expand its own religious and politico-economic presence.

Colonial frontiers are not necessarily of the 'tidal-wave' type where a centre moves into an uncontrolled area, where the civilized gradually subsumes the wild. Many authors have used the metaphor of the sea to describe borderland interactions, whereby the relentless waves rolling in from the civilizational centre would progressively, but ineluctably, wear away the land. Borderland interactions do not leave the centre untouched; it too is altered in the process. The logic underlying the 'frontier of control' has generally been to ensure the continued presence of indigenous communities and their political system. In the words of Ann Stoler and Carole McGranahan $(2007,8)$, 'imperial formations thrive on deferred autonomy, meted out to particular populations incrementally, promised to those in whose lives they intervene'. A key element of imperial formation is the balance between direct and indirect rule exemplified in Qing Empire's periphery by the native office (tusi) system:

Qing expansion into Kham depended on the cooperation of local elites, and in this case the device to lure them toward Beijing was the tusi office. Imperial governance was by necessity a series of compromises, and this was especially true at the empire's edge where the Qing state offered tusi titles and offices, as well as vital military and financial support in return for a declared submission to the Qing throne. (Herman 2014, 79)

This system of indirect rule allowed for the maintenance of indigenous leaders and their political system with a great degree of independence, and sympathetic local leaders were bestowed tusi titles, which became a step 
towards their integration. Full incorporation, however, did not take place until a transition to direct administration had been forcefully achieved, replacing indigenous leaders with state-appointed officials - a process alluded to in several of the chapters in this volume.

The experience of imperialism significantly differed across Tibetan areas and between Central Tibet and Kham or Amdo. The kind of state presence in Kham itself also varied in time and from place to place. For a long time the colonial agenda in Kham focused on controlling trade routes: vital pathways that connected the lowlands of the Sichuan basin to the highlands of the Tibetan plateau. Military colonists were deployed in strategic locales, especially along the southern 'official's road', and merchants from Sichuan and Yunnan took advantage of the military presence to resume trade. There was also, at times, interest in the exploitation of certain natural resources on the territories concerned, which were turned into 'frontiers of extraction'. This came with an increase in the number of settlers, as Relyea and Frank both demonstrate here. For the most part, though these people were not permanent residents, settler colonialism nevertheless became part of evolving policies and ideologies about the frontier, especially in republican times.

Late Qing and later republican era efforts in Kham and the Sichuan frontier resulted in important steps towards the integration of the highlands within the realm of centralized administrations and the nascent nationstate. The chapters in this section delve further into the complexities of the historical context and of the conditions of the time already alluded to in the introductory chapter. The region was repeatedly destabilized by internal strife and by events elsewhere: the development of Western imperialism, the Sino-Japanese war, the rise of provincial warlords, territorial dismemberment, and the growth of nationalism as a new political ideology. As Jack Patrick Hayes (2014) demonstrated in his groundbreaking environmental history study about the northern Sichuan region, the struggle to control people, resources, and land led local residents and elites, other than businessmen, warlords, and government agents, to create environmental and social changes through a series of 'changing market regimes'. In this context, the frontier became both a space for opportunities and a place in need of intervention. The rise of this developmentalist approach and its legacy has survived to this day, and the chapters in this section contribute to show how interventionist policies in Kham, since late imperial and republican times, have contributed to a process of territorialization that transformed the land and the people (see Yeh 2013).

We continue to engage with these issues here, well aware of the need to pursue the exploration of forms of colonialism or expansion in Asian contexts 
(Wade 2014) and the 'civilising missions' that inform them (see Harrell 1995). This section is organized around contrasting approaches to large-scale and externally driven transformations and modes of expansion that led to the progressive integration of Kham. The chapters focus on the historical period that saw rising nationalism, forced integration and reactions to it, and later integration into the newly founded People's Republic of China. Part III, in a complementary fashion, assembles chapters that focus on local instances and individual trajectories that detail the limitations and opportunities provided by these transformations.

One of the underlying questions that tie the chapters together is: how is state control achieved and, more importantly, maintained? External powers might be able to establish control over a brief period, but they could not generally afford to maintain it until the 1950s. This section offers a detailed exploration of the means mobilized to maintain state control as well as of the ideology that inspired it. What is also discussed here is the kind of cultural and ecological determinism that informed much of the colonial thinking in China, just like anywhere else.

Addressing the many faces of the 'civilising mission' in Kham, this section starts with John Bray's depiction of French missionaries' entanglement in economic and political affairs as they settled in the highly contested region of Kham in the second half of the nineteenth century. The story of the attempts by the Société des Missions Etrangères de Paris to settle on Tibetan land and reach Lhasa, the 'Rome of Tibet', is highly revealing of on-the-ground conflicts over territorial control. This chapter discusses the missionaries' involvement in trade as a means of shedding light on wider historical developments in the region and as a lens through which to make plain the status of these borderlands. In trying to advocate for their presence, and in their dealings with various agents of the late Qing Empire and the young Republic, missionaries contributed to increasing political tension. One can hardly think of a more 'external' presence than French missionaries' in Kham but, for the historian, their continuous presence over several decades made them key witnesses of their time (as much as they were key informants for Foreign Affairs services) and their archives can help shed a different light on events as they unfolded locally.

As Mark Frank points out in his chapter (to which I return below), the Tibetologist Ren Naiqiang felt that French missionaries had succeeded where Imperial or Republican interventions had failed: 'Such a vast stretch of fertile earth Han people have not been able to cultivate in over two hundred years of management, he remarked, but the French Catholic church has cultivated it in our place - how disgraceful ought this to be?' (see Frank, this volume). 
During the republican period, concerns about controlling and developing the hinterland and the difficulty in achieving transformation towards 'progress' were often evaluated with regard to the success of some of the Christian settlements in the borderlands. Historian Wang Xiuyu $(2011,3)$ describes Qing expansion into the Tibetan Kham areas of Sichuan in the late nineteenth century as 'episodic escalations of state violence propelled by regional interests, which were distinct from central-level priorities but connected to them in dynamic ways'. The missionaries' presence epitomizes the political fault line that ran through Kham, and which elicited state interventions that can be briefly captured through three main historical figures.

The first is Lu Chuanlin (1836-1910), the Sichuan governor-general who prescribed a forward policy and a more interventionist stance as the imperial government struggled to limit the loss of its control over the frontier, especially after the Tibetan military intervention in Nyarong (see the Chronology and Gros, this volume). He proposed the implementation of direct rule through the process of gaitu guiliu (bureaucratization), an imperial policy by which indigenous rulers who had been granted tusi titles were removed, sometimes forcibly, and replaced with civil officials appointed by Beijing. The implementation of a comprehensive set of policies in Kham influenced by the Westphalian sovereignty model became the strategic mission of the second key figure, Zhao Erfeng (1845-1911) who, in 1906, was appointed the first Sichuan-Yunnan Frontier Commissioner. As many scholars have noted, Zhao Erfeng, who literally launched wars against Tibetan leaders and monastic institutions to establish a new administration in Kham through the forceful implementation of gaitu guiliu, referred to Western and Japanese colonialism as models. As one of the architects of Xikang province, he exemplifies the complex ways in which global factors were connected to internal circumstances - which still need to be evaluated properly. These local conditions are primarily what led to the rise to power of the third and most important figure, the warlord Liu Wenhui (1895-1976), who was made Chairman of the government of Sichuan province in 1929. The territories controlled by Liu Wenhui were combined into Xikang Province in 1939, an idea first formulated in the late Qing, and Liu ruled this part of the highlands as his 'fiefdom' until 1949. Under his rule, Xikang was the target of ambitious modernizing measures for which more settlers were required. Settler colonization became (and somewhat remains) an important activity 
on the frontier, with organizational and environmental consequences, but also with a direct relation to the changing meaning of sovereignty. ${ }^{1}$

As Scott Relyea points out, intense competition for authority within eastern Tibet between the Sichuan provincial government and Lhasa was linked to perceived regional pressure from Western imperialism. In his chapter, he explores the role that settler colonialism played in the consolidation of rule in Kham, in relation to shifting conceptions of territoriality and sovereignty in the late nineteenth and early twentieth centuries. This approach is complemented by M. Frank's study of the role played by agricultural development projects in Kham when the region was converted into the new Xikang Province in 1939. This national agrarian development experimentation inspired confidence in the ability of the Chinese state to implement larger social and environmental interventions on the plateau. These pursuits are of course reminiscent of the socialist state's efforts to transform Tibetan management of land and resources in order to transition to a more 'agrarian' regime, as discussed by Tan in her contribution. Hayes (2014) rightly highlights how the socialist state's interpretation of the local inhabitants' way of 'abusing' their natural resources is crucial for understanding the process of ethnic assimilation of this region. Here, both Relyea and Frank examine some of the antecedents to a vision of what 'proper' use of land and resources was for the Chinese state as of the republican period. There seems to be a clear parallel between the concern for 'proper' crops, discussed in both chapters, and 'good' varieties of practices and associated knowledge. In Frank's case, this concern extended to the search for 'good varieties' of worker, and the influence of the physiocratic movement on some of the Chinese thinkers (Frank, personal communication) calls for a parallel with Michel Foucault's well-known notion of biopolitics as a form of regulatory power characterized by the extension of state control over the biological. One cannot but note the obvious resonance with the contemporary discourse on suzhi ('quality'), which is used to justify various social and political hierarchies, as well as interventions motivated by the will to improve.

These types of intervention were part and parcel of Chinese approaches to modern economic and political development that became sources of ethnic inequality, as the chapter by C. Patterson Giersch affirms. In his chapter, Giersch links the state and the market, and shows that the advent of a

1 The adoption of standards derived from international law introduced a significant change in China's attitude towards its borders, as most notably exemplified by the role of British imperialism in fixing Tibet's geopolitical identity, and the switch from the notion of suzerainty to that of sovereignty. 
market economy is linked to the patterns of dependence among indigenous peoples, and that dependence was exacerbated by the state. This trend became particularly salient during the rise of the powerful developmentalist state during the 1895-1911 modernization efforts. Giersch argues that the engendering of economic inequality along ethnic lines dates back further and is not a product of the communist period alone. As he further demonstrates, there was no immediate singular moment or process of change, but a series of conjunctural changes in politics and trade. The republican period saw greater competition for (economic) power between monasteries, former secular ruling families, and merchants. This competition allowed for new commercial entities to gain power, a process that, when combined with political changes, laid the foundations for modern China's long-term practices of development that disempower local communities. This seems to be of greater relevance across upland Southwest China where land was one source of conflict and, as Joseph Lawson $(2017,3)$ recently argued, 'state officials['s ...] grand plans for the cultivation of land, the opening of mines, and other resource extraction industries, [...] fuelled further cycles of dispossession and conflict'. The 'transformative power of trade', in particular the lucrative tea trade, also provided opportunities to a fringe of local entrepreneurs whose 'bargaining power' increased thanks to their pivotal position as intermediaries (Tsomu 2016) and enabled key individuals to seize opportunities, a point that Lucia Galli discusses in her chapter in Part III.

There is a long history in the Sino-Tibetan borderlands of trans-local networks of trade and interregional connections that are re-emerging today in new forms and involve various actors (see Yeh and Coggins 2014, 100-103). Concurrently, the borderlands are the ongoing target of sweeping infrastructural and economic transformations, as well as biopolitical interventions and disempowerment that characterize some of The P.R.C.'s minority politics.

In the early 2000s, the Great Western Development Strategy (Go West) launched a series of policies and large-scale investments in infrastructural and regional economic growth, designed to reduce inequalities between China's poorer western regions and the industrialized coastal provinces. Some of these policies are reviewed here by Gillian G. Tan in the context of pastoralism in Kham. The push to develop agriculture, she argues, was often based on an understanding of pastoralism as a marginal activity that was undertaken out of environmental necessity. In her chapter Tan discusses the problems with such a biased view, based on her long-term ethnography of a contemporary community of pastoralists in eastern Kham. She further demonstrates how pastoralism can be interpreted as a degree of specialization and shows how its shifting practices are articulated 
around the forces of state policies and forms of governmentality. In their complementary discussion of state 'agrarianism', the chapters by Frank and Tan clearly state that the borderlands are fundamentally configured according to agro-urban standards, imposed on ecological conditions that they attempt to shape. To this day, Kham retains an 'inner frontier' quality and, as such, remains the target of many developmentalist strategies that constitute a continuation of borderland integration.

\section{References}

Harrell, Stevan. 1995. 'Introduction: Civilizing Projects and Reaction to Them'. In Cultural Encounters on China's Ethnic Frontiers, edited by Stevan Harrell, 3-36. Seattle: University of Washington Press.

Hayes, Jack Patrick. 2014. A Change in Worlds on the Sino-Tibetan Borderlands: Politics, Economies, and Environments in Northern Sichuan. Lanham, MD: Lexington.

Herman, John E. 2014. 'Collaboration and Resistance on the Southwest Frontier: Early Eighteenth Century Qing Expansion on Two Fronts'. Late Imperial China 35 (1): 77-112.

Lawson, Joseph. 2017. A Frontier Made Lawless: Violence in Upland Southwest China, 1800-1956. Vancouver: UBC Press.

Stoler, Ann Laura, and Carole McGranahan. 2007. 'Introduction: Refiguring Imperial Terrains'. In Imperial Formations, edited by Ann Laura Stoler, Carole McGranahan, and Peter C. Perdue, 3-44. Santa Fe, NM: School for Advanced Research Press.

Tsomu, Yudru. 2016. 'Guozhuang Trading Houses and Tibetan Middlemen in Dartsedo, the 'Shanghai of Tibet'. Cross-Currents: East Asian History and Culture Review 19: 71-121.

Wade, Geoff. 2014. 'Asian Expansions: An Introduction'. In Asian Expansions: The Historical Experiences of Polity Expansion in Asia, edited by Geoff Wade, 1-30. London: Routledge.

Yeh, Emily T. 2013. Taming Tibet: Landscape Transformation and the Gift of Chinese Development. Ithaca, New York: Cornell University Press.

Yeh, Emily T., and Chris Coggins, eds. 2014. Mapping Shangrila: Contested Landscapes in the Sino-Tibetan Borderlands. Seattle: University of Washington Press. 



\title{
4 Trade, Territory, and Missionary Connections in the Sino-Tibetan Borderlands
}

\author{
John Bray
}

\begin{abstract}
The Missions Étrangères de Paris (M.E.P.) operated in the Sino-Tibetan border region of Kham between 1847 and 1952. The missionaries' prime objective was of course religious, but the division between spiritual and this-worldly aspirations was rarely straightforward. In practice they had to engage with secular rulers, if only to secure the political protection they needed to preach freely. Similarly, they could scarcely avoid entanglement in economic affairs, including trade. This essay discusses the M.E.P.'s involvement with trade as a means of shedding light on wider historical developments in the region in the second half of the nineteenth century.
\end{abstract}

Keywords: Kham, missionaries, Missions Étrangères de Paris, Tibet, trade

\section{Introduction}

In March 1848, a suspicious-looking trader turned up in the eastern Tibetan town of Chamdo. Uncertain of his identity, the Chinese civil mandarin summoned him for interrogation. In the face of detailed questioning, the stranger decided that he had no option but to admit that - contrary to his

Acknowledgements: I gratefully acknowledge the support of the staff of the Archives Diplomatiques de Nantes and the M.E.P. archive in Paris, especially the late Fr. Gérard Moussay, Brigitte Appavou, and Lucie Perrault. I thank Stéphane Gros and Yudru Tsomu for their helpful comments on an earlier draft of this paper.

Gros, Stéphane (ed.), Frontier Tibet: Patterns of Change in the Sino-Tibetan Borderlands. Amsterdam, Amsterdam University Press 2019

DOI: 10.5117/9789463728713_CHO4 
disguise as a Chinese merchant - he was a French national and that his 'trade consisted of selling, without money, the doctrine that leads to heaven'.

The 'trader' was Fr. Charles Renou (1812-1863), a Roman Catholic priest in the service of the Missions Étrangères de Paris (M.E.P.). On this occasion the Chinese authorities forced him to leave Chamdo and turn back to Guangzhou and then Hong Kong. However, he later succeeded in establishing a mission in the Tsarong region of southern Kham, under Lhasa's authority. His successors were expelled from Tsarong in 1865 but were later able to set up a chain of missions in the Sino-Tibetan border areas of Sichuan and Yunnan and maintained a presence there until 1952. Together with their Protestant counterparts, they spent longer periods in the region than any other category of Westerner. This extended engagement qualifies them both as 'participants', intensely involved in local affairs, and as 'observers' whose testimony constitutes a vivid and informative historical source for borderland history. ${ }^{2}$

Founded in 1658 , the M.E.P. was by the mid-nineteenth century enjoying a period of revival and growth. ${ }^{3}$ Its prime objective was of course religious: to share the 'doctrine that leads to heaven'. Indeed, the Monita ad Missionarios (Instructions to Missionaries), which were issued in 1665 and serve as one of the M.E.P.'s foundational texts, explicitly call on missionaries to avoid the slightest taint of commerce (Bousquet 2010, 180). However, the division between spiritual and this-worldly aspirations was rarely straightforward. In practice, M.E.P. missionaries had no choice but to engage with secular rulers, if only to gain access to land and to secure the political protection that they needed to preach freely. By the same token, they could scarcely avoid entanglement in economic affairs, including trade.

In this essay I adopt the theme of nineteenth-century French missionary involvement with trade as a 'prism' or 'lens' through which to shed light on wider historical developments in the Sino-Tibetan borderlands. The essay draws on original sources in the M.E.P. and French diplomatic archives, and is further informed by contemporary missionary publications as well as a range of more recent scholarship. ${ }^{4}$ To set the scene, I begin with a broad

1 Renou to M.E.P. Directors, 28 December 1848. Cited in Launay (1905, vol. 1, 81).

2 For a study of French missionaries' role as 'incidental ethnographers' in a neighbouring region, see Michaud (2007).

3 For a selection of recent reviews of the M.E.P.'s history, see Guennou (1986), Moussay (2008), and Marin (2010).

4 The most important of the missionary publications is Launay's two-volume, Histoire de la Mission du Thibet (1905). Launay was himself an M.E.P. priest. His work is scrupulously documented with references that can still be used as a guide to the M.E.P. archives. I have also 
review of power structures and trade networks in eastern Tibet before examining the M.E.P.'s experiences and observations in greater detail.

\section{The Setting: Interlocking Power Structures and Regional Trade Networks}

The M.E.P.'s engagement with Tibet came as a result of an appeal by Mgr. J.-L. Borghi, an Italian Capuchin bishop based in India who led the so-called Hindustan-Tibet Mission (Launay 1905, vol. 1, 65). In 1707 the Capuchins had established a mission in Lhasa, the capital of Tibet, but they were expelled in $1745 .{ }^{5}$ Ever since, they had retained formal ecclesiastical jurisdiction over Tibet but were short of resources in India, let alone north of the Himalaya. Knowing that the M.E.P. had established missions in Sichuan and Yunnan, Borghi suggested that it should take over responsibility for Tibet.

In 1846 the Vatican ratified this proposal with the establishment of the Apostolic Vicariate of Lhasa - also known as the Vicariate of Tibet - which was to be managed by the M.E.P. The vicariate was intended to cover the territories administered by Lhasa and, as will be seen, later came to include ethnic Tibetan regions in the Sino-Tibetan borderlands. In their writings the missionaries distinguished between 'the kingdom of Tibet' or 'Tibet proper' (Thibet proprement dit), meaning the territories controlled by the Ganden Phodrang administration in Lhasa; and 'Chinese Tibet', referring to the Tibetan chiefdoms or polities located in Sichuan and Yunnan. They rarely referred to 'Kham' except in discussions of the history and administrative structure of the region. ${ }^{6}$

At the outset, the M.E.P. was familiar with conditions in the main centres of Sichuan and Yunnan, but not with the border regions and still less with central Tibet. Their first challenge was therefore to understand the political landscape. As the M.E.P. quickly discovered, the Ganden Phodrang, the Tibetan administration in Lhasa, exercised a high degree of autonomy. Nevertheless, the Qing administration employed a parallel and overarching network of officials not only in Lhasa but also in regional centres such as

benefitted from more recent scholarship, especially Coleman (2014), Deshayes (2008), and Gros $(1996,2001,2016)$. See also my own earlier articles on the M.E.P. in Kham (Bray 1997) and on Christian missionaries and Tibetan trade (Bray 2014).

5 On the Capuchins' eighteenth-century mission in Lhasa, see Petech (1952-1957) and Engelhardt (2005).

6 For example, Desgodins discussed the eighteenth-century division of Kham province in a chapter on the geography of Tibet (Desgodins 1872,165 ). 
Markham and Chamdo. In its attempts to establish a foothold in Tibet, the M.E.P. would need to deal with both sets of officials. A similar pattern applied in the border regions of Sichuan and Yunnan where local chiefs enjoyed varying degrees of local autonomy while acknowledging the ultimate authority of the Emperor (see the Chronology of Major Events, this volume).

In their dealings with Tibetan and Qing officialdom, the M.E.P. would try to leverage their support of the French government. As will be seen, this approach was double-edged. Even the anti-clerical elements in the Paris establishment believed that Catholic missions could be a valuable instrument of French diplomacy. ${ }^{7}$ However, French government support would often fall short of the missionaries' expectations. A still greater problem was the Ganden Phodrang's fear of British expansionism from India. The M.E.P. missionaries emphasized that they were French, not British. The significance of this distinction was lost to many of their Tibetan interlocutors.

At the local level, overlapping political power structures were underpinned by an equally complex set of economic networks. As will be seen, the missionaries were to have no great difficulty in acquiring land to provide livelihoods for their followers, at least temporarily, because landholders were keen to encourage cultivators to settle in their regions. The greater problem was to establish a secure title to their land once they had acquired it.

For local landowners, the scarcest economic resource was not so much land as the labour needed to cultivate it. Taxes were paid in kind, in silver and through a variety of corvée labour obligations, especially transport labour. The difficulty of meeting these demands meant that it was all too easy for ordinary peasants to fall into debt to local landowners or to monasteries. Debt obligations could well lead to one of several different forms of servitude, including local forms of slavery (Gros 2016). Alternatively, peasants might flee the land altogether. In 1857 Renou wrote:

Taxes and corvée labour beyond the capacity of the people have obliged entire villages to leave their homelands, especially in Chinese Tibet, and the land has remained fallow. This class of men who have left their land have lost their civil rights. They form great bands of mendicants who travel in caravans, forcing villages to give them alms, and they are not without danger for the traveller who encounters them in the middle of the desert. ${ }^{8}$

7 On this point see Young (2013).

8 Renou to Count de Courcy, French chargé d'affaires in China at Macao, Tsarong, 26 July 1857. Archives Diplomatiques de Nantes (hereafter A.D.N.), Pékin 37. I am responsible for this and subsequent translations from the French. 
The missionaries believed that one of their key tasks was to protect their followers from this kind of fate.

Outside the monasteries, the majority of the region's inhabitants depended on a combination of agriculture and pastoralism, supplemented by trade. As in other regions on the edge of the Tibetan plateau, local and regional trade typically consisted of the exchange of salt, butter, and other produce from the higher regions in return for agricultural produce from the valleys. Trade was rarely 'free' in the sense that it was typically underpinned by a complex framework of labour obligations. To cite one example, also reported by Gros $\left(2016,15^{2}\right)$, Desgodins described how Tibetans from Tsarong exchanged salt for grain with the Nung, a non-Tibetan ethnic group in the neighbouring Salween valley (C.H. Desgodins 1872, 323). The Nung had to carry 500 to 600 loads of salt from Tsarong every year free of charge, and then exchange it at a pre-determined non-market rate of five loads of cereals for one of salt.

The most important long-distance trade was in tea along the route from Dartsedo via Lithang and Bathang to Lhasa. Tea was of considerable economic and strategic importance to the Qing authorities and to the trading houses (guozhang) of Dartsedo (Yudru Tsomu 2016). Many of the leading Buddhist monasteries served in effect as trading houses in their own right, although there was often an element of compulsion in their sales practices. As Bishop Félix Biet (1838-1901) noted in 1893:

With little respect for the law of supply and demand, the monastery is in effect able to impose the sale of its products on its clients, even against their will. When it has a stock of tea to place, it divides it among rich families in accordance with their wealth and obliges them to take delivery, either in cash or on credit. It is an obligatory purchase - but not free of charge (cited in Groffier 1893, 141).

However, as Renou reported in 1857 , tea was by no means the only medium and long-distance trade item:

English cotton goods are spreading more and more in Tibet. Crockery and many other European objects, introduced by the Nepalis above all, are beginning to present a considerable competition for China. For a long time India has supplied Tibet with pearls, coral and sea-shells. Russia also sends cloth there. ${ }^{9}$ 
Figure 4.1 Chinese coolies carrying tea to Dartsedo

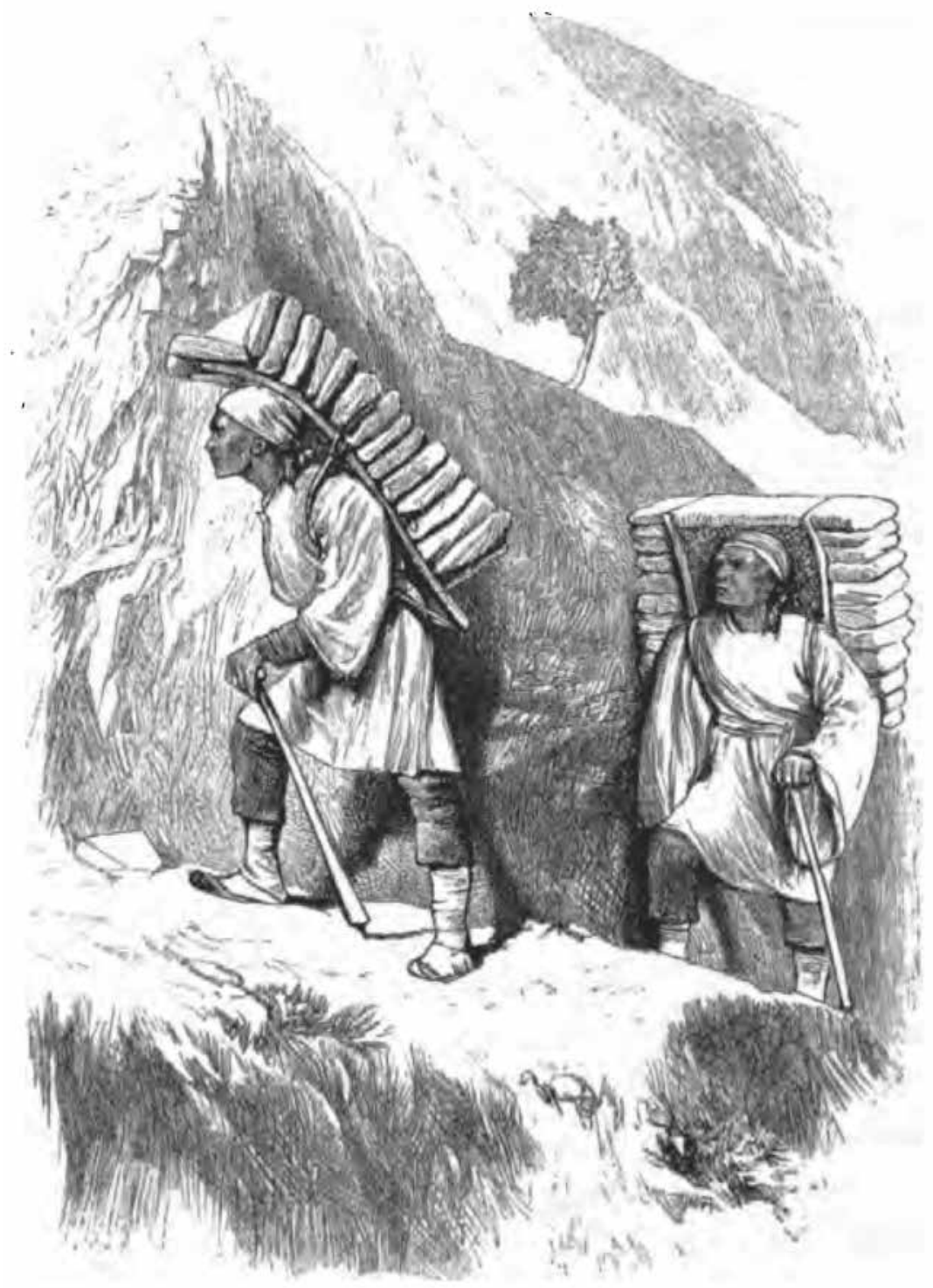

Source: Cooper $(1871,201)$ 
In the same letter, he noted that the British were also having an impact on the musk trade:

What was regarded as the best quality [of musk] was provided by savage tribes, situated to the east of Assam, among them the No-kong, who come each year to Dza-yul to exchange the produce of their country for cloth, chaudières ${ }^{10}$ and agricultural tools. However, since the English have become masters of Assam, these savages prefer European cloth and rupees, and they have begun to sell them their musk directly, and no longer bring so much to Tibet as in the past.

In the 1850 on and 1860 os most local and regional trade took place through barter. However, tea was also widely used as a form of currency, supplemented by silver. Since the early eighteenth century, the Chinese had imported silver often in the form of ingots - to pay its military garrisons in Lhasa and other towns along the main trade routes. Silver ingots were also in circulation in Tsarong in the 1850 s, and used to pay taxes although they were often in short supply. In later decades, as Relyea (2016) has pointed out, the circulation of British rupees increased enormously in Tibet and as far as western Sichuan.

Throughout the period under review, European economic influence was expanding, and this was an important part of the backdrop for the M.E.P.'s activities. At the same time, as pointed out by Yudru Tsomu (2016) and C. Patterson Giersch (this volume), indigenous Tibetan trading houses from Dartsedo and Chinese merchants from Shaanxi and Yunnan were expanding their own networks. The M.E.P. missionaries set themselves the task first of understanding these developments and then - where possible - turning them to the mission's advantage.

\section{Trade, Exploration and Information-Gathering}

When Renou began his explorations of eastern edge of the Tibetan plateau in 1847 , his immediate preoccupation was to work out where to establish the first missionary outpost. From the outset, he made a close study of Sino-Tibetan trade networks as a vital source of intelligence. In his travels, he chose the disguise of a trader because Christian missionary activity was still severely restricted in the interior of China in the 1840s. It would be going

10 The dictionary definition is 'boiler' or 'heater'. Here the word perhaps refers to pots and pans. 
too far to say that his disguise placed him beyond suspicion. The fact that he was able to attempt it at all testifies both to his Chinese language skills and to the rarity of Westerners in the Sino-Tibetan borderlands in that period.

At the outset, Renou argued that the M.E.P. should place a missionary in Dartsedo, which lay within the borders of Sichuan, because it would be the most favourable post for communicating with eastern Tibet. ${ }^{11}$ However, when he arrived there in September 1847, he noted the presence of a large number of Qing officials. He therefore travelled on to Bathang, and then via Markham to Chamdo, both of which lay within the territories administered by the Ganden Phodrang.

Renou's 1848 expulsion from Chamdo at the hands of a Qing official raised questions about the extent and nature of China's authority in Tibet (here referring to the territories administered by Lhasa). At this time Renou argued that if the Chinese could expel a Frenchman from Tibet, it would be necessary to 'accord them the same rights for the kingdoms of Ava, Siam, Cochin-China and others who are subject to them on the same footing as Tibet and Bhutan'. ${ }^{12}$ However, even with the support of the French legation, the M.E.P. was unable to persuade the Qing authorities to accept the argument that Tibet was in effect an independent country. The outcome was a diplomatic stalemate: the Qing administration gave no clear explanation of the nature of their political authority in Tibet. At the same time, they insisted that there was no possibility of Renou being allowed to return there. ${ }^{13}$

In late $185_{1}$ Renou once again disguised himself as a merchant to resume his explorations, this time from Yunnan. By April 1852, he reached the Dali region where he learnt of the regular Tibetan pilgrimages to Mount Jizu, known from its shape as the 'chicken foot mountain'. He also learnt of a local fair which was visited by Tibetan merchants in the third and ninth months of the Chinese lunar calendar. Renou sent two Chinese servants - likewise disguised as traders - on a reconnaissance of the Yunnan/Tibet borders. ${ }^{14}$ They brought back a favourable report, and he decided to follow the same route.

At this point, he sent a request to Rome asking for special dispensation to engage in trade in the light of the M.E.P.'s ban on commercial activity. ${ }^{15} \mathrm{His}$ plea was based on the argument that he needed trade goods to support his

11 Renou to M.E.P. Directors, 29 April 1849. Cited in Launay (1905, vol. 1, 74-75).

12 Renou to the French minister, Hong Kong, 14 December 1848. A.D.N. Pékin 37.

13 See Launay (1905, vol. 1, 88-97) for an account of the arguments on both sides. In Launay's view the outcome was not so much a stalemate as a defeat for French diplomacy.

14 Renou to Directors, Dali, 3 July 1852. Archive des Missions Étrangères de Paris (hereafter A.M.E.P.) 556 , p. 304.

15 Ibid. 
disguise as a merchant. Moreover, the regions in which he hoped to travel were scarcely monetized and most exchanges therefore took the form of barter. Communications with Europe were slow: it would have taken several weeks for Renou's letter even to reach the Chinese coast. Rome eventually granted Renou's request, although he did not receive the confirmation until well after his return to Dali. ${ }^{16}$

On September 1852, Renou set out again, accompanied by a small group of Chinese Christians. A few weeks later, he arrived at the monastery of Döndrupling, where he displayed the goods that he had to sell, mainly cloth. One of the more unusual items in Renou's baggage - a telescope - piqued the curiosity of the monastery's incarnate lama. Renou at first explained that the telescope was not for sale, but then agreed to offer it in exchange for Tibetan lessons. ${ }^{17} \mathrm{He}$ subsequently spent ten months studying at the monastery. He did not fit the characteristic mould of a Chinese trader because - while it was understandable that he might wish to learn spoken Tibetan - it was more unusual that he wished to study Tibetan written texts, and even the niceties of Buddhist philosophical terms. However, it seems that he was not identified as a European, at least not conclusively.

After returning to the Dali region, Renou outlined his proposal to establish a foothold in territory under Lhasa's administrative control in a letter to Paris in February 1854. Among other details, he proposed to engage in a different kind of trade: the purchase of child slaves in order to bring them up in the Christian faith. ${ }^{18}$ He noted that the 'misery that reigns in the lower classes' meant that parents were frequently obliged to sell their children to pay their debts. In the future such children could serve the mission by sharing their faith with their compatriots.

In March 1854, Renou set out again. This time his route took him to the monastery of Changputong on the bank of the upper Salween River, where he again made friends with the incarnate lama. He stayed for another three months, continuing his study of Tibetan, but still in his guise as a merchant:

As for my trade, the pretext for my stay in Tibet, this was easy to conduct because the lama, while saying nice words to us, prevented his subjects from buying or selling anything, whatever it might be, reserving the monopoly for himself in the belief that it must be very profitable for him.

16 See Launay $(1905$, vol. 2, 394) for the Latin text of the decision by the Propaganda Fide, dated 4 May 1853.

17 Renou to the M.E.P. directors, 3 December 1852. Cited by Launay (1905, vol. 1, 206-207). 
Poor lama! Prophet though he claimed himself to be, he scarcely perceived what kind of trade I had come to conduct in his country! ${ }^{19}$

Here he heard of possible land to rent on the far side of the river, just inside the Tsarong district of Tibet proper. Making the acquaintance of Tsewang, one of the richest people in the region, he agreed to lease land in Bonga. Bonga was not a mere patch of land but an entire valley. In the past it had been cultivated by Nung farmers, and had produced good harvests of wheat. However, they had been forced to cede the land because of heavy debts to Tsewang, and had ultimately withdrawn, leaving the land uncultivated.

\section{A Foothold in Southern Kham}

Renou's acquisition of land in Tsarong meant that he had at last established a base in 'the kingdom of Tibet': Tsarong was in the district of Menkong which was itself part of a wider region administered from Markham within the part of Kham under the authority of Central Tibet. In Markham there was a small Qing military garrison. Ironically, in view of subsequent events, Renou at first believed that he was safer in Tsarong than in China where Christianity was still officially forbidden. ${ }^{20}$ The Chinese legal code did not extend as far as Tibet and, according to Renou, no one had thought of banning Christianity there.

Renou had also crossed the boundary from being a pretended merchant to becoming a farmer. At the same time, he changed from being a mere observer of Tibetan life to becoming a full participant, including in local trade. He of course brought with him the attitudes and aspirations of a European outsider, and a Catholic missionary at that. However, in putting his plans into practice, he had to adapt to the social as well as the geographical constraints of the environment in which he worked. It would be too much to claim that he became in any way 'Tibetan'. However, his overall approach may have been more indigenous than he himself realized.

Having acquired the land, Renou now had to consider the greater challenge of securing an adequate labour supply. He addressed the problem in three ways. First, he imported labourers from Yunnan: these included Chinese Christians who were to form the core of the new community, as well as craftsmen who would help construct the mission buildings. Secondly, as

Renou to Count de Courcy, 26 July 1857. A.D.N., Pékin 37. 
he had planned, he purchased orphans with a view to building up a Christian community for the future. Thirdly, he hired labourers from the local villages to clear trees to make room for cultivable land. Meanwhile, he was joined by a fellow-missionary, Jean-Charles Fage (1824-1880).

The missionaries also needed to buy necessities such as grain, salt, and butter, and this was another important point of contact with neighbouring villages. In the first instance they paid for these goods by bartering cloth and other trade goods from Yunnan. However, as Renou explained, there was a local shortage of silver, which was needed to pay taxes. The result was that their neighbours were reluctant to supply the missionaries and their followers unless they gave silver in return. ${ }^{21}$

In 1857, encouraged by Renou's reports of the new missionary outpost in Bonga, the M.E.P. appointed Jacques Thomine-Desmazures (1804-1869) to serve as the first Bishop of Tibet. It also sent a group of younger missionaries to serve as reinforcements. However, the mission did not develop as they had hoped. In September 1858 Tsewang announced that he wished to regain possession of Bonga, and turned up with a band of thugs to expel the missionaries. This episode set in motion a chain of events that brought the mission to much greater official attention in both Lhasa and Beijing. ${ }^{22}$

According to Fage, economic considerations were among the factors leading to attacks on the mission:

I am convinced that we would not have been attacked if our financial resources had permitted us to continue our trading, especially at a time when silver is very rare in Tsarong. The people who earlier found silver only in Bonga would not have wished to oppose us, in the hope that they would still have the means through us to pay their taxes and debts. Only, we had almost no silver left - approximately 200 taëls at the beginning of $1858 .{ }^{23}$

At this point, Thomine-Desmazures decided that it was time for the mission to adopt a much more public stance and to seek overt French diplomatic support. An important factor in this decision was Article 8 of the 1858 Treaty of Tianjin, which declared that Christian missionaries were entitled to the protection of the Chinese authorities. Contrary to their earlier argument that Tibet enjoyed a similar status to Siam, the M.E.P. now argued that it

21 Renou to Libois, 20 August 1856. Cited by Launay, (1905, vol. 1, 51).

22 See Launay (1905, vol. 1, 316-383) and Deshayes $(2008,57-64)$ for more detailed accounts. See also Gros (1996) and Bray (1997).

23 Fage to Libois, 8 August 1859. Cited in Launay (1905, vol. 1, 317). 
was directly subject to Chinese rule. Missionaries therefore enjoyed the same right to Chinese protection in Tibet as they did in China proper. In pursuit of this claim, and flying the French flag as a mark of official status, Thomine-Desmazures marched via Dartsedo and Markham to Chamdo.

During this period, Thomine-Desmazures sent two Chinese Christian merchants to Lhasa to prepare the way for the missionaries (Launay 1905, vol. 1, 371). However, the Ambans expelled them on the grounds that, since they were Christians, they must be in contact with the French and the British. They were forced to leave the capital before they had had an opportunity to sell their merchandise, and they suffered a loss of 2,00o taëls.

In Chamdo the missionaries negotiated with representatives from the Lhasa and the Qing administrations while drawing on long-distance support from the French legation in Beijing. The eventual outcome in 1862 was that the Qing and Tibetan authorities formally acknowledged the M.E.P.'s title to Bonga, and even promised to punish Tsewang for his aggression. However, the missionaries were obliged to accept that they could not now travel to Lhasa, ostensibly because it was not safe to do so. It was clear that the assent of both the Qing and - still more - the Lhasa authorities was at best lukewarm.

In the short term the perception that the missionaries had access to political as well as spiritual power contributed to a series of conversions first of the entire village of Songta close to Bonga, and then of a series of other villages and hamlets. However, such interventions threatened to disrupt local religious and political power structures. The missionaries forbade their converts to make grain contributions to local monasteries, to whom they were often in debt, in return for their prayers. In 1863 the monastery of Menkong responded by demanding immediate repayment of an enormous debt from the recently Christianized village of Aben (Launay 1905, vol. 1, 401).

Renou's death in late 1863 deprived the mission of its most forceful leader at a time when it had become acutely vulnerable. In 1864 a decree issued with the Dalai Lama's seal stated that Lhasa had learnt that the religion of the heretics (mou-ti-pa in the French transcription, probably mutekpa) had been introduced in the region: local officials and monasteries were charged with stamping it out. ${ }^{24}$ The ultimate outcome was that in 1865 , the missionaries were forced to leave Tibetan territory altogether, along with the followers who remained loyal to them. One of the missionaries, Gabriel Durand (1835-1865) was killed, as were several converts.

In their analysis of these events, the M.E.P. complained that the French legation in Beijing failed to give them the wholehearted support that they 
had hoped for. ${ }^{25}$ This complaint was partially justified inasmuch as the legation judged that the Qing authorities in practice exercised limited authority in Tibet, particularly on religious matters. It was therefore both impolitic and impractical to press them too far. The M.E.P.'s argument was now that the Qing had both the authority and the power to protect the missionaries inside Tibet proper, but chose not to do so.

\section{Regrouping in Sichuan and Yunnan}

After their expulsion from Tsarong, the M.E.P. missionaries regrouped in the border regions of Sichuan and Yunnan. In December 1865, Bishop Joseph Chauveau (1816-1877), who had now taken over the leadership of the mission, reaffirmed that the Apostolic Vicariate of Lhasa extended as far as the borders of Kashmir (Launay 1905, vol. 2, 21). However, for the time being, he forbade his missionaries to enter 'Tibet proper'. Instead, while waiting for happier days, they should establish themselves as firmly as possible 'in the country where Chinese authority exercises a more or less decisive influence' (ibid.). He therefore applied to the Vatican for the formal transfer to the Tibet vicariate of fourteen 'principalities' from Sichuan, including Bathang, Lithang, and Chakla (including Dartsedo); as well as four 'towns' from Yunnan, including Adunzi (Deqin). In 1868 the Vatican duly gave its assent (Launay 1905, vol. 2, 29, 396) (see Map 4.1).

The M.E.P's strategy of appealing for the Qing government's protection was based on the Treaty of Tianjin. However, in the borderlands as in 'Tibet proper', the missionaries needed to deal with parallel and often overlapping authorities. In practice, the power of local Qing officials was constrained by poor communication lines to the main centres of authority in Chengdu and Kunming (then known as Yunnanfu), let alone Beijing. Meanwhile, indigenous rulers continued to exercise a high degree of local autonomy, although their positions and status were now formally confirmed by the Qing. The two depas of Bathang are an example. In 1648 the Fifth Dalai Lama appointed the original holders of these posts to collect taxes for a fixed three-year term (Coleman 2014, 49). However, their positions soon became hereditary and, by the time the M.E.P. entered the region, they stood at the apex of a local hierarchy of Kham Tibetan aristocrats whose status was likewise hereditary. The depas had their own trading interests which were supported by rights to corvée labour.

25 I discuss the issues in greater detail, drawing on French diplomatic archives, in Bray (1997). See also Launay (1905, vol. 2, 31-66) and Deshayes (2008, 64-73). 
Map 4.1 The principal M.E.P. mission stations in the Sino-Tibetan borderlands, c. 1900

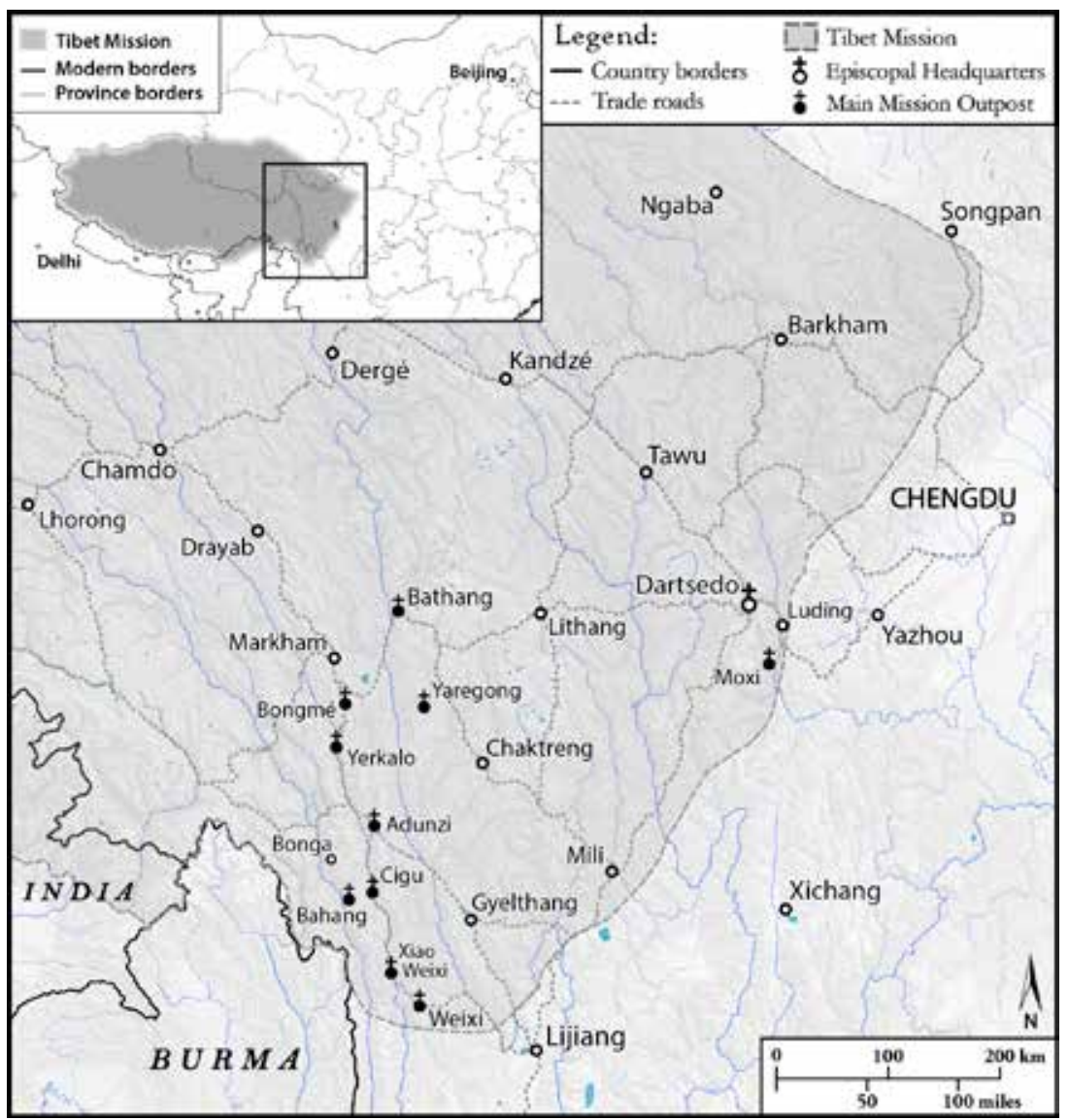

Sources: Based on Desgodins (1872); Launay (1905); SRTM (NASA) and modern administrative borders extracted from GADM database (www.gadm.org, v.2.5 July 2015)

Authors: Rémi Chaix and John Bray

The role of the Buddhist monasteries was a further complicating factor. Again, Bathang is an example. Ba Chöde was the leading local monastery. Since the mid-seventeenth century it had belonged to the Geluk and was therefore closely aligned with Lhasa spiritually and politically. It was also a major regional landowner, possibly administering as much as 40-50 per cent of land in the Bathang district (Coleman 2014, 33, 36-37). Like the depas, the monasteries had their own trading interests.

For the M.E.P. good lines of communication were as important as ever, and Chauveau established his headquarters in Dartsedo because of its status as a 
regional trading centre. For similar reasons, the M.E.P. established outposts at Bathang and at Adunzi in the same period. However, the majority of their stations were more agricultural in nature. Beyond their primary religious objectives, the missionaries' main preoccupation was to provide security and livelihoods for their followers. In this phase of their activities, they no longer needed to disguise themselves as traders or to undertake major trading activities in their own right. However, they continued to depend on regional trading networks for their own logistical support. At the parochial level, their role was to create a secure environment where their followers could engage in local trade as a supplement to their farming. In this they were partially successful, but life remained precarious for their Christians converts, as it did for their Buddhist neighbours.

Yerkalo serves as an example of the challenges. Then lying just inside Sichuan on the slopes above the banks of the river Mekong, Yerkalo is known in Chinese as Yanjing (literally 'salt well') and famous for its salt production, a prime trade item. ${ }^{26}$ The Catholic parish there was originally founded by Biet and Auguste Desgodins (1826-1913) following their expulsion from Tsarong. In 1870 they were able to acquire some abandoned fields in Yerkalo on a $5^{0}$-year rent. ${ }^{27}$ They and their successors gradually built up the settlement so that by the 1880 s it amounted to a substantial Christian village consisting of 21 families (104 people), together with 21 houses as well as stables and barns. ${ }^{28}$

In principle, the salt trade should have been a source of wealth in good years, and an economic safety net in years when harvest yields were poor. However, in practice many of Yerkalo's inhabitants endured no more than a precarious existence. In part this is because of the conditions under which salt was traded. Every year each of the two Bathang depas sent four official salt collectors to the region (Soulié 1904, 103). They had the right to free accommodation and sustenance during their stay of two to three months, and the local people had to carry the salt free of charge to Bathang. In addition, the officials compelled people to buy tea at three to four times the market price. The economic benefits of the salt trade therefore accrued not so much to the local inhabitants as to regional officials. The nineteenth-century village traders of Yerkalo were far from having the economic power of the midtwentieth-century Khampa traders described by Lucia Galli (this volume).

26 Due to twentieth-century boundary changes, Yerkalo now falls within the Tibet Autonomous Region and is no longer part of Sichuan. For an account of the techniques of salt production, see Desgodins (1872, 293-297).

27 Francis Goré (1880-1954). A.M.E.P. Typescript papers. Une mission thibétaine (Yerkalo). Éphémérides de Notre Dame de Sacré-Coeur 1865-1922.

28 Ibid. 


\section{Advocating British Indian Trade with Tibet}

Already in 1865 , feeling 'abandoned' by the French mission in Beijing, Desgodins had suggested that the M.E.P. should seek aid from the British. ${ }^{29}$ Later on, he and other missionaries suggested that the British might be instrumental in opening up Tibet, either through political or military means, or through trade. They therefore took all possible opportunities to lobby the British on the benefits of commercial engagement with Tibet.

One such opportunity came in 1868 , when a young Englishman called Thomas Thornhill Cooper (1839-1878) travelled to Dartsedo and Bathang. Cooper claimed to be acting on behalf of the Shanghai Chamber of Commerce, which was interested in potential new trade routes in southwest China, and he hoped to travel via Lhasa to India or, alternatively, to travel south via Adunzi to Burma. Cooper benefited from the M.E.P.'s logistical network at every stage of his journey. For example, while still travelling up the Yangtze, he mentions meeting a 'Catholic Mission Agent', whom he describes as a wealthy merchant engaged in an extensive trade with Sichuan (Cooper 1871,39). He needed to deal with this merchant to arrange funds for his onward journey to Chongqing.

Similarly, in Bathang Cooper mentions that he met a Chinese merchant who was 'the writer, or chief man of business of the missionaries' (Cooper 1871, 261). Together with his brother, this man had owned a 'drug shop' in Lhasa, but they had been expelled because they were Christians. Cooper does not mention this man's name, but he may have been one of the two merchants whom Thomine-Desmazures had sent to Lhasa in 1862. Apparently, he hoped that Cooper would indeed travel to Lhasa, where he would be arrested and maltreated by the Tibetan authorities. This in turn would provoke British intervention which would benefit the mission and at the same time enable him to recover his business. In the event, Cooper disappointed the merchant by travelling to the south instead of via Lhasa. However, he was forced to turn back before he could reach Dali, let alone the Burmese border. Despite this defeat, he was full of praise for the M.E.P. missionaries who had assisted him throughout his journey.

While still en route, Cooper (1868) wrote a letter to the Royal Geographical Society in London, including a set of 'Notes on Thibet, by a French missionary', probably Desgodins. This includes a discourse on the prospects for sales of Indian tea in Tibet. Cooper returned to this topic in his subsequent book, noting the likelihood of political opposition from the Chinese authorities and the Tibetan monasteries: 
Figure 4.2 Tibetan Inn in Dartsedo

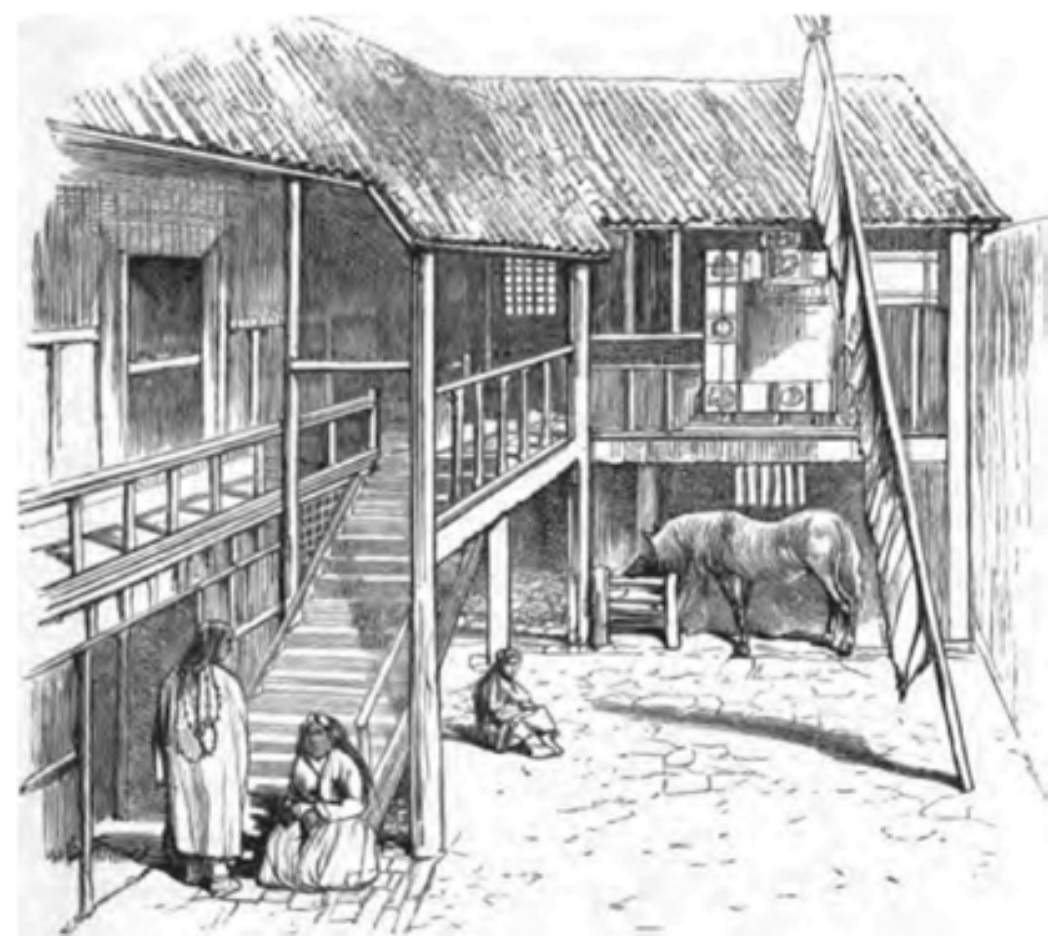

Source: Cooper $(1871,204)$

The Chinese on their part dread the loss of their valuable wholesale monopoly, to maintain which they give the Lamas the monopoly of the retail supply; who by this means, hold in absolute subjection the people, to whom tea is a prime necessity of life. The Lamas, on their part, fear that with the introduction of British trade, the teachers of the new religion would come, and free trade and free thought combined would overthrow their spiritual sway (Cooper 1871, 263).

The book concludes with a memorandum by 'an old resident in China', almost certainly a French missionary. This pays tribute to England as 'the only power on earth sufficiently rich and strong enough to rely together China, Thibet and India', and calls for the establishment of English factories (i.e. trading posts) in Lhasa, Bathang, Dali, and Chongqing.

The M.E.P. likewise offered practical assistance to Captain William Gill (1843-1882), a second British traveller, who travelled to Dartsedo in 1877 
and - unlike his predecessor - succeeded in making the overland journey to Burma. For example, Gill notes that the missionaries helped him gather a supply of British Indian rupees, which were the most convenient currency in southwest China and Tibet: ${ }^{30}$

At the time of our visit, we found it difficult to obtain a large number of rupees; for the embassy that had just arrived from Peking, and was on its way to Lassa, had bought them all up; but Monseigneur Chauveau contrived to find ten thousand for us among his friends and acquaintances. (Gill 1883, 171)

In 1878 , a third British traveller made his way to Dartsedo. This was Edward Colborne Baber (1843-1980), an official in the China Consular Service. According to Launay (1905, vol. 2, 143-145), Baber hoped to become the official British Resident in Lhasa. In pursuit of this ambition, he was assiduous in collecting economic information, and repeatedly plied Biet with questions on the price of tea and cloth in local markets. Although Baber's report makes no reference to M.E.P. sources, it repeats many of the same arguments that they had put forward:

To the Tibetan, tea is more than a luxury, it is an absolute necessary. Deprived of the costly, but indispensable, astringent, he suffers from headache, grows nervous, restless, out of condition, and altogether unhappy. (Baber 1882, 198)

In 1880 Biet sent Desgodins to India where he eventually established an outpost of the mission at Padong, near Kalimpong and close to the southern borders of Tibet. In 1883, in response to a request from the M.E.P., the Vatican formally attached the eastern part of Darjeeling district to the Tibet vicariate (Launay 1905, vol. 2, 184, 404). It also included the Chumbi valley (an outpost of Tibetan territory between Sikkim and Bhutan) and Tawang (now in the Indian state of Arunachal Pradesh but claimed by China). From Desgodins' perspective the references to Chumbi and Tawang were welcome but not strictly necessary because these were in any case part of Tibet and therefore within the mission's original mandate.

Desgodins made extensive contacts in British official circles and published a pamphlet on A Tea Trade with Thibet at the expense of the Bengal Government Secretariat. Writing as though from a British perspective, Desgodins argued that there was an 'export tea market at our doors'. The 
pamphlet goes into some detail on the different types of tea and how they are made. It also discusses the political economy of the trade, including the role of officials acting in a private capacity, and taking advantage of corvée labour:

When Chinese mandarins in charge of the troops and of the Lamas' pay [italics in the original] receive their allowance, they generally expend at Ta-tsien-loo [Dartsedo] part of the money entrusted to them in buying tea. This tea is conveyed at the expense of the people, as extra duty, and given as pay to the soldiers, and even to the Lamas, at the price current in the interior, according to the place. The conveyance having cost nothing, and the price being threefold or fourfold higher than at Ta-tsien-loo, the mandarins realise by this means considerable profits for themselves, in which the Government does not participate. (Desgodins c.1881, 13)

The pamphlet concludes by expressing the view that the tea trade might be the means by which 'the people of Thibet would learn to appreciate and wish for the more enlightened rule with which India is blessed' (Desgodins c.1881, 14). However, on a strictly practical note, he argued that success could only be achieved 'by offering to our customers what they want: tea prepared to suit their tastes' (Desgodins c.1881, 16).

Desgodins' recommendation that Indian tea planters should provide Tibetan customers with what they wanted seems obvious but it was never achieved. The Chinese authorities continued to oppose the Indian tea trade, but their objections were not the only obstacle. The Tibetans did not like the taste or quality of Indian tea and, as Booz (2011) points out, British tea planters had little enthusiasm for the Tibet market. Sales to England were expanding in any case, and there was therefore little incentive to embark on an alternative project that seemed new and strange. Desgodins and his colleagues hoped that Catholicism would follow Indian tea into Tibet. This never happened.

\section{Local Repercussions of International Rivalries}

In 1887 the M.E.P. faced a fresh outbreak of persecution. The epicentre was at Bathang..$^{31}$ The first major sign of trouble came in May when a crowd

31 This episode is discussed at some length, with copious quotations from original correspondence, in Launay (1905, vol. 2, 220-255). See also Deshayes (2008, 102-104). 
threw stones at the missionaries' residence, causing considerable damage. ${ }^{32}$ Tensions continued to build up over the following weeks, and in July a crowd of about a hundred peasants launched a full-scale attack on the residence. The two M.E.P. missionaries, Pierre Giraudeau (1850-1941) and Jean Soulié (1858-1905), found refuge first in the house of the second depa and then with the first depa. On 1 August they fled from Bathang and eventually reached safety in Dartsedo.

In the M.E.P.'s analysis a combination of local and international factors had prompted the attacks. In their view, the root cause was the 'hatred of the lamas', specifically the lamas of Lhasa. ${ }^{33}$ For example, they cited a set of letters issued by the 'king of Lhasa' and the three great monasteries of Lhasa that condemned Christianity and was explicitly addressed to the chiefs, monasteries, and people of Bathang (Deshayes 2008, 321-326). The secondary cause was the Government of India's decision to withdraw plans for an expedition to Lhasa to be led by the British official Colman Macaulay (1849-189o) with a view to promoting trade with Tibet. ${ }^{34}$ The Lhasa monks were strongly opposed to the proposed mission and took the decision to cancel it as a sign of weakness. Having seen off a potential British threat to the south, they believed that they could now turn their attention to the French in Kham.

At the local level, the missionaries believed that a combination of factors were in play. Their main enemy was the Ba Chöde monastery, acting on instructions from Lhasa. The people who actually attacked them were detsodunpo ('people of the seven districts'), villagers who were clients of the monastery and obeyed its orders. The assault on the mission was therefore far from spontaneous. The missionaries believed that the Qing mandarin in Bathang had the authority to stop the attacks but, motivated by a 'deaf jealousy' of the mission, had deliberately failed to do so. ${ }^{35}$ Meanwhile the two depas were caught between opposing forces, ostensibly sympathetic to the missionaries' plight, but ultimately unable to protect them.

The M.E.P. posts in Yaregong and Yerkalo - both in the Bathang domain also came under attack, and the missionaries in these stations were forced to

32 Giraudeau and Soulié to Biet, Dartsedo 1 September 1887, cited in Launay (1905, vol. 2, 228-233).

33 Procès de la Mission Catholique Française au Thibet chinois, 2 November 1893 A.D.N. Pékin

34 On Macaulay see Singh $\left(1988,205^{-210}\right)$.

35 Drawing on Qing sources, Coleman (2014) presents a rather different view of local Qing officials' position, emphasizing that their authority was far from absolute, and that they in practice needed to negotiate with local Tibetan interests in order to achieve their objectives. 
Figure 4.3 Bathang, early twentieth century

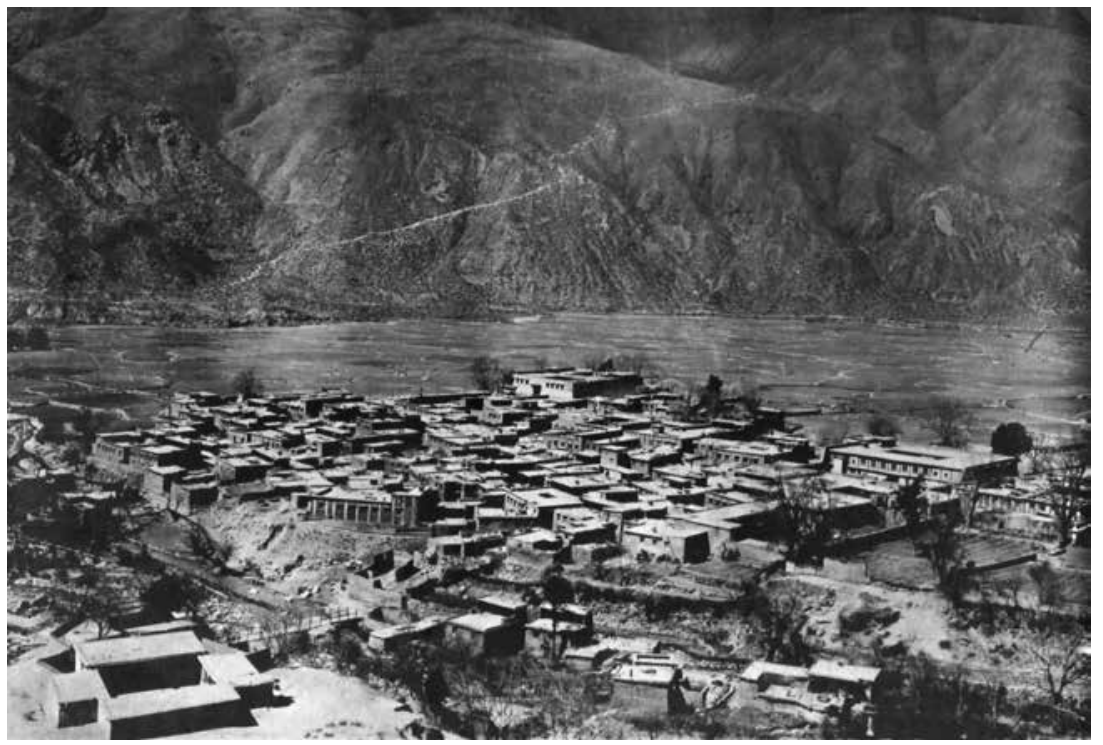

Source: M.E.P. archives, Paris

flee with their followers. In Yunnan, monks in Adunzi monastery, apparently acting in collusion with their counterparts in Bathang, likewise destroyed the local mission station. At the same time, Etienne Dubernard (1840-1905) and some 300-400 Christians were forced to flee from the nearby station of Cigu (Tsekou).

\section{Appeals to French Trading Interests}

Over the next ten years the energies of Bishops Biet and Giraudeau, who was appointed coadjutor in 1892, were almost fully taken up with the demand for reparations for the destruction of the missions. The French legation in Beijing was broadly supportive of the M.E.P. but did not always act with the alacrity that the missionaries wished.

In November 1893, hoping to boost French diplomatic support, Biet wrote a brief on the 'Industrial and commercial advantages for France prepared by the French Catholic mission'. ${ }^{36}$ The brief starts by reviewing British and Russian commercial initiatives in the region, and then points out that 
the only gateway to Tibet from Yunnan and the French colony in Tonkin would be Adunzi, a town occupied by French missionaries for 30 years. The inhabitants of the mountains and valleys regarded the French as 'friends and liberators' because of the missionaries' work in vaccinating them against smallpox. ${ }^{37}$ Dartsedo would be an alternative gateway from Sichuan and, there too, the French were held in high regard:

At very short notice, industrial and commercial France will be able to reap the benefits of the installation of her missionaries in Tibetan territory for 30 years; and the French missionaries of Tibet will always make it a pleasure and a duty to assist with the development of French influence and interests in any way possible. ${ }^{3}$

He then presented a long list of Tibetan exports including wool, yak leather, animal skins, and musk. In return the Tibetans would be pleased to purchase red, purple, and green cloth, cotton goods, camphor, aloes, quinine, knives, scissors, mirrors, musical boxes, stereoscopes, dolls, drugs, telescopes, binoculars, watches, kitchen clocks, and bridles for horses.

The M.E.P. received strong support from Frédéric Haas (1843-1915), a French diplomat who in the early 1890 s served as consul in Hankou (Bensacq-Tixier 2003, 290-294). Haas was an enthusiastic proponent of French commercial expansion, including the development of a commercial route as far as the borders of Tibet. In June 1894, Haas wrote to Biet pledging his personal devotion to the mission in his capacity as a man of faith as well as a French patriot ${ }^{39} \mathrm{He}$ recommended that, in the interests of the mission, Biet should appeal to French commercial as well as political interests. In a subsequent letter, he went so far as to offer to lead an official French mission to Bonga, and suggested that the missionaries should accompany the mission as interpreters. ${ }^{40}$ The Chinese could scarcely object to an official French mission of this nature and, having reached Bonga, the M.E.P. would then be able to take repossession of their former post.

The French expedition to Bonga never took place. However, in late 1895 Haas was appointed to serve as the first French consul of Chongqing. From there he continued to promote the idea that Yunnan qualified as the

37 As early as 1854 , Renou had written to his colleagues to apply for a supply of smallpox vaccine. Renou to Libois, 31 January 1854, A.M.E.P. 556a, 477-483.

38 Biet, Procès de la Mission Catholique Française au Thibet chinois, 2 November 1893, A.D.N.

39 Haas to Biet, 5 June 1894. A.M.E.P., 556G, 841-848.

40 Haas to Biet, 19 June 1894 . A.M.E.P., 556G, 849-856. 
commercial 'hinterland' of the French colonial possessions in Tonkin. This idea attracted a degree of support from the French colonial authorities in Tonkin, but the French never developed significant commercial interests in Tibet.

Nevertheless, Auguste Gérard (1852-1922), the French minister in Beijing, continued to give the M.E.P. political support. In 1897 he ordered Haas to travel in person to Chengdu to take up the missionaries' cause there (Launay 1905 vol. 2, 317). If necessary, he was to accompany the missionaries in person to Bathang. As noted above, Haas never went that far, but it seems that this threat of intervention at last galvanized the Sichuan authorities into taking action. They appointed Ji Zhiwen, a former Bathang civil mandarin, to take up the M.E.P.'s case. Ji quickly reached an agreement with the two depas and the Ba Chöde monastery facilitating the missionaries' return in May 1897, while offering them financial compensation.

A final settlement to the Bathang affair was signed by the two Bathang depas and the head of the Ba Chöde monastery in February 1900 (Launay 1905, vol. 2, 328-330). The settlement confirmed that Bathang natives would have all freedom to become Christians. Those who were already required to pay tribute as part of their land title would continue to do so, but no one could demand extra tribute from them because they were Christians. At the same time they would be exempt from financial or corvée labour contributions for the monasteries.

The settlement addressed the main social issues that had troubled the Tibet mission since its foundation. In that respect, it marked an end to a distinct period in the mission's history. However, it provided no more than an interim respite. In 1905 the M.E.P. was beset by an even worse calamity in the form of an uprising, starting in Bathang, that led to the murder of five missionaries, and formed part of the background to Zhao Erfeng's subsequent military campaign in Kham. ${ }^{41}$ For the purposes of this paper, these events belong to a different era.

\section{Conclusion: Global Forces and Local Responses}

Throughout the nineteenth and early twentieth centuries the M.E.P. retained the hope that they would one day be able to build a church in Lhasa. In that respect the broad contours of their vision of 'Tibet' remained unchanged: it always encompassed the whole of the territories of the Ganden Phodrang 
and, from the 186os onwards, came to include the Tibetan polities in Sichuan and Yunnan as well. Nevertheless, for the M.E.P., the political boundary between 'Tibet proper' and 'Chinese Tibet' proved to be a hard border, not a soft one. The establishment of the Padong mission in India was a reaffirmation of their dreams of reaching Lhasa, but never became more than a geographical anomaly. Although they would never have accepted the term, the 'Vicariate of Tibet' in practice became the 'Vicariate of Kham'. To take the irony a step further, it could even be argued that, by establishing his headquarters in Dartsedo, Bishop Chauveau anticipated the 1928 creation of Xikang Province, which centred on the same town (see Stéphane Gros' Introduction, this volume).

The history of the M.E.P. in the second half of the nineteenth century reflects the tensions between the missionaries' aspiration to bring Christianity to Central Tibet and their own confinement to the borderlands. In pursuit of the broader vision they promoted all possible agents of change, including advocating the Western powers' economic expansion into Tibet proper.

As has been seen, when the missionaries were the only Europeans in Tsarong in the 1850s, Renou was already able to report on the effects of growing Western economic influence. The M.E.P. hoped to accelerate this process of change by advocating more direct British and French political and economic engagement, thus creating more favourable conditions for the 'doctrine that leads to heaven'. In this project they clearly had limited success. The main reasons included the Lhasa authorities' fear of European expansion, their continuing influence on the Tibetan monasteries outside their formal authority in western Sichuan and Yunnan, and the limitations of Qing power in the borderlands. French pressure on the Beijing administration therefore translated into no more than a qualified degree of local protection for the missionaries.

Alongside their wider geopolitical ambitions, the M.E.P. were also intensely local. Indeed, to the extent that they changed people's lives, this was primarily at the parochial level among the villagers of Yerkalo and other settlements. In endeavouring to provide secure livelihoods for their followers through agriculture and trade, they struggled with the same geographical and ecological constraints as their neighbours. Unable to survive in isolation, they sought the support, or at least the acquiescence, of whichever political authorities would listen. In this approach they followed a pattern not so different from that of the Buddhist monasteries for centuries before them.

The M.E.P. fathers certainly started as aliens and, from the perspective of Lhasa as well as the Qing mandarins, they always remained so. 
However, in agricultural settlements such as Yerkalo and Cigu, as well as the markets of Adunzi and Dartsedo, they gradually became part of the fabric of local society. By the end of the century, to evoke the title of Lipman's (1997) work on the Muslims of northwest China, they had become 'familiar strangers', even if they would never have qualified as 'familiar Khampas'.

\section{Glossary of Chinese and Tibetan Terms}

$\begin{array}{ll}\text { Bathang } & \text { 'Ba' thang } \\ \text { Ba Chöde } & \text { 'Ba' chos sde dga' ldan phan bde gling (full name) } \\ \text { Bonga } & \text { Ba nga } \\ \text { Bongmé } & \text { 'Bum nye } \\ \text { Cigu } & \text { 茨姑 var. Tsekou } \\ \text { Chamdo } & \text { Chab mdo } \\ \text { Dartsedo } & \text { Dar rtse mdo (Tib.), Dajianlu 打箭炉(Ch.), var. } \\ & \text { Tatsienlou, Tachienlu. Now Kangding 康定. } \\ \text { depa } & \text { sde ba } \\ \text { detsodunpo } & \text { Sde tsho bdun po } \\ \text { Döndrupling } & \text { Don grub gling (Tib.), Dongzhulin si 东竹林寺 (Ch.) } \\ \text { Ganden Phodrang } & \text { Dga' ldan pho brang } \\ \text { Jizu } & \text { Ri bya rgya rkang chen (Tib.), Jizu Shan 鸡足山 (Ch.) } \\ \text { Lithang } & \text { Li thang } \\ \text { Markham } & \text { Smar khams } \\ \text { Menkong } & \text { Sman khang } \\ \text { mutekpa } & \text { mu stegs pa } \\ \text { Tsarong } & \text { Tsha rong } \\ \text { Tsewang } & \text { Tshe dbang } \\ \text { Yaregong } & \text { Yar ri sgang } \\ \text { Yerkalo } & \text { Yar kha logs (Tib.) (alt. Tsa kha logs), Yanjing 盐井 } \\ & \text { (Ch.). }\end{array}$

\section{References}

\section{Archival sources}

Archives Diplomatiques de Nantes (A.D.N.)

- Pékin 37. 'Dossiers Mission du Thibet' de 1846 à 1912. 
Archive des Missions Étrangères de Paris (A.M.E.P.). Paris

- Tibet letters: Files No 556 A-J.

- Pierre Giraudeau (1850-1941) Correspondence. File No. 1378.

- Francis Goré (1880-1954). Typescript papers. Une mission thibétaine (Yerkalo). Éphémérides de Notre Dame de Sacré-Coeur 1865-1922.

- Pierre-Marie Bourdonnec (1859-1905) 'Une histoire tibétaine à ne pas oublier'. Typescript of letters to Bourdonnec's family.

\section{Published sources}

Anon. c. 1905. 'Mgr Biet, vicaire apostolique du Thibet, 1838-19o1'. Les Contemporains 760.

Baber, Edward Colborne. 1882. Travels and Researches in Western China. London: John Murray.

Bensacq-Tixier, Nicole. 2003. Dictionnaire du corps diplomatique et consulaire français en Chine (1840-1911). Paris: Les Indes Savantes.

Bertsch, Wolfgang. 2009. 'The Use of Tea Bricks as Currency among the Tibetans'. Tibet Journal 34 (2): 35-80.

Booz, Patrick. 2011a. 'Tea, Trade and Transport in the Sino-Tibetan Borderlands'. DPhil thesis. Oxford University.

Booz, Patrick. 2011b. 'Fear of Indian Tea and the Failure of British India to Break the Chinese Tea Monopoly in Tibet'. In Buddhist Himalaya, vol. 1, edited by Alex McKay and Anna Balikci-Denjongpa, 277-29o. Gangtok: Namgyal Institute of Tibetology.

Bousquet, François. 2010. 'L'esprit de famille” des Missions Étrangères de Paris: les Monita ad Missionarios de 1665'. In La Société des Missions Étrangères de Paris. 350 ans à la rencontre de l'Asie, edited by Catherine Marin, 173-182. Paris: Karthala.

Bray, John. 1997. 'French Catholic Missions and the Politics of China and Tibet 1846-1865'. In Tibetan Studies. Proceedings of the 7 th Seminar of the International Association of Tibetan Studies, Graz 1995, vol. 1, edited by Helmut Krasser et al., 83-95. Vienna: Verlag der Österreichischen Akademie der Wissenschaften.

Bray, John. 2014. 'Christian Missionary Enterprise and Tibetan Trade'. In Trade, Travel and the Tibetan Border Worlds. Essays in Honour of Wim van Spengen (1949-2013), edited by Emilia Roza Sulek, John Bray, and Alex McKay. Tibet Journal 39 (1): 11-37.

Coleman IV, William M. 2014. Making the State on the Sino-Tibetan Frontier: Chinese Expansion and Local Power in Batang, 1842-1939. PhD dissertation. Graduate School of Arts and Sciences, Columbia University.

Cooper, T.T. 1868-1869. 'Letter from Mr. T.T. Cooper on the Course of the Tsan-po and Irrawaddy and on Tibet'. Proceedings of the Royal Geographical Society 13: 392-395 
Cooper, T.T. 1871. Travels of a Pioneer of Commerce. London: John Murray.

Desgodins, Auguste. 1864. 'Conversion de plusieurs villages'. Annales de la Propagande de la Foi 36: 313, 325 .

Desgodins, Auguste. c. 1881. A Tea Trade with Thibet. Darjeeling: Bengal Secretariat Press.

Desgodins, C.-H. ed. 1872. La Mission du Thibet de 1855 à 1870 . Verdun: Ch. Laurent. Deshayes, Laurent. 2008. Tibet (1846-1952). Les missionnaires de l'impossible. Paris: Les Indes savantes.

Engelhardt, Isrun. 2005. 'Between Tolerance and Dogmatism: Tibetan Reactions to the Capuchin Missionaries in Lhasa, 1707-1745'. Zentralasiatische Studien 34: 55-97.

Gill, Captain William. 1883. The River of Golden Sand. London: John Murray.

Groffier, Valérien. 1893. 'Travaux géographiques et scientifiques des missionaires Catholiques en 1893'. Bulletin de la Société de géographie de Lyon 12: 129-163.

Gros, Stéphane. 1996. 'Terre de confins, terres de colonisation. Essai sur les Marches sino-tibétaines du Yunnan à travers l'implantation de la Mission du Tibet'. Péninsule 33 (2): 147-208.

Gros, Stéphane. 2001. 'Ritual and Politics: Missionary Encounters with Local Culture in Northwest Yunnan'. Paper presented at the Association of Asian Studies Annual Meeting, 22-25 March 2001.

Gros, Stéphane. 2016. 'Tricks of the Trade: Debt and Imposed Sovereignty in Southernmost Kham in the Nineteenth to Twentieth Centuries'. Cross-Currents: East Asian History and Culture Review 19: 147-173. E-Journal. https://cross-currents. berkeley.edu/e-journal/issue-19/gros. Accessed 7 June 2019.

Guennou, Jean. 1986. Missions Étrangères de Paris. Paris: Fayard.

Launay, Adrien. 1905. Histoire de la Mission du Thibet. 2 vols. Paris: Desclée, De Brouwer et Cie.

Lipman, Jonathan N. 1997. Familiar Strangers: A History of Muslims in Northwest China. Seattle: University of Washington Press.

Marin, Catherine, ed. 2010. La Société des Missions Étrangères de Paris. 350 ans à la rencontre de l'Asie, 1658-2008. Paris: Karthala.

Michaud, Jean. 2007. 'Incidental' Ethnographers. French Catholic Missionaries on the Tonkin-Yunnan Frontier, 1880-1930. Leiden: Brill.

Moussay, Gérard, ed. 2007. Les Missions Étrangères en Asie et dans l'océan Indien. Paris: Les Indes savantes/Missions Étrangères de Paris.

Petech, Luciano. 1952-1957. I Missionari Italiani nel Tibet e nel Nepal. 7 vols. Rome: Instituto Poliografico dello Stato.

Relyea, Scott. 2016. 'Victorianizing Guangxu: Arresting Flows, Minting Coins, and Exerting Authority in Early Twentieth-Century Kham'. Cross-Currents: East Asian History and Culture Review 19:123-146. E-Journal. https://cross-currents. berkeley.edu/e-journal/issue-19/relyea. Accessed 24July 2019. 
Singh, Amar Kaur Jasbir. 1988. Himalayan Triangle. London: British Library.

Soulié, Jean-André. 1904. 'Géographie de la principauté de Batang'. La Géographie 9:87-104.

Tsomu, Yudru. 2015. The Rise of Gönpo Namgyel in Kham: The Blind Warrior of Nyarong. Lanham: Lexington Books.

Tsomu, Yudru. 2016. 'Guozhuang Trading Houses and Tibetan Middlemen in Dartsedo, the "Shanghai of Tibet"'. Cross-Currents: East Asian History and Culture Review 19: 71-121. E-Journal. https://cross-currents.berkeley.edu/e-journal/ issue-19/tsomu. Accessed 7 June 2019.

Young, Ernest P. 2013. Ecclesiastical Colony: China's Catholic Church and the French Religious Protectorate. New York: Oxford University Press.

\section{About the Author}

JOHN BRAY is an independent scholar currently based in Singapore. His research interests focus on the history of Christian missions and Western engagement with Tibet since the seventeenth century. His most recent publications include articles in Buddhist-Christian Studies, Bulletin of Tibetology, Rivista degli Studi Orientali, Tibet Journal and Zentralasiatische Studien as well as an edited collection, Art and Architecture in Ladakh (Brill, 2014, with Erberto Lo Bue). He was President of the International Association for Ladakh Studies (IALS) from 2007 to 2015. He is a member of the Editorial Board of Himalaya. Journal of the Association for Nepal and Himalayan Studies. 


\title{
$5 \quad$ Settling Authority
}

\author{
Sichuanese Farmers in Early Twentieth-Century Eastern \\ Tibet
}

Scott Relyea

\begin{abstract}
From 1907 to 1911, some 4000 commoners from Sichuan ventured west. Enticed by promises of large tracts of uncultivated land, they ascended the Tibetan Plateau seeking new lives - and new benefits for a changing Sichuan Province and Qing polity. Their presence was both the result of and a response to intensifying competition for authority within eastern Tibet between the provincial government and Lhasa, and perceived regional pressures from British India and Imperial Russia. Using Kham as a case study, this chapter explores the role such state-supported settlement played in the consolidation of rule within a state's borderlands and the relationship between shifting conceptions of territoriality within a globalizing structure of international law as substantiation for asserting sovereignty.
\end{abstract}

Keywords: borderlands, colonization, Kham, Qing China, Republican China, sovereignty

民安、國富, 必自無曠土無游民始, 以是謂中國不可一日缓者。

Bringing peace to the people and enriching the state must begin from having no empty lands and no idle people. This is a goal which attainment China cannot delay for a single day. - Zhao Erxun (1909) ${ }^{1}$ 


\section{Introduction}

For more than two centuries, strict central policy officially prevented or restricted emigration from the Qing polity's core provinces into borderland regions spanning the empire's southwest to its northeast and Taiwan. ${ }^{2}$ Yet by the final decades of Qing rule, these regulations began to ease. This prompted neighbouring provinces to encourage its beleaguered commoners to escape overcrowding and settle these regions, at times even providing material support to ensure both their successful cultivation of new lands and the concomitant expansion of imperial tax rolls - as well as their continued loyalty to Qing rule. By the last third of the nineteenth century, in Mongolia and Manchuria, in Taiwan (before 1895) and in Xinjiang, imperial subsidies supported the journey from neidi of many a commoner and his family, providing seeds, tools, even initial tax abatement for reclaiming distant 'wastelands'. Pursuing promises of new opportunities and a fresh start, these settlers by venturing into the empire's borderlands contributed to Qing responses to newly emerging pressures on imperial rule in regions at the edge of its authority which manifest in the late nineteenth and early twentieth centuries.

Much of the literature on Qing era settlement beyond China proper (Perdue 2005, Teng 2004, Millward 1998, Lee 1970, Reardon-Anderson 2005) explores the eighteenth and nineteenth centuries, when a majority of official 'settlers' were soldiers tasked with defending expanded imperial borders and maintaining stable Qing rule in newly acquired territory, such as Xinjiang. During that era, border defense was focused predominately inward, concerned less with repelling external incursion than co-opting local indigenous rulers and forestalling challenges to Qing rule, all while attempting to achieve self-sufficiency through farming. As the nineteenth century unfolded, intensifying demographic pressures in China proper converged with the view that commoner farmers better supported the goals of self-sufficiency to shift official policy toward borderland settlement, just as the increasing intensity of Russian and Japanese imperialism across Qing territory from Xinjiang to Manchuria added a new dimension to its role in the outward focus of border defense (Lan 1999, Lee 1970). Contributing to

2 The Qing polity's core comprises the eighteen provinces commonly called 'China proper' in historical literature and designated neidi ('inner lands') by Qing officials, merchants, and soldiers in contrast to contiguous territory 'beyond the passes', administered by the Lifanyuan (Ministry Ruling the Outer Provinces). In relation to Kham, those traveling west of Dartsedo were said to chuguan ('cross the pass'), i.e. leave neidi. 
scholarship on the processes and goals of settlement in China's borderlands, this chapter explores the connection between state-sponsored settlement and this new dimension manifest in late Qing and early Republican deployment of international law rhetoric and the concept of sovereignty to counter the territorial ambitions of neighbouring imperialist powers.

By the first years of the twentieth century, settlers ascended the Kham region of eastern Tibet, much of which stood within the western boundary of Sichuan Province. But unlike those of the previous 150 years who ventured only as far as the eastern edges of Kham (Lawson 2017, Dai 2009), these commoners traversed high mountain passes to settle deep in the valleys of Kham. The presence of these later settlers was both the result of and a response to intensifying competition for authority within eastern Kham between the provincial government and Lhasa, and perceived regional pressures from British India and Imperial Russia. At the time, Kham was on the cusp of political and economic change. Since the placement of a stele in a pass through the Ningjing Mountains (Tib. Bumla) in 1727 , the region's western half fell under the direct administration of the Ganden Phodrang in Lhasa, its eastern half nominally under the jurisdiction of Sichuan Province (see map 5.1). Rather than integrated into Sichuan's territorial bureaucracy, however, the myriad polities east of the stele were administered indirectly via indigenous, lay rulers invested with $t u s i$ titles who received corresponding seals from the Qing Emperor. While Sichuan officials focused on exerting temporal authority over the territory and inhabitants of Kham largely through these invested tusi, Lhasa projected its spiritual authority on Khampa society via monasteries, both Gelukpa and less so those of other Tibetan Buddhist schools, all of which often held sway over local lay rulers. The resulting bifurcated structure of competing authority persisted in Kham until the turn of the twentieth century.

Before this time, officials in Lhasa and Beijing - as well as in Chengdu - perceived the part of Kham situated east of the stele as little more than a periphery, an intermediate space lying between China proper and 'Tibet proper'. For the latter, the region provided but a conduit, the southern (or officials') road, which tethered Lhasa to the Qing Court via Chengdu; for the former, the region epitomized its toponym as a space 'to be defended or to be made civilized' (Buffetrille, this volume), evinced by Ganden Phodrang actions in eastern Kham both at the end of the seventeenth and in the mid-nineteenth centuries. Yet by the turn of the twentieth century, new regional challenges - both internal and external - converged with the transformative influence of newly globalizing statecraft norms to render continuation of a bifurcated structure of shared, sometimes ambiguous 
Map 5.1 Map showing 1727 stele and the main trade road through Kham. Inset: Location of Kham within the Qing Empire

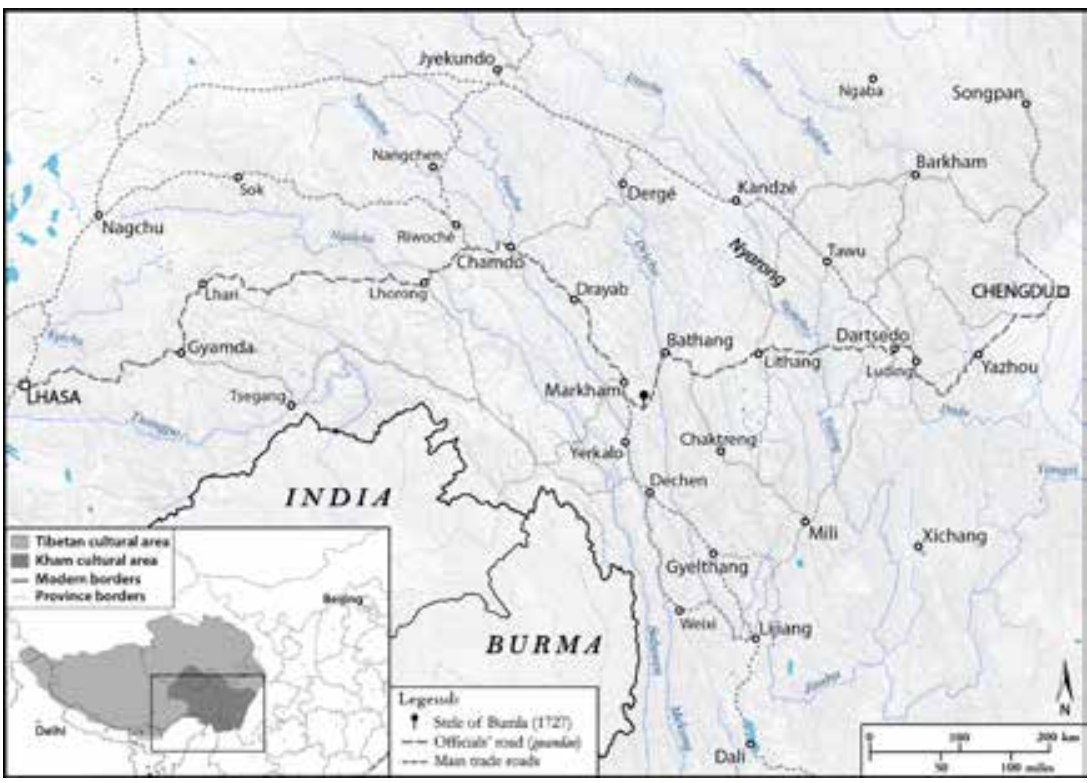

Source: Based on SRTM (NASA) and modern administrative borders extracted from GADM database (www.gadm.org, v.2.5 July 2015)

Authors: Rémi Chaix and Scott Relyea

authority untenable (Relyea 2015b). Once peripheral, Kham thus became central to the Qing-Tibetan, and later Sino-Tibetan relationship. Exploring the nature of internal and regional confrontations, both real and imagined, and the ramifications of late Qing policies in a borderland such as Kham is equally central to understanding the structural and conceptual origins of the Chinese state and its relationship with Tibetan regions.

In the decade spanning the Qing Dynasty's last years and the first years of the Republic of China (R.O.C.), from roughly 1904 to 1914 , a reorientation in both the constitution of and expectations for the settlement of Kham manifest as a consequence of these regional and global stimuli, serving as the impetus for China's assertion of sovereignty on the Tibetan plateau under international law. Using Kham as a case study, this chapter explores the role state-supported settlement plays in the expansion into and consolidation of rule within a state's borderlands and the relationship between shifting conceptions of the territoriality norm within a globalizing structure of international law and such settlement as substantiation for asserting sovereignty. The following discussion focuses on the constitution, results, and rhetoric surrounding 
a multi-faceted endeavour implemented in Kham in the midst of China's tumultuous transition from imperial to state form. This culminates with the subsequent role the endeavour played in negotiations at the Simla Convention (1913-1914), convened by representatives of the British, Tibetan, and Republican Chinese governments to determine the territorial extent of R.O.C. sovereignty on the Tibetan Plateau (McGranahan 2oo3a; Goldstein 1993, 68-75).

Colonizing Kham, supporting the migration of 'idle' commoners from the overcrowded Sichuan Basin to reclaim vast, presumably 'empty' wastelands, was one component of the endeavour initiated by the first Sichuan-Yunnan Frontier Commissioner Zhao Erfeng to incorporate the region into Sichuan province. The ramifications of this endeavour demonstrate the transformative influence on conceptions of authority in borderlands between empires and between states wrought by the influence of European-forged statecraft norms expanding across the globe in the late nineteenth and early twentieth centuries. The indigenization of two such norms - territoriality and sovereignty - by Sichuanese and Tibetan gentry and officials reoriented centuriesold imperial Chinese frontier policy and the conduits through which Lhasa exerted influence in regions of the plateau beyond its administrative reach.

The implicit emphasis of these norms on exerting authority over territory not simply through its rulers, rather more effectively through its inhabitants shifted the goals of settlement within Kham and fostered a new external goal. Rather than despatching soldier-farmers as colonists, Sichuan officials turned to recruiting and supporting non-military commoners whose presence would serve to strengthen exertion of exclusive authority internally. ${ }^{3}$ This settlement in Kham was then deployed to legitimize first Qing and later Republican government assertion of sovereignty externally - to Lhasa, to regional competitors, and to the global community. This represented the external manifestation of a plan proposed by Sichuan Governor-general Lu Chuanlin in the last years of the nineteenth century to exert 'sufficient control' in Kham - and through it Tibet. Both goals were implicated in Zhao's explicit comparison of his multi-faceted endeavour, of which settlement was its cornerstone, with four diverse models of colonialism - England in Australia, France in Madagascar, the United States in the Philippines, and Japan in Hokkaido. ${ }^{4}$ Zhao's first appeal for settlers circulated three

3 In the next chapter, Mark Frank explores a similar focus on recruiting commoners, now citizens, under a Republican Chinese government which used Xikang Province as a laboratory for a Han Chinese form of agrarian nationalism.

4 'Chuandian bianwu shiyi jun guanjin yao...' (The Importance of Sichuan Yunnan Frontier Matters...) (1907: GX33.6.11). In Wu Fengpei $(1984,48)$. 
years before his older brother and Sichuan Governor-general Zhao Erxun submitted a memorial, from which this chapter's epigraph is drawn, asserting that such settlement would strengthen the Qing state. Commoner settlers from the Sichuan basin, and thus largely Han, served a dual role in Zhao Erfeng's endeavour in Kham, first as loyal subjects, later citizens, reclaiming 'wastelands' and expanding taxable land; and second, as models of 'civilization' supporting the efforts of Zhao and his successors to undermine Lhasa's competing authority by acculturating the region's indigenous inhabitants, the Khampas.

In exploring the manifestation of these new external goals for borderland settlement and the reorientation of its inner constitution, this chapter focuses primarily on the first role. Section one briefly introduces the imperial policy of establishing military agricultural colonies in Kham and other borderlands across the Qing Empire, then surveys a shift beginning in the late nineteenth century toward opening such borderlands to settlement by commoners from neidi. At the turn of the century, a new conception of Kham emerging among Sichuan officials and gentry, influenced by the newly globalizing statecraft norms, fostered a parallel shift in the constitution of settlement in Kham toward actively recruiting and supporting commoners. The next section details great expectations and misperceptions underlying these settlement efforts and the concomitant establishment of experimental farms in eastern Kham initiated by Zhao and his predecessors. The final section turns west of the stele to analyse the relationship between the settlement endeavour, territorial authority, and Chinese assertions of sovereignty over Kham from the last year of Qing rule through the first years of the Republic of China.

This turn away from an earlier focus on rulers as conduits of authority over territory to the role of commoners as settlers in early twentieth-century Kham is epitomized by Zhao Erxun's exhortation to fill China's 'empty' lands with once-'idle' people. Built on Lu's proposal to exert 'sufficient control' in the borderland, this shift manifests in the settlement component of Zhao Erfeng's multi-faceted endeavour and its deployment at the Simla Convention as partial substantiation for Republican China's appeal to the international law principle of 'effective occupation' in asserting sovereignty over the entirety of Kham.

\section{Shifting Borderland Settlement}

In 1896, conflict erupted between the rulers of two Kham polities, the chikhyap (Commissioner) of Nyarong, who had been appointed directly by the Ganden Phodrang, and the King of Chakla, who held the Qing-invested 
title xuanwei shisi (Pacification Commissioner). The Governor-general of Sichuan at the time, Lu Chuanlin, seized the opportunity to initiate a transformation in the nature of governance in eastern Kham. Lu's first acts were to implement gaitu guiliu (bureaucratization), a long-standing imperial frontier policy, in two small polities north of Nyarong, Hor Trehor and Hor Drango, in which governance the chikhyap had meddled. Under this policy, indigenous rulers were deposed and replaced by civil officials appointed by the Qing Court, and their polities were incorporated into the junxian system of direct imperial administration, the Qing territorial bureaucracy. Lu also established a military agricultural colony (tuntian) in the two polities (Luhuo'er zhi 2000, 7-8; Coales 1917, 203). ${ }^{5}$ The following year, a succession dispute between two brothers vying to succeed their father, the King of Dergé, in which the chikhyap had also meddled, provided a further opportunity for Lu to enforce his vision of Qing authority and stability not only in Kham, but also across the entirety of the Tibetan Plateau. ${ }^{6}$

Following the Nyarong chikhyap's hasty flight to Lhasa in the face of Lu's soldiers in 1896, and the imprisonment of the feuding Dergé brothers in Chengdu in 1897, Lu memorialized the Qing Court for permission to implement gaitu guiliu and also establish new military agricultural colonies in both Nyarong and Dergé. At the time, Sichuan gentry perceived that Kham and Tibet together formed a fence protecting the province from external encroachment. Responding to their fears for perceived threat to the stability of the fence from British India and Imperial Russia, Lu's goals for bureaucratization were three-fold. By removing the chikhyap and ceasing his persistent meddling in the affairs of neighbouring Kham polities, Lu sought to stabilize Qing temporal authority in eastern Kham as a demonstration of imperial power to an 'obstinate' Dalai Lama, who would then be compelled to accept once again the oversight of the Amban (Qing Imperial Resident) in Lhasa. That acceptance, Lu asserted, would further encourage the Dalai Lama to abandon his apparently deepening relationship with the Russians, perceived as groomed by the Buryat monk Agvan Dorjiev (Kuleshov 1996). Concerned that such provocative actions would instead anger the Dalai Lama, driving him closer to Imperial Russia, the Qing Court rejected Lu's proposals, ordering the chikhyap and all deposed tusi reinstated.

Though thwarted, and rotated to a new post the following year, Lu continued to advocate bureaucratization and colonization in Kham, compiling

5 The colony, which lasted into the early twentieth century, was known as Luhuo Tun.

6 For background on Lu's efforts in Nyarong and Dergé, see Wang (2009). On the origins of the chikhyap in Nyarong, see Tsomu (2014, Chapter 7). 
his Nyarong memorials and related writings into a book published in 190o. Its preface reflects the influence of both international law and the two globalizing norms of statecraft. Referring to the regional goals of his proposed actions in Kham, he wrote, 'If we can sufficiently control Tibet, then England will be willing to acknowledge that Tibet is under our control. Under international law, states do not invade each other, thus we can use this to repel Russia'7 (Lu 1900, 5). Lu asserted that regional powers would be dissuaded from interfering in Tibet only by demonstration of direct Qing authority in Tibetan territory, and thus over the Dalai Lama, effected by implementation of his proposals. For Lu, establishing 'sufficient control' over the territory of Kham encompassed both the exertion of direct authority through imperial officials rather than tusi, and, by establishing colonies, the exertion of authority over the territory also through settlement. Lu's memorials, and later his book, contributed to a gradual shift in conceptions of the Kham borderland among Sichuan officials and gentry from an inert, two-dimensional protective fence, administered only indirectly, to a potentially fertile and productive three-dimensional territory, a storehouse of natural resources of value to Sichuan and the Qing (Relyea 2015a). This paralleled a shift earlier in the nineteenth century in conceptions of the globalizing norm territoriality from a focus solely on boundaries to what happened within those boundaries (Maier 2006, 41-46). This shift was at the core of the definition of 'effective occupation', introduced in Article 35 of the General Act of the Berlin Conference (1884-1885), by which European empires legitimized their colonial claims in West Africa, and manifest in R.O.C. justification for its claim to sovereignty over Kham at the Simla Convention.

The likely models for Lu's settlement proposals were five military agricultural colonies established in 1776 in Gyelrong, at the eastern edge of Kham, following Qing victory in the second Jinchuan War. Such military agricultural colonies, ideally self-sufficient garrisons of soldier-farmers, can be traced to the Han dynasty during the second century B.C.E. (Yu 1986) The most common imperially-sponsored and supported form of settlement in borderland regions until the last decades of Qing rule, these colonies were often established in the aftermath of imperial intervention in the affairs of indigenous rulers to either suppress local rebellion or forcefully mediate a succession dispute. They were established both in polities which indigenous rulers had been recently replaced through bureaucratization and in polities

7 On the relationship between sufficient control and Lu's understanding of international law, see Relyea (2017). 
where such rulers remained in power, presumably restrained by imperiallyinvested titles (Gong 1997). Their self-sufficiency depended on opening or reclaiming wastelands, a process generally styled kaiken, which encompassed the transformation of 'empty', uninhabited space into cultivable land which harvests would provide food for the entire garrison. Yet soldier-farmers alone were often unable to achieve self-sufficiency. Instead, they relied either on indigenous farms or on fields cultivated by commoner settlers for additional foodstuffs. For example, by the early nineteenth century, in addition to a complement of roughly 2500 soldiers, more than 5000 households of farmers from neidi settled near the five Gyelrong colonies. All had received imperial support including initial travel expenses, a house, $30 \mathrm{mu}$ of land (roughly 4.5 acres), seed, and farm implements. Their presence proved essential not only to feeding the garrison, but also to maintaining stability across the region and providing a 'civilizing' influence for the indigenous population (Zeng 2016; Xu 1995).

Such settlement by non-military subjects from imperial China's core regions has an equally long history, mostly spontaneous and sometimes initiated with imperial support, both of which continued into the Republican-era as Mark Frank discusses in the next chapter. Of the former, commoners emigrated to escape warfare, natural disasters, or overcrowding in their home districts and to find arable land to cultivate and begin their lives anew, to escape taxation or imperial authority, even to flee from a criminal past. Yet the growing presence of settlers in borderland regions often prompted the institutions of imperial governance to follow, sometimes to protect indigenous inhabitants from the rapaciousness of settlers, but more often to return these immigrants and their newly acquired lands to the imperial tax rolls. Both settlers and imperial Chinese governments alike were also drawn by the discovery of bountiful natural resources in some corners of the borderlands, the latter ultimately extending its authority through bureaucratization. This occurred most successfully during the Ming dynasty in the region which would become Guizhou Province in 1413, and in the southward expansion of Yunnan Province to absorb Sipsongpanna in the early eighteenth century under the Qing dynasty (Herman 2007, Shin 2006, Giersch 2006, Yang 2008).

Sending non-military settlers to the borderlands with imperial support, often to supplement the food production of soldier-farmers in frontier garrisons, as in Gyelrong, also dates to the early Han dynasty. In 169 B.C.E., Chao Cuo proposed a policy loosely known as yimin shibian, 'settle people to support the border'. Under this policy, settlers, initially convicts, exiles, and slaves, were despatched to the fringes of imperial territory, provided 
with housing and farm implements, and assigned land to reclaim in order to provide sustenance for locally garrisoned soldiers. Chao asserted that the happiness and success of these first settlers would entice the poor commoners of neidi to follow them, thereby providing more food for the garrison and further strengthening both stability and imperial authority along its frontiers (Chang 2007, 18-21; Gong 1997, 66). Despatching commoners to open wastelands in support of military agricultural colonies established in the northern and northwestern borderlands of the early Han dynasty was a response to the persistent threat of Xiongnu incursion into imperial territory. Similarly, Lu's proposals for Kham some two millennia later were prompted by concern among Sichuan officials and gentry that Imperial Russia sought to expand its 'Great Game' of territorial conquest with British India onto the Tibetan Plateau. Yet the implications of this later threat were different.

The details of Chao's proposals to strengthen the borderlands through colonization resonate especially in the components of Zhao Erfeng's settlement endeavour, as well as in the content of his appeals to the commoners of Sichuan. Yet by the early twentieth century, regional circumstances had changed. The emergence of powerful, more capable competitors to Qing authority in Central Asia and especially on the Tibetan Plateau converged with the transformative influence of newly globalizing norms of statecraft to structure his actions and contribute to Lu's conception of sufficient control. Together, these stimuli reoriented the constitution and goals of settlement in imperial borderlands such as Kham. Attaining regional acknowledgment of exclusive and unchallenged Qing authority over the borderland necessitated demonstrating the exertion of exclusive authority over its inhabitants in all facets of life within a clearly delimited territory, thus fulfilling the parameters of sovereignty as defined by international law texts introduced to China in the latter half of the nineteenth century (Svarverud 2007). Around the same time, an evolving conception of Kham as a region with plentiful open land and bountiful natural resources seemed to mirror conditions which had stimulated independent emigration of Han commoners into Guizhou and Sipsongpanna, and the subsequent extension of Qing authority through bureaucratization. The geological difference between these regions and Kham notwithstanding - especially the latter's altitude - this apparent parallel may have contributed to Zhao Erfeng's great expectations for a flood of Sichuanese answering his call for settlers.

More than military garrisons, the presence of numerous commoners from neidi in the Kham borderland promised to further demonstrate sufficient control and strengthen the exertion of exclusive authority in two ways. First, by colonizing the borderland with loyal imperial subjects, who would serve 
as models of that loyalty for the indigenous inhabitants, both the geographic reach and legitimacy of Qing authority would be expanded. Second, these settlers would also serve as models of civilization, reinforcing policies focused on acculturating the Khampas as a means to undermine Lhasa's exertion of competing authority on Kham society via local monasteries. Zhao Erfeng's comprehensive endeavour, and especially his emphasis on recruiting commoners rather than establishing the military agricultural colonies initially proposed by Lu, evinces a shift away from exerting authority over the territory and people of the borderland only through rulers or garrisons to a geographically wider conception of authority exerted through the loyalty of all its inhabitants.

Similar efforts to demonstrate expanded territorial authority and forestall potential external encroachment by encouraging borderland settlement manifest in regions across the empire in the last few decades of the nineteenth century, most notably in Taiwan and Manchuria. Officially, migration from the former Ming territory into the Manchu homeland beyond the Willow Palisade had been banned from the earliest years of the Qing dynasty, but periodic imperial ambivalence, settler ingenuity, and Manchu landlords seeking income resulted in a small population of agricultural settlers, both legal and illegal, cultivating lands particularly along the Liao and Yitong Rivers (Reardon-Anderson 2000, 515). Yet as land use across Manchuria remained sparse and the population small, especially in regions abutting the border with Imperial Russia established by the Treaty of Nerchinsk (1689), the latter's eastward expansion in the nineteenth century, itself influenced by globalizing norms, endangered Qing authority over these open spaces. Consequently, in 1860, the ban on Chinese migration was rescinded, allowing an influx of agricultural settlers to bolster the scattered banner garrisons and older settlements in hopes of deterring Russia's looming territorial ambitions (Reardon-Anderson 2000, 516; Hunt 1973, 8-9).

In the empire's southeast, a more immediate territorial threat unfolded in 1874 as Japanese soldiers briefly occupied a corner of southeast Taiwan in retribution for the slaughter of marooned Ryukyuan sailors by a group of aborigines three years earlier. Despite this aggressive act, the real challenge to Qing authority on the island arose in negotiations. Asserting that the 'savage' region of Taiwan's east coast lay beyond Qing jurisdiction, the Qing initially refused to pay reparations to Japan for the sailors' slaughter, both in its immediate aftermath and following the Japanese incursion. Further negotiations compelled the Qing to pay the indemnity and also acknowledge Japanese sovereignty over its once-tributary, the Ryukyu Kingdom, in exchange for recognition of Chinese sovereignty, this time over 
the entire island of Taiwan (Stern 1979, Chapter 4; Gordon 2007, Chapters 4-5). The Court and local officials on Taiwan then focused on transforming this assertion of sovereignty into a demonstration of their substantive exertion of authority throughout the island. As in Manchuria before and Kham after, commoners as settlers were central to the effort.

After the Qing seized control of Taiwan in 1683, only males were allowed to emigrate to the island, but immigration surged in 1786 when the island was opened also to family members of these prior immigrants. Finally, in 1860 all restrictions were lifted except the prohibition against settlement east of the 'savage boundary', running roughly along Taiwan's central mountain range $^{8}$ (Chen 1999, 135-136; Roy 2003, 22-24). In a direct response to Japan's earlier challenge to Qing authority east of the boundary, Shen Baozhen initiated a policy of 'Opening the Mountains and Pacifying the Savages' (kaishan fufan). This policy paralleled both the shift in conceptions of the Kham borderland prompted by discovery of its presumed natural resource wealth and the dual role of Han settlers in Zhao Erfeng's comprehensive endeavour. Government-supported establishment of farming villages in eastern Taiwan was intended both to demonstrate exclusive authority through occupation of the once-disputed region and to provide models of 'civilization' to bolster acculturation of the indigenous community (Teng 2004, 211-215; Chang 2008, 18-21). Emigration and acculturation would thus foster a loyal population as further demonstration of authority.

In both Manchuria and Taiwan, the government enticed the commoners of neidi to cross barriers to settle presumably empty, but potentially fertile wastelands ripe for reclamation and conversion to productive agriculture, but these were regions with a history of illicit Han settlement. By contrast, the terrain beyond the Dartsedo barrier had rarely attracted settlers from Sichuan or elsewhere to its east. The plateau was high, the climate inhospitable, and the journey arduous. Demonstrating authority in the context of the globalizing norms was thus more challenging - but as the nineteenth century closed, also more pressing.

\section{'No empty lands'}

In Kham, as well as Manchuria and Taiwan, settlement was only one component of the local effort to exert exclusive, unchallenged internal

8 On the origins of the 'savage boundary' and debates regarding its continuation, see Chang (2008). 
authority as substantiation for Qing assertion of sovereignty to regional competitors and the global community. In addition to bureaucratization, Zhao Erfeng's comprehensive endeavour also encompassed the opening of schools, the expansion of mining to exploit natural resources, the establishment of manufacturing and other industries, the expansion of local and export-oriented commerce, and the integration of the land and its products, animal, vegetable, and mineral, into the territory and economy of Sichuan. Roughly a year after detailing these components for the Qing Court, however, Zhao acknowledged that settlement was the cornerstone of his efforts. 'In my humble opinion', he wrote in 1908, 'to manage the whole of Tibet, it is most appropriate to give priority to colonization (zhimin)' (No. 0167 (1908: GX34.5.24) QCBDS, 186-187).

Settling Kham with Han commoners provided crucial support for Zhao Erfeng's comprehensive endeavour. While each component contributed to the effort to sever Lhasa's competing, spiritual authority on Kham society, acculturative policies centred on compulsory schooling in Confucianism, nationalism, and a range of 'civilizing' subjects for Khampa children and young adults most directly challenged that authority. In addition to their anticipated numbers, the presence of these commoners in Kham as models of loyalty and 'civilization' was expected to reinforce this acculturation and bolster the effort to transform the Khampas into Qing subjects and later Chinese citizens. To demonstrate exclusive authority in the borderland and thus fulfil the parameters of sovereignty externally, it was essential that both the territory and the people inhabiting that territory were perceived as integral to Sichuan and the Qing as a whole. These new goals for settlement were epitomized by Zhao Erxun's assertion that China's prosperity and stability depended on having 'no empty lands and no idle people'.

By the early twentieth century, vast stretches of level terrain across Kham remained uncultivated. Yet with the region's southern reaches stretched across six mountain ranges and four river valleys, none of the latter below 2000 metres in altitude, and its northern, more level reaches encompassing grasslands towering some 4,000 metres above sea level, how much of this land was suitable for reclamation by potential settlers from the Sichuan Basin? In an initial report from early 1904, Wu Xizhen, the Commissary Official in Bathang, site of the first, limited effort to reclaim wastelands in eastern Kham, identified some $4610 \mathrm{mu}$ (roughly 700 acres) of potentially fertile, but uncultivated land at four sites near Bathang town. Several months later, $\mathrm{Wu}$ reported another $28,500 \mathrm{mu}$ (roughly 4,300 acres) of potential wasteland further afield, at several sites in neighbouring polities. $\mathrm{Wu}$ proposed recruiting some 100 settlers from neidi to reclaim and cultivate 
these lands, but under mild imperial pressure for speedy results instead reassigned more than a quarter of the Bathang garrison's 83 soldiers to full-time agricultural work. By mid-year, $300 \mathrm{mu}$ had been reclaimed at three sites near Bathang, and of that only $70 \mathrm{mu}$ were under crop, mostly buckwheat ${ }^{9}$ (Mei 1934, 220-223; No. 0010 (1904: GX34.5) QCBDS, 11-14). With much of the best and most fertile land already under Khampa cultivation, the only spaces left for possible reclamation lay further up the slopes of the mountains surrounding the valley, where the soil was rockier and irrigation more difficult.

These first, tentative steps laying the groundwork for the introduction of predominately Han settlers from neidi to cultivate crops alongside Khampas in the fertile Bathang Valley were taken only after careful negotiations with both the junior and senior depa (governor) of Bathang and the khenpo (abbot) of Ba Chöde Monastery. Despite persistent reservations from Khampa monk and layman alike, reclamation proceeded without incident until the arrival in late 1904 of Fengquan, the newly-appointed Assistant Amban to Tibet. ${ }^{10}$ After four ambitious - and contentious - months in the valley, an uprising forced him to flee. Roughly a week earlier, Alexander Hosie, the British Consul at Chengdu, had described Fengquan as 'headstrong', writing, ' $[\mathrm{I}] \mathrm{t}$ is evident that his plans must create serious disturbances, unless the Chinese garrisons in east Tibet are strengthened' (FO 228/2571, D1, 13, NA). Those plans included the expansion and acceleration of land reclamation. Soon after his arrival, Fengquan identified another five to six thousand $m u$ of Bathang land suitable for immediate reclamation, planning to despatch as many as 300 soldiers to locations across the polity to bring roughly 1,000 $m u$ of land under cultivation annually (No. 0025, QCBDS, 38-39). As these wastelands newly designated for reclamation encroached on land controlled by the monastery, threatening its income and the harvests of Khampa farmers, when the effort began in earnest during the first months of 1905, they responded with violence. ${ }^{11}$ During a negotiated retreat from Bathang, Fengquan was ambushed and slaughtered in a narrow pass called the Parrot's Beak (Yingge zui) on the road to Chengdu just south of town.

9 See also 'Huiyi Batang liangyuan bing zun ban kenwu bing ni zhangcheng ying zhun zhaoban xiang wen' (Discussion of the Batang Commissary's Report on Reclamation, his Proposed Regulations, and Allowing Him to Pursue Them), Sichuan guanbao 20 (1904: GX30.8.10): 8a-9b. 10 As Assistant Amban, Fengquan was posted to Chamdo, northwest of the stele, but soon after arriving in Bathang, he memorialized the throne for permission to remain there for at least part of the year. Though ordered to proceed to Chamdo forthwith, he remained in Bathang.

11 It should be noted that other grievances against Fengquan contributed to the rebellion, but his land reclamation effort was perhaps the most visible catalyst. 
In the aftermath of Qing reprisals for this 'uprising', Zhao Erfeng assumed the newly created post of Frontier Commissioner, establishing his base in Bathang. Though initially tasked only with reconstituting Qing garrisons across Kham, in early 1907 he advanced an even more ambitious plan than his predecessors for the reclamation of wastelands throughout the Bathang Valley, as well as in other polities across Kham. Like Wu, Zhao sought to entice the commoners of Sichuan to ascend the plateau, but unlike his predecessor, Zhao would neither settle for reassigning his soldiers to the task nor expected this would be necessary. Believing that fertile, unused land was plentiful in Bathang and across eastern Kham, as were 'idle' farmers in the overpopulated Sichuan Basin, he ordered 50,00o blank title deeds printed in Chengdu and shipped to Bathang in anticipation of an avalanche of settlers (He 2001, 43; 'Lubian jin xin' 1906, 1a). In the immediate aftermath of his soldiers' brutal pacification of Qicungou, the Gully of Seven Villages situated some 50 kilometres up the valley from Bathang town, in late 1905, many farmhouses and fields indeed lay abandoned, their Khampa occupants either driven out or slaughtered. But those who survived returned and the fields were again cultivated by Khampas as the region calmed in the wake of Zhao Erfeng's subsequent departure for Chaktreng and later Chengdu with the bulk of his soldiers. This again left only the rocky, unproductive plots initially reclaimed under Wu available for settlement in Qicungou. ${ }^{12}$ Nevertheless, Zhao's first appeal for settlers emphasized the plight of the average Sichuan farmer, vast tracts of uncultivated land, and the potential to forge a better life in the higher, greener fields of Kham.

Written in vernacular Chinese (baihua), the 1300-character proclamation was posted outside local Yamen and other government buildings in every hamlet, village, and district across Sichuan in the last days of 1906, and published in Sichuan guanbao the following month. Zhao Erfeng opened with a sympathetic tone, conveying his awareness of the plight of the average Sichuan farmer. 'Knowing that you Sichuanese are many yet land is limited, and that your lives are difficult, I have taken it upon myself to find some better places for you to cultivate'. He contrasted the hardships in an over-populated Sichuan with the benefits awaiting both married and unmarried settlers in Kham, assuring them that life was more economical than in neidi. For those settlers without families, he proclaimed that the women of this land [are] numerous and the men few, the women industrious and the men lazy. If you take a local maiden as your wife, she might very

12 No. 0362 (1909: XT1.7.28) QCBDS, 404-405; No. 0356 (1909: XT1.7.18) QCBDS, 398-400; Edgar 1908, 44-45; L/P+S/2o/87-2, IOR; MssEur F157/304C, 6, IOR. 
well be able to assist in the work, carrying water, cooking food, hoeing the ground, and cutting firewood' ('Qinchai duban chuandian bianwu dachen Zhao zhao ken baihua gaoshi' 1907, 2a-b).

Beyond potential free labour - and companionship - commoners were promised generous material incentives, both assistance for the arduous journey and support once they reached their designated settlements ('Bianwu dachen zisong guanwai kenwu zhanxing zhangcheng' 1910, 7a-8b). They received travelling expenses in the amount of one silver qian, the equivalent of one tenth of a tael, per day for each adult and half that for each child younger than twelve years of age, and food was provided throughout the journey. On arrival, each settler was provided with cattle and farm implements for ploughing, seeds for planting, and additional daily food rations during at least the first year and until such time that their land produced sufficient harvest both to feed him and any accompanying family members. After three or four years, settlers were expected to begin reimbursing the government for its investment. And once the entirety of the loan had been repaid, each settler would receive one of the 50,000 deeds of ownership guaranteeing the right to farm the land in perpetuity - and the duty to pay land taxes equal to those assessed in neidi. ${ }^{13}$

In principle, each settler sent to Kham satisfied stringent requirements, detailed in Zhao Erfeng's first appeal, though in practice it is uncertain how many in fact did. And due to the considerable investment - Zhao had set aside the initial sum of 6o,0oo taels to support the settlements - each settler was required to provide his local magistrate satisfactory assurance that he would not turn back before reaching his final destination. Keenly aware that the success of the endeavour would depend greatly on the quality and ability of the settlers, Zhao sought only those commoners who were strong and healthy, no more than 30 years of age, and smoked no opium. They should also have committed no crimes and belonged to a noble and honest family. Thus, in addition to being capable workers and farmers, expanding tax income for the provincial treasury, these settlers were expected to fulfil dual roles in Kham. As loyal subjects, grateful for the Emperor's - and the Commissioner's - benevolence, each settler and his farm, perhaps unwittingly, provided regional demonstration of the Qing's exclusive territorial authority in the borderland. They also served as excellent models of 'civilization', their

13 Though deeded in perpetuity, the settler's rights ended with farming as the state still owned the land, which he was expressly forbidden from buying or selling. If the settler were either unable to adhere to the terms of the agreement or fell ill without an heir, the land would revert to government ownership. 
presence in borderland communities reinforcing the acculturation of the Khampas by both modelling morality and the 'proper' way of life, including the demonstration of 'proper' agriculture.

Zhao Erfeng was surprised to discover that the Khampa farmers knew nothing of fertilizer and continued to use wooden ploughs, which were less efficient than the iron ploughs of neidi, implying that the addition of such implements and the knowledge and experience of Sichuan's farmers would render their surprisingly good harvests magnificent ('Qinchai duban chuandian bianwu dachen Zhao zhao ken baihua gaoshi' 1907, 2a-b). Wu Xizhen, based on his prior experience in Bathang, held a much dimmer view of Khampa farmers, advising, 'We should make distinctions when recruiting. Since the Khampas are foolish and ignorant of agriculture, it is absolutely necessary to recruit men from neidi' ('Weiguan Batang liangwu tongzhi Wu Xizhen kaiban kenwu liu tiau qing zhe' 1906, 4b). Though disproved by green Khampa fields carpeting the Bathang Valley, and the fertile lands in other districts, this flawed perception was part of the conceit of Han gentry and central Qing officials toward societies at the fringes of imperial territory - and 'civilization'. Official memorials and opinion pieces published in newspapers from Sichuan and elsewhere in the late nineteenth and early twentieth centuries persistently characterized both Tibetans and Khampas as either 'simple-minded and muddle-headed' (hunhun'e'e) or 'ignorant and uncivilized' (mengmei). More than the Khampas' presumed poor agricultural skills - or knowledge of fertilizer - it was the inextricable link between rice cultivation and 'civilization' which fostered perceptions of them as incapable farmers, because they did not cultivate 'proper' crops, as further discussed by Mark Frank in his chapter.

In addition to his benevolent desire to elevate the agricultural skills of the Khampas, Zhao Erfeng also understood that future settlers from the Sichuan Basin would not easily adapt to a diet of tsampa and yak meat, requiring instead pork, rice, and familiar vegetables. He thus brought agricultural specialists to Kham, two from Japan and several more from Sichuan, to oversee the reclamation of wastelands, assist settlers in irrigation and planting, improve the productivity of Khampa fields and teach them to diversify their crops (He 2001, 43). In 1910, two experimental farms were established, the Batang Farming Test Field (Batang nongye shiyan chang) and the Dengke Farmers Test Field (Dengke nongmin shiyan chang), the latter situated in Dergé to Bathang's north. Precursors of the experimental fields set up by the Xikang Provincial Bureau of Agricultural Improvement (Frank, this volume), these farms tested the viability of growing vegetables and grains introduced from neidi and around the world, including several 
varieties of wheat, maize, potatoes, soybeans, rapeseed, beans, and squashes, as well as walnuts, tangerines, and pears.

Both farms also required local headman to send one Khampa from each community to study the cultivation of new crops. They were then expected to disseminate both these new methods and new seeds to their neighbours. Similarly, Zhao reportedly required Khampa farmers to attend lectures on new agricultural methods presented sporadically in primary schools then opening across Kham. Despite Wu's earlier caution regarding indigenous agricultural skill, the Dengke farm also worked in tandem with the Farming Improvement Institute (Nongshigailiang suo) to extend to destitute Khampas the same terms offered to settlers from neidi: the loan of farm implements and seeds repayable in full after an initial three- to four-year period of supported cultivation. Pastoral nomads inhabiting the northern plains of Kham were not forgotten in the effort to 'civilize' agriculture as an Animal Husbandry School (Xumu xuexiao) was also established in Dengke with eight heads of dairy cows from Holland and 24 dairy goats from Australia joining donkeys and horses from Shaanxi. ${ }^{14}$

The observations of two missionaries, however, suggest that these experimental farms were largely a failure. ${ }^{15}$ On separate visits to Lithang in 1910, both the American missionary J.H. Edgar and the French diplomat Pierre-Rémi Bons d'Anty observed spinach, lettuce, carrots, turnips, potatoes, and two kinds of cabbage growing within a sheltered experimental nursery similar to the experimental farms further west. All were well fertilized with manure, but 'hopelessly stunted'. In fact, the Chinese official tending the nursery seemed 'astonished' by the suggestion that such crops might not flourish at Lithang's 4000 metres altitude. According to local Chinese, the turnips and lettuce from the nursery, though selling for ten times the normal price, were fit only for pigs. Perhaps also due to its altitude, though lower at roughly 2700 metres, several rice fields in the Bathang Valley observed by Bons d'Anty at first seemed to flourish, but never matured. Rice may have been the most difficult cereal to cultivate in Kham, yet also the most essential to ensure the success of the settlement endeavour. Thus, when Zhao's armies encountered a new region west of the stele standing a mere 2300 metres above sea level with a history of rice cultivation, it became the focus of his third and final appeal for settlers, discussed in the next section.

14 No. 0583 (1910:XT2.4.23) QCBDS, 640-642; No. 0771 (1911:XT3.2.10) QCBDS, 860-861; No. 0786 (1911: XT3.2) QCBDS, 888; He 2001, 43.

$15 \mathrm{~L} / \mathrm{P}+\mathrm{S} / 20 / 87-2$, IOR; FO 228/2573 D13, NA. 
Despite acknowledging the suffering of Sichuan's farmers and offering such enticements as virtually free labour and a seemingly easy-going life for the 'idle' men of Sichuan, and a new start for its families, few settlers responded to Zhao Erfeng's first appeal. Between hopeful memorials and possibly over-ambitious reports, reliable figures for early settlers are somewhat difficult to discern. Encompassing the fifteen month period from roughly April 1907 to November 1908, when Zhao posted his second, more impassioned appeal, one document suggests that a mere 141 settlers accompanied by only two dependents registered for their onward journey in Dartsedo. All but four were destined for Bathang; the rest headed for Chaktreng (Jin 1932a, 13-15). In a telegram dated only the $34^{\text {th }}$ year of the Guangxu Emperor's reign, Zhao reported the division of 800 settlers, of which 370 were dependents, into groups of 200 , which were then despatched to four settlement sites: Dabpa, Bathang, Hekou, and East Eluo (No. 0258 (1908: GX34) QCBDS, 278). Though larger, this second figure still fell far short of Zhao's expectations. And those who did reach their destinations may not have stayed for long. Bons d'Anty characterized the first settlements as complete failures, writing that 'Chinese colonists, discouraged, sold everything that they could to draw together money and took the road to Sichuan; many fell into deep poverty, begging at the doors of lamaseries and along the main road' (Bons d'Anty. 1908, 279-281). Zhao's second appeal took a different tack from his first, more clearly reflecting the influence of the globalizing norms of statecraft on the settlement endeavor.

Published in Chengdu Daily (Chengdu ribao) in December 1908, the appeal's rhetoric went beyond extolling the vast potential for settlers in Kham. After once again expressing his empathy for the impoverished commoner toiling in hardship on scarce land in the Sichuan Basin, Zhao Erfeng proclaimed, 'The Heavens have bestowed this colony on the poor of Sichuan and tasked them with its revival' ('Zhu Zang Chuandian Bianwu Dachen xiaoyu baixing guanwai kaiken liyi baihua gaoshi' 1908, 1b). He then tickled their nascent nationalism, challenging Sichuanese to seize their destiny on the plateau as foreigners had done across the globe:

You see, foreigners pay close attention to colonization. Their commoners also follow the same maxim, so, no matter where, they are ready to go. They need only hear of it. Whether they must traverse tens of thousands of $l i$, whether they must climb mountains or cross seas, they neither see the distance as too far, nor are they afraid of danger as they strive to open wastelands. [...] You decide if this is worthy of respect or not, that 
the foreigner in fearing no hardship can ensure the prosperity of his family and business.

Zhao then assured potential settlers that the ascent to Kham had been rendered considerably less arduous. 'Now the lands beyond the barrier are still Sichuan's lands. You need go little more than 10 stages beyond Dartsedo to find cultivable wastelands. This is far superior to taking your family on a journey of tens of thousands of li.' As new settlers would traverse widened and smoothed mountain roads, no longer sleeping in the open, instead resting in a series of newly constructed inns all serving the dishes of neidi, the journey was perhaps characterized as almost luxurious in comparison with the hardships endured by colonizing foreigners. As further incentive, Zhao also increased the daily stipend for travel.

In April 1909, the magistrate of Pengzhou, Zai Gengtang, posted a proclamation in honour of 97 residents who responded to this second appeal to ascend the plateau, urging others to follow in their footsteps (Jin 1932b, 15-17). Zai's proclamation echoed the appeal's tenor of nationalistic duty, a sentiment just beginning to capture the imagination of an awakening Chinese nation in the early twentieth century, though perhaps more pronounced among the gentry than the commoners targeted by Zhao Erfeng. Zai compared the settlement of Kham with internal state expansions in Europe and America, casting his residents as pioneers as great as the settlers of the American West or the Russian Far East, venturing into dangerous spaces in service to the nation. Closer to home, he also compared the endeavour with the state-sponsored settlement of the empire's northwest two decades earlier.

Whereas eighteenth-century settlement in Xinjiang had centred on recruiting commoners to join soldiers in together reclaiming wastelands in support of Qing garrisons, renewed settlement in the late nineteenth century comprised part of the Qing effort to forestall Russian territorial encroachment after the region's re-conquest in the 1870 . The arrival of new settlers contributed to demonstrating the exertion of territorial authority over the region and served as prelude to the establishment of Xinjiang Province in 1884. Similarly, rescinding the prohibition on settlement along Taiwan's eastern coast demonstrated the exertion of territorial authority both by occupying previously ignored territory beyond the 'savage boundary' and by forging a loyal population through emigration and acculturation, buttressing the formation of Taiwan Province in 1887. Fostered by this reorientation in the internal constitution of settlement first emerging at the end of the nineteenth century in Taiwan, Xinjiang, as in Manchuria, the establishment of a province further demonstrated the exertion of exclusive authority in the borderland 
and substantiated the assertion of sovereignty to regional competitors and the global community. ${ }^{16}$ Indeed, further explaining his goals of stabilizing the people and enriching the state in the memorial which opened this chapter, Zhao Erxun continued, 'On discussing the policy of colonization, if we speak of these goals, it is essential to convert Tibet and Mongolia into provinces. ${ }^{17}$ The dual role which once-idle Sichuanese settlers were to fulfil in Kham, reclaiming wasteland and reinforcing the comprehensive endeavour's acculturative challenge to Lhasa's competing, spiritual authority, laid the foundation for both the late Qing proposal to establish Xikang Province and subsequent R.O.C. territorial claims at the Simla Convention.

Coupled with the reference to a competitive nationalism in Zhao Erfeng's second appeal, demonstrating territorial authority through the settlement and cultivation of lands by presumably loyal Qing subjects from neidi proved especially important after Zhao's frontier army entered Dzayül in early 1910, a corner of Kham southwest of the 1727 stele. After crossing the 'boundary' ostensibly delimited by the stele in the last days of 1909, his army implemented gaitu guiliu in polities throughout western Kham, severing the direct administration of the Ganden Phodrang. Tenuously extending Qing authority to (Kongpo) Gyamda, within 250 kilometres of Lhasa and outside the traditional territory of Kham, this westward expansion was a concern not only to Tibetan officials, but also to the British. Among the newly created districts, Dzayül in particular offered great promise for Zhao's settlement endeavour, featuring prominently in his third appeal, but its proximity to British India also portended potential peril for the then-ambiguous northern boundary of Assam.

\section{Extending Borderland Authority}

In August 1910, just five months after his soldiers had glimpsed the vast, fertile fields of Dzayül, Zhao Erfeng circulated his third and final appeal for settlers. ${ }^{18}$ Expressing empathy this time not only for the plight of farmers in

16 Conversion into a province, the highest level in the administrative structure of both the Qing Empire and the R.O.C., signified the borderland region's unequivocal incorporation into the Qing territorial bureaucracy.

17 Zhao Erxun 543 Roll 70, Record 361 (1909: XT1), QA. Zhao's reference to Mongolia in addition to Tibet is likely influenced by proposals to carve both regions into several provinces circulating in Beijing at the time.

18 'Bianwu dachen zhao ren kaiken baihua gaoshi' 1910, 1a-2a; FO 228/2571 D19, NA; Liu 1995, 207-208. 
Map 5.2 Full extent of Zhao Erfeng's bureaucratization and location of main farming settlements, with indication of Tibetan and Chinese claims at Simla Convention (1913-1914)

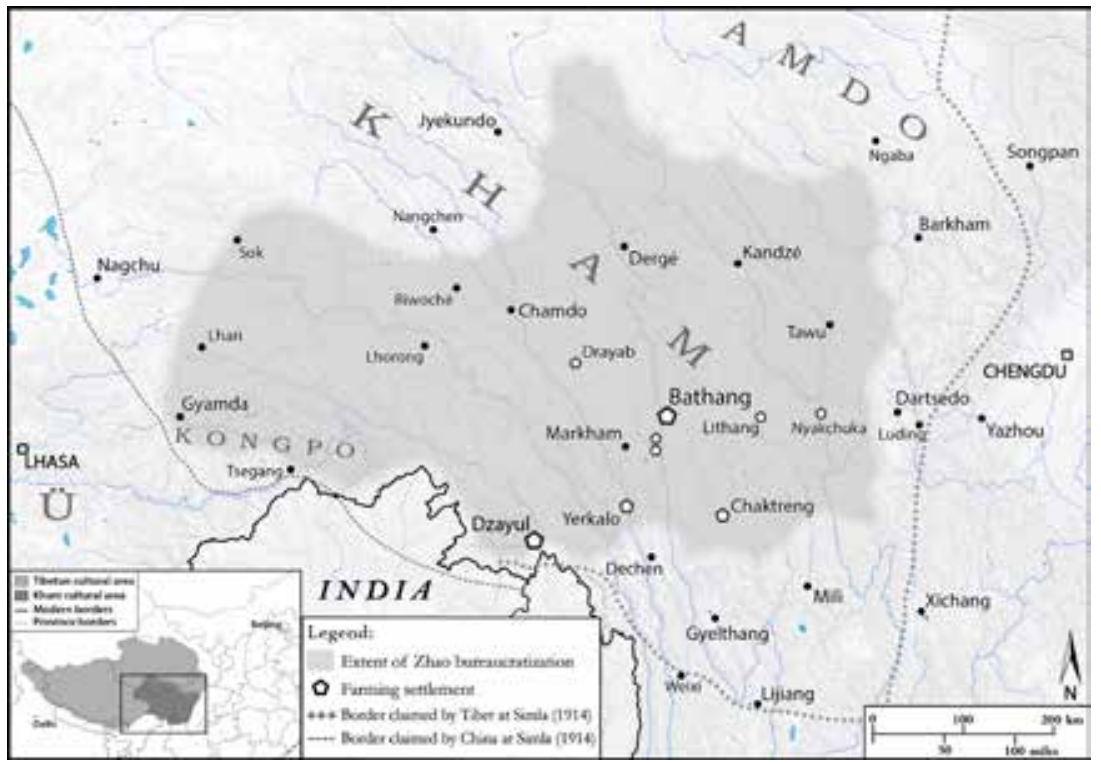

Sources: Based on SRTM (NASA) and modern administrative borders extracted from GADM database (www.gadm.org, v.2.5 July 2015)

Authors: Rémi Chaix and Scott Relyea

the Sichuan Basin, but even more for those who had answered his previous two calls, he proclaimed the discovery of this new, more promising - and potentially more satisfying - destination. 'Last year I despatched soldiers especially to seek lands where rice always has been sown. Now a place called Dzayül has been found not more than 10 days' journey from Bathang. It is a wide plain where rice once had been grown and its climate resembles that of Chengdu'.

With barely a hundred Khampa families reportedly cultivating no more than one one-hundredth of its fertile and well-irrigated lands, stretching for several hundreds of $l i$, Dzayül perhaps seemed to fulfil the image of 'Eden' painted in his first two appeals - open fields ripe for reclamation. Yet Zhao Erfeng ignored the reality that more than 1000 settlers had discovered on reaching Bathang, Chaktreng, and other initial settlements during the previous three years - that open, cultivable land was scarce. Instead, he placed the blame for their hardships - and flight back to Sichuan - squarely on the absence of rice in their plateau diet. Though this was undoubtedly 
a hindrance to the success of the settlement endeavour, more detrimental were conditions such as those observed by Edgar in Chaktreng in 1910. With all fertile corners of the district densely populated by Khampas, the few Sichuan settlers inhabited the crumbling remains of Sampheling Monastery, left to cultivate only the dusty, deserted streets of the surrounding town (L/ $\mathrm{P}+\mathrm{S} / 20 / 87-2, \mathrm{IOR})$. Despite periodic reports of newly identified wasteland for reclamation even in Chaktreng, ${ }^{19}$ before Zhao's soldiers crossed the stele, fertile land not under indigenous cultivation, and thus available to settlers, remained scarce.

Standing at an altitude of only 2300 metres, lower and more temperate than the Bathang Valley, Dzayül promised to solve both problems simultaneously. The region encompassed a reported ten million $m u$ (more than 1.5 million acres) of open land awaiting settlers, and had a history of small-scale rice cultivation. Diverging from both his own and Wu Xizhen's stronger condemnation of Khampa agricultural skill, perhaps implicitly acknowledging what previous settlers had observed east of the stele, Zhao Erfeng explained that the inhabitants of Dzayül were neither lazy nor incompetent. Rather, preferring tsampa to rice, they cultivated only small crops of the latter, which they sold to Yunnanese merchants and Han residents of Chamdo and elsewhere in Tibet. With only a small, scattered population, Dzayül provided vast potential for Zhao's settlement endeavour, but also required a significant mass of settlers to demonstrate the exertion of authority across its territory, a situation not lost on British observers.

Travel expenses and the three-year term of repayment all remained the same as in previous appeals, as did Zhao's assertion that a settler needed only a little bit of hard work to change his lot in life. In addition, for the first time, those with independent capital were explicitly encouraged to hire men to collect the travel stipend and head to Dzayül essentially as tenants, carving a farm of hundreds or thousands of $m u$ from the wastelands on their future landlord's behalf. Undoubtedly also aware of the questionable qualifications of previous settlers, Zhao emphasized one new requirement at the very end of his appeal, that those applying for the opportunity in Kham must be both hardworking and legitimate, experienced farmers. 'If you are evil-doers or idlers who live not by honest labour', he warned, 'I cannot extend this opportunity' ('Bianwu dachen zhao ren kaiken baihua gaoshi' 1910). Encouraged by this third appeal, and accompanying enthusiastic

19 See, for instance, No .0627. 1910 (XT2.6.6). QCBDS, 680-681. In mid-July 1910, the weiyuan (expectant official) in Chaktreng reported another $1320 \mathrm{mu}$ (nearly 7200 acres) of potentially cultivable wastelands. 
reports, most of the perhaps 2000 Sichuanese settlers to ascend the plateau in 1911 took the longer road toward Dzayül and several other, newly discovered destinations immediately west of the stele (He 2001, 43).

It is difficult to determine from available records how many of these settlers headed to Dzayül, how many stayed, or if those who answered this third call indeed possessed the agricultural skills Zhao Erfeng sought. However, a report detailing the plight of a group of settlers who crossed the stele in late 1910 and a report from Dzayül by British Captain F.M. Bailey nearly a year later offer some clues. The settlers had chased their dreams of a better life in a site near Drakyap, north of Dzayül close to the Ningjing Range, only to find a nightmare. 'Believing a preposterous rumour that rice, millet, wheat, and beans all sprout from the ground on their own and a mountain of glutinous rice cakes provides food for the taking', the report explained, 'the foolish people were tricked into hastening toward a place called Baimaguan' (Qing 7-956, SA). Many who embarked on the journey fell ill en route with half never reaching their destination. As with many who answered Zhao's calls, these settlers had abandoned everything on leaving the comfortable surroundings of neidi. But this group was lucky. Feeling pity for their foolishness, rather than punishing them on their return to his district, the local magistrate granted each family a small parcel of land to cultivate. On a visit to Dzayül in early 1911, Bailey caught sight of nary a settler, instead encountering a band of some 200 frontier soldiers encamped near a small village, living in huts surrounded by small plots in which they tended several varieties of vegetable and maize (MssEur F157/304C, 6, IOR; Bailey 1945, 116).

From early 1910, the British consul-general in Chengdu, W.H. Wilkinson, had monitored the movement of Zhao's frontier army in the regions west of the stele, largely through missionary reports, relaying his increasingly concerned findings to the British Minister in Beijing. More than the proximity of the frontier soldiers to British Indian territory, it was Zhao's proposed settlement of the region - purportedly welcomed by the local inhabitants - which further heightened Wilkinson's apprehension. In his cover letter accompanying a translation of Zhao Erfeng's third appeal, he wrote of the new target for settlement, 'if [Zhao] does succeed, there will eventually be found, north of Rima, a Chinese agricultural colony that will gradually spread until it impinges on northern Burma and the north-east frontier of Assam' (FO 228/2571 D19, NA). This contributed to a growing concern that the Qing and later R.O.C. governments sought to consolidate Chinese authority throughout the eastern Himalayas, perhaps even intent on infringing on British Indian territory, a situation which seemed to catch British officials 
by surprise (Guyot-Réchard 2016, 31-32). Even more problematic was the Indian Office's prior hesitation either to extend direct British authority into the mountainous regions north of Assam or to clearly delimit a boundary with Tibetan regions. Periodic proposals to carve new provinces from the Tibetan plateau advanced during the Qing's last years, and especially an R.O.C. Presidential Order from April 1912 equating the administration of Tibet with the provinces of neidi, further attested to the role these initial soldiers and settlers could play in substantiating Chinese assertions of sovereignty. ${ }^{20}$

When Capt. Noel Williamson, an Assistant Political Officer in Assam, reported seeing Chinese flags in the Mishmi Hills in February 1911, beyond what the British considered Tibetan territory, the government of Assam expressed concern that the Chinese might attempt to stretch their authority even further south, seizing the 'tea gardens north of the Brahmaputra' (Reid 1942, 217). Coupled with Bailey's report of Zhao Erfeng's frontier soldiers in Dzayül, noted above, and his observing 'evident signs of friendliness' toward them among most locals, the government of Assam recommended expanding demonstration of clear British authority into the Mishmi Hills. With neither Delhi nor London taking definitive action, Williamson again headed north in March, without official permission but at the invitation of the leaders of a non-Tibetan group, the Abors, with whom he had been friendly in the past. Venturing closer to Dzayül, further up the Siang Valley than ever before, in order to assess Qing influence, Williamson and his party were murdered by his hosts. ${ }^{21}$ In reprisal, a detachment of British soldiers headed to the region in October to force the Abors to acknowledge British authority and pay an indemnity. A team of surveyors followed, whose first detailed maps of the region would contribute to the later delineation of Assam's border some 60 miles further north than the greatest prior demonstration of effective British authority (Grunfeld 1987, 63; The Annual Register 1911 1912, 412-413; Reid 1942, 223-225; and Guyot-Réchard 2016, 40-44; Gunter 1915). With these actions, the British hoped to preclude any potential Chinese encroachment into Assam, whether military or settler, by ending decades of ambiguity in the Mishmi Hills.

20 Issued on 22 April 1912, the Order read in part: 'The Republican government [...] considered Mongolia, Tibet, and Turkestan as equal in status to the provinces of neidi and in the future the governments of each would be under the auspices of the Interior Ministry'. See 'Beijing lai dian' $(1912,2)$. See also 'Yuan Shikai Zongtong guanyu gonghe zhengfu bu she lifan zhuanbu ling' 2005 and FO 228/2575 D66, NA.

21 For further details of concern for Qing actions in Dzayül among Assam officials and Williamson's fateful trip, see Guyot-Réchard (2016, 36-40). 
These British incursions into and near Dzayül worried officials of the Great Han Sichuan Military Government (Da Han Sichuan jun zhengfu), established in March 1912 in the aftermath of the Qing dynasty's collapse. It inherited and vigorously defended territorial claims across the entirety of Kham, including Dzayül, bolstered by the presumed success of Zhao Erfeng's comprehensive endeavour during the previous years. In response to the prospect of continued British incursions, Huang Xuchang, director of the newly-established Office for Managing the Frontier (choubianchu, shortened C.B.C.), proposed despatching soldiers from Bathang to line the southern border of Dzayül with a row of R.O.C. flags (FO 228/2575 D57, NA). Fluttering in the plateau wind, these flags would have served as both a practical and performative demarcation of the territorial extent of China's claim to sovereignty in the region, a manifestation of both bureaucratization and settlement carried out west of the stele. Huang reportedly observed, 'All we have to do is to station a few soldiers, and fly the flag, where foreign troops, however bold, would not venture to press forward' (FO 228/2575 D51, NA).

Although a 'fence' of flags might never have been raised, several Chinese border markers, remnants of the Qing era, still stood in the Mishmi Hills as late as 1914. The first, discovered by the British survey team in a village then known as Menilkrai in early 1912, bore the inscription: "The southern frontier of Zayul on the borders of the Szechuan Province of the Chinese Empire' (Guyot-Réchard 2016, 45-47). These markers, and the diligence with which the British ensured their removal, were a testament to persistent territorial ambiguities across the contentious Himalayan region and the increasing potential for confrontation, which contributed to the opening of the tri-partite Simla Convention in October 1913. It was during these negotiations that the legacy of Zhao Erfeng's comprehensive endeavour in the Kham borderland - and especially the success of settlements - were assessed.

In principle, the reoriented internal goals of settlement, colonizing the borderland with loyal subjects and models of civilization to support the acculturation of the Khampas, had transformed the structure of governance in Kham. These cornerstones of the entire endeavour effectively demonstrated Chinese exertion of exclusive authority within, thus fulfilling the parameters of sovereignty, substantiating its assertion to a regional audience - the Russians, and especially British India. In the latter half of 1911, the perceived success of the comprehensive endeavour prompted Zhao Erfeng and his successor as Frontier Commissioner, Fu Songmu, to propose the establishment of Xikang Province across the entire region ostensibly 
bureaucratized by Sichuan's frontier army. Roughly two years later, this perceived success also bolstered appeal to the international law principle of effective occupation in support of the R.O.C. plenipotentiary's assertion of sovereignty over the entirety of Kham at the Simla Convention. However, in the Simla Accord, initialled by all three plenipotentiaries in April 1914, this assertion was rejected. Instead, the British proposed what would be known as the 'McMahon Line', which divided the Kham borderland into an 'inner' Tibet, situated east of the stele wherein Chinese sovereignty was recognized, and an 'outer' Tibet, wherein the R.O.C. possessed only suzerainty (McGranahan 2003b, 44-46).

Despite voluminous historical documents submitted in support of the Tibetan claim to authority over all of Kham as far east as Dartsedo, and the R.O.C.'s submission of but a single document in support of its explicit assertion of effective occupation of the same territory, British officials seemed most persuaded in determining the boundary between 'inner' and 'outer' by the legacy of the 1727 stele - and by Fu Songmu. While imprisoned outside Chengdu in the aftermath of Sichuan Province's declaration of independence from the Qing Empire, Fu (1912) compiled and published $A$ Record of Province-building in Xikang (Xikangjian shengji). For the British, a close reading of Fu's book, as much a work of ethnography and geography as of history and policy, suggested that the territorial reach of Zhao Erfeng's comprehensive endeavour was more tenuous than either the Sichuan or R.O.C. governments had asserted. Although indigenous officials had nominally been replaced throughout Kham, and schools and mines had been opened and settlements established in polities immediately west of the stele, including Dzayül, most demonstrable activity occurred to its east (see Map 5.2). The initial draft of the Accord first presented in March was perhaps also a product of British desire to ensure that substantive Chinese action remained east of the stele, thereby preserving Tibet proper as a buffer between British India and the R.O.C., coupled perhaps with concern for a potential increase in Chinese activity in Dzayül. Following more than eight months of negotiation, tri-partite accord became bilateral agreement on 3 July 1914. The McMahon Line reinstituting the limits of Chinese sovereignty on the plateau roughly along the border originally set by the 1727 stele compelled the R.O.C. plenipotentiary ultimately to withhold his signature. (L/P+S/18/B212, IOR; Anonymous. 1940, 101-114, 124-129)

Just days earlier, in a perhaps direct rebuke to the McMahon Line and despite agreeing to a stipulation against converting Tibet into a province, the R.O.C. government officially established the Sichuan Frontier Special Administrative Region (Chuanbian tebie xingzhengqu, S.A.R.) (Min 195 
juan 9 (16 June 1914), SA). ${ }^{22}$ Stretching from Luding Bridge east of Dartsedo to Gyamda, designated Taizhao Prefecture ( $f u)$ in early 1913, the S.A.R.'s territory encompassed the initial proposal for Xikang Province and the greatest extent of bureaucratization carried out by Zhao Erfeng's frontier army. Yet substantiation for both the assertion of effective occupation at the Simla Convention and this subsequent establishment of the Sichuan Frontier S.A.R. was based largely on an exaggerated perception of what Zhao Erfeng's comprehensive endeavour had accomplished - widespread settlement and acculturation of the Khampas - ignoring its contraction in the tumultuous early years of the Republic of China. Contrary to the conclusions drawn by British officials from a close reading of his text, the serialization of Fu's 1912 book in the popular Shanghai periodical Dongfang zazhi on the eve of the Simla Convention likely generated this perception of the endeavour's lasting success, particularly for readers outside Sichuan (Fu 1912; 'Xikang jiansheng tan' 1913). At the same time, the R.O.C. established three additional Special Administrative Regions in the Mongolian grasslands, a borderland similarly threatened by external imperial encroachment and which had seen an increase in agricultural Chinese settlement since the last decades of Qing rule. Occupying a contiguous stretch of territory corresponding with much of today's Inner Mongolia, the three S.A.R.s, Rehe, Chaha'er, and Suiyuan, were converted into provinces in $1929 .{ }^{23}$ Xikang Province, however, would not appear on maps for another decade.

Settlement remained an important method for both managing and claiming the territory of the Kham borderland. In August 1912, Acting Sichuan Military Governor Hu Jingyi proposed treating Kham differently from Tibet, absorbing the former into Sichuan. Among his four reasons for this action was the benefit of colonization, and its contribution to making the region self-sufficient. 'The country is really fertile, a paradise not yet exploited', he wrote with hyperbole echoing the ambitions of late Qing era gentry. 'If we establish county organisation, and settle the land with colonists, in a few years time the land and other taxes will suffice to pay all expenses of administration and of military occupation' (FO 228/2577 D6oA, NA). The C.B.C.'s structure also suggests the importance of colonization for Sichuan in Kham. One of its four primary divisions was the Department

22 In 1924, the S.A.R. was renamed the Xikang Special Administrative Region (Xikang tebie xingzhengqu), See also Jagou, this volume.

23 'Dong Meng gaisheng zhi chouyi' (1914, 9-10); 'Neimenggu gaisheng zhi jinxing' (1913, 28-29). For a detailed and excellent examination of the origins of Suiyuan and its evolution from special administrative region in 1914 to the province's abolition in 1954, see Justin Tighe (2005). 
for Colonization (zhimin si), which oversaw both agriculture and education (FO 228/2575 D51, NA). Though available records from the C.B.C.'s brief existence remain scarce, indicative perhaps of other proposals circulating at the time, in the summer of 1913 the Sichuan Branch of the Agricultural Society (kenzhi xiehui Sichuan zhibu) advocated sending 10,00o settlers to reclaim new wastelands across Kham on both sides of the stele ('Yimin shi bian' 1913, 1). They never went.

In the months following establishment of the C.B.C. and as several expeditions continued to expand British knowledge of the Mishmi Hills and beyond, re-asserting Sichuan authority politically and militarily, reestablishing peace and stability on Chinese terms across the borderland region re-envisioned as Xikang took precedence over despatching new settler commoners. Explicitly citing increased British presence south of and potentially encroaching on Dzayül, observed during an investigation of Kham in August 1912, C.B.C. Director Huang proposed an action more substantive than a fence of flagpoles. Rather than establishing a separate Xikang Province, he advocated the extension of Sichuan's western border beyond the stele and the incorporation of Dzayül, Chamdo, and polities in between directly into Sichuan's territorial bureaucracy as most effective to both exert and assert demonstrable authority.

A measure of Sichuan authority was reinstated across much of Kham by a Western Expedition (xizheng) led by the first Republican era Frontier Commissioner, Yin Changheng, from autumn 1912 to the end of 1913. Though his soldiers initially reached Gyamda, Tibetan forces pushed them further east to the banks of the Salween (Ngül) River where a stalemate held until 1917. During the course of the Simla Convention, the extent of Yin's control encompassed a smaller region than that claimed by the R.O.C. plenipotentiary and later encircled by the borders of the Sichuan Frontier S.A.R., both based on the greatest territorial extent of bureaucratization implemented by Zhao Erfeng's frontier army. The accomplishments of Yin's new frontier army - and subsequent Frontier Commissioners - reinstating Chinese authority within Kham were never sufficient to substantiate assertions of sovereignty across the entire region. Thus the R.O.C. plenipotentiary explicitly referenced not the contemporaneous actions of Yin's army, rather the accomplishments of Zhao Erfeng's comprehensive endeavour, with settlement as its cornerstone, as substantiation for his appeal to the principle of effective occupation during negotiations at Simla. The new internal constitution of settlement, Zhao's recruitment of commoners, as a crucial component of his comprehensive endeavour, corresponded with the expectations of effective occupation - and thus fulfilled the parameters of sovereignty. 


\section{Conclusion}

Settling farmers in the borderland was an old imperial policy, most often manifest in the establishment of colonies of solider-farmers, but the influence of newly globalizing norms of statecraft coupled with new regional challenges to Qing authority in the late nineteenth and early twentieth centuries transformed the policy's internal constitution and introduced new external goals. As international law evolved in this same era, claiming territory, asserting sovereignty over a borderland region came to require a state's demonstrable exertion of exclusive authority. In addition to state actions within the borderland, whether military or commercial, this authority necessitated a demographic shift, both in the indigenous community and through the introduction of a stable, loyal population transplanted from the state's core region. Conceptions of the territoriality norm marked a shift away from focusing on local rulers as conduits of state authority over vast stretches of their territory to the direct extension of that authority throughout the borderland region through individual settlers, each claiming a parcel of stable, taxable land. Recruiting commoners to reclaim 'wastelands' in these distant borderlands rather than assigning soldiers to the task represented a related reorientation in the internal constitution of settlement which manifest across the Qing Empire in the last decades of the nineteenth century, and especially in Kham in the early twentieth.

This reorientation in turn supported the pursuit of new external goals for settlement fostered by changing regional and global conceptions of statecraft in the early twentieth century. As models of 'civilization' and loyalty to a supportive state, these settlers would simultaneously reinforce internal state efforts to acculturate the indigenous Khampas, thereby further expanding state authority over territory through its inhabitants, both indigenous and emigrant. Their presence was expected to cultivate a borderland population which acceptance of exclusive Qing authority would fulfil the parameters of sovereignty, perhaps even support the eventual establishment of a province, and thereby forestall either British Indian or Russian encroachment on the Tibetan Plateau. Once perceived as a periphery by Qing officials in both Beijing and Chengdu, from the dynasty's last years, the Kham borderland had become central to the establishment of a Chinese state and a crucible for early R.O.C. assertion of territorial sovereignty to the global community. The R.O.C. plenipotentiary's appeal to effective occupation at the Simla Convention represented the intersection of Zhao Erfeng's and his successors' great expectations for the success of settlement, grounded in the shift to recruiting once-'idle', but worthy and able commoners and the resulting exertion of exclusive authority throughout the Kham borderland's once 'empty' lands. 


\section{Glossary of Chinese and Tibetan Terms}

baihua
Batang nongye shiyan chang
Bathang
Bumla
Chaha'er
Chao Cuo
chikhyap
choubianchu
Chuanbian tebie xingzhengqu
Da Han Sichuan jun zhengfu
Dengke nongmin shiyan chang
depa
Dongfang zazhi
Drakyap
Fengquan
Fu Songmu
gaitu guiliu
Gyamda
Hor Drango

Hor Trehor

Hu Jingyi

Huang Xuchang

hunhun'e'e

junxian

kaiken

kaishan fufan

kenzhixiehui Sichuan zhibu

khenpo

Lithang

Lu Chuanlin

Luhuo tun

mengmei

neidi

nongshigailiang suo

Nyarong

Yinggezui

\section{白話}

巴塘農業試驗場

'Ba' thang (Tib.), Batang 巴塘 (Ch.)

'Bum la

察哈爾

晁錯

spyikhyap

籌邊處

川邊特別行政區

大漢四川軍政府

鄧科農民試驗場

sde pa

東方雜誌

Brag gyap (Tib.), Zhaya 乍Y (Ch.)

鳳全

傅嵩炑

改土歸流

Rgya mda' (Tib.), Jiangda 江達 (Ch.)

Hor brag mgo (Tib.), Huo'er zhanggu 霍爾章谷 (Ch.)

Hor tre hor (Tib.), Huo'er zhuwo 霍爾 竹窩 (Ch.)

胡京伊

黃煦昌

渾渾哥哥

郡縣

開墾

開山撫番

墾植協會四川支部

mkhan po

Li thang (Tib.), Litang 理塘 (Ch.)

鹿傳霖

爐霍屯

蒙昧

內地

農事改良所

Nyag rong

嬰鳥哥嘴 


$\begin{array}{ll}\text { Pengzhou } & \text { 蓬州 } \\ \text { qian } & \text { 錢 } \\ \text { Qicungou } & \text { 七村溝 } \\ \text { Rehe } & \text { 熱河 } \\ \text { Shen Baozhen } & \text { 沈葆禎 } \\ \text { Suiyuan } & \text { 綏遠 } \\ \text { Taizhaofu } & \text { 太昭府 } \\ \text { ting } & \text { 廳 } \\ \text { tuntian } & \text { 屯田 } \\ \text { tusi } & \text { 土司 } \\ \text { Wu Xizhen } & \text { 吳錫珍 } \\ \text { xi zheng } & \text { 西征 } \\ \text { Xikang tebiexingzhengqu } & \text { 西康特別行政區 } \\ \text { xuanweishisi } & \text { 宣慰使司 } \\ \text { xumuxuexiao } & \text { 畜牧學校 } \\ \text { Yin Changheng } & \text { 尹昌衡 } \\ \text { Zai Gengtang } & \text { 載賡唐 } \\ \text { Zhao Erfeng } & \text { 趙爾豊 } \\ \text { Zhao Erxun } & \text { 趙爾巽 } \\ \text { zhimin si } & \text { 殖民司 } \\ \end{array}$

\section{References}

\section{Archives and Primary Source Collections}

IOR India Office Select Materials, British Library, London

NA The National Archives, London

QCBDS Qingmo Chuandian biawu dang'an shiliao [Studies of the Reports of Sichuan and Yunnan Affairs at the End of the Qing Empire]. 1989. Beijing: Zhonghua shuju

QA The First Historical Archives of China, Beijing

SA Sichuan Provincial Archives, Chengdu, China

\section{Primary and Secondary Sources}

Anonymous. 1940. The Boundary Question between China and Tibet: A Valuable Record of the Tripartite Conference between China, Britain, and Tibet held in India, 1913-1914. Beijing.

Bailey, Lt.-Col. F. M. 1945. China--Tibet--Assam:AJourney, 1911. London:Jonathan Cape. 
'Beijing lai dian' (Telegram from Beijing).(21 April 1912) Yanjin Bao 37 (7 May 1912): 2.

'Bianwu dachen zhao ren kaiken baihua gaoshi' (Frontier Commissioner's Notice Seeking Settlers). Sichuan guanbao (Sichuan Officials' Gazette) 19 (1910: XT2.7.30): 1a-2a.

'Bianwu dachen zisong guanwai kenwu zhanxing zhangcheng' (Temporary Regulations Governing Settlers beyond the Barrier). Sichuan guanbao (Sichuan Officials' Gazette) 18 (1910:XT2.7.20): 7a-8b.

Bons d'Anty, Pierre-Rémi. 1908. 'Les Projets de Réorganisation des Marches Tibétaines'. Bulletin Mensuel du Comité de L'Asie Française 8: 279-281.

Chang, Chun-shu. 2007. The Rise of the Chinese Empire: Frontier, Immigration, and Empire in Han China, 130 B.C.-A.D. 157. Ann Arbor, Mich.: University of Michigan Press.

Chang, Lung-chih. 2008. 'From Quarantine to Colonization: Qing Debates on Territorialization of Aboriginal Taiwan in the Nineteenth Century'. Taiwan shi yanjiu (Studies of Taiwan's History) 15(4): 1-30.

Chen Chiukun. 1999. 'From Landlords to Local Strongmen: The Transformation of Local Elite in Mid-Ch'ing Taiwan, 1780-1862'. In Taiwan: A New History, edited by Murray A. Rubinstein, 133-162. Armonk, N.Y.: M.E. Sharpe.

Coales, Oliver R. 2003 (1917). 'Narrative of a Journey from Tachienlu to Ch'amdo and Back via Batang'. In The History of Tibet, edited by Alex Mckay, Vol. 3: 202-238. New York: RoutledgeCurzon.

Dai, Yingcong. 2009. The Sichuan Frontier and Tibet: Imperial Strategy in the Early Qing. Seattle: University of Washington Press.

'Dong Meng gaisheng zhi chouyi' (The Plan to Convert Eastern Mongolia into a Province). (15 January 1914). Shufeng bao (The News of Sichuan) 4(4): 9-10.

Edgar, J.H. 1908. The Marches of the Mantze. London: Morgan \& Scott, Ltd.

Fu, Songmu. 1988 (1912). Xikangjianshengji (Record of Province Building in Xikang). Beijing: Zhongguo Zangxue chubanshe.

Giersch, Charles Patterson. 2006. Asian Borderlands: The Transformation of Qing China's Yunnan Frontier. Cambridge, Mass.: Harvard University Press.

Goldstein, Melvyn C. 1993. A History of Modern Tibet, 1913-1951: The Demise of the Lamaist State. Berkeley, Calif.: University of California Press.

Gong Yin. 1997. 'Gudai bianjiang minzu diqu tunken kaifa gai shuo' (A Brief Introduction to Stationed Troops' Opening up Wasteland for Development in Minority Frontiers in Ancient Times). Xinan Minzu Xueyuan Xuebao (Zhexue shejhui kexue ban) (Journal of Southwest Nationalities College [Philosophy \& Social Science Edition]) 18(1): 65-72.

Gordon, Leonard H. D. 2007. Confrontation Over Taiwan:Nineteenth-Century China and the Powers. Lanham, Md.: Lexington Books.

Grunfeld, A. Tom. 1987. The Making of Modern Tibet. Armonk, N.Y.: M.E. Sharpe. 
Gunter, C. P. 1915. 'The Mishmi Mission Survey Detachment'. The Royal Engineers Journal 21:1-28.

Guyot-Réchard, Bérénice. 2016. Shadow States: India, China and the Himalayas, 1910-1962. New York: Cambridge University Press.

He, Yimin. 2001. '20 shiji chunian chuanbian zangqu zhengzhi jingji wenhua gaige shulun' (On the Reformation of Politics, Economics and Culture in Tibetan Region of Western Sichuan at the Beginning of the Twentieth Century). Xinan minzu xueyuan xuebao - zhexue shehui kexue ban (Journal of Southwest University for Nationalities. Philosophy and Social Sciences) 22(6): 39-49.

Herman, John E. 2007. Amid the Clouds and Mist: China's Colonization of Guizhou, 1200-1700. Cambridge, Mass.: Harvard University Press.

'Huiyi Batang liangyuan bing zun ban kenwu bing ni zhangcheng ying zhun zhaoban xiang wen' (Discussion of the Batang Commissary's Report on Reclamation, his Proposed Regulations, and Allowing Him to Pursue Them), Sichuan guanbao (Sichuan Officials' Gazette) 20 (1904: GX30.8.10): 8a-9b.

Hunt, Michael H. 1973. Frontier Defense and the Open Door: Manchuria in ChineseAmerican Relations, 1895-1911. New Haven, Conn.: Yale University Press.

Jin, Fei. 1932a. 'Luting bingbao ge xian kending chuguan renshu yilan biao' (Table Showing the Number of Settlers from Each County to Cross the Barrier as Reported by Dajianlu Sub-Prefecture). Bianzheng (Frontier Affairs) 9: 13-15.

Jin, Fei. 1932b. 'Pengzhou zhizhou Zai Gengtang chengsong kending chuguan wen' (Pengzhou Magistrate Zai report on sending settlers beyond the barrier). Bianzheng (Frontier Affairs) 9: 15-17.

Kuleshov, Nikolai S. 1992. Russia's Tibet File: The Unknown Pages in the History of Tibet's Independence. Dharamsala: Library of Tibetan Works and Archives.

Lan, Mei-hua 1999. 'China's “New Administration” in Mongolia'. In Mongolia in the Twentieth Century:Landlocked Cosmopolitanism, edited by Stephen Ktokin and Bruce A. Ellerman, 39-58. Armonk, N.Y.: M.E. Sharpe, 1999.

Lawson, Joseph. 2017. A Frontier Made Lawless: Violence in Upland Southwest China, 180o-1956. Vancouver: UBC Press.

Lee, Robert H.G. 1970. The Manchurian Frontier in Ch'ing History. Cambridge, Mass.: Harvard University Press.

Liu, Zanting. 1995. Minguo Chayu xian tuzhi (Gazetteer of Republican Chayu [Dzayül]) Chengdu: Bashu shushe.

Lu, Chuanlin. 1968 (1900). Chou Zhan shugao (A Draft Record of the Plan for Zhandui). Taipei: Wenhai chubanshe.

Luhuo'er difangzhi bianzuan weiyuanhui (Luhuo County Annals Compilation Committee), ed. 2000. Luhuo'er zhi (Annals of Luhuo County). Chengdu: Sichuan renmin chubanshe 
Maier, Charles S. 2006. 'Transformations of Territoriality 1600-200o'. In Transnationale Geschichte: Themen, Tendenzen und Theorien, edited by Gunilla-Friederike Budde, Sebastian Conrad, and Oliver Janz, 41-46. Göttingen: Vandenhoeck \& Ruprecht.

McGranahan, Carole. 2003a. 'Empire and the Status of Tibet: British, Chinese, and Tibetan Negotiations, 1913-1934'. In The History of Tibet, Vol. 3, edited by Alex Mckay, 269-274. New York: RoutledgeCurzon.

McGranahan, Carole. 2003b. 'From Simla to Rongbatsa: The British and the "Modern" Boundaries of Tibet'. The Tibet Journal 28(4): 39-6o.

Mei, Xinru. 1934. Xikang. Nanjing: Zhengzhong Shuju Yinxing.

Millward, James A. 1998. Beyond the Pass: Economy, Ethnicity, and Empire in Qing Central Asia, 1759-1864. Stanford, Calif.: Stanford University Press.

'Neimenggu gaisheng zhi jinxing' (The Process of Converting Inner Mongolia into Provinces). (15 December 1913). Shufeng bao (The News of Sichuan) 3(3): 28-29.

Perdue, Peter. 2005. China Marches West: The Qing Conquest of Central Eurasia. Cambridge, Mass.: Harvard University Press.

'Qinchai duban chuandian bianwu dachen Zhao zhao ken baihua gaoshi' (Notice of Frontier Commissioner Zhao Seeking Settlers). Sichuan guanbao (Sichuan Officials' Gazette) 35 (1907: GX32.12.10): 1a-2b.

Reardon-Anderson, James. 2000. 'Land Use and Society in Manchuria and Inner Mongolia during the Qing Dynasty'. Environmental History 5(4): 503-530.

Reardon-Anderson, James. 2005. Reluctant Pioneers China's Expansion Northward, 1644-1937. Stanford, Calif.: Stanford University Press.

Reid, Sir Robert. 1983 (1942). History of the Frontier Areas Bordering on Assam from 1883-1941. Delhi: Eastern Publishing House.

Relyea, Scott. 2015a. 'Conceiving the "West": Early Twentieth-Century Visions of Kham'. Twentieth-Century China 40(3): 181-200.

Relyea, Scott. 2015b. 'Yokes of Gold and Threads of Silk: Sino-Tibetan Competition for Authority in Early Twentieth-Century Kham'. Modern Asian Studies 49(4): 963-1009.

Relyea, Scott. 2017. 'Indigenizing International Law in Early Twentieth-Century China: Territorial Sovereignty in the Sino-Tibetan Borderland'. Late Imperial China 38(2): 1-6o.

Roy, Denny. 2003. Taiwan: A Political History. Ithaca, N.Y.: Cornell University Press. Shin, Leo K. 2006. The Making of the Chinese State: Ethnicity and Expansion on the Ming Borderlands. New York: Cambridge University Press.

Stern, John Peter. 1979. The Japanese Interpretation of the 'Law of Nations', 1854-1874. $\mathrm{PhD}$ dissertation, Princeton University.

Svarverud, Rune. 2007. International Law as World Order in Late Imperial China: Translation, Reception and Discourse, 1847-1911. Boston: Brill. 
Teng, Emma Jinhua. 2004. Taiwan's Imagined Geography: Chinese Colonial Travel Writing and Pictures, 1683-1895. Cambridge, Mass.: Harvard University Press.

The Annual Register 1911. 1912. New York: Longmans, Green, and Co.

Tighe, Justin. 2005. Constructing Suiyuan: The Politics of Northwestern Territory and Development in Early Twentieth-Century China. Leiden: Brill.

Tsomu, Yudru. 2014. The Rise of Gönpo Namgyel in Kham: The Blind Warrior of Nyarong. Lanham, MD: Lexington Books.

Wang, Xiuyu. 2009. 'Lu Chuanlin's "Great Game” in Nyarong: Moving Frontiers and Power Projection in Qing Tibet, 1865-1897'. The International History Review 31(3): 473-498.

'Weiguan Batang liangwu tongzhi Wu Xizhen kaiban kenwu liu tiau qing zhe' (Temporary Batang Commissary and Magistrate Wu Xizhen Prepares Six Points for Opening Wastelands). Sichuan guanbao (Sichuan Officials' Gazette) 8 (19o6:

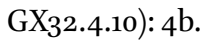

Wu, Fengpei, ed. 1984. Zhao Erfeng Chuanbian zoudu (Memorials of Zhao Erfeng). Chengdu: Sichuan renmin chubanshe.

'Xikang jiansheng tan' (Speaking on the Creation of Xikang Province). 1913. Dongfang zazhi (Eastern Miscellany) 9(11): 1-6 to 1-16 and Dongfang zazhi 9(12):1-5 to 1-10.

Xu, Huaibao. 1995. 'Qingdai Jinchuan gaitu guiliu' (The Transformation of Jinchuan Domains into Garrisons during the Qing Era). Shoudu shifan daxue xuebao (shehui kexue ban (Journal of Capital Normal University [Social Science Edition]) 5:56-63.

Yang, Bin. 2008. Between Winds and Clouds: The Making of Yunnan (Second Century $B C E$ to Twentieth Century CE). New York: Columbia University Press.

'Yimin shi bian' (Filling the Frontier with Immigrants). (20 August 1913). Sichuan shiye gongbao (Sichuan Industrial Magazine) 8: 1.

Yu Ying-shih. 1986. 'Han Foreign Relations'. In The Cambridge History of China, Vol. 1, edited by Denis Twitchett and John K Fairbank, 377-462. Cambridge: Cambridge University Press.

'Yuan Shikai Zongtong guanyu gonghe zhengfu bu she lifan zhuanbu ling' (President Yuan Shikai's Order Regarding the Republican Government Not Establishing a Special Bureau of Colonial Affairs). 2005 (22 April 1912). In Minguo Zangshi shiliao huibiani (A Compilation of Historical Materials on Tibetan Affairs in the Republic of China) Vol. 4, edited by Zhang Yuxin and Zhang Shuangzhi, 14. Beijing Xuewan Press.

Zeng Xianjiang. 2016. 'Hanren yimin yu qingdai Jinchuan tunqu diyu shehui de zhonggou ji fazhan' (Chinese Immigration and the Reconstruction and Development of Regional Society in the Area of Jinchuan Military Agricultural Colony during the Qing Dynasty) Xinan minzu daxue xuebao (renwen sheke ban) [Journal of Southwest University for Nationalities (Humanities and Social Science Edition)] 8: 203-208. 
'Zhu Zang Chuandian Bianwu Dachen xiaoyu baixing guanwai kaiken liyi baihua gaoshi' (Frontier Commissioner Notifies Commoners of Benefits of Opening Wastelands beyond the Barrier). Chengdu ribao (Chengdu Daily) 287 (1908: GX34.11.13): $1 \mathrm{~b}$.

\section{About the Author}

Scott RelyeA is assistant professor of Asian history at Appalachian State University in North Carolina, U.S.A. A historian of late imperial and modern China, his research centres on state-building and the transition from imperial to state formation in the southwest borderlands of China. He also focuses on the global circulation of concepts of statecraft and international law, particularly as received in eastern and central Asia, in the late nineteenth and early twentieth centuries. He earned a PhD from the University of Chicago and MA degrees from the School of Oriental and African Studies and the George Washington University. 



\title{
6 Wheat Dreams
}

Scientific Interventions at Chinese Model Farms in Kham, 1937-1949

\author{
Mark E. Frank
}

\begin{abstract}
China's direct control over the Tibetan Plateau was long limited to relatively low-altitude sites where intensive agriculture was viable. The integration of Kham into Xikang Province in 1939 was accompanied by a programme of experimental agriculture under the Bureau of Agricultural Improvement (B.A.I.) that sought to extend the elevational limits of intensive agriculture and 'improve' agricultural production. Based on archival and print materials, this essay contextualizes the work of the B.A.I. within national agrarian developments and offers a portrait of everyday life at two of its experimental farm stations in Kham. I contend that these sites, though diminutive, inspired confidence in the ability of the Chinese state to implement larger social and environmental interventions on the plateau.
\end{abstract}

Keywords: agricultural history, environmental history, ecology, history of science and technology

In politics everything hangs together and all politics starts with a grain of wheat. - Victor de Riqueti, Marquis of Mirabeau $(1775)^{1}$

\section{Introduction}

Historians are by now accustomed to thinking about 'the frontier as a discursive process' as Lawrence Epstein once urged (2002, 2), but recently China historians have paid closer attention to the frontier as an environmental

1 Quoted from Fox-Genovese (1976, 47-48).

Gros, Stéphane (ed.), Frontier Tibet: Patterns of Change in the Sino-Tibetan Borderlands. Amsterdam, Amsterdam University Press 2019

DOI: 10.5117/9789463728713_CHO6 
process. ${ }^{2}$ In line with the broader field of environmental history, some recent scholarship emphasizes that while ideas about environmental difference have historically been central to distinguishing between China proper (neidi) and the lands 'beyond the pass' (guanwai), these environmental differences are not reducible to pure discourse (Bello 2016, 2, 7). In the twentieth century, scientific approaches to diagnosing and circumnavigating environmental obstacles were integral to the process of 'frontier reconstruction' that Stéphane Gros points to in his Introduction. This chapter examines how the Chinese nation-state addressed ecological challenges in its attempt to settle Kham during the early twentieth century.

Specifically, Chinese of the early twentieth century associated Kham's 'frontier' status with its relatively low production of recognizable food grains. That concern came to a head when Kham was incorporated into China's new Xikang Province in 1939. The subsequent decade saw a spirited discussion of the 'food grain problem' (liangshi wenti) in Kham, the so-called 'problem' being that local soils could not produce large volumes of the crops that Han settlers desired (see Duan 1944). A 1943 agricultural survey concluded that 'since there are many mountain slopes, the altitude is high, and the temperatures are low [...] food grain production amounts are insufficient to provide for a dense population' (Zhang Yuxin and Zhang Shuangzhi 2009, 412). The following year, Xikang agriculture chief Duan Tianjue concurred that 'food grain production in the Kham dependency is sufficient only for the consumption of a small portion of residents within the territory' (1944, 16). Even so, there was a growing confidence that climate would not forestall the march of Chinese progress - confidence that was inspired by a series of small-scale interventions in the landscape.

Consider the experience of Zhang Jinquan, an agronomist from faraway Zhejiang Province. The Japanese invasion of east China in 1937 drove him west, and in June 1942 he became the chief of an experimental farm station in Kham called Taining Pastures (Taining mu chang) where he endeavoured to grow wheat (S.A., Min 249-1-156). He sowed his first crop at Bamei in the spring of that year, much as he would have in lowland Zhejiang, but early frosts kept his stalks from producing ears in the fall. It must have been cold comfort when the Department of Agriculture and Forestry telegrammed from Chongqing to recommend that Zhang find more frost-resistant strains of wheat to plant next year. Faced with hunger, he consigned himself to growing highland barley like Khampa farmers and learned to forage for

2 Recent environmental histories of the Chinese frontier/borderlands include Bello 2016, Schlesinger 2017, Kinzley 2018. 
wild ginseng roots in the high grasslands like Khampa nomads (Zhang Jinquan 1947, 27).

But Zhang was undeterred. 'Highland barley is no good for Han people', he complained. Wheat was the most common grain on earth; if Siberia could grow wheat, Zhang reasoned, so could Kham. As war with Japan raged in the interior provinces, Zhang waged his own war against hunger in the highlands. By 1944 he had assembled 25 varieties of wheat seed from different Chinese institutions for a variety comparison experiment, which he ran at two different sites near the town of Kangding. By 1946 he had identified and re-tested three high-yielding, cold-resistant varieties that the government could plant throughout the Kham region at elevations of up to 3500 metres (Zhang Jinquan 1947).

Zhang's experience is extraordinary, but not unique. He belonged to a new professional class of agriculturalists that were university-educated, mobile, and well connected. In the late 1920 S Zhang matriculated at the agricultural college of National Central University, where he likely brushed shoulders with prominent American agronomists, including the missionary John Lossing Buck. ${ }^{3}$ He graduated from the Department of Agricultural Land Reclamation (Nongyi kenzhi ke) in 1931, and served as an agricultural technician in the eastern provinces of Anhui, Fujian, and Zhejiang before his thousand-mile exodus to Kham, where he joined the government of the newly-established Xikang Province. During Zhang's time at the Anhui Province Cotton Improvement Station he had served alongside brothers Duan Tianjue and Duan Tianzhen, both of whom would join him in the Xikang Provincial Bureau of Agricultural Improvement (Xikang sheng nongye gaijin suo, henceforth B.A.I.). ${ }^{4}$ There they shared quarters with migrants from several other provinces at experimental farm stations modelled on those of the interior provinces, where they managed small local labour forces. The work these agriculturalists did, and the topic of this essay, was 'improvement' (gaijin, or gailiang).

Improvement was in many ways a precursor to the notion of 'development' that found prominence in the latter half of the twentieth century (see Giersch and Tan, this volume). The origins of improvement are in early modern Europe where it clearly signified agricultural innovation, although by the twentieth century 'improvement' referred more broadly to a range of

3 The American agronomist and missionary John Lossing Buck moved from Anhui to Nanking University in 1920 (Stross 1986, 161). He remained until 1944, traveling intermittently to the United States and elsewhere.

4 These biographical details are gleaned from personnel files in S.A., Min 249-156. 
technocratic interventions in society and the environment. Anthropologist Tania Murray Li cogently identifies two core features of global improvement schemes: the first is problematization, or 'identifying deficiencies that need to be rectified', and the second is rendering technical, or assigning resolution of the problem to experts in a neatly-defined field $(2007,7)$. This understanding of improvement fits the B.A.I., which conceived its mission in opposition to the supposed 'food grain problem'. It also fits the general approach to the 'frontier service' and forms of social work that, as Gros reminds us in the Introduction, formed a new ideology for borderlands integration.

In the long view, the B.A.I. was part of a process that began in the late Qing Dynasty. In 1904 Fengquan, an Assistant Amban commissioned by the Qing court, launched an unprecedented agricultural colonization effort that provoked to local unrest and his subsequent murder by Khampa hands (Gao Lao 1913, 7; Relyea, this volume). Rather than dissuade the imperial state, Fengquan's death catalyzed Qing intervention in Kham, beginning with Frontier Commissioner Zhao Erfeng's campaign to consolidate power in the region (Wang 2011, 212). As part of this effort, Zhao conceived an elephantine scheme to settle Kham with farmers from Sichuan, commissioning 50,00o title deeds for migrant settlers. Most of these settlers either failed to materialize or deserted after realizing that Kham's growing potential did not meet expectations (Relyea, this volume). But in the late 1930s, the incorporation of the Kham region into a 'Xikang Province' of the Republic of China reinvigorated land reclamation efforts there under the governorship of warlord Liu Wenhui. As the Christian Science Monitor reported in 1939:

Government heads at Chungking have decided that with the New Year, Sikang - formerly known as 'Inner Tibet' - will be a new province and given full recognition for its role as site of vast land-reclamation projects which are to be pushed by both Government and semiofficial circles. [...] Sikang will become to China what the Japanese used to say Manchuria was to them - a 'life line'. ('China Builds Inner Empire' 1939)

Superficially, the Republic of China appeared to inherit its Kham doctrine from the Qing empire. Scott Relyea (this volume) notes several features of Zhao Erfeng's colonization push that resonate with subsequent efforts under Liu Wenhui: namely, reliance on civilian migrants, the establishment of experimental farms, the introduction of nonnative crops, and the conceptualization of land reclamation as a civilizing project. Yet Republican state-builders perceived that Zhao had failed. 'Zhao Erfeng once implemented migrant cultivation', wrote Kham scholar Ren Naiqiang, 
'but unfortunately, he did not see results' (2009 [1931], 3). In reprising an ill-fated imperial project, were officials trying to do the same thing and get different results?

This chapter demonstrates that fundamental changes in Chinese agrarianism differentiated Republican-era agricultural colonization in Kham from that of the late Qing. A new agrarianism emerged that was distinctly nationalist in character, and that offered a holistic vision of China's place in the international community: China, some said, was 'a country founded on agriculture'. Politicians employed this vision to enhance the popular appeal of migrant land reclamation, construing it as an avenue for broad participation in what Benedict Anderson $(2006,7)$ calls the 'deep, horizontal comradeship' of the nation. This 'agrarian nationalism' was also characterized by a turn to the international paradigm of scientific, industrial agriculture. Experimental farms were not entirely new to China, but China's experimental farms of the 1930 s and beyond were linked in unprecedented ways to networks of bio-matter, information, and agricultural professionals.

The Tibetan plateau proved to be a unique challenge for agrarian nationalism, which presumed isometry of national territory with fertile earth. The elevation and topography of Eastern Tibet militated against the cultivation of the food crops that Chinese settlers desired. Wheat cultivation was exceedingly difficult, rice impossible. I have previously contended that the elevational limits of grain agriculture were effectively the material limits of the Chinese state apparatus (Frank 2016, 115-123). This essay chronicles how the Xikang provincial government sought to extend its limits by technical means through the agronomists of the Bureau of Agricultural Improvement. Through their research on 'high-cold' (gao han) crops and livestock, technicians like Zhang Jinquan contributed to ameliorating national territory and local soils. Drawing deeply from the unpublished archives of the Xikang Province Bureau of Agricultural Improvement, I analyse everyday practice at two experimental sites, Simaqiao and Taining, that occupied different ecological niches within the Kham region. Both sites entailed creative adaptations of agrarian nationalism to challenging local conditions, with mixed results.

\section{Reclaiming Kham}

Chinese land reclamation policy of the twentieth century turned its attention from the imperial practice of establishing discrete military colonies (tuntian) to land reclamation as a continuous civilian and military enterprise, now 
referred to as tunken or kaiken (Relyea 2010, 50). ${ }^{5}$ Kate Merkel-Hess describes tunken-style development as 'a distinct alternative to rural reconstruction's remaking of the countryside' that nevertheless co-opted rural reconstruction's village utopianism $(2016,82)$. Kham was among the earliest regions to institutionalize this approach with the 1926 establishment of the Xikang Tunken Commissioner (Xikang tunken shi). In 1928 the Nanjing government identified fourteen zones for institutionalized land reclamation, most of which were in the borderlands, including Xikang (Huang Fensheng 1946, 182). ${ }^{6}$

It was in this milieu that a certain Zhang Yunping published a manifesto in 1931 entitled 'Tunken Recommendations Regarding the Moving of Soldiers to Xikang' (Duiyu yi bing Xikang zhi tunken jianyi). The thrust of Zhang's proposal was that Xikang administrators could settle all of its 34 counties with farmer-soldiers who would 'turn stony fields into fertile land', and who could revert to civilian status and receive titles to their land after three years of continuous cultivation (Zhang Yunping 1931, 47). The author hailed from Sichuan's Maogong, which had been a land reclamation station (tunwu ting) since the eighteenth century. At the heart of his manifesto was an agrarian philosophy of the Chinese nation, which he articulated as follows:

Our country is a country founded on agriculture; the refinement of poetry and the discipline of calligraphy take their restraint from agriculture and their diligence from agriculture. The governance of agriculture is done by expert officials, who in directing the hardships of sowing and reaping must lead by example and inspire their countrymen. (Zhang Yunping 1931, 43)

The phrase 'our country is a country founded on agriculture' (wo guo yi nong li guo) was a watchword of a conservative vein of nationalism that originated with the influential writer and statesman Zhang Shizhao. ${ }^{7}$ Zhang introduced the slogan that 'China is a country founded on agriculture' in the 1920 after his experiences as a student in Tokyo and then Edinburgh, which

5 These words were often used interchangeably in Republican-era discourse, but tunken implies land reclamation overseen by the army while kaiken has no military implication.

6 The other thirteen locations slated for tunken development were Xing'an, Songhua Jiang, Rehe, Chahar, Gansu, Xining, Qinghai, Xinjiang, Outer Mongolia, Tibet, Yunnan, Sichuan, and Guizhou.

7 The phrase Zhongguo yinong liguo is difficult to translate. A more literal translation might be 'China erects the country with agriculture', but I have opted for the translation 'China is a country founded on agriculture', which I believe sounds more natural while maintaining functional equivalency with the Chinese phrase. 
were instrumental in his embrace of what he perceived to be traditional Chinese values (Boorman 1967, 105-106). He outlined a fundamental, binary opposition between 'agrarian states' (nong guo) and 'industrial states' (gong guo), associating the agrarian state with the virtues of thrift, modesty and the ancient principle of $w u$ wei (non-action) but the industrial state with greed that begat capitalism and imperialism (Zhang Shizhao 1926). His agrarianism inspired a number of disciples, corresponding to what historian Zhuang Junju describes as a loosely-aligned 'country founded on agriculture' clique (yi nong li guo pai) (Zhuang Junju 2007, 94).

Zhang Yunping's rhetoric in 'Tunken Recommendations' echoed Zhang Shizhao's, including the latter's depiction of imperialist powers as posing an existential threat to a fundamentally agrarian China. But equally troubling to Zhang Yunping were the nomadic ways of the Khampas. He conjured the image of a Kham stuck in the 'nomadic age' (youmu shidai) and populated with 'restless people, wriggling around, accustomed to drink, given to drunken stupors, stark raving mad (ru kuang ru chi), with cattle shit all over their tents' (Zhang Yunping 1931, 44). His agrarianism thus figured as a sort of middle ground between two extremes: the nomadic and the industrial.

Agrarian thought in Republican China paralleled similar ideas in Japan, where discontent with rapid urbanization and industrialization fuelled an 'agrarian nationalism' among certain statesmen and intellectuals who 'shared a conviction that agriculture was crucial for creating a stable, harmonious Japan' (Havens 2015, 7). Japanese agrarian nationalists like Katō Kanji advocated mass agricultural emigration to Manchuria under the belief that it would simultaneously create utopian farming villages on the Manchurian frontier and revitalize struggling villages on the home islands (Young 1999, 309-310). In a similar vein, Chiang Kai-shek implored Chinese youths to ease population pressure in the industrialized treaty ports by migrating to the borderlands for tunken work, calling it 'a great task of the highest order in the building of our nation' (Jiang Jieshi 1943, 28). The ethnologist Huang Fensheng seized on Chiang's terse tunken remarks to write his own manifesto, which he published in 1946 as the Borderlands Tunken-worker's Handbook (Bianjiang tunken yuan shouce). Huang wrangled a multitude of facts and figures into a narrative on the historical trajectory of tunken practice covering two millennia of Chinese history, in which tunken figured as an enabling condition of the development of borderlands into Chinese provinces. ${ }^{8}$ His rhetoric reflects both Zhang Yunping's holistic

8 Scott Relyea notes that the conversion of borderlands into provinces, including Xikang Province, was a project that linked the late Qing dynasty with the Republican era (2010, 50-51). 
interpretation of tunken and Chiang Kai-shek's concern with population redistribution:

The land (tudi) of a nation should be harmonized with the people of the nation. Only then can this land be possessed by the people, be exploited by the people, be enjoyed by the people. Otherwise, the relationship between humans and earth will be in discord. There are some areas where the human population is densely concentrated, and there are other areas where humans have not left their footprints and the land is gone to waste. This gives rise to lopsided development; not only does it influence citizens' livelihood, but it threatens the very existence of the nation (minzu). (Huang Fensheng 1946, 183-184)

Huang's Handbook inundated its readers with startling population statistics: for instance, it compared the population density of Henan at 211.16 people per square kilometre with that of Xikang, at 5.76. Of China's 11,562,888 square kilometres, only 9,300,000 (about twelve per cent) was under cultivation - far less than that in most industrialized states - and most of this uncultivated land was in the borderlands. Huang offered an ambitious solution: 'more than one hundred million people should be distributed from the population of the interior to various locations in the borderlands' (Huang Fensheng 1946, 194).

Tunken's ascendancy in national policy provided the provincial and central governments with a common idiom regarding land use policy. In 1940 Liu Wenhui petitioned the central Administrative Yuan to supplement his funding for military tunken in Xikang, with the reason that 'the population of this province is scant and the soldiers deployed are limited' (AS 20-00-63-017-13). In May of the same year, Xikang's provincial government promulgated a set of twelve stipulations for the reclamation of public land, which the central Administrative Yuan approved. Province-wide figures on the total number of migrants and the total area reclaimed are exceedingly hard to come by, because reclamation was a piecemeal activity rather than a centrally-coordinated strategy; various provincial organs ran their own reclamation programs on the land under their control. ${ }^{9}$

Hundreds of migrants from other provinces, including many war refugees, came to Xikang each year as participants in land reclamation, but few of

9 For example, in 1940 the Provincial Council office in Hanyuan welcomed 53 war refugees to settle as cultivators in Yichang and nearby counties, while the nationally-administered Xikang Student Headquarters settled 81 war refugees (including 60 students) in the Xikang counties of Ya'an, Hanyuan, and Xichang (J.S.G. 18-21-16-o20-o1). 
these wound up in the Kham region. Hesitant to financially subsidize Liu Wenhui's province-building project, the nationalist government in Chongqing instead authorized the redrafting of Xikang's eastern border to incorporate fourteen fertile lowland counties and three proto-counties (shezhi ju) from west Sichuan as of September 1939 (JDKQ 59; see also Jagou, this volume). ${ }^{10}$ These counties, corresponding to the province's new Ya and Ning dependencies, would absorb most of Xikang's incoming tunken settlers, thanks in large part to the 1939 establishment of a Xikang Province Ning Dependency Tunken Council (Xikang sheng Ning shu tunken weiyuan hui). All of this production subsidized rapid institutional growth. Historian Joseph Lawson writes that the Ning dependency metropolis of Xichang 'flourished during the war' and that, according to one contemporary observer, it was 'a city of civil servants' (Lawson 2018, 163-164). The situation was different in the Kham region, where the state farms were barely solvent, there was little investment from the central government, and Han migrants remained distinctly in the minority. To colonize Kham, the state would need to confront that region's environmental peculiarity.

\section{Kham as an Empirical Problem}

Tunken discourse tended to elide regional differences. Historian Wang Xiuyu notes that 'the very compound term tunken evokes the agrarian ideals of the central plain: that of expanding productive farm land by opening up wastelands and the venerable tradition of farm colonization' $(2013,212)$. If advocates of migrant land reclamation offered a vision for harmonizing borderland soils to the needs of the nation, they did so based on dubious claims about soils. Zhang Yunping's 'Tunken Recommendations' was unequivocally optimistic about Kham's cultivation potential. He described the fields of Kham as level and fertile, conducive to herding and conducive to planting' $(1931,40)$, and elsewhere referred to Kham's 'boundless fertile soil' (43). Huang Fengshen's Handbook spoke of limitless virgin land' and beckoned youths to 'create an ideal environment upon the white paper of this swathe of nature' $(1946,192)$. Ignoring local ecologies and indigenous peoples, these agrarian nationalists imagined the Inner Asian borderlands as an empty scroll upon which migrant farmers might inscribe the nation. Their optimism lacked any clear evidentiary basis.

10 'Proto-counties' here refers to shezhiju. In the administrative system of the Republic of China, provinces instituting new counties first established a shezhiju (literally 'establishment office') that eventually achieved full status as a county. 
Field surveys produced more cautious forecasts, though some early reports were in fact quite optimistic. Feng Yunxian of the national TibetanMongolian Affairs Council performed county surveys that seemed to support bold claims about the region's potential, prompting her to return optimistic reports to the Council and issue public calls for citizens to settle Kham as tunken workers. In a 1931 essay on 'Essentials of Reforming Contemporary Xikang' in the journal New Asia she claims the 'Lamaist religion' (Tibetan Buddhism) inducts so many young Khampa men into monasteries that there is plenty of abandoned land for the taking. Feng writes that in Kangding (Dartsedo), Jiulong (Gyezil), Luhuo (Drango), Danba (Rongdrak), Daofu (Tawu), and Ba'an (Bathang), only three tenths of the arable land was under cultivation, while in the more remote counties of Yajiang (Nyakchu), Lihua (Lithang), Ganzi (Kandzé), Zhanhua (Nyarong), Daocheng (Dabpa), Yanjing (Yerkalo), and Derong (Dérong), only half of the arable land was under cultivation. She proposed a dual programme of encouraging citizens to migrate to the Kham region and resettling soldiers there as tunken workers once the civil war has ended. 'We should absolutely implement cultivation (kaiken)', she urges, 'so as to open up the spring of benefits' (Feng Yunxian 1931, 62). The same year in a private memorandum to the Tibetan-Mongolian Affairs Council, Feng would write that 'this land is situated in the southwest epicentre of national defence', and that 'the fertility of the land and the bounty of its production are not less than those of the interior (neidi)' (Z.D.E. 374).

Scientific analyses of Kham's growing conditions began in earnest during the late 1930s. These were sobering. The National Agricultural Research Institute (Zhongyang nongye shiyan suo) carried out an extensive survey of soils in west China after the Japanese invasion of 1937 forced that institute to relocate from Nanjing to Chengdu. ${ }^{11}$ Among the research team was the London-trained soil scientist H.L. Richardson, who summarized his findings in a report on 'Soil and Man in West China'. West China, he explained, suffered from a phenomenon called 'fertility migration' in which fast-flowing rivers (especially the Yangtze and its tributaries) washed nutrients to the south and east, such that 'the high productivity of east China has been obtained at the expense of the west'. Further, soils in upland and far northern settings were subject to 'podzolization', a process in which key nutrients are leached from higher to lower levels of soil because cool temperatures inhibit decomposition near the surface. And western Kham was exceptionally arid

11 The provinces surveyed included Gansu, Shanxi, Sichuan, Hubei, Hunan, Yunnan, Guizhou, and Guanxi as well as Tonkin in Indo-China. 
because the 'Szechuan alps' (Zheduo mountains) intercepted precipitation (Richardson 1940). The implication, he contended, was that the political hype over agrarian migration was unmerited:

The existence of these immense areas of uncultivated land has suggested to many that there must be a fine field in the west for resettlement and the disposal of some of the surplus population of the east. Actually this is not so, at least with present methods of land utilization and the traditional Chinese pattern of cultivation. China has already reached the stage where almost all the land which should be cultivated is being cultivated, and much is already being cultivated which should not. (Richardson 1940, 124)

Chinese land use surveys roughly concurred. In 1943, Xikang officials participated in the first county-by-county 'National Survey of Land Use Status.' ${ }^{12}$ Existing farmland in most Kham counties was estimated to comprise about five to ten per cent of total area, and arable waste (the site of agrarian potential) was generally estimated at well under ten per cent of total area. Ning counties, by contrast, were believed to feature more arable waste in spite of this region's far greater Han population - as much as 20 per cent of Xichang's area was unused and arable. There was great variation within Kham as well, consistent with Feng's observations; counties along the southern route such as Ganzi and Danba were associated with greater growing potential than those along the northern route, such as Dengke, where it was felt that there was no potential for farm expansion. The greatest obstacle was Kham's high-altitude climate. Land labelled 'severely cold and not conducive to forestry or pastoralism' (industries more cold-resistant than cereal farming) reached 20 per cent in Dengke and Lihua and an incredible 40 per cent of total area in mountainous Derong (S.A., Min 234-1-253).

In 1941 a 'University Summer Term Borderlands Service Group', comprised of students from various Chinese universities, embarked on a survey tour of Xikang, the outcome of which was their 'Western Sichuan Survey Report'. The team departed westward from Chengdu on 15 August and spent over a month conducting surveys of indigenous peoples, geography, economy, agriculture, and animals along the courses of the Zagunao and Min rivers. As educated youths, these students would appear to have been the target demographic for Chiang Kai-shek's call to tunken service, but even their brief visit was beset by environment-related difficulties. The two teams that conducted the agricultural surveys suffered attrition from the elements; 
the report notes that several people (not numbered) had to retreat because of 'bodily weakness' and that 'limitations on the survey could thus not be avoided'. Even in summer the climate was severe; though afternoons felt pleasantly similar to 'mid-autumn in the lands along the Yangtze', mornings and evenings were bitterly cold. What arable fields the surveyors found among the mountains and valleys were plagued by a lack of rainfall and an excess of salt that ran down from the mountaintops when it did rain (Zhang Yuxin and Zhang Shuangzhi, 439-440).

In spite of all this, the agricultural survey report ends on a high note with recommendations on how to 'improve' (gailiang) agriculture in Kham. These focused heavily on variety selection. Different varieties of corn and wheat were optimal for various elevations, but the surveyors noted that local farmers did little to prevent these varieties from cross-pollinating. By sowing selectively, modern farmers could keep varieties with longer growing periods at low altitude and varieties with shorter periods at high altitude, maximizing production. By isolating crops with one annual harvest from those with two, farms could conserve manpower. The surveyors also recommend replacing much of Kham's corn with potatoes, which yield more food at high altitudes (Zhang Yuxin and Zhang Shuangzhi, 447-449). These student opinions of course contended with a multitude of professional opinions, but they did so using the shared vocabulary of 'improvement' agriculture, based on the notion that the agricultural productivity of a particular region was not a given, but could be altered through scientific methods.

\section{The Mission to Improve Kham}

The new paradigm of agricultural 'improvement' helps to explain renewed interest in cultivating Kham during the mid-twentieth century in spite of decades of seemingly fruitless labour. It was largely a matter of faith. The outcome of any given improvement effort was unpredictable, and 'improvement' in this context might best be understood not as a result, but as a protocol by which crops, livestock, implements, and methods were altered through experimentation to optimize performance in a given region. Institutionally, these efforts were spearheaded by a local improvement bureau that exchanged personnel, material, and information with national and international improvement networks, and it is this network aspect that differentiated Liu Wenhui's experimental programme from that of Zhao Erfeng during the late Qing. Insofar as the local agriculture organ had yet to 
implement a modern improvement protocol, Kham stood to be improved. This is what the manuscript for the Xikang Tongzhi implied, for example, by a remark that 'everywhere there are fertile grasslands that remained uncultivated with grain, and enormous herds of livestock whose quality remains unimproved' (emphasis added, X.T.G. 346).

'Improvement' had its origins in England of the eighteenth and nineteenth centuries, where it fuelled a dramatic increase in agricultural production that we now call the 'British agricultural revolution'. The emergence of market capitalism in northern Europe, and England in particular, prompted the marketization of crops, which in turn drove the consolidation or 'enclosure' of land under wealthy landowners. The ensuing privatization of commons provided new incentive for increasing yields, and agriculture became an intellectual pursuit of the bourgeoisie, who took advantage of the new technologies of printing to share knowledge about it. Noel Kingsbury writes that 'by 1640 it was possible for an English landowner to have quite a serviceable library on farming matters' $(2009,57)$. The United States inherited and improvised on these developments; Randall Stross notes that there were over 400 farm periodicals in the United States before $1860(1986,4)$. The English and American improvement movements benefited from relatively low population density and the emergence of print capitalism.

The population explosion that China experienced during the Qing ensured that it did not share the conditions that facilitated the agricultural revolution in the western hemisphere even after the fall of the dynasty. The average size of a farm in north China of the 1930 s was 5.1 acres, and the average size in the south was 2.8 acres. In the United States of the 1930s, 'the average farm family of 4.2 people lived on 157 acres; in China, the average farm family of 6.2 people drew its sustenance from about 4.2 acres' (Eastman 1988, 54). Developments in (mainland) Chinese agriculture fell far behind those in Korea, Japan, and Taiwan during the twentieth century because of population pressure; its agricultural history in the twentieth century more closely resembles that of India than those of its East Asian neighbours (P. Huang 2016, 340). With such diminutive farms, there was little room for most Chinese farmers to produce more food than they needed for sustenance and thus little incentive to invest in crop improvement. Mass marketization of food crops would not occur in China until the 1980 s.

Accordingly, agricultural innovation was propelled mainly by the state. Late imperial officials provided seeds to peasants, allocated funds for experimental fields, and sometimes even invested in agricultural experiments (Perdue 1987, 22). Some late Qing statesmen were impressed by agricultural development in the west, including Kang Youwei, who in 1895 unsuccessfully 
proposed to the Guangxu Emperor a programme of state-guided agricultural improvement modelled on the U.S. Department of Agriculture, which, we should note, had been established only three decades prior (Stross 1986, 11). Nevertheless, Japan's stunning victory in the Sino-Japanese war of 1894-1895 jolted the provinces into implementing their own experiment stations modelled on Japanese and American precedents. Some of these stations survived the Chinese revolution of 1911, but Peter Lavelle observes several marked shifts in agricultural programs during the 1920s. Japanese influence waned and the United States emerged as the dominant influence on Chinese agronomy. Universities, rather than provincial governments, were now the epicentre of agricultural improvement, and they narrowed their focus to a select few industrial and food crops, like wheat and cotton (Lavelle 2015, 340-341).

By the 1930s, however, circumstances had changed. China had developed its own network of agricultural improvement organs thanks in part to direct exchanges with the United States, as institutions (most famously the Rockefeller Foundation) and missionaries (most famously John Lossing Buck) made inroads at Chinese institutions (especially in Nanjing). Meanwhile, improvement agriculture in the U.S. was experiencing its own changes. Deborah Fitzgerald chronicles the rise of an 'industrial ideal in American agriculture', in which farming came to resemble factory manufacturing during the $1920(2003,22-23)$. Certain aspects of this transformation were impractical for China, such as mechanization, which was too costly to implement and uneconomical on small farms. However, the Guomindang's agrarian organs did implement other aspects of farm industrialization. These include the establishment of agricultural colleges, which led to the emergence of an agricultural professional class, and concomitantly what Fitzgerald describes (in the American context) as a 'reliance on managerial (rather than artisanal) expertise, and a continual evocation of "efficiency" as a production mandate' $(2003,23)$, at least at the state-run agricultural stations.

By the 1930 s there was renewed interest in implementing a programme of experimental agriculture in Kham in line with those of more developed provinces. Multiple authors presaged the eventual founding of the Xikang Province Bureau of Agricultural Improvement; for example, Chen Chongwei's The Xikang Problem (Xikang wenti) envisioned agricultural experimentation stations and an Agricultural Research Council under a Ministry for the Management of Agricultural and Forestry Affairs $(1930,192)$, while Zhang Yunping's 'Tunken Recommendations' similarly proposed that the Xikang administration establish agricultural experiment bureaus in each county 
$(1931,43)$. In the following decade Huang Fensheng invoked the goal of developing scientific and industrial agriculture on the frontier, pontificating that 'primitive modes of agriculture no longer meet our national defence needs in the borderlands' $(1946,185)$. Huang's statement in particular reflects the synthesis of industrialist and agrarian ideals in the larger discourse on the Chinese nation. When Xikang Province officially launched its Bureau of Agricultural Improvement in 1939, these aspirations provided it with a clear mandate: to grow where no Han had grown before.

\section{The Xikang Provincial Bureau of Agricultural Improvement}

The Xikang Provincial B.A.I. was chartered in April of 1938 but was officially launched on January first, 1939, the inaugural day of the province. Under the direct authority of the Xikang Province Establishment Office, the B.A.I. oversaw public forestry, husbandry, and agriculture in the province's three administrative zones of Kham, Ning, and Ya. Its programmes in the relatively low-altitude Ning and Ya zones were ecologically diverse and included paddy (rice) farming and silk production, but its Kham farms were designated as sites for research on 'high-cold' (gao han) crops and livestock. The bureau's two chief sites were located in Simaqiao, near Kangding, and Taining, to the northeast of Kangding bordering Daofu County.

An immediate benefit of Xikang's establishment as a province is that the provincial B.A.I., being under the tutelage of the national Department of Agriculture and Forestry (Nonglin bu), could tap into a national network of educated professionals, including agrarian specialists educated at China's premier schools of agriculture. The typical professional (zhiyuan) migrant to Xikang was a male between the ages of 20 and 40 with some higher education, but staff came from diverse geographical and professional backgrounds. Duan Tianjue typifies these professionals; a native of Anhui Province, he graduated from National Southeast University in 1925 and made a career of education and scientific cotton farming in his home province, then travelled to the United States on the provincial dime for an agricultural survey tour. Shortly thereafter he moved to Xikang to become a member of the Provincial Establishment Council (Jian sheng hui). Duan became vice-chairman of the B.A.I. and then chairman in 1945, frequently intermediating between its various sites and Governor Liu. Many other professionals moved to Xikang from sites along the war-torn and heavily-populated east coast, including Hubei, Anhui, Jiangsu, Zhejiang, and Shanghai (S.A., Min 249-156). 
The B.A.I. was also linked to a national network of plant matter. Experimental sites like that at Simaqiao sent letters soliciting seed packets to research sites and schools of agriculture around the country, as well as other B.A.I. sites within Xikang, and catalogued their holdings on hundreds of index cards. The largest donor by far was the National Central University, conveniently based in Chongqing during the war. The Xikang B.A.I. received seed stock for nationally-designated 'good varieties' (youliang pinzhong) of major crops and tested them at experimental stations in Kham to see whether they could thrive in a 'high-cold' environment. In turn, Liu Wenhui authorized the extension of certain premium varieties in the Kham administrative zone as designated by the B.A.I., some of which came from other regions but some of which were apparently indigenous. If late Qing officials were dismissive of Khampa farmers because 'they did not cultivate "proper" crops', as Scott Relyea highlights (this volume), these culinary prejudices were institutionalized in Republican China through the designation of good varieties.

However diminutive they were in relation to Kham's vast land area, the sites run by the B.A.I. were models of agrarian nationalism that melded economic and social functions in keeping with the modern tunken vision. They were farms and laboratories, but they were also model communities that engaged neighbouring communities. I would argue that through the B.A.I., the modern Chinese state employed what James Scott calls 'miniaturization' as a response to adverse conditions in Kham, which he defines as 'the creation of a more easily controlled micro-order' in such things as model villages and model farms $(1998,4)$. Much as American agronomists in Republican China 'generally dwelt in protective bubbles' (Stross 1986, 13), the Han personnel at Xikang's Kham dependency stations were relatively isolated within their agricultural micro-orders. It was the manageability of these sites, rather than their size, that allowed Han agronomists to envision large-scale transformations in Kham.

Whereas Zhao Erfeng had focused his agrarian efforts on the Bathang valley, the administration of Liu Wenhui turned its attention south. In principle, each Xikang county was to have its own agricultural station, or nongchang, subordinated to the county government. But only two farm sites within the Kham administrative region were directly administered by the province: Simaqiao and Taining (see Map 6.1). These were the B.A.I.'s primary interface with the growing conditions of Kham, and experimental results at these sites were distilled into directives to extend (tuiguang) premium varieties and growing methods throughout the counties of Kham. Below I employ a rich body of bureau archives to reconstruct a virtual tour through each of these sites. 
Map 6.1 Map of Xikang territory showing the locations of the Simaqiao and Taining experimental stations

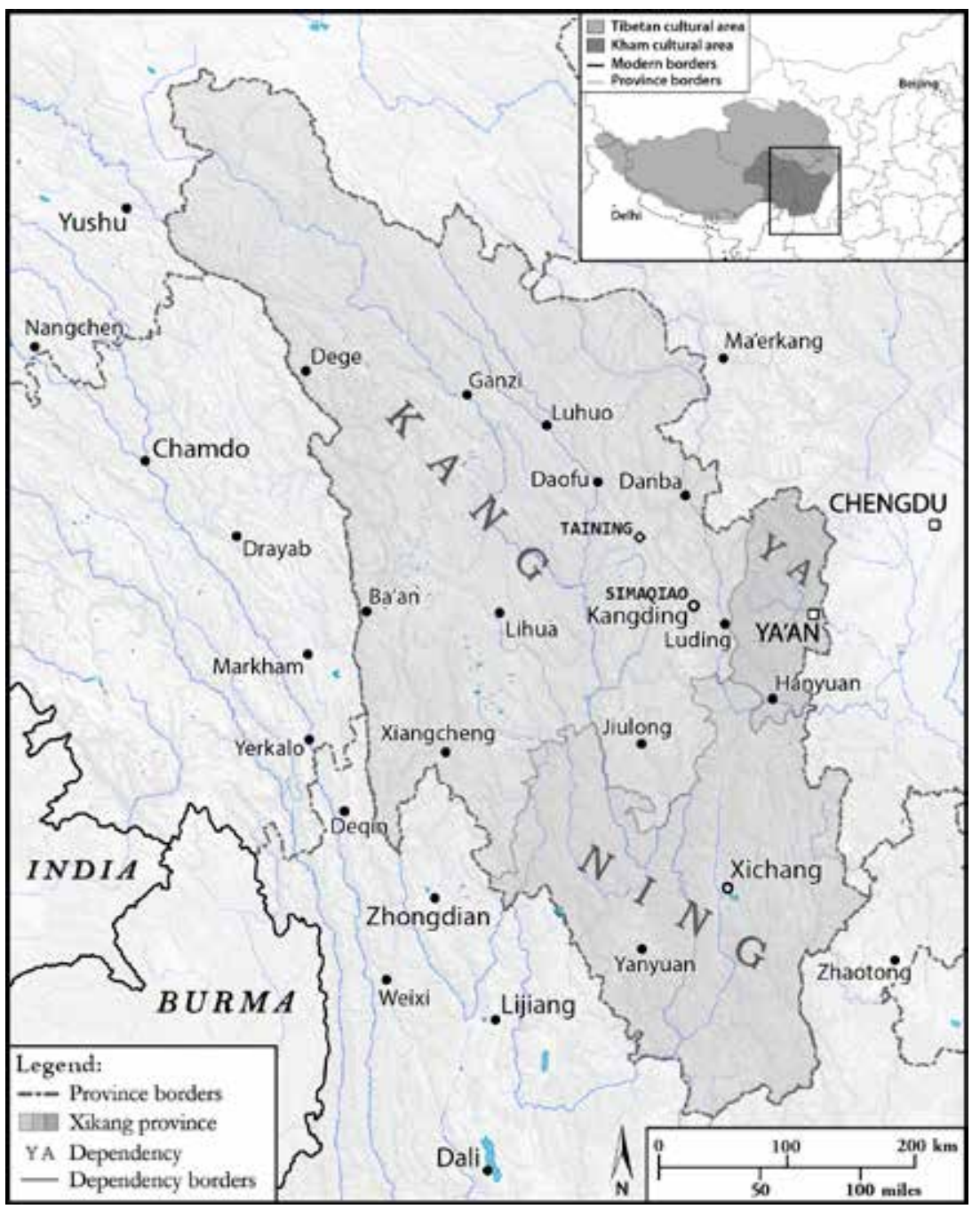

Sources: Based on Chen \& Chen $(2003,22)$; SRTM (NASA) and modern administrative borders extracted from GADM database (www.gadm.org, v.2.5 July 2015) Authors: Rémi Chaix and Mark Frank

\section{Simaqiao}

Situated in a mountain valley at 2650 metres above sea level and fifteen $l i$ $(7.5 \mathrm{~km})$ south of the provincial capital of Kangding, the experimental site 
at Simaqiao was founded in 1940 by the provincial B.A.I. and charged with overseeing research on 'high-cold' crop varieties. Kangding (Dartsedo) in southern Kham was set at the confluence of two rivers and host to a large Han population, so it seemed like a natural site for the province's first crop experimentation station. The site initially planted some $84 \mathrm{mu}$ of farmland, expanding this on a yearly basis.

Interestingly, the B.A.I. leased most of this land from local landlords, including the French Catholic mission in Kangding and at least two prominent Tibetan guozhuang trading houses: the Wesekyap (Ch. Wasidiao) trading house and the Zhabpetsang (Wangjia) trading house. ${ }^{13}$ The largest tract of land belonged to the See, which provided $40 \mathrm{mu}$ (6.6 acres) of waste (S.A., Min 249-1-140). The mission had in turn purchased this land from the Chakla King (Mingzheng tusi), at a price of 3000 taels of silver, and hired labourers to open it for cultivation at a wage of eight yuan per $m u$, then rented it to tenants (Ren Naiqiang 2009 [1931], 3-4). The mission had also cultivated plots in Luding and Ba'an, and Kham scholar Ren Naiqiang felt that the French had succeeded where Zhao had failed. 'Such a vast stretch of fertile earth Han people have not been able to cultivate in over two hundred years of management, he remarked, but the French Catholic church has cultivated it in our place - how disgraceful ought this to be?' (Ren Naiqiang 2009 [1931], 4).

The B.A.I. began planting land in Kangding under informal lease agreements, but the concerned county magistrate implored the bureau to sign formal contracts 'to avoid conflict'. At 10 a.m. on 29July 1940 the acting head of the B.A.I. met with representatives of its three Simaqiao landlords at the office of the magistrate to negotiate lease terms and sign contracts. These each stipulated a 20-year lease term at a price the equivalent of sixteen jin of highland barley per mu per year after the harvest at current prices, but they made an exception according to a local custom: newly opened wasteland (uncultivated earth) was rent-free for the first three years in compensation for the labour of clearing and tilling it (S.A., Min 249-1-81). The B.A.I. additionally negotiated a contract for use of the county's state farm, with the condition that land from the Catholic church and other landlords be used first. Absorption of the state farm would disrupt its current work, and farm labourers were to be compensated for labour and materials over the past season; the B.A.I. was also to offer current farmers position as farm labourers (nong gong), or assist in their relocation (S.A., Min 249-1-81, p. 98 ). Ten farmers received compensation for human labour, cattle labour, fertilizer

13 Many thanks to Yudru Tsomu for personally helping me to identify these trading houses by their Chinese names. More can be found on both trading houses in Tsomu (2016). 
and seeds, totalling 2453.6o yuan, and they appear to have been retained as labourers (S.A., Min 249-1-81, p. 96). Under the administration of the B.A.I., the repurposed Simaqiao state farm had the ambitious goal of transforming agriculture in Kham by working on modest parcels of (mostly) rented land.

As with other sites run by the B.A.I., there was a division of labour between administrative staff (zhiyuan) and labourers (gongyi). Labourers were more likely to be local in origin, slept in cramped dorms, and were responsible for the back-breaking work of clearing waste, tilling fields, planting and harvesting, and so on. From approximately February through September of each year workers tended to their crops, while October through February were devoted to various other activities: threshing the harvest, clearing the fields, experimenting with winter planting, composting fertilizer, but also the critical (if tedious) task of kaiken, or opening up waste to cultivation. Quotas were set for how much waste a single labourer was to reclaim per day: if they shouldered their own yoke, 500 square shichi ( 167 square metres); with a single-ox plough, $2.5 \mathrm{mu}$ (1536 square metres); with a double-ox plough, at least $3 \mathrm{mu}$ (1843 square metres) (S.A., Min 249-1-11).

Improvement work at Simaqiao focused on staple crops. Highland barley (qingke) was the predominant crop in the environs of Kangding and a staple of Tibetan diets, but it was not particularly palatable to Han migrants and the Simaqiao station sought viable alternatives. It also sought options for increasing the number of growing seasons in the region from one to two by experimenting with different crops and methods. In some ways its mission was anticipated by the Catholic church, which had been introducing new bio-matter for years. Among the bureau's earliest experiments in Simaqiao was a planting period experiment on a variety of rye that was introduced to local communities by the French priest, to determine its viability as a winter crop. Other crops grown at Simaqiao initially included wheat, potatoes, barley, highland barley, oats, broad beans, French beans, peas, corn, and buckwheat. In 1940, potatoes provided the largest yield by far at 4072 jin, followed by highland barley at 1078 jin.

Shortly after its establishment, the Simaqiao Agricultural Experimental Site performed a survey of farming practices in the surrounding area and found that wheat, though morphologically similar to highland barley, was entirely absent from nearby farms. The surveyors learned that local farmers had little interest in wheat since it competed with barley for time and farm space, but did not perform as well. Because wheat was far more palatable than highland barley to Han migrants, introducing wheat to the region was an early priority. The challenge was finding a suitably cold-resistant variety: the maiden crop of wheat planted in the spring of 1940 put forth 
ears but yielded a disappointingly low amount of grain, which researchers attributed to the region's short growing season (planting occurred later than in lowland regions) (S.A., Min 249-1-33).

Potatoes were already moderately popular in the region by 1939, and the site worked to further encourage their cultivation. This aligned with national policy, since experts promoted potatoes throughout China as a solution to the Chinese famine of 1942-1943. In a memo to B.A.I. chief Duan Tianjue, the Simaqiao site chief Liang Daxin noted that 'potatoes are a disaster relief crop and a wonderful vegetable, and the environment (fengtu) of Kangding is very amenable to the production of this crop. Our site has observed this and thus decided to implement large-scale planting, and to encourage planting among farmers in the vicinity' (S.A., Min 249-1-78, S.A., p. 10). Though promotion work was a large part of the Bureau's mission, usually through lectures and demonstrations, Simaqiao was exceptionally aggressive in promoting potatoes. Not only did it distribute 6050 jin of seed to fourteen nearby households, but it leased out $26 \mathrm{mu}$ of land to four households with the stipulation that they pay yearly rent in potatoes. When loaning potato seed, the site forecasted 600 per cent returns and levied $5^{\circ}$ per cent interest, such that a farmer receiving 1000 jin of seed should expect a yield of 6000 jin and return 1500 jin to the bureau. At the same time, the site planted 70 $m u$ of its own land with potatoes and anticipated a harvest of 84,00o jin in the fall of 1943 (S.A., Min 249-1-78, S.A.).

Meanwhile, the B.A.I. persisted with its wheat experiments. After his disastrous attempt to grow wheat in Bamei at 3500 metres above sea level, Zhang Jinquan moved south to Kangding and repeated his attempt at lower altitude. There was no guarantee that this would succeed, and indeed, technicians at Simaqiao had thus far failed to grow edible wheat in their plots outside the southern gate. Over a span of three growing seasons from 1944-1946 Zhang experimented with altering two major variables in wheat production: the planting period and the varieties planted. In the first year Zhang solicited 25 wheat varieties from the Central Bureau for Agricultural Research (Zhongyang nongye shiyan suo), and by the second year he had narrowed the list to nine viable varieties, which he then tested the indigenous staple of highland barley. In the third year Zhang re-tested these, adding Simaqiao's original wheat variety (Zhang Jinquan 1947).

By 1946 he arrived at a breakthrough: Not only did wheat variety Zhongda III 23-2419 (known today simply as 'Nanjing Wheat') put forth full ears, it also out-produced the control variety of highland barley. Two other wheats, \#100 and \#69o matched this top yield within the margin of error. Moreover, Zhang simultaneously tested the same ten varieties in Bamei (3500 metres) and East 
Eluo (3100 metres) in 1946 and found that the same varieties out-performed local highland barley there as well. Another variety, \#487, displayed the shortest growing period, making it a candidate for higher elevations. Planting period trials further demonstrated that the best results were achieved by planting as soon as the earth thawed in the spring, given the early onset of frost at harvest time. In his report, Zhang concluded that 'these four varieties can be extended throughout Kham, and that generally wherever highland barley can grow, these wheats can grow' (Zhang Jinquan 1947, 32). Finally, the ambition of the B.A.I. to replace indigenous barley with wheat seemed empirically feasible.

Though Simaqiao would continue to operate until the Communist takeover and beyond, its prominence as a research site seems to have peaked with the culmination of this experiment. In 1946 it reported an 'enormous funding shortage', and its scope encompassed little more than wheat and grazing grass improvement (S.A., Min 249-147, S.A.). In its role as an experiment station, Simaqiao was eclipsed by the more ambitious target of Bamei, situated in the Taining Experimental Zone.

\section{Taining}

About a half-day's ride to the northwest between Kangding and Daofu counties was a stretch of hills and grasslands known as Taining, site of Xikang Province's oldest experimental farms (see Figure 6.1). ${ }^{14}$ Taining was already a Qing military post by the early eighteenth century, but the rapid expansion of Chinese mining operations and seizure of Khampa farms in 1904 led to discontent among indigenous locals and, ultimately, an anti-settler uprising the following year (Relyea 2015, 190-192). This only resulted in consolidation of Qing power over the area, and it became an early target for state intervention in livestock and agriculture. In 1913 an agricultural society proposed Taining as the initial site for a large-scale colonization project in Kham (Relyea 2015, 199). Zhang Yunping's 1931 Tunken Recommendations accurately predicted both Taining and the environs of Kangding as initial sites for a renewed attempt at migrant land reclamation. Presciently, Zhang $(1931,42)$ understood that the Chinese state must venture into yak husbandry if it wished to control Kham, and that Taining was well suited for such a venture.

14 Taining was the oldest extant experimental zone in Xikang Province after 1939; Qing experimental farms predate it but were closed by the time that Xikang Province was founded. 
Figure 6.1 B.A.l. staff member (name unknown) standing in front of an entrance to the headquarters of the Xikang Provincial Taining Pastures in 1939

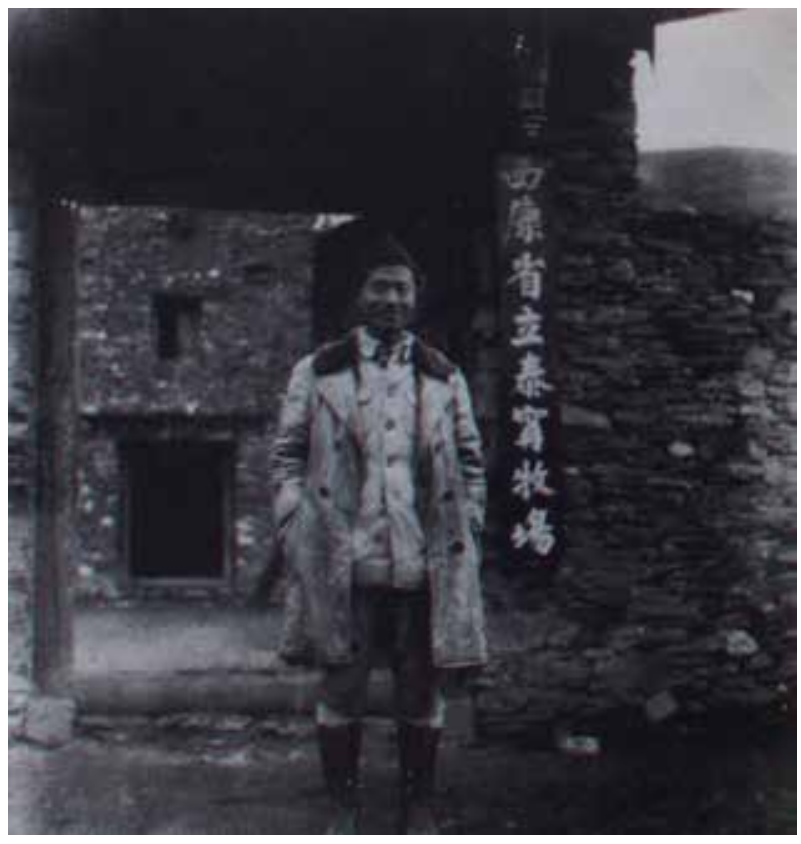

Source: Sun and Zhang $(2003,150)$

The experimental station at Taining preceded the establishment of the provincial B.A.I., and indeed, the establishment of Xikang Province itself. It was founded in 1937 by the Provincial Preparatory Committee as the Taining Cultivation and Pastoralism Experimental Site (Taining kenmu shiyan chang), then placed under the B.A.I. in 1942 and renamed the Xikang Provincial Taining Pastures (Xikang sheng Taining muchang). By 1946 it managed a large swathe of land, including 23,000 shimu of pasture and 4200 shimu of farmland (S.A., Min 249-147). Though Taining was deceptively close to Simaqiao, its climate was considerably harsher. In 1939 a provincial weather observer stumbled into the meteorological bureau in Kangding after a disastrous attempt to reach Taining on horseback; his partner's horse had collapsed, and the pair had fallen ill after being 'caught in the wind and rain'. Days later, another meteorologist travelled from Kangding to Taining for survey work and developed a hacking cough that would plague him until his evacuation from Kham the following year (S.A., Min 249-1-170).

In contrast to Simaqiao, Taining seems like a counterintuitive site for heavy state investment. The Xikang Tongzhi raves about the region's 
potential, calling it 'conducive to pastoralism and conducive to agriculture' (X.T.G., S.A., 111). But other, more detailed sources paint a less sunny picture: as of 1943, 70 per cent of Taining's area was deemed to be 'incapable of production' and 40 per cent suffered from a 'severely cold climate unsuitable for forestry or pastoralism' (S.A., Min 234-01-0253). The county experienced as little as 45 days of frost-free growing time annually. In 1943 frosts are recorded as continuing until June fifth; on July twentieth temperatures reached 23 degrees Celsius during the day but once again dropped to zero degrees overnight. Workers awoke to find that frost had obliterated the entire potato crop, half of the peas, a large portion of the wheat and some of the highland barley. In a petition to the central Ministry of Agriculture and Forestry, administrators predicted that 'if frost continues to descend, there will be nothing to harvest in the entire Taining belt this year'. Yet provincial funding for the Taining site nearly kept pace with Simaqiao, ballooning from about 64,00o yuan in 1939 to about 66o,ooo in 1946 (S.A., Min 249-147). Why?

The establishment of the Taining site was predicated on an understanding that the economy of Kham was dominated by mobile pastoralism, and that the state would need to engage this livelihood if it hoped to remain viable (Frank 2018, 32-33). The focus here was on high-altitude livestock of the sort conventionally held by indigenous Khampas - chiefly yaks (and hybrid $d z o$ ), sheep, and to a lesser extent, horses. Initially the Taining ranch supplied livestock for a state-run Animal Transport Company (Muyun gongsi) that was founded in 1938, although that was a short-lived enterprise (Lawson 2013, 306). The B.A.I.'s long-term priorities were to improve wool quality and quantity of sheep wool, and to increase the stature and dairy production of yaks (X.T.G. 319-320). In a 1945 work report, the Taining site's activities were enumerated as follows: 1) choosing livestock varieties; 2) improving livestock technology; 3) improving and transporting livestock products; 4) grazing grass and fodder crops experiments; 5) promoting optimal livestock breeds; 6) managing livestock hygiene and preventing veterinary disease; 7) survey and statistics on livestock; 8) other matters pertaining to livestock improvement (S.A., Min 249-1-13).

Taining was a more ethnically mixed community than Simaqiao, although roles were allotted unevenly. Formally educated Han migrants occupied all administrative positions while Khampas as well as local Han were most likely to be herders or labourers. By 1946, the site employed sixteen staff, eight manual labourers, and an additional four farm and livestock hands (S.A., Min 249-1-147). Considerably larger than Simaqiao, the Taining Pastures were actually three branch sites in a triangular arrangement linked by the 
seasonal migration of livestock. Facilities at each site allowed for the migration of workers, somewhat resembling a bureaucratic version of indigenous drokpa (pastoralist) clans that also migrated their animals between three to four seasonal pastures. The primary branch was at Bamei, where, as of 1945, the headquarters enclosed three offices, a laboratory, an animal clinic, ten livestock pens, multiple store rooms and granaries, and facilities for the on-site workers (S.A., Min 249-1-13).

Even as livestock specialists mimicked indigenous pastoral practices, they sought to improve on them through agriculture. Globally, modern industrial livestock farming had turned to fodder as the primary avenue for 'improving' animals, which generally meant increasing their fat, wool, and dairy content (depending on the animal). Indigenous Khampas grazed their animals freely on the grasslands, a practice that the Chinese livestock scientists referred to as 'natural grazing' (tianran fangmu). An early and impactful experiment at Taining under Zhang Zhiyuan set out to determine the effects of fodder feeding versus natural grazing on yak-cattle hybrids (Tib. $d z o$; Ch. pianniu), effectively pitting indigenous practices against Chinese modernity. The results seemed to prove unequivocally that grain-fed $d z o$ developed significantly higher fat and dairy content than naturally-grazed animals, but with the caveat that it was uneconomical to import grain from Xichang, which had provided the fodder used in the experiment (Zhang Zhiyuan 1939). ${ }^{15}$

From that point on, Taining fixed its sights on growing food for yaks and sheep, including fodder crops but also superior grazing grasses that scientists hoped would replace indigenous ones. Fodder crops included (in order of prevalence) highland barley, wheat, oats, hay, and peas, supplying livestock with a diet heavy in carbohydrates and protein (S.A., Min 2491-13). As at Simaqiao, crop scientists at Taining conducted experiments to determine the most productive varieties and the optimal planting periods and methods. International grazing grasses also vied against one another in experiments. The American west served as a model for bovine and ovine production, and in 1946 Taining received an infusion of 56 American grasses to be tested against indigenous varieties, and found eleven of these to be viable; as of 1947 the site cultivated twelve grazing grasses from China and sixteen imported from other countries, primarily the United States (S.A., Min 249-1-136).

After establishing the value of fodder, two more major victories over indigenous methods - this time farming methods - seemed evident when 
scientists attempted to employ deep ploughing and to subvert the local practice of leaving fields to fallow every other year. The only reason a fallow year was necessary, they suspected, was that local farmers did not fertilize properly. Manure production was a major enterprise for the B.A.I., and in fact much of it was made of plants that were grown and composted specifically to produce what is known as 'green fertilizer'. 'After applying fertilizer and planting equally each year', wrote site chief Liang Daxin, 'the result is that crop viability is the same as planting every other year, effectively smashing the superstition among Khampas that crop viability will be poor if they plant every year' (S.A., Min 249-1-13, p. 46). Scientists also experimented with using deeper ploughs than were used by locals, and found that a single shidou of wheat seed now yielded six shidou of grain instead of the usual three - an astounding 100 per cent increase. Imagining the combined results of deep ploughing and fertilizing rather than fallowing, Liang wrote that 'if we are able to extend (tuiguang) these experimental results throughout the Kham region, Kham's grain could increase four-fold' (S.A., Min 249-1-13, p. 46).

By the late 1940s Taining expanded into human food. The site held vastly more land than it needed for experiments, and much of this - tens of thousands of $m u$ - was put to use through the 1944 establishment of a Taining Tunken Zone, through which the state solicited cultivators to convert waste into farmland. In 1947 the experimental zone at Taining Pastures officially branched into growing and experimenting with its own food crops, chiefly wheat and highland barley. But it also began working with greenhouse vegetables, among them carrots, cabbages, peas, garlic, onions, and American cucumbers. Liang Daxin explained that 'the lands beyond the pass (guanwai) are lacking in vegetables and [Taining] has no vegetables to speak of; nutritional vitamins and nutrients cannot be obtained' (S.A., Min 239-1-136, p. 12).

Taining Pastures was broadly touted as a success in its time. One headline read 'Migration for Planting the Borderlands Sets Great Example, Xikang Experimental Planting Succeeds, Taining Experimental Zone Plants over $300 \mathrm{Mu}$ ', and intoned that 'one cannot but beam with happiness' (' $Y i$ min zhi bian', 15). In 1947 the region surrounding Taining Pastures was established as its own county, Qianning County, and the following year the site was renamed the Qianning Provincial Agricultural and Pastoral Site (Shengli Qianning nong mu chang). In 1950 the Communists would rename it the Bamei Agricultural Experimentation Site (Bamei nongye shiyan chang), and this would eventually develop into the Agricultural and Pastoral Scientific Research Institute (Nongmuye kexue yanjiusuo) in 1963 (Wang Chuan 2005, 69). Bamei is to this day a thriving (and largely Han) 
township. While Simaqiao was a fairly conventional growing site, Taining showcased the adaptability of scientific agrarianism to unconventional and environmentally challenging settings.

\section{Beyond the Experiment Stations}

Administrators envisioned the B.A.I.'s experiment stations as incubators for a comprehensive programme of tunken-style development in Kham. In 1942 the provincial government, in consultation with the central Ministry of Agriculture and Forestry, set a land reclamation target of 45,000 shimu in Kham spanning ten counties. ${ }^{16}$ Development was to begin on the outskirts of the Simaqiao and Taining stations, which were declared 'model cultivation districts' (kenzhi shifan qu), and radiate gradually outward. The experiment stations would perform the dual role of modelling scientific land reclamation for neighbouring areas and providing seed for 'good varieties' to incoming migrants in their respective regions. The Simaqiao site was to oversee extension work, including seed distribution, in southeast Kham, while the Taining site would oversee extension west of the Zheduo mountains (A.S. 20-00-63-017-09). ${ }^{17}$

Reclamation efforts were further consolidated in 1944 when the Ministry of Agriculture and Forestry established a 'Taining Tunken Experimental Zone' (Taining tunken shiyan qu) that subsumed all wasteland in the five counties of Kangding, Taining, Daofu, Luding, and Ganzi (A.S. 20-26-039-15). The Ministry appointed a management staff of several dozen personnel, including administrators, technicians, a physician, and a full complement of policemen. Some of the administration held concurrent positions in the provincial B.A.I., including Duan Tianjue, who was appointed head of the experimental zone, and Zhang Jinquan, who was appointed to the role of technician (A.S. 20-87-270-04). In 1944 the Experimental Zone recruited eleven migrant households that opened some 1269 shimu to new cultivation. Meanwhile, recruiters journeyed to northern Sichuan as well as Xikang's own Hanyuan county in an effort to recruit a further 500 cultivators (kenmin) who might eventually colonize 200,000 $\mathrm{mu}$ of wasteland in the cultivation zone (A.S. 20-26-039-15).

16 The ten counties slated for land reclamation included Danba, Jiulong, Yajiang, Luhuo, Ganzi, Ba'an, Lihua, Taining, Luding, and Kangding (20-00-63-017-09, A.S.).

17 Specifically, the Simaqiao agricultural station was assigned to oversee extension in Kangding, Luding, Danba, and Jiulong counties. 
These local schemes meshed neatly with the national tunken ideal of ethnic assimilation through agricultural migration. In the scenario that Duan Tianjue and Xikang superintendent of grain production Liu Yiyan jointly proposed to the central government in 1942, tens of thousands of Han migrants would transform the landscape over several years by planting empirically tested 'good varieties' of wheat, potatoes, highland barley, rye, and peas. The 1943 work plan for Taining alone would require 30,000 migrants to clear and till wasteland, and another 7000 to cultivate it. Duan and Liu specified Han labourers, claiming that Khampas were indisposed to arduous reclamation work by nature. Provincial estimates set the cost of land reclamation in the Kham dependency at twice that of simultaneous reclamation in the Ning and Ya dependencies per shimu, due mainly to the cost of labour (A.S. 20-00-63-017-09). ${ }^{18}$

In retrospect the goals of these extension schemes were unrealistic because they were prohibitively expensive. Theoretically, the province was to pay for tools, fertilizer, and migrant resettlement with loans from the Farmer's Bank of China (Zhongguo nongmin yinhang) and repay these loans with sales proceeds after the harvest. But runaway inflation during the war made long-term financial planning all but impossible. In fact, the Ministry of Agriculture and Forestry was unable to adequately fund even the management office of the Taining Tunken Experimental Zone, which complained in 1944 that its stipends covered less than half of personnel expenses after inflation, such that staff were 'all beset by hardship' (A.S. 20-26-039-15). By the time of the Communist takeover in 1949, labourers had reclaimed at least several thousand shimu within Kham's two model districts, but it is unclear how far the project progressed beyond these areas. ${ }^{19}$

\section{Conclusion: The B.A.I. in Critical Perspective}

Unlike Zhao Erfeng's agrarian exploits during the late Qing, those of the Xikang Provincial Bureau of Agricultural Improvement have been regarded kindly by Chinese historians. The historiography of the P.R.C., while devoting

18 Budgeted land reclamation expenses included seed stock, fertilizer, and farm implements, but worker wages comprised a majority of the budget for the 1943 work plan (20-0-63-017-09, A.S.).

19 There is undoubtedly more information on the outcome of Kham land reclamation efforts in the P.R.C.-era archives of Xikang and Sichuan provinces at the Sichuan Provincial Archives, but I was not granted access to P.R.C.-era documents during my research. See Tan (this volume) for contemporary parallels. 
little attention to Xikang Province, appraises the B.A.I. as having made impressive contributions to both Kham's regional economy and the national war effort in spite of adverse conditions. Wang Chuan writes that the work of the B.A.I. 'may be considered the beginning of agricultural and husbandry modernization for the areas inhabited by Sichuan's Tibetan, Yi and other ethnic groups' (2009, 234), while Liu Jun notes that Xikang became a major domestic supplier of wool products to the war-torn interior, such that 'the people of the borderlands made their own appropriate contribution to the War of Resistance' $(1988,326)$. It is not difficult to imagine that the provincial government might have come closer to realizing its ambitious land reclamation goals had it not been impeded by the bleak wartime economy.

But in evaluating the success of Xikang's 'improvement' efforts, we ought to ask: for whom was agriculture improved? The history of U.S. agricultural interventions in the developing world during the mid-twentieth century, commonly known as the Green Revolution, offers an instructive analogy. The Green Revolution has been widely praised for roughly doubling agricultural production in much of the developing world, but it has also come under criticism. Some scholars argue that the United States initiated environmentally unsustainable patterns of growth by disregarding local ecologies and indigenous practice. Others observe that national security, not altruism, was the driving factor behind these interventions, and that they fostered economic dependence upon the United States. ${ }^{20}$ The logic of 'improvement' foreshadows the developmentalist approach that informed subsequent policies in Kham and greatly impacted local economies, as Giersch aptly shows in his chapter.

Similar criticisms are applicable to the study of Chinese agricultural interventions in Kham. We should not ignore that where the B.A.I. achieved results that it considered successful, it did so according to criteria that it imputed on indigenous agriculture. This is most evident in two scientific endeavours of the B.A.I. that I chronicled in this essay: the effort to identify wheat varieties that could replace highland barley, and the effort to develop a sedentary mode of yak production that out-performed nomadic yak production. In both cases, technicians ultimately seemed to arrive at 'improved' methods that produced higher yields than indigenous methods. In pursuing those results, however, they were driven by ethnocentric concerns that were extraneous to production targets: namely, a cultural preference for wheat over barley, and a cultural preference for sedentism over nomadism. The latter preference is particularly problematic, since Chinese and international

20 For a critique of the environmental impact of the Green Revolution, see Shiva (1989); for a critique of Green Revolution politics, see Perkins (1997). 
scientists now increasingly recognize that nomadic pastoralism has salubrious effects on the grasslands ecology of the Kham region, which faces serious degradation from other human causes. ${ }^{21}$ Nor is mobile pastoralism a more primitive mode of production than sedentary agriculture. Drokpa pastoralism relies on an elaborate system of indigenous knowledge that has been cultivated over many generations, even if this knowledge goes largely unappreciated by the Chinese state (Tan, this volume; Frank 2018, 23-28).

The politics of 'improvement' are especially legible in the context of national discourses on borderlands agriculture. This essay situated local improvement projects within the broader milieu of agrarian nationalism, which looked to agriculture as a source of national strength. The mission of the B.A.I. aligned especially well with national discourses on tunken, a practice that aimed to consolidate (Han) Chinese control in the borderlands through population redistribution. However, the careful reader may have observed a quirk in the timeline: state actors articulated clear visions of tunken development in Kham well before Chiang Kai-shek endorsed that strategy at the highest level. Further inquiry may illuminate the extent to which state-building in Kham informed national policy during the Republican era, and the extent to which tunken-style projects in various borderlands regions informed one another.

\section{Glossary of Chinese Terms}

Bamei

Bamei nongye shiyan chang

Dajinhuang

Danba

Dengke

Derong

Duan Tianjue

Duan Tianzhen

Duiyu yi bing Xikang zhi tunken jianyi

fengtu

Fengquan

Feng Yunxian

gaijin

gailiang
八美

八美農業試驗場

大金黃

丹巴

鄧科

德榮

段天爵

段天楨

對於移兵西康之屯墾建議

風土

鳳全

馮雲仙

改近

改良 


\begin{tabular}{|c|c|}
\hline gongyi & 工役 \\
\hline Ganzi & 甘孜 \\
\hline gao han & 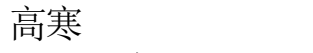 \\
\hline gexin zhidu pai & 革新制度派 \\
\hline gongguo & 工國 \\
\hline gongren shouce & 工人手册 \\
\hline gongzuo fuze & 工作负责 \\
\hline gongzuo qinlao & 工作勤劳 \\
\hline Guangxu & 光绪 \\
\hline guanwai & 關外 \\
\hline guo tu & 國土 \\
\hline jiankang & 健康 \\
\hline Jian sheng hui & 建省會 \\
\hline Jun shizazhi & 軍事雜誌 \\
\hline Kangding & 康定 \\
\hline Kang Youwei & 康有為 \\
\hline kaiken & 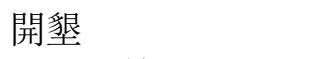 \\
\hline kenzhi shifan qu & 墾殖示範區 \\
\hline Liang Daxin & 梁達新 ～ \\
\hline Litang & 理塘 \\
\hline Liu Wenhui & 劉文輝 \\
\hline Min jiang & 岷江 \\
\hline Mingzheng tusi & 明正土司 \\
\hline $\operatorname{minzu}$ & 民族 \\
\hline Mu yun gongsi & 牧運公司 \\
\hline neidi & 内地 \\
\hline Ning & 寧 \\
\hline Niujiaoshi & 牛角石 \\
\hline nongchang & 農場 \\
\hline nong gong & 農工 \\
\hline nong guo & 農國 \\
\hline Nonglin bu & 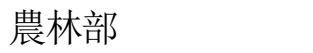 \\
\hline Nongmuye kexue yanjiusuo & 農牧業科學研究所 \\
\hline Nongyi kenzhi ke & 農藝墾殖科 ～～ \\
\hline pianniu & 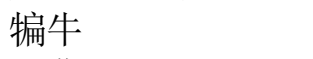 \\
\hline quannong & 勸農 \\
\hline Ren Naiqiang & 任乃强 \\
\hline Shaoniaosi & 少鳥寺 \\
\hline Shengli Qianning nong mu chang & 省立乾寧農牧場 \\
\hline shichi & 市尺 ～～～～～～～～～～～～ \\
\hline
\end{tabular}




\begin{tabular}{|c|c|}
\hline shidou & 市斗 \\
\hline shimu & 市亩 \\
\hline Simaqiao & 馾馬橋 \\
\hline Taining & 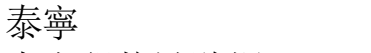 \\
\hline Taining kenmu shiyan chang & 泰寧墾牧試驗場 \\
\hline Taining mu chang & 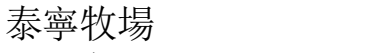 \\
\hline taowang hu & 逃亡户 \\
\hline tianran fangmu & 天然放牧 \\
\hline tudi & 土地 \\
\hline tunken & 屯懇 \\
\hline tuiguang & 推廣 \\
\hline tuntian & 屯田 \\
\hline tunwu ting & 屯務廳 \\
\hline Wangjia & 汪家 \\
\hline Wasidiao & 瓦斯碉 \\
\hline wo guo yi nong liguo & 我國以農立國 \\
\hline$w u w e i$ & 無為 ～～～～～～～～ \\
\hline Xiaojinhuang & 小金黄 \\
\hline Xikang & 西康 ～～～～～～～ \\
\hline Xikang sheng Ning shu tunken weiyuan hui & 西康省寧屬屯墾委員會 \\
\hline Xikang tunken shi & 西康屯墾使 ～～～～ \\
\hline xixiao & 嬉笑 \\
\hline Xin nongbenzhuyi pipan & 新農本主義批判 \\
\hline Ya & 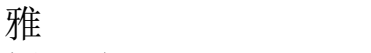 \\
\hline Yang Kaidao & 楊開道 \\
\hline yinong liguo pai & 以農立國派 \\
\hline youliang pinzhong & 優良品種 \\
\hline Zhang Shizhao & 章士釗 \\
\hline Zhang Jinquan & 張錦泉 \\
\hline Zhang Yunping & 張允平 \\
\hline Zhang Zhiyuan & 張志遠 \\
\hline Zhao Erfeng & 趙爾豐 \\
\hline zhiyuan & 職員 \\
\hline Zhongda & 中大 \\
\hline Zhongguo ren & 中国人 \\
\hline Zhou Xianwen & 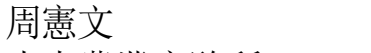 \\
\hline Zhongyang nongye shiyan suo & 中央農業實驗所 \\
\hline zhongyuan & 中原 ～～～～～～～～～～～～～～ \\
\hline Zagunao & 杂谷脑 \\
\hline zhongzu & 種族 \\
\hline
\end{tabular}




\section{Glossary of Tibetan Terms}

$\begin{array}{ll}\text { Bathang } & \text { 'Ba' thang } \\ \text { Dabpa } & \text { 'Dab pa } \\ \text { Dartsedo } & \text { Dar rtse mdo } \\ \text { Tawu } & \text { Rta 'u } \\ \text { Dérong } & \text { Sde rong } \\ \text { Drango } & \text { Brag'go } \\ \text { dra } & \text { sbra } \\ \text { drokpa } & \text { 'brog pa } \\ \text { dzo } & \text { mdzo } \\ \text { Kandzé } & \text { Dkar mdzes } \\ \text { Gyezil } & \text { Brgyad zil } \\ \text { Kham } & \text { Khams } \\ \text { Khampa } & \text { Khams pa } \\ \text { Lithang } & \text { Li thang } \\ \text { Nyakchu } & \text { Nyag chu } \\ \text { Nyarong } & \text { Nyag rong } \\ \text { Rongdrak } & \text { Rong brag } \\ \text { Wesekyap } & \text { Dbal gsas skyabs } \\ \text { Zhabpetsang } & \text { Zhabs pad tshang }\end{array}$

\section{References}

\section{Archives and Primary Source Collections}

A.S. Archives of the Institute of Modern History, Academia Sinica, Taipei J.D.K.Q. Jindai Kang qu dang'an ziliao xuanbian 近代康区档案资料选编 (Selected Archival Sources from Modern Kham). Sichuan sheng dang'an guan 四川省档案馆 (Sichuan Provincial Archives), and Sichuan minzu yanjiusuo 四川民族研究所 (Sichuan Ethnic Research Institute), 1990. Chengdu 成都: Sichuan daxue chubanshe 四川大学出版社

S.A. Sichuan Provincial Archives, Chengdu, P.R.C.

X.T.G. Xikang Tongzhi Gao 西康通志稿 (上册) (Manuscript of the Unified Annals of Xikang Province [Volume 1]). Sichuan sheng difang zhi gongzuo bangongshi 四川省地方志工作办公室 (Office of Sichuan Province Local Gazetteers), 2015. Beijing 北京: Fangzhi chubanshe 方志出版社 
Z.D.E. Zhongguo di er lishi dang'an guan suo cun Xizang he Zang shi dang'an huibian di shisan ce 中国第二历史档案馆所存西藏 和藏事档案汇编. 第十三册 (Collection of Archives on Tibet and Tibetan Affairs Stored at China's Number Two Historical Archives) (Bi Hua 毕华, 马振犊, 中国藏学研究中心, and 中国藏 学研究中心. 2012. Beijing 北京: Zhongguo Zangxue chubanshe 中国藏学出版社)

\section{Primary and Secondary Sources}

Anderson, Benedict. 2006. Imagined Communities: Reflections on the Origin and Spread of Nationalism. London: Verso.

Bello, David A. 2016. Across Forest, Steppe, and Mountain:Environment, Identity, and Empire in Qing China's Borderlands. Cambridge: Cambridge University Press.

Boorman, Howard L. 1967. Biographical Dictionary of Republican China. New York: Columbia University Press.

Cheek, Timothy. 2016. The Intellectual in Modern Chinese History. Cambridge: Cambridge University Press.

Chen Chao 陈潮, and Chen Hongling 陈洪玲, eds. 2003. Atlas of Administrative Divisions of the People's Republic of China 中华人民共和国行政区划沿革地图 集, 1949-1999. Beijing: Zhongguo ditu chubanshe 中国地图出版社.

Chen Chongwei 陈重为. 1930. Xikang wenti 西康问题 (The Xikang Problem). Zhonghua shuju 中华书局.

Chen Yanxiang 陈颜湘. 1933. 'Xikang de Nongye Wenti' 西康的农业问题 (Agricultural Problems in Xikang). Zhongguo geming 中国革命 (Chinese Revolution) 1 (11): 15-19.

Chiang Kai-shek (Jiang Jieshi) 蒋介石. n.d. 'Zhongguo Zhi Mingyun 中国之命运' (China's Destiny). Zheng Qi 正气 (Righteous Spirit) 7:29-31.

'Chuan Xi Diaocha Ji' 川西調查記 (Western Sichuan Survey Report). 2009. In Tang Song Yuan Ming Qing Zang Shi Shiliao Hui Bian 唐宋元明清藏事史料汇编 (Compilation of Historical Materials on Tibetan Affairs in the Tang, Song, Yan, Ming, and Qing Dynasties), edited by Zhang Yuxin 张羽新, and Zhang Shuangzhi 张双志, 第1版, 91:387-449. Beijing 北京市: Xueyuan chubanshe 学苑出版社.

Duan Tianjue 段天爵. 1944. 'Xikang nongye jianshe zhi qianzhan' 西康农业建设 之前瞻 (Forecast for Xikang's Agricultural Development). Xikang Jingji Jikan 西康经济季刊 (Xikang Economy Quarterly) 8: 16-20.

Eastman, Lloyd E. 1988. Family, Fields, and Ancestors: Constancy and Change in China's Social and Economic History, 1550-1949. Oxford: Oxford University Press. Epstein, Lawrence. 2002. 'Introduction'. In Khams Pa Histories: Visions of People, Place and Authority, edited by Lawrence Epstein, 1-6. Leiden: Brill. 
Feng Hao. 2017. 'Yaks Unleashed in Fight against Desertification'. China Dialogue. 14 September 2017. https://www.chinadialogue.net/article/show/single/en/10070Yaks-unleashed-in-fight-against-desertification. Accessed 7 June 2019.

Feng Yunxian 馮雲仙. 1931. 'Muqian Xikang Xingge Zhi Yaodian: Xin, Kaiban Tunken' 目前西康興革之要點: 辛、開辦屯墾 (Essentials for the Reform of Contemporary Xikang: Eight, Initiate Tunken). Xin Yaxiya 新亚细亚 (New Asia) 2 (5):81.

Fitzgerald, Deborah. 2010. Every Farm a Factory: The Industrial Ideal in American Agriculture. New Haven: Yale University Press.

Frank, Mark E. 2016. 'Planting and Its Discontents: Or How Nomads Produced Spaces of Resistance in China's Erstwhile Xikang Province'. Resilience: AJournal of the Environmental Humanities 3:112-141.

Frank, Mark E. 2018. 'Hacking the Yak: The Chinese Effort to Improve a Tibetan Animal in the Early Twentieth Century'. East Asian Science, Technology, and Medicine 48: 17-48.

Fox-Genovese, Elizabeth. 1976. The Origins of Physiocracy: Economic Revolution and Social Order in Eighteenth-Century France. Ithaca: Cornell University Press. Gao Lao 高勞. 1913. 'Xikang Jian Sheng Tan' 西康建省談 (A Discussion on the Establishment of Xikang Province). Dongfang Zazhi 东方杂志 (Oriental Magazine) 9 (11): 6-16.

Havens, Thomas R.H. 2015. Farm and Nation in Modern Japan:Agrarian Nationalism, 1870-1940. Princeton: Princeton University Press.

Huang Fensheng 黃奮生. 1946. Bianjiang tunken yuan shouce 邊疆屯墾員手冊 (The Borderland Tunken Workers' Handbook). Qingnian chuban she 青年出版社.

Huang, Philip C.C. 2015. 'China's Hidden Agricultural Revolution, 1980-2010, in Historical and Comparative Perspective'. Modern China 42 (4): 339-376.

Kingsbury, Noel. 2009. Hybrid: The History and Science of Plant Breeding. Chicago: University of Chicago Press.

Kinzley, Judd C. 2018. Natural Resources and the New Frontier: Constructing Modern China's Borderlands. Chicago: Chicago University Press.

Lavelle, Peter. 2015. 'Agricultural Improvement at China's First Agricultural Experiment Stations'. In New Perspectives on the History of Life Sciences and Agriculture, edited by Denise Phillips and Sharon Kingsland, 323-344. Archimedes: New Studies in the History and Philosophy of Science and Technology, vol. 40. New York: Springer.

Lawson, Joseph. 2013. 'Warlord Colonialism: State Fragmentation and Chinese Rule in Kham, 1911-1949'. The Journal of Asian Studies 72 (2): 299-318.

Lawson, Joseph. 2017. A Frontier Made Lawless: Violence in Upland Southwest China, 1800-1956. Vancouver: UBC Press.

Lei Dongjun. 2013. 'Climate Change, Not Grazing, Destroying the Tibetan Plateau'. China Dialogue. 21 January 2013. https://www.chinadialogue.net/article/show/ 
single/en/5621-Climate-change-not-grazing-destroying-the-Tibetan-Plateau. Accessed 7 June 2019 .

Li, Tania Murray. 2007. The Will to Improve. Durham: Duke University Press.

Lin, Hsiao-Ting. 2007. Tibet and Nationalist China's Frontier: Intrigues and Ethnopolitics, 1928-49. Vancouver: University of British Columbia Press.

Liu Jun 刘君. 1988. 'Jian lun Xikang jian sheng' 简论西康建省 (A Brief History of the Establishment of Xikang Province). In Minguo dang an yu Min guo shi xueshu yantao hui 民国档案與民国史学術研讨会文集 (Selected Papers on Republican Archives and History), 321-331. Nanjing 南京市: Dang'an chubanshe 档案出版社.

Liu Zhaoyou 劉兆佑, ed. 2002. Guoxue daodu 國學導讀(Chinese Cultural Heritage Guided Reader). Taipei 台北市: Wunan tushu chuban gufen youxian gongsi五 南圖書出版股份有限公司.

Merkel-Hess, Kate. 2016. The Rural Modern: Reconstructing the Self and State in Republican China. Chicago: University of Chicago Press.

Chen, Zhihong. 2012. "Climate's Moral Economy”: Geography, Race, and the Han in Early Republican China'. In Critical Han Studies: The History, Representation, and Identity ofChina's Majority, edited by Thomas Mullaney, James Leibold, Stéphane Gros, and Eric Vanden Bussche, 73-91. Berkeley: University of California Press.

Perdue, Peter C. 1987. Exhausting the Earth: State and Peasant in Hunan, 1500-1850. Cambridge: Harvard University Asia Center.

Perkins, John H. 1997. Geopolitics and the Green Revolution: Wheat, Genes, and the Cold War. Oxford: Oxford University Press.

Relyea, Scott. 2010. Gazing at the Tibetan Plateau: Sovereignty and Chinese State Expansion in the Early Twentieth Century. PhD dissertation, University of Chicago. Relyea, Scott. 2015. 'Conceiving the "West”: Early Twentieth-Century Visions of Kham'. Twentieth-Century China 40 (3): 181-200.

Ren Naiqiang 任乃強. 2010 (1931). 'Xikang zhaji' 西康札記 (Assorted Notes on Xikang). In Ren Naiqiang 任乃強 Minguo Chuanbian Youzong ZhiXikang Zhaji 民国川边游踪之西康札记 (Assorted Notes on Xikang from the Republican-Era Excursion), 1-59. Beijing 北京: Zhongguo zangxue chubanshe 中国藏学出版社.

Richardson, H.L. 1940. 'Soil and Man in West China'. Journal of the West China Border Research Society 12B: 102-133.

Schlesinger, Jonathan. 2017. A World Trimmed with Fur: Wild Things, Pristine Places, and the Natural Fringes of Qing Rule. Stanford: Stanford University Press.

Scott, James C. 1998. Seeing Like a State: How Certain Schemes to Improve the Human Condition Have Failed. New Haven: Yale University Press.

Sun Mingjing孙明经 and Zhang Ming张鸣. 2003. 1939 nian: zou jin Xikang 1939 年: 走进西康 (1939: Enter Xikang). Jinan: Shandong hua bao chubanshe山东 画报出版社. 
Shiva, Vandana. 2016. The Violence of the Green Revolution: Third World Agriculture, Ecology, and Politics. Lexington: University Press of Kentucky.

Stross, Randall E. 1986. The Stubborn Earth: American Agriculturalists on Chinese Soil, 1898-1937. Berkeley: University of California Press.

Sun Tong 孤桐 (Zhang Shizhao). 1926. 'Nong Guo Bian' 農国辨 (A Treatise on Agrarian Countries).Jia Yan (Beijing) 甲寅(北京) 1 (26): 8-13.

The Christian Science Monitor. 1939. 'China Builds “Inner Empire” with "Go-West” Movement'. 25 January 1939.

Tsomu, Yudru. 2016. 'Guozhuang Trading Houses and Tibetan Middlemen in Dartsedo, the "Shanghai of Tibet." Cross-Currents: East Asian History and Culture Review. E-Journal 19 (June): 71-121.

Wang Chuan 王川. 2009. Xikang Diqu Jindai Shehui Yanjiu 西康地区近代社会 研究 (Research on Modern Society in the Xikang Area). Beijing 北京: Renmin chubanshe 人民出版社.

Wang, Xiuyu. 2011. China's Last Imperial Frontier: Late Qing Expansion in Sichuan's Tibetan Borderlands. Lanham, MD: Lexington Books.

'Yi Min Zhi Bian Shen Zuo Jiejing, Xikang Shiyan Kenzhi Chenggong' 移民殖邊 堪作借鏡,西康實驗墾殖成功 (Moving People to Colonize the Borderlands Serves as a Great Example, Xikang Experimental Cultivation Succeeds). 1937. Xibei Daobao 西北導報 (Northwest Guide) 3 (12):15-16.

Young, Louise. 1999. Japan's Total Empire: Manchuria and the Culture of Wartime Imperialism. Berkeley: University of California Press.

Zhang Jinquan 張錦泉. 1947. 'Xikang Sheng Kangding Qu Gailiang Xiaomai Shifan Shiyan Zhi Jieguo' 西康省康定區改良小麥示範試驗之結果 (Results of the Model Wheat Improvement Experiment in the Vicinity of Kangding). Zhonghua Nongxue Huibao 中華農學會報 (Chinese Agronomy Proceedings), no. 185:27-32. Zhang Yuxin 张羽新, and Zhang Shuangzhi 张双志. 2009. 'Chuan Xi Diaocha Ji' 川西調查記(Western Sichuan Survey Report). In Tang Song Yuan Ming Qing Zang Shi Shiliao Hui Bian 唐宋元明清藏事史料汇编 (Compilation of Historical Materials on Tibetan Affairs in the Tang, Song, Yan, Ming, and Qing Dynasties), Volume 91, 387-449. Beijing 北京市: Xueyuan chubanshe学苑出版.

Zhang Zhiyuan張志遠. 1939. 'Xikang Runiu Chan Ru Jiliang Shiyan' 西康乳牛產 乳極量試驗 (Experiment on Maximal Dairy Production among Xikang Dairy Bovine).Jianshe Zhouxun建設週訊 (Establishment Weekly) 8 (5).

Zhou Xianwen 周宪文. 1945. 'Zhongguo bu neng yi nong li guo' 中國不能以農立 國 (China Cannot Be a Country Founded on Agriculture). In Zhou Xianwen (ed.) Xin nongben zhuyipipan 新農本主義批判 (A Critique of the New Agrarian Fundamentalism). Guomin chubanshe國民出版社.

Zhuang Junju 庄俊举. 2007. “Yi Nong Li Guo” Haishi “Yi Gong Li Guo" - Dui 19201940 Niandai Guanyu Nongcun Jianshe Zhenglun de Pingxi”以农立国还是“以 
工立国' - 对 1920-1940 年代关于农村建设争论的评析 ('A Nation Founded on Agriculture' or 'A Nation Founded on Industry' - An Evaluation of the Rural Reconstruction Debate of 1920-1940).Jingji Shehui Tizhi Bijiao 经济社会体制 比较 (Comparison of Economic and Social Structures) 2 (130).

Zhang Shizhao 章士釗. 1996. Wei zhengshangyi lun:Zhang Shizhao wenxuan 为政 尚异论: 章士钊文选 (Selected Works of Zhang Shizhao). Shanghai yuan dong chubanshe 上海远东出版社.

\section{About the Author}

MARK FrAnK is a PhD candidate at the University of Illinois at UrbanaChampaign, Department of East Asian Languages and Cultures. He is currently writing an environmental history of Chinese state-building in Kham from 1905-1950. His archival research in mainland China and Taiwan has been supported by American Council of Learned Societies and Institute of International Education Fulbright grants. 



\title{
$7 \quad$ The Origins of Disempowered Development in the Tibetan Borderlands $^{1}$
}

\author{
C. Patterson Giersch
}

\begin{abstract}
Recent research demonstrates that, for over fifty years, the People's Republic of China has tended to pursue development policies that disempower non-Han inhabitants of borderlands regions. Using Kham as a case study, this chapter demonstrates that the production of economic inequality, especially across ethnic lines, did not originate in the Communist period nor in actions of the state alone; instead, the sources of ethnic inequality were deeply entangled with trends in private corporate commercialization as well as with nascent statist approaches to modern economic and political development. To reevaluate the key elements of Chinese development, we must employ longer-range historical frameworks, and we must consider borderlands regions such as Kham, where diverse, and sometimes unexpected, actors have produced long-term impacts.
\end{abstract}

Keywords: borderlands, economic inequality, ethnicity, Kham, modern commerce

\section{Introduction}

In 1957, when Communist Party work teams entered Qiongshan Village in the old Khampa region of Drakteng (Danba), they were looking for links

1 I wish to thank Stéphane Gros and Yudru Tsomu for their many fine suggestions for this chapter. Their contributions were invaluable, but any remaining mistakes are mine.

The term 'disempowered development' is borrowed from the book title of Fischer (2014).

Gros, Stéphane (ed.), Frontier Tibet: Patterns of Change in the Sino-Tibetan Borderlands. Amsterdam, Amsterdam University Press 2019

DOI: 10.5117/9789463728713_CHO7 
between exploitation and poverty, and they found them. One farmer, a Khampa named Peldengyel (Bandeerjia), farmed 7.5 mu (o.5 hectares) of land granted to him by the local Drakteng king (gyelpo), also known as the Badi tusi. In return, Peldengyel owed grain tax and corvée labour. But these burdens had proven too great at some point in the past, and, to make ends meet, Peldengyel had mortgaged three $m u$ of his land, taking on the dreaded high-interest loans that helped reinforce regional hierarchies of power and subordination. To pay the interest, Peldengyel continued to farm all his assigned land, but the grain from his three mortgaged $m u$ went to pay interest on his debt, leaving his family of six to subsist on a measly 400 litres (four dan) of grain for the year. This amount of grain provided, perhaps, just enough calories for one adult male, ${ }^{2}$ and the family did what 80 per cent of their neighbours did: To make ends meet, they sought sidelines, which, in this case, was collecting plant and animal products that could be sold into China's vast herbal medicine markets ('Danbaxian Badi xiang Qiongshan cun shehui diaocha' 1958, 28-29).

In March of 1957, Peldengyel's family collected twenty kilos (forty jin) of qinjiao (Gentiana macrophylla), which they sold for two silver dollars (dayang), and in April, they dug 100 caterpillar fungi (chongcao), which they sold for one silver dollar. In June, they dug a half kilo of beimu (Fritillaria thunbergii), which earned them another four silver dollars, and then in August, they had their best month, digging about fifteen kilos of qianghuo (Notopterygium incisum) and 25 kilos of Chinese rhubarb (dahuang), for a take home of eight silver dollars. Since each silver dollar could be exchanged for ten litres of grain, the fifteen silver dollars was the equivalent of producing another 150 litres of grain. At some point during the year, the family also harvested four musk deer, and they exchanged the musk pods for about 400 litres of grain. They also hunted other wild animals, bringing in the equivalent of 200 litres of grain. Like so many Khampas in his region, then, Peldenyel relied heavily on market-oriented sidelines to survive; his land grant produced only a net of 400 litres of grain, but his sales of medicinal materials brought in the equivalent of another 750 litres of grain. This grain

2 The grain was most likely barley and/or corn. Corn has more calories than barley, so if we assume that the entire crop was corn, then we can make the following calculations: according to the U.S.D.A., there are 2561 calories per litre of white corn. Four hundred litres of corn thus contains 1.0244 million calories, providing the family with an average of a little over 2877 calories per day - or just enough for one adult male. Active adult males need at least 2800 calories per day. Active adult females need 2200 to 2400 calories per day. Sources: United States Department of Agriculture, Agricultural Research Service, 'National Nutrient Database'; United States Department of Agriculture, Centre for Nutrition Policy and Promotion, 'Estimated Calorie Needs per Day'. 
provided up to an additional 5395 calories per day, which was still probably not enough, but got the family much closer to their caloric needs than farming alone. Thus, Peldenyel's non-farming income constituted almost two thirds of the total, a relatively large percentage in a village where the average for sideline work was about one third of total income ('Danbaxian Badi xiang Qiongshan cun shehui diaocha' 1958, 28-29).

The Party work teams used this type of information to demonstrate how people such as Peldengyel were trapped in cycles of poverty. They owed rents, taxes, labour, and interest to the powerful kings, headmen, or monasteries who granted them land, and these obligations might be associated with a loosely-defined sort of feudalism. But lying in plain sight alongside this 'feudal' exploitation were two other powerful mechanisms of economic disempowerment that the Communist Party would, ironically perhaps, find very useful to wield themselves: the market and the state. Long before collectivization, much less the post-1979 market reforms, the Sichuan provincial and national Chinese states, along with powerful merchant interests, were already limiting the financial opportunities for most Khampa families. This chapter explores how this process - usually associated with the Communist era - originated in the early twentieth century. As Stéphane Gros notes in the Introduction, the study of the borderlands allows us to challenge centrist narratives, including the cherished idea of the 1949 Revolution's heralding a radically new era. Recent scholarship has demonstrated how ideas and institutions from the Republican era influenced minority communities into the 1950s and beyond (Mullaney 2011). In the case of this chapter, our investigation into disempowered development is critical for understanding China's past and present because it suggests that the production of economic inequality, especially across ethnic lines, did not begin in the Communist period; instead, the sources of ethnic inequality were deeply integrated in Chinese institutions, both public and private, from the beginnings of modern economic and political development.

\section{Disempowered Development in the Borderlands}

In studies of China's economic development, it is well known that the state and market have been used to disadvantage indigenous communities in their own homelands, but these studies are generally limited to the post-1949 or post-1979 eras. ${ }^{3}$ In her work on Tibet, for example, Emily Yeh (2013) describes

3 See, for instance, Bhalla and Qiu (2006); Gustafsson (2016); Shih (2007); Sturgeon (2010). One notable study of earlier eras is Kinzeley (2018). 
how the Communist Party, after 1956, violently imposed state farms and communes in order to imprint Chinese authority over Tibet. In the reform era (1979-present), the state orchestrated investment projects and selective market reforms to 'gift' development to Tibetans; however, this gift has facilitated Han domination of new economic opportunities, leaving Tibetans both marginalized economically and victims of largely successful efforts to depict them as backwards and underdeveloped (Yeh 2013, 6, 21). One main cause of marginalization, Andrew Martin Fischer (2014) argues, is the Chinese state's vision of development, which removes decision-making power from the region and its inhabitants. As a result, Tibet has an economic structure, says Fischer $(2014,24)$, that 'is effectively very similar to that of a colonial-type economy', meaning there are high degrees of aid-dependence and political disempowerment; the control of development funds usually rests in the hands of Han Chinese-dominated institutions.

The imposition of such economies on indigenous peoples is not unique to China. While statesmen and economists have long waxed lyrically on the benefits of development, its implementation in conquered communities is at best a tricky process and, at worst, an often intentional process of disempowerment and subjugation. In the United States, for example, Native American reservations have long been notorious for their levels of economic distress. For white Americans, these conditions became naturalized. Poverty and dependency, it was believed, were the inevitable outcome of primitive lifestyles and backwards cultures (White 1983, 315). But Native American dependency was not a product of culture. Many indigenous communities had successful and stable food security in the nineteenth century. But this food security was undermined by the growth of two crucial institutions: the American state and markets. Poverty and dependence were imposed from the outside (White 1983, 315-321).

In the U.S., the advent of market economics has long been linked to the patterns of dependence among indigenous peoples, and that dependence was exacerbated by the state. As early as the 1920s, the U.S. federal government introduced economic development schemes onto Native American reservations, but policymaking and control of resources remained in the hands of outsiders. It was only in the 1980 s, after a decade or more of efforts to return developmental autonomy to indigenous communities, that some tribes began to experience some economic successes. The White Mountain Apaches of Arizona, for example, developed nine tribal enterprises, including a ski resort and sawmill, that employed a mostly Apache workforce and brought in over U.S. $\$ 46$ million per year. According to work by Cornell and Kalt, the White Mountain Apaches and other successful tribes share 
one crucial trait - they all gained control over economic decision-making and institutions (Cornell and Kalt 1989, 24). Those tribes who lost control to outsiders found it hard to implement successful development plans. Cornell and Kalt could not find any other factor that was as uniformly important to success as developmental autonomy - not even resource endowment or culture (in the form of governance institutions and economic organization). The most important factor was local control over firms and resources.

As did the U.S., the People's Republic of China has usually prevented local communities from gaining control over resources and development decisions. In Xinjiang since the 1950s, the Party, state, and military have dominated the institutions of development and made Xinjiang a region run by State Owned Enterprises (Becquelin 2004, 44-64). In other borderlands provinces, where non-Han indigenous populations are numerous, State Owned Enterprises also control abnormally high percentages of the economy (Batson 2015). As in the U.S., there have been some efforts to return control to local communities. In 1985, for example, the Guizhou provincial government began to use tourism as a developmental strategy in impoverished areas, and planners focused on locating tourism in poor counties and facilitating local participation in new business opportunities. The Guizhou economy did not grow as quickly as did neighbouring Yunnan Province's economy, where tourism was also being promoted as a development strategy, but in Guizhou poverty rates declined more rapidly than in Yunnan. One reason was Guizhou's decision to facilitate local participation. In contrast, Yunnan allowed outside investors and firms to dominate the growing tourism industry, thus excluding locals from many opportunities (Donaldson 2007).

Guizhou's approach to poverty reduction seems to be an outlier in the history of modern China. Overall, the Beijing and provincial governments tend to pursue development policies that disempower non-Han inhabitants of the borderlands regions. As Fischer notes,

within the context of continued political disempowerment of Tibetan locals, centrally directed development strategies since the mid-199os have channeled massive amounts of subsidies and subsidized investments [...] through Han Chinese-dominated state structures, corporations, and other entities based outside the Tibetan areas, thereby accentuating the already highly externalized orientation of wealth flows in the local economy. (Fischer 2014, 29)

Thus, Fischer and other scholars of development in contemporary China point to state decision-making and, as with Yeh (2013), to markets controlled 
by migrant Han, in order to understand the disempowerment of indigenous communities.

The Chinese Communist Party (C.C.P.) is clearly responsible for the strategies of disempowered development over the last sixty years. But if this were the end of the story, then the solution would be clear (but not simple) - note how blame lies at the feet of the C.C.P. and then reform its development ideas and strategies. However, the problem is that the story does not begin with the C.C.P.'s socialist transformation in the $1950 \mathrm{~s}$ and continue with the market reforms of the post-Mao era. The ideas and institutions that underpin disempowered development in China emerged in the borderlands at the same time as the concepts of Chinese nation-state formation and economic development themselves.

For Peldengyel and other ordinary Khampas, disempowerment was not something lurking in the future - once the Party gained control. They had already experienced major economic, political, and social changes caused by market economics and a powerful developmentalist state. To the south of Peldengyel's Drakteng home, in the regions surrounding Dartsedo (Kangding), lay the old lands of the Chakla King. Like the king in Drakteng, the king in Chakla had owned vast swaths of farmland, which he granted out to tenants in return for labour and tax obligations. But the king did not survive the last dynasty's modernization efforts of 1895-1911. Instead, the last Chakla king was deposed and died attempting to escape from his imperial captors (IOR L PS 10884 [1922]). After removing the king from power, the state took over his lands, and local farmers now found themselves to be tenants to a new master. As first the Qing state and then subsequent provincial and national states sought to impose new forms of sovereignty and economic change on Khampas, they came to own property and gain access to natural resources, which concentrated the power of development in state, rather than local, hands.

Over the course of the early twentieth century, moreover, in and around Dartsedo, Khampa farmers found themselves increasingly to be neighbours of Han settlers (see Relyea, this volume). Before the Communist state even began its violent and traumatic transformations, market, state, and Han migrants were already impacting the Kham regions ('Kangding xian Wazexiang diaocha baogao' 1963, 4-6). In Peldengyel's home region of Drakteng, for instance, Han were increasingly present by the early 1930 s. One estimate from the early 1930 s places the Han population in Drakteng at 2540; Khampas numbered 21,350 (Mei 1934, 281-285). As the Han population grew, however, Han merchants tended to gain more control over local trade, although Khampa trading companies and traders also grew in power and 
reach (Galli, this volume). As this chapter will demonstrate, the growth of Chinese merchant activity reflected important changes in corporate organization, which allowed firms to gain power over resources in Kham. This, in turn, often limited ordinary Khampas' ability to profit from commercial growth.

To understand these changes, we need to reevaluate the key elements of Chinese development by using a longer-range, multi-scalar historical framework that includes careful consideration of borderlands history. This chapter is therefore designed to prompt, but not complete, the process of reevaluation, and it is organized around a simple puzzle. In the early eighteenth century in Kham, there emerged for the first time a robust commercial economy. When the Kangxi emperor (r. 1661-1722) designated Dartsedo as a trade mart, it was intended that trade benefit Khampas and central Tibetans, and there is no doubt that some were able to take advantage of trade to enrich and empower themselves (Booz 2011; Galli, this volume). In the long run, however, we know that the Chinese state and Han traders would gain control of development policy in the ways revealed by Fischer and Yeh, thus disempowering Tibetans. When did this turnaround begin?

The answer to this question is multifaceted and contingent. There was no immediate singular moment or process of change, but a series of conjunctural changes in politics and commerce that were concentrated not in the post-1949 period, but in an earlier era, the 1880s-1940s. The chapter cannot examine all of the important changes of this era, so it focuses on commercial changes, charting the ways in which Khampa communities became enmeshed in more intense networks of regional and global trade. The larger book project, of which this chapter is a part, also considers the ways in which Khampas were subjected to powerful state-building projects emanating from the national and provincial capitals of Beijing, Nanjing, and Chengdu. There are two reasons for examining these conjunctures. First, I am interested in understanding the processes by which non-Han elites were transformed rhetorically from integral and legitimate local rulers in the High Qing imperium to denigrated and often illegitimate (in the eyes of the Chinese states) competitors for formal power in the modern Chinese nation state. This was clearly an effort to disempower indigenous elites and, only by looking at the long durée, can we see the effectiveness of the processes. Second, I am interested in analysing how commerce - both private and state-led - contributed, sometimes inadvertently, to the processes of excluding indigenous communities from controlling local resources and trade. Both of these developments constitute, I believe, core elements of 
China's particular transition to modernity. In other words, while most analysts look to coastal China and the interior to understand the most important reasons for China's modern development, I am suggesting that the borderlands provide equally important insights, in part because the repercussions of disempowered development today are dire - for borderlands communities and for China as a whole.

To understand the commercial changes of the 1880s through $1940 \mathrm{~s}$ requires a 'kaleidoscopic view of [...] historical trajectories' (Gros, this volume) and actors, some local, some regional, and some global. I first explain the growth of commerce and powerful trade institutions, including newly powerful private corporations coming from Yunnan. These trade institutions were, in many cases, able to link more Kham producers to larger and more extensive networks of trade. Then, the chapter provides initial descriptions of the impact of the new trade institutions by examining the changing local dynamics of commodity production and sales. The lessons are these: As the Southwest borderlands became integrated into broader global markets, there emerged a contingent set of conditions that pushed for more intensive commercial development in the rugged areas of the Southwest, including Kham. Those conditions included the development of Chinese private trading firms that were well capitalized and could reach more deeply into local communities to purchase and move highland products to Chongqing, Kunming, Mandalay, and even Shanghai and Hong Kong. Demand for highland products seems to have increased worldwide as musk was shipped to Paris to be used by the burgeoning perfume industry and Chinese Traditional Medicine products, such as caterpillar fungus, were increasingly in demand in Guangdong and Hong Kong. The ability of merchant firms to extend their business in Kham was, perhaps counterintuitively, aided by the destabilization of the region by the Qing in 1905-1911. This destabilization was provoked by Qing adoption of Euro-American models of colonialism in the wake of the British invasion of Lhasa. There followed a brutal military campaign to suppress - and even eradicate - indigenous institutions of power in Kham. After the Qing regime fell in 1911-1912, Kham became an arena for competition as monasteries, former secular ruling families, merchants, and various forms of the new Republican Chinese state competed for power. While commerce was frequently interrupted by conflict, this period of competition actually allowed for new commercial entities to gain power, a process that, when combined with the political changes, laid the foundations for - but did not lead inevitably to - modern China's long-term practices of development that disempowers local - especially non-Han - communities. 


\section{The Growth of Commerce}

Long-distance trade was not new in the modern era to Kham and the Qing empire's Southwest borderlands. In fact, it was in the eighteenth century that migration, population growth, urbanization, and state promotion of mining had spurred on the rise of commerce. In the more remote past, southwesterners had been incorporated into the twelfth-century tea, horse, and salt exchanges. ${ }^{4}$ Nevertheless, the mechanisms of trade changed dramatically from the late nineteenth century onwards. Building on earlier business developments, men from Shaanxi, Sichuan, and, later, Yunnan developed more powerful firms with the ability to reach deeper into the Southwest in general and Kham in particular, where they extracted a larger volume of goods that were in demand across a wider global geography.

In eighteenth-century Kham, it had been the Shaanxi merchants who were the first outsiders to make their mark. By the 1730s, Shaanxi merchants were increasing in Dartsedo, and they held the majority of the tea permits for shipping Sichuan tea via Kham to greater Tibet (Shi and Zou 2011, 5-11). Patrick Booz reports that by the mid-Qing, eighty tea firms, many of them Shaanxi-run, were operating out of Ya'an, Sichuan, with branches in Dartsedo, where the Shaanxi merchants often dealt with the famous achak khapa or guozhuang, Khampa innkeepers with roots as hereditary nobility tied closely to the Chakla king. The achak khapa served to mediate exchanges between the Chinese tea merchants and Tibetan wholesalers, many of whom were merchant representatives of monasteries both in Kham and Central Tibet (Booz 2011, 152; Tsomu 2016).

At first, Shaanxi firms operated primarily in the official trade mart at Dartsedo, importing tea and cloth to trade for Kham products. By the nineteenth century, however, the geographical range of Shaanxi merchant activity was expanding. For instance, Shaanxi firms developed the ability to set up branches in other Kham trade towns and to even purchase mountain products from low-level wholesalers, who, in turn, purchased directly from producers. The apprentices at many Shaanxi firms were expected to learn Tibetan in Dartsedo before being sent out into the field, and many Shaanxi merchants also learned to dress, ride horses, and eat like Tibetans. Shi and Zou argue that the Shaanxi traders who left Dartsedo and entered smaller settlements acculturated to Tibetan ways, often intermarrying and even sending their sons into the monkhood (Shi and Zou 2011, 6, 8).

4 A number of works cover this earlier trade. To name just three of these works: Smith (1991), Ren (1997), Yang (2009). 
Shaanxi merchants were crucial to developing Kham markets, but there were other Chinese who followed them into Kham, most notably Sichuanese merchants. In addition, Muslim Chinese firms worked through Chengdu, Songpan, and the northern routes to Qinghai and Gansu (Chengdu shi Yisilanjiao xiehui in Duan and Yao 2002, 277). And, in the late nineteenth and early twentieth century, Yunnanese merchants began to extend their reach from northern Yunnan into Kham. Some travellers found Lijiang merchants in Dartsedo as early as 1890, but most Yunnanese caravans carried tea or textiles north from Dali to Gyelthang (Zhongdian) or, perhaps, to Dechen (Adunzi), where they would, without venturing further north, sell to Tibetan traders (Rockhill 1891 284-285; Hosie 2001 [1905], 76-77; Shen 2004, 260-262). This would change over the course of the early twentieth century as the Yunnanese scale of activity expanded, and the Yunnanese merchants thus provide a good case study for investigating the changing nature of Kham trade.

To trace the rise of Yunnan merchants in Kham and Tibet requires some detective work. This is because they were relatively late on the scene - at least in any numbers - and, like many merchant firms, they are relatively poorly documented. Foreign observers began to note an increase in Yunnanese activity in the 1910s. In 1915, Oliver Coales reported that Yunnan firms sold about $£_{30,000}$ (200,00o taels) of opium in Dartsedo; the merchants reported that the opium was from Burma and, as a demonstration of their ties to Burma, the Yunnanese cashed checks drawn from Rangoon banks, revealing that international trade networks were helping capitalize their reach into Kham. In Dartsedo, the Yunnanese bought Indian rupees, which were imported into silver-poor Yunnan (Coales 1916).

According to Coales, the Yunnanese were able to expand into Dartsedo and challenge Shaanxi and Sichuanese merchant firms because of political instability. What Coales meant by political instability was limited to the 1911 revolution in Sichuan, which disrupted the old tea trade regime, significantly decreasing tea imports from Ya'an, Sichuan. The Shaanxi firms in Dartsedo tended to control this trade, and, as tea imports declined, their numbers dwindled, from fifty down to twenty (Coales 1916).

However, if we wish to understand commercial change in Kham, it is important to think about political instability in broader terms. In August 1905, the Qing court had created the Sichuan-Yunnan Frontier Affairs Commission (Chuan Dian bianwu dachen), which was a new institution designed to implement direct control over Kham. At its head was the notorious Zhao Erfeng, an activist commissioner who would seek to turn Kham upside down in his effort to transform it. As in other borderlands around the empire, a new era had dawned, an era of direct governance that imitated Euro-American 
colonial practices and rejected any significant cooperation with indigenous elites (Wang 2011, Chapter 4). From 1905-1911, the Qing state committed itself to implementing European concepts of sovereignty and direct rule in many borderlands territories, including Kham (Relyea, this volume). In Kham, these new concepts were, however, introduced with a level of brutality and barbarity rarely seen elsewhere. Under the leadership of Zhao Erfeng and his military commander, Ma Weiqi, Qing troops attacked Bathang, Lithang, and Chaktreng (Xiangcheng). In each place, leading secular and religious elites were executed as the Qing, in conscious imitation of Euro-American colonial policies, sought to seize control of politics, trade, and land (Coleman 2002, 50-51; Sperling 1976, 10-36). Overall, then, the late Qing state sought to radically realign local administration, taxation, and land ownership. Whereas originally land ownership lay in the hands of secular rulers and monasteries, and those who worked the land owed rents, tax-in-kind, and labour, the state began to claim the power to rent land, to allow Han migrants to open new lands, and to encourage the monetization of rents as a way to undermine older, servile relationships. In these ways, the Qing worked to extend state power through administration, state-control of property, and the market (Wang 2011, Chapters 6 and 7).

Zhao Erfeng's influence in Kham lasted for six years, and he met his end in December 1911 when he was executed by Sichuanese revolutionaries. That same year, the remnants of Qing troops in Kham were reorganized into the Sichuan-Kham Defence Force (Chuan Kang bianfangjun) and gained financial support from the Sichuan provincial government (Lawson 2013, 300-302). In 1912, the newly autonomous Sichuan military government created the Office for Managing the Frontier (choubianchu), which, as Scott Relyea (2015, 996-1000) notes, was designed to continue implementing policies for transforming Kham. But the Sichuanese government faced two major challengers. First, the Ganden Phodrang sent troops into Kham, extending Lhasa's control in western parts of the region (ibid.). And, second, the Yunnan Army invaded Sichuan proper and began extending their influence into eastern Kham as well (Lawson 2013, 300-302; Relyea 2015, 1006-1009). By 1916, the Yunnanese had gained control of the Frontier Commissioner position, appointing Yin Chenghuan, who had been trained in the Yunnan military college. Yin reached into the Yunnan Tibetan Buddhist hierarchy for help, bringing a leading monk from Lijiang to help oversee the Buddhist communities in Dartsedo (IOR L PS 10435 [1916]; IOR L PS 10435 [1917]). At the same time, Yunnanese troops were gaining control of the remains of the Defence Force, and, by 1917, there were Yunnanese officers and troops controlling Bathang and Chamdo. 
Although the Yunnan Army's influence in Kham did not last long, its short foray into Kham seems to have helped Yunnanese firms, which were gaining the capacity to project their trade further afield at this time. To accomplish this, Yunnanese firms were developing the organizational means to raise sufficient capital, orchestrate trade across vast distances, and ensure profits for their investors (Giersch 2014). Founded in 1903, the Yunnan firm Yongchangxiang is an archetypical example. By the 1910s, the firm was beginning its growth from a small partnership, with three managing partners, five investors, and approximately 11,00o taels in share capital, to a limited liability firm with an estimated 32 billion (RMB) in fixed and liquid assets distributed among its import/export businesses, its stake in silk-reeling workshops, and its investment in tin mines and refineries (Yang 1989, 50-52). Although founded at a later date, the Maoheng firm shared a similar trajectory of growth from simple trading partnership to large, limited liability trading and holding company with interests in everything from transport to cotton textiles. What made these companies different from earlier, simple trading partnerships were their numerous permanent outposts in trading centres large and small. These outposts, in turn, provided these firms with access to raw materials, finished goods, whole-sale markets, financial capital, and currency remittance services that allowed them to cover remarkable distances throughout East and Southeast Asia. Part of their expansion included Kham and Tibet.

The Yunnan firms' expansion into Kham seems to have filled part of the void left as Shaanxi merchants and the Sichuan-Kham tea trade declined. As Booz notes, the Yunnanese were busy becoming the largest supplier of brick tea to Lhasa and southern Kham - something that they would accomplish for the first time ever in the 1920s and 1930s (Booz 2011, 163-164). This was made possible by firms such as Yongchangxiang, which developed the infrastructure to reach into Kham. Yongchangxiang's managers, for example, learned to process southern Yunnan tea for the Tibet market in Xiaguan, Yunnan, as did a number of other Yunnan firms, including Maoheng (Yang 1989, 64-65; Huang 1991, 38).

From Xiaguan and Lijiang, the firms began to project further north. If we examine the available company archives, we can begin to reconstruct these firms' major expansion into Kham, though it is still unclear when they first established permanent outposts. By the 1920s at the latest, Yongchangxiang was exporting from Kham thousands of ounces of silver worth medicines. We can tell this by examining the Yongchangxiang General Ledger (for the Kunming headquarters) in 1930. Among the commodities that were in stock by the end of this fiscal year were over 1300 kilos (2699 jin) of beimu, 
worth 23,353.06 yuan silver and smaller amounts of zhimu and caterpillar fungus worth a total of 1576.87 yuan (YPA 132-4-93, 2-15). In other words, Yongchangxiang was tapping into the growing medicinal materials trade and relying on its extensive distribution networks in China proper in order to profit from Kham products. Evidence from Maoheng's company books reveals the firm to have been a major importer of tea and cloth into Kham. With growing access to the traditional Yunnan tea production as well as imported yarns and textiles from India and Europe, Maoheng developed trading outposts and warehousing to distribute these goods into Kham from Jianchang (Xichang), to the southwest of Ya'an. Based on records from the 1940 trading season, the company imported over 30,000 spools of yarn to sell in Sichuan and Kham; they also brought in over 3000 Indian piece-goods (YPA 132-4-17, 51-57). Meanwhile, the Xiaguan, Yunnan branch of Maoheng managed the tea trade into Kham (YPA 132-4-17, 51-57).

In all of these endeavours, Yongchangxiang and Maoheng were not alone. Merchants from some of the northern Yunnan (Lijiang and Heqing) firms came to specialize in the Kham trade (Shu and Su 1988, 273). This specialization came to include the establishment of permanent branches in northernmost Yunnan and in Dartsedo, Bathang, and Lithang (Zhou 2006, 226-228). Throughout the 1930 s and into the wartime and post-war periods, the Heqing firm of Hengshenggong maintained branches at Dechen and Dartsedo. These branches frequently shipped Kham exports via Lijiang to Kunming and beyond. To do so, they contracted with individual caravan companies and their leaders (ma guotou) (YPA 132-4-71, 43-51).

In addition, Hengshenggong was also doing business in Lhasa; however, they were not shipping goods via Kham but instead shipping Yunnan tea via Burma and India into Tibet from Kalimpong (Waijiaobu to Meng Zang weiyuanhui 1940). One 1943 government report claimed that Hengshenggong had been doing this since the early 1920 - and that a competitor, Hongsheng, had been doing it since the early 1910s (Liu and Cao 2005, 423-424). During the wartime period, moreover, when the Burma-India export route was blocked, both Maoheng and Yongchangxiang extended from Kham to engage directly in trade through Lhasa to Kalimpong and Kolkata (YPA 132-2-10, 4-7). Through the correspondence of Maoheng managers, we can also know that the Yunnan firms of Renhechang and Hongxingyuan were operating in Kham and Tibet during wartime years (YPA 132-2-10, 4-7, 8).

Based on company and state archival evidence, then, Yunnan firms were increasingly active in Kham, suggesting that they had built their networks into the region from approximately 1910 onward. But why were there such opportunities for extending directly into Kham? If we look to understand 
why these firms were becoming more active in Kham, especially by the 1920 s and 30 s, then we must understand political changes taking place. This was an era of tremendous disruption, a period when power was being reconfigured, and yet, despite periodic disruptions of trade, the instability seems to have provided opportunities for businesses to gain more commercial power. These opportunities corresponded with a period in which Yunnan businesses were becoming better institutionalized and capitalized.

\section{The Differential Impact of Commerce}

The growth of Yunnanese firms corresponded with increased Han Chinese involvement in the Kham economy. In the industry and commerce section of the Republican-era Kham Gazetteer, Zhou Taixuan argued that the late Qing and early Republican periods brought a major change in government interference in trade, which, in turn, led to greater support for Han merchants in Kham. Zhou is vague about what policies were introduced, but he credits an early Sichuan officer, Yin Changheng, with promoting migration, which led to more Han merchants and their spread into places such as Tawu (Daofu), Drakteng, and Yerkalo (Yanjing) (Zhou 1990 (n.d.), 220-223). ${ }^{5}$ Their roles and impact can be explained by discussing the process by which medicinal materials were collected and exported.

In Kham, medicines could be collected from three different sources: vegetable, animal, and mineral. Plant-based medicinal materials included zhimu (Anemarrhena asphodeloides), beimu, qinjiao, Chinese rhubarb (dahuang), and huanglian (Chinese goldthread). The most expensive animal product was musk (shexiang), but other important animal products included pilose antler (lurong), deer antler (lujiao), bear gall bladder (xiongdan), leopard bones (baogu), and, of course, the famous caterpillar fungus. Mineral-based medicinal materials included sulfur, sodium borate, and mica (Zhou 1990 (n.d.), 227).

In one of the increasingly numerous surveys of the Kham economy, investigators found in the late 1930 s that these products were widely dispersed in terms of geography and ecology. Wild huanglian grew on the precipitous sides of the mountains, while beimu flourished in the alpine meadows. Zhimu could be found among the debris in rocky crags ('Xikangsheng yaocao diaocha baogaoshu' 1939/2005, 407-410). The best musk, some said, came

5 The original copy of this gazetteer is stored in the Sichuan archives, but there is no date of publication. It was probably published in the 1940 . 
from Kham's river gorges and forests, not from the grasslands, and it was in demand in Shanghai and European markets (Zhou 1990 (n.d.), 227). ${ }^{6}$

The medicinal materials trade was worth a great deal of money. In the 1940s, beimu might sell for about 250 yuan per liang (31.25 grams) or about half the price of musk. Zhimu sold for about one-third the price of musk, and, in the 1940s, the compilers of the Kham Gazetteer reported that exports might total 30,000 to 40,00o liang for each product, meaning that about a metric ton of each product was being exported (Zhou 1990 (n.d.), 227). If a liang of beimu was worth 250 yuan, then a kilo was worth 8000 yuan, and a metric ton was worth 80 million yuan. A metric ton of musk was worth 160 million. If Khampa families collected all of the beimu to be exported and each family collected roughly the same amount as Peldengyel's half kilo, then 2000 families might be involved in the harvest and, theoretically, they might each earn 4000 yuan. This was not how it worked, of course. Khampas hunted musk deer, mostly likely in the spring and fall, when the bucks' musk was considered to be strongest. Or they collected caterpillar fungus and beimu during the slack seasons, when they were not herding or tending their crops. They would then trade their medicines in return for tea and cloth, though they sometimes sold their products for money (Xikang tongzhigao, nongmupian 1990 (n.d.), 231-232; 'Xikangsheng yaocaidiaocha baogaoshu' 2005 (1939), 410).

If we wish to understand who controlled the profits of production in Kham, then we need to understand the variety and hierarchy of commercial institutions. If individual Khampa households occupied the bottom of the hierarchy, then the next level was occupied by the petty merchants. These small-time peddlers were called bachong, and they specialized in dealing with the primary producers. While there is no doubt that these bachong travelled widely in agricultural and pastoral areas, there is some doubt as to who they were. Most Chinese language reports list them as Han who lived among the Khampas, but at least one report notes that the bachong came from among the Khampas themselves ('Xikangsheng yaocai diaocha baogaoshu' 2005 (1939), 410; Zhou 1990 (n.d.), 221). Most likely there were some bachong who were Khampas, which the Communist noted in their surveys, but most were probably descendants of Shaanxi merchants who had, in some cases, acculturated to Khampa ways (Shi and Zou 2011, 7). The bachong, then, were permanent residents in Khampa areas, and they wandered among the large and small farming villages - or in the yak herding grounds - buying medicinal materials.

6 For a good listing of the markets that medicinal materials were shipped to, see 'Xikangsheng yaocaidiaocha baogaoshu' 2005 (1939), 413-414. 
The bachong made it easier for Khampas who did not live near markets to sell or trade goods, thus broadening the net of commercialization throughout the region. In one government investigation in 1947, for example, researchers found that itinerant merchants gathered animal products in grassland areas far from the nearest markets. In Sershül (Shiqu County), for example, there was no regular market, but the bachong facilitated the export of about 12,500 pieces of cattle hide and 1000 kilos (2000 dan) of sheep wool to Dartsedo each year (ASIMH 20-00-63-016-03 1947). In selling their medicines or other products, however, local Khampas were often restricted to the prices that bachong offered, meaning that they rarely could earn high prices or make lucrative trades.

The bachong were, in turn, subject to the next layer of the collection hierarchy. The bachong (and sometimes producers who lived near markets) sold to the shopkeepers in the nearest market towns. An alternative was to sell to family-based or monastery-sponsored merchants. These shopkeepers then dealt with the larger merchant firms based in Dartsedo and other big towns (Zhou 1990 (n.d.), 227-230). As we will see below, the shopkeepers in parts of Kham were increasingly Han.

As the twentieth century unfolded, the collection of medicines became professionalized. This was done by Han migrants, usually Sichuanese, who, in contrast to the Khampa agriculturalists and herders, could be classified as medicine workers (yaofu oryaofuzi). They formed teams called medicine sheds (yaopeng) and set out into the mountains each summer to harvest wild medicines under the oversight of their shed heads (pengzhang). The shed heads funded the venture, purchasing food and supplies. The shed heads also paid a mountain rent (shanzu) to whomever had rights to the land on which they gathered. Usually, however, they were not gathering in areas that were claimed. These independent harvesters did not work through the bachong, but had the autonomy to transport their goods to larger markets, something that the Khampa gatherers often could not do ('Xikangsheng yaocai diaocha baogaoshu' 2005 (1939), 410-411). Some of these Han medicine workers, moreover, were hired and capitalized by larger merchant firms, who then were paid with the medicines after the yaofu came out of the hills at the end of the season (Xikang tongzhigao, nongmupian 1990 (n.d.), 231). As medicine gathering was professionalized, Chinese firms developed direct access to raw materials, thus bypassing the bachong and Khampa producers. While this did not eradicate the role of Khampa gatherers, it did provide them with competition.

Once goods arrived in Dartsedo or other larger trade towns like Bathang - whether through the bachong and shopkeepers or through the medicine 
workers - the larger firms gained control of them. While these larger firms continued to include Tibetan and Khampa groups (monastic and secular) (Booz 2011, 299-304; Galli, this volume), the percentage of Chinese firms increased over time, as did their absolute numbers. In 189o, notes Booz, Chinese controlled about 6o per cent of the business capital in Dartsedo, while Tibetan merchants controlled about 40 per cent (Booz 2011, 305). As the Sichuan tea trade declined after the 1911 Revolution, however, local Khampa businesses - including the famous achak khapa or guozhuang, went into decline (Tsomu 2016; Ren 1990 (1936), 258-259). Into their place came new Chinese firms, including the Yunnanese firms like Maoheng, which might bypass Dartsedo altogether.

Thus, Han Chinese merchants were increasingly influential in the importing and exporting Kham's commercial goods. This does not mean that Han Chinese firms took over Kham. The important firms were managed by people of several backgrounds - Shaanxi, Sichuanese, Yunnanese, specific monasteries, and particular Khampa families ('Xikangsheng yaocao diaocha baogaoshu' 2005 (1939), 411; Galli, this volume). In some areas, the large monasteries were among the largest traders and controllers of production (Xikang tongzhigao, nongmupian 1990 (n.d.), 231-232). Still, the trend was that Chinese merchant firms were making greater inroads into Kham. The point is, moreover, that commerce, while opening opportunities for families like Peldengyel's to supplement their livelihoods with the collection of medicines, was also limiting the possibilities that Khampa families might gain real economic leverage through the market.

If we expand our investigation to include other products, including minerals and metals, we see revealed yet another important transformation: various forms of the Republican state were gaining control over Kham's resources (Zhou 1990 (n.d.), 226-227). We have already seen how the state, from Zhao Erfeng's time, was increasingly involved in claiming rights to land. This process was supplemented by new mining policies which furthered state inroads into Kham. For example, the state promoted the creation of a number of large and small-scale companies that sought to develop Kham's gold-mining areas. Some companies were well-capitalized, such as the Puyi gongsi or the Qunxing gongsi, and some were smaller-scale operations, but all were subject to new state claims on land and resources. The state itself put efforts into developing state-private mining concerns, including a gold-mining company in the Muli areas that was under the Ministry of Finance's Xikang Gold Mining Bureau. In order to begin its operations in Muli, moreover, the Bureau wrested control of mining from the local monastic elite, a development that occurred in conjunction with efforts to 
pursue the Red Army into the region in 1935 (ASIMH 18-24-05-63-001-01, 1939). In Muli and other parts of Kham, the mining techniques remained traditional and production outputs low, and miners might be Sichuanese or Khampa, but clearly the state was extending its claims so that companies often petitioned the state for mining rights (Zhou 1990 (n.d.), 226-227).

It is beyond the scope of this chapter to explain all the changes throughout Kham, but we return to Peldengyel's home of Drakteng to help us evaluate the increasing power of commercial firms and the state. In 1913, Drakteng had been transformed into a directly-ruled county, and over the decades the state undermined the power of local indigenous elites. By the early 1930s, the old hereditary elite still wielded some power, but the Republican state was able to implement some of its developmental policies. The state collected local taxes, enforced compulsory transport corvée service, and even created an experimental agricultural station. Locally, commerce came to be concentrated in the hands of Han shopkeepers in the county seat, who imported tea, cloth, and European products. They also exported to Dartsedo musk, beimu, and other medicines that had been collected by Khampas and bartered in return for tea, cloth, tools, and salt. For the most part, then, it was the shopkeepers and Han firms that mediated Drakteng's interaction with the larger commercial world. Locally, Han dominated commerce and the skilled professions (carpentry, wine making, silversmithing) despite the fact that, in the mid-1930s, there were only one Han for ten Khampas. Khampas farmed, herded, hunted, and collected medicines (Mei 1934, 281285; Zhang 2010 [1939]).

Thus, the outlines of Peldengyel's life in the 1950s had already been put in place by the 1930s. The commercial economy was a powerful factor, and, though the C.C.P. work team did not emphasize it, Han merchants were some of the most powerful commercial forces in Drakteng. And, though this was not the case in Peldengyel's village, Han settlers were increasingly prevalent, which the C.C.P. found in other parts of Drakteng. And the state was a powerful economic force, too.

It is important to clarify that not all of Kham was like Drakteng. In contrast, He Yong (1989) has detailed how the major Lithang monastery, Jamchen Chokhorling, continued its economic dominance of its region into the early 1950s. Various institutions within the monastery might invest in and manage trade, and the monastery extended its trade networks through Lhasa into India, as well as into Sichuan and Yunnan. The monastery's basic approach was to collect local goods, especially medicinal materials and export them for sale. They then would import salt, tea, cloth, and daily-use items. The power of the monastery rested in its local status as both political 
and religious authority, a power that was rebuilt in the wake of the Qing attacks in 1905 (He 1989, 13-14). There were some Han merchant firms active in Lithang, but it is clear that the most powerful trade institution was monastic.

Lithang was not unique, but neither was Drakteng, and when we consider both together, we begin to gain a kaleidoscopic picture of Kham in which larger-scale institutions were increasingly in control of commerce - and thus of people's livelihoods. And these larger-scale institutions were often in conflict with each other long before the Communist Party arrived on the scene. In the early 1940s, Lu Yuxin worked for the Republican state as it sought to extend its cooperative loans programme into northern Kham (Gartar, Tawu, Drango, Kandzé, and Nyarong). Lu was, however, frustrated by the structures of the local economy in which headmen and monastic officials exercised tremendous power. In terms of commerce and finance, the monasteries dominated trade and moneylending. When the author went to Nyarong (Zhanhua) to disburse loans to the Cooperative (hezuo she), he found that the chair of the coop was a former headman and lama, and this raised Lu's suspicions. He investigated and learned that before the coop was organized, this area of Dake (Dagai) had over 200 impoverished residents who were exploited through usury. Many wanted to join the coop but the lamas continued to try to prevent this. Only through decisive actions by the state was the coop established, but it was still difficult to overcome local elite resistance (Lu 1942, 115-120).

While it is certainly accurate to note how monastic officials, monasteries, and Khampa traders remained influential in trade networks (Galli, this volume), it is also important to recognize elsewhere the growing power of Han Chinese merchant firms and the state. Based on this initial work, it is clear that outside forces, including both private firms and state institutions, were making inroads into Kham and gaining control over resources. The power to make decisions about local economies was slowly being removed from these locales, although this was a process that, given a different set of conjunctural developments, might have been reversed. But, even in areas such as Lithang, where local influence was still strong, it has to be noted that the growing Han Chinese discourses on nation and development cast local secular and religious elites as opponents, as backwards figures who were imagined to be obstacles to the development of both political and economic modernity. Thus, from the early twentieth century forward there were two crucial trends of exclusion and disempowerment at work in the borderlands of Kham, one in the realm of actual economic and political relationships and one in the ongoing evolution of the Chinese national imaginary. While neither trend was yet at the stage where it guaranteed 
the levels of marginalization and disempowerment that manifested in the People's Republic, both would come to shape the Sino-Tibetan borderlands for decades to come. To understand how these trends originated and developed, we need to develop multi-scalar, kaleidoscopic borderlands histories.

\section{Glossary of Chinese Terms}

\begin{tabular}{|c|c|}
\hline Adunzi & 阿敦子 \\
\hline bachong & 壩充 \\
\hline Bandeerjia & 板得尔家 \\
\hline Baogu & 豹骨 \\
\hline beimu & 貝母 \\
\hline chongcao & 虫草 \\
\hline Chuan Dian bianwu dachen & 川滇邊務大臣 \\
\hline Chuan Kang bianfang jun & 川康邊防軍 \\
\hline dahuang & 大黃 \\
\hline dan & 石 \\
\hline Danba & 丹巴 \\
\hline Dan & 擔 \\
\hline Daofu & 道浮 \\
\hline dayang & 大洋 \\
\hline guozhuang & 鍋莊 \\
\hline Hengshenggong & 恆盛公 \\
\hline hezuo she & 合作社 \\
\hline huanglian & 黃連 \\
\hline Jianchang & 建昌 \\
\hline jin & 斤 \\
\hline Kangding & 康定 \\
\hline lujiao & 鹿角 \\
\hline lurong & 鹿茸 \\
\hline maguotou & 馬鍋頭 \\
\hline pengzhang & 棚長 \\
\hline qianghuo & 㒸活 \\
\hline qinjiao & 秦艽 \\
\hline shanzu & 山租 \\
\hline shexiang & 鹿香 \\
\hline Shiquxian & 石渠縣 \\
\hline tusi & 土司 \\
\hline Xiangcheng & 乡稱 \\
\hline
\end{tabular}




$\begin{array}{ll}\text { xiongdan } & \text { 熊膽 } \\ \text { Yanjing } & \text { 鹽井 } \\ \text { yaofu(zi) } & \text { 藥夫, 藥夫子 } \\ \text { yaopeng } & \text { 藥棚 } \\ \text { Yin Changheng } & \text { 尹昌衡 } \\ \text { Yin Chenghuan } & \text { 殷承獻 } \\ \text { Zhanhua } & \text { 瞻化 } \\ \text { Zhao Erfeng } & \text { 趙爾豐 } \\ \text { zhimu } & \text { 知母 } \\ \text { Zhongdian } & \text { 中甸 }\end{array}$

\section{Glossary of Tibetan Terms}

$\begin{array}{ll}\text { achak khapa } & \text { a lcags kha pa } \\ \text { Bathang } & \text { 'Ba' thang } \\ \text { Chakla } & \text { Lcags la } \\ \text { Chamdo } & \text { Chab mdo } \\ \text { Chaktreng } & \text { Phya phreng } \\ \text { Dartsedo } & \text { Dar rtse mdo } \\ \text { Dechen } & \text { Bde chen } \\ \text { Drakteng } & \text { Brag steng } \\ \text { Gyelthang } & \text { Rgyal thang } \\ \text { Jamchen Chokhorling } & \text { Byams chen chos 'khor gling } \\ \text { Nyarong } & \text { Nyag rong } \\ \text { Peldengyel } & \text { Dpal ldan rgyal } \\ \text { Sershül } & \text { Ser shul } \\ \text { Tawu } & \text { Rta'u } \\ \text { Yerkalo } & \text { Yar kha logs, var. Tsha kha logs }\end{array}$

\section{References}

\section{Archives}

ASIMH. Academia Sinica, Institute for Modern History archives. 18-24-05-63-001-01. 1939. Xikangsheng guanshang heban Muli jinkuang gongsi, 6 September ASIMH. Academia Sinica, Institute for Modern History archives. 20-0o-63-01603. 1947. Xikangsheng to Nonglinbu, Bensheng xumu jingji zhuangkuang, 28 November 
IOR. India Office Records. 1916. L PS 10 435. Consul General Chengtu to Secretary of the Government of India, 9 November

IOR. India Office Records. 1917. L PS 10 435. Hewlitt, W. Meyrick, Acting Consul General, Chengtu to Foreign Secretary to the Govt of India, 5 February

IOR. India Office Records. 1922. L PS 10 884. King, Louis, British Consular Officer, Tachienlu to His Majesty's Minister, Beijing, 28 June

Coales, O.R. 1916. 'Report of Trade of Tachienlu and the Marches'. File 921/15. India Office Records L/PS/11/9o

YPA. Yunnan Provincial Archives. 132-2-10, pp. 4-7 and p. 8. Maoheng company letters.

YPA. Yunnan Provincial Archives. 132-4-17, pp. 45-50. Maoheng Xikang fenzhan Jianchang zhan jinjiang Minguo 29 nian yiyue yiri qi zhi shier yue sanshi ri zhi, suoyou huotuo shoufa, yihuo ruchu, zaoju qingce.

YPA. Yunnan Provincial Archives. 132-4-17, pp. 51-57. Jinjiang Maoheng Xiaguan fenzhan zi Minguo 29 nian yiyue yi ri qi zhi shieryue sanshiyi rizhi, suoyou yinhuo ruchu shoufa dengshao zaoju qingce.

YPA. Yunnan Provincial Archives. 132-4-71, pp. 43-51. Hengshenggong transport contracts.

YPA. Yunnan Provincial Archives. 132-4-93, pp. 2-15. Yongchangxiang Dianzhuang shijiunian hongzhangce.

\section{Primary and Secondary Sources}

Batson, Andrew. 2015. 'Mapping China: Which Provinces are Most Dominated by State-Owned Firms?' http://andrewbatson.com/category/maps/ (15 October). (last accessed 28 August 2017).

Becquelin, Nicholas. 2004. 'Staged Development in Xinjiang'. In China's Campaign to "Open Up the West": National, Provincial, and Local Perspectives, edited by David S.G. Goodman, 44-64. The China Quarterly Special Issues New Series, No. 5. Cambridge, U.K.: Cambridge University Press.

Bhalla, A. S. and Shufeng Qiu. 2006. Poverty and Inequality among Chinese Minorities. London; New York: Routledge.

Booz, Patrick Ramzi. 2011. 'Tea, Trade and Transport in the Sino-Tibetan Borderlands'. DPhil Thesis, Oxford University.

Chengdu shi Yisilanjiao xiehui. N.d.; 2002. Huixun, 22: 23. Reprinted in Zhongguo nanfang Huizu jingji shangmao ziliao xuanbian, edited by Duan Jinlu and Yao Jide, 277. Kunming: Yunnan minzu chubanshe.

Coleman, William M. 2002. 'The Uprising at Batang: Khams and Its Significance in Chinese and Tibetan History'. In Khams Pa Histories: Visions of People, Place and Authority, edited Lawrence Epstein, 31-56. Leiden: Brill. 
Cornell, Stephen and Joseph P. Kalt. 1989. 'Pathways from Poverty: Development and Institution-Building on American Indian Reservations'. PRS89-5, Harvard Project on American Indian Economic Development, Malcom Wiener Centre for Social Policy, John F. Kennedy School of Government, Harvard University.

'Danbaxian Badi xiang Qiongshan cun shehui diaocha (1958)'. 1963. In Ganzi Zangzu zizhizhou Kangding Daowu Danba diaochacailiao, 28-33. Beijing: Zhongguo kexueyuan minzu yanjiusuo.

Donaldson, John A. 2007. 'Tourism, Development and Poverty Reduction in Guizhou and Yunnan'. The China Quarterly 190: 333-351.

Fischer, Andrew Martin. 2014. The Disempowered Development of Tibet in China: A Study in the Economics of Marginalization. Lanham, MD: Lexington Books.

Giersch, C. Patterson. 2014. 'Borderlands Business: Merchant Firms and Modernity in Southwest China, 1800-1920'. Late Imperial China 35 (1): 38-75.

Gustafsson, Bjorn. 2016. 'Ethnic Disparities in Economic Well-being in China'. In Handbook on Ethnic Minorities in China, edited by Xiaowei Zang. Cheltenham, UK and Northampton, MA: Edward Elgar.

He Yong. 1989. 'Litang jiefang chuqi de minzu shangye'. Minzu yanjiu 2: 13-14.

Hosie, Alexander. 2001 (1905). Mr. Hosie's Journey to Tibet, 1904: A Report by Mr. A. Hosie, His Majesty's Consul at Chengtu, on a Journey from Chengtu to the Eastern Frontier of Tibet. London: Harrison and Sons; reprint London: The Stationery Office.

Huang Huairong. 1991. 'Maoheng shanghao jianjie'. In Tengchong wenshi ziliao xuanji 3, 37-42. Tengchong: Tengchongxian yinshuachang.

'Kangding xian Wazexiang diaocha baogao (1958)'. 1963. In Ganzi Zangzu zhizhizhou Kangding Daowu Danba diaochacailiao, 1-10. Beijing: Zhongguo kexueyuan minzu yanjiusuo.

Kinzley, Judd C. 2018. Natural Resources and the New Frontier: Constructing Modern China's Borderlands. Chicago: University of Chicago Press.

Lawson, Joseph D. 2013. 'Warlord Colonialism: State Fragmentation and Chinese Rule in Kham, 1911-1949'. The Journal of Asian Studies 72 (2): 299-318.

Liu Limei and Cao Bihong, eds. 2005. Minguo shiqi Xizang ji Zangqujingji kaifa jianshe dang'an xuanbian. Beijing: Zhongguo Zangxue chubanshe.

Lu Ren. 1997. Yunnan dui waijiaotong shi. Kunming: Yunnan minzu chubanshe.

Lu Yuxin. 1942. 'Kangbei jingji zatan'. Xikang jingji jikan 1:115-120.

Mei Xinru. 2006 (1934). Xikang. Zhengzhong shuju. Reprinted in Minguo Xinan bianchui shiliao congshu: Kang Zang juan, vol. 7, 281-285. Beijing: Quanguo tushuguan suo wei fuzhi zhongxin.

Mullaney, Thomas S. 2011. Coming to Terms with the Nation: Ethnic Classification in Modern China. Berkeley, CA: University of California Press.

Relyea, Scott. 2015. 'Yokes of Gold and Threads of Silk: Sino-Tibetan Competition for Authority in Early Twentieth-Century Kham'. Modern Asian Studies 49 (4):963-1009. 
Ren Hanguang. 1990 (1936). 'Kangshi guozhuang diaocha gaoshu'. Reprinted in Jindai Kangqu dang'an ziliao xuanbian, edited by Sichuansheng dang'anguan and Sichuan minzu yanjiusuo, 258-26o. Chengdu: Sichuan daxue chubanshe.

Rockhill, William W. 1891. The Land of the Lamas: Notes of a Journey Through China, Mongolia and Tibet. New York: The Century Company.

Shen Xu. 2004. 'Dali Baizu mabang yu shangbang de xingcheng yu fazhan' (Emergence and Development of the Dali Bai Nationality's Caravan and Commercial Groups). In Zhongguo Xinan wenhua yanjiu (Research in the Culture of Southwest China), edited by Na Qi. Kunming: Yunnan minzu.

Shi Shuo and Zou Libo. 2011. 'Jindai Kangqu Shaanshang zai Han-Zang hudong yu wenhua liuzhong de juese'. Sichuan daxue xuebao (zhexue shehui kexueban), 174: 5-11.

Shih, Chih-yu. 2007. Autonomy, Ethnicity, and Poverty in Southwestern China: The State Turned Upside Down. New York: Palgrave MacMillan.

Shu Zizhi and Su Songlin. 1988. 'Heqing 'Xingshenghe' shanghao shilue'. In Baizu shehui lishi diaocha, vol. 3. Kunming: Yunnan renmin chubanshe.

Smith, Paul J. 1991. Taxing Heaven's Storehouse: Horses, Bureaucrats, and the Destruction of the Sichuan Tea Industry, 1074-1224. Cambridge, MA: Harvard Council on East Asian Studies.

Sperling, Elliot. 1976. 'The Chinese Venture in K'am, 1904-1911, and the Role of Chao Erh-feng'. The Tibet Journal 1 (2): 10-36.

Sturgeon, Janet C. 2010. 'Governing Minorities and Development in Xishuangbanna, China: Akha and Dai Rubber Farmers as Entrepreneurs'. Geoforum 41: 318-328.

Tsomu, Yudru. 2016. 'Guozhuang Trading Houses and Tibetan Middlemen in Dartsedo, the "Shanghai of Tibet"'. Cross-Currents: East Asian History and Culture Review 19: 71-121.

United States Department of Agriculture, Agricultural Research Service. N. d. 'National Nutrient Database for Standard Reference Release 28, Basic Report: 20314, Corn Grain, White'. https://ndb.nal.usda.gov (last accessed 31 May 2017).

United States Department of Agriculture, Centre for Nutrition Policy and Promotion.

N. d. 'Estimated Calorie Needs per Day by Age, Gender, and Physical Activity Level'. https://www.cnpp.usda.gov (last accessed 31 May 2017).

'Waijiaobu to Meng Zang weiyuanhui, 1940 May 9'. Republished in Minguo shiqi Xizangji Zangqujingji kaifa jianshe dang'an xuanbian, edited by Liu Limei and Cao Bihong, 292-295. Beijing: Zhongguo Zangxue, 2005.

Wang, Xiuyu. 2011. China's Last Imperial Frontier: Late Qing Expansion in Sichuan's Tibetan Borderlands. Lanham, MD: Lexington Books.

White, Richard. 1983. The Roots of Dependency: Subsistence, Environment, and Social Change Among the Choctaws, Pawnees, and Navajos. Lincoln: University of Nebraska Press. 
'Xikangsheng yaocai diaocha baogaoshu'. 2005 (1939). Originally published in Xikangsheng jianshe congkan, 1(2) (December). Republished in Minguo shiqi Xizangji Zangqujingji kaifa jianshe dang'anxuanbian, edited by Liu Limei and Cao Bihong. Beijing: Zhongguo Zangxue.

Xikang tongzhigao, nongmupian 1990 (n.d.). In Sichuansheng dang'anguan and Sichuan minzu yanjiusuo, ed.Jindai Kangqu dang'an ziliao xuanbian. Chengdu: Sichuan daxue chubanshe.

Yang, Bin. 2009. Between Winds and Clouds: The Making of Yunnan. New York: Columbia University Press.

Yang Kecheng. 1989. Yongchangxiangjianshi. In Yunnan wenshi ziliao xuanji, vol. 9. Kunming: Yunnan renmin chubanshe.

Yeh, Emily T. 2013. Taming Tibet: Landscape Transformation and the Gift of Chinese Development. Ithaca, New York: Cornell University Press.

Zhou Taixuan. 1990 (n.d.). Xikang tongzhigao, gongshangzhi. In Sichuansheng dang'anguan and Sichuan minzu yanjiusuo, ed.Jindai Kangqu dang'an ziliao xuanbian. Chengdu: Sichuan daxue chubanshe.

Zhou Zhisheng. 2006. Shangren yu jindai Zhongguo Xinan bianjiang shehui: Yi Dian xibei wei zhongxin (Merchants and Modern China's Southwestern Borderlands Society: Northwest Yunnan as Case Study). Beijing: Zhongguo shehui kexue chubanshe.

Zhuang Xueben. 2010 (1939). 'Xikang Danba diaocha'. Xinan bianjiang 6: 10-24. Reprinted in Minguo bianzheng shiliao xubian, vol. 5, edited by Ma Dazheng, 96-114. Guojia tushuguan.

\section{About the Author}

C. Patterson Giersch is Professor of History and current Chair of the Department of History at Wellesley College, U.S.A. His research focuses on the intersection of empire and ethnicity in Southwest China in the 1700s, and on transnational trade networks in the twentieth century. He is the author of Asian Borderlands: The Transformation of Qing China's Yunnan Frontier (2006) and of multiple articles on China's borderlands. His second book, Corporate Conquests: Business, the State, and the Origins of Ethnic Inequality in Southwest China, will be out with Stanford University Press in spring 2020. 



\title{
8 Pastoralists by Choice
}

\author{
Adaptations in Contemporary Pastoralism in Eastern Kham
}

Gillian G. Tan

\begin{abstract}
The Chinese state's categorical distinction between mumin (herder) and nongmin (farmers) views the former as a mode of production conducted out of environmental necessity in places unable to be productively cultivated by dominant agrarian settlements. Such a view has been integral in narratives of Chinese state legibility. Focusing on a contemporary community in eastern Kham and their everyday practices as well as narrative choices to remain drokpa, or pastoralists, this chapter re-examines pastoralism as a degree of specialization. In the process, it seeks to demonstrate how local specificities and experiences not only clarify a general understanding of Tibetan pastoralism but also complicate a presentation of Chinese state governmentality.
\end{abstract}

Keywords: mumin, pastoralism, degree of specialization, adaptation, state legibility, margins

\section{Introduction}

Among a group of nomadic pastoralists in the Minyak area of Kham (see Map 1), ${ }^{1}$ a recent development related to the scope of pastoral activity has occurred. Beginning around 2010, increased numbers of pastoral households have started to plant leaves' (loma) in the fenced enclosures of their winter houses. These fenced enclosures and winter houses were built in the 1990s as a direct result of the Chinese government's 'Four

1 Minyak (also Minyag) derives its name from Minyak Rab, one of the six ranges that comprises the region of Kham, which is also known as 'four rivers, six ranges' (chushigangdruk).

Gros, Stéphane (ed.), Frontier Tibet: Patterns of Change in the Sino-Tibetan Borderlands. Amsterdam, Amsterdam University Press 2019

DOI: 10.5117/9789463728713_CH08 
Constructions that Form a Set' (si peitao) policy that sought to introduce material improvements in pastoral areas. This policy saw the construction of winter houses, fenced enclosures for annual forage, barns for animals, and fenced winter pastures in an effort to reorganize pastoral populations from the cooperatism of the earlier period towards individual households and enhanced technical productivity. Presently, this group of pastoralists in Minyak Kham continues to herd yaks and to move with them from pasture to fresh pasture during the summer and autumn months. During the winter and spring months, the pastoralists live in simple stone-and-mud houses. By directing their efforts and labour primarily towards animal husbandry and orienting their lives towards movement, these pastoralists identify as drokpa, 'people of the pastures' who live on the hoof (Ekvall 1968) and consider themselves different from both rongpa or farmers, and rongmadrok or semi-pastoralists. The latter especially have been written about in the literature as agropastoralists who engage in practices of animal husbandry but whose primary orientation is towards their agricultural fields and the fixity of residence in houses (Ekvall 1968). Given the pastoralists' self-presentation as drokpa, the relatively recent attention to planting requires greater consideration.

The planting of these 'leaves', which are a small Chinese cabbage (Ch. xiao bai cai, Tib. tshal dkar, sp. Brassica rapa subsp. Chinensis), is not the first or only activity of small-scale planting by these pastoralists. In the early 2000s, an international development organization working in the area had initiated a grass-seed planting project. The organization handed out grass-seeds to each household and urged them to plant the seeds in the fenced enclosures of their winter houses in order to encourage pastoralists to supplement their animals' annual forage by supplying fodder. ${ }^{2} \mathrm{~A}$ handful of households dutifully scattered the seeds in their fenced enclosures in the first year; yet despite the efforts of the organization, most pastoralists did not enthusiastically take up the grass-seeding project. Many regarded the seeds as 'feeding the birds' rather than resulting in fodder for the animals. Either because of lack of attention or skill, the seeds did not produce the harvest fodder expected and interest soon waned. While the grass-seeding project has now been left fallow, the planting of 'leaves' in recent times

2 Bringing fodder to animals rather than leading animals out to pasture is an act that distinguishes ranching from pastoralism: by enabling greater capital investment in the animals, the rancher is able to achieve higher productive intensity in terms of milk and meat (Chang and Koster 1994, Ingold 1980). Pastoralism, on the other hand, refers to a set of unimproved activities around animal husbandry and produces relatively low yields (Asad 1978, Bates and Lees 1977). 
has gained steady momentum. Of the approximately 80 households in the community, around half of these have planted leaves in the past eight years. This chapter will probe the ethnographic reasons behind this example to better understand its overall import in the complex interplay between environment, livelihood, and culture for contemporary Tibetan pastoralists of Minyak Kham. It will demonstrate, moreover, how the ethnographic data reveal limitations of overly determined categories of livelihood and way of life, such as mumin (herder) and nongmin (farmer), as they play out in state policies and modes of legibility.

State delineations of what 'counts' as agriculture - with respect to labour required, kinds of crops planted, and scale in which the crops are cultivated - need to be probed further. This chapter picks up one thread in the literature, namely that what counts as agriculture is determined largely by state categories and measures of production intensity and volume, kind of crops planted, and sedentism, in other words, the 'scientific agriculture' proposed by Scott (1998) as part of high modernist ideology. Thus, in the context of the Chinese state, we have seen from Mark Frank's contribution (this volume) that the 'agrarian nationalism' of the Republican government favoured cereal farming and specific crops of wheat and corn, as it harboured the belief that scientific agriculture was an 'improvement' (Ch. gaijin, gailiang). Such nationalism assumed not only a binary opposition between 'agrarian states' and 'industrial states' but also an internal opposition between a dominant farming population and marginalized herder populations. This internal opposition was shaped also by sentiments of superiority and civility by the Chinese state - built on Han agricultural sedentism - over the notable pastoral populations within its territoriality. This superiority is certainly echoed in Mark Frank's presentation of Zhang Yunping's manifesto (see Frank, this volume). From the perspective of state legibility, then, nomadic herders comprise a simplified and abstracted category that is articulated in opposition to sedentary farmers. Countering this perspective is not, however, to merely refute a state perspective but to pay careful attention to how empirical practices of pastoralism do not necessarily exclude other livelihood activities. It also demands an empirically-derived refinement of state legibility to examine how processes of governmentality also include practices of illegibility, namely how Minyak drokpa not only resist but also adapt to policy implementations. This last point bears particularly on the question posed in Stéphane Gros' Introduction to Part II of this volume about how state control is achieved and maintained in borderland regions, which often express realities that run counter to centrist narratives. 


\section{State Legibility}

In his work, Seeing Like a State (1998), the political scientist James Scott highlights how state governmentality works according to processes of legibility that include acts of simplification and abstraction. In order to control its subjects and engineer social projects, the state must first reduce complex realities to simplified and standard categories. The category most relevant to this examination of Chinese state legibility is the term mumin, or herder. It is a category that operates on several levels of definition and meaning, and these levels are often blurred, even in policy documents. At the productive level, the term mumin is drawn in clear distinction with nongmin, or farmer. As a mode of production, herding refers to the activity of keeping livestock as a primary source of livelihood. It may or may not entail nomadism. In terms of state legibility, it is distinct from farming, which refers to the activity of planting (and animal husbandry) as a primary mode of livelihood. Because of their reliance on fields, farmers also denote a settled population. For the Chinese state, mumin applies to all populations (usually minority groups) that primarily herd and who, according to policy documents such as the Nomad Settlement Project (Ch. you mumin dingju), share similar conditions, including having no fixed abode, lacking in production and living conditions, and suffering from the onslaught of natural disasters.' ${ }^{3}$ Such a categorization applies irrespective of whether those concerned are from Tibet, Xinjiang, or Inner Mongolia, of the kinds of animals herded, and of the historical or cultural factors that have influenced their lives as herders.

The term mumin is not only deployed in terms of mode of production, however. It is also and simultaneously a social category, one that is described in policy documents through often derogatory language. Mumin are generally portrayed as traditionalists who have relied on the heavens for good fortune (rather than on scientific and technical progress). ${ }^{4}$ For example, the Nomad Settlement Project policy document describes herders as 'one of the weak links in building a well-off society in an all-rounded way'.5 The most consistent descriptor used in relation to mumin is 'backward' (luo hou),

Chinese government document 2011, 2.

4 Interestingly, this attitude and language are reminiscent of the more general Han Chinese sense of self, 'as the vanguard of the proletariat' (Gladney 1998, 9). Harrell's articulation of the three metaphors - sexual, educational, historical - that inflect how the civilizing centre (Han) regards its peripheral peoples (Others) offers another perspective on this view, particularly as the ethnic identification project (minzu shibie) occurred under Communist rule (Harrell 1995, 23).

5 Chinese government document 2011, 2. 
which reveals the state's generally derisive and superior attitude towards this group. That herders are often from minority nationalities adds to the emphasis of Han superiority.

Interpretive levels based on mode of production and social distinction of mumin are often conflated and collapsed in processes of Chinese state legibility. In his examination of Han Chinese ecological identity, Dee Williams (2002) writes that the Chinese term huang not only denotes unfamiliar ecological zones as 'waste' or 'barren', and therefore carries assumptions on the kinds of productive activity that can be achieved in such regions, but it also carries connotations for behaviour and character. On this point, references made towards the emptiness of the grasslands or the absence of domestication have been reinforced in Chinese idioms, such as 'herders eat unethical grain' (Ch. mumin chi kuixin liang), which criticized the herders for living off grain they did not produce (Hong 2005, 648). By extension, mumin were viewed as lazy and slothful because they were perceived as not tilling the land and not labouring productively (Williams 2002, 32). Being mumin is thus represented in policy documents through a set of collective physical and social problems, such as 'poor hygienic conditions' (wei sheng tiao jian ji cha), 'breed degradation' (pin zhong tui hua), and 'weak disaster prevention and mitigation capacity' (fang zaijian zainengli ruo). The category of mumin as one of state legibility contains assumptions of ecological determinism, social characterization, and moral deficiency.

For Scott, state legibility and the simplified, abstracted categories created are the basis on which the state develops its various projects of 'improvement'. By 'improvement', Scott refers to efforts to achieve an assumed evolutionary pinnacle of civilization: organized nature, permanent settlements, maximized production, and social engineering informed by high modernist ideology. The last, in particular, is based on a confidence in 'scientific and technical progress [and] the expansion of production' (Scott 1998, 4) that undergirds Chinese state policies towards its pastoral populations. This echoes the observations made by both Mark Frank and Pat Giersch in this volume on state agricultural 'improvement' and state development initiative. It is observed by Emily Yeh (2007) in her article on how the trope of indolence combines with state development discourse to recreate notions of what constitutes 'proper work' in Lhasa, Tibet. ${ }^{6}$ In the case of the contemporary Chinese state, the language of science, of technical improvements, and of

6 The specifically local idioms of development and their role in allowing local manoeuvre of state discourses operate in ways not dissimilar to what I suggest here, following Das and Poole's (2004) formulation of 'margins'. 
intensive production is used liberally in plans to 'improve' the conditions of living and production for mumin. Starting from the policies of Four Constructions that Form a Set (si peitao jianshe) in the 1990s to the Develop the West (xibu dakaifa) and Restoring the Pastures (tuimu huancao) policies of the 200os and the more recent policies of Ecological Migration (shengtai yimin) and Nomad Settlement (you mumin dingju), these policy templates have been explicitly designed to alter the material bases of livelihood and production for all herders (see Table 8.1). Therefore, the Nomad Settlement Project focuses on 1) building a well-off society in a well-rounded way, 2) transforming the development of animal husbandry in pastoral places, 3) protecting grassland ecology, and 4) maintaining national unity and frontier stability. Specifically, the Nomad Settlement Project promotes the construction of houses, livestock sheds, and storage huts for fodder in an effort to increase the productive yields of pastoral regions.

Table 8.1 Overview of selected government policies in Kham, 1990s-present

\begin{tabular}{lll}
\hline Three Constructions that Form a Set, san peitao jianshe & 三配套建设 & 1990s-2000s \\
Four Constructions that Form a Set, si peitao jianshe & 四配套建设 & $1990 \mathrm{~s}-2000 \mathrm{~s}$ \\
Develop the West, xibu dakaifa & 西部大开发 & 2000 \\
Restoring the Pastures, tuimu huancao & 退牧还草 & $2003-2012$ \\
Ecological Migration, shengtai yimin & 生态移民 & 2003 \\
Nomad Settlement, you mumin dingju & 游牧民定居 & 2009 \\
\hline
\end{tabular}

However, 'improvement' relates not just to the material conditions and environment of the mumin, but also to the mumin themselves, revealing more clearly the connections among ecological determinism, mode of production, and social and moral characterization of the state category of mumin. Therefore, while the san peitao and si peitao constructions and tuimu huancao policy focused on the construction and management of material grassland 'improvements', policy refinements now extend to a 'transformation of people and methods' (zhuan ren, zhuan fangshi) by 'raising efficiency' (dixiao). In order to achieve these measures, government departments increasingly conduct training sessions with local communities. For instance, the Animal Husbandry Bureau of Dartsedo County selects and trains people in targeted communities in order to set up 'demonstration households' (shifan hu). Local nomadic pastoralists are increasingly called on to participate in meetings in which they register their households and livestock in order to receive subsidies of grain feed. Along with information from additional forums such as the National Conference on Pastoral Regions 
and the creation of monetary schemes, current policies are clearly facilitating change with a different emphasis: intensifying pastoral production to achieve economic development. By moving from extensive herding to an intensive market-oriented livestock industry that takes advantage of growing conditions in pastoral regions, the Chinese state intends to transform Tibetans from 'backwards' nomadic pastoralists to neoliberal, market-oriented, and governable subjects (Gaerrang 2015, Yeh and Gaerrang 2011).

Categories of mumin and nongmin, examined through policy documents, reveal modes of legibility. Yet, focusing only on state legibility runs the danger of presenting a state that is practically solid and coherent. This may be heuristically convenient, but as anthropologists of the state such as Veena Das and Deborah Poole (2004) have noted, the state not only functions to create and maintain order (to which categories belong) but also exists as a ghostly form, a 'spectral state' that looms as a power to be resisted or subverted (Mueggler 2001). In this conceptual articulation, and through its modes of legibility, the state appears as 'a self-reproducing, totalizing constellation of forces' (Kapferer 2010, 128). However, Das and Poole (2004, 6, 9-10) observe that illegibility, where modes of legibility break away from intent, is part of the process of state governmentality, and practices of illegibility most frequently occur at the margins. These margins include borderland regions such as Kham, which - through processes of aligning with, yet also adapting, state policies - reveal state-margins relationships as dynamic and mutually constitutive, as I will discuss in the final section of this chapter. Actual practices of daily life as $d r o k p a 7$, for one pastoral group in Minyak Kham, and the specific conditions that historically frame their continuing self-presentation as drokpa elaborate how being drokpa is equally about a way of life as it is about sustaining a livelihood. This self-expression goes beyond ecological and cultural determinants of the category of mumin, and instead, complicate simplified abstractions. Activities such as planting leaves, caterpillar fungus gathering, and trade, while fully coherent to drokpa themselves, are read as illegible in the context of state legibility.

\section{Being Minyak Drokpa}

The pastoralists in question live in the eastern section of the Hengduan mountain range on high-altitude pastures (3900-4200 metres above sea

7 In this regard, I translate drokpa as pastoralist in order to signal a more inclusive definition than that of mumin (herder). 
level) that are now part of the administrative township of Tagong (Lhagang) in Kangding (Dartsedo) County, Ganzi (Kandzé) Tibetan Autonomous Prefecture, Sichuan Province. During the winter and spring months, the community of around 80 households live in simple houses, variously constructed of mud and stone and of concrete. The location of the late autumn, winter, and early spring pastures is along a high valley (3900 metres above sea level) in the foothills of a snow-capped mountain named Zhamo (5270m). According to locals, Zhamo is the wife-mountain of a more dominant snow peak, Zhara Latse $(5650 \mathrm{~m})$. Ecologically, the pastures are in a 'subtropical montane coniferous forest zone of southeastern Tibet, high-cold vegetation' ecoregion (Chang 1981) with specific characteristics given by altitude and orientation. The Kobresia sedge is a currently dominant plant species in these pastures. During the late spring, summer, and early autumn months, these pastoralists move with their animals to higher elevation (4200 metres above sea level) and live in black yak-hair tents. While adaptations to household organization have seen growing numbers of elderly pastoralists remaining in winter houses during the summer and autumn months, the orientation of the community continues to be towards the herding and care of animals, mainly yaks, and movements with the herd. Pastoralists in the community often refer to themselves as 'Minyak drokpa', with drokpa displaying a primary orientation towards the herd and movement rather than towards the house and fields as displayed by semi-pastoralists. Drokpa, therefore, is more than the practice of animal husbandry; it encompasses a way of life.

The specificity in the way these pastoralists refer to the term Minyak requires some explanation. In common use, Minyak is a self-identifying term rather than one that refers to an abstract territory or region of clear boundaries. The identification is complex and relies on multiple factors, which may shift in emphasis depending on the community and context. For this community in a contemporary context, an important part of being Minyak drokpa is the mountain Zhara Latse. Zhara is a mountain with several meanings and practices attached to it: it is a zhidak or territorial master, which is part of the host of immanent deities in a Tibetan life-world; it is a lari or soul mountain, which houses the la, or soul, of a particular community; and it is also a néri or pilgrimage mountain/site, which is a site of ritual practice. ${ }^{8}$ As a néri, it is referred to as Minyak Latse in the nineteenth-century narrative map of the Nyingma master, Chogyur Lingpa, called the Twenty-five Great Sites of Kham. The map, which was further elaborated by Jamgon Kongtrul of Palpung monastery, contained sacred sites

8 For more details on each of these terms, see Huber (1994), Tan (2016). 
that expressed the extent of the region of Kham (see Gros, this volume). ${ }^{9}$ As one of the twenty-five great sites of Kham, Minyak Zhara Latse is the southeasternmost point of the region of Kham and is a focal ritual and narrative site for the pastoralists living in its vicinity. Pastoralists in this community enact the multiple meanings attached to Zhara as part of their continuing self-representation as Minyak drokpa.

Another aspect of identity lies in the community's continuing self-presentation as Minyak drokpa. To further understand this, we must appreciate the community's history. 'More than a hundred years ago', as it was explained to me, this pastoral community moved from the vicinity of Nanglang lake in what is now Pelyul County to the grasslands where they currently live. To place this move in historical context, Nanglang lake is located in what was the area comprising the lower districts of Nyarong, and the grasslands presently occupied were part of the Chakla kingdom. ${ }^{10}$ To appreciate the cause of the move, some further historical details will be considered.

Prior to the creation of Xikang Province by the Chinese Republican government in 1939, the physical area delineated by the region of Kham was dominated by the presence of four large Tibetan kingdoms, known in Chinese as the 'four great tusi' (si da tusi). ${ }^{11}$ These kingdoms were Dergé, Lithang, Bathang, and Chakla, and they gave their allegiance to the Qing emperor. In addition to these kingdoms, there were also smaller fiefdoms; the British Consul Teichman (1922) noted that, in the early twentieth century, there were as many as twenty Khampa states 'under Chinese protection' (excluding the Gyelrong kingdoms). Such a proliferation of 'states' - both dominant and minor - created a historical situation where the rule of law of a central authority could not be guaranteed. Expressed at the level of self-identity, Khampas fought and resisted both the Chinese administration in Beijing and Tibetan administration in Lhasa. On a political level, the Chinese presence in Kham served as an immediate counter-manoeuvre to Central Tibet and its attempt to establish rule in Kham. Moreover, the

9 Gardner $(2006,154)$ notes that Jamgon Kongtrul's revision of the map was intra-sectarian because it combined sacred sites of the Nyingma, Kagyu, Sakya, and Bon traditions. However, it explicitly expressed resistance to the real enemy of the day, namely Lhasa and its dominant Gelukpa order.

10 While it is common to associate the Chakla kingdom with the area of Minyak, the two are not entirely coterminous.

11 The word tusi is an official Chinese title bestowed by the Qing emperor and refers to the Tibetan titles for gyelpo, depa, and ponpo. Teichman (1922) glosses the first as 'king', and the other two as 'hereditary officials'. The latter term, 'hereditary officials', is how tusi and tuguan are generally glossed in English. However, Gardner $(2003,72)$ notes that the kingdoms that were officially tusi and tuguan are difficult to distinguish from each other. 
involvement of foreign powers in Kham activated both a strategic use of resistance among the kingdoms and a system of patronage that was mirrored previously in the seventeenth century when the Mongols defeated in Lithang the Jang kingship of Lijiang and established priest-patron relationships with the Geluk sect of Tibetan Buddhism. The interplay between kings and foreign powers in maintaining local autonomy on the one hand, and in jostling for the right to rule on the other, characterized the historical struggles of Kham.

These historical struggles had direct bearing on nomadic pastoralists who were often recruited to fight because of their prowess on horseback and with weapons. The struggles also influenced the movements of communities of pastoralists and, in some cases, instigated migrations across valley and mountain ranges. One struggle, noteworthy in relation to my fieldsite, was an uprising that occurred in 1837. The military leader Gönpo Namgyel, also known as the 'Nyarong demon', began a military uprising in the valley of Nyarong. Gönpo Namgyel waged war in Nyarong and united the upper, middle, and lower districts under his control. He also succeeded in bringing together neighbouring nomadic tribes (Gardner 2003). By the early 1860s, Gönpo Namgyel had conquered most of northwestern Kham, taking Dergé in 1862. Shortly after, a counter-move to the authority of Gönpo Namgyel came from the Chakla kingdom based in Dartsedo and a trade bastion for the Chinese since the Ming dynasty (Tsomu 2016). According to oral history, this counter-move by the Chakla kingdom occurred at the approximate time - 'more than a hundred years ago' - that the pastoral community moved from the vicinity of Nanglang lake in the lower districts of Nyarong to the grasslands that were part of the Chakla kingdom.

When the pastoralists first moved from Nanglang lake, they first grazed their animals on the pastures that are now the location of their summer pastures. This explains why their monastery is located in the grasslands of the summer pastures since pastoral rotations once revolved around that location. As the community grew, it gradually incorporated other pastures at slightly lower altitude into their grazing rotations. Different parts of the community occupied different pastures in the area and, under the current Chinese system, the original community is divided into four administratively distinct 'villages' (cun), each with its own 'village leader' (cun zhang) and 'village party secretary' (cun shuji). The particular group, or 'village', of my fieldwork eventually occupied its current winter pastures in the high valley at the foothills of the Zhara and Zhamo mountains that were once inhabited by farmers, or rongpa. Even now, households of farmers are located further along the valley towards the direction of Dartsedo. 
Nonetheless, when the pastoralists eventually incorporated the pastures into their winter and spring grazing rotations, living in winter black tents woven from yarn made from the thick down of their animals, they continued a pastoral way of life. Their continuing identification as drokpa is - to no small extent - because they were drokpa in Pelyul and choose to persist with this way of life.

This point is especially relevant given that environmental conditions in these pastures allowed the planting of highland barley and other crops associated with small-scale agriculture. Moreover, the relative proximity of villages of farmers further along the valley made it important for these pastoralists to distinguish themselves by re-asserting their pastoral identity, echoing Robert Ekvall's $(1968,85)$ observation in Golok that the drokpa identify as such, and usually by asserting a general superiority over farmers. Their assertion as drokpa is also practically manifest in their current pastoral movements: households typically move seven times a year over a maximum distance of approximately seven kilometres across an altitude range of 300 metres (see Table 8.2). While several of the moves are dictated by ecological benefit such as the movement to pastures at a higher altitude at a later period of the summer season, the other moves - particularly the first move of around 100 metres from the winter house to winter-spring pastures, and the last move from one part of the winter pastures to another - are not ecologically necessary.

Table 8.2 Detail of pastoral movements

\begin{tabular}{llll}
\hline Movement & $\begin{array}{l}\text { Approximate Month } \\
\text { (according to Tibetan } \\
\text { calendar) }\end{array}$ & $\begin{array}{l}\text { Approximate Altitude } \\
\text { (metres above sea level) }\end{array}$ & $\begin{array}{l}\text { Approximate Distance } \\
\text { (metres) from previous } \\
\text { location }\end{array}$ \\
\hline One & Fourth & 3900 & 100 \\
Two & Fourth & 3900 & 500 \\
Three & Fifth & 4100 & 7000 \\
Four & Sixth & 4200 & 1000 \\
Five & Seventh & 4100 & 5000 \\
Six & Seventh & 3960 & 1000 \\
Seven & Eighth & 3900 & 500 \\
\hline
\end{tabular}

Thus, while literature on pastoralism has both explained movement in terms of ecological determinants such as altitude, herd size, access to land and water (Dyson-Hudson and Dyson-Hudson 1980, Hjort 1981, Western and Dunne 1979), and analysed movement as crucial because it maximizes environmental resilience (by minimizing risk of disease, for example), this 
group of pastoralists moves more than is ecologically required and, indeed, more than other groups of pastoralists in Kham. For instance, pastoralists of the Sershül tribes move four times in a year corresponding with the four seasons and distinct sets of seasonal pastures. Yet here in Minyak Kham, it would seem that pastoralists are committed to moving with their animals above and beyond what is ecologically necessary. Given that Minyak pastoralists are committed to pastoralism in a location where small-scale agriculture is viable, any argument that yak-rearing is a marginalized practice because of high altitude and unviable agriculture also does not apply. In Minyak Kham, pastoralists choose to continue moving with their animals because of cultural and historical self-identification as drokpa and not because of environmental factors.

\section{Shifting Mumin}

To return to the pastoralists' increased attention to planting leaves, it is important to first appreciate that this activity supplies leaves for personal consumption rather than as fodder for animals. This point is significant because growing barley for animal fodder is one key policy measure of the Nomad Settlement Project. Yet while that measure has not been taken up by pastoralists in this community of Minyak Kham, the planting of Brassica rapa has been consistent over the past five to seven years. The larger context is that growing numbers of pastoralists elsewhere in Kham have increased their consumption of vegetables or 'leaves' and either decreased their meat consumption or removed meat altogether in their diet. The increase in instances of 'vegetarianism' among nomadic pastoralists in both Kham and Amdo has been addressed extensively by Gaerrang (2016), who notes that vegetarianism for nomadic pastoralists and Tibetans generally is enacted in different ways. For example, it may be practiced only during religious periods; it may involve abstinence from only certain kinds of meat; or it may involve abstinence only on certain days (Gaerrang 2016). Among Tibetan pastoralists, vegetarianism is a practice that is flexible and, importantly, it is instigated out of respect for and obedience to the reincarnate lamas. The so-called vegetarian movement that is currently growing across eastern Tibet is the result of the efforts of one incarnate lama in particular, Khenpo Tsultrim Lodrö of Larung Gar, a Tibetan Buddhist complex in Serthar County, Ganzi Tibetan Autonomous Prefecture. Gaerrang (2012) has related the movement towards teachings on vegetarianism directly with a sharp increase in livestock sales to slaughterhouses in some pastoral communities. 
Contemporary motivations towards vegetarianism has multiple aspects, but one clear motivation is to counter the increasing commodification of animals for meat production and its clash with Buddhist ethics on slaughter. In Kham, the teachings and influence of Khenpo Tsultrim Lodrö, who is of the Nyingma sect of Tibetan Buddhism, have extended beyond communities with high slaughter rates.

In this community of pastoralists in Minyak Kham, slaughter rates of yaks are relatively low, yet the general increase in consumption of vegetables and corollary decrease in meat consumption is the result of instruction from its own incarnate lama, also of the Nyingma sect of Tibetan Buddhism. Out of obedience to this lama, many households in this community now have at least one member who does not eat meat. To supplement the household's growing consumption of vegetables, these pastoralists now use the enclosure of small plots from the 'four that form a set' constructions of the 1990s to grow vegetables for their personal use. Even though the sentiment of many who have increased their consumption of vegetables is that 'leaves are not tasty', they continue to follow the practice. Vegetables are consumed fresh when the harvest is recent and bunches are dried to be added to Tibetan noodles, in the cooler months. In most cases, the amount of vegetables planted and harvested is not sufficient for the entire year and households supplement their intake by also purchasing vegetables in the nearby township seat. The money used to purchase vegetables is derived from the household's caterpillar fungus (yartsa gunbu) sales in the year.

Interestingly, the care of these plants has mainly fallen on male members of households, who tend to have more additional time and labour than female pastoralists to spend on 'other' activities - namely activities not directly associated with animal husbandry. This in itself reveals that planting (and consuming) leaves has not in any way replaced a pastoral mode of production and way of life. The care of animals and use of animal products, mainly milk but also hair and fur, for their daily sustenance and living needs continues to be the primary orientation of these pastoralists. As one older pastoralist has said in response to the household's continued practice of animal husbandry: 'If we didn't have our animals, how could we eat?' This statement is not, of course, necessarily directed to the consumption of animals. Literature on pastoralist practices around the world has demonstrated that the primary product of animal husbandry is milk because it is a renewable product (Galaty and Johnson 1990), and not meat. For communities that do not necessarily have external capital to regenerate the herd and that practice a low-yield and low-intensity form of animal husbandry, a continued reliance on the renewable products of their animals is vital. 
In these pastures, small-scale agriculture is possible and growing 'leaves' has become important because of pastoralists' increased consumption of vegetables. The growing period in this place is relatively brief with hail and frost still likely in June (typically the fifth Tibetan month). Even though the 'leaves' are generally frost hardy and adapted to cooler climates, Brassica rapa does require between 40 and 60 days from sowing to harvesting. For this reason, the best time to plant them in this place is in the sixth Tibetan month, which also coincides with the grazing rotation at the summer pastures. Depending on household demographics, the planting is done either by elder members of the household who increasingly do not move with the herd and other family members to the summer pasture or by male members of the household who travel back on horseback to the winter house to plant the 'leaves'. The fenced enclosure in front of the winter house, which is where the animals are herded into during the nights in the winter and spring seasons, is manure-rich despite daily clearing for dried yak dung (ciwa) during the winter and spring. As such, this fenced enclosure is rich with muck soil that is conducive for growing Brassica rapa. Environmental conditions support small-scale agriculture in this place, a fact also confirmed by previous farming of highland barley by households of farmers.

Even though planting Brassica rapa for human consumption (and not as fodder for animals) is a practice of illegibility with regard to mumin and assumptions associated with this category of legibility, it is readily interpreted within pastoralism. Pastoralism is a way of life and sustenance, defined generally as animal husbandry, or the breeding, care, and use of herd animals as a way to sustain life and as a mode of production. It is often viewed as 'production for subsistence' (Asad 1978, 58) because it does not give naturally high yields. Within these definitions, pastoralism emphasizes a set of unimproved productive activities to secure food in the form of milk, meat, and blood, and items for the maintenance of daily life. Despite a shared foundation in animal husbandry, pastoralism is generally thought to be different from ranching, although the factors for claiming difference vary by kind and degree. One suggested distinction is that ranching depends on a production system predicated on individual access to animals and individual appropriation of pastures (Ingold 1980). This definition is often supported by the argument that ranching is based on a primary relationship to animals as capitalist commodity. By contrast, pastoralism highlights a production system where 'pastoralists employ a system of social relations, which combines the principles of divided access to animals and common access to pasture' (Chang and Koster 1994, 5). The methods for establishing common access vary: for example, Tibetan nomadic pastoralists in Serthar 
had a grazing allocation that was redistributed every three years to ensure fair access to good or bad pastures (Gelek 2002). Additionally, pastoralism is thought to encompass a set of relationships to animals that is more than a relationship premised on the fundamental value of a commodity (Ingold 1980). In the case of Minyak drokpa, animals are incorporated into the meaningful dimensions of culture as symbol, offering, and exchange such as Buddhist liberated life (tshe thar), where animals are 'released' from herding or capture for reasons associated with generating merit or offerings to worldly deities (Tan 2016).

In practice, animal husbandry readily combines with a variety of other activities such as agriculture. Thus, it is usually more fruitful to think about degrees of specialization of pastoralism and agriculture, rather than ideal-types based on the binary between mumin and nongmin. In this way, pastoralism is fully specialized when pursued as exclusive reliance on animal husbandry ${ }^{12}$ and generalized when the strategy is combined with raising at least some crops or pursing some other form of sustenance (Bates and Lees 1977). ${ }^{13}$ Specialization also depends on the analytic interaction of people-animals-land. The ratio of animals to land area, also called density (Galaty and Johnson 1990, 12-14), is often represented by a low ratio in pastoralist communities. Moreover, a lower density corresponds with a greater degree of pastoral specialization. The ratio of people to animals is termed intensity, where high-intensity ratios are marked by low population density in proportion with large animal holdings. In this configuration, pastoral systems are relatively low-density and low-intensity systems in comparison with ranching, dairying, and mixed farming. In the case of pastoralism in Kham, increasing density expressed through a high ratio of animals to land area is impacted by a high rate of 'non-productive', that is male, animals in a herd. This means that, despite a comparatively low density, Tibetan pastoralists often have to resort to additional forms of livelihood activity; that is, they have a lesser degree of specialization for the low density displayed.

Contemporary pastoralism in Kham - even in those northern and western regions such as Sershül where unimproved agriculture is not possible - is generalized in that other activities are conducted alongside

12 Using fieldwork data among Baluchi pastoralists in Iran, Salzman (1972) argues against attributing pastoral identity to a model of 'pure' pastoralism or even to pastoralism as a fully specialized activity.

13 Transhumance would constitute a specific form of generalized pastoralism, with limited migration between two places, as analysed by Jones (2005). 
animal husbandry. Migrant jobbing in the form of road construction labour, driving tractors, and hire of motorcycle transport is a popular activity that generates supplemental household income. The gathering of grassland products such as a medicinal bulb (Ch. bei mu, Fritillaria sp.) and an edible tuber (Tib. gro ma, Potentilla anserina L.) continues to be done for personal consumption or small-scale trade with local doctors and other contacts. The gathering of yartsa gunbu, or caterpillar fungus, has increased exponentially in some pastoral areas, particularly in Sershül County, Kandzé Prefecture and in Yushul Prefecture, Qinghai Province, over the past twenty years. This phenomenal addition to pastoral income for some households is directly related with the similarly phenomenal growth in the Chinese market in the past two decades. When nomadic pastoralism is studied and evidenced in all its complexity, Philip Salzman (1972) suggests that it should be viewed as a mode of production that depends on multiple strategies of livelihood and multiple uses of resources, highlighting how pastoralism - in practice - relies on multi-resource nomadism.

In Kham, these corollary activities are not recent phenomena; patterns of multi-resource nomadic pastoralism can be traced historically. In the kingdom of Dergé, pastoralists of the estate of Zilphukhog had a reciprocal and complementary relationship with their hereditary masters (Thargyal 2007) that allowed pastoral dependents freedom to move to other areas of the kingdom - when not assisting with the estate's labour needs - for barter and trade of grassland products in exchange for tea, gunpowder, and musk. Lattimore reminds us that even the fiercely independent Golok pastoralists conducted trade with Muslims in Gansu (Lattimore 1962 [1951], 212). It was during the early-to-mid twentieth century that a trade embargo was placed on pastoral products from the Golok and Washul Serthar pastoralists, which restricted their ability to acquire tea, grain, and salt and thus led to predatory raids by these pastoralists. The trade embargo was placed on the pastoralists by Ma Bufang, the Muslim warlord of Qinghai. By imposing this embargo on pastoral products, Ma Bufang forced these pastoralists to raid others and attack caravans of wealthy merchants using both the Yushu-Songpan and Dartsedo trade routes (Gelek 2002, 45-48). Yet the Golok pastoralists were also more than predators since they strategically supplied animals for caravans in central Asia and were, in this regard, entrepreneurs (Lattimore 1962 [1951]). For the group of pastoralists in Minyak Kham, the relative proximity of their grasslands to Dartsedo - itself a trade bastion for the Chakla kingdom and the Qing empire - as well as the location of the grasslands along the northern Sichuan-Tibet road meant that they were in relatively early contact with Tibetan traders. One account in local folklore 
is that the legendary Tibetan merchant, Tsongpo Norbu Zangpo, himself stayed in the grasslands of the winter pastures for some time and that one of his precious $g z i$ stones ${ }^{14}$ was lost - and still remains - somewhere in the pastures.

Within the framework of multi-resource nomadism and generalized pastoralism, the practice of animal husbandry as a primary mode of pastoral livelihood incorporates other activities from migrant jobbing to gathering of grassland products and from trade to entrepreneurship. The planting of Brassica rapa in order to satisfy increased personal consumption of vegetables as a result of an edict by the local incarnate lama is readily interpreted within this frame. What this further implies is that the mode of livelihood - pastoralism as fully specialized, and therefore the only livelihood activity, or as generalized, and therefore one of different types of livelihood activity - is not always nor necessarily determined by environmental conditions. The choice to identify as drokpa is influenced by a complex of factors: historical movements and narratives, networks of relationships that involve animals and territorial masters (Tan 2018), strategies of mobility that allow for unexpected opportunities such as caterpillar fungus gathering, and a sense of identity that is distinct from others such as farmers and semi-pastoralists.

\section{From the Margins}

In their work theorizing the margins of the state, anthropologists Veena Das and Deborah Poole $(2004,8)$ suggest that margins are sites where nature is imagined as wild and uncontrolled at the same time as where the state is constantly refounding its modes of order and law-making. This resonates strongly with the Chinese concept of huang, as both geographic wasteland and social category of moral deficiency while simultaneously a place for state order and improvement. Yet they also argue against the idea that the state is 'about' its legibility, thus constituting an actor with full intentionality and insight. Rather, ethnographies of the state point to 'the many different spaces, forms, and practices through which the state is continually both experienced and undone through the illegibility of its own practices, documents, and words' (Das and Poole 2004, 10). In this final section, I consider how the practices of Minyak drokpa constitute margins - similar to the

$14 G z i$ stones are a kind of natural agate that is used as beads in necklaces and bracelets. It is thought to have auspicious benefits for the wearer. 
'remote areas' discussed by Gros in his introductory chapter - understood as sites of adaptation to state modes of legibility and expressed in ways that are 'invisible' to the state.

Referring again to the Nomad Settlement project, the associated policy document contains detailed specifications about housing construction. The houses themselves must be at least 6 o square metres. ${ }^{15}$ Livestock sheds are specified according to animal species, with sheep sheds required to be 0.5-0.7 square metres, yak calf sheds to be 1.4-1.8 square metres, and adult yak sheds to be 2.5-3.0 square metres. Further specifications on the costs of houses and sheds are provided, and disbursed through county-level animal husbandry bureaux. These specifications and disbursements are practically neglected in actual construction. In one county of Sichuan Province, the county government offered RMB30,00o worth of materials and labour to each household through external building contractors, and the households themselves were expected to pay any remaining costs for the house. For that community, the specifications were followed by the external contractors although there was concern about the quality of materials used. However, other households in another community took the money directly form the county government and used it to construct the houses themselves using traditional methods and materials. Individual households altered the specifications, and many found ways to save on construction costs. Animal sheds and greenhouses were yet to be constructed in either of these communities.

Of the houses themselves, intended to be the primary residence for pastoralists, there were also adaptations that rendered the houses illegible in the context of the policy. In one community, many houses remained vacant or were used as storage for the household's supply of tsampa and other sundry items. If the household had enough family members, then an elderly member of the house might take up residence in the newly constructed house while other members of the household continued living in their previous residence and herding animals. Not all households of a given community would take up the offer of money; some stated that they could not afford to contribute to the new houses because their caterpillar fungus harvest was not good enough, and they did not want to take up a state loan. More resourceful households were considering ways to include the new houses in a multi-resource strategy: one village leader thought it was possible to take advantage of the new houses' location beside a new road and wondered if the houses could be used as accommodation for tourists. 
Both modifications to the specifications of houses as well as adaptations to their use are read, in this instance, as practices that remake state legibility in ways that render the margins as integral to processes of governmentality. Forms of illegibility and partial belonging that are found in the margins of the state may constitute its necessary condition as a theoretical and political 'object' (Das and Poole 2004, 6).

To return, also, to the categories of mumin and nongmin, these have been employed by the state to simplify and abstract complex local realities. On the one hand, the Chinese state creates an internal opposition between a superior Han and agrarian-based majority with 'backward' minority pastoral populations. Yet a closer examination of state processes of legibility also reveals that Chinese state governmentality is not a static act but rather one that is able to incorporate local experiments to modify the way it implements its high modernist ideology. The environmental capacity for small-scale agriculture in eastern Tibet along with the coexistence of multiple sources of livelihood for pastoralists have long been known to the Chinese state. The contributions from Scott Relyea and Mark Frank (this volume) demonstrate how the state was testing agricultural improvements in the Republican period. One could read these ventures, where the borderlands were used as experimental sites, as a way of testing the limits, or margins, of the state and of state governmentality. A tension is displayed between two coexisting assumptions of how the Chinese state regards the minority pastoralists within its territoriality: 1 ) as a category of mumin articulated in opposition with nongmin and dependent on an ideal-type and 2) as a specific understanding of actual pastoral practices - including pastoralism as a degree of specialization and small-scale agriculture - that refines and modifies policy plans and implementation.

For the most part, pastoralism in eastern Tibet has been approached from a perspective that prioritizes environmental conditions to explain a mode of livelihood and a way of life. Notwithstanding that there are undoubted ecological benefits to, and constraints on, the practice of mobile animal husbandry, environmental determinants do not always account for decisions to be drokpa. This chapter has demonstrated that pastoralism in Minyak Kham is based on a complex of reasons including cultural and historical factors and that pastoralism, as animal husbandry and way of life, is therefore not only environmentally determined. Understanding that pastoralists identify as drokpa both for a variety of cultural and historical reasons and through a range of actual practices opens up to a wider exploration of the concept of pastoralism itself. The everyday practices of those who identify as drokpa are more varied than is assumed under 
an ideal-type model of pastoralism, particularly when defined in opposition to agriculture. Under this definition, activities such as planting are antithetical to pastoralism. Yet as the ethnographic example has shown, the activity is carried out by pastoralists and without any contradiction to how they continue to regard themselves as drokpa. Moreover, multiple strategies of livelihood and multiple uses of resources have been practically employed by pastoralists around the world, leading to a perspective that pastoralism is better understood as a degree of specialization, which ranges from fully specialized at one end to generalized at the other end. The data and analyses presented in this chapter suggest that processes of state governmentality and legibility themselves shift and adapt in order to remain viable. The shifts and adaptations - to some extent - respond to what unfolds in 'the margins of the state' (Das and Poole 2003), which are themselves never static or even, from the perspective adopted in this chapter, marginalized. The discursive processes occurring between the state and its margins continue to influence how pastoralism - as activity and way of life - offers important insights into Chinese state governmentality.

\section{Glossary of Chinese and Tibetan terms}

$\begin{array}{ll}\text { Chushi gangdruk } & \text { chu bzhi sgang drug } \\ \text { ciwa } & \text { lci wa } \\ \text { cun } & \text { 村 } \\ \text { cun shuji } & \text { 村書記 } \\ \text { cun zhang } & \text { 村長 } \\ \text { Dartsedo } & \text { Dar rtse mdo } \\ \text { depa } & \text { sde pa } \\ \text { dixiao } & \text { 抵銷 } \\ \text { Dokham Nechen Nyernga } & \text { Mdo khams gnas chen nyer lnga } \\ \text { drokpa } & \text { 'brog pa } \\ \text { droma } & \text { gro ma, gyo ma } \\ \text { fangzaijian zainengliruo } & \text { 防災減災能力弱 } \\ \text { Gelukpa } & \text { Dge lugs pa } \\ \text { gyelpo } & \text { rgyal po } \\ \text { huang } & \text { 荒 } \\ \text { Kagyu } & \text { Bka' brgyud } \\ \text { Kangding } & \text { 康定 } \\ \text { la } & \text { bla }\end{array}$




$\begin{array}{ll}\text { lari } & \text { bla ri } \\ \text { Lhagang } & \text { Lha sgang } \\ \text { loma } & \text { lo ma } \\ \text { luo hou } & \text { 落後 } \\ \text { Minyak Rab } & \text { Mi nyag rab sgang } \\ \text { mumin chi kuixin liang } & \text { 牧民吃雐心糧 } \\ \text { néri } & \text { gnas ri } \\ \text { Nyingma } & \text { Rnying ma } \\ \text { pin zhong tui hua } & \text { 品種退化 } \\ \text { ponpo } & \text { dpon po } \\ \text { rongmadrok } & \text { Rong ma brog } \\ \text { rongpa } & \text { Rong pa } \\ \text { Sakya } & \text { Sa skya } \\ \text { shifan hu } & \text { 示範戶 } \\ \text { si da tusi } & \text { 四大土司 } \\ \text { si peitao } & \text { 四配套 } \\ \text { Tagong } & \text { 塔公 } \\ \text { tshe thar } & \text { tshe thar } \\ \text { Tsongpo Norbu Zangpo } & \text { Tshong dpon Nor bu Bzang po } \\ \text { weisheng tiaojian ji cha } & \text { 衛生條件極差 } \\ \text { yartsa gunbu } & \text { dbyar rtswa dgun bu } \\ \text { Zhamo } & \text { Bzhag mo } \\ \text { Zhara Latse } & \text { Bzhag bra lha rtse } \\ \text { zhidak } & \text { zhing bdag, gzhi bdag } \\ \text { zhuan ren, zhuanfangshi } & \text { 專人專方式 } \\ & \end{array}$

\section{References}

Asad, Talal. 1978. 'Equality in Nomadic Social Systems? Notes Towards the Dissolution of an Anthropological Category'. Critique of Anthropology 3 (11): 57-65.

Bates, Daniel G. and Susan H. Lees. 1977. 'The Role of Exchange in Productive Specialisation'. American Ethnologist 79 (9): 824-841.

Chang, Claudia, and Harold A. Koster, eds. 1994. Pastoralists at the Periphery: Herders in a Capitalist World. Tucson: University of Arizona Press.

Chang, D.H.S. 1981. 'The Vegetation Zonation of the Tibetan Plateau'. Mountain Research and Development 1 (1): 29-48.

Chinese government document. 2011. Quanguo youmumin dingju gongchengjianshe, shi er wu guihua (Construction of the National Nomadic Settlement Project, Twelfth Five-Year Plan). 
Das, Veena, and Deborah Poole, eds. 2004. Anthropology in the Margins of the State. Santa Fe, NM: School of American Research Press.

Dyson-Hudson, Rada and Neville Dyson-Hudson. 1980. 'Nomadic Pastoralism'. Annual Review of Anthropology 9 (1): 15-61.

Ekvall, Robert. 1968. Fields on the Hoof: Nexus of Tibetan Nomadic Pastoralism. Prospect Heights, IL: Waveland Press, Inc.

Gaerrang. 2016. 'Tibetan Identity and Tibetan Buddhism in Trans-Regional Connection: The Contemporary Vegetarian Movement in Pastoral Areas of Tibet (China)'. Études Mongoles et Sibériennes, Centrasiatiques et Tibétaines (EMSCAT) 47. URL: http://emscat.revues.org/2755 ; DOI: $10.4000 /$ emscat.2755

Gaerrang. 2015. 'Housing Projects in the Nomadic Areas of China's Eastern Tibetan Plateau: Representation, Market Logic and Governmentality'. Nomadic Peoples 19: 261-280.

Gaerrang. 2012. Alternative Development on the Tibetan Plateau: The Case of the Slaughter Renunciation Movement. PhD dissertation, University of Colorado-Boulder

Galaty, John, and Douglas Johnson, eds. 1990. The World of Pastoralism: Herding Systems in Comparative Perspective. New York: Guilford Press.

Gardner, Alexander. 2006. The Twenty-five Great Sites of Khams: Religious Geography, Revelation, and Nonsectarianism in Nineteenth-Century Eastern Tibet. $\mathrm{PhD}$ dissertation, The University of Michigan.

Gardner, Alexander. 2003. 'Review Article - Khams pa Histories: Visions of People, Place and Authority'. Tibet Journal 28 (3): 61-96.

Gelek, Losang. 2002. 'The Herders of Eastern Tibet: Notes from an Anthropological Field Study'. Chinese Sociology and Anthropology 35 (1): 21-81.

Gladney, Dru C. 1998. Ethnic Identity in China: The Making of a Muslim Minority Nationality. Fort Worth, TX: Harcourt Brace College Publishers.

Harrell, Stevan, ed. 1995. Cultural Encounters on China's Ethnic Frontiers. Seattle, WA: University of Washington Press.

Hong, Jiang. 2005. 'Grassland Management and Views of Nature in China Since 1949: Regional Policies and Local Changes in Uxin Ju, Inner Mongolia'. GeoForum 36: 641-653.

Hjort, Anders. 1981. 'A Critique of "Ecological" Models of Pastoral Land Use'. Ethnos: Journal of Anthropology 46 (3-4): 171-189.

Huber, Toni. 1994. 'Putting the Gnas Back in Gnas-skor: Rethinking Tibetan Buddhist Pilgrimage Practices'. The Tibet Journal 19 (2): 23-6o.

Ingold, Tim. 1980. Hunters, Pastoralists and Ranchers: Reindeer Economies and Their Transformations. Cambridge: Cambridge University Press.

Jones, Schuyler. 2005. 'Transhumance Re-examined'. Journal of the Royal Anthropological Institute 11 (2): 357-359. 
Kapferer, Bruce. 2010. 'Aporia of Power: Crisis and the Emergence of the Corporate State'. Social Analysis 54 (1): 125-151.

Lattimore, Owen. 1962 (1951). Inner Asian Frontiers of China. Boston: Beacon Press. Mueggler, Erik. 2001. The Age of Wild Ghosts: Memory, Violence, and Place in Southwest China. Berkeley: University of California Press.

Salzman, Philip C. 1972. 'Multi-resource Nomadism in Iranian Baluchistan'.Journal of Asian and African Studies 7 (1-2): 6o-68.

Scott, James C. 1998. Seeing Like a State: How Certain Schemes to Improve the Human Condition Have Failed. New Haven, CT: Yale University Press.

Tan, Gillian G. 2018. Pastures of Change: Contemporary Adaptations and Transformations Among Nomadic Pastoralists of Eastern Tibet. Geneva: Springer.

Tan, Gillian G. 2016. "Life" and "Freeing Life" (tshe thar) Among Pastoralists of Kham: Intersecting Religion and Environment'. Études Mongoles et Sibériennes, Centrasiatiques et Tibétaines (EMSCAT) 47. URL: http://emscat.revues.org/2755; DOI: $10.4000 /$ emscat.2755

Teichman, Eric. 1922. Travels of a Consular Officer in Eastern Tibet. Cambridge: Cambridge University Press.

Thargyal, Rinzin. 2007. Nomads of Eastern Tibet: Social Organization and Economy of a Pastoral Estate in the Kingdom of Dege. Leiden: Brill.

Tsomu, Yudru. 2016. 'Guozhang Trading Houses and Tibetan Middlemen in Dartsedo, the Shanghai of Tibet'. Crosscurrents: East Asian History and Culture Review 5 (2): 291-349.

Yeh, Emily T. and Gaerrang. 2011. 'Tibetan Pastoralism in Neoliberalizing China: Continuity and Change in Gouli'. Area 43 (2): 165-172.

Yeh, Emily T. 2007. 'Tropes of Indolence and the Cultural Politics of Development in Lhasa, Tibet'. Annals of the Association of American Geographers 97 (3):593-612.

Western, David and Thomas Dunne. 1979. 'Environmental Aspects of Settlement Site Decisions Among Pastoral Maasai'. Human Ecology 7 (1): 75-98.

Williams, Dee Mack. 2002. Beyond Great Walls: Environment, Identity and Development on the Chinese Grasslands of Inner Mongolia. Stanford, CA: Stanford University Press.

\section{About the Author}

GILLIAN G. TAN is senior lecturer in anthropology at the School of Humanities and Social Sciences at Deakin University. Her research has looked at contemporary social and environmental changes on the Tibetan plateau, in particular how analysis and comparison of the different epistemologies and norms about the concept of 'change' are vital to critical appraisal of 
developments - often contested - on the grasslands of Eastern Tibet. 'Change' is a highly complex concept that does not simply denote observable shifts in ideology and practice produced over time; it is additionally described and analysed as the processes of either adaptation or transformation, which produce shifts in social structures and value systems. Her current work examines human-nonhuman relationships among Tibetan pastoralists as well as the theoretical and practical intersections between ecology and religiosity. 


\section{Part III}

Strategic Belongings 



\title{
Introduction
}

\author{
The Editor
}

The varied political entities in Kham exhibited forms of authority and legitimization that can in themselves be regarded as exemplifying different conceptions and formulations of sovereignty. Yet it is doubtful that an autonomous history of places could be written independently of the distant centres of power. The question then becomes: how are Tibetan and Chinese governments' respective visions of sovereignty translated in practical terms and in the lives of the people inhabiting these borderlands that progressively lost their own centrality and integrity? There is no straightforward answer to this question, but it can inform a more nuanced approach to the entanglement of local, national, and global political economies at the frontier. The chapters in this section emphasize forms of agency and local responses to past and present changes. A micro-sociological approach and attention to life trajectories of some key individuals help us to understand the lived worlds and the subjectivities of the actors engaged in - or caught in - the upheavals of the time, their fears, hopes, and projects alike.

The chapters consider a spectrum of strategic positionings that include forms of 'declarations of dependence' on the one hand and more active refusal on the other, rather than positing a reductionist or a priori framework of domination and resistance. In their respective take on the transformations that unfolded at the frontier or which are still ongoing, the chapters present us with various components of the dynamics of change. First, they make clear that the centres themselves are not static entities, nor are the means of control they deploy. Second, they show how the 'state effect' has influenced horizontal relations at local level, not just at the level of vertical power relations between centre and periphery. Finally, these chapters also show how practices at the periphery contribute to shaping to some extent the political institutions of the colonizing centre, and the state itself. Indeed, paying proper attention to Kham as a 'field of relations' that emerges inbetween power centres implies a particular view of state space. At the same time, it forces us to recognize the extent to which - in a similar fashion to what Guyot-Réchard (2017, 23-24) describes for the disputed frontier zone of North-East India - those living in the 'shadow' of the state actually found 'acceptable' or 'even welcomed' 'a certain kind of state presence'. In various ways the chapters in this section engage with the question of how people at the frontier deal with their state. 
Imperial ventures are projected but never fully realized; they are contingent, ambiguous processes that meet with counter-strategies. This also holds true for China's nation-building project which, while it creates a hegemonic landscape, is appropriated in different ways across the territory. In the early twentieth century, the emergence of regionalism and ethno-provincial politics further complicated forms of attachment and belonging and the very nature of nationalism. Local leaders found themselves entangled in border politics, adapting their political behaviour to this period of turmoil. In the chapters to follow, we also see the gradual influence of new ideologies from outside and how the terms of the relationship are being redefined. The advent of the nation-state introduced some irrevocable changes that affected territories and ethnic groupings regarding the way they are now conceived and experienced. These have led to competing narratives of belonging and to the historicizing of statecraft that support claims of identity and sovereignty.

We start with an essay by Lucia Galli who examines the rising influence of eastern Tibetan merchants on political matters and their socio-economic role in the 1940 s and 1950s. Her chapter complements the discussion on trade institutions and the development of trade networks offered by Giersch in the previous section, as she returns to the crucial role played by Khampa traders and the increasing political and economic power acquired by members of the most influential eastern Tibetan trading firms. In referring to the travel journal of a Khampa trader spanning a period of thirteen years (1944-1956), her chapter adds an insider's perspective. Furthermore, in her analysis we see the emergence of what she calls 'proto-identitarian' awareness among Khampa traders, as Tibetan merchants became increasingly present on a burgeoning political scene enlivened by a new educated elite.

The mobility of traders and the importance that commerce played in the wealth of power holders parallel the 'bargaining' that took place at political level. For example, in the border town of Dartsedo, the hub of commercial activity, such bargaining and shifting political alignments were common practice for the Chakla king. Following military intervention by the Sichuan Governor in Kham in the summer of 1912, the king's concerns were summarized by Louis King, the British Consul, as follows: 'He was not in sympathy with democratic ideas, and deplored the change from Empire to Republic [...] He hoped that one day his kingdom would be restored to him - that was the leit-motif of his life' (Kobayashi 2014, 101). Just as the kings had acquiesced in the past to the Qing tusi institution because it served their interests, integration into the new republic was not motivated by the political ideal of 'the Republic of Five Races' (wuzu gonghe) but represented 
a possible opportunity of reclaiming a status lost as a consequence of Zhao Erfeng's termination of the tusi office.

Local polities that had long established ties with Chinese central powers adapted to the political changes that had taken place after the collapse of the Qing dynasty. Fabienne Jagou explores one such case in her chapter: that of the little-known kingdom of Trokyap, located on the fringes of Sichuan province. As the small kingdom became a bone of contention between the Sichuan and Xikang authorities in the 1930s, we see how rivalries unfolded between regional and national power holders. The ambivalent position of the Trokyap king - whose voice can be heard by reading between the lines of the archive documents - shows how uncertain the state-building process was. Interestingly, the Trokyap king did not seek independence but seemed more interested in securing the stability of his position by maintaining a mutually beneficial form of allegiance.

This stance contrasts with that of an increasing number of Khampa Tibetans in the 1930s, who tried to shape the republican rhetoric to suit their own interests. "Applying the logic of "national autonomy" to their own situation', as Yeh $(2007,83)$ put it, they launched the 'Khampa rule of Kham' movement and demanded autonomy from both China and Central Tibet (see Peng 2002). As Yudru Tsomu shows in her chapter, this period saw the emergence of a new elite of 'political strongmen' that did not rely on traditional hereditary and ascribed status. She focuses on the situation in Dergé, historically one of the most powerful polities in Kham, and on the rise to power of a local headman, Jagö Topden, who successfully challenged the established authority. A strongman like Jagö Topden formed alliances with various forces that contended for control of Kham and ultimately emerged as the dominant figure to compete with the Dergé king. While Jagö's ascendency reminds us of the charismatic figure of Gönpo Namgyel who defeated several polities in Kham, including Dergé, their demeanours contrast significantly, as well as the conditions of their rise to power. Jagö did not prove to be a fierce warrior but a fine and somewhat opportunistic politician.

It becomes clear from these chapters that the 'empire to nation' transition is rather confused in the case of China, and in the frontier zone in particular one finds some obvious continuities: republicans, no differently than communists, did not operate in a vacuum. Continuity, however, not in a rigid power structure but in the dynamic ways political cultures and institutions were generated, adapted, or transformed.

If we look back at China's centuries-long politics of expansion, the initial Chinese Communist Party (C.C.P.) project must have seemed to be full of 
promises for those who envisioned self-determination. Article 14 of the 1931 C.C.P. constitution recognized the right to self-determination, including the complete separation and the formation of an independent state, for each minority 'minzu' (nationality). Indeed, Bapa Püntsok Wangyel, who was from Bathang and started his education in a Chinese school there, founded a secret Tibetan Communist Party in the 1930s, with the idea of an independent Tibet after a communist revolution (Goldstein, Sherap, and Siebenschuh 2004, 47). However, adoption of this new ideology was not often straightforward, if not simply rejected. In her chapter, Dáša P. Mortensen discusses the need to adapt to the changing political landscape and shows that even a fierce defender of local autonomy in Gyelthang, such as Wangchuk Tempa, nevertheless had to join forces with representatives of the Chinese communist state in the 1950 in response to mounting social and political pressure. She illustrates how Party officials resorted to 'political persuasion' to prompt recalcitrant Khampa leaders to cooperate and to strengthen nascent Party control in Gyelthang. The particular political climate of the time makes the strategic positioning of a Wangchuk Tempa a revelatory example of the negotiated trajectories of the new educated elite Tsomu refers to in her own chapter. As D. Mortensen makes clear, a simplistic reading in terms of resistance, collaboration, or collusion distorts the intricate factors that led to certain kinds of compromises, and it also flattens the power of political education and propaganda. 'Political persuasion', as D. Mortensen calls it, and other types of 'thought work' have since gone a long way in many different spheres of public and political life in the P.R.C.

In the contemporary period, a revival of traditional historiography has contributed to revisiting the political entanglements of the past, and more fundamentally, to reconstructing local identities as Maria Turek shows with regard to Nangchen, one of Kham's main historical kingdoms. She focuses on contemporary chronicles that are deeply rooted in Tibetan Buddhist orthodoxy and historical imagination. In these new historiographies, the kingship narrative recasts the kingdom of Nangchen as an autonomous power centre. As Turek rightly points out, there is a certain political sensitivity in these attempts at regaining control of their own history and at recalling the past glory of kingship. Alternative futures are being formulated by looking into the past. This re-imagined centrality in the historiography of Kham's polities is not limited to Nangchen but is part of a broader trend. Revivalist practices have gained prominence in the last three decades, and narratives about secular and religious power play a vital role in the promotion of local identity. The revival is predominantly active outside Lhasa and other areas within the Tibet Autonomous Region that are more 
tightly controlled. Kham is well known for the diversity and vitality of its religious traditions, which have taken on new forms in the contemporary period. A particularly astonishing phenomenon is the emergence of religious figures of treasure-revealers (tertön), as already described in Buffetrille's chapter in the first section, whose teachings have attracted thousands of followers and whose institutes have grown exponentially to form extremely large monastic camps: with more than 10,00o practitioners, they outdo the largest monasteries in Central Tibet prior the 1950s.

Yasmin Cho examines in her chapter one of these most striking and distinctive forms of Buddhist community: the mega-sized encampment of Yachen, located in an isolated valley in Baiyu (Pelyul) County, Ganzi Tibetan Autonomous Prefecture. Many monks and nuns have come to settle in Yachen, originally founded in the mid-1980s, when the even larger-size encampment of Larung Gar in Serthar had been partly demolished in 2001. Both encampments have since been the object of new demolitions and evictions, and of various restrictions and forms of control. Cho addresses the transformations that are taking place in Yachen through the lived experience and 'material engagement' of its nuns. Indeed, Yachen is made up essentially of small individual-size huts most of which were built by nuns of different origins. Instead of focusing on the religious figures who triggered this ongoing religious revival, Cho pays ethnographic attention to the daily practices of the nuns who create, shape, and inhabit the space of the encampment. This perspective adds a rich sensitive texture to the experience of a form of autonomy beyond spirituality, making gender a key component of her exploration of the precarious efforts by some Tibetans to (re)claim spaces that belong to them. It is, of course, telling that the charismatic religious figures who run Larung Gar or Yachen Gar are famous treasure-revealers, a form of visionary prophetic leadership that emerges in opposition to existing forms of authority. To be more precise, Cho's analysis of the encampment in its evolving material form and in its inherent incompleteness and inclusiveness, sheds light on the spatial nature of state control and on the constraints it imposes on the astonishing density of this 'island' zone, as she calls it. As such, this 'island' brings to mind the image of the beyul, valleys hidden by Padmasambhava where Tibetans can seek refuge when dangers threaten the country. However, these encampments are not strictly speaking Tibetan enclaves, as many Han Chinese are attracted to this spirituality - instead they could be called 'Buddhist Temporary Autonomous Zones'.

The burgeoning popularity of Tibetan religion among the Han is a growing state concern. It is seen as a potential threat to the internal foundations of social order - a threat that reveals the vulnerability of social order and 
generates a form of uncertainty about where in fact the boundaries are. In the words of anthropologists Valentina Napolitano, Nimrod Luz, and Nurit Stadler (2015, 96), 'borderlands avail partitions and segregation but may also generate processes of subversion (sometimes seductive) of state sovereignty'. Finally, with Cho's chapter we return to some of the opening questions of this volume regarding space and power, and forms of inclusion and exclusion. The encampment captures our imagination as we seek to rethink the borderlands, and it perhaps offers a concrete image of the claim made by Gros in the introductory chapter that some processes exceed conventional geometric figures.

\section{References}

Goldstein, Melvyn, Dawei Sherap, and William R. Siebenschuh. 2004. A Tibetan Revolutionary: The Political Life and Times of Bapa Phuntso Wangye. Berkeley: University of California Press.

Guyot-Réchard, Bérénice. 2017. Shadow States: India, China and the Himalayas, 1910-1962. Cambridge: Cambridge University Press.

Kobayashi, Ryosuke. 2014. 'Tibet in the Era of 1911 Revolution'. The Journal of Contemporary China Studies 3 (1): 92-113.

Napolitano, Valentina, Nimrod Luz, and Nurit Stadler. 2017. 'Introduction: Materialities, Histories, and the Spatialization of State Sovereignty'. Religion and Society: Advances in Research 6: 90-97.

Peng, Wenbin. 2002. 'Frontier Process, Provincial Politics and Movements for Khampa Autonomy During the Republican Period'. In Khams pa Histories: Visions of People, Place, and Authority, edited by L. Epstein, 57-84. Leiden: Brill.

Yeh, Emily T. 2007. 'Tibetan Indigeneity: Translations, Resemblances, and Uptake'. In Indigenous Experience Today, edited by M. de la Cadena and O. Sarn, 69-97. Oxford: Berg. 


\title{
9 Money, Politics, and Local Identity
}

\author{
An Inside Look at the 'Diary' of a Twentieth-Century \\ Khampa Trader
}

\section{Lucia Galli}

\begin{abstract}
This chapter analyses the socio-economic role played by Khampa traders in twentieth-century Tibet, focusing in particular on the increasing political and economic power gained in the 1940 s and 1950 s by members of the most influential eastern Tibetan trading firms. The discussion is enriched by information drawn from the travel journal of Khatag Dzamyag, an otherwise unknown Khampa trader. The author's recollection, spanning over a period of thirteen years (1944-1956), mainly spent journeying, trading, and pilgrimaging, provides the scholar with an insider's perspective on events until now known only through the conventional historiographical writing.
\end{abstract}

Keywords: Khampa traders, twentieth-century Tibet, Khampa identity, travel journal.

\section{Introduction}

Recent developments in the field of Tibetan studies have forced an increasing number of scholars - inside and outside the narrow confines

\footnotetext{
Acknowledgements: I am extremely grateful to Charles Ramble for bringing Dzamyag's nyindep to my attention and to Ulrike Roesler for her support during my doctorate at the University of Oxford. I thank Stéphane Gros and Yudru Tsomu for their kind suggestions and helpful comments on the earlier draft of this paper. My deepest appreciation and gratitude go to Tsering Dhondup Gonkatsang, to whose loving memory this work is dedicated. This chapter is the first of a series of publications I aim to dedicate to the life and work of Khatag Dzamyag. The content of his journal (nyindep), as well as its format, much deserve an in-depth analysis the extent of which necessarily falls outside the limited scope of the present work.
}

Gros, Stéphane (ed.), Frontier Tibet: Patterns of Change in the Sino-Tibetan Borderlands. Amsterdam, Amsterdam University Press 2019

DOI: 10.5117/9789463728713_CHO9 
of the discussion on the Sino-Tibetan relationships - to move away from an assumptive framework based on a priori stipulation of identities and boundaries towards a recognition of the main role played by mobility and flux - rather than fixity and stasis - in shaping those territories labelled as 'borderlands'. In this chapter, I approach frontier territories such as the eastern Tibetan regions of Amdo and Kham in light of an understanding of 'borderlands' as 'a dynamic, permeable, and shifting space', following the definition proposed by Gros in his Introduction to the present volume.

The indisputable globalizing character of the world-empire system of the Qing (Brook 2009) determined the rules of cultural, economic, political, social, and military integration and exchange on the borderlands - and the same could be said, to a lesser extent, of the Ganden Phodrang. Nevertheless, the easternmost fringes of the Tibetan plateau were any thing but 'peripheral'. From the late nineteenth to the mid-twentieth centuries, Kham in particular was, to use Gros' (this volume) words, 'a fragmentary politico-religious landscape and complex cultural matrix', both 'multivocal' and 'multilocal'. In the construction of a sense of Tibetanness, political identity failed to match the importance of its cultural and religious counterparts. While becoming de facto subjects of the Manchu Empire by the mid-eighteenth century, the Tibetans living in the multiethnic regions of Amdo and Kham consistently perceived themselves as connected to the central areas of Ü-Tsang by religious and cultural bonds rather than political affiliations. ${ }^{2}$ Khampa identity, with its rich ecological, social, and religious diversity, constitutes a world of its own, diverse from Central Tibet and certainly distinct from China proper.

Whereas the heuristic and analytic convenience of labelling the regions along the Sino-Tibetan frontier as 'borderlands' is irrefutable, the question about the suitability of applying such a term to the whole extension of Kham remains. In his Introduction, Stéphane Gros convincingly broaches the context of the Sino-Tibetan borderlands 'not as a regionally confined space but as process-oriented spatial formation'. By framing the region as 'a fragmentalized space of interconnected and interdependent locales and people', Gros makes of Kham 'a good-to-think-with category'; by operating a topological reversal, he invites us to move away from prior preconceptions based on a Lhasa-centric and/or Sino-centric historical perceptions. To

1 On new takes on the historical, cultural, and socio-economic developments of the SinoTibetan borderlands, see for instance Hayes (2014), Elliot (2014), Gros (2016), Giersch (2010b; 2016).

2 The same concept applies to the westernmost Himalayan regions of Ladakh and the southernmost areas of Bhutan and Sikkim, which fell into the British India orbit in the nineteenth century (Carrasco 1959, 12-13). 
see the Sino-Tibetan borderlands in terms of 'frontier dynamics' accommodates the inherent paradox of Kham, both 'named regional category' and 'heterogenous frontier zone and nexus of power', a grey area where different forms of authority overlapped. Other frontier areas, such as that studied by C. Patterson Giersch in Southern Yunnan province, exhibit a similar pattern:

[F]rontiers [...] were 'borderlands', or regions without clearly defined political boundaries where multiple expansive powers competed for resources and indigenous allies. They were also 'middle grounds', places of fluid cultural and economic exchange where acculturation and the creation of hybrid political institutions were contingent on local conditions. (Giersch 2006, 3-4)

The political fragmentation of Kham, internally divided into a variety of polities and communities, appears to support the perception of Tibet as intrinsically 'stateless' (Samuel 1982). However, the situation on the ground suggests that the main local polities ultimately conceived themselves as 'centres', despite external attempts at peripherization (see Turek, this volume). The seemingly chaotic patchwork of chieftainships, micro-states, and monastic estates presented within itself forms of secular administration of a certain bureaucratic sophistication. That was indeed the case of nineteenth-century Dergé $^{3}$ and early twentieth-century Nangchen, 'a self-referential sphere with a long legacy of religious and political power and autonomy' (Turek, forthcoming). ${ }^{4}$ The establishment in 1939 of the Xikang province further supports the importance that 'peripheral' and 'ethnic' elements played, not only in China's metamorphosis from empire to nation-state, but also in the emergence of a Khampa identity politics (Lawson 2011; Peng 2002).

Whilst the influence exerted by trade and commerce on the process of empire and state-building has been acknowledged by many scholars (e.g. Millward 1998; Perdue 2005; Kim 2008; Giersch, this volume), the way the intertwining of commercialization and political control affected the Sino-Tibetan borderlands is still very much uncertain. External inputs, such as the implementation of state-controlled interventions and the impact on China of European imperialist threats, have been for a long

3 On the history and bureaucratic structure of the kingdom of Dergé, see Hartley (1997).

4 I would like to thank M. Maria Turek for making available to me a copy of her article 'Monastic Obligations, Hat Change and Lhasa Encroachment: Notes on the Economic System in the Historical Kingdom of Nang chen', presented at the Fontainebleau conference (December 2013) 'When the Taxman Cometh: Tax, Corvée and Community Obligations in Tibetan Societies', and soon to be published as part of the proceedings of the SHTS (Social History of Tibetan Societies). 
time presented as the only causes of change in the Sino-Tibetan frontier, yet recent studies prompt the scholars' attention toward a new narrative of change, acknowledging the role of both insiders and outsiders as promoters of socio-economic innovations (Giersch 2010; Tsomu 2016a, 2016b; Bray, this volume). Fresh approaches to political and economic geographies have been recently proposed by different scholars. Whilst talking about the Songpan region of northern Sichuan, for instance, Jack Hayes (2014, xviii) offers a new perspective on the interpretation of trade networks, inter-cultural relations, regional economic cycles, and political and religious developments in Kham, by acknowledging their development as the outcome of indigenous efforts rather than the byproduct of external forces. Such a perspective is in continuation with that of Giersch (2010b) who focuses his attention on the foundations of trading networks and their impacts on the socio-political developments of local societies in Kham, seeing trade - and trade flows - as a heuristic device designed to challenge the confines of traditional spatial categories, moving away from preconceived geographical scales, such as civilizations, empires or nations, and regions.

The transformative power of trade, especially in the Sino-Tibetan borderlands, is better understood through the analysis of the impacts that trading networks have on the local societies. For instance, the local gentry of Dartsedo acted as brokers for Central Tibetan monasteries and merchants, using their indigenous status to safely navigate the cross-cultural environment of the borderlands (Booz 2011; Tsomu 2016a, 2016b). Whereas the tea trade was tightly controlled by Chinese companies in partnership with monasteries located in Yunnan, Sichuan, and Qinghai, the locals used their connections to the territory to act as go-betweens and interpreters between Central Tibetans and Han and Hui merchants. ${ }^{5}$ Trade networks in fact penetrated territories subject to the indirect rule of the Qing empire and the Lhasa-based government, crossing boundaries and incrementing the bargaining power of political representatives and local elites vis-à-vis the 'centre', whether the Manchu court or the Ganden Phodrang.

\section{A Pilgrim's Diary}

The different frontier policies put in act both by the late Qing and the Nationalist and Republican government in the Kham area - subject of many

5 On the vital role of the trading houses (Ch. guō zhuāng) in Dartsedo prior to 1950s, see Booz (2011, 265-318) and Tsomu (2016a). 
recent studies (Wang 2011; Tsomu 2013, 2015; Elliot 2014; Relyea 2015a, 2015b, 2016a, 2016b; Giersch 2014, this volume) - provide the political background to the present chapter. The rising influence of eastern Tibetan merchants on political matters, as well as the emergence of what could be called a 'protoidentitarian' awareness among Khampa traders and their socio-economic role in the decades preceding 1959 are here examined through the lenses of the autobiographical travel journal of Khatag Dzamyag, an otherwise unknown chief-merchant (tsongpön). ${ }^{6}$ The text, originally written in a scroll-paper format and covering a span of thirteen years (1944-1956), mainly spent by the author journeying, trading, and pilgrimaging, was later edited by The Tibet House in Delhi and published by Indraprastha Press in 1997 with a bilingual title - for the sake of convenience, I will henceforth refer to the text by its English heading, i.e. A Pilgrim's Diary: Tibet, Nepal and India 1944-1956. The word 'diary' loosely translates the Tibetan nyindep, a term indicating a category of texts, literary 'day-books' or 'journals', belonging to the wide genre of Tibetan life writing. ${ }^{7}$ Whereas the content and structure of Dzamyag's nyindep - with its lists of private exchanges, monetary transactions, days spent travelling, teachings and empowerments received - support its inclusion in the genre of journal writing, more cautious should be the identification of it as a 'diary'. ${ }^{8}$ The topic concerning the categorization of Dzamyag's work within the Tibetan literary corpus is beyond the scope of the present chapter, suffice to say that the nyindep mirrors the author's self-perception as trader and self-proclaimed pilgrim (né korwa).

Dzamyag's travel account covers what is probably one of the most significant decades in the history of Indo-Sino-Tibetan relationships, and it does so from the perspective of a Tibetan trader mostly interested in depicting himself as a simple pilgrim, in spite of the substantial economic means at his disposal. The problematic and oft-times outright ambiguous attitude shown by the author in regards to the exact amount of his wealth is at

6 Known in Tibetan as tsongpön, these merchants handled trade and business affairs for hundreds of monasteries (Tsomu 2016b, 20). Khatag Dzamyag earned this title by acting as trade agent for one of the labrang of Ngor $\mathrm{E}$ wam chöden, a Sakya establishment in the central region of Tsang.

7 Forms of Tibetan life writing include, but are not restricted to, biography and autobiography (namthar), accounts of previous lives (kyérap, trungrap), personal histories (jungwa, jöpa), receipt records (topyik, senyik), journals and daybooks (nyindep, nyinto) (Quintman 2015, 24).

8 Although the text has a diary format, the retrospective character of the recollecting process, as well as the absence of any 'confessional' features, suggest its categorization as a form of autobiography rather than a personal journal. Given such a difficulty in reaching a clear taxonomy for the text, I will henceforth refer to the work either as 'journal' or nyindep. On Dzamyag's nyindep and its position within Tibetan diary-keeping practices, see Galli (2019). 
the core of several inconsistencies related to the trader's financial means, especially at the time of his departure from his ancestral land of Rabshi, in Gakok (nowadays Yushu prefecture), ${ }^{9}$ an event that marks the beginning of the trader's journey and subsequently of his nyindep. The events leading to what will turn out to be a life-long exile - Dzamyag was never to return to Rabshi - support the notions of 'multivocality' and 'multilocality' proposed by Gros (this volume). Although nominally subsumed within the Xikang province, the territory of Nangchen was still under the political and juridical control of indigenous rulers, as the case of our trader clearly demonstrates. In the first lines of his journal, written in 1944 and recounting events occurred in 1940, Dzamyag briefly summarises his involvement in a feud between representatives of the local ruling family and some of the major reincarnations of a Geluk establishment with which he was connected. Accused of complicity in the murder of the family's heir, Dzamyag was incarcerated, put to trial, and, with no proof of his personal involvement, condemned to six months of prison at the end of which he was ousted as a 'new beggar' (sartrang). The confiscation of his wealth and estate by the lord of Rabshi is indicative of the unchallenged authority wielded by local rulers, regardless of the Nationalist government's ban to any form of indigenous chiefdoms.

The loss of financial means and source of income, reported by the trader as the initial driving force behind his travels, appear to have been partially overcome three years later, when Dzamyag commissioned, as a propitiatory ritual for his departure, a full reading of the Kangyur, a task for which he donated 258 silver sang (Kha stag 'Dzam yag 1997, 12). It appears plausible to ascribe the monetary influx - presented in the journal as a fait accompli - to a fortunate combination of financial shrewdness and social expertise. In particular, the presence of several hints in the beginning of the nyindep reveals the trader's plan to capitalize on the custom of carrying out business transactions on a credit basis. His journey from eastern Tibet to Lhasa was punctuated by continuous business dealings, necessary to settle old debts and loans, and to pay visits to some of the representatives of the local nobility. The socio-economic network built by Dzamyag in the years preceding his journey was not restricted to governmental officials and local nobility but included many representatives of the mercantile world too; traders, tsongpön, and even members of the Sandutsang household, one of the wealthiest Khampa trading families, could be counted among his contacts. 
Although Dzamyag never elaborates on the relationship tying him to the Sandutsang, the connections he made with representatives and brokers of the family suggest a certain familiarity with their dealings. Whereas the largest eastern Tibetan trading firms are relatively well-known, an in-depth socio-historical study of minor trader households who moved their business to Central Tibet in the early twentieth century is still sorely missing. The Pangdatsang, ${ }^{10}$ the Sandutsang, and the Andrutsang paved the way to a substantial number of smaller Khampa trading families, of whose internal organization we know little to nothing. Scanty, yet fascinating, information is contained in an essay-memoir by a Lhakpa Döndrup, a novelist and previous trader, who provides a description of the inner structure of the Lhasa-based Khampa community in which eastern Tibetan trading households played a representative role. The wealthiest among the merchants were appointed as 'headsmen' (gotso) of their own co-regionals, in consideration of both their professionalism and loyalty to a common 'ancestral land', or phayül. According to Lhakpa Döndrup, the Pangdatsang acted as referents for those hailing from the areas of Markham and Sandu, the Gyanagtsang for those from Karzé and Trehor, the Andrutsang and the Jamatsang for the Khampas from Lithang, the Tsatrültsang and the Chödruktsang for those from Gojo, whereas the traders Dampa Lodrö and Abak were the representatives of the people from Tsaprong (Lhag pa don grub 2009, 369). This Lhasa-based community presented a clan-like inner structure, with a leader, recognized as a primus inter pares, acting as spokesman and regulator for his own co-regionals - each phayül maintained and preserved within a larger container fashioned in the terms of a Khampa proto-identity still largely understood by its own members in via negationis. In the light of this, Dzamyag's dealings with the Sandutsang followed an expected line of action: although by then settled in Trehor, the trading firm originated from the area of Gakok, at the easternmost borders of the kingdom of Nangchen, and they must have therefore appeared as the most suitable referents to the Rabshi-born Dzamyag.

As an active member of the Khampa trading communities in Central Tibet, Khatag Dzamyag belonged to the social stratum that Alice Travers $(2013,144)$ calls 'elite commoners'. ${ }^{11}$ By the early twentieth century, the scale of operation of the trade networks connecting Inner Asia to South

10 For more information on the Pangdatsang, see McGranahan (2002, 2015).

11 On social conditions of pre-modern Tibet, with particular attention paid to the central areas of Ü-Tsang, see Carrasco (1959), Stein (1972), Goldstein (1968; 1971; 1973; 1986; 1989a, 1989b); Miller (1987; 1988), Coleman (1998), Barnett (2008), Petech (2013), and Bischoff (2013). 
and Southeast Asia had sensibly increased; due to the expansion of the European influence in India, China, and South Asia, borderland regions became more and more involved in global trade flows (Coales 1919; Teichman 1922; van Spengen 2000; Harris 2013; Giersch 2006, 2010b). Khampa trading families responded to the new market demands by opening branches in some of the most important trade hubs in Tibet, northern India, Sikkim, and Nepal and by shifting their main offices to Lhasa, where they started mingling with the upper strata of the Lhasan society. Interactions between the upper middle stratum and members of the lower ranking aristocracy were common and often officialized by marriage or ennoblement. It was in this fuzziness of social boundaries that Dzamyag and other affiliates of the most important Khampa trading families moved their steps, carefully threading socio-economic networks that allowed them to gain a substantial political weight in a remarkably short amount of time. By opening the path for other ambitious eastern Tibetan traders, the largest trader households contributed, albeit indirectly, to the rise of other eastern Tibetan trading families and their agents, becoming instrumental in the socio-economic consolidation of the 'intermediate class' by fostering the creation of an environment conducive to Dzamyag's business.

In the first eight years following his forced departure from Rabshi (i.e. from 1944 to 1952), Dzamyag struggled to reassert himself financially. He traded mainly on a small to medium scale, often cashing in old debts and resorting to friends' help. Although the nyindep generally lacks detailed information regarding the author's business dealings, the obsessive care with which the author lists the amount of his offerings to the various monasteries and shrines visited along the way contributes to our understanding of his financial conditions. The flow of money - barely a trickle in the 1944-1952 period - increments substantially as from 1953, in the aftermath of a trip to Kalimpong that marked a watershed moment in Dzamyag's life.

Such a change in fortune began in the last months of 1952, when the trader, at the time guest of the Sandutsang at their mansion in Shigatse, was summoned by the treasurer of the Khangsar labrang of Ngor E wam chöden and requested to supervise the investment of some of the abbot's funds in a business venture to Kalimpong. Whereas every Tibetan could be virtually considered a 'born trader' (Bell 1928, 125), only a few had the resources and abilities to achieve the status of monastic trade agent. Interestingly, the call from the Khangsar labrang reached Dzamyag after a five-month stay at the Sakya establishment, where he had attended a series of teachings and empowerments. At the time, he was accompanied by Rinchen Dorje, a business partner and dharma brother from Trehor. Dzamyag's relationship 
with Rinchen Dorje, himself a tsongpön and renowned Sandutsang agent, represents a constant feature in the trader's life, and it is representative of that intangible yet unbreakable network connecting Khampas throughout the plateau and beyond. Rinchen Dorje is in fact first mentioned in a note dated to 1946 in occasion of a visit paid by Dzamyag to Tashilhunpo, and his name appears time and time again as one of the author's business partners (Kha stag 'Dzam yag 1997, 46; 61-62) and companions during his pilgrimage to India (Kha stag 'Dzam yag 1997, 143). Most of the subsequent journal entries are a testimony to the existence of a 'familiar' territory carved by Khampas in a 'foreign' - be it Central Tibetan or Indian - environment; it is through these cultural and social 'corridors' that most of Dzamyag's business transactions occurred. ${ }^{12}$

At the time of his sojourn at Ngor E wam chöden, our trader claimed to have outdone his dharma companions with the generosity of his offerings, a factor that possibly contributed to attracting the attention of the labrang's treasurer: prodigality towards religious institutions was in fact traditionally associated with trustworthiness, a feature expected from a monastic trade agent. It may also be argued that Dzamyag's connection with well-known agents of the Sandutsang may have increased his status in the eyes of his clients. Be as it may, the Khangsar labrang invested in the trading venture more than 15,000 yin gor (dbyin sgor). ${ }^{13}$ Only scanty information is provided in the nyindep regarding the hiring of a caravan leader and two assistants

12 As the journal tells us, from Tashilhunpo, the trader moved to Shalu where he attended the celebrations for the saga dawa (the fourth month of the Tibetan calendar) of the Fire Dog Year (May 1946), together with another companion from Trehor, a monk named Pema Namgyal. Once back in Shigatse, Dzamyag acted as a trade agent for a certain Tashi Norbu, the treasurer and government appointed trader of the Dra'u household, the strongest lord of the Yushu area. At the time he dealt mainly in butter; he transported from Shigatse to Lhasa about $600 \mathrm{~kg}$ and bought on his way back more than 10,500 kg of butter packed into 96 leather bags, paying for each load (c. $13 \mathrm{~kg}$ ) 33 silver coins (sang). In addition to those, he bought further $990 \mathrm{~kg}$ of butter, paying for them 780 silver coins; by selling these goods, he earned more than 26,297 silver sang (Kha stag 'Dzam yag 1997, 68). Again in 1946, he handled trade for a certain Tashi Tsering, an official appointed with the title of secretary and treasurer (drön nyer) (Kha stag 'Dzam yag 1997, 74). Tashi Norbu makes another appearance in a note dated to the second month of the Iron Tiger Year (March 1950), when Dzamyag made a donation to Ngor E wam chöden on his behalf (Kha stag 'Dzam yag 1997, 189)

13 The term yin gor is generally used in Tibetan language to indicate British currency, yet in this context its reading as 'rupees' appears more likely. Indian rupees are usually rendered in Tibetan as hin gor, but at the time of Dzamyag's business venture (1952) the relatively new independence of India could have justified the use of yin either as a near-homophone for hin or as a slight anachronism for the [British]-Indian rupee. I am grateful to Charles Ramble for clarifying the difficult interpretation of the term for me (private conversation, June 2017). 
for the loading of the pack animals; in spite of the lack of details recorded, it is clear that the author was acutely aware of representing the abbot's interests. In his journal he reports to have kept track of all the exchanges on a separate ledger, ${ }^{14}$ presented to the Khangsar treasurer upon his return to the Sakya establishment in Tsang, and to have personally ensured that the goods were safely allocated (Kha stag 'Dzam yag 1997, 224).

From 1953 onwards, Dzamyag's business increased sensibly, ${ }^{15}$ with a ripple-down effect that also affected his religious behaviour. The substantial offerings made by the trader in the decade following $195^{2}$ demonstrate the financial importance that wealthy sponsors, such as the tsongpön and the largest trading families, had for masters and monastic communities, as well as their increasing weight in internal political matters. In the late 1940s, whilst the government of the Ganden Phodrang was desperately evaluating the possibility of a Chinese encroachment on the Tibetan territory, the economic, and consequentially political, influence of largest Khampa trading firms continued to increase. It is evident from Dzamyag's notes that the trade flows connecting the Sino-Tibetan trade hubs (e.g. Dartsedo, Dergé, Jyekundo) to the towns of Central Tibet (e.g. Lhasa, Shigatse, Gyantse) and the market places of India (e.g. Kalimpong, Calcutta) were still very active, despite the political uncertainty. Already in 1947, the Sandutsang were exporting wool directly to the United States and to England (Goldstein 1989b; Sadutshang 2016, 95), a business Dzamyag himself was very familiar with. By 1950 he had already travelled several times to the nomadic areas of Nagchu to collect wool loads to be transported by pack animals to the towns of Shigatse and Lhasa, and from there to Kalimpong. In his business ventures, Dzamyag was often helped either by his nephew Lojam, who acted as his proxy in Kham, or other chief-merchants working for the Sandutsang, mostly hailing from the family's estate in Trehor. As remarked above, the influx of eastern Tibetan traders to the bustling towns of Central Tibet contributed to the creation, already in the early twentieth century, of small bubbles of Khampa identity. Khampa traders, such as Dzamyag, could thus easily find familiar places and names recreated by the expatriated

14 During the trading trip, Dzamyag kept a separate ledger where he noted every transaction, from the goods loaded and unloaded to his own personal expenses; it is unfortunate that he did not include this information in his personal journal. The reference to other textual sources ascribable to the author may explain the general lack of details concerning his business, which could have been recorded on separate ledgers to which the trader had no longer access at the time of writing his nyindep.

15 Like many other traders from the Ü-Tsang, Dzamyag dealt directly with the nomads living in Nagchu and Barkham. 
community. The embedment of the largest trading firms in the social and economic fabric of the Lhasan society did not weaken their perception of their own identity. Acculturation and adaptation were skills necessary to navigate the intricate trade fluxes (Giersch 2010b, 220; Tsomu 2016a, 2016b), but under the Central Tibetan clothing, the language proficiency, the ability to juggle with different cultural schemes, the core of the Khampa merchants' identity never faltered. The identitarian awareness shared by eastern Tibetans clearly transpires from the nyindep as well. Throughout his account, Dzamyag never questions his identity; he is first and foremost a Khampa, and his relation to his homeland deeply influences the way he perceives himself and his surroundings. It is evident in the author's narrative that, to borrow Ovid's words, 'our native soil draws all of us, by I know not what sweetness, and never allows us to forget'. ${ }^{16}$

\section{Political Weight of Traders in Mid-Twentieth-Century Tibet}

Whereas the impact of state policy on Kham is undisputable, even more interesting is the way local people, and especially traders, influenced the political and social developments of the Lhasa-based government in the decades preceding and following the incorporation of Tibet into the People's Republic of China in 1950.

Dzamyag does not discuss political events in his journal, yet passing mentions are made both to the Communist invasion and the Khampa resistance. In an entry dated to the third day of the fourth month of the Earth Pig Year (5 May 1959), the trader records in his nyindep that early in the morning news of calamities caused by 'red flames', as the author calls them, trickled to Shigatse, where he was based. Dzamyag left in a hurry, taking with him only some cloth-wrapped texts and leaving to his nephew Lojam the dispatch of pack animals loaded with food and beddings to the Ngor Luding labrang. From Ngor E wam Chöden, they set off in the direction of Kalimpong, a trip that marked the beginning of their exile in India (Kha stag 'Dzam yag 1997, 248). Despite the pathos transpiring from this brief note, the author does not remark on the dramatic events following the Chinese occupation, and more information on the ensuing events must be gathered from the introduction to the edited version of his journal. Here it is said that, due to such a hasty departure, one of the scroll-papers on which

16 Nescio qua natale solum dulcedine cunctos ducit et inmemores non sinit esse sui (Ovid Ex Ponto III, 35-36). 
the nyindep had been recorded, namely that covering the events from the twenty-fifth day of the sixth month of the Fire Monkey Year (1 August 1956) to the thirteenth of the tenth month of the Earth Dog Year (24 November 1958) was lost in Shigatse, and no trace of it was to be found at the time of publication in 1997 (Kha stag 'Dzam yag 1997,8$).{ }^{17}$

Direct allusions to the political situation of the time may be lacking, yet Dzamyag's nyindep is filled with valuable socio-economic and religious information. By the mid-twentieth century, the largest Khampa trading firms had moved their headquarters to Lhasa; whereas branches were still active along the Sino-Tibetan borderlands, the heads of the households played their cards mainly on the political tables in Lhasa. In the 1940s, members of the Pangdatsang and the Sandutsang were raised to the ranks of the Lhasa government, holding positions as officials, an honour traditionally reserved to the Lhasan nobility (Tsomu, 2016b, 25; Sadutshang 2016, 100-101). While some representatives of the Khampa trading firms made their way into the Ganden Phodrang government, others pursued a more radical affirmation of their local identity, by fostering the ideal of a 'Khampa rule of Kham'. Proposed in 1935 by Gara Lama and enthusiastically embraced by several of the most powerful chieftains and headsmen of eastern Tibet, among whom there was Pangda Topgyal, the movement for a Khampa 'self-determination' and 'self-rule' failed to gain momentum, and it was only in 1949 that the so-called 'Association for the Promotion of Autonomy of Kham and Tibet' was established in Dartsedo (Tsomu 2016b, 32-33). By that time, the Sino-Tibetan borderlands had already become theatre of warfare guerrilla that later developed into the volunteer force group known as 'Four Rivers, Six Ranges' (Chushi Gangdruk), led by another representative of a Khampa trading family, Andrug Gönpo Tashi (Andrutsang 1973; McGranahan 2010).

Interestingly, the frenzy of the time finds no room in Dzamyag's notes. The years $195^{\circ}$ and 1951 are remarkably devoid of any political or social events. He spent most of his time travelling back and forth between Lhasa and Shigatse, visiting monasteries and keeping up with his business transactions. In 1953 the socio-political situation in Rabshi must have appeared quite unfazed, so much so that Dzamyag wrote a letter to the new incarnation of the local monastery, asking about an ailment for himself and one of his sisters in exchange for the livestock still in his possession (Kha stag 'Dzam yag 1997,

17 A brief account of the events that occurred between 1956 and 1961, year of the author's death, is provided in the last of the scrolls preserved by Dzamyag's relatives and handed down to the editors of The Tibet House in the 1990s. 
225). It was clear to the trader which entity wielded authority at the local level: due to Mao's gradualist approach, monasteries and chieftains were still recognized as agents of power in most of the borderlands as late as the mid-1950s. Not much appears to have changed since his imprisonment in 1940; the real power was firmly in the hands of chieftains and reincarnates, who ruled over a complex, 'multivocal' region (Gros, this volume).

As it often occurs with autobiographical writings, minor narratives lay underneath the main one, waiting to be discovered, contextualized, and interpreted against the historical backdrop of the time. As an active member of the trading community, Dzamyag was involved in various communal activities, such as the offering of a golden throne to the Fourteenth Dalai Lama as a sign of appreciation for the 1957-bestowal of the Kälacakra and Lamrim Chenmo teachings to the traders of Kham and Amdo, an event held concurrently with a tenshug (Kha stag 'Dzam yag 1997, 8). ${ }^{18}$ The author seems sincerely unaware of the underlying political significance of the offering, presented in his journal as a pious gesture in a time of uncertainty and struggles. In reality, the ritual, originally proposed and strongly desired by Gönpo Tashi Andrutsang, was part of a carefully planned project. ${ }^{19}$ The news regarding the Dalai Lama's willingness to bestow a three-day initiation with teachings spread like wild fire throughout the Tibetan regions, quickly assuming a nationalistic nature and threatening the Chinese control over the plateau. Gönpo Tashi's initiative, at first restricted to the sole Khampa traders, gained the approval of Jyampa Gyatso, a prominent merchant from Labrang, and consequently the economic support of the whole Lhasa-based Amdowa community. Riding the wave of excitement and public expectations, the committee in charge of the event proposed the donation of a golden throne to be realized with the offerings coming not only from the wealthy traders of Amdo and Kham, but from all the good-willing people of Tibet, in a show of loyalty and faith towards the figure of the Dalai Lama (Andrustang 1973, 51-52; Jamyang Norbu 2014).

18 Elaborate longevity ritual consisting in the making of offerings to the protector deities to ensure the long life of the Dalai Lama (Ardley 2002, xii).

19 One of the most powerful and wealthy Khampa trading households in Lhasa, the Andrutsang played an important role in the years following the Chinese invasion, when their head Gönpo Tashi, a businessman turned into a freedom fighter, created a network of merchants united against the Chinese. Their group, initially focused on exerting pressure over the P.R.C. for the release of political prisoners and spreading support to the Dalai Lama, evolved in 1958 into a guerrilla army, the 'Khams Four Rivers, Six Ranges Tibetan Defenders of the Faith Volunteer Army', best known as 'Four Rivers, Six Ranges' (Chushi Gangdruk). For more information on the Chushi Gangdruk, see Andrugtsang (1973), Ardley (2002), Goldstein (2007), McGranahan (2010). 
The involvement of traders in the political scene was not restricted to members of the most important trading families. In 1956, a merchant from Lithang named Alo Chödze Tsering Dorje, ${ }^{20}$ together with two low-ranking government officials, promoted the creation of a group claiming to represent the masses in their desire for a free Tibet. ${ }^{21}$ The leading organizers of the movement were mainly traders and government officials: Gönpo Tashi Andrutsang himself was among the activists (Powers and Templeman 2012, 439). Despite not having been an active part of the movement, Dzamyag enthusiastically joined the project for the realization of the golden throne, thus adding his economic weight to the political influence the trading community was able to exert on the political scene.

Dzamyag's disconcerting lack of concern regarding the volatile political situation of the time appears less problematic once we keep in mind that, after the signing of agreement, several prominent Tibetans favoured the accommodation with the Chinese Communist Party (C.C.P.). Furthermore, the years between his appointment as tsongpön and his flight into exile saw Dzamyag's focus turning inwards: whereas on a mundane level he actively took advantage of the volatile economic conditions of the time, his narrative persona appears completely absorbed by esoteric rituals and initiations, the money perceived as a mere means towards the accumulation of merit. The news of an imminent arrival of the 'red flames' breaks in on a routine made of offerings, circumambulations, and prayers, suddenly and violently bursting the atemporal bubble created by Dzamyag in his nyindep.

Before concluding my discussion of the political power gained by Khampa traders in twentieth-century Tibet, I would like to briefly pause on the intertwining of religious and economic interests. It is worth noting that there are several references in the nyindep to the presence and direct involvement of representatives of Khampa trading firms to rituals held in the largest monasteries of Central Tibet, regardless of their sectarian denomination. The unbiased approach to all Tibetan Buddhist traditions - a common feature among the eastern Tibetan traders in general, and Khampas in particular - appears to be one of the factors promoting their socio-economic paramountcy in twentieth-century Tibet, as demonstrated by the ease

20 Successful trader, Alo Chödze Tsering Dorje's fortunes came primarily from the commerce between Tibet and India. He was famous for having introduced the use of iron supports, thus revolutionizing the traditional construction techniques (Powers and Templeman 2012, 439). 21 The principal activities carried out by the group consisted in the putting up of posters calling for the end of the Chinese rule, the sponsorship of long-life rituals for the Dalai Lama and the propitiation of wrathful deities, and welfare initiatives in support of the refugees escaped from eastern Tibet (Powers and Templeman 2012, 439). 
with which Pangdatsang Nyigyel dealt with various monastic institutions, regardless of his own family affiliation. Whereas the fostering of religious tolerance and intellectual liberalism has been repeatedly associated with the non-sectarian (rimé) movement, ${ }^{22}$ the economic impact that the nonsectarian values had on the socio-cultural environment of the plateau in the twentieth century appears to be surprisingly understudied. As pointed out by Turek $(2012,429)$, the rimé masters cultivated spiritual goals that 'did not exclude some hints of a political agenda, as they promoted eastern Tibetan cultural value and autonomy'; since non-sectarianism did contribute to the emergence of a socio-political Khampa identity, it may not be far-fetched to ascribe to members of the trading community the application of a similar attitude for the sake of economic gain.

A certain pragmatism was, after all, present since the very beginning of the rimé movement; in the nineteenth century, the royal family of Dergé had prized religious tolerance by supporting six large monasteries of various religious denominations, i.e. Sakya, Nyingma, and Kagyü. At a closer look, though, it is clear that the royal sponsorship was mutually convenient; whereas the establishments enjoyed an official protectorate and could influence the court through the dispatch of royal chaplains, the king could in turn rely on the presence of strong local monasteries to contain the rise of influence of the Geluk school, and, with it, the political encroachment of the Ganden Phodrang government. Dergé and Nangchen are but two instances where realpolitik used the rimé values to pursue non-religious aims; I would suggest, as a working hypothesis, that the same could be said of the economic pragmatism shown by Khampa traders, such as Pangdatsang Nyigyel and Dzamyag himself, in their dealings with establishments of diverse religious denomination. Prodigality towards monastic institutions was in fact traditionally associated with trustworthiness, a feature expected from a monastic trade agent; by proving their religious piety and supporting the 'field of merit' ${ }^{23}$ that was the religious community, the traders increased their social status and influence.

\footnotetext{
22 The mid-nineteenth century saw the reinvigoration of a non-sectarian approach and the revival of minor lineages and practices; this tendency, controversially defined in Western scholarship as a 'movement', deeply imbued the socio-cultural environment of eastern Tibet, thus providing unifying values to the growing Khampa trading communities that had relocated to Ü-Tsang. On the rimé movement, see Samuel (1993), Gardner (2006), Powers (1995), Smith (2001), and Turek (2013). 23 The idea of monastic communities (Skt. saingha) as a 'field of merit' (Skt. punyakṣetra; Tib. tsokzhing) is found in many Pāli texts. The laymen's offerings to the monastic community are conceived as seeds of good karma sown in the 'field of merit'; by bringing them to fruition, the sangha allows the donors to reap the benefits of their actions (Mills 2003, 61).
} 


\section{Conclusion}

It is said that history is made of personal stories, and Dzamyag's is certainly one of them. The perspective provided by his journal is rather unique: trader and pilgrim, Khampa and Tibetan, sponsor and protégé, the text offers the scholar of pre-modern Tibetan history a different point of view on events mainly known through the formal channels of history making. The emergence of a proto-identitarian awareness among the Khampas in the first decades of the twentieth century goes hand in hand with the increasing political influence exerted by the largest trading firms hailing from eastern Tibet. As early as the 1930s and 1940s, indigenous movements aimed at local independence appeared in southwest China - in particular in Sichuan and, from 1939, in the Xikang province. The majority of the Khampa self-rule movements evolved militantly toward the goal of autonomy, a sentiment that kept simmering even during Mao's gradualist approach in the early 1950s (Peng 2002, 77). In the first half of the twentieth century, the combination of the Khampa 'ancient sense of centrality', as Michael Aris $(1992,13)$ aptly puts it, and the concepts of 'self-determination' and 'self-rule' that began to circulate globally created an explosive situation. The establishment of the 'Four Rivers, Six Ranges', a resistance group set up by Gönpo Tashi Andrugtsang, was met with enthusiasm by the representatives of the other trading families; Lo Gendun Sandutsang joined the guerrillas and died helping the Dalai Lama to flee Lhasa in 1959; Rapga Pangdatsang, despite maintaining his pro-Kuomintang view, actively participated in the revolts against the Communists.

Dzamyag's journal offers an insider's glimpse of two decades - the 1940s and the 1950s - that had been crucial to the history of Tibet. Member of the 'elite commoners' and active participant of the expatriated community of Khampa traders in the central regions of Ü-Tsang, the author does not dwell on the political events of the time, providing the scholars with cause for reflection on the perception harbored by those sections of society not involved in the decision-making process regarding the rapid changes occurring in the Sino-Tibetan relationships. At the same time, his account bears testimony to the correlation between economics and politics: the heavy reliance of the Tibetan government on the services of the Khampa traders gave them considerable bargaining power in the political field. The role played by commerce and trade networks in shaping the empire and nation-building in China was partially replicated in Tibet as well: the tight-knit communities of Khampa traders living in the Central Tibetan towns of Lhasa, Shigatse, and Gyantse used their economic influence to 
shape the nation-building process, strengthening in the meanwhile their own sense of local centrality. As noted by Giersch (2014, 379-380) 'transfrontier merchants were people who engaged with new ideas, created new types of families, and, ultimately, were actively engaged in the major transformations of China, Burma, and - to a lesser degree - India.' In this chapter, I have tried to highlight the transformative power exerted by other transfrontier merchants, namely the Khampa traders, in shaping the politics of Tibet in the first half of the twentieth century.

\section{Glossary of Tibetan Terms}

$\begin{array}{ll}\text { Abak } & \text { A bag } \\ \text { Andrustang } & \text { A 'brug tshang } \\ \text { Chamdo } & \text { Chab mdo } \\ \text { chöyön } & \text { mchod yon } \\ \text { Chödruktsang } & \text { Chos drug tshang } \\ \text { Chushi Gangdruk } & \text { Chu bzhi sgang drug } \\ \text { Dampa Lodrö } & \text { Dam pa Blo gros } \\ \text { dowo } & \text { do bo } \\ \text { drönnyer } & \text { mgron gnyer } \\ \text { Dzawa Pomda } & \text { Rdza ba Spom mda' } \\ \text { Gakok } & \text { Sga khog } \\ \text { Ganden Phodrang } & \text { Dga' ldan pho brang } \\ \text { Geluk } & \text { Dge lugs } \\ \text { gotso } & \text { 'go gtso } \\ \text { Gyanagtsang } & \text { Rgya nag tshang } \\ \text { Jamatsang } & \text { Ja ma tshang } \\ \text { jöpa } & \text { brjod pa } \\ \text { jungwa } & \text { byung ba } \\ \text { Kagyü } & \text { Bka' brgyud } \\ \text { khel } & \text { khal } \\ \text { kyérap } & \text { skyes rab } \\ \text { labrang } & \text { bla brang } \\ \text { Lhakpa Döndrup } & \text { Lhag pa don grub } \\ \text { namthar } & \text { rnam thar } \\ \text { nékorwa } & \text { gnas skor ba } \\ \text { nyak } & \text { nyag } \\ \text { nyindep } & \text { nyin deb } \\ \text { Nyingma } & \text { Rnying ma } \\ & \end{array}$




$\begin{array}{ll}\text { nyinto } & \text { nyin tho } \\ \text { Pangdatsang } & \text { Spang mda' tshang } \\ \text { rimé } & \text { ris med } \\ \text { Saga dawa } & \text { sagazla ba } \\ \text { Sakya } & \text { Sa skya } \\ \text { Sandutsang } & \text { Sa'du tshang } \\ \text { sang } & \text { srang } \\ \text { sartrang } & \text { gsar sprang } \\ \text { senyik } & \text { gsangyig } \\ \text { Tashilhunpo } & \text { Bkra shis lhun po } \\ \text { topyik } & \text { thobyig } \\ \text { trung rap } & \text { 'khrungs rabs } \\ \text { Tsatrültsang } & \text { Tsha sprul tshang } \\ \text { tsokzhing } & \text { tshogs zhing } \\ \text { yingor } & \text { dbyin sgor/hin sgor }\end{array}$

\section{References}

Andrugtsang, Gompo Tashi. 1973. Four Rivers, Six Ranges: Reminiscences of the Resistance Movement in Tibet. Dharamsala: Information and Publicity Office of H.H. the Dalai Lama.

Ardley, Jane. 2002. The Tibetan Independence Movement: Political, Religious and Gandhian Perspectives. London: Routledge Curzon.

Aris, Michael. 1992. 'The Tibetan Borderlands'. In Lamas, Princes, and Brigands:Joseph Rock's Photographs of the Tibetan Borderlands of China, edited by M. Aris, P.R. Booz, S.B. Sutton, 13-19. New York City: China House Gallery, China Institute in America.

Barnett, Robert. 2008. 'What Were the Conditions Regarding Human Rights in Tibet before Democratic Reform?' In Authenticating Tibet: Answers to China's 100 Questions, edited by A. Blondeau and K. Buffetrille, 81-84. Berkeley: University of California Press.

Bischoff, Jeannine. 2013. 'Right There but Still Unnoticed: Information on dGa' ldan pho brang Mi ser from Archival Material Published in Germany'. In Tibetans who Escaped the Historian's Net: Studies in the Social History of Tibetan-speaking Societies, edited by Charles Ramble, Peter Schwieger and Alice Travers, 9-25. Kathmandu: Vajra Books.

Booz, Patrick R., 2011. Tea, Trade and Transport in the Sino-Tibetan Borderlands. DPhil thesis. University of Oxford.

Brook, Timothy. 2009. 'Tibet and the Chinese World-Empire'. In Empires and Autonomy: Moments in the History of Globalization, edited by William D. Coleman, 
Stephen M. Streeter, and John C. Weaver, 24-40. Vancouver: University of British Columbia Press.

Carrasco Pizana, Pedro. 1959. Land and Polity in Tibet. Seattle: University of Washington Press.

Coales, Oliver. 1919. 'Economic Notes on Eastern Tibet'. The Geographical Journal 54 (4): 242-247.

Coleman, William M. 1998. 'The Discourse of Serfdom in Tibet'. In Writing Tibetan History: The Discourses of Feudalism and Serfdom in Chinese and Western Historiography. Master's thesis, 1-29. East-West Centre, University of Hawaii.

Elliot, Mark C. 2014. 'Frontier Stories: Periphery as Centre in Qing History'. Frontier of History in China 9 (3): 336-36o.

Galli, Lucia. 2019. 'The Crafting Memory of the Self. Reflections on Tibetan DiaryKeeping'. Life Writing. DOI: http://dx.doi.org/10.1080/14484528.2019.1669427.

Gardner, Alexander P. 2006. The Twenty-five Great Sites of Khams: Religious Geography, Revelation, and Nonsectarianism in Nineteenth-Century Eastern Tibet. $\mathrm{PhD}$ dissertation, University of Michigan, Ann Arbor.

Giersch, C. Patterson. 2006. Asian Borderlands: The Transformation of Qing China's Yunnan Frontier. Cambridge, Mass: Harvard University Press.

Giersch, C. Patterson. 2010a. 'Cotton, Copper, and Caravans: Trade and the Transformation of Southwest China'. In Chinese Circulations: Capital, Commodities and Networks in Southeast Asia, edited by Wen-Ching Chang and Eric Tagliacozzo, 37-61. Durham, NC: Duke University Press.

Giersch, C. Patterson. 2010b. 'Across Zomia with Merchants, Monks, and Musk: Process Geographies, Trade Networks, and the Inner-East-Southeast Asian Borderlands'. Journal of Global History 5 (2): 215-239.

Giersch, C. Patterson. 2014. 'Commerce and Empire in the Borderlands: How Do Merchants and Trade Fit into Qing Frontier History?' Frontier of History in China 9 (3): $361-383$.

Giersch, C. Patterson. 2016. 'Afterword: Why Kham? Why Borderlands? Coordinating New Research Programs for Asia'. Cross-Currents: East Asian History and Culture Review 19: 202-213. URL: https://cross-currents.berkeley.edu/e-journal/issue-19/ giersch. Accessed 7 June 2019.

Goldstein, Melvyn C. 1968. An Anthropological Study of the Tibetan Political System. $\mathrm{PhD}$ dissertation, University of Washington. Photocopy of typescript. Ann Arbor, Michigan: University Microfilms International.

Goldstein, Melvyn C. 1971. 'Serfdom and Mobility: An Examination of the Institution of "Human Lease" in Traditional Tibetan Society'. The Journal of Asian Studies 30(3): 521-534.

Goldstein, Melvyn C. 1973. 'The Circulation of Estates in Tibet: Reincarnation, Land and Politics'. The Journal of Asian Studies 32 (3): 445-455. 
Goldstein, Melvyn C. 1986. 'Reexamining Choice, Dependency, and Command in the Tibetan Social System: “Tax Appendages” and Other Landless Serfs'. The Tibet Journal 11 (4): 79-112.

Goldstein, Melvyn C. 1989a. A History of Modern Tibet, 1913-1951: The Demise of the Lamaist State. Berkeley: University of California Press.

Goldstein, Melvyn C. 1989b. 'Interview Hoo59: with Sandutsang, Rinchen [tib. sa 'du tshang rin chen], (India, 26 August 1989): Part no. 1 of 2'. In Tibetan Oral History Archive Project (Asian Division), Library of Congress. URL: https://www. loc.gov/item/tohap.Hoo59/ Accessed 7 June 2019.

Goldstein, Melvyn C. 2007. A History of Modern Tibet. Volume 2: The Calm before the Storm (1951-1955). New Delhi: Munshiram Manoharlal Publishers.

Gros, Stéphane. 2016. 'Introduction to "Frontier Tibet: Trade and Boundaries of Authority in Kham"'. Cross-Currents: East Asian History and Culture Review 19: 1-26. URL: http://cross-currents.berkeley.edu/e-journal/issue-19/gros. Accessed 7 June 2019.

Gruschke, Andreas. 2004. The Cultural Monuments of Tibet's Outer Provinces: Kham. Volume 2: The Qinghai Part of Kham. Bangkok: White Lotus.

Harris, Tina. 2013. Geographical Diversions: Tibetan Trade, Global Transactions. Athens, Ga: University of Georgia Press.

Hartley, Lauran R. 1997. A Socio-Historical Study of the Kingdom of sDe-dge (Derge, Kham) in the Late Nineteenth Century: Ris-med Views of Alliance and Authority. MA thesis, Indiana University.

Hayes, Jack P. 2014. A Change in Worlds on the Sino-Tibetan Borderlands: Politics, Economies, and Environments in Northern Sichuan. Lanham, MD: Lexington Books.

Jackson, David P. 2003. A Saint in Seattle. The Life of the Tibetan Mystic Dezhung Rinpoche. Boston: Wisdom Publications.

'Jam dbyangs tshul khrims 1995. Khams stod lo rgyus thor bsdus. Volume 1. Lan khru'u: Kan su'u mi rigs dpe skrun khang.

Jamyang Norbu, 2014. 'The Political Vision of Andrutsang Gompo Tashi'. [Blog] Shadow Tibet. URL: http://www.jamyangnorbu.com/blog/2014/og/27/thepolitical-vision-of-andrugtsang-gompo-tashi/ Accessed 7 June 2019.

Kapstein, Matthew. 2006. The Tibetans. Malden, Mass.: Blackwell Pub.

Kha stag'Dzamyag. 1997. Phyi lo 1944 nas 1956 bod dang bal po rgya gar bcas la gnas bskor bskyod pa'i nyin deb / A Pilgrim's Diary: Tibet, Nepal and India 1944-1956, edited by Ācārya 'Jam dbyangs dbang rgyal. New Delhi: Indraprastha Press (CBT).

Kim, Kwangmin. 2008. Saintly Brokers: Uyghur Muslim, Trade, and the Making of Qing Central Asia, 1696-1814. Berkeley: University of California Press.

Lawson, Joe. 2011. Xikang: Han Chinese in Sichuan's Western Frontier, 1905-1949. Unpublished PhD dissertation, Victoria University of Wellington. 
Lhag pa don grub, 2009. 'De sngon bod ljongs nang khul dang bod hin bar gyi tshong las byed srol dang phyir gtong nang 'dren sogs kyi skor rags tsam'. In Bod kyi rig gnas lo rgyus dpyad gzhi'i rgyu cha bdams bsgrigs, 20 (1), 366-386. Khreng tu'u: Si khron mi rigs dpe skrun khang.

McGranahan, Carole. 2002. 'Sa spang mda' gnam spang mda': Murder, History, and Social Politics in 1920s Lhasa'. In Khams pa Local Histories: Visions of People, Place, and Authority: PIATS 20oo: Tibetan Studies: Proceedings of the Ninth Seminar of the International Association for Tibetan Studies, Leiden 20oo, edited by Lawrence Epstein, 104-125. Leiden: Brill.

McGranahan, Carole. 2010. Arrested Histories: Tibet, the CIA, and Memories of a Forgotten War. Durham, N.C.: Duke University Press.

McGranahan, Carole. 2015. 'On Social Death:The Spang mda'tsang Family and the $20^{\text {th }}$ Century Tibetan History'. In Festschrift for Elliot Sperling. edited by Gedun Rabsal, Roberto Vitali, and Nicole Willock, 199-205. Dharamsala: Amnye Machen Institute.

Miller, Beatrice D. 1987. 'A Response to Goldstein's “Reexamining Choice, Dependency, and Command in the Tibetan Social System"'. The Tibet Journal 12 (2): 67-68.

Miller, Beatrice D. 1988. 'Last Rejoinder to Goldstein on Tibetan Social System'. The Tibet Journal 13 (3): 64-66.

Mills, Martin A. 2003. Identity, Ritual and State in Tibetan Buddhism: The Foundations of Authority in Gelukpa Monasticism. London: Routledge Curzon.

Millward, James A. 1998. Beyond the Pass: Economy, Ethnicity, and Empire in Qing Central Asia, 1759-1864. Stanford, Calif.: Stanford University Press.

Peng, Wenbin. 2002. 'Frontier Process, Provincial Politics and Movements for Khampa Autonomy During the Republican Period'. In Khams pa Histories: Visions of People, Place and Authority. PIATS 20oo: Tibetan Studies: Proceedings of the Ninth Seminar of the International Association for Tibetan Studies, Leiden 20oo, edited by Lawrence Epstein, 57-84. Leiden: Brill.

Perdue, Peter C. 2005. China Marches West: The Qing Conquest of Central Eurasia. Cambridge, Mass.; London: Belknap Press of Harvard University Press.

Petech, Luciano. 2013. 'Aristocracy and Government in Tibet, 1728-1959'. In The Tibetan History Reader, edited by Gray Tuttle and Kurtis R. Schaeffer, 437-456. New York: Columbia University Press. [First edition 1973. Serie Orientale Roma, Volume 45. Rome: Istituto Italiano per il Medio ed Estremo Oriente]

Powers, John. 1995. Introduction to Tibetan Buddhism. Ithaca, N.Y.: Snow Lion.

Powers, John and Templeman, David. 2012. Historical Dictionary of Tibet. Lanham, Maryland: Scarecrow Press Publications.

Quintman, Andrew. 2015. The Yogin and the Madman: Reading the Biographical Corpus of Tibet's Great Saint Milarepa. New York: Columbia University Press.

Relyea, Scott. 2015a. 'Conceiving the "West”: Early Twentieth-Century Visions of Kham'. Modern China 4 (3): 181-200. 
Relyea, Scott. 2015b. 'Yokes of Gold and Threads of Silk: Sino-Tibetan Competition for Authority in Early Twentieth-Century Kham'. Modern Asian Studies 49 (4): 963-1009.

Relyea, Scott. 2016. 'Victorianizing Guangxu: Arresting Flows, Minting Coins, and Exerting Authority in Early Twentieth-Century Kham'. Cross-Currents: East Asian History and Culture Review 19: 122-146. URL: http://cross-currents. berkeley.edu/e-journal/issue-19/relyea. Accessed 7 June 2019.

Sadutsang, Rinchen. 2016. A Life Unforeseen: A Memoir of Service to Tibet. Boston: Wisdom Publications.

Samuel, Geoffrey. 1982. 'Tibet as a Stateless Society and Some Islamic Parallels'. Journal of Asian Studies 41 (2): 215-229.

Samuel, Geoffrey. 1993. Civilized Shamans: Buddhism in Tibetan Societies. Washington: Smithsonian Institution Press.

Smith, Gene E. 2001. Among Tibetan Texts: History and Literature of the Himalayan Plateau, edited by Kurtis R. Schaeffer. Boston: Wisdom Publications.

Spengen, W. van, 200o. Tibetan Border Worlds: A Geohistorical Analysis of Trade and Traders. London: Kegan Paul International.

Stein, Rolf A. 1972. Tibetan Civilization. Stanford, Calif.: Stanford University Press. Teichman, Eric. 1922. Travels of a Consular Officer in Eastern Tibet: Together with a History of the Relations between China, Tibet, and India. Cambridge: Cambridge University Press.

Travers, Alice. 2013. 'How Should we Define Social Status? The Study of "Intermediate Groups" in Central Tibet (1895-1959)'. In Tibetans who Escaped the Historian's Net: Studies in the Social History of Tibetan-speaking Societies, edited by Charles Ramble, Peter Schwieger and Alice Travers, 141-16o. Kathmandu: Vajra Books.

Tsomu, Yudru. 2013. 'Taming the Khampas: The Republican Construction of Eastern Tibet'. Modern China 39 (3): 319-344.

Tsomu, Yudru. 2015. The Rise of Gönpo Namgyel in Kham: The Blind Warrior of Nyarong. Lanham, MD: Lexington Books.

Tsomu, Yudru. 2016a. 'Guozhuang Trading Houses and Tibetan Middlemen in Dartsedo, The "Shanghai of Tibet"'. Cross-Currents: East Asian History and Culture Review 19: 71-121. URL: https://cross-currents.berkeley.edu/e-journal/ issue-19/tsomu. Accessed 7 June 2019.

Tsomu, Yudru. 2016b. 'Traders as Cultural Brokers on the Sino-Tibetan Borderland during the Republican Period'. Zangxue xuekan 藏学学刊 (Journal of Tibetan Studies) 14: 1-44.

Turek, Maria M. 2013. 'In This Body and Life': The Religious and Social Significance of Hermits and Hermitages in Eastern Tibet Today During Recent History. PhD dissertation, University of Berlin. 
Turek, Maria M. Forthcoming. 'Monastic Obligations, Hat Change and Lhasa Encroachment: Notes on the Economic System in the Historical Kingdom of Nang chen'. In When the Taxman Cometh: Tax, Corvée and Community Obligations in Tibetan Societies, edited by Charles Ramble, Peter Schwieger, and Alice Travers. Wang, Xiuyu. 2011. China's Last Frontier: Late Qing Expansion in Sichuan's Tibetan Borderlands. Lahnham, MD: Lexington Books.

Yul shul rdzong: dgon sde'i lo rgyus mdor bsdus [n.p./n.d.]. Yul shul rdzong srid gros, yul shul rdzong 'thab phyogs gcig sgril khang, yul shul rdzong mi rigs chos lugs don gcod khang [TBRC WooEGS1016676].

\section{About the Author}

LUCIA GALLI is a research fellow at the Centre de recherche sur les civilisations de l'Asie orientale (C.R.C.A.O., Paris) and a member of the École pratique des hautes études (EPHE - PSL), where she is currently working within the framework of the ANR/DFG funded research project Social Status in the Tibetan World (TibStat). She holds a DPhil in Oriental Studies from the University of Oxford with a thesis on the nyindep ('diary') of the Khampa trader Khatag Dzamyag. 



\title{
10 The Dispute between Sichuan and Xikang over the Tibetan Kingdom of Trokyap (1930s-1940s)
}

\author{
Fabienne Jagou
}

\begin{abstract}
Located on the Sichuan-Xikang border, Trokyap was targeted by local authorities after the Guomindang (G.M.D.) placed this Tibetan kingdom under Xikang jurisdiction in the late 1930s. Documents from Academia Historica shed light on the affair - including the Trokyap king's response when faced with attempts by China's central government to control its southwestern border. These events are analysed nationally with regard to the G.M.D., provincially concerning Sichuan and Xikang authorities, and locally for the Trokyap king. How each party pursued its own military, political, and economic goals is discussed. Control of Trokyap reveals the balance of power between the protagonists and demonstrates how a small Tibetan kingdom could have jeopardized the state-building process implemented by the G.M.D.
\end{abstract}

Keywords: Trokyap, Sichuan, Xikang, Kham, Guomindang (G.M.D.), state-building process.

\section{Introduction}

The beginning of the twentieth century was a major turning point in the history of Sino-Tibetan relations. In 1904, the British invaded Tibet; beginning in 1906, there was the Manchu military intervention in Kham; and 1912 marked the collapse of the Qing dynasty and the foundation of the Chinese Republic. Subsequently, relations between Qing Emperors in Beijing and the Dalai Lama as head of Tibet came to an end. From then on, both Tibet and

Gros, Stéphane (ed.), Frontier Tibet: Patterns of Change in the Sino-Tibetan Borderlands. Amsterdam, Amsterdam University Press 2019

DOI: $10.5117 / 9789463728713 \_$CH10 
China sought to build modern nation states with competing sovereignty claims (see Gros and Relyea's chapters in this volume).

The Tibetan government set up a War Department and implemented new policies that would allow it to form an army (Travers 2015, 2016). It then dispatched military and administrative officials all over its territory, including the eastern region of Kham. These efforts to strengthen administrative control encountered a great deal of resistance both in Central Tibet and in remote areas. In Central Tibet, religious authorities, such as the ninth Panchen Lama (1883-1937) and many civil officials, refused to join this national effort (Jagou 2011). Kham, a patchwork of fragmented political entities made up of a number of kingdoms headed by local independent chieftains, resisted any interference from Lhasa (Peng 2002).

China itself was far from fully united: the period from 1912 to the foundation of the Nanjing government in 1928 was a time of great unrest with provincial warlords fighting each other. When faced with the Japanese invasion in 1937, nationalists, communists, and warlords reluctantly joined ranks under the nominal authority of the Chinese Nanjing government. Nevertheless, in its efforts to become a nation-state, China attempted to keep intact the Qing Empire's territory beyond China proper - including Tibet and its borderlands. At the very beginning of the twentieth century, the Manchus had already tried to implement administrative, political, and economic policies in Eastern Tibet. This area - and the Kham region in particular - took on paramount geopolitical importance (Sperling 1976, Coleman 2002, Wang 2011). Because the British in India had rapid access to China via Tibet, the Chinese built a buffer zone to protect China proper. This resulted in creating the short-lived Chinese province of Xikang (19391955) to govern Kham. The process of establishing Xikang revealed the Chinese Chongqing government's difficulty in implementing its policies and in exercising its authority over its southwestern border (Epstein 2002, McGranahan 2003, Jagou 2006, Relyea 2015).

Kham was not a discrete uniform regional entity; rather, its various kingdom-centred realms constituted a discontinuous landscape. When faced with Central Tibet's tentative take-over and with China's claim to authority over particular territories, Kham offered a polyphonic response. Moves to grant Khampas self-rule in the 1930s - despite their claim to fight under the slogan 'Kham for the Khampas' - did not involve the whole of Kham. ${ }^{1}$

1 Khampas, as individuals, were not necessarily fighting for Kham province as a whole. Rather, their priority was the autonomy of their own territory within Kham. For example, Kelzang Tsering (Tib. Bskal bzang tshe ring, died in 1941) was a member of the nationalist government 
Against this historical background of overlapping or conflicting sovereignty claims, the case of Trokyap, a small kingdom located in northern Kham, sheds some light on the strategic position that local rulers had to adopt at the time. As I will show in this chapter, the Trokyap king did not choose self-rule. He sought to maintain the Manchu privileges he had benefited from since the beginning of the twentieth century under Qing rule. He asserted this by requesting to remain part of Sichuan province, as though the political situation had not changed. The Trokyap example expands upon the role a former constituency (Tibet) of the Qing Empire played in the process of shifting from a specific imperial organization to a modern nation-state. It is also interesting to see how the Trokyap king was able to influence Chinese central government's policies regarding the kingdom's borders.

The tentative administrative incorporation of this Tibetan territory into China proper was by no means a straightforward process. Besides the Trokyap king who rejected Chinese central government's decision to include his territory in Xikang province, there were two other key protagonists. Liu Xiang (1890-1938), the Sichuan governor, based his own claims on the prevailing situation of his province at the end of the Manchu dynasty; thus, he totally rejected the policy his government implemented in the 1930 s to revise some of the province's territorial demarcations. By contrast, Liu Wenhui (1895-1976), governor of Xikang, tried to take advantage of the new policy to acquire a larger territory. As one of the many Tibetan principalities in the fragmented landscape of the Tibetan Kham area, the case of Trokyap sheds light not only on the confrontation that occurred between Xikang and Sichuan authorities. It also reveals difficulties the Chinese government experienced in managing its provincial governors. ${ }^{2}$

and well aware of its national policy. Taking advantage of his position as Xikang Party Affairs Special Commissioner (Xikang dangwu te paiyuan), he tried to get rid of Liu Wenhui in Bathang; from Bathang, he expected to establish himself as the new Xikang Provincial Commander of the nationalist army in 1932 (Peng Wenbin, 2002).

2 Trokyap (khro skyabs) is one of the eighteen kingdoms of Gyelmorong. Gyelmorong is the abbreviation for Shargyelmo tsawa rong, meaning 'The Hot Valley of the Queen in the East'. The eighteen kingdoms of Gyelmorong are: Chakla, Tsenla (Xiaojin), Trokyap, Chuchen (southeast of Dzamtang), Gotang, Gomé, Gotö (east of Dartsedo), Drakteng, Pawang, Geshitsa, Gyelkha, Okzhi, Lunggu (Wenchuan), Muchi (on the southeastern fringe of Gyelmorong region), Somo, Choktsé, Dzigak, Tenpa (in the northeastern part of Gyelmorong). Today, Trokyap (Ch. Chuosi jiabu) kingdom is located northwest of Jinchuan County within the Aba Autonomous Prefecture of Sichuan province. It should be distinguished from Trokyab, which is the Tschokiab of Tafel (1914, vol. II, 224) and the Choschia of Zhonghua Minguo xin ditu (1943, Scale 1:250000o) located on the bank of the Dajinchuan river about 110 miles due north of Dartsedo (Wylie 1980, 103; 184n.638). 
The events discussed here began in 1937. At that time, the Nationalist government decided to integrate Trokyap into Xikang against the will of Sichuan provincial authorities. The events end in 1940 with the endorsement of this decision by the Ministry of Home Affairs. ${ }^{3}$ Both the manner in which this dispute between the two provinces unfolded and the intervention of the Chongqing government set the Trokyap case apart from other Tibetan polities in Kham that actively sought to maintain self-rule during the $1930 \mathrm{~s}$ (Peng 2002). Emphasis is often laid on the forms of resistance to state integration; however, the case of Trokyap is not a plea for self-rule. Rather, it is an appeal to remain outside Xikang province but still under the administration of Sichuan province. It also can be seen as a prelude to what would happen much later.

Two sets of archival records about the incorporation of Trokyap kingdom bring this case to light. The exchange of correspondence between the two provincial governments (Sichuan and Xikang), the Ministry of Home Affairs in Chongqing, and the Trokyap king is characteristic of the negotiations that took place between the parties involved. The archived documents help to analyse the motivations and arguments of all the parties involved in the dispute. Underlying the conflicting positions adopted by the protagonists was the question of the Nationalist government's capacity to implement its policies and to impose its authority over the Tibetan border area and provincial authorities. Published and edited in 1984 - well after the events themselves - the collection Selections of Historical Materials (wenshiziliao xuanji) reveals the economic importance of Trokyap in terms of its gold production. ${ }^{4}$ Included in this collection is a testimony left by Li Hou'an, one of the actors in the 1930s negotiations. This witness account completes the record in the archived documents, which only mention in passing the fight over the kingdom's gold mines. ${ }^{5}$

3 Academia Historica, archive file number 026000009629 A, order of the Executive yuan (xingzhengyuan), 26 September 1937, confirmed on 11 October 1937 and order of the Executive yuan, 15 October 1940.

4 Selection of Historical Materials is a collection of witness accounts of events that occurred in this area of the Republic of China. These accounts were collected from the 1950s onwards by members of the Chinese Communist Party and edited by the National Committee of the Chinese People's Political Consultative Conference in 1980. I would like to thank Tenzin Jinba for providing me with this material.

5 Archive file number 026000009629 A/B from the Academia Historica, Xindian, Taiwan. The titles given to these two files are the following: the question of the administrative subordination of Trokyap (lishu wentian) and the incorporation of Trokyap within the regular administration (gai liu'an). The first file includes documents from every protagonist; the second file mainly contains correspondence issued by Sichuan provincial authorities. 
In order to determine whether the Trokyap king's arguments were heard and understood by the Nationalist government, this chapter presents each party's irreconcilable arguments for imposing its own will and for striving toward different goals.

\section{Centre Stage: Nationalist Government's Southwestern Policy}

\section{Territorial Control and the Creation of Xikang}

During the period that ranged from the beginning of the new Republic proclaimed by Sun Yat-sen (1866-1925) on 1 January 1912 to the establishment of the Nanjing government (1928), negotiations took place to define the border between China and Tibet, but to no real avail. The Simla Convention (1913-1914) was never ratified by China. The Chinese government had to appoint military officials to control the region because its own authority had not been fully established. Nevertheless, the Beijing government continued to differentiate the administrative status of the Tibetan areas of Amdo and Kham as separate from the status of Central Tibet. ${ }^{6}$ Central Tibet remained 'Xizang' (Tibet) and the Kham Tibetan territory became the 'Sichuan Border' (Chuanbian). In fact, Chuanbian did not correspond to a Chinese government administrative unit; rather, it seemed to be a geographical term to qualify the territory situated beyond the western border of Sichuan province. When Chuanbian was used to name parts of Kham, it was precisely because Kham was not yet under the Nationalist government's administrative control. Once it had been integrated - and only then - would an administrative denomination and structure be defined. In 1914 the Republicans granted administrative status to Kham for the first time referring to it as 'Sichuan Frontier Special Administrative Region' (Chuanbian tebie xingzheng qu). Later on, it became the 'Xikang Special Administrative Region' (Xikang tebie xingzheng $q u$ ), and troops were subsequently stationed there (see Relyea, this volume). This territory was divided into two circuits (dao): the 'Eastern Border Circuit' (bian dong dao) and the 'Western Border Circuit' (bian xi dao). In 1916 both circuits merged to form a single circuit called 'Sichuan Border Circuit' (Chuanbian dao). After the Nanjing government had been set up in 1928, the Nationalist government added to the twenty-two provinces that were remnants of the Qing dynasty's four provincial-level 'Special

6 Tibet is divided into four major regions: southwestern Tibet (Ngari), Central Tibet (Ü-Tsang), southeastern Tibet (Kham) and northeastern Tibet (Amdo). 
Administrative Regions' (tebie xingzheng quyu): Jehol, Suiyuan, Chahar, and Chuanbian. This move allowed them to recover the Manchu Empire's entire territory. In August of the same year (1928), Xikang's status of Special Administrative Region was changed to 'province' (sheng). However, still no civil provincial government was tasked with administering Xikang province even though some counties were administered by military officers. It was only several years later that a Preparatory Committee for the establishment of Xikang province (Xikang jiansheng weiyuanhui) was created (1935) and set up in Ya'an, headed by Liu Wenhui. He was one of the most powerful ex-warlords in southwestern China and its provincial governor (Liu Ziqian 1944, 21). The headquarters of this Preparatory Committee were transferred to Dartsedo (Ch. Kangding), which became the capital of Xikang in 1936.7 A year later the government introduced its policy to lay claim to Trokyap.

At the time of the promulgation of its Provisional Constitution in June 1931, the Nanjing government strove to implement new policies regarding the management of all its provinces and the de facto integration of independent regions of Mongolia and Tibet into its territory (Lin Hsiao-ting 2006, 21). ${ }^{8}$ The attempt to include parts of Kham in the new Chinese administrative structure contributed to the reorganization of powers on the latter's southwestern border. The policy was first geared toward controlling local warlords and then toward their integration into the Chinese administrative or military hierarchy. In order to control the five subnational militarists based in Sichuan or on its borders, five 'garrison areas' ( fangqu) were created, each under the responsibility of an army commander (junzhang), who was an ex-warlord (Kapp 1973, 34, 36). ${ }^{9}$ Moreover, the most powerful warlords were removed and/or made provincial governors. A finely tuned strategy had to be implemented to ensure that the local ex-warlords' power would be recognized in such a way that they would serve the interests of the Nationalist government without acquiring too much power. For example, the Chinese government did not want Liu Wenhui to become Sichuan provincial governor. Instead, Liu Wenhui was ordered to form Xikang province and not to interfere in the affairs of Sichuan province. Once ousted from Sichuan, this new official responsibility still allowed him to acquire power on the

7 On the choice of Dartsedo as the capital of Xikang, see Ren Naiqiang 1933, 77-80.For the discussed limits of Xikang province, see Jagou 2006.

8 Before the war with Japan, the Nanjing government administered 28 provinces with the addition of Ningxia and Qinghai provinces.

9 Yang Sen's army was known as the Twentieth National Revolutionary Army, Liu Xiang's as the Twenty-first, Liu Wenhui's as the Twenty-fourth, Deng Xihou's as the Twenty-eighth, and Tian Songyao's as the Twenty-ninth. 
southwestern border of China. Throughout the Republican period, two options were equally favoured: to make Kham the territorial basis for the new Xikang province or to integrate these territories into Sichuan province. The Trokyap case illustrates how crucial this question was for both Chinese provinces, especially in terms of income.

\section{Defining the Border Between Sichuan and Xikang}

While Nanjing's influence over the two southwestern provinces was practically non-existent until the Japanese invasion (from 1937 to 1945), the Chinese government's retreat to Chongqing in Sichuan in 1938 offered it new perspectives regarding Tibetan territories. New laws governing the Sichuan border were promulgated. Xikang and Sichuan provinces disagreed about the delimitation of their respective borders. Thus, the same year an advisor to the 'Ministry of Home Affairs' (neizheng bu) asked both Xikang and Sichuan provinces to send emissaries to define their joint border in accordance with Article 8 of the general law 'Conditions for Drawing the Borders of Provinces, Towns and Sub-prefectures' (sheng shi xian kan jie tiaoli). A particularly fierce dispute over Trokyap kingdom broke out after the Ministry of Home Affairs placed this territory under the jurisdiction of Xikang province. This arbitrary partition acted like a detonator. In this type of case the Mongolian and Tibetan Affairs Commission (M.T.A.C.) should have settled the matter because its purpose and objective were precisely to integrate Tibetan and Mongolian territories: in this case, the Ministry of Home Affairs remained the only intermediary. Its intervention shows how this case received special attention.

The official decision to incorporate Trokyap territory into Xikang was taken in 1937. Archived documents do not mention the advance of communist troops as a factor in this decision. However, the Long March took communist troops through Kham. They fled southern China and began their Long March to the North to escape the threat represented by nationalists. One of their armies, the Fourth Front Army entered Xikang territory. There the communists set to work to create a revolutionary base and strove to control the Tibetan population by setting up several Tibetan revolutionary bases. The most important of these was the 'Böpa People's Republic' which was established in Kandzé in May $1935 .{ }^{10}$ However, these attempts proved

10 According to Jinba Tashi, whom I thank for sharing this information, the Communist Committee of Jinchuan (Gele desha gongheguo) was founded in 1935. The Tibetan Communist Committee (Boba renmin gonghe guo) was created in Kandzé County in 1936. 
unsuccessful and the Tibetans were soon regarded as 'indomitable' (Liu 2004, 85, 95; Dreyer 1995, 199-200). Save for one document that recounts how the Red Bandits (chifei) burned the county archives in Daofu in reaction to the local people's refusal to levy taxes for communist soldiers, ${ }^{11}$ the archives about the Trokyap case say nothing of these developments. They do not even mention the burden the Fourth Front Red Army imposed on the Tibetan people in the form of its 45,000 soldiers and their subsequent food requirements. Nonetheless, the communist presence from 1935 to 1936 in the Gyelmorong area where Trokyap was situated turned out to be an opportunity for the Nationalist government to drive out the communists and to establish itself firmly in this area (Aba Zangzu zizhizhou gaikuang comp. 1985, 86-93; Ganzi Zangzu zizhizhou gaikuang comp. 1986, 111-112); it was perhaps no coincidence that the official limit between Xikang and Sichuan was drawn the next year (1937).

The advance of the communists in Sichuan and Xikang clearly provided the Nationalist government with an opportunity to strengthen its relationship with the Lhasa government. After the death of the Thirteenth Dalai Lama in 1933, Lhasa had agreed to meet and negotiate with representatives of the Nationalist government. The Tibetans responded positively to Chiang Kai-shek's (1887-1975) plea to resist the advance by the communist army across the Jinsha River to the West (by then the official border between Central Tibet and China). However, for fear that the Tibetans would be swept up in the military offensive, Chiang Kai-shek ordered Liu Wenhui, who was acting as his decentralized agent, to station his army on the opposite bank of the Jinsha River to ensure that the Tibetans would not take this opportunity to cross it eastwards (Aba Zangzu zizhizhou gaikuang comp. 1985, 102-105; Ganzi Zangzu zizhizhou gaikuang comp. 1986, 113-119).

\section{Trokyap as a Buffer County}

For the Nationalist government, the Trokyap was problematic due to its strategic position between Xikang and Sichuan. As was the case for other kingdoms in Kham, such an 'interstitial' or 'in-between' area was viewed as a no man's land (outuo) by the Nationalists who wished to turn the whole area into a buffer zone. Trokyap was regarded as a natural border between the two provinces as its terrain is marked by steep wooded mountains

11 Academia Historica, archive file number 026000009629A, opinion expressed by the Preparatory Committee for the establishment of Xikang Province to the Ministry of Home Affairs, 6 May 1937. About the levy of taxes in Daofu (Liu 2004, 97). 
Map 10.1 Localization of the Kingdom of Trokyap, c. 1940

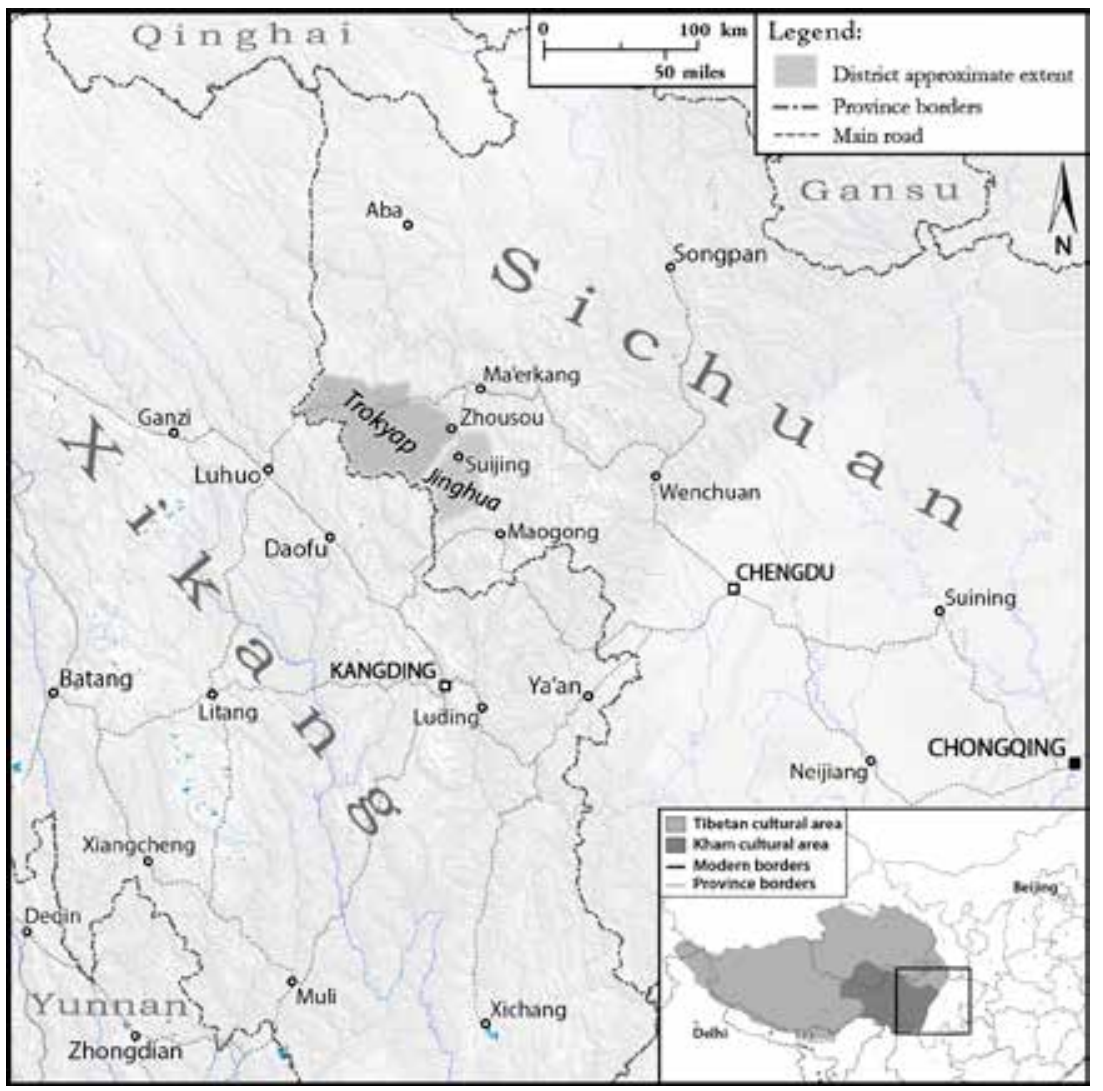

Source: Based on Academia Historica, archive file number 026000009629A; SRTM (NASA) and modern administrative borders extracted from GADM database (www.gadm.org, v.2.5 July 2015) Author: Rémi Chaix

and river valleys. However, keen to prevent local power from developing or strengthening and reassured by the fact that it had granted positions of authority to ex-warlords, the Nationalist government concentrated its efforts on creating intermediate administrative units called 'Administrative Inspection Districts' (xingzheng ducha qu) (Fitzgerald 1999, 105). Provinciallevel authorities were expected to act as a link between central government and the counties. The Nationalist government suggested that the main issues regarding the future of Trokyap kingdom were its subordination and the question of the preservation or dissolution of Jinghua County in which Trokyap was included. In addition, there was also the question of administering Trokyap once it fell under Xikang's jurisdiction. 
As a matter of fact, a document dated 22 October 1937 mentions the administrative history of Trokyap: Trokyap became part of Sichuan's Jinghua County along with two county-level tun, Suijing and Chonghua, at the beginning of $1937 .^{12}$ Xikang provincial authorities contested this earlier appropriation by Sichuan.

The set of documents about the Trokyap dispute helps to trace the Chinese administrative history of Trokyap since the end of the Qing dynasty from the point of view of the parties involved. Xikang authorities acknowledged the need to reform the territorial administration and accepted the rationale behind Trokyap's joining the new Jinghua County. Nevertheless, they advanced practical arguments for maintaining the kingdom under its administration. For them, before the creation of Jinghua County, Trokyap was managed by the military garrison from Suijing (Suijing tun) and indirectly by Maogong sub-prefecture (Maogong zhili ting). In 1913, following government guidelines to simplify provincial administrative divisions, sub-prefectures (ting) and prefectures $(f u)$ became counties. While Maogong sub-prefecture became Maogong County, Trokyap remained under the jurisdiction of the Suijing military garrison. The kingdom was therefore automatically included in the newly created Jinghua County. Owing to Trokyap's modest population and territory, Xikang authorities argued that its integration into Jinghua County was not the best option. They contended that it would be easier to merge Trokyap with other neighbouring territories to create another district within Xikang province. Hence the Chinese central government envisaged integrating Trokyap into Xikang while pondering the validity of Jinghua County's existence without it. To them, the latter's surface area would then be insufficient to form a county. ${ }^{13}$ It ultimately suggested adding another town, Fubian (at that time under Maogong County's administration), to Suijing and Chonghua to form Jinghua County to allow Trokyap to join Xikang province, the latter thus becoming a county in itself. The Nationalist government pointed out that Xikang was a new province with only 32 counties; Sichuan, which was large and overpopulated, included 150 counties. The government concluded that, unlike Xikang, Sichuan had admirably fulfilled the task of tracing its new borders and of sending emissaries to check them, and that Sichuan had encountered no opposition from Gansu and Qinghai. The Ministry of Home Affairs insisted that Trokyap was large and difficult to manage. Thus, were Trokyap to join Xikang, it would be easier to control,

12 Academia Historica, archive file number 026000009629A, opinion expressed by the Ministry of Home Affairs to the government of Sichuan, 22 October 1937.

13 Without Trokyap kingdom, Jinghua County would have lost one third of its area. 
though the reasons behind this rationale were not fully explained. The Ministry also stated that from the very beginning Sichuan had agreed to the creation of Xikang and that the two respective provinces' roles had been clearly defined: the very purpose of creating Xikang was to control and protect the Sichuan border. As far as the Ministry was concerned, defining the inner limits and deciding on which of the two provinces Trokyap should belong to was not a major issue or a real concern at national level. ${ }^{14}$ The prime objective was to incorporate Trokyap in the Republic's administrative framework, to establish the Tibetan kingdom as a county, and to make it part of the Chinese territory. All of these were in keeping with the government's purpose of implementing the state-building policy.

The integration of Trokyap into Xikang was not without its own problems. Discussions took place about merging this kingdom with Luhuo (Drango) County or with Daofu (Tawu) County. Both of these counties were part of the 'Administrative Inspection District' independently administered by Liu Wenhui but still part of Sichuan Province. However, Xikang had already started implementing a policy to define its territory's inner administrative limits and had decided to turn the ex-tusi kingdoms into counties. Hence, administratively speaking, Trokyap had already become a county. The Ministry of Home Affairs accepted this course of events, because Trokyap was rich in natural resources and in livestock and could therefore be self-sufficient. It also considered that it would be an opportunity for Xikang to oversee the exploitation of its own mineral resources. ${ }^{15}$ From the perspective of Sichuan authorities, Kham - the so-called 'Sichuan Border' territory - was part of Sichuan at the time the Republic of China was founded (1912) and should remain within its borders. ${ }^{16}$

Sichuan provincial authorities suggested that Trokyap kingdom become part of Daofu County, which at the beginning of the twentieth century lay within the Sichuan Border Area and belonged to Sichuan. ${ }^{17}$ They claimed that the Chinese government was backing Xikang province regardless of the historical facts. From their point of view, historical precedent justified

\footnotetext{
14 Academia Historica, archive file number 026000009629A, opinion expressed by the Ministry of Home Affairs to the government of Sichuan, 22 October 1937.

15 Academia Historica, archive file number 026000009629 A, opinion expressed by the Ministry of Home Affairs to the government of Sichuan, 22 October 1937.

16 Academia Historica, archive file number $026000009629 \mathrm{~A}$, opinion expressed by the Preparatory Committee for the establishment of Xikang Province to the Ministry of Home Affairs, 6 May 1937 .

17 Academia Historica, archive file number $026000009629 \mathrm{~A}$, copy of a letter by Liu Xiang in an internal missive of the Ministry of Home Affairs, 20 April 1937.
} 
the integration of Trokyap into Sichuan. In fact, both parties made reference to the policy that Manchu officials had adopted on the Sichuan border at the end of the Qing dynasty but disagreed with the implementation of the gaitu guiliu policy. Often glossed as a form of 'bureaucratization', this policy consisted in modifying ( $\mathrm{gai}$ ) the status of a local ruler $(t u$, here the Trokyap king) to make him join (gui, literally rally) the regular administration (liu, literally mainstream) ${ }^{18}$

As far as the Ministry of Home Affairs was concerned, both Sichuan and Xikang advanced valid arguments. However, the Ministry stressed that both authorities had to adapt to present conditions and that the law governing the delimitation of provinces, counties, and towns should prevail. ${ }^{19}$

After listening to the arguments put forward by both parties, the Chongqing government decided in favour of Xikang, citing the Kham territories' strategic position. In July 1938 Chiang Kai-shek approved the transfer from Sichuan to Xikang of seventeen districts (see also Frank, this volume), a request that Liu Wenhui had been making since 1934 and which had been repeatedly turned down by Nanjing (Lin 2006, 109). This concession came with an effort to better integrate Xikang. As Lin Hsiao-ting argues, 'in exchange for the additional tax revenues from the new territories and abundant natural resources, Liu Wenhui agreed to accept that his Xikang territory be upgraded from "preparatory" status to a formal province, and henceforth to recognize orders and instructions from the KMT government' (ibid.). Liu Wenhui shared the nationalists' interest in bureaucratic reform because this could give him total control over a given area and extra tax revenues. At the time, he was contending with difficulties in maintaining his power in Sichuan after being challenged by other Sichuan warlords from the beginning of the 1930 (Kapp 1973, 35). ${ }^{20}$ From then on, the Chongqing government was able to intervene in Sichuan's internal affairs. On 5 October 1940, it accepted Liu Wenhui's final proposal that Trokyap kingdom be included for the time being in Danba County (Tib. Rongdrak), part of Xikang province.

The question of defining the inner administrative borders, as mentioned above, may seem rather trivial compared to the other issues the Nationalist government had to address. Indeed, the delimitation of counties was still being discussed when the Nanjing government retreated to Chongqing

18 See Gong Yin (1992), Herman (1997).

19 Academia Historica, archive file number 026000009629 A, Minister of Home Affairs to the Preparatory Committee for the establishment of Xikang Province, 8 May 1937.

20 Liu Wenhui transferred his headquarters from Chengdu to Xikang in 1933. 
and was struggling to survive there, faced with much greater challenges than the demarcation of inner territories. Although Chongqing was one of the biggest trade centres on the Yangtze River above Hankou, the strategic road to Burma was of vital importance and concern at that time for the Nationalist government. The Nationalists used it to bring in vital supplies from outside. And when the road was closed in 1939, as James Leibold points out, Chiang Kai-shek envisaged building another road that would link India to southwestern China via Xikang and Tibet (Leibold 2005, 189). As a matter of fact, Chiang Kai-shek needed Liu Wenhui's full support to implement this policy. Thus, they made some concessions to him independently of any other considerations. In fine, the survival of the Nationalist government depended on how well it controlled the local authorities. In fact, Chiang Kai-shek readily succeeded in manipulating the local authorities regardless of the powers of the local Chinese or Tibetan authorities. Furthermore, the example of Trokyap throws new light on the rivalry between Xikang and Sichuan and on a specific Tibetan reaction to the creation of Xikang province.

\section{The Decentralized Centre: Local Chinese Authorities and Chinese Central Government Policies}

For any provincial ex-warlord, to lose a county was inexcusable. Although supposedly part of the military and administrative structure of the Nationalist government, the different ex-warlords continued to act as independent leaders, at least within the limits of their own territories. The reaction of Sichuan provincial officials to the Nationalist government's decision to relinquish a kingdom (or a county) - which they originally considered their own - to Xikang province was therefore intolerable. And, as expected, their arguments totally contradicted those put forward by the Nationalist government.

Contrary to their government that strove to regain Qing imperial territory and to unite this territory, local authorities blatantly defied the Nationalist government. However, they sought its approval in the case of Trokyap kingdom; indeed, both the government and local authorities said the provinces had failed to reach an agreement.

In keeping with its decision to include Trokyap in Xikang, the Ministry called to order the Sichuan authorities, stressing the fact that the question concerned China's territory and the delimitation of its inner divisions, and that knowing what belonged to $\mathrm{A}$ or $\mathrm{B}$ was not the overriding issue: 
the transformation of the former Qing Empire territory into a Chinese nation-state was the issue at stake. ${ }^{21}$

\section{The Validity of the Arguments}

Archived documents make no mention of the troubled times of Zhao Erfeng (1845-1911) and Fu Songmu (1869-1929). Border Commissioners for Sichuan and Yunnan (duban Chuan Dian bianwu dachen) respectively, Zhao and Fu were tasked with implementing the gaitu guiliu policy. The main bone of contention between Sichuan and Xikang authorities was the validity of the sources that attest to the arguments put forth by both parties. Both authorities contributed to writing the history of Trokyap by marshalling historical facts and evidence. For example, Liu Wenhui accused the Sichuan authorities of spuriously quoting the book Account of the Establishment of Xikang Province (Xikang jian sheng ji) by Fu Songmu. This is because Liu Wenhui viewed this book not as a historical document but only a private account. ${ }^{22} \mathrm{He}$ saw the need to reference archived documents that could serve as irrefutable proof. According to him, there was no factual evidence to prove that Trokyap had become part of Daofu County because Daofu County archives had been destroyed by the communists. Furthermore, there was counter evidence in the Dartsedo archives, which dated from the time of the 'Sichuan Border area'. According to the Xikang authorities, sources in these archives helped prove that Trokyap was not part of Daofu; the latter did not receive taxes from Trokyap, and the king of Trokyap was not in possession of a seal that proved he was part of the regular Chinese administration. ${ }^{23}$ The Xikang authorities conducted archive research and discovered that three files on the gaitu guiliu policy adopted by Zhao Erfeng and Fu Songmu still existed. One was about Kongsa (Tib. Khang gsar), and two others dating from 1911 pertained to the incorporation of Trokyap into the regular administration. The Xikang authorities also addressed the issue

21 Academia Historica, archive file number $026000009629 \mathrm{~A}$, opinion expressed by the Ministry of Home Affairs to the Sichuan government, 22 October 1937.

22 Academia Historica, archive file number 026000009629 A, opinion expressed by the Preparatory Committee for the establishment of Xikang Province to the Ministry of Home Affairs, 6 May 1937 .

23 Academia Historica, archive file number $026000009629 \mathrm{~A}$, copy of a letter by Liu Wenhui in an internal missive of the Ministry of Home Affairs, 20 April 1937; Opinion expressed by the Preparatory Committee for the establishment of Xikang Province to the Ministry of Home Affairs, 6 May 1937; memoir sent by the Preparatory Committee for the establishment of Xikang Province to the Minister of Home Affairs, 5 June 1937. 
of the seal that the king of Trokyap should have been granted as proof of his siding with the Manchu administration and which in the end he did not receive. These documents refer to the sense of urgency at the time on both (Tibetan and Manchu) sides in receiving or granting official status as a member of a new administrative structure or in preventing a local rebellion against Qing authorities. The unrest in China had prevented the Trokyap king from receiving this seal. As such, doubts were expressed about the fate of Trokyap at the very end of the Manchu dynasty.

According to secondary Chinese sources, the Trokyap king recognized the authority of the Qing in 1700 and received the title of Pacification Commissioner (anfusi) in 1702. Then, at the end of the Second Jinchuan War (1771-1776) during which he sided with the imperial armies, he was promoted to Pacification Propagator Commissioner (xuanfusi). ${ }^{24}$

However, as noted by the Sichuan authorities and confirmed by their Xikang counterparts, nothing is known about the title this local chieftain supposedly received between 1904 and 1911 when the gaitu guiliu policy was implemented by Zhao Erfeng. The Trokyap king himself attributed the fact that he had never officially received his title to the move by the 'Sichuan border area' office to Dartsedo that took place at that time. ${ }^{25}$ In fact, in the archived documents the Trokyap king is still addressed as Chuosijiabu tusi at least until the end of 1939. Indeed, even the Xikang authorities referred to the king of Trokyap as tusi, even though he himself did not sign any letters in this capacity. ${ }^{26}$

The Trokyap king signed one of his letters (translated into Chinese; the Tibetan version is not in the archives) as the Pacification Propagator Commissioner (xuanfushi) ${ }^{27}$ In fact, the incorporation of Trokyap is discussed in the documents, but there is no reference to a discussion about the title the Trokyap king would have received after the decision had actually been taken.

24 'An Overview of Trokyap' by Yudru Tsomu (13 July 2011), unpublished manuscript, previously available at URL: http://places.thlib.org/features/23689/descriptions/1297.

25 Academia Historica, archive file number $026000009629 \mathrm{~A}$, translation into Chinese of a letter from the Trokyap local chieftain to the County Officer of Jinghua, 8 March 1937.

26 The Xikang authorities referred to two tusi: the father, Lawang Norbu, was locally called 'senior local chieftain' (lao tusi); the son, Kelsang Gyeltsen (Ch. Sigerangjia canyidan lejianzan) was locally called 'junior local chieftain' (xiao tusi). Due to the father's advanced age, the son became the acting local chieftain before actually inheriting this position.

27 Academia Historica, archive file number $026000009629 \mathrm{~A}$, translation into Chinese of a letter from the Trokyap local chieftain to the County Officer of Jinghua, 8 March 1937. Nawang Le'erwu is likely an alternative transliteration of Lawang Norbu; copy of a letter from the Preparatory Committee for the establishment of Xikang Province, 26 January 1937 and included in an opinion expressed by the Ministry of Home Affairs to the Preparatory Committee for the establishment of Xikang Province, 20 April 1937. 
It is possible there was no need to discuss it because when Zhao Erfeng had implemented the gaitu guiliu policy, he had promised the 'distinguished' (gongshun) local chieftains, then simply known as tusi, that he would grant them a 'hereditary Chinese official position' (shixi Han guan zhi zhi) in order to gain their support. ${ }^{28}$ Ultimately, after the final decision to include Trokyap into Xikang, this change of status implied an obligation to 'rally the regular Chinese administration again' (chongxing gailiu). ${ }^{29}$

Faced with these arguments and given that territorial reorganization was already under way, the Nationalist government decided to send emissaries to Trokyap to meet with the Sichuan and Xikang authorities.

\section{Nationalists Emissaries to Trokyap}

Although the Chinese government had been based in Chongqing since 1938, it still relied on local authorities to implement its southwestern border policy. For example, Liu Xiang, the Sichuan governor, had made repeated demands from the government to send emissaries from Nanjing to the border. In response, the Chongqing government claimed that the matter should first be settled at the local level and therefore asked the provincial authorities to carry out their own inspections; only after that, if necessary, would it send its own emissaries. The aim of these missions was to draw Trokyap's border in keeping with Nationalist government guidelines..$^{30}$ One of the two officials from Xikang was Du Dediao, commander of the peace preservation forces. Du had been specially appointed to Trokyap (Chuosijia tezhong bao'an daduizhang) after initially being posted to Jinghua County. The other was Zhou Wenzao, the Xikang emissary (Xikang zhuanyuan) who had been escorted by Du Dediao in the course of his survey. Their duties consisted in collecting data on the situation of every local chieftain territory (population, territorial limits, natural resources, etc.). Sichuan province sent to Trokyap Yan Guangxi, the emissary of the sixteenth district of Sichuan province (Sichuan sheng shiliu qu

28 Academia Historica, archive file number $026000009629 \mathrm{~B}$, translation into Chinese of a letter from the Trokyap local chieftain to the County Officer of Jinghua, 8 March 1937. This policy was called 'reform of the hereditary rank' (shixiyange) and is explained in Wu Yongzhang (1988, 261-262); see also Gong Yin (1992, 123-124). I translate gongshun tusi as 'distinguished' because this title indicates that the said person received a salary and sometimes a military escort from the Manchu government as a form of reward.

29 Academia Historica, archive file number $026000009629 \mathrm{~B}$, order from the Executive yuan, 17 January 1939.

30 Academia Historica, archive file number 026000009629A, opinion of the Ministry of Home Affairs, April 1938. 
xingzheng ducha zhuanyuan), which was an intermediate unit that ensured communication between the province and the counties.

The Xikang emissaries' reports are largely quoted in the archives and give details of Trokyap's geographical situation and natural resources. They also mention the 'vile acts' people from Jinghua County carried out on behalf of the Sichuan authorities who had already relayed rumours about what they called 'the unscrupulous intentions' of Xikang people three years earlier. ${ }^{31}$ The Sichuan authorities reported the local point of view that the Trokyap people would never agree to become part of Xikang province and were ready to fight the Xikang army by involving many other Tibetan kings. Sichuan warned Chongqing that the border situation might become a national issue if Japan seized the opportunity to cross this fragile border and to advance into Chinese territory. ${ }^{32}$

\section{Economic interests}

Nevertheless, the key question for the Xikang emissaries was whether the Trokyap kingdom was economically self-sufficient. Trokyap had already been described as sparsely populated, with no fertile land, but very rich in natural resources and livestock..$^{33}$ The latter were potential sources of revenue for both Sichuan and Xikang provinces. With two gold mines already in operation, Trokyap had much to offer. ${ }^{34}$ These mines were objects of envy to both the Chinese and Tibetans throughout the first half of the twentieth century. Indeed, the Trokyap king had defeated the Chinese - who were all too keen to take over these mines - and subsequently remained on the alert. ${ }^{35} \mathrm{He}$ managed this after having mobilized soldiers from among his own people and from other Tibetan kingdoms which, thanks to marital

$3^{1}$ Academia Historica, archive file number 026000009629A, advice from the Xikang government and transmission of reports from the field, 15 December 1940.

32 Academia Historica, archive file number 026000009629A, memoir from the Sichuan government, 26 October 1937.

33 Academia Historica, archive file number 026000009629A, report from the Ministry of Home Affairs, 26 October 1937.

34 Academia Historica, archive file number 0260oooog629A, report from Zhou Wenzao, 1939.

35 A letter from the sixteenth district of Sichuan, an enclosure to a letter from the Ministry of Home Affairs, 20 April 1937, which recalls that the events happened at the beginning of the twentieth century: as early as the 1910s, during Yuan Shikai's rule (1912-1916), people from Yuhua Company were sent to open the gold mine in Ere. The company met with resistance from the Sichuan warlords well before reaching the heart of Trokyap. According to the archives, this company exceeded its rights and started competing with a Sichuanese firm called Zhuokai Company that was already operating the mine. The Yuhua Company, whose manager was the Minister of Finance in the Peking government, therefore compromised the interests of the local firm. Finally, the whole mine operation project was abandoned for some time. 
alliances, maintained close ties with him. At the end of the 1930s, when Trokyap reappeared on the political and military scene, control of the gold mines once again became a key issue, this time between the two provincial governments. However, for the Trokyap king, who had already refused to grant access to the gold mines to either the Chinese or the Tibetans from Central Tibet, the determining issue concerned the taxes and corvée service that Xikang province would inevitably demand (Li 1984, 45-48).

\section{The Local Situation: The Trokyap King's Opinion}

In the archives, the Trokyap king's opinion is mentioned only indirectly. All of the letters, save one, are written in Chinese. Written in Tibetan and dated 28 February 1941, this particular letter came directly from the king of Trokyap. Though for G.M.D. the matter was already closed, this letter requested in rather vague terms that the border of Trokyap be (re)defined. In the letter, the king agrees with the Chinese central government's plan to reorganize its territory, but he does not disclose his opinion about whether Trokyap should belong to Xikang or Sichuan. His view, as quoted by the Sichuan authorities, was that he did not want to see his territory become part of Xikang. Again, according to the Sichuan authorities, his arguments were that his kingdom had been under the administration of Daofu County since the reform implemented by Zhao Erfeng and Fu Songmu; therefore, it belonged to Sichuan province. According to the Sichuan provincial government, the king went even further to say that he preferred to remain in Jinghua County within Sichuan province. However, let us not forget that this was before the Xikang province project had ever been scheduled. At the time this area was called the 'Sichuan Border' ${ }^{36}$ The Sichuan authorities went on to add that Trokyap threatened to oppose the decision to include it in Xikang province. Their resistance could be traced to when Liu Wenhui and his men had retreated to Xikang in 1935 and had got as far as Trokyap. This military intrusion had seriously affected Trokyap and its population who had had to provide for this army. 37

36 Academia Historica, archive file number 026000009629A, copy of a letter signed by the assembly of local chieftains of Gyelmorong, 8 March 1937, an enclosure to a letter disclosing the opinion of the Ministry of Home Affairs to the Preparatory Committee for the establishment of Xikang Province, 15 May 1937.

37 Academia Historica, archive file number 026000009629A, quotation from a letter from the Sichuan province government in a letter disclosing the opinion of the Ministry of Home Affairs to the Preparatory Committee for the establishment of Xikang Province, 15 May 1937; Memoir from the Sichuan government, 26 October 1937; Opinion of the Sichuan government, 1939. 
In fact, the excessive taxes, especially the transportation corvée (ulak) levied by Xikang, were the main reason that Trokyap wished to remain under the administration of the Sichuan Border. Indeed, it would seem that the Trokyap king attempted to negotiate tax exemptions with the Xikang provincial government and threatened to start a war with China if his demands were not met. The emissary of Xikang province conveyed this opinion after meeting with the Trokyap king:

In April 1939, the Xikang provincial government sent an emissary to Jinghua County in Sichuan province to negotiate the Trokyap affair with the Jinghua authorities. The Trokyap king, having been influenced by others, asked to be exempted from taxes forever. The Xikang government directly answered this request by arguing that Trokyap should first agree to become part of Xikang province. A year later, the Xikang government agreed to abstain from levying taxes for a three-year period. The Trokyap king answered in an ambiguous manner: the border had still not been drawn, and therefore Trokyap wanted to keep its current privileges and particular situation that it had always had. Regarding the delimitation of the border, it wanted to remain free of any engagement; otherwise it would inform all the Khampa kings of the Chinese decision to incorporate its territory into Xikang and would form a coalition that would destabilize the development policy. ${ }^{3}$

A witness account of the affair was even more specific. Li Hou'an, a protagonist in this affair, writes that the Trokyap king did not want his territory to be assigned to Xikang. He preferred Sichuan because taxes were extremely high in Xikang and the corvée even more substantial. According to this testimony, the Trokyap king justified his arguments by taking as an example the journey made by the Xikang emissary: the latter had taken advantage of the corvée system and had requisitioned people from three different kingdoms to carry his luggage. He particularly insisted that such high taxes and corvée labour would be a terrible burden on his people. He concluded that the people of Trokyap would prefer to die rather than belong to Xikang (Li 1984, 49).

There were considerable economic interests at stake, as illustrated by the gold mine issue mentioned above and by the fact that Liu Wenhui made this a priority as soon as he had secured Trokyap's integration in Xikang (Li 1984, 50). The excessive taxes and the obligation to do corvée labour

38 Academia Historica, archive file number 0260oooog629A, report from Zhou Wenzao, the emissary of Xikang province to Trokyap, to the Ministry of Home Affairs, 15 April 1940. 
which would have been imposed on the people of Trokyap deterred their king from allowing his kingdom and his subjects to become part of Xikang.

It is true that the Trokyap king maintained close ties with other rulers through matrimonial alliances. Nevertheless, it is still difficult to determine whether he was trying to protect himself against other Khampa rulers, or if he simply wanted to create his own delimited territory. He undoubtedly used Khampa forces to oppose the Xikang authorities.

\section{Conclusion}

The case of Trokyap kingdom, a small principality on the fringes of the eastern Tibetan Kham region, exemplifies the situation in which more and more political entities, though relatively independent vis-à-vis Central Tibet, were being swallowed up by Chinese territory in the early twentieth century during the transition from an empire to a nation-state. Tibetan efforts to build a nation-state and to draw Kham into its new administration system are not even mentioned in the Trokyap archive file, and we do not know what the Tibetan government's opinion on this case was. The priority of the Chinese central government was to define the border territory and consolidate Xikang province. Any arguments regarding the ethnicity of the protagonists (Tibetan or Chinese), not to mention Sun Yat-sen's political thoughts on race equality, were ignored.

Caught up in the dispute between the two provinces, the Trokyap king attempted to retain his previous Manchu privileges and had little concern for whether the nation-state became Tibetan or Chinese. However, as his interests converged with those of the Chinese central authorities, he was the only one among the three local protagonists of this territorial dispute to actually take part in the state-building policy implemented by the new Chongqing government. In contrast, Sichuan and Xikang authorities sought to defend their own interests independently of their government policy. The king did not even consider acquiring autonomy, a status that Sun Yat-sen granted the border areas of China and which others in Kham tried to assert in vain. The fragmented organization of the Kham Tibetan province and its former organization into various kingdoms prevented the unification of the area. Had this been possible, it would have allowed the creation of a Kham Tibetan autonomous province, just as Inner Mongolia became autonomous in 1947. However, the subsequent creation by China of Tibetan autonomous prefectures and counties in the former Tibetan Kham province is a visible sign of today's recognition of the entire Tibetan territory and of its unity. 


\section{Glossary of Chinese terms}

$\begin{array}{ll}\text { Anfusi } & \text { 安撫司 } \\ \text { Bian dong dao } & \text { 邊東道 } \\ \text { Bian xi dao } & \text { 邊西道 } \\ \text { Boba renmin gonghe guo } & \text { 波巴尼共和國 } \\ \text { caizheng ting zhang } & \text { 財政廳長 } \\ \text { Chaha'er } & \text { 察哈爾 } \\ \text { Chengdu } & \text { 成都 } \\ \text { chifei } & \text { 赤匪 } \\ \text { Chonghua } & \text { 崇化 } \\ \text { Chonghua tun } & \text { 崇化屯 } \\ \text { Chongqing } & \text { 重慶 } \\ \text { chongxing gailiu } & \text { 重行改流 } \\ \text { Chuan bian } & \text { 川邊 } \\ \text { Chuan bian dao } & \text { 川邊道 } \\ \text { Chuanbian tebie xingzheng quyu } & \text { 川邊特別行政區域 } \\ \text { Chuosi jiabu } & \text { 绰斯甲布 } \\ \text { Chuosijia tezhong bao'an daduizhang } & \text { 绰斯甲特种保安大队長 } \\ \text { Danba } & \text { 丹巴 } \\ \text { dao } & \text { 道 } \\ \text { Daofu } & \text { 道孚 } \\ \text { duban Chuan Dian bianwu dachen } & \text { 督辦川滇邊務大臣 } \\ \text { Du Dediao } & \text { 杜德塔 } \\ \text { Ere } & \text { 俄热 } \\ \text { fangqu } & \text { 防區 } \\ \text { fu } & \text { 府 } \\ \text { Fubian } & \text { 撫邊 } \\ \text { Fu Songmu } & \text { 傅嵩炑 } \\ \text { gaitu guiliu } & \text { 改土歸流 } \\ \text { Gansu } & \text { 甘肅 } \\ \text { Ganzi } & \text { 甘孜 } \\ \text { Gele desha gongheguo } & \text { 格勒得沙共和国 } \\ \text { gongshun tusi } & \text { 恭顺土司 } \\ \text { Hankou } & \text { 漢口 } \\ \text { Jehol } & \text { 热河 } \\ \text { Jiang Jieshi } & \text { 蔣介石 } \\ \text { Jinchuan } & \text { 金川 } \\ \text { Jinghua county } & \text { 靖化縣 } \\ \text { Jinsha } & \text { 金沙 } \\ & \end{array}$




\begin{tabular}{|c|c|}
\hline junzhang & 軍長 \\
\hline Kangding & 康定 \\
\hline Kongsa & 孔薩 \\
\hline Liu Wenhui & 劉文輝 \\
\hline Liu Xiang & 劉湘 \\
\hline Luhuo & 爐霍 \\
\hline Maogong & 杽功 \\
\hline Maogong zhili ting & 榻功直隷廳 \\
\hline Nanjing & 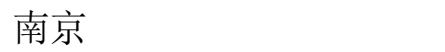 \\
\hline Nei zheng bu & 内政部 \\
\hline Ningjing mountains & 寧静山 \\
\hline Outuo & 歐拖 \\
\hline Qing & 清 \\
\hline Qinghai & 青海 \\
\hline sheng & 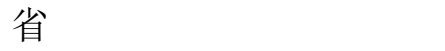 \\
\hline Sheng shi xian kan jie tiaoli & 省市縣勘界條例 \\
\hline shixi Han guan zhizhi & 世袭漢官之職 \\
\hline shixiyange & 世袭沿革 \\
\hline Sichuan & 四川 \\
\hline $\begin{array}{l}\text { Sichuan sheng shiliu qu xingzheng } \\
\text { ducha zhuanyuan }\end{array}$ & 四川省十六區行政督察专員 \\
\hline Sigerangjia canyiri lejianzan & 四格攘甲参一日勒堅賛 \\
\hline Suijing & 绥靖 \\
\hline Suijing tun & 绥靖屯 \\
\hline Suiyuan & 綏遠 \\
\hline Sun Yat-sen & 孙中山 \\
\hline tebie xingzheng quyu & 特別行政區域 \\
\hline ting & 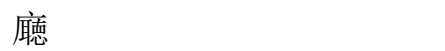 \\
\hline tusi & 土司 \\
\hline Wuhan & 武漢 \\
\hline Xikang & 西康 ～～～～～～～～～～ \\
\hline Xikang dangwu te paiyuan & 西康黨物特派員 \\
\hline Xikang jian shengji & 西康建省記 \\
\hline Xikang jian sheng weiyuan hui & 西康建省委員會 \\
\hline Xikang tebie xingzheng qu & 西康特別行政區 \\
\hline Xikang zhuanyuan & 西康专員 \\
\hline xingzheng ducha qu & 行政督察區 \\
\hline Xingzhengyuan & 行政院 \\
\hline Xizang & 西藏 \\
\hline xuanfusi & 宣撫司 \\
\hline
\end{tabular}


Ya'an

Yan Guangxi

Yangzi jiang

Yuhua Company

Zhao Erfeng

Zhou Wenzao
雅安

燕光熙

揚子江

玉华公司

趙爾豐

周文藻

\section{Glossary of Tibetan terms}

\begin{tabular}{ll} 
Amdo & A mdo \\
Bathang & 'Ba' thang \\
Böpa & Bod pa \\
Bön & Bon \\
Chakla & Lcags la \\
Choktsé & Cog tse \\
Chuchen & Chu chen \\
Dartsedo & Dar rtse mdo \\
Drakteng & Brag steng \\
Dzamtang & 'Dzam thang \\
Dzigak & Rdzi 'gag \\
Géshitsa & Dge shis tsa \\
Gomé & Mgo smad \\
Gotang & Mgo thang \\
Gotö & Mgo stod \\
Gyelkha & Rgyal mkha \\
Gyelmorong & Rgyal mo rong \\
Kandzé & Dkar mdzes \\
Kelsang Gyeltsen & Bskal bzang rgyal mtshan \\
Kelzang Tsering & Bskal bzang tshe ring \\
Kham & Khams \\
Kongsa & Khang gsar \\
Lawang Norbu & Lha dbang nor bu \\
Lunggu & Lung dgu \\
Muchi & Mu phyi \\
Ngari & Mnga' ris \\
Okzhi & 'Og gzhi \\
Pawang & Dpa' dbang \\
Murdo & Dmu rdo \\
Rongdrak & Rong brag \\
\hline
\end{tabular}




$\begin{array}{ll}\text { Shargyelmo Tsawarong } & \text { Shar rgyal mo tsha ba rong } \\ \text { Somo } & \text { So mo } \\ \text { Tenpa } & \text { Bstan pa } \\ \text { Trokyap } & \text { Khro skyabs } \\ \text { Tsang } & \text { Gtsang } \\ \text { Tsenla } & \text { Btsan lha } \\ \ddot{U} & \text { Dbus } \\ \text { ulak } & \text { 'u lag }\end{array}$

\section{References}

Aba Zangzu zizhizhou gaikuang bianxiezu 阿坝藏族自治州概况编写组. 1985.Aba Zangzu zizhizhou gaikuang 阿坝藏族自治州概况 (Overview of the Autonomous Prefecture of Aba). Chengdu: Sichuan minzu chubanshe.

Coleman, William. 2002. 'The Uprising at Batang: Khams and its Significance in Chinese and Tibetan History'. In Khams pa Histories: Visions of People, Place and Authority, edited by Lawrence Epstein, 31-56. Leiden: Brill.

Dreyer, Edward L. 1995. China at War 1901-1949. London: Longman.

Epstein, Lawrence, ed. 2002. Khams pa Histories: Visions of People, Place and Authority. Leiden: Brill.

Epstein, Lawrence and Peng, Wenbin. 1999. 'Ganja and Murdo: The Social Construction of Space at Two Pilgrimage Sites in Eastern Tibet'. In Sacred Spaces and Powerful Places in Tibetan Culture, edited by Tony Huber, 322-342. Dharamsala: Library of Tibetan Works and Archives.

Fitzgerald, John. 1999. 'Administration and Autonomy: A History of Bureaucratic Provincialism in $20^{\text {th }}$ Century China'. In Imagining China: Regional Division and National Unity, edited by Shu-min Huang and Cheng-Kuang Hsu, 91-132. Taipei: Institute of Ethnology (Academia Sinica).

Ganzi Zangzu zizhizhou gaikuang bianxiezu. 甘孜藏族自治州概况编写组. 1986. Ganzi Zangzu zizhizhou gaikuang 甘孜藏族自治州概况 (Overview of the Ganzi Autonomous Prefecture). Chengdu: Sichuan minzu chubanshe.

Gong Yin 龚荫. 1992. Zhongguo tusi zhidu 中国土司制度 (The System of Native Office in China). Kunming: Yunnan minzu chubanshe.

Herman, John E. 1997. 'Empire in the Southwest: Early Qing Reforms to the Native Chieftain System'. Journal of Asian Studies 56 (1): 47-74.

Jagou, Fabienne. 2006. 'Vers une nouvelle défınition de la frontière sino-tibétaine: la Conférence de Simla (1913) et le projet de création de la province chinoise du Xikang'. Extrême-Orient Extrême-Occident, Special Issue 'Desseins de frontières' 28: 147-167. 
Jagou, Fabienne. 2009. 'Liu Manqing: A Sino-Tibetan Adventurer and the Origin of a New Sino-Tibetan Dialogue in the 1930s'. Revue d'études tibétaines 17: 5-20. Jagou, Fabienne. 2011. The Ninth Panchen Lama (1883-1937), A Life at the Crossroads of Sino-Tibetan Relations. Chiang-Mai: EFEO/Silkworm.

'Jam dpal chos kyi bstan 'dzin 'phrin las, and Tashi Tsering. 1980. 'Dzam gling rgyas par bshad pa thag ring gsal bar mthong byed durba na, Or, 'dzam gling chen po'i rgyas bshad snod bcud kun gsal me long: The Rare 1830 Redaction of the Monumental Tibetan Work on the Geography of the World. Delhi: Ngawang Sopa [Translated in bTsan-po Bla-ma and Wylie, The Geography of Tibet.]

Kapp, Robert A. 1973. Szechwan and the Chinese Republic, Provincial Militarism and Central Power, 1911-1938. New Haven: Yale University Press.

Li Hou'an 李厚安 [testimony transcribed by Li Zhongkang 李仲康]. 1984. 'Zhuosijia tusi yu Guomindang difang zhengfu 绰斯甲土司与国民党地方政府' (The Local Chieftain of Trokyap and the G.M.D. Government). Aba Zangzi zizhu zhou wenshi ziliao xuanji 阿坝藏族自治州文史资料选辑, 1: 44-50.

Lin Hsiao-ting. 2006. Tibet and Nationalist China's Frontier: Intrigues and Ethnopolitics, 1928-49. Vancouver: University of British Columbia Press.

Leibold, James. 2005. 'Un-mapping Republican China's Tibetan Frontier: Politics, Warlordism and Ethnicity along the Kham/Xikang Borderland'. The Chinese Historical Review 12 (2): 167-201.

Leibold, James. 2007. Reconfiguring Chinese Nationalism. How the Qing Frontier and its Indigenes Became Chinese. New York: Palgrave Macmillan.

Liu Xiaoyuan. 2004. Frontier Passages: Ethnopolitics and the Rise of Chinese Communism, 1921-1945. Stanford: Stanford University Press.

Liu, Ziqian 劉自乾. 1944. Jianshe xin Xikang shi jiang 建設新西康十講 (Ten Discourses about the Construction of the New Xikang). Unknown place of publication: Jian Kang shuju.

McGranahan, Carole. 2003. 'Empire and the Status of Tibet: British, Chinese and Tibetan Negociations, 1913-1934'. In History of Tibet, edited by Alex McKay, 267-295. London: Curzon.

Peng, Wenbin. 2002. 'Frontier Process, Provincial Politics and Movements for Khampa Autonomy during the Republican Period'. In Kham pa Histories: Visions of People, Place and Authority, edited by Lawrence Epstein, 57-84. Leiden: Brill.

Que Dan 雀丹. 1995. Jiarong Zangzu shi zhi 嘉线藏族史志 (Historical Monography of Gyalrong). Chengdu: Sichuan minzu chubanshe.

Relyea, Scott. 2015a. 'Conceiving the "West”: Early Twentieth-Century Visions of Kham'. Modern China 4 (3):181-200.

Ren Naiqiang任乃強. 1933. Xikang tujing (jingyu pian) 西康圖經 (境域篇) (An Illustrated History of Xikang: Territories Section). Shanghai: Nantian shuju. 
Sperling, Elliot. 1976. 'The Chinese Venture into K'am, 1904-1911, and the Role of Chao Erhfeng'. Tibet Journal 1 (2): 10-36.

Travers, Alice. 2015. 'The Tibetan Army of the Ganden Phodrang in Various Legal Documents (17th-2oth Centuries)'. In Secular Law and Order in the Tibetan Highland: Contributions to a Workshop Organized by the Tibet Institute in Andiast (Switzerland) on the Occasion of the 65th Birthday of Christoph Cüppers from the 8th ofJune to the 12th ofJune 2014, edited by Dieter Schuh, MONUMENTA TIBETICA HISTORICA, Abteilung III Band 13, Andiast, IITBS GmbH, p. 249-266. Travers, Alice. 2016. 'The Lcags stag dmag khrims (1950): A New Development in Tibetan Legal and Military History?'. In Social Regulation: Case Studies from Tibetan History, edited by Jeannine Bischoff and Saul Mullard, 99-125. Leiden, Brill. Wang, Xiuyu. 2011. China's Last Imperial Frontier: Late Qing Expansion in Sichuan's Tibetan Borderlands. Plymouth: Lexington Books.

$\mathrm{Wu}$, Yongzhang. 吴永章. 1988. Zhongguo tusi zhiduyuanyuan yu fazhan shi 中国 土司制度渊源与发展史 (The Origins of the Local Chieftain System in China and Its Development). Chengdu: Sichuan minzu chubanshe.

Yudru, Tsomu. 2011. 'An Overview of Trokyap'. Unpublished manuscript.

Zhonghua Minguo xin ditu 中华民国新地图 (New Map of the Republic of China) (1943, Scale 1:250000o). Printed at the Survey of India offices (H.L.O.). First edition in 1936; reprinted with minor corrections in 1943 on two sheets.

\section{About the Author}

Fabienne Jagou (PhD Paris, École des Hautes Études en Sciences Sociales) is an historian and associate professor with habilitation at the École française d'Extrême-Orient (E.F.E.O.). She teaches at the École Normale Supérieure, Lyon. Her researches focus on the Sino-Tibetan political and cultural relations from the eighteenth century to the present. She is the author of Le ge Panchen Lama (1883-1937): Enjeu des relations sino-tibétaines (Paris: EFEO, 2004), published in English under the title The Ninth Panchen Lama (1883-1937): A Life at the Crossroads of Sino-Tibetan Relations (Chiang Mai: Silkworm/EFEO, 2011). She is the editor of 'Conception et circulation des textes tibétains', Cahiers d'Extrême-Asie ( $\left.\mathrm{n}^{\circ} 15,2005\right)$; co-editor (with Paola Calanca) of 'Border Officials', Sinologie française $\left(\mathrm{n}^{\circ} 12,2007\right.$, in Chinese) and editor of The Hybridity of Buddhism: Contemporary Encounters between Tibetan and Chinese Buddhism in Taiwan and the Mainland (Paris: EFEO, Coll. 'Études thématiques' $\left.\mathrm{n}^{\circ} 29,2018\right)$. Her forthcoming book is entitled: Gongga Laoren (1903-1997): Son rôle dans la diffusion du bouddhisme tibétain à Tä̈wan. 


\title{
11 The Rise of a Political Strongman in Dergé in the Early Twentieth Century
}

\author{
The Story of Jagö Topden
}

Yudru Tsomu

\begin{abstract}
This chapter discusses the emergence of a new elite class of 'political strongmen' in Kham in the late nineteenth and early twentieth centuries. The case of Jagö Topden demonstrates a shift from authority based on traditional hereditary and ascribed status to political recognition achieved through diverse political strategies, based on individual charisma, ambition, and consummate political skills. Unlike traditional forces in Kham, Jagö Topden had a relatively clear understanding of the general political situation of the time, and he appropriated new ideas for reforms. He formed alliances with various forces that contended for control of the region and adopted the regional identity of a united Kham. Ultimately, he emerged as the dominant figure to compete with the Dergé king.
\end{abstract}

Keywords: Jagö Topden, nationalism, Xikang, new elite, political strongmen, Dergé

\section{Introduction}

In the late nineteenth and early twentieth centuries, Kham polities were undergoing a period of upheaval and radical changes due to both exogenous and endogenous factors. The disruption fostered growing contention over the control of polities in Kham, a buffer zone between the larger political entities of Central Tibet and Qing China as well as an in-between area. As I have argued elsewhere (Tsomu 2015, 1), this

Gros, Stéphane (ed.), Frontier Tibet: Patterns of Change in the Sino-Tibetan Borderlands. Amsterdam, Amsterdam University Press 2019

DOI: 10.5117/9789463728713_CH11 
made Kham a contingent region, with a host of political, cultural, and economic complexities. ${ }^{1}$ During this period, the Kham region became a zone of contestation, resulting from the growing assertion of power and authority by both Qing and Nationalist China and the attempt to check the Chinese penetration by the Tibetan government (the Ganden Phodrang). The situation created political flux where belongings and allegiances of various polities in Kham were put to the test (Gros 2016, 209).

The struggle for authority was also endogenous, in that this period also saw a newly emergent elite that sought to wrest power from traditional hegemonic hereditary ruling families, i.e. families of the local gyelpo (king), depa (governor), or pönpo (chief), or from monasteries represented by religious leaders such as reincarnated lamas or khenpos (abbots). Part of this new group of leaders, the so-called 'modern educated elite'2 that had received a modern education, was well represented by Kelzang Tsering, the well-known Khampa official working in the Nationalist government. By climbing Kham society's traditional hierarchy thanks to their modern education, this elite group achieved upward social mobility and turned its attention toward a wider national stage and social changes. ${ }^{3}$ The new elite also included Khampa trader families such as the Pangdatsang in Markham, located in western Kham, west of the Drichu River (Ch. Jinshajiang). After having become part of a modern middle class that

1 I examine the geo-political situation of Kham at length in my book The Rise of Gönpo Namgyel in Kham: The Blind Warrior of Nyarong (2015).

2 I refer to the emergent elite in Batang as modern because they were different from the traditional elite in that they had received a modern education and had ventured beyond the traditional cultural milieu. This elite formed a close alliance with the Nationalists. Within less than five years, from November 1907 to June 1911, during gaitu guiliu (the policy of 'substituting chieftains with state appointed civilian officials'), over 200 schools were opened in the Sichuan borderlands. However, after the collapse of the Qing dynasty in 1912, except for schools in Luding (Chakzamkha), Kangding (Dartsedo), and Bathang, most of them stopped recruiting students. For details about the impact of modern education in Kham, refer to Zhang Jingxi (1939, 1-85); Wang Di (1986, 55-62); Lin Junhua (1993, 39-46, 17); Liu Xianqiang (2007, 90-95; 2008); Ma Tinzhong (2008, 68-74; 2012, 205-209); Xue Jiangang (2013, 1-54).

3 As officials in the Nationalist government, Kelzang Tsering and other Khampa elites who had received a 'modern education' were deeply influenced by ideals of social and political modernization. Their political ambition had also shifted beyond narrow local perspectives, and they were influential in shaping the Nationalist government's Tibet policies. They were also instrumental in initiating the 'Khampa rule of Kham' movement, which targeted the Sichuan warlord and encroachments on Kham by Central Tibetan troops. For details about the movement, see Peng Wenbin (2002, 57-84); You Zhen (2010, 104-108); Wang Juan (2013, 25-30); Luo Shaoming $(2015,1-5)$. 
had emerged in Lhasa, the Pangdatsang also began to become actively involved in local Kham politics and larger politics regarding Sino-Tibetan relations since the 1930 s. $^{4}$

In addition, former headmen, such as Jagö Topden in Dergé - a powerful kingdom in northern Kham - and others subordinate to aforementioned hegemonic traditional rulers such as gyelpo, pönpo, and depa rose to become dominant rulers in various regions of Kham. Some of these new authority figures replaced traditional hegemonic rulers. ${ }^{5}$ In contemporary sources these new political actors are referred to as jöntang chenpo, which literally means 'men of ability'. ${ }^{6}$ A man of ability is a term generally applied to a person capable of achieving success. However, in the case of Jagö, describing him simply as 'an able man' does not do him justice. He could be considered a 'great man', but the Tibetan term mi chenpo (literally meaning 'a person with high rank/status', i.e. great man) is usually equated with hereditary hegemonic rulers or people of noble birth. One of the secondary Tibetan sources describes Jagö Topden as a khadrak wangshechen, which literally means 'a person who is domineering/dictatorial' in Kham (Lodrö Püntsok 1994, 191). I consider that the indigenous term used to refer to Jagö comes very close to the English term 'strongman'. Thus, I will refer to these new political actors as 'strongmen', a coinage that also emphasizes that they are not from traditional hereditary families and constituted a newly emerging category of leaders in Kham politics. These 'strongmen' came to the fore in Kham politics by adapting to and negotiating with the broader political milieu. With initial support from a small coterie of like-minded followers, these men drew on their strong character, personal ambition, charisma, and ability to negotiate and 'collaborate' with power holders at

4 For the rise of the family and its role in the politics of Kham and Central Tibet, refer to Goldstein (1989, 180); McGranahan (2005, 253-274); Zhang Faxian (2011, 25-30, 138); Meilang Zongzhen [Mönlam Tsöndrü] (2005a, 15-21; 2005b, 50-55; 2009, 71-80); Tsomu (2016, 177-210); Galli, this volume.

5 After the collapse of Qing rule in 1912, except for a few low-ranking commanding Officers (zhangguan si) who restored their rule over remote areas in Lithang and Nyachukha (Yajiang), the Bathang and Lithang depas were unable to restore their authority; see Wu Fengpei $(1984,195)$. In southern Kham, in particular Chaktreng and Dabpa regions that used to be under Bathang and Lithang depas (governors), new political actors came to the fore after the collapse of Qing rule in 1912. These groups, consisting of former headmen who were subordinate to the traditional rulers, rose to fill the power vacuum after the traditional rulers were unable to restore their power.

6 For example, Jagö Topden is described as 'wise in political decision-making' (chapsi kyi chawar khedzang denpa) in Lodrö Püntsok et al. $(1995,191)$. Furthermore, Püntsok Wangyel portrays Jagö as namrik denpa, literally meaning 'the wise'; see Chung Tsering $(2006,83)$. 
different levels to build their power. Like certain former headmen, these strongmen distinguished themselves by their outstanding leadership and bravery in predatory raids against neighbouring areas and/or sometimes in military exploits against Nationalist troops stationed in local regions. Consequently, they emerged as the new ruling elite. ${ }^{7}$ Here it might be worthwhile comparing the local strongmen represented by Jagö Topden in Dergé in 1900 s with another strongman - Nyarong Gönpo Namgyel, who rose to become a dominant power in Nyarong and Kham in the mid-nineteenth century. These two shared similar traits - such as being strong-willed, very ambitious, charismatic, and capable of taking advantage of popular sentiment and of establishing a collaboration network with various forces. However, the latter rose to power under very different circumstances. At the time of the Gönpo Namgyel's ascendancy (1836-1865), external forces such as Qing China and Central Tibet were powerful but distant centers. In most cases, their control of various Kham polities was nominal, weak, and indirect. ${ }^{8}$ Affairs in Kham and those in various Kham polities were determined by the local context. This included Kham's social-political milieu, the local structure of authority, the local political culture - kinship loyalty, regional allegiance, moral and political commitments, worldview, as well as culturally specific values and beliefs such as machismo, honor, and revenge. ${ }^{9}$

This chapter examines the way political authority shifted in Kham in the early twentieth century through the case study of the rise of Jagö Topden, a charismatic headman who successfully challenged the power of the Dergé king in the early part of the twentieth century. The case of Jagö Topden is particularly revealing about Kham as a political territory and the shifting nature of authority and the growing legitimacy of Kham in the late nineteenth and early twentieth centuries. The situation in the 1920 , at the start of Jagö's ascendancy, was unlike the aforementioned circumstances in which Gönpo Namgyel ascended to power. In this later period, Kham found itself at the center of growing competition over its control between the Tibetan government in Lhasa, the Chinese Nationalist government, the Chinese warlord Liu Wenhui, and the Khampa elite that was striving for the 'Khampa rule of Kham' (Tib. Kangpé rangsi rangkyong

7 For details about these self-made strongmen in Chaktreng and Dabpa counties, refer to van Spengen (2002, 7-29); Qin Heping (2007, 1-9); Wang Haibing (2013, 69-74).

8 One exception to the general situation is the Qing control in Batang. For details, refer to Coleman (2014).

9 For details, refer to Tsomu $(2015,81-118)$. 
or Kangpé rangdé rangpön; Ch. Kangren zhi Kang). Thus, as a new emergent strongman with ambition, it was imperative for Jagö to strategize and operate not only in the confines of Dergé court politics but also to be cognizant of the broader politics of the Kham region, Central Tibet, and China. This case study shows the agency of the local elite in responding to the Chinese government's efforts to incorporate the contested Kham region as an inalienable part of Chinese national space. In doing so, it reveals the complicated interactions between local Chinese authorities and local society in the process of establishing a nation state in modern Chinese history.

This case study also demonstrates how the nature of authority based on traditional hereditary and ascribed status began to shift to the recognition of achieved status. In addition to the external forces discussed above, the challenge to traditional authority also came from indigenous strongmen and their reliance on personal charisma, ability, and ambition, as typified by Jagö. The latter's ascendancy resulted from the weakening of the Dergé king's power and authority due to increasing control by the Qing administration (following the gaitu guiliu policy) since 1909, and by the direct rule of a commander sent by the Central Tibetan government in 1918 following its military intervention. Through his personal ambition and political skills of aptly mediating and collaborating with various forces he rose to become an alternative focus of power in the 1930s and started to increasingly usurp the power and authority of the royal family following the death of the Dergé king, Tsewang Düdül (1916-1942). For the purpose of this chapter, I will first briefly introduce the Dergé polity and provide an overview of the court politics and decline of the Dergé royal family. Next, I will focus on how Jagö Topden gradually rose to prominence in Kham where there was constant strife and describe how he eventually became a dominant local force who was on a par with the Dergé king. Through his upbringing and education among children of aristocratic families in Lhasa, Jagö became familiar with the workings of the Lhasa government and with some Tibetan officials. Furthermore, his studies at the 'Institute of Public Security and Administration of Xikang' (Xikang bao'an xingzheng jiangxihui) run by Liu Wenhui in Dartsedo helped him not only to understand the Nationalist ideology and the working of the Chinese administration of Kham but also to embrace new ideas. All this experience forged his cosmopolitan view of the world and enabled him to have the upper hand. Astute and resourceful, Jagö took full advantage of various opportunities to establish formal and informal alliances with various forces as a means of extending his own power and authority. 


\section{The Authority of the 'Dergé Kingdom' and Its Decline}

\section{The Political Structure and Authority in Dergé}

Before any discussion can take place about the political competition that ensued in the late nineteenth and early twentieth centuries, a brief outline of the structure of the political system in Dergé needs to be given. Located in the river basin of the Upper Yangtze in northwestern Kham, the Dergé kingdom was believed to be the most densely populated area and the 'richest agricultural and manufacturing district of eastern Tibet' (Rockhill 1891, 227) (see Map 11.1). In the mid-eighteenth century, when Dergé was ruled by king Lodrö Püntsok, there were 25 districts with a total of 33 local chiefs/headmen (dzong go) and 43 nomadic tribes. ${ }^{10}$ Dergé could be described as a feudal state with a decentralized bureaucracy formed by a system in which land was granted to hereditary officials in exchange for administrative responsibilities.

Although the personalities and management methods might have changed during different periods, the core principle of the right of hereditary ruler remained constant. The highest levels of bureaucracy consisted of 200 aristocrats. Each of the four larger designated districts - Yilhung in the east, Garjé in the south, Drongpa in the west, and Sershül in the north - had a chief or head official/minister (nyerchen, literally 'the chief steward') who was selected from families of aristocratic retinue appointees (dünkörkhak/dünkör). These officials served on the highest secular political body in the king's court known as the Council of Ministers and Stewards (nyerchak lhengyekang). They were known as pöngozhi (four chief officials) or pönchenzhi (four great officials) (Tubten Püntsok 2010, 78). Together with the treasurer (chakdzö), secretary (drungyik), and chamberlain (zimpön), they formed the first rank of officials and resided mostly in the capital itself (Lhalung Chimé Dörjé and Dayang 2009, 49-50; Tubten Püntsok 2010, 78).

The second level of officials consisted of 33 local chiefs/headmen (dzong go) that headed the 25 districts (dzongkhak or dechok), who were also selected from among aristocratic retinue appointees and were mostly hereditary. ${ }^{11}$

10 Its domain included present-day Dergé, Pelyül, Sershül, and Jomda counties as well as the western part of Kandzé County.

11 Among the 33 local chiefs, four 'outer officials' (chipöngo) from four leading families retained power during most of Dergé's history. These four 'outer officials' were from Gamongna, Sokmotsang, Nyakshik Setsa, and Gojo Samdrup. These four officials were responsible for providing soldiers to protect Dergé borders when necessary. See Karma Gyeltsen (1994, 78-79). However, Tubten Püntsok calls them pöngosum; he also holds that Gamongna Sokmotsang should be one instead of two as listed in Karma Gyeltsen. See Tubten Püntsok (2010, 8o). 


\section{Map 11.1 Dergé at the Time of Jagö Topden}

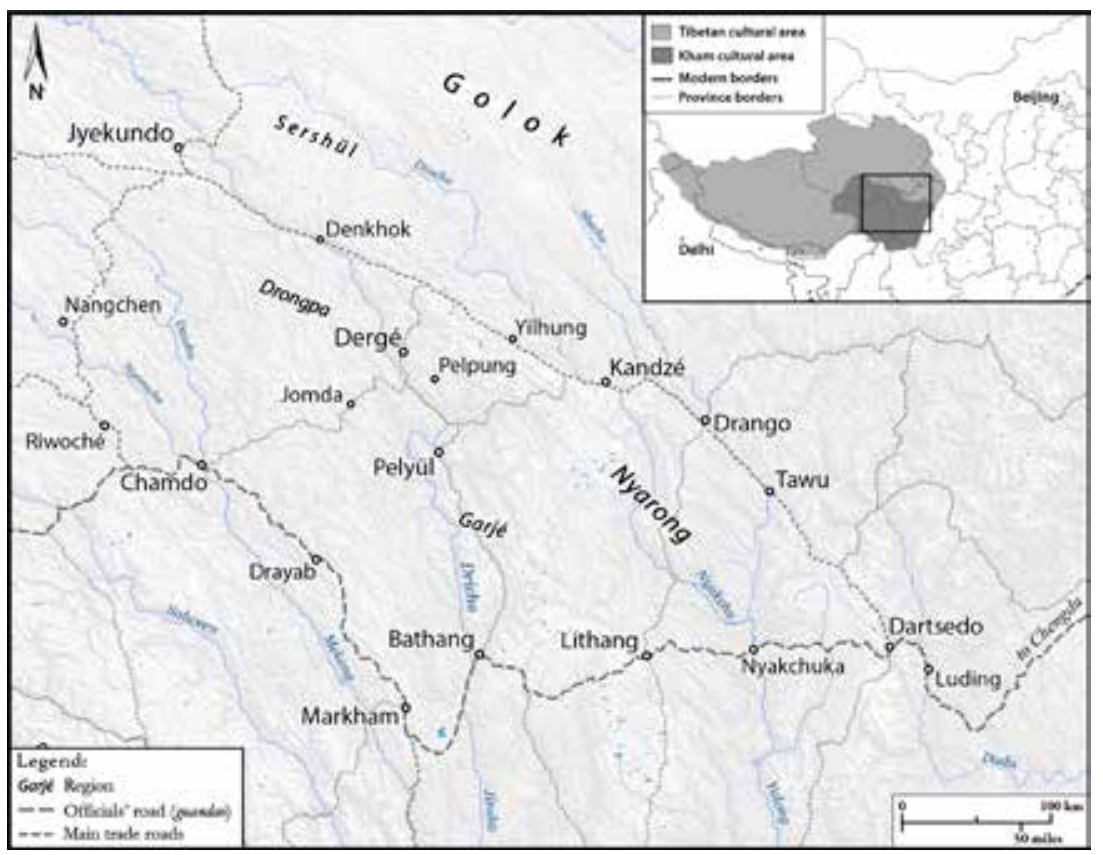

Sources: Based on SRTM (NASA) and modern administrative borders extracted from GADM database (www.gadm.org, v.2.5 July 2015)

Author: Rémi Chaix

The second strata of officials also included another 41 aristocratic retinue appointees. ${ }^{12}$

Lastly, the third rank of officials consisted of 8 o local representatives or village headmen (hördra), who functioned as the king's representatives or deputies responsible for administering corvée labour (ulak). ${ }^{13}$ Under the local representatives, there were leaders ( $\mathrm{gopa}$ ) who did not have an official rank. These leaders were chosen from among the common people to assist the local representative in collecting taxes, administering labour services, and requisitions. The first two ranks of officials were required to perform administrative services in Dergé's central government in exchange for the land granted to them by the king. However, except for the first rank of officials, most hereditary chiefs were not required to reside in the capital.

12 Tubten Püntsok states that there are 43 aristocratic retinues. For a detailed list, refer to Tubten Püntsok (2010, 86-89).

13 Tubten Püntsok lists 88 hördra. For details, see Tubten Püntsok (2010, 90-93). 
Thus, it was likely that chief officials/ministers (nyerchen), local chiefs (dzong go), or aristocratic retinue appointees (dünkörkhak) in Dergé set themselves up as territorial rulers on their own estates and became excessively powerful. Consequently, these hereditary chiefs and aristocratic retinue appointees maintained a high degree of local autonomy. The division of land among hereditary local chiefs resulted in alternative foci of power that could counter the authority of the king. This would make the king primus inter pares, if local districts became exceptionally powerful or allied with one another (Hartley 1997, 25).

The political system of the Dergé Kingdom is commonly portrayed as 'the alliance between secular and religious powers' to differentiate it from 'the merging of religion and politics' (Tib. chösi zungdrel; Ch. zhengjiao heyi), by later Chinese researchers (Du Yongbin 1989, 85-99; Zeng Wenqiong $1988,17-25)$. The royal family of Dergé, through close alliance with monastic hierarchs, assumed secular power and had religious power in its service. To balance the power of local hereditary chiefs, the kings accommodated and patronized monasteries of different traditions (Hartley 1997, 30, 38). Until the early nineteenth century, the king of Dergé usually served as the abbot of Lhundrupteng monastery, commonly known as Dergé Gönchen, which belonged to the Sakya school of Tibetan Buddhism. Yet, the royal family also kept close ties with chaplains (üla) from five head monasteries (ügön) that belonged to Nyingma and Kagyü traditions.

\section{The Decline of the Power and Authority of the Dergé King's Family}

Dergé had flourished as a cultural center with the patronage of the Dergé royal family and the Manchu court. In the late eighteenth century, the power and authority of the Dergé kingdom began to wane. The chief reason for its decline is worthy of a Shakespearian drama. The main source of discord involved rivalry for the throne within the royal family as well as competition for power between the king and his subordinate headmen. In 1790, as the Dergé prince Tsewang Dörjé Rikdzin (1786-1847) was still young, his mother, the dowager queen Tsewang Lhamo served as the regent (Ronis 2011, 61-81; Tubten Püntsok 2010, 50). During her reign (1790-1806/1808), ${ }^{14}$ Dergé battled with its northern neighbour Lingtsang, and the queen's rule was challenged by a number of lamas and aristocrats who were highly displeased with her. Eventually, war with the Kharnang tribe in Dzatö in 1808 forced her to leave

14 Though her son was enthroned in 1798, she ruled as before until 1806. See Tubten Püntsok $(2010,51)$. 
the capital (Tsewang Dörjé Rikdzin 1989, 100-101; Ronis 2011, 61-81). ${ }^{15}$ The king, who later authored The Genealogy of the Dergé Kings, ${ }^{16}$ was said to have taken no interest in governing, preferring instead to devote his time to religion by becoming a fully ordained monk in 1826 (Tubten Püntsok 2010, 52). ${ }^{17}$ The combination of internal strife and a disinterested king naturally undermined the power and authority of the kingdom. The situation barely improved during the reign of the eighteenth king, Damtsik Dörjé (1811-1853), from 1847 to 1853 . This weak king was unable to restore the authority of the royal family.

While internecine strife undoubtedly undermined the royal family's ability to assert control over the region, the situation was further aggravated by the emergence of Nyarong chief Gönpo Namgyel as the key figure on Kham's local political scene in the nineteenth century. ${ }^{18}$ Gönpo Namgyel's occupation of Dergé ${ }^{19}$ in the mid-nineteenth century forced the Dergé king, Chimé Tapei Dörjé (1840-1896), to seek military assistance from both the Qing and Lhasa authorities (Tsomu 2015, 169-172). However, help from Lhasa did not come without a price. Having defeated Gönpo Namgyel, Lhasa began to exert a certain degree of authority over the northern Kham region - including Dergé via the Tibetan High Commissioner's Office in Nyarong (Nyarong Chikhyap) in 1865-1866. Thereafter, the Dergé king's family forged a closer relationship with Lhasa authorities and the latter began to exert growing influence in Dergé. ${ }^{20}$

15 Dege xianzhi explicitly mentions that resentment towards the mother was caused by her impropriety in her private life and by unduly trusting the monks of Dzokchen monastery. It also recounts that in 1799, when the headmen failed to persuade the king's mother to return the political power to her son, they successfully mobilized armed forces to oust the royal mother and to crown the young thirteen-year-old king. However, as Jann Ronis (2011) convincingly argues, this was in fact a misreading of a passage in the Royal Genealogies about a ceremony for the crown prince, Tsewang Dorjé Rikdzin, which was performed in 1798. The Genealogy of the Dergé Kings written by the king himself clearly states that he did not take over the government until 1806 or 1808 . See Sichuan sheng Dege xianzhi bianzuan weiyuanhui $(1995,445)$.

16 The king wrote the work in 1828 , and its full title in Tibetan is Dpal sa skyong Sde dge chos kyi rgyal po rim byon gyi rnam thar dge legs nor bu'i phreng ba 'dod dgu rab 'phel bya ba.

17 In 1826 in the presence of Ngör khenchen Jampa Kunga Tendzin, he took the gelong (bhiksu, fully ordained with 253 precepts) vow and became a fully ordained monk. When the king was ordained, he was given the name Jampa Künga Sanggyé Tenpai Gyeltsen. He was considered to be a great scholar well versed in the teachings of Ngör sub-school of the Sakya school. See Tubten Püntsok $\left(2010,5^{2}\right)$.

18 For a more detailed study of the rise of Gönpo Namgyel, refer to Tsomu (2015).

19 At the time Dergé was ruled by its nineteenth king, Chimé Takpé Dörjé, who was only nine years old in 186o. To prevent the whole Dergé region from revolting against his rule, Gönpo Namgyel took the king, his mother, and local revered lamas as hostages to Nyarong. See Yelé Tsültrim (n.d., 26); Kongtrül Yönten Gyatso and Karma Trinlé (1997, 293).

20 For details about the authority of the Tibetan commissioner over Dergé, see Tsomu (2015, 224-26). 
By the 1870 , competition for power and authority between the Dergé king and his subordinate headmen - a common recurring theme in the history of Dergé since the late eighteenth century - reemerged. In particular, a weak king gave local chiefs (dzong go) ample opportunity to become foci of power to contest his authority. The intensification of internal unrest resulted from resentment on the part of the king's 30 chiefs (dzong go) toward the king for handing over a follower to the amban during their pilgrimage to Central Tibet in 1871. The follower was accused of killing a Chinese member of staff under the amban's responsibility; eventually he was executed by the latter. The king's action was probably interpreted as an act of cowardice and weakness. The event deepened the rift between the king and his subordinate chiefs. By the late 1870 , all 30 chiefs were believed to have increasingly defied the king (Ge Le 1984, 259; Sichuan sheng Dege xianzhi bianzuan weiyuanhui 1995, 471).

Furthermore, in the 1890 s, amidst the intense competition for power between the king and his subordinate headmen, great discord arose between King Chimé Tapei Dörjé and Queen Tseten Drölkar from the aristocratic family known as Ragashak in Lhasa, which led to an intense struggle between the king's two sons for succession to the throne. This plunged Dergé into factional politics which lasted until the 1940s. The two factions associated with the Dergé brothers - Dörjé Senggé (commonly known as Aja), who succeeded his father and his brother Ngawang Jampel Rinchen (commonly known as Baba), who received support from the queen - resorted time after time to their old strategies of seeking assistance and support from either successive Sichuan or Lhasa authorities. ${ }^{21}$ Late Qing Sichuan authorities and the Ganden Phodrang under the Thirteenth Dalai Lama had both launched projects to strengthen their control and authority in Kham. Both also actively participated in the succession struggles and attempted to settle their favored candidate on the throne (Lu Chuanlin 2001a, 467-470; 2001b, 474-479). ${ }^{22}$ In the end, with the support of General Zhao Erfeng, Dörjé Senggé was able to

21 For details about the Chinese official Zhang Ji's attempt to replace the Dergé king and his headmen with government-appointed officials by taking the king, the queen, and their two children to Chengdu, see Tubten Püntsok (2010, 56-57); Lodrö Püntsok (1994, 79-8o).

22 It is interesting to note that the Lhasa authorities seemed to have supported both candidates at one point or another, depending on their interests at a particular time. With the support of the Tibetan government, the two brothers were able to return to Dergé in 1897 after their parents had passed away in Chengdu in the previous year. The Tibetan government had Dörjé Senggé succeed to the Dergé throne. They also had him married to Sönam Tsomo, the daughter of an aristocratic family known as Nangsotsang from the Penpo area near Lhasa. See Tubten Püntsok $(2010,57)$. For instance, though the Tibetan troops stationed in Nyarong dispatched representatives and cavalry to Dergé in 1906 to support Ngawang's claim to the throne, the 
force his brother Ngawang and his followers to flee to Golok (Zhao Erfeng 2001, 504-505). Later, they followed the Thirteenth Dalai Lama to Central Tibet (Karma Gyeltsen 1994, 61; Ge Le 1984, 262; Baima Dengdeng and Xiake Zelang 2008, 189), where Ngawang was granted the title of theji of third rank ${ }^{23}$ and became an official of the Ganden Phodrang (Baima Dengdeng and Xiake Zelang 2008, 189; Sichuan sheng Dege xianzhi bianzuan weiyuanhui 1995, 472).

Meanwhile, when the Dergé kingdom underwent gaitu guiliu (the policy of 'substituting chieftains with state-appointed civilian officials') in 1909, Dörjé Senggé was granted the hereditary civilian position of $d u s i$ (commander) and took up residence in Bathang (Sichuan sheng Dege xianzhi bianzuan weiyuanhui 1995, 446). ${ }^{24}$ When the Qing collapsed in 1912, many indigenous kings, chieftains, and headmen in the Kham borderland re-established their rule at the time, with Dörjé Senggé also returning to Dergé. Chinese officials in Dergé continued to rely on Dörjé's authority to preside over the common people and the headmen in Dergé. He was given official titles such as 'the battalion commander of indigenous soldiers' (tubing yingzhang) and 'the commissioner in charge of the corvée labour and grain tax' (chailiang zongban) (Ren Naiqiang 2009, 186-187). In 1918 when Tibetan troops invaded Kham, they occupied Dergé. At that time, the Lhasa government escorted Dörjé Senggé and his wife to Central Tibet, placing them under house arrest (Ren Naiqiang 2009, 187; Sichuan sheng Dege xianzhi bianzuan weiyuanhui 1995, 16). Dörjé Senggé passed away in 1919 in Central Tibet, leaving a son and three daughters (Lodrö Püntsok 1994, 86; Tubten Püntsok 2010, 62; Lhalung Chimé Dörjé and Dayang 2009, 182).

\section{Jagö Topden's Rise to Power}

As we have seen, from the end of the nineteenth to the early twentieth century, the Dergé royal family was caught up in rivalry over the administration

Lhasa authorities also supported his brother Dörjé Senggé in fighting against Jampel. See Ma Guangwen (1990, 493-497); Sichuan sheng Dege xianzhi bianzuan weiyuanhui (1995, 472).

23 Theji was originally a Mongol title that referred to a prince and was similar to the Chinese term taizi (crown prince). It later became an official title with the third rank within the Tibetan government. The relevant accounts in Chinese about the title granted to Ngawang maintains he received the title of theji with the fourth rank, which seems to be based on oral sources and is because these authors do not know that the official with the title theji is the one with the third rank with the Tibetan government. Interestingly, Tubten Püntsok $(2010,60)$ simply states that Ngawang was given the official position with the fifth rank, without specifying the actual title. 24 His annual salary was 3000 taels of silver. See Sichuan sheng Dege xianzhi bianzuan weiyuanhui $(1995,446)$. 
of the kingdom. This resulted in decades of social unrest amidst growing contention for the control of Kham between the Ganden Phodrang and the Qing court as well as the successive Chinese regimes. It also created a conflict of interest among the elite and provided an opportunity for ambitious local figures to become alternative foci of power, usurping the power and authority of the royal family. One such figure was Jagö Topden, one of the Dergé dünkör (aristocratic retinue appointees).

\section{Jagö Topden's Family Background}

Jagö Topden was born in Hakhok in Dergé in 1901. His family had been very much involved in the internal wrangling within the Dergé royal family throughout the late nineteenth and early twentieth centuries. His grandfather, Jagö Pema Ledrup, served as chief steward at the Dergé king's court. ${ }^{25}$ Later, his father, Jagö Tashi Namgyel, inherited the position of the chief minister of Dergé and championed the cause of the younger Dergé brother, Ngawang. He was believed to have been poisoned by the faction supporting the elder Dergé brother, Dörjé Senggé, in 1906-1907 (Lodrö Püntsok 1994, 189; Lhalung Chimé Dörjé and Dayang 2009, 179; Tubten Püntsok, 2010, 58). Since Jagö Topden and his older brother Jagö Tsenam were too young to be chief minister of Dergé, his mother Tsewang Drölma inherited her husband's position and continued to be loyal to Ngawang's faction. ${ }^{26}$ Having been defeated by Dörjé Senggé's faction and the Qing troops under Zhao Erfeng in April 1909 (Zhao Erfeng 2001, 504; Sichuan sheng Dege xianzhi bianzuan weiyuanhui 1995, 14-15; Baima Dengdeng and Xiake Zelang 2008, 189), Tsewang Drölma, together with all her children, followed Ngawang and the Thirteenth Dalai Lama to Lhasa. They first settled in the Nakchu region in northern Tibet (Ge Le 1984, 262; Karma Gyeltsen 1994, 61; Baima Dengdeng and Xiake Zelang 2008, 189). As stated above, while Ngawang was granted the title of theji, the head of the Jagö family was appointed gopa (headman) of Janggyap in Nakchu region. Thereupon,

25 Pema Ledrup, known to be brave and resourceful, gained the king's trust for having rescued the king from Nyarong in the 1860 s. According to oral traditions, as he had directly intervened in the regent mother Chöying Zangmo's illicit affair with a subordinate headman, it was believed that the regent had poisoned him. For details about Jagö Pema Ledrup's role in bringing down Gönpo Namgyel and rescuing the king, see Tsomu $(2015,187,215)$.

26 Jagö Topden's mother was considered to be one of the three most powerful women during the period, popularly known as 'three demonesses of Kham'. The other two were the seventh chief of Khangsar Yangchen Khendro (also known as Khangsar Yangchen Drölma) and Gyari Chimé Drölma of Upper Nyarong. For details, refer to Tsomu (2018). 
they all became part of the Ganden Phodrang. ${ }^{27}$ In 1910-1911, Ngawang and his subordinates assisted the Lhasa troops to fight against the Qing troops in Gyantsé. Their bravery and outstanding performance in the fight against the Qing troops established their reputation and earned them recognition from the Thirteenth Dalai Lama. The Dalai Lama granted estates (zhika) to the Jagö and Drebö families near Sera monastery in Lhasa and near Yardrok Yumtso in Tsang, respectively. He also assigned over a dozen khölpa families to each of the two families (Baima Dengdeng and Xiake Zelang 2008, 191; Lhalung Chimé Dörjé and Dayang 2009, 179-180; Lodrö Püntsok 1994, 190).

The Jagö family's goal of restoring their authority in their home region in Dergé coincided with the period when the Lhasa government under the Thirteenth Dalai Lama was engaged in nation-building projects to extend their control and to strengthen their authority in Kham. With new-found patronage from the Dalai Lama, Tsewang Drölma made a great effort to restore her family's power and authority in Dergé. In 1918 when the Ganden Phodrang army seized Chamdo, at Tsewang Drölma's request the Thirteenth Dalai Lama wrote to Kalön Lama Jampa Tendar, Kham's high commissioner (Domé chikhyap), whose office was first established in 1913 (Tu Ga 2009, 164), demanding that Tibetan troops restore power to the Jagö family in Dergé and exempt the family from all corvée labour and taxes. Fearing the threat posed by Dörjé Senggé's faction, the Jagö family temporarily settled in Wangpotö to the west of the Drichu River. To ensure that her sons Jagö Tsenam and Jagö Topden would receive the best education, she took the farsighted action of sending them to Tsé Lopdra, a school that prepared the Lhasa aristocracy for service in the Ganden Phodrang. This training, which Jagö Topden completed within three years with excellent results, enabled him not only to become familiar with the Tibetan government's affairs and the situation in Central Tibet but also to become acquainted with future Ganden Phodrang officials (Lodrö Püntsok 1994, 190; Lai Zuozhong 1996, 97; Baima Dengdeng and Xiake Zelang 2008, 192; Lhalung Chimé Dörjé and Dayang 2009, 181). What happened later proves that this training was very useful for the Jagö family's restoration of their power and authority in Dergé (Lhalung Chimé Dörjé and Dayang 2009, 181; Baima Dengdeng and Xiake Zelang, 2008, 192; Lai Ziozhong 1996, 97). Since 1918, Lhasa troops had been occupying areas such as Dergé, Pelyül, Sershül, and Jomda - all

27 Having first fled to Golok, following a recommendation from Jamyang Zhepa, the head lama reincarnate of Labrang Trashikhyil, they sought refuge with warlords in Qinghai and temporarily settled in Tsolho (Ch. Hainan). With the assistance of Jamyang Zhepa, they followed the Thirteenth Dalai Lama to Central Tibet. 
under the rule of the Dergé king (Sichuan sheng Dege xianzhi bianzuan weiyuanhui 1995, 445-446; Baima Dengdeng and Xiake Zelang 2008, 192). By 1921, when Jagö Topden returned to Dergé as a headman, he became a useful ally for the Ganden Phodrang. In addition, his familiarity with Lhasa nobles and the Ganden Phodrang's strategies provided him with a secure footing in dealing with Lhasa and in his effort to restore his family's power and authority in Dergé. In 1926 Dörjé Senggé's son Tsewang Düdül (1916-1942) was authorized by Domé chikhyap to rule Dergé (Tubten Püntsok 2010, 62; Lodrö Püntsok 1994, 86). ${ }^{28}$ But military and political power was still controlled by the Dergé Commissioner's Office (Dergé chikhyap) that had been set up in 1918 and was headed by the dapön (the regimental commander) of Tibetan troops in Dergé. ${ }^{29}$ To restore his family's power, Jagö had to do his best to gain the support of the dapön of Lhasa troops stationed in Dergé. As Jagö was unable to forge a good relationship with regimental commander Chungrangpa, a Lhasa aristocrat, he had to settle for the position of minor headman (a common dünkör) (Lodrö Püntsok 1994, 190; Dengdeng and Xiake Zelang, 2008, 192; Lhalung Chimé Dörjé and Dayang 2009, 182). $3^{0}$

\section{The Gradual Rise of the Jagö Family}

Jagö's fortune changed when Khemé became regimental commander in 1929. They were old acquaintances from Lhasa, and Khemé entrusted Jagö with handling some important matters in Sershül and Pelyül. Jagö was not only shrewd, capable, and experienced, but also decisive in handling affairs; hence, he was able to win Khemé's trust. Around 1930, he was eventually

28 Tubten Püntsok $(2010,63)$ states that in 1919 the young king was enthroned by Domé chikhyap. Since he was only four years old, Situ rinpoché Pema Wangchok of Pelpung monastery served as regent. Furthermore, in 1926 the Thirteenth Dalai Lama's decree of enthroning Tsewang Düdül was shown at the assembly attended by the regiment commander of Tibetan troops stationed in Dergé, the king and all the officials under the king. This is probably the reason that the Gazetteer of Dergé (16) maintains that Tsewang was chosen to accede to the Dergé throne by the Thirteenth Dalai Lama in 1926.

29 According to an oral source, Dergé King Tsewang Düdül and others could only have had rather low living expenses, and even the 'tribute' paid by the various major and minor headmen all belonged to the Tibetan troops. See Lhalung Chimé Dörjé and Dayang $(2009,182)$.

30 At the time ministers in charge of the Office of Ministers and Stewards included Nyerchen Gyangkhang rinpoché, Hörcho Peldo, headman of Tsari called Tsari Nyergé, the Great Chamdzö Namsé Tsega, the Minor Chamdzö Wokma Sonam Tsering, and others. Later, the Great Chamdzö Namsé Tsega was removed from office for accepting bribes in Jomda. Wokma Sonam Tsering was promoted to Great Chakdzö. See Lhalung Chimé Dörjé and Dayang $(2009,182)$; Baima Dengdeng and Xiake Zelang $(2008,192)$. 
appointed chief minister (nyerchen) of the Dergé royal court under King Tsewang Düdül. With this appointment, Jagö had accomplished the first step of restoring his family's power in Dergé. He was said to be courageous, insightful, very eloquent, and good at socializing with all kinds of people. Jagö now positioned himself in the inner circle of the Dergé court and gradually consolidated his power.

Jagö also made great efforts to gain the trust of King Tsewang Düdül after the latter had regained control of Dergé in 1932. The Dergé royal family regained some stability with the support of the Ganden Phodrang. However, the Ganden Phodrang's position in regions east of the Drichu River had not been completely secured; hence, there was constant fighting between Lhasa and Chinese troops. In 1932 the two parties reached what became known as the 'Kamtok Agreement' (Kamtok dröchö/Kamtok dröching). According to this agreement Lhasa consented to withdraw its troops from the regions east of the Drichu River. ${ }^{31}$ Jagö managed to gain the king's trust, and he in turn appeared to be loyal to the king. He led forces to suppress the rebellion against the Dergé king by headmen from Hörpo and other areas in Pelyül (Sichuan sheng Dege xianzhi bianzuan weiyuanhui 1995, 19; Lai Zuozhong 1996, 98).

Although the Lhasa government had withdrawn its troops from the Kham region, including Dergé, it continued to seek to levy grain taxes from Jomda, the regions to the west of the Drichu River that remained under the Dergé king's authority. As Jagö began to mobilize the local populace against the Ganden Phodrang's authority (Lodrö Püntsok 1994, 191; Lai Zuozhong 1996, 98; Lhalung Chimé Dörjé and Dayang 2009, 179; Chengdu junqu silingbu 1957, 6), the people of Dergé recognized him as an able and loyal minister of the Dergé court..$^{22}$ The king also came to be dependent on him to carry out many of the affairs of the court.

The aforementioned actions show that Jagö was fully aware that his own position in Dergé at that time depended on the king's patronage. In the meantime, Jagö also fully understood that he would not be able to

31 At that time Tsewang Düdül was seventeen years old and was appointed to positions such as Supervising Official in Charge of the Militia Affairs of the Five Counties including Dergé, Pelyül, Denkhok, Sershül and Battalion Commander of the Indigenous Troops by the Dergé County government under Liu Wenhui's control. Like any other government-appointed official, he was given a monthly salary. Jagö Topden and others also arranged to have Tsewang Düdül take the daughter of the Nangchen king named Jamyang Pelmo as his wife.

32 Many years later, in 1945 or 1946, he also incited the local people in Jomda to the west of the Drichu River to refuse to pay grain taxes to the Lhasa government. See Lai Zuozhong (1996, 98) and Chengdu junqu silingbu $(1957,6)$. 
totally secure his position in the king's court without a strong power base in Dergé itself - especially when key subordinate headmen under the Dergé king were competing for the position of head of the Office of Ministers and Stewards in Dergé. To further consolidate and expand his power base, like many other elites in Kham, Jagö resorted to the common strategy of forming matrimonial alliances. In 1933, he married Sönam Chömtso, the daughter of the Lhari chief Kelzang Püntsok in Yilhung, who was powerful and ruled over 1000 households (Lai Zuozhong 1996, 98; Baima Dengdeng and Xiake Zelang 2008, 192-193; Lhalung Chimé Dörjé and Dayang 2009, 183; Lodrö Püntsok 1994, 151-152).33 After the Lhari chief's only son died in a riding accident, he soon controlled the region itself. Later, one of his sons-in-law, Pomkha Namgyel Dörjé, served as commander-in-chief of Yilhung (Lhalung Chimé Dörjé and Dayang 2009, 184). In addition, he also arranged for some of his relatives and his trusted followers to establish marriage alliances with families of powerful headmen in Dergé as well as with Khangsar and Mazür chieftain families in Kandzé. ${ }^{34}$

\section{Jagö Topden and the 'Khampa Rule of Kham' Movement}

In the mid-1930s Jagö was quick to grasp the political situation in inland China, and fully understood the significance of the political developments. His appreciation of Chinese politics differentiated him to some degree from other more conservative traditional Khampa elites who were ill-informed of the dramatic changes taking place in China at the time. With political aspirations that went beyond simply restoring his family's authority and position in Dergé, he began to turn to larger affairs relevant to the entire Kham region. Extending his interest and participation in political activities outside of Dergé, he became one of the key political figures in Kham.

In 1935 Jagö became actively involved in the 'Khampa rule of Kham' movement launched by Gara Lama (also known as Nörla Hutuktu), an

33 See Lai Zuozhong (1996, 98); Baima Dengdeng and Xiake Zelang (20o8, 19-23); Lhalung Chimé Dörjé and Dayang (2009, 183); Lodrö Püntsok (1994, 151-152). Jagö Topden took two daughters of the Lhari chief as his wives. See Genzao Fashi and Mixian Fashi (1995, 30).

34 Jagö Topden also established a good relationship with important people from other regions by arranging marriage alliances between his trusted followers and other powerful chiefs and headmen. He had Juchung Tsedör of Juchung family become the son-in-law of the Khangsar chief's family in Kandzé; he had Jamga of Dimgo family become the son-in-law of the Atup Lakartsang family; and he had Rapga of the Zhingmo family marry into the family of Mazür chief in Kandzé. Thus, he had the support of chiefs and headmen in Kandzé. See Lhalung Chimé Dörjé and Dayang (2009, 184-185); Lai Zuozhong (1996, 98). 
influential lama from Riwoché monastery who harbored the ambition of driving both Lhasa troops and the warlord Liu Wenhui's troops out of Kham. In the 1930s, Khampa elites began to oppose interference from the Ganden Phodrang and the Nationalist authorities and also to promote the idea of self-rule for Khampas. Launched in 1932 by Kelzang Tsering, a representative of the modern 'educated elite', the movement strove for local autonomy with the aim of creating a unified Kham identity by asserting local power based on ethnicity. This represented a major strategy for Khampa elites to assert their influence in regional affairs. In 1935, when Gara Lama was dispatched by the Nationalist government to block the advance of the Red Army in Kham, he summoned powerful figures from various regions of Kham to Dartsedo (Kangding) to an assembly in which Jagö Topden participated (Jiang Anxi et al. 1983, 65; Feng Youzhi 1994, 145). Deeply attracted by the Gara Lama's idea of local autonomy, Jagö regarded 'the Khampa rule of Kham' movement not only as a means to restore the stability of Kham but also as a way to enable the Kham region to avoid interferences from both the Ganden Phodrang and the Nationalist government. According to the recollection of his brother, Jagö Tsenam, during the aforementioned assembly convened by Gara Lama, Jagö himself noted five guiding principles of 'implementing regional autonomy; striving for equality for all minzu; eliminating the ulak system; improving farming and herding techniques; and developing culture and education' and some tentative ideas and plans. ${ }^{35}$

At the beginning of 1936, Jagö, together with Pangda Topgyé, Gara Lama, and a key headmen under the Beri king in Kandzé known as Döndrup Namgyel (known as Deng Dejie in Chinese), secretly formed the group 'four harmonious friends' (tünpa pünzhi) to realize the political aspirations of the 'Khampa rule of Kham' movement that had been influenced by both Nationalists' and Communists' rhetoric. Jagö formed a close alliance with the Gara Lama and backed the latter's subordinates in killing Chen Rongguan, the Dergé Country magistrate; Zhang Ziyu, the Denkhok County magistrate; and others appointed by Liu Wenhui. However, the movement eventually had to be suspended due to the death of the Gara Lama. Nevertheless, Jagö Topden, Pangda Topgyé, and others continued to promote the 'Khampa rule of Kham' idea. However, the premise that Jagö would support and participate in the 'Khampa rule of Kham' movement was a guarantee that no external forces would interfere in the politics of Kham. This principle was reflected in how he dealt with another 'Khampa rule of Kham' movement launched by Panchen Lama's camp (zhükgar) and the Khangsar family in 
1939. Armed clashes broke out between the ninth Panchen Lama's camp and the Khangsar family on the one side and troops under the Chinese warlord Liu Wenhui stationed in Kandzé on the other side. The former, in the name of openly advocating 'the Khampa rule of Kham', sought military assistance from Jagö and the Dergé king, but Jagö refused to be involved in the conflict. Even though the ninth Panchen Lama's camp had appointed magistrates in Kandzé, Nyarong, and Drango counties, they were unable to interfere in Dergé affairs (Lhalung Chimé Dörjé and Dayang 2009, 191-192; Tsewang Düdül 1990, 492; Jagö Topden 1990, 492). This fully attests to the status and power that Jagö enjoyed at the time in Kham.

Jagö's stand during this period is noteworthy. Earlier he had actively supported Gara Lama's 'Khampa rule of Kham' movement and his military actions to oust the Chinese warlord Liu Wenhui's troops. For a number of reasons, Jagö began to shift his allegiance. First, Jagö changed his perception of the strength of Liu Wenhui's troops and understood that it was very difficult to dislodge them. Second, he was unwilling to jeopardize, as shown in the next section, his newly established ties with Liu Wenhui. Another reason for Jagö's distancing himself from the 'Khampa rule of Kham' movement was that he did not want Panchen Lama's camp to be the paramount force in northern Kham. In accordance with Püntsok Wangyel's recollection, like Kelzang Tsering, Jagö also viewed Khampas as a different ethnic group from Tibetans who lived to the west of Drichu River.$^{36} \mathrm{He}$ did not like the conduct and deeds of Lhasa aristocrats and of the Ganden Phodrang troops in Kham. In his view, when the Dergé chikhyap ruled Dergé at the beginning of the twentieth century, central Tibetans were regarded as the oppressors of Khampas (Goldstein et al. 2004, 54).

\section{Jagö Topden's Connection with the Red Army}

The Red Army's journey through the Kham region during their 'long march' provided Jagö with an opportunity to come into contact with and to learn about the Red Army's view points and policies. When the Red Army reached Tawu, Drango, and Kandzé in the spring of 1936, Jagö was dispatched by the Dergé king to Kandzé to block their advance (Lhalung Chimé Dörjé and Dayang 2009, 188; Lai Zuozhong 1996, 98-99; Zhonggong Ganzi zhouwei dangshi yanjiushi 2012, 185). ${ }^{37}$ Dergé forces were defeated by the Red Army,

36 The term mirik in Tibetan can be translated either as 'nationality' or 'ethnic group'.

37 Other officials include Wokma Chamdzö Sönam Tsering, Nyerchen Lodrö Jamyang, Drumo Tubten, Dekha Chimé. See Lhalung Chimé Dörjé and Dayang (2009, 188). 
and Jagö was injured and captured (Baima Dengdeng and Xiake Zelang 2008, 194; Lhalung Chimé Dörjé and Dayang 2009, 188). $3^{8}$ It appears that Jagö was well treated by the Red Army, and Li Xianian himself, the political commissar of the No. 30 Red Army met with Jagö (Li Xiannian zhuan bianxiezu deng 2011, 136; Lai Zuozhong 1996, 99; Zhonggong Ganzi zhouwei dangshi yanjiushi 2012, 186). The commander-in-chief of the Red Army, Zhu De, also met with Jagö, introducing to him the Communist Party's policies toward minzu and religion as well as its political opinions. While captive, Jagö sent a letter in Tibetan to the Dergé king, asking the king not to oppose the Red Army. He was later authorized by the Dergé king to sign a 'Non-Aggression Pact' with Wang Weizhou under the leadership of the Red Army representative Li Xiannian (Deng Junkang and Li Kunbi 2009, 1, 190; Lai Zuozhong 1996, 99; Zhonggong Ganzi zhouwei dangshi yanjiushi 2012, 186). In May 1936, under Zhu De's initiative, the Central Tibetan People's Government of the Chinese Soviet was established in the town of Kandzé, 39 and Jagö was elected as head of the military affairs department (Zhonggong Ganzi zhouwei zuzhibu 1991, 16-17; Den Junkang and Li Kunbi 2009, 19o; Zhonggong Ganzi zhouwei dangshi yanjiushi 2012, 187).$^{40}$ Without contemporary sources attesting to how the Khampa elites, including Jagö, understood the programme, it would be hard to determine whether the Kham elites genuinely believed in the Communists' vision or were simply being opportunistic. It seems clear, however, that the Khampa elites joined 'the Böpa Soviet' to oppose the warlord Liu Wenhui and the G.M.D. government rather than simply for the sake of an ideological conversion. Jagö and other Khampa leaders wanted Chinese Communist Party (C.C.P.) support to advance their own cause of achieving Kham self-rule. It is also possible that these Khampa elites were compelled to support the Red Army as the latter was the strongest military force at the time. ${ }^{41}$ Nonetheless, Jagö assisted Red Army soldiers and helped

38 Jagö Topden's troops mainly consisted of reincarnated lamas and monks from Gönchen monastery. They established their camp at Atup Ripuk in Rongpatsa; the forces under Wokma Chakdzö and Lodrö Jamyang set up their camp at Getok. The Red Army launched a surprise attack at night and defeated the Dergé forces. Wokma Chakdzö led his fleeing troops back to Dergé. See Lhalung Chimé Dörjé and Dayang $(2009,188)$.

39 The name of the soviet in Tibetan is krung hwa su'u we ed bod pa dbus sde pa mi dmangs srid gzhung, and in Chinese it is known as Zhonghua Suwei'an boba zhongyang renmin zhengfu.

40 For details about the Communists' visions for the pan-Tibetan organization and the Central Tibetan People's Government, refer to 'Guiding Principles of the Central Government of Tibetan People's Soviet' (Zhonggong ganzi zhouwei dangshi yanjiushi 2012, 112-113).

41 It seems that some of the Khampa youth, such as the educated Göngpo Tsering (Hai Zhengtao) and Trashi Wangchuk, who were appointed as directors in charge of military affairs, later became communists, and in particular Trashi Wangchuk, who joined the Red Army to travel north. 
the communists collect badly needed resources in Kham. It is reported that with Jagö's help the Red Army secured 400 yaks and 100 horses in the Kandzé area alone. He also provided guides and interpreters for the Red Army (Lai Zuozhong 1996, 99; Lhalung Chimé Dörjé and Dayang 2009, 190).42 Jagö's strong ties with the Communists and his ability to mediate between the Communists and Khampas enhanced his fame among both (Lhalung Chimé Dörjé and Dayang 2009, 189-19o; Lai Zuozhong 1996, 98-99; Baima Dengdeng and Xiake Zelang 2008, 194). ${ }^{43}$

\section{Jagö Topden's Relationship with Liu Wenhui}

After the Red Army had left the region, the Sichuan warlord Liu Wenhui began to reassert his power, and he had many reasons for targeting Jagö. He resented Jagö's involvement with Gara Lama, and Jagö's increasingly close contact with the Communists. In 1937, fearing that Liu Wenhui would retaliate against him, Jagö made plans to flee to Central Tibet. Liu Wenhui fully understood the importance of benefiting from the support of the Dergé king and other indigenous chieftains and headmen to ensure stability in Kham. Thereupon, he dispatched Fan Changyuan, Pelyül County magistrate, to meet with the Dergé king and his ministers. It was said that Fan brought a message from Liu that sought to win over the king and his ministers (Deng Junkang and Li Kunbi 2009, 190; Lhalung Chimé Dörjé and Dayang 2009, 190). Liu declared that he would not take action against those who had rallied behind Gara Lama in his attempt to drive Liu's forces out of Kham. It appears that the king was convinced by Liu's message, and he urged Jagö to apologize to Liu Wenhui in person (Lhalung Chimé Dörjé and Dayang 2009, 190; Lai Zuozhong 1996, 98-99). Although the situation appeared to be humiliating to Jagö, he was able to turn it round in his favour. The meeting between Jagö and Liu in Dartsedo provided an opportunity for Jagö to establish a personal relationship with Liu. ${ }^{44}$

\footnotetext{
42 It is interesting to note that the article written by Deng Junkang and Li Kunbi states that Jagö Topden gave 150 yaks, over 50 horses, and some grain to the Red Army. The amount mentioned in Lai Zuozhong's article is somewhat different, and it is possible that the amount provided in Deng Junkang and Li Kunbi's article refers to the amount provided by Jagö Topden himself. See Deng Junkang and Li Kunbi (2009, 190).

43 To block the advance of the Red Army, in 1936 the forces of the Qinghai warlord Ma Bufang also began to station in Dergé, Denkhok, Pelyül, and Sershül. This caused the Dergé king and his family to flee to Jomda west of the Drichu River.

44 They blamed Gara Lama for killing the magistrates of Dergé and Denkhok (Lhalung Chimé Dörjé and Dayang 2009, 190).
} 
Having realized the growing influence of Liu Wenhui in Kham compared to the declining authority of the Ganden Phodrang, Jagö saw the need to establish strong ties with Liu and also to become familiar with viewpoints of various Chinese authorities in Sichuan province. Thereupon, in 1938 Jagö attended the 'Institute of the Public Security and Administration of Xikang' (Xikang bao'an xingzheng jiangxihui) run by Liu Wenhui in Dartsedo. The institute was a modernist project aimed at bringing in local leaders for training in what were regarded as modern administrative skills. Although all local Khampa leaders were encouraged to attend the institute, they usually sent their servants or subordinate officials for training instead. Demonstrating his willingness to forego status and to actively learn modern knowledge, Jagö was the only senior leader who attended it (Ren Naiqiang $2009,188)$. His participation proved to be beneficial. Not only did he begin to learn Chinese, but his time at the institute also provided firsthand contact with emerging Chinese officials in Kham.

In 1939, Liu Wenhui became the chairman of the newly established Xikang province, which comprised the region of Chuankang (the Kham region in Sichuan province), the No. 18 administrative region of Sichuan province (the Xichang Yi region), and the No. 15 administrative region of Sichuan province (Ya'an). As a way of coping with Japanese attempts to invade Sichuan, Xikang province was established thanks to efforts to promote the construction of the area under G.M.D. rule far from the battlefront during the Anti-Japanese War of Resistance. As a result, Liu Wenhui began to further strengthen Kham's political rule, integrating more and more former indigenous chieftains and headmen in its administrative system. Impressed by Jagö's attitude and actions, Liu Wenhui appointed him deputy commander of the Xikang Special Public Security Brigade (xikang tezhong bao'an fu duizhang): this office gave Jagö the same rank as the Dergé king in the administration and made him one of the most powerful figures in Kham. Liu was later informed by Dergé County magistrate that Jagö could not occupy the same position as the king. The king was, therefore, given the title of regional deputy commander (Qu fuzhihui). On the surface, it seemed that power rested with the Dergé king, but Jagö Topden was the one who wielded the real power. This was demonstrated not only by outside groups negotiating with him but also, increasingly, by local people beginning to view him as such (Ren Naiqiang 2009, 188). Jagö's role and status in Liu's administration of Kham grew quickly. He occupied positions such as Councilor of Xikang Province (Ch. Xikang sheng canyiyuan) and Head Councilor of Dergé County (Dege xian canyizhang), etc. (Lhalung Chimé Dörjé and Dayang 2009, 190-191). Jagö accordingly made great efforts to implement all Xikang Provincial 
government's decrees and ordered the children of his family and relatives to take the lead in enrolling in Chinese schools in the region. All Chinese officials who had any contact with Jagö were believed to have praised him highly, and in Kham he enjoyed a great reputation (Ren Naiqiang 2009, 188).

Another means used by Jagö Topden to expand his power and authority was to join the Nationalist Party, ${ }^{45}$ and his action coincided with the period when the Nationalist Central Committee was making great efforts to extend the Nationalist Party's influence in Kham. After the Chinese warlord Liu Xiang, Chairman of Sichuan province, passed away in 1938, Chiang Kai-shek and Zhang Qun governed Sichuan successively. With efforts to control Sichuan and Kham, and to weaken the power holders in these regions intensifying after the creation of Xikang province in 1939, they took the measure to recruit new party members among the local elite and to establish Nationalist Party committees at provincial and county levels. Under the circumstances, Jagö also began to form a close association with other Khampas in the G.M.D., such as Pangda Topgyé, Kelzang Yeshé, Kelzang Chönjor (also known as Liu Jiaju, secretary-general of the ninth Panchen Lama's camp), and Döndrup Namgyel (Lai Zuozhong 1996, 99; Lhalung Chimé Dörjé and Dayang 2009, 191).

By 1940 Khampa politics became increasingly drawn into larger rivalries between the Communist and Nationalist Parties. Khampa elites were divided into three factional groups: those allied to the Nationalists, those in favor of the Communists, or those who sought to maintain the status quo and preserve local rulers. In particular, a new group of Khampas who allied with the Communists were those who had embraced new ideas and sought nothing less than total transformation of the social system. A notable example is Bapa Püntsok Wangyel, commonly known as Pünwang. He wrote: 'I began by developing a relationship with Chagö Tomden (Jagö Topden), one of the most famous aristocrats in Dergé. He was a member of one of the wealthiest and most powerful families and a top minister in the Dergé government. He had the ability to call up at a moment's notice an armed militia of hundreds [...]' (Goldstein et al. 2004, 53). Pünwang tried to wean Jagö away from Liu Wenhui, stating that Liu would not safeguard Dergé's independence. Liu's acceptance of Dergé's independence was merely temporary, as Liu had more pressing problems to deal with. Pünwang also began to propose a

45 Having been recommended for party membership by the Republican official Wan Tengjiao and the abbot of Nyintso (Nyatso; Nyi mtsho/Nya mtsho) Mawang Chöndzé (Machöwang; Mawur Chöndzé; Ma dbang chos mdzad/Ma chos dbang/Ma bur chos mdzad), Jagö joined the Nationalist Party. See Lai Zuozhong (1996, 99); Lhalung Chimé Dörjé and Dayang (2009, 191). 
new idea of establishing a pan-Tibetan movement that would encompass all Tibetan-speaking regions. Jagö was suspicious of the idea. Moreover, as Pünwang wrote, he had doubts about trying to dislodge the Chinese. He and his family would have a lot to lose by trying to expel the Nationalist troops and officials. He worried that if anything were done to remove the Chinese county government, more Chinese were sure to come into Kham' (Goldstein et al. 2004, 54-55). However, Jagö's falling out with Liu came from a more traditional form of political concern.

In 1942, King Tsewang Düdül passed away. The heir to the Dergé throne, Urgyenkyap (also known as Wuga), was only four years old. At the time, Jagö saw an opportunity to impose his choice of the candidate to the throne of Dergé; he proposed that Jampel Rinchen's son Kelzang Wangdül (1912-1984) marry his cousin's widow Jamyang Pelmo and succeed to the throne of Dergé. ${ }^{46}$ The proposal was unacceptable not only to Liu Wenhui but also to the faction supporting the Dergé family that descended from Dörjé Senggé. Kelzang Wangdül had been brought up as a member of Lhasa's aristocracy. ${ }^{47}$ Liu feared that the Lhasa government would be able to extend its influence to Dergé again through Kelzang Wangdül. Instead, the faction supporting Dörjé Senggés line suggested that the highly respected and revered Situ rinpoché of Pelpung monastery should act as temporary regent. Jagö's faction opposed their proposal for a number of reasons. First, it seemed that Dörjé Senggé's faction maintained closer ties with Pelpung monastery. Second, Jagö's faction feared that once a lama had been appointed it would be difficult to remove him from power (Lai Zuozhong 1996, 99; Lhalung Chimé Dörjé and Dayang 2009, 191-194). The issue was finally settled by having Tsewang Düdül's widow, Jamyang Pelmo, act as regent until the heir reached majority. Liu Wenhui knew clearly that Jagö Topden was craving a power base for himself and was increasingly becoming one of the most influential figures among the Khampa leaders. In addition, Liu was not sure whether Jagö was loyal to him. In 1944, Jagö had one of his rivals, the Atup chief Wangga in Kandzé assassinated. Wangga was 'the indigenous battalion commander' appointed by Liu Wenhui and was also a loyal follower of Liu. It was a well-known fact that Jagö was behind the assassination. Thus, Liu ordered

46 Jagö is also believed to have proposed to take charge of Tsewang Düdül's illegitimate son, whose name is unknown. He was brought up by Jagö to succeed to the throne of Dergé, but this was also opposed by the other party. See Chengdu junqu silingbu $(1957,8)$.

47 In 1943, when appointed as the attendant with the fourth rank for Yutok dzasak Trashi Döndrup, the Commissioner of Domé, Kelzang Wangdül accompanied the latter to take up position in Chamdo. In 1946 he became the ninth regiment commander, who was dispatched to garrison Drayap first and was later stationed in Markham. 
Gong Gengyun, the commander-in-chief of the Security Forces of Region Six in Dergé, to execute Jagö for the crime. Before Gong could carry out the order, Dergé magistrate Fan Changyuan, who was also an intelligence officer of the Military Commission of the G.M.D. Government, informed Jagö of Liu's order and allowed him to escape arrest and execution.

\section{Contesting the Authority of the Regent}

When Jamyang Pelmo began to serve as regent in Dergé, she seemed to be well aware of Jagö's growing power and authority, and considered the latter as a major threat to her son's future rule. To counter Jagö, Jamyang Pelmo relied on his rivals, including two chief ministers Wokma Chakdzö Sönam Tsering and Juchung Tsedör. With these officials wielding the actual power at Dergé royal court, Jagö was to a certain degree pushed aside by them (Lhalung Chimé Dörjé and Dayang 2009, 197). ${ }^{48}$ In 1946, Wokma Chakdzö instigated his subordinates to hold a feast for Jagö Topden and planned to poison the latter on this occasion. Because Jagö became aware of the plan, the conspiracy failed. This intensified Jagö's conflict with the Dergé king's faction even further. Having refused to return to the Dergé king's central government in Gönchen, Jagö returned to his family seat in Yilhung, thereby openly breaking with Jamyang Pelmo (Chengdu junqu silingbu 1957, 6-7; Den Junkang et al. 2009, 190-191; Lhalung Chimé Dörjé and Dayang 2009, 195, 201-214; Lodrö Püntsok 1994, 197-200).

In the same year, a dispute over pastureland led to the assassination of Drebö Lhagyel, a headman in Pelyül, by two families in Menshör - the Sokmo and Juchung families. The two headmen's families were supported by the Dergé king's family, while the Drebö family had been on friendly terms with the Jagö family for generations. Thus, the rift between the Dergé king's faction and the Jagö faction deepened further. ${ }^{49}$ At the time, having realized the importance of establishing his own power base, Jagö began to adopt a more populist approach. He redefined himself as a social reformer

48 In reality, when Jagö Topden became chief minister (nyerchen) in charge of daily affairs in Dergé in 1929 and later when he gained the trust of King Tsewang Düdül, it caused his rivals to resent him. The rivals formed an alliance to compete against Jagö for power and authority.

49 The Drebö family was Ngawang Jampel Rinchen's loyal supporters who, together with Jagö's family, followed the latter to Central Tibet. Jagö harbored great animosity toward the headmen who had assassinated Drebö Lhagyel and were also hostile toward and harbored grudges against Jamyang Pelmo. See Lai Zuozhong (1996, 100); Den Junkang et al. (2009, 191); Baima Dengdeng and Xiake Zelang (2008, 197-199). 
and defender of ordinary people against the royal family. Thus, in 1947 he openly advocated deposing the Dergé royal family, eliminating the 'tusi system', and abolishing the corvée labour system..$^{50} \mathrm{He}$ also called himself 'Yilhung tusi' and 'gyalo gyelpo' (literally meaning 'A-hundred-year-old king') (Chengdu junqu silingbu 1957, 9). He further proposed to establish 'Miser Gyelkhap' (The People's Nation), where 'the Khampa rule of Kham' would be implemented (Lai Zuozhong 1996, 100; Baima Dengdeng and Xiake Zelang 2008, 201). The use of the term miser (originally meaning 'serf' or 'subject'; in this context, having the connotation of common people or citizen $)^{51}$ is interesting and clearly signifies a radical transformation. In the same year, Jagö urged local people not to provide corvée labour to the Dergé king's family to repair the government office. As a consequence, only one third of trelpa (tax-payer) families provided corvée labour. In one or two places armed resistance even emerged against providing corvée labour (Zhongkeyuan minzu yanjiusuo Sichuan diaochazu 1963, 32). After the three major families in Menshör went into exile following their dispute with the Drebö family, Jagö also distributed their land, houses, and grain to their tenants. This action was warmly welcomed by poor households and began to attract other farmers to his cause (Lai Zuozhong 1996, 100; Baima Dengdeng and Xiake Zelang 2008, 201).

Soon after the Dergé regent dispatched her subordinate officials to levy grain taxes in Hörpo of Pelyül dzong, Jagö Topden ordered various villages to refuse to hand them over. The regent decided to dispatch troops to levy the grain taxes, and Jagö assembled local forces to resist them. With the support of the common people, he had the dzongpön (magistrate) dispatched by the Dergé king driven out of Hörpo..$^{2}$ Jagö's strategy proved to be popular, and people of many areas under Dergé's influence began to follow him. His power and authority also gradually increased. Consequently, in one of his articles published in 1947, Ren Naiqiang, the famous Chinese ethnologist and Tibetan Studies expert of the Republican period, portrayed Jagö as the

$5^{0}$ See Jagö Topden's letters to He Long and Deng Xiaoping dated 5 January 1951, in the Sichuan Archives.

$5^{1}$ For the meaning of the term miser, refer to the relevant entries in Goldstein (2001, 805).

$5^{2}$ The villagers elected the commoner Pema Chömpel as dzongpön with support from Jagö. While Jagö dispatched Nyaktrük Rinchen to serve as zhinyer (manager in charge of 200 households) in Hörpo of Pelyül, he also sent Dzakhok rinpoché Pema Ngenam to be dzongpön of Rakha in Pelyül. In addition, he also appointed his close follower Nyaktrük Lhagyel, a leading headman, as dzongpön of Dzinkhok, and appointed the commoner Wola Wangdzin as zhinyer of Barong in Pelyül. See Lai Zuozhong (1996, 100-101); Baima Dengdeng and Xiake Zelang (2008, 201). 
most powerful indigenous leaders in Kham (Ren Naiqiang 2009, 188). In 1947, the Chinese masters Genzao and Xianmi spent over a year at Jagö's home in Yilhung, when they went to study esoteric Buddhism in Kham. Jagö's great reputation and strong links with other Khampa leaders and reincarnated lamas was reflected in their account. During their stay at his home, Genzao and Xianmi reported that many guests came to visit him. In particular, many reincarnated lamas came to recite prayers and scriptures (Genzao Fashi and Xianmi Fashi 1995, 30). In addition, a Chinese monk named Tongxiao Fashi, who had studied for ten years in Lhasa, learned that Jagö Topden was a famous person in Kham and came to pay the latter a visit at home on his way to Kandzé via Yilhung (Genzao Fashi and Xianmi Fashi 1995, 50).53

By the 1950s, Jagö's faction consisted of nearly 100 major and minor headmen, with over 17,00o households under their jurisdiction. Their power and authority predominated in Pelyül, Denhok, Sershül, and Dergé counties, thereby becoming a major political network in northern Kham. In contrast, the Dergé king's family had only $5^{\circ}$ or so major and minor headmen under its control, with approximately 5000 households under their jurisdiction. The Dergé king's family had power and authority mainly over most parts of Tangpuk (present-day Jomda County), such areas as Gönchen, Menshör (also known as Meshö), Pelpung and Pewar in Dergé County, as well as regions under the jurisdiction of the Atup family in Denkhok. (Qin Heping 2014, 65-79; Chengdu junqu silingbu 1957, 1, 18).

As mentioned above, the campaign launched by Jagö in 1947 exemplified an apparent switch in his political strategy in terms of mobilizing and appealing directly to the people. He campaigned under the slogan 'Don't provide corvée labour for the tusi and don't hand in grain tax to the tusi' (bugei tusi fu chaiyi, buxiang tusi jiao fushui). ${ }^{54}$ Realizing that Jagö was gaining popularity and was becoming a growing threat to the Dergé court, the Dergé regent, Jamyang Pelmo, planned to assemble her subordinates and to unite with the troops of her brother (i.e. the Nangchen king) so as to counter Jagö's rise by force. The growing influence of Jagö in Kham also presented a challenge to the warlord Liu Wenhui, who secretly ordered the regimental commander Fu Dequan to gather his troops in Kandzé and to prepare to make a move against Jagö as well. In 1949 the Communist

53 According to Masters Genzao and Mixian, they were introduced to Jagö Topden by Döndrup Namgyel (Deng Dejie) whom they met in Dartsedo. In 1954, at Jagö Topden's invitation, they again travelled to study under Gyelsé rinpoché at Ngazang monastery in Tromtar, Pelyül. See Genzao Fashi and Mixian Fashi (1995, 10, 85, 94-100).

54 These slogans were probably originally in Tibetan, but the Chinese source provided them in Chinese. 
Party defeated the Nationalist Party and ultimately became victorious. In November of the same year, Jagö Topden, Getak rinpoché, and others sent representatives to Beijing to pay respect to the Chinese Central Government and Chairman Mao Zedong, by presenting them with banners. They requested that Tibetan regions be liberated. ${ }^{55}$ The Dergé court and Liu Wenhui's campaign against Jagö collapsed as the No. 18 army of the P.L.A. took over Dergé in June 1950 (Lai Zuozhong 1996, 101; Lhalung Chimé Dörjé and Dayang 2009, 215).

Both Jagö Topden and Jamyang Pelmo dispatched their representatives to welcome the P.L.A., expressing their willingness to support the Communist Party and the Chinese central government. At the time, Jagö served as deputy director of Kangding Military Control Commission (Kangding junguanhui). He contacted Getak rinpoché, Pangda Topgyé, and others, and they wrote a letter to General Liu Bocheng (1892-1986), chairman of the Southwest Military and Political Commission (xinanjunzheng weiyuanhui zhuxi). In the letter, they expressed their willingness to support the Communist Party and requested that national autonomy and self-management be implemented in Tibetan areas in Xikang. ${ }^{6}$

Uninterested in allying themselves with particular factions in Kham, the Communists, unlike previous Chinese regimes, were not bothered about playing one faction against another. They were motivated by broader issues of bringing the entire Kham region within the realm of the central administration. They could achieve this only by co-operating with different Khampa factions and interest groups. Thus, through mediations with multi-parties, Jagö Topden and Jamyang Pelmo eventually ended their estrangement and resolved their conflict. ${ }^{57}$ Meanwhile, the Communists realized that each Kham faction had to be appeased without seeming to favor one particular group. While Jagö Topden was appointed member of the Southwestern Military and Political Commission as well as vice-chairman of the People's Government of Xikang Provincial Tibetan Autonomous

55 The representatives dispatched by them stated 'Tibetan compatriots' longing for being liberated quickly', and their willingness to accept the leadership of the Chinese Central Government. Zhu De met with these representatives on 19 February 1950. See Wu Dianyao $(2006,1367)$.

56 See the original letter written by Jagö Topden and others to Liu Bocheng of the Southwest Military and Political Commission, in the Sichuan Archives.

57 Jagö Topden wrote to He Long and Deng Xiaoping, thanking them for sending a message to him. In his letter, he mentions that in their message they hoped he would make an effort to get along with Jamyang Pelmo and to achieve unity between them. He also expresses his willingness to take the lead in resolving the conflicts between the Dergé king's family and the common people. See Jagö Topden's original letter to He Long and Deng Xiaoping on 5 January 1951, in the Sichuan Archives. 
Region (Xikang sheng zangzu zizhiqu renmin zhengfu), Jamyang Pelmo was appointed deputy director of the Chamdo Regional Liberation Committee (Changdu diqujiefang weiyuanhui) (Deng Junkang and Li Kunbi 2009, 191)..$^{8}$

In the early period of Communist rule, unlike in Chinese provinces that were populated by Han Chinese, in ethnic minority areas the Communists did not seek to eliminate traditional ruling families, as they were aware that the Communists had very little support or organizational bases. Communist rule in minority areas would be achieved through appeasement and incorporating the ruling elite. The Communists' dealings with Jagö Topden provide a good example of this strategy. In the early 1950s, Jagö was appointed to be a member of the National People's Congress (quanguo renda daibiao), vice-chairman of Sichuan Provincial Political Consultative Conference (Sichuan sheng zhengxiefuzhuxi), deputy governor of Kandzé Tibetan Autonomous Prefecture (Ganzi zangzu zizhizhou fuzhouzhang), and vice-chairman of Kandzé Tibetan Autonomous Prefectural Political Consultative Conference (Ganzi zangzu zizhizhou zhengxie fuzhuxi). Jagö played a crucial role in helping the government of the People's Republic of China establish political power in Kham, and this is why he surpassed other monastic and lay elites in Kham (Qin Heping 2014, 65-79). In particular, given his cooperation with the C.C.P., later Chinese sources credit Jagö with having made great contributions to the regional autonomy of Tibetan areas of Xikang province and having provided assistance to P.L.A.'s march toward Central Tibet (Deng Junkang and Li Kunbi 2009, 191-192).59

$5^{8}$ Jamyang Pelmo was successively appointed member of the People's Government of Xikang Provincial Tibetan Autonomous Region and vice-chairman of Xikang Provincial Tibetan Autonomous Regional Political Conference (Xikang sheng zangzu zizhiqu zhengxie). She also served as deputy-director of Kangding Regional National Consultative Conference (Kangding diqu minzu xieshanghui), member of Southwest Democratic Women's Federation (xinan minzhu funü lianhehui), deputy-director of Xikang Provincial Women's Federation (Xikang shengfulian), executive committee member of All China Democratic Women's Federation(Zhonghua quanguo funü lianhehui), etc. See Deng Junkang and Li Kunbi (2009, 185-187).

59 Tibetan areas of Xikang province were equivalent to present-day Kandzé Prefecture. As Qin Heping has pointed out, Jagö's attitude toward 'democratic reform' is ambivalent. He basically accepted the reform and did not cause too much 'trouble'. However, the reform affected his personal vital interests and those of his respective class. As such, his words and actions were inconsistent with his understanding. It was said that Jagö began to have misapprehensions about the reform and became undecided about it. He even adopted some 'extreme' measures concerning the reform. The reason for his ambivalence about the reform was not only due to his personal concerns but also to the ambiguity of the reform's principles and policies adopted at the time. These principles and policies influenced his words and actions. See Qin Heping (2014, 65-79). 
The victory of the Communists meant a total shift in the nature of politics in Kham. Neither Jagö nor any other Kham leaders were able to deal effectively with the Communists. In part, this was because of the vast superiority of the Communist forces in terms of both their number and fighting capacity. More importantly, the Communists were united by a clear ideological objective. The arrival of the Communists marked the end of the traditional political system in Kham and of Jagö's personal ambition. Jagö died of an illness in 1960, thereby ending his legendary life.

\section{Conclusion}

The figure of the ambitious and charismatic Jagö Topden and his rise in both the politics of the kingdom of Dergé and that of the larger Kham region, is an exceptional example of the new elite that emerged in Kham at the end of the nineteenth century and the beginning of the twentieth century. As a representative of the new educated elite in Kham who challenged the traditional authority, Jagö Topden however differs from other representative figures of this new elite group. Many of the Khampa elite, such as Kelzang Tsering, were politically active in inland China itself; similarly, the religious elite in exile in inland China, represented by Gara Lama, were active not only in Kham but also in inland China. Although Jagö Topden had to contend with various political forces outside the Kham region, his political activities were mainly concentrated in Kham.

The ascendancy of Jagö Topden, who was a subordinate headman under the Dergé king, is also the epitome of the declining power of the traditional hegemonic rulers and the rise of their subordinate headmen during the Republican period. The rise of these headmen was partly the consequence of the weakening and even destruction of the traditional hegemonic ruler's power in Kham in the aftermath of the policy of substituting chieftains with state-appointed civilian officials that was implemented by Zhao Erfeng in the 190os. It was also closely related to the traditional political structure of hegemonic rulers, such as the Dergé king, which was decentralized and based on the hereditary hierarchy. In particular, the decentralized political structure caused hegemonic rulers to divide the land among local hereditary headmen, and this enabled the latter to form alternative foci of power that could counter the authority of hegemonic rulers. Consequently, these headmen were able to set themselves up as territorial rulers in the regions under their jurisdiction, to become excessively powerful, and to maintain a high degree of local autonomy. We can see that a similar structure allowed 
for the emergence and rise of headmen in Gyelrong regions during the Republican period.

This case study reveals how the negotiated space of the Kham frontier was transformed into the fixed 'place' of the newly established modern Chinese nation. It also demonstrates the complex, multivariant interactions between the local Chinese governments and the local power holders and indigenous chieftains (tusi) in the frontier zone. During the Republican period, Kham formed special internal political and cultural frontiers of the Republic of China together with other regions in the half-moon-shaped zone extending from Gansu and Qinghai regions in the northwest to the Yunnan-Guizhou plateau in the southwest. At the time, in the newly imagined geo-space of the Republic of China, frontier people were inscribed as co-nationals and the contested Kham region emerged as an inalienable part of the Chinese national space (Tsomu 2012).

As exemplified by the case of Dergé discussed in this chapter, successive warlords who governed the Kham region, such as Liu Wenhui, managed to extend the administrative control of the state over Kham polities and incorporate into the bureaucratic system the former hegemonic rulers and headmen who had only temporarily restored their power and authority at the beginning of the Republican period by appointing them at different levels of the new administration (Kangding minzu shizhuan bianxiezu 1994, 49). Meanwhile, they similarly integrated newly risen self-made leaders in southern Kham in local government institutions (Chen Peibin 2014, 174). In addition, the representative reincarnated lamas and eminent monks in Kham had been appointed to various government and party positions, including commissioner and adviser of Xikang province, councilor and alternate councilor of the First Provisional Council of Xikang province, among other important positions (Wang Chuan 2006, 81-82). ${ }^{60}$

The Republican period is characterized by a regionalization process involving the emergence of forms of regional consciousness and regional politics (Duan Jinsheng 2014, 31-40). Consequently, as this chapter shows, the Nationalist central government's influence was rather limited due to fierce resistance by local warlords in Kham, who remained dominant

6o They also held positions such as delegate of the National Assembly of Xikang province, member of the Supervisory Committee of the Nationalist Central Committee, and member of the Supervisory Committee of Sichuan Provincial Nationalist Party Headquarters, etc. Furthermore, while some of them were also elected president of the Buddhist Society at county level, others were selected to serve as master to propagate Buddhism (xuanjiao shi/xuanhua shi) and master to safeguard Buddhism ( fujiao shi), who were responsible for assisting in supervising local government affairs and playing the role of helping local military and government organizations to pacify local society. See Wang Chuan (2009, 80-81). 
in the administration of the region. Indeed, local secular and religious leaders were not passive participants. As the case of Jagö shows, to adapt to the new political order and to consolidate their own position in local society, local leaders took the initiative to maintain good relations with the Chinese authorities in order to play a more important role in the Chinese administration of the region. Thereupon, during the Republican period, three major forces co-existed: the Nationalist bureaucratic warlords, the former tusi (indigenous chieftains), and the headmen and the new self-made leaders as well as major monasteries. ${ }^{61}$ No matter which force was dominant in handling government affairs, as the case of Dergé shows, local leaders and monasteries still controlled local society; government officials had to rely on them to levy corvée labour and grain taxes. The relationship between the Chinese governments and the tusi in the Kham region was entirely similar to that of other frontier regions in the northwest and southwest where tusi ruled, as described by Lin Chunsheng, the Chinese ethnologist and anthropologist of the Republican period (Lin Chunsheng 1944, 8-9).

The new twentieth-century Kham elite represented by Jagö Topden was the product of this particular historical period in Kham - an era of enormous political and social change. Unlike the majority of traditional forces in Kham, who had a parochial outlook and only cared about what happened in territories under their jurisdiction, Jagö Topden and other new Khampa elites were more open-minded and farsighted. Therefore, they were able to emerge as the new leading figures in Kham politics at that time. After Jagö's return to Dergé in the early 1920s, over the following 30 years during which various powers competed for control of the Kham region, he continuously fought on several fronts against the Dergé king's family, the Ganden Phodrang in Lhasa, the Chinese warlord Liu Wenhui of Xikang, and the Muslim warlord Ma Bufang of Qinghai Province. By competing and negotiating with these different political figures, he acquired an understanding of their respective political views, and also constantly extended his power and authority by collaborating with them whenever possible. Thus, in the 1930 and 1940 s he became one of the most influential leaders in the history of Kham and was able to contest the authority of the king of Dergé. Jagö Topden also legitimized his authority through both the construction of a regional identity of a politically united Kham and the appropriation of new ideas and reforms. In this guise, Jagö appeared to be both modern and progressive. He was certainly aware of the undergoing ideological and social changes in inland

61 As for which force was dominant in the administration of the local counties in Kham, there were distinctive regional differences. For details, see Chen Peibin (2014, 173-174). 
China. He effectively adopted the populists' cause of social reform, was able to wrest power from the king, and positioned himself as the paramount authority in Dergé. In the dispute for control of Kham in general, and over Dergé in particular, the successive Chinese regimes, from the Qing to the establishment of the People's Republic of China and the Ganden Phodrang under the Thirteenth Dalai Lama, created a period of instability. Amidst this unrest, Jagö Topden, regarded as the 'political strongman' who had kept up with the times and was adept at acting as mediator between different power holders at local, regional, and state levels, proved to be a skillful player on the political chessboard as demonstrated by his connivance with external powers as well as by his appeal for popular support. As Dáša Mortensen's study of Wangchuk Tempa, another prominent local leader in southern Kham (in this volume), shows, Jagö Topden's savvy negotiation and 'collaboration' with various powers also demonstrates the degree of control exerted by local leaders in Kham during this turbulent era. The people of Dergé were tired of the instability and saw Jagö as a leader who could ensure peace in the territory. Thus, they allowed Jagö to emerge as the new independent ruler of Dergé. Had it not been for the victory of the Communists and the establishment of the People's Republic of China, Jagö Topden might well have become the new ruler of Dergé.

\section{Glossary of Tibetan Terms}

amban

Aja

Atup

Atup Lakartsang

Atup Ripuk

Adzom

Baba

Bapa Püntsok Wangyel

Barong

Bathang

Beri

Böpa

chakdzö

Chakdzö Namsé Tsega

Chakdzö Wokma Sönam Tsering am ban

A ja

A thub

A thub l'a dkar tshang

A thub ri phug

A 'dzom

Ba ba

'Ba' pa Phun tshogs dbang rgyal

Ba rong

'Ba' thang

Be ri

Bod pa

phyag mdzod

Phyag mdzod Rnam sras tshe dga'

Phyag mdzod 'Ok ma Bsod nams tshe ring 
Chakzamkha
Chamdo
chapsi kyi chawarkhedzang denpa

Chaktreng

Chimé Tapei Dörjé

chipöngo

chösi zungdrel

Chöying Zangmo

Chungrampa

Dabpa

Damtsik Dörjé

dapön

Dartsedo

Dechen Wangmo

dechok

Dekha Chimé

Denkhok

depa

Dergé

Dergé chikhyap

Dergé Gönchen

Dilgo

Dimgo

Domé chikhyap

Döndrup Namgyel

Dörjé Namgyel

Dörjé Senggé

Drango

Drebö

Drebö Lhagyel

Drichu

Drongpa

Drumo Tubten

drungyik

dünkör

dünkörkhak

Dzakhok rinpoché Pema Ngenam

Dzatö
Lcags zam kha

Chab mdo

chab srid kyi bya bar mkhas mdzangs

ldan pa

Phyag phreng

'Chi med rtag pa'i rdo rje

phyi dpon 'go

chos srid zung 'brel

Chos dbyings bzang mo

Khyung ram pa

'Dab pa

Dam tshig rdo rje

Mda' dpon

Dar rtse mdo

Bde chen dbang mo

Sde phyogs

'Das kha 'Chi med

'Dan khog

sde pa

Sde dge

Sde dge spyi khyab

Sde dge dgon chen

Dil mgo

Dis mgo

Mdo smad spyi khyab

Don grub rnam rgyal

Rdo rje rnam rgyal

Rdo rje seng ge

Brag 'go

Bre 'bod

Bre 'bod Lha rgyal

'Bri chu

'Brong pa

Gru mo Thub bstan

drung yig

mdun skor

mdun skor khag

Rdza khog rin po che Pad ma nges

rnam

Rdza stod 


\begin{tabular}{ll} 
Dzinkhok & 'Dzin khog \\
Dzokchen & Rdzogs chen \\
dzong & rdzong \\
dzong go & rdzong 'go \\
dzongkhak & rdzong khag \\
dzongpön & rdzong dpon \\
Gamongna & Rga mong sna \\
Ganden Phodrang & Dga' ldan pho brang \\
Gara Lama & Mgar ra bla ma \\
Garjé & Sgar rje \\
Gelong & Dge slong \\
Getak rinpoché & Dge rtag rin po che \\
Getok & Gad thog \\
Gojo Samdrup & Go 'jo Bsam grub \\
Golok & 'Go log \\
Gönchen & Dgon chen \\
Gönpo Namgyel & Mgon po rnam rgyal \\
Göngpo Tsering & Mgon po tshe ring \\
gopa & 'go pa \\
Göza & Mgos gza' \\
Göza Wanggyel & Mgos gza' dbang rgyal \\
gyalo gyelpo & bgya lo rgyal po \\
Gyantsé & Rgyal rtse \\
Gyangkham Dechen & Gyang khang bde chen \\
Gyari Chimé Drölma & Rgya ri 'chi med sgrol ma \\
gyelpo & rgyal po \\
Gyelsé rinpoché & Rgyal sras rin po che \\
Hakhok & Hya khog \\
Hörcho Peldo & Hor cho pad rdor \\
hördra & hor 'dra \\
Hörpo & Hor po \\
Jagö Pema Ledrup & Bya rgod Pad ma las grub \\
Jagö Tashi Namgyel & Bya rgod Bkra shis rnam rgyal \\
Jagö Topden & Bya rgod Stobs ldan \\
Jagö Tsenam & Bya rgod Tshe rnam \\
Jamga & 'Jam dga' \\
Jampa Künga Sanggyé Tenpai & Byams pa kun dga' sangs rgyas bstan \\
Gyeltsen & pa'i rgyal mtshan \\
Jampa Tendar & Byams pa bstan dar \\
Jamyang Pelmo & 'Jam dyangs dpal mo \\
& \\
& \\
\hline
\end{tabular}


Jamyang Zhepa

Janggyap

Jomda

jöntang chenpo

Juchung

Juchung Tsedör

Kagyü

Kalön Lama

Kamtok dröching

Kamtok dröchö

Kangpé rangdé rangpön

Kangpé rangsi rangkyong

Kandzé

Kelzang Chönjor

Kelzang Püntsok

Kelzang Tsering

Kelzang Wangdül

Kelzang Yeshé

khadrak wangshechen

Kham

Khampa

Khangsar

Khangsar Kyamgön

Khangsar Yangchen Khandro

Khangsar Yangchen Drölma

Kharnang

Khemé

khenpo

khölpa

Labrang Trashikhyil

Lhari

Lhasa

Lhundrupteng

Lingtsang

Lithang

Lodrö Jamyang

Lodrö Püntsok

Machöwang

Markham

Mawang Chöndzé
'Jam dbyangs bzhad pa

Byang rgyab

'Jo mda'

'jon thang chen po

'Ju chung

'Ju chung Tshe rdor

bka' rgyud

Bka' blon bla ma

Skam thog gros chings

Skam thog gros chod

Khams pas rang sde rang dpon

Khams pas rang srid rang skyongs

Dkar mdzes

Bskal bzang chos 'byor

Bskal bzang phun tshogs

Bskal bzang tshe ring

Bskal bzang dbang 'dul

Bskal bzang ye shes

kha drag dbang shed can

Khams

khams pa

Khang gsar

Khang gsar skyabs mgon

Khang gsar Dbyangs can mkha' 'gro

Khang gsar Dbyangs can sgrol ma

Mkhar nang

Khe smad

mkhan po

khol pa

Bla brang bkra shis 'khyil

Lha ri

Lha sa

Lhun grub steng

Gling tshang

Li thang

Blo gros 'jam dbyangs

Blo gros phun tshogs

Ma chos dbang

Smar khams

Ma dbang chos mdzad 


\begin{tabular}{ll} 
Mawur Chöndzé & Ma bur chos mdzad \\
Mazür & Ma zur \\
Meshö & Sme shod/Sman shor \\
Menshör & Sman shor \\
mi chen po & mi chen po \\
mirik & mi rigs \\
miser & mi ser \\
Miser Gyelkhap & Mi ser rgyal khab \\
Nakchu & Nag chu \\
namrik denpa & rnam rig ldan pa \\
Namsé Tsega & Rnam sras tshe dga' \\
Nangchen & Nang chen \\
Nangsotsang & Nang so tshang \\
Ngawang Jampel Rinchen & Ngag dbang 'jam dpal rin chen \\
Ngör & Ngor \\
Ngör khenchen Jampa Künga & Ngor mkhan chen Byams pa kun dga' \\
Tendzin & bstan 'dzin \\
Nörla Hutuktu & Nor bla/lha Hu thug thu/Ho thog thu \\
Nyachukha & Nyag chu kha \\
Nyarong & Nyag rong \\
Nyarong chikhyap & Nyag rong spyi khyab \\
Nyarong Gönpo Namgyel & Nyag rong Mgon po rnam rgyal \\
Nyakshik Setsa & Nyag shig se tsha \\
Nyaktrük Lhagyel & Nyag phrug Lha rgyal \\
Nyaktrük Rinchen & Nyag phrug Rin chen \\
nyerchak lhengyekang & gnyer phyag lhan rgyas khang \\
nyerchen & gnyer chen \\
Nyerchen Gyangkhang rinpoché & Gnyer chen Gyang khang rin po che \\
Nyerchen Lodrö Jamyang & Gnyer chen Blo gros 'jam dbyangs \\
Nyingma & Rnying ma \\
Nyintso & Nyi mtsho \\
Nyatso & Nya mtsho \\
Pangda Topgyé & Spang mda' Stobs rgyas/Spom mda' \\
Pangdatsang & Stobs rgyas \\
Pelpung & Spang mda' tshang \\
Pelyül & Dpal spungs \\
Pelyül dzong & Dpal yul \\
Pema Chömpel & Dpal yul rdzong \\
Pema Wangchok & Pad ma chos 'phel \\
& Pad ma dbang mchog \\
& \\
\hline &
\end{tabular}


Penpo

Pomda Topgyé

Pomdatsang

Pomkha Namgyel Dörjé

pönchenzhi

pöngozhi

pönpo

Püntsok Wangyel

Pünwang

Ragashak

Rakha

Rapga

Raru Jamyang Lobdrö

Riwoché

Rongpatsa

Sakya

Sera

Sershül

Situ rinpoché

Sokmo

Sokmotsang

Sönam Chömtso

Sönam Tsomo

Tangpuk

Tawu

theji

Trashi Wangchuk

trelpa

Tromtar

Tsari

Tsari Nyergé

Tsang

tsé lopdra

Tseten Drölkar

Tsewang Dörjé Rikdzin

Tsewang Drölma

Tsewang Düdül

Tsewang Lhamo

Tsolho

tünpa pünzhi
'Phan po

Spom mda' Stobs rgyas

Spom mda' tshang

Spom kha Rnam rgyal rdo rje

dpon chen bzhi

dpon 'go bzhi

dpon po

Phun tshogs dbang rgyal

Phun dbang

Ra ga shag

Ra kha

Rab dga'

Ra ru'Jam dbyangs blo gros

Ri bo che

Rong pa tsha

Sa skya

Se ra

Ser shul

Si tu rin po che

Sog mo

Sog mo tshang

Bsod nams chos mtsho

Bsod nams mtsho mo

Thang phug

Rta'u

tha'i ji

Bkra shis dbang phyug

khral pa

Khrom thar

Rtsa ri

Rtsa ri Gnyer dge

Gtsang

rtse slob grwa

Tshe brtan sgrol dkar

Tshe dbang rdo rje rig 'dzin

Tshe dbang sgrol ma

Tshe dbang bdud 'dul

Tshe dbang lha mo

Mtsho lho

mthun pa spun bzhi 


$\begin{array}{ll}\text { ügön } & \text { dbu dgon } \\ \text { üla } & \text { dbu bla } \\ \text { ulak } & \text { 'u lag } \\ \text { Urgyenkyap } & \text { O rgyan skyabs } \\ \text { Wangga } & \text { Dbang dga' } \\ \text { Wangpotö } & \text { Dbon po stod } \\ \text { Wokma Chakdzö Sönam Tsering } & \text { 'Og ma phyag mdzod Bsod nams tshe } \\ & \text { ring } \\ \text { Wola Wangdzin } & \text { 'O la dbang 'dzin } \\ \text { Wönpoteng } & \text { Dbon po steng } \\ \text { Wuga } & \text { O dga' } \\ \text { Yardrok Yumtso } & \text { Yar'brog g.yu mtsho } \\ \text { Yilhung } & \text { Yid lhung } \\ \text { zhika } & \text { gzhis ka } \\ \text { Zhingmo } & \text { Zhing mo } \\ \text { zhinyer } & \text { gzhis gnyer } \\ \text { zhükgar } & \text { bzhugs sgar } \\ \text { zimpön } & \text { gzim dpon }\end{array}$

\section{Glossary of Chinese Terms}

Anzhang (si)

bugei tusifu chaiyi, buxiang tusijiao fushui

Chailiang zongban

Changdu diqu jiefang weiyuanhui

Chen Rongguang

Chiang Kai-shek

Chuankang

Dege xian canyizhang

Deng Dejie

Deng Junkang

Deng Xiaoping

dusi

Fan Changyuan

Fu Dequan

fujiao shi

gaitu guiliu

Gansu

\section{安章 (寺)}

不給土司服差役, 不向土司交賦稅

差糧總辦

昌都地區解放委員會

陳榮光

蔣介石

川康

德格縣參議長

鄧德傑

鄧俊康

鄧小平

都司

範昌元

付德銓

輔教師

改土歸流

甘肅 
Ganzi zangzu zizhizhou fuzhouzhang 甘孜藏族自治州副州長

Ganzi zangzu zizhizhou zhengxie 甘孜藏族自治州政協副主席 fuzhuxi

Genzao

根造

Gong Gengyun

壟耕耘

Hai Zhengtao

海正濤

Hainan

海南

He Long

賀龍

Hui

回

Jinshajiang

金沙江

Kangding

康定

Kangding diqu minzu xieshanghui

Kangding junguanhui

Kangren zhi Kang

Lai Zuozhong

Li Kunbi

Li Xianian

Ling Chunsheng

Liu Bocheng

Liu Jiaju

Liu Wenhui

Luding

Ma Bufang

Mao Zedong

minzu

Mixian

Qin Heping

Qinghai

qu fuzhihui

quanguo renda daibiao

Ren Naiqiang

Sichuan

康定地區民族協商會

康定軍管會

康人治康

來作中

李昆壁

李先念

淩純聲

劉伯承

劉家駒

劉文輝

瀘定

馬步芳

毛澤東

民族

密顯

秦和平

青海

區副指揮

全國人大代表

任乃强

四川

Sichuan sheng zhengxie fuzhuxi

四川省政協副主席

taizi

太子

Tongxiao fashi

通孝法師

tubing yingzhang

tusi

土兵營長

土司

Wan Tengjiao

萬騰蛟

Wang Weizhou

王維舟

Xichang

西昌 


$\begin{array}{ll}\text { Xikang } & \text { 西康 } \\ \text { Xikang bao'an xingzhengjiangxihui } & \text { 衛行政講習會 } \\ \text { Xikang sheng canyiyuan } & \text { 西康省參議員 } \\ \text { Xikang sheng fulian } & \text { 西康省婦聯 } \\ \text { Xikang sheng zangzuzizhiqu renmin } & \text { 西康省藏族自治區人民政府 } \\ \text { zhengfu } & \\ \text { Xikang sheng zangzu zizhiqu } & \text { 西康省藏族自治區政協 } \\ \text { zhengxie } & \\ \text { Xikang tezhong bao'anfu duizhang } & \text { 西康特種警衛副隊長 } \\ \text { xinanjunzheng weiyuanhuizhuxi } & \text { 西南軍政委員會主席 } \\ \text { xinan minzu funü lianhehui } & \text { 西南民族婦女聯合會 } \\ \text { xuanjiao shi } & \text { 宣教師 } \\ \text { xuanhua shi } & \text { 宣化師 } \\ \text { Ya'an } & \text { 雅安 } \\ \text { Yajiang } & \text { 雅江 } \\ \text { Yi } & \text { 彝(族) } \\ \text { Zhang Ji } & \text { 張繼 } \\ \text { Zhang Qun } & \text { 張群 } \\ \text { Zhang Ziyu } & \text { 張子愚 } \\ \text { Zhao Erfeng } & \text { 趙爾豐 } \\ \text { zhengjiao heyi } & \text { 政教合一 } \\ \text { Zhonghua quanguofunü lianhehui } & \text { 中華全國婦女聯合會 } \\ \text { Zhu De } & \text { 朱德 }\end{array}$

\section{References}

Anon. 1982. 'Xiage Daoden chuanqi de yi sheng' 夏克刀登传奇的一生 (The Legendary Life of Jagö Topden). https://fengsu.supfree.net/up.asp?id=16192. Accessed 7 June 2019 .

Baima Dengdeng and Xiake Zelang. 2008. 'Dege tusi jiazu neibu jiqi xiashu touren zhijian de fenzheng' (Disputes and Fighting within the Dergé King's Family and with Their Subordinate Headmen), translated by Lang Jia (Namgyel) and Wei Gang, and compiled by Lai Zuozhong. Ganzi zhou wenshi jicui [The Selected Cultural and Historical Materials of Kandzé (Ganzi) Prefecture], vol.1: $185^{-203}$.

Chen Peibin. 2014. 'Minguo kangqu xianzhi yanjiu' (On the County Administration System in the Kham Region in the Period of the Republic of China). Sichuan shifan daxue xuebao (Journal of Sichuan Normal University) 41 (5): 171-176. 
Chengdu junqu silingbu. 1957. Kangqu beibu shehui qingkuang diaocha (Investigation into the Social Conditions of Northern Kham). Chengdu: Chengdu junqu silingbu (For internal circulation only).

Chung Tsering (trans.). 2006. Bod migsar brje bazhig (A Tibetan Revolutionary). Da ram sa la: Bod kyi dus bab.

Coleman, William M. 2014. Making the State on the Sino-Tibetan Frontier: Chinese Expansion and Local Power in Batang, 1842-1939. PhD Dissertation, Columbia University.

Deng Junkang and Li Kunbi. 2009. 'Xike daodeng' (1900-1960) (Jagö Topden [19001960]). Ganzi Zangzu zizhizhou wenshi jicui (The Selected Cultural and Historical Materials of Kandzé [Ganzi]), vol. 2 (part 2): 188-192.

Du Yongbin. 1989. 'Dege tusi xiaqu de zhengjiao jiqi tedian' (The Politics and Religion as Well as Their Features in the Territory under the Jurisdiction of the Dergé King). Zhongguo zangxue (China Tibetology) 3: 85-99.

Duan Jinsheng. 2014. 'Difang yishi yu defang zhengzhi: zhengzhi quyuhua changing xia biangjiang zhili-yi' (The Local Consciousness and the Local Politics: Borderland Governance in the Context of Political Regionalism - Focusing on Yunnan during the Period of Nanjing Government). Zhongguo bianjiang shidi yanjiu (China's Borderland History and Geography Studies), 24 (1): 31-40.

Feng Youzhi.1994. Xikang shi shiyi: wenshi ziliao (Supplemental History of Xikang: Historical Document). Kangding: Zhongguo renmin zhengzhi xieshang huiyi Sichuan sheng Ganzi zagnzu zizhizou weiyuanhui.

Ge Le (Dge legs). 1984. Ganzi zangzu zizhizhou shihua (History of Kandzé (Ganzi) Tibetan Autonomous Prefecture). Chengdu: Sichuan minzu chubashe.

Genzao Fashi and Mixian Fashi. 1995. Qiufa huiyi lu (Memoirs of Seeking for Dharma). New York: Da Yuanman xinsui yanjiu zhongxin (Maha Sandhi Yoga Center). Goldstein, Melvyn C. 1989. A History of Modern Tibet, 1913-1951: The Demise of the Lamaist State. Berkeley: University of California Press.

Goldstein, Melvyn C., Dawei Sherap and William Siebenschuh. 2004. A Tibetan Revolutionary: The Political Life and Times of Bapa Phüntso Wangyé. Berkeley: University of California Press.

Goldstein, Melvyn C., T. N. Shelling and J. T. Surkhang. 2001. The New Tibetan-English Dictionary of Modern Tibetan. Berkeley: University of California Press.

Gros, Stéphane. 2016. 'Introduction to "Frontier Tibet: Trade and Boundaries of Authority in Kham"'. Cross-Current: East Asian History and Culture Review 5 (2): 209-238.

Hartley, Lauren. 1997. A Socio-Historical Study of the Kingdom of Sde-dge (Derge, Kham) in the Late Nineteenth Century: Ris-med Views of Alliance and Authority. MA Thesis, Indiana University. 
Jiang Anxi, Lai Zuozhong and Deng Junkang. 1983. 'Nuona shibian jilüe' (A Brief Account of the Nörla Incident). Sichuan wenshi ziliao xuanji (The Selected Cultural and Historical Materials), vol. 29, 64-77. Chengdu: Sichuan renmin chubanshe.

Kangding minzu shizhuan xianxiezu. 1994. Ganzi zangzu zizhizhou minzuzhi (History of Nationalities in Kandzé Tibetan Autonomous Prefecture). Beijing: Dangdai Zhongguo chubanshe.

Karma Gyeltsen. 1994. Sde dge chos 'byung (History of Buddhism of Dergé). Hang kong: Ya gling dpe skrung khang.

Kongtrül Yönten Gyatso and Karma Trinlé. 1997. Kong sprul yon tan rgya mtsho'I rnam thar (Autobiography of Kongtrül Yonten Gyatso). Khren du'u: Si khron mi rigs dpe skrun khang.

Lai Zuozhong. 1996. 'Xiake Daodeng zhuanlüe' (A Short Biography of Jagö Topden). Sichuan sheng wenshi ziliao jicui (minzu zonjiao, huaqiaobian) (The Selected Cultural and Historical Materials of Sichuan Province [The Edition about Ethnic Minorities, Religion and Overseas Chinese]), vol.5, 97-101. Chengdu: Sichuan renmin chubanshe.

Lhalung Chimé Dörjé and Dayang. 2009. Khams sde dge rgyal po'i srid don lo rgyus (A Political History of the Dergé Kings of Kham). Be cin: krung go'i bod kyi shes rig dpe skrun khang.

Li Xiannian zhuan bianxiezu. 2011. Li Xiannian nianpu (diyi juan) (Chronology of Li Xiannian), vol. 1. Beijing: Zhongyang wenxian chubanshe.

Lin Chunsheng. 1944. 'Zhongguo bianzhen zhi tusi zhidu' (The Tusi System in China's Frontier Towns). Bianzheng gonglun (Research on Frontier Affairs) 2-3: 8-9.

Lin Junhua. 1993. 'Ganzi zangqu xuexiao jiaoyu kaifa shi gaisuo' (A Study of the Development History of School Education in Kandzé (Ganzi) Tibetan Region). Xizang yanjiu (Tibetan studies) 2: 39-46, 17.

Liu Xianqiang. 2007. 'Er-shi shiji shang banye kangqu shifan jiaoyu fazhan shulun' (On the Development of Normal Education in the Kham Region in the First Half of the Twentieth Century). Xizang yanjiu (Tibetan Studies) 1: 90-95.

Liu Xianqiang. 2008. 'Er-shi shiji shang banye Kangqu xuexiao jiaoyu yanjiu' (A Study of School Education in the Kham Region in the First Half of the Twentieth Century). PhD dissertation, Sichuan University.

Lodrö Püntsok. 1994. Sde dge’i lo rgyus (History of Dergé). Dgon chen: Srid gros Sde dge rig gnas lo rgyus rgyu cha bsdu sgrig u yon lhan khang.

Lodrö Püntsok, Samten, Tsewang Tashi, Jangchuk Chömpel, Dönwang, Ngawang Tendzin and Pema Dönden. 1995. Sde dge rig gnas dang lo rgyus (Culture and History of Dergé). Dgon chen: Srid sgros sde dge rdzong rig gnas lo rgyus o yon lhan hang. 
Lu Chuanlin. 2001a. 'Xiangchen chouban Dege tusi shiqing, tongguan jici qingzha, qingci xinren duchen chabanshu' (Memorial with a Detailed Report about the Actual State of Affairs Concerning Dealing with the Dergé Tusi, the In-fighting by my Colleagues with Excuses and Requesting to Order the Newly Appointed Governor-general to Investigate and Deal with Accordingly).Jindai Kangzang zhongda shijian xuanbian (Selected Important Events of Modern Kham and Central Tibet) (Part One), vol.1: 474-479. Lasa: Xizang guji chubanshe.

Lu Chuanlin. 20o1b. 'Chaban De-er ge-te tusi xiandi guicheng, qing xu gaitu, bingshang chuli renyuan zhoupian' (Memorial Concerning Investigating and Handling the Dergé Tusi's Offering his Land and Submitting, Requesting to be Allowed to Carry out the Policy of 'Substituting Chieftains with State Appointed Civilian Officials' and Rewarding Those People Who Have Exerted Themselves in Connection to the Matter).Jindai Kangzang zhongda shijian xuanbian (Selected Important Events of Modern Kham and Central Tibet) (Part One), vol.1: 467-470. Lasa: Xizang guji chubanshe.

Luo Shaoming. 2015. 'Minguo shiqi de kangzang jingying yu 'kangren zhikang' yundong' (The Khampa Elite and the Movement of the 'Khampa Rule of Kham' during the Republican Period). Sichuan minzu xueyuan xuebao (Journal of Sichuan University for Nationalities) 24 (3): 1-5.

Ma Guangwen. 2001. 'Shu Fuhe xie Ma Guangwen bing Dege tusi zhengxi an' (The Report about the Case of Contention for the Position of the Dergé Tusi by the Acting Commander of Fuhe Division). Jindai Kangqzang zhongda shijian shiliao xuanbian (diyi bian: shang) (Selected Important Events of Modern Kham and Central Tibet) (Part One), vol.1. Lasa: Xizang guji chubanshe.

Ma Tinzhong. 2008. 'Lun minguo shiqi Ganzi diqu de xuexiao jiaoyu' (On School Education of Kandzé (Ganzi) Region during the Republican Period). Xinan minzu daxue xuebao (Journal of Southwest University for Nationalities) 5:68-74.

Ma Tinzhong. 2012. 'Minguo shiqi Xikang sheng minzu jiaoyude fazhan' (On the Development of Education for Ethnic Minorities in Xikang Province during the Republican Period).Xinan minzu daxuexuebao (Journal of Southwest University for Nationalities) 12: 205-209.

McGranahan, Carole. 2005. 'In Rapga's Library: The Texts and Times of a Rebel Tibetan Intellectual'. Cahiers d'Extrême-Asie 15 (1): 253-274.

Meilang Zongzhen (Mönlam Tsöndrü). 2005a. "Bangdacang” fanpan gaxia zhengfu shimo kao' (A Study of the Whole Story of the Pangda Family's Revolt against the Tibetan Government). Xizang Yanjiu (Tibetan Studies) 4:15-21.

Meilang Zongzhen (Mönlam Tsöndrü). 2005b. 'Cong "liulang shangren” dao Gaxia zhengfu de "shangshang" - Bangda Nyijiang kao' (From an Itinerant Trader to the Trade Agent of the Tibetan Government - A Atudy of Pangda Nyigyel). Xizang daxue xuebao (Journal of Tibet University) 20 (3): 50-55. 
Meilang Zongzhen (Mönlam Tsöndrü). 20o9. 'Lun er-shi shiji sanshi sishi niandai de Bangda Duoji' (On Pangda Topgyé in 1930s and 1940s). Xizang yanjiu 1: 71-80. Peng, Wenbin. 2002. 'Frontier Process, Provincial Politics and Movements for Khampa Autonomy During the Republican Period'. Khams pa Histories: Visions of People, Place and Authority, edited by Lawrence Epstein, 57-84. Leiden: Brill. Qin Heping. 2007. 'Xiangcheng tutou tongzhi de youlai jiqi shanbian' (Origins and Changes of the Rule by the Indigenous Leaders in Xiangcheng). Xizang yanjiu (Tibetan Studies) 2: 1-9.

Qin Heping. 2014. 'Cong fandui tusi dao jiehou minzhu gaige - guanyu Xiake Daodeng de yanjiu' (From Opposing the Tusi to Accepting the Democratic Reform - A Study of Jagö Topden). Zhongguo zangxue (China Tibetology) 1: 65-79.

Ren Naiqiang. 2009. 'Dege tusi shipu' (The Genealogy of the Dergé Kings). In Ren Naiqiang zangxue wenji (The Selected Tibetan Studies Works by Ren Naiqiang), vol.3, 166-192. Beijing: Zhongguo zangxue chubanshe.

Rockhill, William W. 1891. The Land of Lamas: Notes of a Journey through China Mongolia and Tibet. New York: The Century Co.

Ronis, Jann. 2011. 'Powerful Women in the History of Dege: Reassessing the Event of Reign of the Dowager Queen Tsewang Lhamo (d.1812)'. Revue d'Etudes Tibétaines 21: 61-81.

Sichuan sheng Dege xianzhi bianzuan weiyuanhui. 1995. Dege xianzhi (Gazetteer of Dergé County). Chengdu: Sichuan renmin chubanshe.

Tsewang Dörjé Rikdzin. 1989. Sde dge rgyal rabs (Genealogy of the Dergé Kings). Khren du'u: Si khron mi rigs dpe skrun khang.

Tsomu, Yudru. 2013. 'Taming the Khampas: The Republican Construction of Eastern Tibet'. Modern China, 39 (3): 319-344.

Tsomu, Yudru. 2015. The Rise of Gönpo Namgyel in Kham: The Blind Warrior of Nyarong. Lanham, MD: Lexington Books.

Tsomu, Yudru. 2016. 'Traders as Cultural Brokers on the Sino-Tibetan Borderland During the Republican Period'. Zangxue xuekan (Journal of Tibetan Studies) 14: 177-210.

Tsomu, Yudru. 2018. 'Women as Chieftains in Modern Kham History'. Inner Asia 20: 107-131.

Tubten Püntsok. 2010. Sde dge'i lo rgyus spyi don zla 'od gsar ba'i me long (History of Dergé). Lha sa: Bod ljongs mi dmangs dpe skrun khang.

Tuttle, Gray. 2013. 'Uniting Religion and Politics in a Bid for Autonomy: Lamas in Exile in China and America'. The Tibetan History Reader, edited by Tuttle, Gray and Kurtis R. Schaeffer, 561-582. New York: Columbia University Press.

van Spengen, Wim. 2002. 'A Glimpse of Ethnicities and Societies on the Frontier Through European Travel and Historical Literature in Southern Khams'. Khams 
pa Histories: Visions of People, Place and Authority, edited by Lawrence Epstein, 7-29. Leiden: Brill.

Wang Chuan. 2009. 'Liu Wenhui yu Xikang diqu wangchuan fojiao jie guanxi sulun' (An Account of Liu Wenhui and his Relationship with the Tibetan Buddhist Circle in Xikang). Zhongguo Zangxue (China Tibetology) 3 (2006): 78-84.

Wang Di. 1986. 'Qingmo chuanbian xingxue gaishu' (A Brief Account of Promoting Education in the Sichuan Borderlands at the End of the Qing Period). Xizang yanjiu (Tibetan Studies) 2: 55-62.

Wang Haibing. 2013. 'Luanshi qiucun: minguo shiqi Xiangcheng diqu de tutou tongzhi' (Struggling to Survive at Trouble Times: The Rule of Indigenous Leaders in Chaktreng (Xiangcheng) during the Republican Period). Xinan minzu daxue xuebao (Journal of Southwest University for Nationalities) 6: 69-74.

Wang Juan. 2013. 'Bianjiang zizhi yundong zhong de defang chuantong yu guojia zhengzhi - yi er-shi shiji sanshi niandai de sanci "kangren zhikang" yundong wei zhongxin' (The Regional Tradition and the National Politics in Movements for Borderland Autonomy: Focusing on the Three Movements for 'the Khampa Rule of Kham' in 1930s). Xinan minzu daxue xuebao (Journal of Southwest University for Nationalities) 12: 25-30.

Wu Dianyao. 2006. Zhu De nianpu (xinbianben) (The Chronology of Zhu De) (New Edition). Bejing: Zhongyang wenxian chubanshe.

Wu Fengpei. 1984. Zhao Erfeng chuanbian zoudu (Zhao Erfeng's Memorials of the Sichuan Borderland). Chengdu: Sichuan renmin chubanshe.

Xiake daodeng (Jagö Topden).199o. 'Shi'er yue Xiake Daodeng dian' (The Telegram Sent by Jagö Topden [to Liu Wenhui, the Chairman of Xikang Province] in December [1939]).Jindai Kangqu dang'an ziliao xuanbian (The Selected Archives of Modern Kham). Chengdu: Sichuan daxue chubanshe.

Xiake Daodeng [Jagö Topden]. 199o. 'Shi-er yue Xiake Daodeng dian' (The Telegraph Sent by Jagö Topden in December [1939]). Jindai Kangqu dang'an ziliao xuanbian (The Selected Archives of Modern Kham). Chengdu: Sichuan daxue chubanshe.

Xue Jiangang. 2013. Shilun Qingmo Zhao Erfeng chuanbian xingxue jiqi yingxiang (19o6-1911) (A Tentative Discussion of Promoting Education by Zhao Erfeng in the Sichuan Borderlands and its Impact). MA thesis, Zhongyang minzu daxue.

Yelé Tsültrim, n.d. Lcags mdud mgon rnam pa’i lo rgyus rag rim brjod pa (A Brief Account of the History of Chakdü Gönpo Namgyel). Unpublished manuscript. You Zhen. 2010. 'Quanli zhengzhi yu defang zizhi: er-shi shiji sanshi niandai de kangren zhikang yundong' (Power Politics and Regional Autonomy: The "Khampa Rule of Kham" Movement in the 1930s). Xizang daxue xuebao (Journal of Tibet University) 25 (3): 104-108. 
Zeng Wenqiong. 1988. 'Lun kangqu de zhengjiao lianmeng zhidu' (On the System of Alliance between Politics and Religion). Xinan minzu daxue xuebao (Journal of Southwest University for Nationalities) 2: 17-25.

Zewang Dengdeng [Tsewang Düdül]. 199o. 'Shi'er yue shisan ri Zewang Dengdeng dian' (The Telegram Sent by Tsewag Düdül on December 13 [1939]).Jindai Kangqu dang'an ziliao xuanbian (The Selected Archives of Modern Kham). Chengdu: Sichuan daxue chubanshe.

Zhang Faxian. 2011. 'Jindai Xizang jushang bangdacang' (Pangdatsang, the Great Trader's Family in Modern Tibet). Xizang minzu xueyuan xuebao (Journal of Tibet Nationalities Institute) $3^{2}$ (2): 25-30, $13^{8}$.

Zhang Jingxi. 1939. Sanshi nian lai zhi Xikang jiaoyu (shangjuan) (Education of Xikang for the Past 30 Years), vol. 1. Shanghai: Shangwu yinshuguan.

Zhao Erfeng. 2001. 'Zhao Erfeng dian Zhao Erxun, gao zunzhi jinjiao Ang ni, bing chuanyu Zhandui fanguan, qing daizou dian' (Zhao Erfeng's Telegraph to Zhao Erxun Reporting his Attack against the Rebel Ngawang Jampel Rinchen upon the Imperial Order, Instructing the Tibetan Commissioner Stationed in Nyarong and Requesting to Memorialize on his Behalf). In Jindai Kangzang zhongda shijian xuanbian (Selected Important Events of Modern Kham and Central Tibet) (Part One), vol.1, 504-505. Lasa: Xizang guji chubanshe.

Zhonggong Ganzi zhouwei dangshi yanjiushi. 2012. Hongjun changzheng zai Ganzi zangqu (di'er bian) (The Red Army's Long March in Kandzé (Ganzi) Tibetan Region). (2nd edition). Chengdu: Chengdu keji daxue chubanshe.

Zhonggong Ganzi zhouwei zuzhibu. 1991. Zhongguo gongchadang Sichuan sheng Ganzi zangzu zizhizhou zhuzhi shiliao (The Selected Historical Materials of the Organization of the Kandzé (Ganzi) Tibetan Autonomous Prefecture, Sichuan Province of the Chinese Communist Party). Chengdu: Sichuan renmin chubanshe.

Zhongkeyuan minzu yanjiusuo Sichuan diaochazu. 1963. Dege diqu shehui diaocha baogao (The Report of the Social Investigation of the Dergé Region).

\section{About the Author}

YUDRU TsOMU received her PhD in 2006 from Harvard University in the field of Tibetan Studies and was a postdoctoral fellow at Stanford University in 2007. Her research interest includes Tibetan history, in particular the history of Kham, the study of Tibetan society in Kham as well as cultural interaction and blending in the Sino-Tibetan borderlands. Her present project is entitled 'Eastern Tibet in the Eyes of Chinese Intellectuals during the Republican Period', funded by the Chiang Ching-Kuo Foundation, the 
American Philosophical Society, and the American Council of Learned Society. Her monograph entitled The Blind Warrior of Nyarong: The Rise of Gönpo Namgyel in Kham was published by the Lexington Books in 2015. She has presented her research work at major international academic conferences, and has published articles in English and Chinese, including 'Constructing Images of Mgon po rnam rygal: a Hero or a Villain?' in Revue d'Etudes Tibétaines (2012); 'Taming the Khampas: The Republican Construction of Eastern Tibet', in Modern China (2012). 



\title{
12 Harnessing the Power of the Khampa Elites
}

\author{
Political Persuasion and the Consolidation of Communist \\ Party Rule in Gyelthang
}

Dáša Pejchar Mortensen

\begin{abstract}
The fascinating life story of Wangchuk Tempa (1886-1961), a fierce defender of local autonomy in Gyelthang, illustrates how the Chinese Communist Party utilized the power and charisma of local political and religious leaders to consolidate its rule in southern Kham between $195^{\circ}$ and 1958. Wangchuk Tempa's legendary actions reveal that 'collaboration' is too simplistic a concept to explain why some local leaders joined forces with representatives of the Chinese state in response to mounting social and political pressures in the 1950s. Party officials turned to 'political persuasion' to entice recalcitrant Khampa leaders, such as Wangchuk Tempa, to cooperate, and they strategically granted pre-revolutionary local elites positions in the post-1950 government, in order to strengthen nascent Party control in Gyelthang.
\end{abstract}

Keywords: Gyelthang, tusi system, Khampa rebellions, political persuasion, political tourism, land reform

Acknowledgements: The research for this chapter was made possible through a Charlotte W. Newcombe Doctoral Dissertation Fellowship, a Harry Frank Guggenheim Foundation Dissertation Fellowship, a Jacob K. Javits Fellowship, an Esherick-Ye Family Foundation Fellowship, and grants administered by Davidson College's Dean Rusk International Studies Program and the Faculty Study and Research Program. I am very grateful to my interlocutors and colleagues living in Gyelthang for sharing with me their knowledge of Wangchuk Tempa's exploits and legendary reputation. The convenors and participants of the 2016 international conference on 'Territories, Communities, and Exchanges in the Sino-Tibetan Borderlands' provided valuable feedback on an earlier draft of this chapter.

Gros, Stéphane (ed.), Frontier Tibet: Patterns of Change in the Sino-Tibetan Borderlands. Amsterdam, Amsterdam University Press 2019

DOI: $10.5117 / 9789463728713 \_C H 12$ 


\section{Introduction}

Numerous accounts of the early years of Chinese Communist Party (C.C.P.) involvement in Gyelthang mention the exploits of Wangchuk Tempa (18861961), an early-twentieth-century political and military leader in northwest Yunnan Province. ${ }^{1}$ While a few short testimonials written by C.C.P. officials who interacted with Wangchuk Tempa in the early 195 os recall him as a 'bandit leader' and 'anti-revolutionary rebel' who later came to see the error of his ways (Liao 1987 and Sun 1987), Gyelthang residents today often refer to his legendary actions in laudatory and mythic terms. ${ }^{2}$ Wangchuk Tempa's life story illustrates the extent to which certain members of the Tibetan political and religious elite played crucial roles in the C.C.P.'s consolidation of their rule in Gyelthang. A close examination of these local elites' actions reveals that the C.C.P.'s use of 'political tourism' and 'political persuasion work' to control Gyelthang was far more penetrating than the level of political control that could have been achieved through military conquest alone. ${ }^{3}$

Aside from competing monastic powers in the area, not a single unified political authority or hierarchical social organization formed the basis of collective identity and governance in Gyelthang until the Chinese Communist government exerted its control over the region in the mid-1950s. In the late seventeenth century, the desirability of the area led the Fifth Dalai Lama to dispatch troops from the Central Tibetan (Ganden Phodrang) army

1 Gyelthang is located in the easternmost foothills of the Himalaya Mountains in the northwest corner of present-day Yunnan Province in southern Kham. From 1724 until 2001, this area was referred to as Zhongdian in Chinese. In 2001 Zhongdian County was renamed Xianggelila County. Some of the more detailed Chinese-language sources that describe Wangchuk Tempa's resistance to the Chinese Communist government in Gyelthang in the late 1940s and early 1950s include Sulang 1990, Huang 1998, and Gesang 2010.

2 Interviews with Gyelthang residents in July, 2012, October, 2012, and June, 2014. Jamyang Norbu (Norbu 2009) maintains that Gyelthang residents called Wangchuk Tempa by his Tibetan nickname, Aku Lemar, meaning 'Uncle Hairless', since he was bald, whereas Tibetans from other areas called him Wangchuk Tempa. According to the Zhongdian County Gazetteer, villagers in Termarong (Ch. Dongwang) and Ketsak (Ch. Geza) called him Wangchuk Tembu, whereas villagers from Gyelthang and Yangthang (Ch. Xiao Zhongdian) referred to him affectionately as 'Uncle Wangchuk Tempa'. Yangthang is located 40 kilometers south of Gyelthang's administrative centre, which the Qing government named Zhongdian ting after establishing their garrison there in 1724. The Chinese Communist government later renamed this administrative centre Zhongxin zhen. Tibetans in other areas allegedly insulted Wangchuk Tempa by calling him Wangchuk Tempa Lemar, meaning 'Wangchuk Tempa with the Red Forehead' (Zhongdian xianzhi 1997, 909).

3 For an explanation of 'political tourism', see Bulag (2012). For more on 'political persuasion work', see Mullaney $(2010,105)$. 
to support the growing influence of the Geluk school of Buddhism (Tsomu 2015, 22-23). Although the Karma Kagyü monasteries in Gyelthang resisted this Geluk influence, the Fifth Dalai Lama successfully ordered subjects of the Muli king, located just to the southeast of Gyelthang, to unite with Tibetan-Mongolian allied forces and suppress the Kagyü monasteries' armed insurrection (Wang 1995, 89-151). By the end of the seventeenth century, the Ganden Phodrang had converted many important Kagyü monasteries to the Gelukpa tradition, and due to kinship ties between monastic and secular rulers in Gyelthang, the political influence of the Gelukpa monastic institutions soon became closely intertwined with that of the local wealthy secular rulers (Schwieger 2015, 69). However, despite its influence over the monastic institutions in the region, the Ganden Phodrang government never exerted direct political control over Gyelthang in any consistent manner (Schwieger 2011; Holmes-Tagchungdarpa 2015, 348). In 1724, after successive campaigns in the region by the Qing military, the Qing government stationed garrisons in Gyelthang (Ch. Zhongdian), Dechen (Ch. Deqin), and Balung (Ch. Weixi) and formally incorporated these three districts into Yunnan Province (Wang 1995, 108-109, 159, 171). Yet, even after it came under the nominal jurisdiction of Yunnan Province, day-to-day issues of governance were still largely resolved at the local level in Gyelthang. Up until the Chinese Communist Party consolidated its control over the area in the mid-twentieth century, villages in Gyelthang bonded together primarily for the purpose of dealing with external threats and maintaining social cohesion at the local level. ${ }^{4}$ The way that Wangchuk Tempa mediated between different power holders at the local, regional, and state levels vividly demonstrates how savvy local leaders managed to exert a great deal of control in southern Kham during an era of enormous political and social change. ${ }^{5}$

\section{Wangchuk the Rebel}

Lobsang Nima, or Wangchuk Tempa as he was known later in life, was born into a relatively poor household in Termarong (Ch. Dongwang xiang) in

4 Yudru Tsomu (2015, xxviii-xxix) maintains that a similar system of social organization existed in Nyarong in the nineteenth and early twentieth centuries. Also see Mueggler (2001) for interesting parallels amongst the neighbouring Lòlop'ò.

5 For an account of another charismatic and savvy Khampa strongman, see Yudru Tsomu's chapter in this volume on Jagö Topden. See also Pirie and Huber, eds. (2008). 
1886. ${ }^{6}$ At ten years old, Wangchuk Tempa entered the monastic life, and after receiving ten years of monastic training at Ganden Sumtseling Monastery in Gyelthang, he moved to Lhasa to continue his education one of the monastic colleges (kangtsen) in Sera Monastery for one year (Zhongdian xianzhi 1997, 909). He returned to the Termarong monastic college in Sumtseling Monastery in Gyelthang in 1907, and eight years later he became a teacher in that monastic college.

At the time, Gyelthang was frequently targeted by bandits from Chaktreng and Termarong, where villagers formed bands based on kinship ties and frequently engaged in raids on neighbouring towns. ${ }^{7}$ A group of nearly 100 Sumtseling monks were organized in 1916 to defend the monastery against such bandit attacks, and the leaders of the eight monastic colleges appointed Wangchuk Tempa the leader of this bandit defense force (Zhongdian xianzhi 1997, 909; Gesang 2010, 425-426).

In 1919, after the Chinese Nationalist army stationed in Gyelthang (Zhongdian Town) levied a heavier grain tax on Gyelthang residents in order to support their troops in the area, villagers from 300 households in Termarong rebelled (Zhongdian xianzhi 1997, 909). ${ }^{8}$ Wangchuk Tempa and eleven other Sumtseling monks from Termarong returned to Termarong to participate in the uprising, and villagers soon selected Wangchuk to

6 Wangchuk Tempa was born in the present-day village of Zhalujiangzhong Wang Xueding Village, located in Xinlian Administrative Village in Termarong, which is currently part of Xianggelila County in Diqing Tibetan Autonomous Prefecture in Yunnan Province. The previous name for this village was Kenading, meaning 'above the stockade'. According to the Zhongdian County Gazetteer, the local pronunciation of the name of this village closely resembled the word 'Kanading', which in the Gyelthang Tibetan language had the inauspicious meaning of 'Black Mouth'. When Lobsang Nyima travelled to Lhasa as a young man to continue his studies, he consulted with monastic authorities and was told that Kenading residents had long suffered from poverty because they had the misfortune of living in this ill-named village. Lobsang Nyima was therefore advised to change the name of his village to Wangchuk Tempa, meaning 'wealth and power'. From then on, people in his village started referring to him as 'the one from Wangchuk Tempa Village' (Yunnan sheng difangzhi 2002, 452; Zhongdian xianzhi 1997, 909).

7 According to Yudru Tsomu $(2015,20)$, it was conventional in this region for bandits first to compensate the families of bandits who had died or been wounded during raids, and then to divide what was left of the spoils of war amongst the surviving raiders. For more on banditry in Chaktreng, Termarong, and Gyelthang, see Van Spengen (2002, 15-22); Goullart (1955, 91-92); and Wong (2002a, 17-19).

8 Van Spengen $(2002,19)$ claims that in 1922 'Chungtien [Zhongdian] fell to the Tongwa [Dongwang people] from Konkaling [Gongling near Yading]. It had already fallen into the hands of regular Tibetan troops in 1917, but had been handed over again to the Chinese in 1918. The Tongwa drove out the Chinese officials and robbed the Chinese soldiers of their rifles'. In compiling this historical narrative, van Spengen draws on Rock $(1947,251,257)$ and Kingdon Ward $(1923,29)$. 
lead the rebellion (Zhongdian xianzhi 1997, 909; Yunnan sheng difangzhi bianzuan weiyuanhui 2002, 452; Zhongguo renmin zhengzhi 2003, 141). In the aftermath of the Termarong rebellion, Wangchuk Tempa and his rebel troops turned to banditry, and by the mid-1920s he had recruited a well-armed militia of 2500 men on horseback (Zhongdian xianzhi 1997, 910). ${ }^{9}$ This local militia not only protected Gyelthang from roaming bandits and Chinese military incursions, but also led profitable raids on neighbouring towns (van Spengen 2002, 19). Wangchuk Tempa acquired more military, political, and economic influence over the next few years. In 1923, Luo Shuchang, the provincial garrison commander of Balung, travelled to Termarong to meet with Wangchuk Tempa and appointed him the Deputy Commander of the District Defense Force (tuanfang) for Gyelthang, Balung, and Dechen (Zhongdian xianzhi 1997, 909). Wangchuk Tempa set up his government headquarters in Zhongdian Town and used his considerable political and military clout to enforce strict security in the region (Gesang 2010, 426).

Bandit raids from Termarong and Chaktreng continued to plague Lijiang and the Tibetan areas just to the south of Gyelthang, and in 1927 the Zhongdian County Governor appointed Wangchuk Tempa the commander of Zhongdian's monk and layperson militia (sengsu tuanwu zhihui) (Zhongdian xianzhi 1997, 910). Due to Wangchuk Tempa's willingness to ruthlessly suppress all uprisings in the area, his military, political, and economic power base quickly surpassed that of any of the 23 tuguan and county governors in Gyelthang, Balung, or Dechen (Zhongdian Xianzhi 1997, 910). The Nationalist government appointed Kelzang Tsering, a Khampa from Bathang, to be the Commissioner for Guomindang Affairs of Xikang, and in $193^{2}$ the Nationalist government sent him to Bathang to establish a Nationalist Party organization in the region and weaken the influence of the Sichuan warlord Liu Wenhui (Tuttle 2005, 147-150). ${ }^{10}$ Kelzang Tsering joined with local people to launch the 'Khampa rule of Kham' (Kangren zhi Kang) movement from his home town of Bathang, and in 1932 he gave

9 Joseph Rock $(1925,453)$ reports on one battle in 1923, in which 1200 Tibetan 'bandits' crossed the Yangtze River and fought the 'Battle of Peshwe Bridge' within 20 miles of Lijiang, killing many Chinese soldiers. Van Spengen $(2002,19)$ urges us to be cautious about the accuracy of Rock's report, since Rock indicates that almost the entire Chinese army was killed, compared to only one of the reportedly 1200 Tibetan 'bandits' who fought in this battle.

1o Nationalist government officials, Chinese de facto military leaders in Kham (such as Liu Wenhui), and Republican intellectuals (such as Ren Naiqiang) referred to Kham as 'Xikang' well before the province of Xikang was officially established in 1939. Tsomu (2013) and Relyea (this volume) describe many of the competing political discourses regarding the Kham frontier during the Republican era. 
Wangchuk Tempa the power to investigate all incidents of unrest in the southern Kham regions of Gyelthang, Dechen, and Balung and use his local militia to restore peace (Zhongdian xian zhi 1997, 910; Gesang 2010, 428). ${ }^{11}$

\section{Encountering the Communists}

When the Chinese Workers' and Peasants' Red Army passed through northern Yunnan Province in May, 1936, Wangchuk Tempa commanded his militia to attack the bedraggled and half-starved Communist troops. ${ }^{12}$ A total of 160 soldiers and five officers were killed and many more were wounded during armed skirmishes with Wangchuk Tempa's militia during the seventeen days that the Red Army spent gathering supplies or crossing the mountain passes in Gyelthang (Sun 2011). ${ }^{13}$ While many Gyelthang residents joined Wangchuk Tempa's militia in fighting against the Red Army, others appear to have been at least partially won over by the Red Army soldiers' actions, speeches, and musical performances in town. ${ }^{14} \mathrm{~A}$ growing

11 For more on Kelzang Tsering's role in the Guomindang government, the 'Khampa rule of Kham' movement, and the power struggle between Liu Wenhui, the Nationalist government, and Kelzang Tsering in Xikang, see Goldstein et al. (2004, 10-14), Peng (2002, 72), Tuttle (2005, 148-149), and Lawson (2013).

12 As various Communist armies in the south attempted to evade being captured by Nationalist troops, different divisions of the Chinese Workers' and Peasants' Red Army (Zhongguo gongnong hong jun) took part in a series of marches that later came to be known collectively as the 'Long March'. Arguably the best known division of the Red Army is the First Front Army of the Chinese Soviet Republic, which marched from Jiangxi Province to Shaanxi Province between October, 1934 and October, 1935. In Yunnan, the Long March took place much later, as Commanders He Long and Xiao Ke led 18,0oo troops in the Second and Sixth divisions of the Red Army through Gyelthang and into Sichuan Province between 25 April and 9 May 1936. As an important landmark in the history of the Communist Party, the Long March is currently commemorated in the Diqing Red Army Long March Museum in Gyelthang, as well as at other former sites along the Red Army's route. One of the main streets that runs from north to south in Zhongxin Town was named Long March Road (Changzheng lu) in 1982 (Sulang 1990, 108; Diqing zhouzhi 2003, vol. 1, 22). The Second Front Army described the challenges that it faced in securing adequate food provisions in Kham during the Long March in 'Zhongguo gongnong hongjun er fangmian jun zhengzhi bu' (1991). Sperling (1976a) and Liu (2004, 96-98) analyze the major linguistic, political, and logistical obstacles that the Red Army faced in Kham.

13 The Yunnan Provincial Gazetteer reports that over 200 Red Army soldiers and five officers were killed during battles with Wangchuk Tempa's militia in 1936 (Yunnan sheng difangzhi bianzuan weiyuanhui 2002, 452).

14 Some Gyelthang residents joined the Red Army as translators when the army came through town and seven of these translators died in battles just a few days after joining the army. Interview with the director of the Diqing Red Army Long March Museum in Gyelthang in July, 2014. There are also (somewhat questionable) accounts of pregnant Tibetan slaves, who were so impressed 
underground Communist Party (dixia dang zuzhi) gained support among young, well-educated, and relatively wealthy Tibetan and Naxi residents in Gyelthang during the fourteen years between the Red Army's departure from Gyelthang in 1936 and the People's Liberation Army's arrival in $1950 .{ }^{15}$

A small group of Tibetan Communist activists proposed to use Dechen as their base of operations from $1945^{-1946}$, since there were not any permanently stationed Guomindang troops in Dechen at that time. Moreover, the de facto governor of Dechen was Gönpo Tsering (Ch. Hai Zhengtao), a Tibetan Communist Party sympathizer who had joined the government of the short-lived independent 'Böpa People's Republic', or 'Greater Tibetan State' (Ch. Da Xizangguo) set up by the Red Army in Ganzi (Kandzé) in Sichuan Province, when the Red Army crossed through Kham during the Long March (Wangyal 2007, 5; Goldstein et al. 2004, 94; Liu 2004, 95-99). In order to stave off an invasion by the Japanese military, which was in control of nearby Burma in 1945, the Guomindang sent Gönpo Tsering to Dechen with a supply of 300 guns and a mandate to establish a local Tibetan guerilla force to defend the area. Gönpo Tsering soon became the commander of the Dechen military and the governor of Dechen County; Han Chinese residents of Dechen called him 'Commander Hai' (Hai siling) (Deqin xian zhi 1997, 343; Goldstein 2004, 94).

In September, 1946, Gönpo Tsering, Bapa Püntsok Wangyel from Bathang, Ngawang Kesang from Xikang, and He Qichang from Gyelthang secretly established the 'Eastern Tibetan People's Autonomous Alliance' (Böshar gyümi mang rang kyong na tün; Ch. Dongzang renmin zizhi hui) in Yunniang Village, located in Shengping Town in Dechen (Sun 2011). ${ }^{16}$ The Charter of the Eastern Tibetan People's Autonomous Alliance cited Sun Yatsen's Three Principles of the People as its guiding philosophy and announced the alliance members' intentions to improve Khampas' lives by introducing new farming techniques, building roads, and abolishing the corvée tax system. Chinese Communist-style guerrilla warfare tactics would be utilized to overthrow

by the Red Army commanders' speeches about the need to do away with social inequality in Gyelthang that they named their newborn children 'Communist' (Le'an 2003, 84).

15 The biographies of Tashi Tsering and Bapa Phüntsok Wangyel provide useful insights into why some young Tibetans found communism attractive in this early period (Wangyal 2007; Goldstein et al., 1997; Goldstein et al., 2004). On Naxi support for the underground Communist movement in Lijiang in the 1940s, see White $(2002,134)$.

16 He Qichang was a Tibetan merchant who came from a powerful and wealthy family in Gyelthang. His father, He Rongguang, served as the Police Chief of Zhongdian County and the company commander (qianzong) of the defense force in Ketsak during the Republican period until he was assassinated by the monk warlord Ajian from Termarong in 1930 (Feng 2013, 151; Zhuoma 2015, 4). 
local Guomindang-backed warlords and establish a truly autonomous region for Tibetans in southern Kham (Goldstein et al. 2004, 99-100, 319-324). The leaders of this alliance intended to recruit Dechen Middle School students to join their organization and to finance their expanding organization by taking control of the Guomindang tax office in Dechen. However, their plan was foiled when the Guomindang preemptively discovered their intentions and killed Gönpo Tsering. ${ }^{17}$

In the wake of this failed uprising against the Guomindang-backed Chinese warlords in southern Kham, the number of Gyelthangpa in the Communist Party gradually grew in the late 1940s, but the majority of Gyelthang's secular and religious leaders remained wary of joining the underground C.C.P. ${ }^{18}$ Ever since the Guomindang government had appointed Wangchuk Tempa the Vice Governor of Zhongdian County in the early 1940s, it had become increasingly dangerous for revolutionary-minded Gyelthang residents to agitate for local political, social, or economic change. Throughout the 1940s, Wangchuk Tempa continued to consolidate his power by engaging in well-planned attacks on his enemies, including a highly-esteemed lama from his home town of Termarong. In the aftermath of one particularly vengeful attack, during which Wangchuk Tempa's troops looted and burned 72 houses in a village near Ganden Sumtseling Monastery, Ngawang Lobzang Tendzin (1899-1967), the seventeenth reincarnation of the Zangbum Lama of Ganden Sumtseling Monastery in Gyelthang, reportedly became very alarmed. He summoned Wangchuk Tempa to ask him when he intended on turning his wrath against the Rinpoche himself (Zhongdian xian zhi 1997, 911; Wong 2002b, 11).

Wangchuk Tempa allegedly expressed remorse for the hundreds of lives he had taken in battle, and in 1947 he travelled to Lhasa to rededicate himself to

17 The C.C.P. posthumously awarded Gönpo Tsering membership in the Communist Party (Deqin xian zhi 1997, 6; Le'an Wangdui 2009, 17). Püntsok Wangyel subsequently fled and spent the next few months in hiding; he eventually ended up becoming one of the most influential and controversial Tibetan leaders in the Communist Party (Goldstein 2004).

18 Apart from He Qichang, a few other young Gyelthangpa joined the underground Communist Party in Lijiang in 1947 and quickly rose through the ranks of the Party. One such student was Liu Hanxun (1918-1972), the second son of Liu En (1888-1967), a powerful tusi in Gyalthang. As a young man, Liu Hanxun travelled to Lijiang to take the entrance exam for high school. Upon failing the exam, he became a horse caravan (mabang) leader and merchant on the Tea Horse Road (cha ma gu dao) that ran from southern Yunnan, through Gyelthang, and west to Lhasa (Yang 2013). Leather workers in Gyelthang, as well as Nyishar potters, who had become famous for their beautiful black clay pottery, also used the Tea Horse Road trade network to sell their commissioned wares to Tibetan patrons in Lhasa (Interview with Nyishar potter on 26 April 2013). 
Buddhist studies. However, just one year later, he returned back to Gyelthang, since monastic leaders in Lhasa had urged him to defend his home town from Communist aggression after the P.L.A.'s recent military successes in other areas of Kham (Zhongdian xian zhi 1997, 911).

In April 1949, Li Liesan, the leader of the Snow Mountain Society (Xueshanshe), a trade insurance association (baoshangdui) based in Lijiang, invited Wangchuk Tempa's nephew, Wang Qupi, to dinner and appointed him the director of the Gyelthang office of the Snow Mountain Society. ${ }^{19}$ The next month, at the invitation of the Snow Mountain Society, Wangchuk Tempa sent one of his trusted embassaries to Lijiang to meet with He Qichang and inquire about cooperating with the underground Communist Party to expel a bandit gang from southern Kham (Zhongdian xian zhi 1997, 911).

In late August 1949, the Communist Party sent ten members of the Western Yunnan Work Group to meet with Wangchuk Tempa and the monastic leaders of Ganden Sumstenling Monastery and discuss the C.C.P.'s ethnic and religious policies (Zhongdian xian zhi 1997, 911; Song and Tao 1992a, 39). The Party representatives were prepared to write a very glowing report about the progress the Party had made in Tibetan areas of Yunnan, when they were blindsided. On 3 September 1949, as they rode through the south gate of Zhongdian town, accompanied by a security retinue of a dozen members of Gyelthang's City Defense Volunteer Militia (chengfang yiwu dadui) - including founding members of the Gyelthang branch of the underground Communist Party - they were intercepted by Lobsang Wangdü, Wangchuk Tempa's trusted friend and the commander of the Yangthang Civilian Corps (Xiao Zhongdian mintuan dadui).$^{20}$ According to a first-person

19 In the late 1940s, two of the most successful traders in southern Kham were Li Liesan, a wealthy merchant from Lijiang who controlled much of the horse caravan trade in Gyalthang in the 1940s, and the Heqing merchant Bao Pinliang. Li and Bao joined together in 1947 to form a very successful trade insurance association (baoshangdui), called the Snow Mountain Society (Xueshanshe), which expanded its membership base to over 40,00o merchants across Kham and into southern Yunnan Province by the late 1940s. Liu Hanxun and He Qichang worked directly under the command of Li Liesan and engaged in a thriving horse trade caravan business (Feng 2013, 119). Many prominent members of the Snow Mountain Society also joined the underground Communist Party in Heqing and Lijiang in 1948 and 1949.

20 During the late 1940s, wealthy landholders in Southern Kham frequently worked together to fund privately-run Civilian Corps (mintuan dadui) to military defend their regional interests and protect their towns from bandit raids. The leader of the Yangthang Civilian Corps was Lobsang Wangdü, who much like Wangchuk Tempa, was a former monk-turned-brigade leader. In 1927, after the Zhongdian County Governor appointed Wangchuk Tempa the commander of Zhongdian's monk and layperson militia, Wangchuk Tempa turned over the job of defending Yangthang to his trusted friend, Lobsang Wangdü (Zhongguo renmin zhengzhi xieshang huiyi 2005, 9). 
narrative account written by Song Guozhu, one of the commanders of Gyelthang's City Defense Volunteer Militia and the squad leader (bazong) of Gyelthang, Lobsang Wangdü announced that Wangchuk Tempa insisted his Yangthang Civilian Corps should escort the Western Yunnan Work Group members from Gyelthang to Jiangbian to ensure their safe passage. The Gyelthang City Defense Volunteer Militia members were wary of Wangchuk Tempa's intentions, and they refused Lobsang Wangdü's offer three times, but eventually they were persuaded to hand over responsibility for the security of the Western Yunnan Work Group to the Yangthang Civilian Corps (Song and Tao 1992a, 41). Later that afternoon, local bandits launched a surprise raid on the Western Yunnan Work Group, killing six members of the work group, including Li Liesan, and injuring five others (Zhongdian xian zhi 1997, 911). Although Wangchuk Tempa adamantly denied responsibility at the time, he was widely rumoured to have orchestrated the attack (Song and Tao 1992a, 41). ${ }^{21}$

On 20 October 1949, Wangchuk Tempa assembled the chieftains from Gyelthang, Dechen, and Balung, along with the monastic leaders of Sumtseling and the surrounding monasteries, to discuss the region's future. At the meeting, Rinpoche Ngawang Lobzang Tendzin of Ganden Sumtseling Monastery, and Zhao Baohe, the Tibetan commander of Gyelthang's City Defense Volunteer Militia and a relatively new member of the Communist Party, tried to convince Wangchuk Tempa that the P.L.A. was too powerful and that he should try to negotiate rather than fight a losing battle (Le'an 2003, 18). Wangchuk Tempa ignored this advice and organized a number of local militias to engage in a well-coordinated attack on the P.L.A. on 29 October 1949. The attack was successful, and Wangchuk Tempa's coalition militia killed many P.L.A. soldiers and work team members, burned Party offices, and stole valuable P.L.A. property. ${ }^{22}$

One of the C.C.P.'s most strategic moves in governing ethnic minority regions was its United Front policy of incorporating local ethnic leaders into its post-1949 government. From 29 August 1950 until 31 January 1951, the central Chinese government in Beijing dispatched a delegation

21 In a confession he wrote in 1959, which he most likely penned under duress after undergoing a series of interrogations during the Anti-Rightist Campaign, Wangchuk Tempa expressed remorse for having planned this deadly ambush (Wang 1989, 615).

22 According to the Zhongdian County Gazetteer, Wangchuk Tempa met with the tusi and monastic leaders in Gyelthang, Dechen, and Balung, to raise funds and support for a militia to repel the P.L.A. from the region. Many battles took place during the winter of 1949-1950, including one battle in which 330 houses were burned in Judian (Zhongdian xian zhi 1997, 911). 
of anthropologists, linguists, and Party workers to learn more about the social and economic conditions in northern Yunnan Province (Mullaney $2010,8)$. The delegation's 1951 report provided the foundational knowledge necessary to implement its United Front policy designed to win over the support of local elites. ${ }^{23}$ Under this policy, the C.C.P. officials gave Tibetan religious leaders and wealthy traders prominent positions in the Zhongdian government in the early 1950s, while the People's Liberation Army worked to fully secure this frontier region. Some of the founding members of the C.C.P. in Zhongdian were the educated sons and grandsons of wealthy landlords and tusi (native chieftains). ${ }^{24}$ Young Tibetan C.C.P. members utilized the United Front policy to ensure that their own relatives retained their pre1949 political authority in the region. ${ }^{25}$ The C.C.P. hoped to minimize the possibility of resistance in ethnic minority areas where Party control was weak and its ignorance of local customs was potentially dangerous. This policy of cooperation with the 'patriotic upper strata' also enabled the C.C.P. to handle a dire expertise gap, as local elites often served as translators, mediators, or cultural brokers, and were used to smooth relations between the Party and the populace.

According to Communist Party historiography, Gyelthang was officially 'peacefully liberated' (heping jiefang) on 10 May 1950 (Zhongdian xian zhi 1997, 911). Two days later the P.L.A. sent Wangchuk Tempa's good friend, Lobsang Wangdü, who had already been persuaded to work on behalf of the C.C.P., to urge Wangchuk Tempa to negotiate with the new Communist government. Flanked by his personal bodyguards, Wangchuk Tempa met with the P.L.A. General, Liao Yunzhou, and the Zhongdian County Governor, Sun Zhihe, along with Liu En and Nyetsang Tsering Püntsok, two Tibetan native liutenants (tuqianzong) who had begun working with representatives of the underground Communist government the previous year, on the

23 The Visitation Team published their results in July, 1951 in a document titled The Report of Sub-group Two of the Central Visiting Delegation to Investigate the Conditions of the Ethnic Minorities in Yunnan Province. In 1986 the Yunnan Nationalities Publishing House reprinted this document for general circulation; see Yunnan sheng bianji zu 1986. For more on the United Front policy, see Smith (1994, 55); Bulag (2010, 17), and Weiner (2012).

24 For more on the tusi system in Zhongdian, see Qi $(1993,198)$.

25 On 28 August 1949, the first underground Communist Party branch was established inside the town limits of Zhongdian. By the time the P.L.A. arrived in Gyelthang in May, 1950, more than thirty young Tibetan, Naxi, Bai, and Han residents of Gyelthang had joined the Communist Party or the Communist Youth League (Feng 2013, 138, 151; Le'an Wangdui 2009, 17). The Khampa elites that were in power in the 1930s and 1940s in Gyelthang, Termarong, and Nyishar either remained in power or passed their positions of power onto their sons in the 1950 s and early $1960 \mathrm{os}$, until many of them were killed during struggle sessions at the height of the Cultural Revolution. 
Jingkou mountain pass and negotiated his surrender to the P.L.A. ${ }^{26}$ As a sign of good will, Wangchuk Tempa presented General Liao with four yaks and a Tibetan blanket piled high with gold and silver coins. According to General Liao, who published his account of this meeting in Diqing Prefecture's first volume of officially-collected 'Cultural and Historical Materials' (wenshi ziliao), Liao agreed to accept the four yaks and the blanket out of respect for local gift-giving customs, but he turned Wangchuk Tempa's gold and silver over to the P.L.A. finance office (Liao 1987, 13) ${ }^{27}$ General Liao congratulated Wangchuk Tempa on being appointed to the position of Vice-Governor of Zhongdian County, and he tried to persuade Wangchuk Tempa to accept this post, but Wangchuk Tempa was reportedly reticent to do so (Zhongdian xian zhi 1997, 912).

26 All told, between 1948 and 1953, Wangchuk Tempa battled the P.L.A., surrendered, and then fought them again before professing to surrender again, betraying his allegiance to the P.L.A. and the C.C.P. at least four times. Each time, Chinese Communist Party organizers in Gyelthang tried hard to win Wangchuk Tempa over by giving him even more prominent official government posts (Wong 2002, 11). Liu En was born in the Gyelthang town centre in 1888. He was fluent in both Chinese and Tibetan, and in 1904 he became the native second lieutenant (tubazong) of Yangthang. In 1912, when the Yunnan Republican army came through Gyalthang on its westward march, Liu was given the responsibility of provisioning the Republican army with grain. According to Zhongdian County records, Liu carried out his official duties honorably, and he was awarded a medal of distinction by the Republican government. In 1913 he was appointed to be the native lieutenant (tuqianzong) of Nyishar. In 1932 he successfully organized a local Gyelthang militia to defend the town from Chaktreng bandit attacks, and in acknowledgement of his success, the Guomindang government subsequently appointed Liu to be the Governor of Zhongdian County. In 1944 he was appointed to a new post as Vice-Governor of Zhongdian County (Diqing zangzu zizhizhou minzu zongjiao shiwu weiyuanhui, ed. 20o1, 236; Zhongguo renmin zhengzhi xieshang huiyi, ed. 2003, 144-147; Zhongguo renmin zhengzhi xiesheng huiyi, ed. 2005, 32-33). Nyetsang Tsering Püntsok (Ch. name: Qi Yaozu), was born in 1927 in the Gyelthang town centre. He inherited the post of native lieutenant of Nyishar after his father passed away in 1946 (Zhongguo renmin zhengzhi xiesheng huiyi, ed. 2005, 68-70).

27 Starting in the early 1980 s, Political Consultative Conference members in the Diqing Tibetan Autonomous Prefecture in Yunnan Province began to compile carefully edited, detailed accounts of early Communist Party involvement in this area. Nine volumes of testimonies penned by Tibetan, Naxi, Bai, Han, and Hui religious and political leaders in Diqing were published as wenshi ziliao (cultural and historical materials) between 1987 and 2013. Many of these published documents were local Political Consultative Conference (zhengzhi xieshang huiyi) members' recorded recollections of critical moments between 1949 and 1957 when the People's Liberation Army and the Chinese Communist Party faced local armed resistance in Diqing. These accounts all conclude with the ultimate triumph of the Communist Party after P.L.A. commanders and C.C.P. cadres negotiated with landholders, monks, and warlords, and assured them of the Party's benign religious and ethnic policies. For more on the United Front and the political goals of wenshi ziliao production in the reform era, see Mortensen (2017) and Fromm (2019, 110-153). 
It is likely that Wangchuk Tempa surrendered to the P.L.A. in order to buy time to plan a series of well-coordinated militia campaigns, since he organized two more armed rebellions against P.L.A. troops and Communist leaders in the region in late May, 1950, leading to the deaths of many P.L.A. soldiers, work-team members, and self-defense forces. ${ }^{28}$ On 21 May 1951, Wangchuk Tempa supported a rebellion in the ethnically Naxi area of Sanba, located approximately 120 kilometers to the southeast of Termarong, by sending troops, weapons, and supplies, but the rebellion was suppressed by the P.L.A. (Zhongguo renmin zhengzhi xieshang huiyi, ed. 2003, 62). His nephew, Wang Qupi, started another uprising in March, 1952, when he killed six merchants from Zhongxin Town who were travelling through Yangthang under the protection of General Liao (Sulang 1990, 112; Zhongguo renmin zhengzhi xieshang huiyi, ed. 2003, 62). This uprising lasted until Wangchuk Tempa's troops bore the brunt of a particularly lengthy and devastating exchange of fire in Barlungdrong village (Zhongguo renmin zhengzhi xieshang huiyi, ed. 2003, 63; Thondup 1992; McGranahan 2010, $67){ }^{29}$ The injured Wangchuk Tempa fled with his nephew and 60 of his surviving militia members to a mountain cave in Termarong (Zhongdian xian zhi 1997, 912).

In order to persuade Wangchuk Tempa to come out of the mountains, surrender, and join the new C.C.P. government, General Liao asked one of Wangchuk Tempa's former bodyguards, a Tibetan monk from Yangthang, to join Liao in explaining the C.C.P.'s religious policy to Wangchuk Tempa (Song and Tao 1992b, 86). General Liao also requested Liu En and Nyetsang Tsering Püntsok, the two native liutenants who had been working for the Communist government in Gyelthang since 1950, to negotiate again with Wangchuk Tempa. These Tibetan leaders promised Wangchuk Tempa that if he surrendered to the Communists, he would not be harmed or prosecuted, but instead made a member of the Lijiang Special District United

28 For more on the organizational work that the Communist Party did in Gyelthang to support these predominately Tibetan self-defense forces (ziwei dui yuan), which were referred to locally as the hulu dui, and which later became part of the broader national coalition army known as the 'people's militia' (minbing), see Zhongdian xian zhi $(1997,409)$.

29 The extent of local resistance to the People's Liberation Army's advances is on display today in Gyelthang's Memorial Park, where numerous P.L.A. soldiers who were killed during the so-called liberation of Gyelthang have been buried. Located at the entrance to the Old Town at the southern end of Long March Road, Memorial Park has recently been remodelled. It now boasts an impressive bronze statue of a P.L.A. soldier, a colourful mural with inscriptions observing the event in both Tibetan and Chinese, and newly-planted flowers and trees near the tombs of the fallen soldiers. Every year on Tomb Sweeping Day (Qingming jie), teachers bring their pupils to the Memorial Park cemetery and require them to sweep the P.L.A. soldiers' tombs. 
Government Committee (Lijiang zhuanqu lianhe zhengfu weiyuan). In the end, Wangchuk Tempa capitulated and, accompanied by his four most loyal bodyguards, travelled to Zhongdian Town to meet General Liao and other members of the Lijiang-based United Front Department (Zhongdian xian zhi 1997, 912). The C.C.P. cadres' patience and tenacity in repeatedly engaging in prolonged negotiations with Wangchuk Tempa, despite frequent setbacks and betrayals, demonstrates the extent to which the Party was willing to go to entice powerful Khampa elites to join the United Front.

\section{Wangchuk's Adventures as a Political Tourist}

Wangchuk Tempa was initially very wary of the Party's policies and skeptical that the Communists had the Tibetans' best interests in mind, but he attended United Front officials' lectures in Zhongdian and Lijiang about the Party's ethnic minority policies and eventually, in 1953, he agreed to go on a trip to Chongqing. In Chongqing, Wangchuk Tempa encountered Commander He Long for the first time since they last met on the battlefield in 1936 during the Second Red Army's Long March through Yunnan. According to Communist Party wenshiziliao sources, much to Wangchuk Tempa's surprise, Commander He expressed little animosity toward Wangchuk Tempa for his past actions, including his violent attack on Commander He's own caravan in 1936 (Gesang 2010, 443-444). Instead, Commander He assured Wangchuk Tempa that the Party would not prosecute him for his past crimes, maintaining that Wangchuk Tempa had actually assisted the Communist Party by adroitly defending the autonomy of the Gyelthang people. Commander He listed three ways that Wangchuk Tempa had resisted the imposition of Nationalist government policies in Gyelthang: he had opposed the Nationalist government's efforts to conduct land surveys in Gyelthang, prevented the Nationalist army from conscripting Gyelthang residents, and blocked the circulation of Nationalist-government-issued currency in 1948 (Zhongdian xian zhi 1997, 912).

After a lengthy conversation and many cups of tea, Commander He made arrangements for Wangchuk Tempa to attend Party education classes in Chongqing for the duration of the week (Zhongdian xian zhi 1997, 912). The next week a different battalion commander accompanied Wangchuk Tempa to Beijing to attend Party classes. In Beijing he was welcomed by representatives of the United Front Department and the Nationalities Affairs Committee. Over the course of the next few years, Wangchuk Tempa joined United Front Department cadres and other ethnic minority leaders on 
official tours to schools, factories, and farms in Hunan Province, Beijing, and Kunming. The purpose of these tours was to show the former elite class the progress that China was making under a new socialist system. ${ }^{30}$

Travel and sightseeing, or what the anthropologist Uradyn Bulag has termed 'political tourism', played an important role in the Chinese Communist Party's attempt to win over and transform ethnic minority leaders (Bulag 2012, 147-148). After the C.C.P. came to power, Communist leaders made a concerted effort to invite so-called 'representative figures of the upper echelon' - ethnic minority members of the traditionally elite strata who had not joined the Communist Party - to participate in political tourism. The most important quality for selection as an invitee was the person's 'radiating power' (fusheli), which was measured by the number of people that this person could directly or indirectly influence (Bulag 2012, 143). Although the delegates' attitudes toward the Communist Party were investigated ahead of time, hostile attitudes did not necessarily exclude elites from being invited to participate in political tourism. In fact, as Bulag points out, 'the more powerful or hostile they were, the greater the chances of being invited to Beijing' (ibid.). Certain elites, like Wangchuk Tempa, were even permitted to bring their bodyguards.

The rationale for these political tours originated in a proposal that Ren Naiqiang (1894-1989), a Chinese ethnologist specializing in southwestern frontier issues, made to the Sichuan warlord, Liu Wenhui, in 1934. Ren suggested that 'sightseeing' (guanguang) would be one of the most effective ways to promote the assimilation of Tibetans into a newly constituted Chinese nation. He maintained that ethnic minority leaders who had been to China proper and interacted with the Chinese over a long period of time tended to be more politically submissive, whereas those with limited knowledge of China were more arrogant. Ren alleged that, living in isolation, the frontier people were 'like frogs in a well', convinced that the small circle of sky visible above them was actually the entire heavens. When ethnic minority leaders were 'told about the great size of China and the large population of the Han Chinese people by outsiders who had visited Nanjing and Shanghai', Ren explained, 'they roared with laughter, dismissing it as a lie' (Ren 1934, 232). By Ren's reasoning, the frontier people's resistance to integration was not a political request for maintaining a separate polity for themselves; rather it stemmed from their ignorance of Chinese political and economic policies.

30 In an interview with Melvyn Goldstein in 2003, a Khampa recalled how popular these political tours were amongst young Khampas living in Kandzé in the early 1950s (Goldstein $2014,117)$. 
Their alleged belligerence was attributed to geographical isolation, and the only way out of it was for the frontier people to travel to China and personally observe the country's modernity. ${ }^{31}$

Building on Ren's civilizing logic, the United Front Department designed political tours to positively shape minority leaders' impressions of China. Bulag maintains that:

Prior to each visit, minority leaders would be fed with particular lines of information, and after the visit, they would be organized to have a seminar discussion, not to explore issues from different angles, but to achieve a unified understanding or consensus of what they had seen. Should one of them have a different, or rather 'wrong' opinion, he or she would be 'helped' to understand why they were in the wrong. At the end of the tour, minutes would be drafted, which would then be sent to the provincial or prefectural party committee for approval. The minutes were usually filled with lines of how elite visitors were impressed by Chinese hospitality, how advanced Chinese regions were, and most importantly how powerful the Chinese were. [...] The minority visitors would each be given a copy of the minutes and then charged with going back to their villages to make oral reports on what they had seen. (Bulag 2012, 145-146)

Party documents suggest that Wangchuk's tour of inland China may have helped convince him of the power of the Communist government, or at least of the futility of fighting against it (Gesang 2010, 444). A few months after returning back to Gyelthang in 1953, Wangchuk expressed his willingness to work with the leadership of the Communist Party, and later that same year he agreed to serve as the Vice Governor of Zhongdian County under C.C.P. rule.

\section{The Socialist Transformation of Gyelthang}

As the C.C.P. worked to incorporate Gyelthang into their vision for a new 'modern' Chinese Communist nation-state in the early 1950s, the C.C.P. initially adopted a 'gradualist approach’ to implementing socialist reforms,

31 As Yudru Tsomu points out, 'historical analogy was useful for Ren to justify the assimilation of the people of Kham into China', as it suggested that 'frontier peoples are living in an earlier stage of historical development' and 'civilizing them is simply a matter of bringing them forward in time' (Tsomu 2013, 336). 
since Party officials recognized the importance of gaining the support of local Tibetan, Naxi, Bai, and Han residents while they worked to secure administrative control over the region..$^{32}$ The C.C.P. leaders understood that winning the trust and loyalty of the Gyelthang elites would require patience and perseverance during numerous discussions, private meetings, and public speeches.

The C.C.P.'s United Front Department was responsible for using a variety of tactics to co-opt local elites and build a broad consensus among non-Party members and ethnic minority residents for Party-supported programs and goals. One such tactic was political tourism. Another was 'political persuasion work' (zhengzhi shuifu gongzuo), which entailed lengthy meetings between recalcitrant Tibetan leaders and other local elites who had already been won over by the Communists. Treaties were signed and ceremonies were held to mark the success of winning over particular elites. Rather than deposing, imprisoning, or killing these elites, Communist Party officials encouraged them to join the new government's efforts to govern Gyelthang.

However, while many C.C.P. officials who arrived in Gyelthang after $195^{\circ}$ believed that a policy of compromise was crucial to forming good relations with the local elites, they nevertheless remained suspicious of the political loyalties of these elites. ${ }^{33}$ With rare exceptions, the older generation of wealthy and powerful local elites were not invited to join the C.C.P.; they were instead given government positions that corresponded with the Party's assessment of their potential future value. The C.C.P.'s intent was to maintain traditional symbols of power while gradually changing the content that they symbolized. The Party's policy of compromise was never intended to be permanent; it was only meant to be implemented until the Party's position had been consolidated in Gyelthang. As the Party gained support, as young Gyelthang residents completed their training as new C.C.P. cadres, and as recently-arrived Chinese cadres became familiar with the situation in Gyelthang, the Party envisioned having more room to manoeuvre against the will of the local elites.

The early stages of Communist Party consolidation and state making were welcomed by some residents of Gyelthang, as they seemingly represented a new Chinese administration willing to work alongside local leaders and power holders. Other Gyelthang elites remained wary of C.C.P. rule, having

32 Mao and others within the central Party leadership initially supported this national strategy of gradualism in Yi and Tibetan regions of western China (Goldstein 2014, 4-16, 88).

33 For more on the Communist Party Central Visitation Team's concerns in $195^{1}$ about the political loyalties of the former tusi leaders in Zhongdian, see Wang 1987, 18-20. 
learned early on that landlords in neighbouring Jiangbian had been subjected to violent struggle sessions, tortured, and killed. ${ }^{34}$ Tibetan elites feared that if land reform was implemented in Gyelthang, they would also be struggled against and perhaps killed. They knew very well that they would be targeted by the so-called 'democratic reforms' (minzhu gaige) - the version of land reform (tudigaige) deemed appropriate for ethnic minority areas - despite the fact that the C.C.P. leadership had insisted land reform would be introduced only after consultation with local power holders.

In order to assuage the local elites' concerns, the C.C.P. gradually introduced social and political reforms in Gyelthang. Fearing that a strong emphasis on class would alarm the upper social strata, C.C.P. officials appointed Tibetan elites - often the same people who had served as intermediaries under the Guomindang and its allies - to posts in the newly-established C.C.P. government in Gyelthang, where they served both as filters and conduits between the masses and the state. ${ }^{35}$ While there were obvious risks in allowing the secular and religious elites to retain real power in the short term, the long-term benefits of winning over the Tibetan population were so significant that the C.C.P. was willing to make extraordinary concessions. It was a shrewd strategy that traded short-term setbacks (permitting local religious leaders to retain power and the manorial estate system to continue) for the achievement of longer-term national interests (Tibetans' gradual acceptance of political and economic reforms under Chinese rule).

But from the earliest days of the C.C.P. there had been a fierce debate within its ranks about how long to wait before enacting radical reforms in ethnic minority areas. Leftist voices within the Party leadership argued that, since the elite are rarely won over anyway, there was no point in delaying radical reforms, such as land redistribution and class struggle. Since the Central Committee had not provided clear guidelines for determining when conditions were ripe for reforms, provincial leaders initially had latitude to interpret Mao's instructions as they wished (Goldstein, 2014, 93). However, by late 1955 Yunnan provincial leaders found themselves under increasing pressure to evaluate when local conditions would be appropriate for launching land reform in Gyelthang.

34 Wangchuk Tempa wrote a letter to General Liao on 8 May 1951, expressing his concern that landlords had been struggled against in Jiangbian, just to the south of Gyelthang. Representatives who had returned from a meeting with other ethnic minority leaders in Kunming reassured Wangchuk Tempa that they had been told class struggle would not be carried out in Gyelthang (Wang 1994, 166-167).

35 Benno Weiner notes that a similar gradual approach was used in Tsékhok (Zeku County) in Amdo (Weiner 2012, 33-34). 
In a speech to provincial Party secretaries on 31 July 1955, Mao proclaimed that widespread collectivization would provide the surge in agricultural production necessary to meet the targets outlined in the C.C.P.'s first Five Year Plan. Mao's electrifying speech effectively ended the gradualist approach to reforms in most ethnic minority areas and ushered in a nationwide push for partial collectivization known as the 'High Tide' in socialist transformation (Barnett 2014, xxx) $\cdot^{36}$ Provincial leaders were encouraged to begin implementing reforms by December, 1955 , so that they would have enough time to report their concrete achievements at the next meeting of the National People's Congress in Beijing in March-April 1957 (Goldstein 2014, 102).

The C.C.P. embarked on a new strategy in particularly politicallychallenging ethnic minority areas of the country, designed to persuade local religious and secular elites to accept reforms in exchange for maintaining their current standard of living and social status. These reforms were referred to as 'peaceful democratic reforms' (heping minzhu gaige), to distinguish them from the methods that had been used during 'land reform' (tudigaige) in other regions in China, where landlords and wealthy peasants were subjected to humiliating public struggle sessions. ${ }^{37}$ The Chinese Communist Party announced its new policy of 'adjusting land ownership, renegotiating rent, and liberating the slaves' (tiaotian yizu, jiefang nuli) in Diqing Tibetan Autonomous District in late 1955. However, efforts to demonstrate that the Tibetan masses were demanding these reforms and that the Tibetan elites in Zhongdian would therefore welcome them quickly proved to be problematic.

36 It was during this closed-door speech that Mao famously criticized colleagues who favored a more cautious approach by remarking that 'some of our cadres are tottering along like a woman with bound feet, always complaining that others are going too fast'. Mao complained that these colleagues seemed incapable of taking the bold step of increasing the size and number of agricultural cooperatives (Mao 1977, 184).

37 Goldstein $(2014,91-92)$ explains some of the main differences between, peaceful democratic reforms, and the kinds of land reform carried out in other areas of China:

The salient difference was that [peaceful democratic reforms] were to be done without the humiliation, physical beatings, demeaning tasks, and expropriation of wealth and property that characterized reforms done in inland China - that is, without the elite suffering material impoverishment, social degradation, and political isolation. With peaceful reforms, the former elite who did not oppose reforms would have the status of full citizens, and the state would provide them a standard of living equal to what they had before. Moreover, in many cases, they would be given leadership positions in government. The key leverage when pressuring the Tibetan elite to accept reforms, therefore, was that there would be no struggle sessions and that their standard of living would not decline after reforms were implemented. 
The first stage of reform entailed categorizing the local population according to the Chinese Communist Party's class categories. Local leaders and officials were ordered to collect information about every household in the area and then assign each household one of the following class labels: chieftain (tusi), slave owner (nulizhu), serf owner (nongnu zhu), land owner (dizhu), wealthy farmer (funong), middle-class farmer (zhongnong), poor farmer (pinnong), serf (nongnu), or slave (nuli). $\cdot^{8}$ In Gyelthang, as in many other parts of Kham, Tibetan society was far less strictly divided than in Central Tibet. Unlike in Lhasa, there were not any aristocratic families in Gyelthang, and neither were there 'unpure' (Tib. drib) outcast families, such as blacksmiths and corpse cutters. However, there were wealthy landowners, some of whom held hereditary servants, known locally as shenyog, which could be bought and sold by their owners. ${ }^{39}$ In 1955 it was announced that land that belonged to chieftains, owners of slaves or serfs, landowners, and wealthy farmers would be confiscated and either kept as government-controlled communal lands or redistributed to the poorest members of society (Zhongdian xian zhi 1997, 302-306). This announcement set the stage for a series of armed conflicts between the P.L.A. and wealthy Tibetan farmers, landowners, and monks.

$3^{8}$ The Zhongdian County Gazetteer provides statistics on several of the class categories introduced by the C.C.P. officials during this period. It also provides information about the amount of farmland that was transferred from wealthy landowners to the government or poor peasants. Nearly 80 per cent of Zhongdian County's households were affected by the land reform campaigns (Zhongdian xian zhi 1997, 304). According to Gompo Tashi Andrugtsang, a Tibetan trader from Lithang who led the Khampas in the Chushigandru insurgent army, the C.C.P. implemented reforms as early as 1953 in Gyelthang. Andrugtsang likely is referring to the predominately ethnically-Han, Bai, and Naxi area of Jiangbian, located just north of Lijiang, where reforms were carried out a full two years before they were implemented in ethnically Tibetan areas of Gyelthang (Goldstein 2014, 119). In his autobiography, written in exile and published in 1973, Andrugtsang claims that the population of Gyelthang in 1953 was 'divided into five strata and a terror campaign of selective arrests launched by the Chinese. People belonging to the first three strata were either publically humiliated or condemned to the firing squad' (Andrugtsang 1973, 38).

39 Chinese historians have tended to translate the local Tibetan term, shen, as 'slave' (nuli), while taking yog to mean 'servant'. The term nang'zin was used locally as a more general term for servant (Kolås 2008, 42). In an interview the author conducted in Hala Village in April 2013, one 93-year-old Tibetan resident of Nyishar claimed that she spent the first 30 years of her life as a slave working for a wealthy family in a village near Feilai Temple (Feilai si) in Deqin County. She maintained that after the Communist 'liberation' of northern Yunnan Province, she and seven of her siblings were given a document granting their freedom. A great deal of controversy remains regarding the extent and variety of slavery and serfdom in Kham prior to the Chinese Communist Party's involvement in the area (Goldstein 1986, 79-112, Miller 1987, 65-67, Goldstein 1988, 61-65, and Gros 2016). 


\section{The Khampa Rebellions of 1955-1957}

In order to introduce new land reform policies, Chinese Communist cadres accompanied by P.L.A. escorts entered Tibetan villages in the Chaktreng area in February 1954. According to a monk from Chaktreng Sampheling monastery, most people in the villages refused to cooperate with the cadres, and in a few cases, they attacked the cadres and P.L.A. troops. ${ }^{40}$ Tibetan villagers later managed to block the Chinese cadres and P.L.A. troops' access to a brook for fifteen days, cutting off the Chinese camp's sole source of water. After months of fighting in the surrounding areas, by February 1956, thousands of villagers had taken refuge in Chaktreng Sampheling Monastery, living alongside the nearly 3000 resident monks. The P.L.A. sent airplanes to drop leaflets urging the monks and villagers to surrender, and following an intense and lengthy standoff, the P.L.A. sent a military jet to bomb Chaktreng Sampheling Monastery. The monastery was ruined and the Tibetans who survived the attack either surrendered to the P.L.A. or fled overland to Lhasa (Shakya 1999, 140; Goldstein 2014, 236).

Meanwhile, in 1955, the abbot of Ba Chödeling Monastery (Dingningsi) in neighbouring Bathang sent a letter to Ngawang Lobzang Tendzin, the abbot of Ganden Sumtseling Monastery in Gyelthang, asking him to send troops to support this revolt aimed at protecting Tibetan religion in Kham. The abbot of Ba Chödeling Monastery also sent messengers to monastic officials in Lithang and Chaktreng requesting all Khampas to unite against the Chinese. The letter carried by the Bathang messengers stated:

Lingkha shi of $\mathrm{Ba}$ is already engaged in fighting against the Chinese. No matter what the Chinese Communists say, their aim is to occupy Tibet in the name of Ngabo's Seventeen-Point Agreement. Therefore, every Tibetan must unite and fight until even if there are no men left, women will have to take up weapons. If we let China do whatever it wants, Tibetan Buddhism and the Tibetan race will become extinct. Our property will be confiscated. Evil people will be the leaders and good people will be the servants. It is clear that things will happen which have never before happened in this world. Therefore, we must not be deluded by the Chinese deceit, and we must rise up in unison. We must completely forget personal and collected resentments that 
exist between our different areas, and confront together the enemy of our region. (Lobsang 1971, 134) ${ }^{41}$

The letter asked that Tibetan rebels coming through Gyelthang be given necessary supplies. According to Sulang Jiachu, a Tibetan historian of Gyelthang, the letter also stated that Bathang rebels threatened to burn the homes of villagers in Gyelthang who refused to aid the rebels (Sulang 2007, 276). When this letter arrived in Gyelthang, Ngawang Lobzang Tendzin was meeting with Tibetan abbots and Chinese government representatives in the Tibetan Autonomous Region. Before Ngawang Lobzang Tendzin left Gyelthang to take part in this meeting, he supposedly told his assistant at Sumtseling Monastery: 'We are located along the Han-Tibetan border and we are different from other Tibetan districts. We must be prudent and refrain from participating in the southern Kham rebellion' (Sulang 2007, 277)..$^{2}$ As a result, lamas in high positions of authority at Sumtseling Monastery did not initially participate in the early stages of the Khampa uprisings.

In 1956, Wangchuk Tempa received letters from monastic leaders and secular leaders in Lithang, Bathang, and Chaktreng, asking him to lend his support to the Kham rebellion against Chinese rule and the Communist policy of land reform. ${ }^{43}$ According to a former Communist Party official in charge of implementing land reform in Gyelthang, Wangchuk Tempa responded that he had learned a lesson from his failed rebellions of the past and that he thought it best for the monastic leaders in Kham to compromise and submit to Communist rule in the area (Huang 1998, 37). Wangchuk Tempa refused to join the rebels; instead he held meetings with village leaders to persuade them that the Communist Party had their interests at heart. He reportedly claimed that the C.C.P. had treated him fairly, considering all

41 Cited in McGranahan (2010, 87). For the full text of the 'Seventeen-Point Agreement' that Tibetan and Chinese government representatives signed on 23 May 1951, see Shakya (1999, 449-452).

42 The 1955-1956 uprising in Eastern Tibet is often called the 'Southern Kham Unified Rebellion' (kangnan lianhe panluan) by Gyelthang-based historians writing in Chinese. Chinese scholars based elsewhere in China have termed this rebellion the 'Kangding Rebellion', since Kangding was the headquarters of Eastern Tibet.

43 According to published Communist Party histories, armed uprisings against land reform took place in early 1956 in Derong, Chaktreng, Daocheng, Liangshan, Yanbian, Yanyuan, and Muli in Sichuan Province (Zhongguo renmin zhengzhi xieshang huiyi, ed. 2003, 63). Based on an exile Tibetan history of Lithang, along with a 2003 interview he conducted in India with a Lithang villager who was involved in the uprising, Goldstein maintains that Khampa rebels sent letters to Lithang, Bathang, Gyelthang, Chaktreng, Derge, Nyarong, and Horkhok in January-early February, 1956 (Goldstein 2014, 125). 
of the grief he had caused the Party in the past (Gesang 2010, 445). Wangchuk Tempa allegedly declared that the Party never forced him to write a selfcriticism or engage in a 'speak bitterness' (suku) meeting, and he was never made the target of a class struggle session. According to Communist Party accounts, the C.C.P. had a track record of treating cooperative members of the Gyelthang upper-class well, and Wangchuk Tempa purportedly assured the village heads and the monastery representatives that they had nothing to fear (Huang 1998, 37).

It is possible that Wangchuk Tempa felt pressured to serve as a statecommunity intermediary and support land reform after accepting a position as Vice Governor of Zhongdian County under C.C.P. rule in 1953 (Sulang 1990, 113). Wangchuk Tempa's decision to maintain a neutral stance on land reform may also have been influenced by the fact that, having been privy to many internal government briefings, he understood that the Chinese Communist government was capable of easily suppressing any rebellion with armed force, if necessary. Faced with escalating tensions in the Tibetan Autonomous Region and outright armed rebellion in many areas of Kham, the C.C.P. had gradually abandoned the strategy of the nationalities policy in favor of coercion (Smith 1994, 67). In order to carry out 'democratic reforms' in Gyelthang, the C.C.P. organized peasant self-defense forces that would be responsible for taking control of the guns and ammunition taken from the landlords and rich peasants. By 1956, the C.C.P. had provided guns, ammunition, and basic weapon training to more than 2000 villagers in Gyelthang, including local members of the police force, work team members, and a self-defense troop, with the goal of creating a strong local security force to suppress uprisings (Huang 1998, 37). ${ }^{44}$

In November, 1956, the first rebellion took place at Ganden Sumtseling Monastery after monks publically decreed that all Gyelthang residents should 'Oppose the Peaceful Negotiation of Land Reform and Maintain the Tuguan System, Protect People's Rights and Their Freedom to Practice Religion' (Sulang 2007, 277). Sumtseling monks protested on the streets of Zhongdian, carrying banners proclaiming: 'Protect Ethnicity, Protect Religion' (baozu, baojiao). The People's Liberation Army eventually dispelled this rebellion after a lengthy armed stand-off.

On 3 March 1957, one day after the start of the Tibetan New Year, the Diqing Party Committee announced that necessary preparations had been

44 These people's militias expanded rapidly and by 1959, Gyelthang had 12,117 people's militia members, comprising nearly 39 per cent of the entire labour force in the region (Zhongdian xian zhi 1997, 409). 
completed and land redistribution could now begin in Gyelthang. Three days later, a second major uprising commenced. According to a Gyelthang Tibetan historian of C.C.P. history, village leaders, wealthy farmers, and monks in two of the monastic colleges within Sumtseling Monastery organized an armed rebellion and 1525 rebels, including 364 monks, attacked C.C.P. work teams in the area over the next few weeks (Sulang 2007, 278). The Lijiang Prefectural Party Committee consequently sent Wangchuk Tempa, Ngawang Lobzang Tendzin, and another Tibetan representative to order the rebels to hand over their weapons and horses and attend an official meeting to discuss land reform. However, the rebels not only refused to meet, they insulted and swore at the Tibetan leaders representing the Communist government, denouncing them as 'traitors' (Gyelthang Tib.jya ga) (Huang 1998, 35). Any attempt at reconciliation between the C.C.P. and the rebels ceased at this point.

The Lijiang Prefectural Division of the P.L.A. surrounded Sumtseling monastery with their army vehicles and sent their soldiers to fight the monks and villagers who had barricaded themselves inside. The rebels were defeated after a few days of heavy fighting, and after the battle, the Party stationed Tibetan cadres at the monastery to serve as translators for the P.L.A. soldiers guarding the monastery's valuables. These cadres were also responsible for confiscating the more than 100 weapons they found in the monastery (Sulang 2007, 279).

By early autumn, 1957, resistance to land reform in Zhongdian had been fully suppressed, ushering in a marked decline in the region's autonomy, an irony that was compounded by the establishment of the Diqing Tibetan Autonomous Prefecture in September 1957. Out of consideration for their refusal to support the Sumtseling monks' revolts against land reform earlier in the year, Ngawang Lobzang Tendzin was appointed the Governor of Diqing Tibetan Autonomous Prefecture, and Wangchuk Tempa was made the Vice Governor of this newly established autonomous prefecture. In order to crack down on the power of Sumtseling Monastery and to make sure that the monks could not join with villagers to yet again foment unrest, 46 monks at Sumtseling were arrested. Land deeds that had been stored inside of the monastery were destroyed, additional weapons were confiscated, and the majority of the monks residing at the monastery were sent back to their villages or fled to the mountains (Le'an 2009, 83). ${ }^{45}$

45 Interview with a monk at Dokhar monastic college (kangtsen) in Sumtseling Monastery, July 2014. This locally highly respected lama, who fled to India in 1959, was allowed to return to Sumtseling Monastery in 2006 after he signed a document promising the Chinese government that he would refrain from giving tantric initiations in Gyelthang. 
Land reform in Gyelthang not only redistributed land, it also made obsolete previously hegemonic cultural orderings of the local social landscape, since it eliminated the political and economic power of the monks and the other elite members of Gyelthang society. ${ }^{46}$ Party documents from the 1960 s present the Land Reform Campaign as the final blow to local structures of religious and political power. ${ }^{47}$ Like Wangchuk Tempa, most village elites in Gyelthang held onto their power or passed their positions of authority to their sons as C.C.P. influence grew in the area in the 1940s and 1950s, until the old shuka and tusi administrative systems were finally dismantled during land reform. Many of the religious and secular leaders, such as Ngawang Lobzang Tendzin and Liu En, who accepted official positions under the new government in the early 1950s, served as intermediaries and negotiated on behalf of the Communist government right up until they became targets during the Cultural Revolution in late 1966.

The implementation of land reform in Gyelthang overlapped with the national Anti-Rightist Campaign of 1957-1958, and while the C.C.P. work teams implemented land reform between January and September, 1958, Wangchuk Tempa and other senior local officials and formerly wealthy landlords in Gyelthang were taken to Kunming to participate in struggle sessions and undergo 'rectification' (Zhongguo renmin zhengzhi xieshang huiyi 2003, $64) \cdot{ }^{48}$ After one particular struggle session, Wangchuk Tempa expressed his

46 Tsering Shakya supports this claim, maintaining that 'the dissolution of the economic power base of the monasteries was the most significant social and political event in the history of Tibet since the introduction of Buddhism' (Shakya 1999, 254).

47 The timeframe for land reform in Gyelthang closely followed that of Lithang, Bathang, and Chaktreng in the neighbouring Ganzi Autonomous District of Sichuan Province. In Ganzi, reforms for agricultural areas were initially propagandized in January 1956 and by September 1958, 95 per cent of the Tibetan and Yi population of Sichuan was reported to have undergone 'democratic reforms' (Sangye Yeshi, 1958 [1968], 322). See also Goldstein (2014, 233-277) and the documents reprinted in Diqing zangzu zizhizhou gaikuang bianxiezu, ed. (1960).

48 The Anti-Rightist Movement of 1957-1958 ushered in a much more hardline nationality policy that equated 'local nationalism' (difang minzu zhuyi) with anti-Party, anti-socialist opposition. Deng Xiaoping filed a report in 1957 attacking 'reactionary' ethnic minority cadres, who had supported special policies in ethnic minority areas in order to undermine socialist policies in general. Deng argued that:

social education and anti-Rightist struggles among the minorities have the same content as in the Chinese areas, but stress should also be laid on opposition to tendencies of local nationalism. It should be clearly recognized that all those who make use of local nationalist sentiments and the estrangement between nationalities left over from the past in order to divide national unity and undermine the unification of the motherland act contrary to China's Constitution and jeopardize the socialist cause of our country. They are all anti-socialist Rightists (Deng 1957, 41). For more about the C.C.P.'s attack on 'local nationalism' during the Anti-Rightist Campaign, see Smith (1994, 59-6o), Weiner (2015). 
regret for all of the 'anti-Party acts' in which he had previously engaged as a trader, businessman, and warlord in Gyelthang. ${ }^{49} \mathrm{He}$ was permitted to return to Gyelthang once the Rectification Campaign ended, and on 30 June 1961, he allegedly fell ill and passed away at the age of 76 . On 2 July, religious and political ceremonies were held in his honor. The Diqing Prefectural Party and government, Zhongdian County Party and government, the military, and the local schools all participated in the government-affiliated funeral ceremony (Qi and Xiluo 1990, 45). The Yunnan Provincial government also publically displayed their respect for Wangchuk by placing his funeral announcement in the Yunnan Daily newspaper on 9 July 1961 (Sheng minwei 1961).

\section{Conclusion}

Wangchuk Tempa's life experience as a monk, bandit, strongman, antiCommunist resistance fighter, and eventually a government official who worked to implement Chinese Communist Party-state policies in Gyelthang helps complicate the notion of what constitutes 'the Chinese state' in rural ethnic minority areas. In 'Létat, c'est nous, or We Have Met the Oppressor and He Is Us: The Predicament of Minority Cadres in the PRC', Stevan Harrell (2007) explores how China's cadres have often been called upon to play a dual role that involves representing the state to the community and representing the community to the state.

Throughout the history of the People's Republic of China, the ability of cadres to negotiate state-community relations has been crucial to the success of policy implementation. Harrell argues that 'if state-minority relations, or state-community relations in minority areas, were [simply] Han-minority relations, there would be very little to write about' - it would be a 'situation of clear and direct colonial rule' (Harrell 2007, 223). Yet, in the early 1950s, the C.C.P. government brought ethnic minority citizens into the state as cadres at various levels - not only at the brigade or village level, but also 'as salaried government cadres at the [...] township, county, prefectural, and provincial levels of the administration' (ibid.). As state-community intermediaries, influential local leaders like Wangchuk Tempa increasingly found themselves in double-bind situations.

As this chapter has discussed, Communist Party officials in Gyelthang used the dual strategies of 'political tourism' and 'political persuasion 
work' to entice Wangchuk Tempa and other recalcitrant members of the 'pre-liberation elite' to accept their offers to join the new government. In addition, work team members attempted to cultivate a sense of revolutionary consciousness among non-elite residents of Gyelthang. Patient 'thought work' (sixiang gongzuo) was a crucial component of the Communists' efforts in Gyelthang to create a sense of the voluntary and natural participation of the people in land reform and collectivization.

After land reform was implemented in Gyelthang, local residents were required to attend 'speak bitterness' (suku) meetings and produce testimonials ascertaining their consciousness of class-based oppression in the so-called 'old society' and their present 'liberation' in the 'new society'..$^{\circ}$ 'Speak bitterness' testimonials from young, female Tibetan villagers, in particular, were very effective weapons that enabled state cadres to directly attack Gyelthang's Tibetan Buddhist monastic order. These testimonials were public performances designed to radically upend local hierarchies, which had traditionally mandated respect for elder Tibetan men and lamas. Monks who participated in the 1956-1957 rebellion were also forced to take part in these 'speak bitterness' sessions in late 1958. Some willingly admitted that the pre-liberation era was one of bitterness while others, who refused to speak ill of the pre-land-reform era, were sent away to join production brigades in the villages. ${ }^{11}$ The 'speak bitterness' meetings therefore served to create a new form of socialist consciousness while simultaneously transforming the very structure of local society.

By harnessing the power and charisma of local Khampa religious and secular leaders, the C.C.P. was able to consolidate its political control in Gyelthang during the 1950s. Yet, how appropriate or theoretically useful is the concept of 'collaboration' when it comes to explaining why some religious and secular leaders joined forces with representatives of the C.C.P. in the post-1949 period (Barnett 2006)? Can and should the choices, adjustments, and compromises that Tibetans made under Chinese Communist rule be

$5^{0}$ As many scholars have pointed out, these first-person testimonials of the rural masses' experiences of feudal exploitation and then liberation from class oppression were the narrative backbone of the Chinese Communist revolution (Anagnost 1997, Hershatter 2011, Sun 2013, Makley 2005, and 2008).

$5^{1}$ Only 367 monks were permitted to live at the monastery after 1958 . They were required to work on a collectivized production brigade and to elect one representative from each monastic college to serve on a new monastery democratic organizing committee. Under a new C.C.P. policy titled 'Let the Monastery Take Care of Itself' ( yi si yang si) these remaining monks were ordered in $195^{8}$ to prepare uncultivated land for farming, maintain fertile fields year-round, and supply their own food, water, and fuel (Qi and Xiluo 1990, 47; Kolås 20o8, 43). 
viewed as 'collusion?' Attempting to navigate a binary between resistance and collaboration/collusion may not be the most fruitful way forward when it comes to exploring what actually occurred in Gyelthang during the 1950s. As James Leibold reminds us, and as many of the contributors to this volume demonstrate, in the ethnically diverse Sino-Tibetan borderlands, 'political actors operated in a complex, circuitous, and multilayered environment with multiple centers of authority' (Leibold 2005, 196). These flexible political webs of interaction reveal the limitations of using static 'centre-periphery' or 'state-local' models to describe the dynamic and contingent processes that resulted in new forms of political allegiances in Kham in the 1950 .

When underground Communist Party agents first started negotiating with Tibetan elites in Gyelthang in the late 1940s, it is unlikely that many Tibetans suspected that these negotiations would turn into a lengthy and much more intrusive form of Chinese political involvement in Kham. After all, Gyelthang residents had become accustomed to being ruled by whichever military leader, village head, tusi, or Guomindang government representative held power in the area at any given time. The day-to-day struggles that villagers faced were roughly the same regardless of who held the reins of power, so people often got on with their lives, even when doing so meant adjusting to the demands of external powers. This made the fact that they were being governed by Tibetan village heads who reported to the Chinese Communist government as plausible as the fact that they used to be governed by the same elite group of Tibetan leaders who reported to the Guomindang-backed warlords, and prior to that, Qing government officials. Indeed, Gyelthang's religious and secular leaders could not have foreseen in the late 1940s how complicated their lives would quickly become in the decades ahead.

\section{Glossary of Chinese and Tibetan Terms}

Ajian

Axi dukou

Ba Chödeling Monastery

Balung (Tib.)

Bao Pinliang

baoshangdui

baozu baojiao

Bapa Püntsok Wangyel
阿坚

阿喜渡口

(Tib.) 'Ba' chos sde gling, (Ch.) Dingningsi 丁宁寺

'Ba'lung, (Ch.) Weixi 维西

鲍品良

保商队

保族, 保教

(Tib.) 'Ba' pa phun tshogs dbang rgyal, (Ch.) Pingcuo Wangjie 平措汪阶 / Min Zhicheng 闵志成 


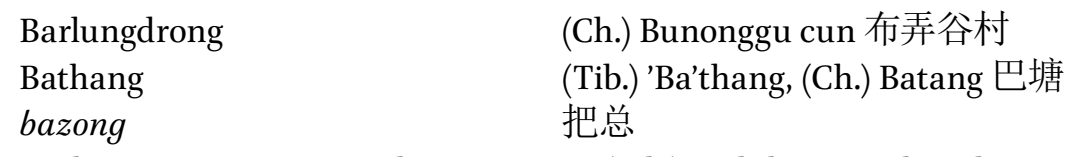

Böshar gyümi mang rang kyong na tün, (Tib.) Bod shar rgyud mi dmangs rang skyong mna' mthun, (Ch.) Dongzang renmin zizhi hui 东藏人 民自治会 / Dongzang renmin zizhi tongmeng jianzhang 东藏人民自治 同盟简章

cha magu dao 茶马古道

Chamdo

Changzheng lu

(Ch.) Changdu 昌都 长征路

Chaktreng

chengfang yiwu dadui

Phyag phreng, (Ch.) Xiangcheng 乡城 城防义务大队

Dali

大理

Dechen

(Tib.) Bde chen, (Ch.) Adunzi / Deqin 阿墩子 / 德钦

difang minzu zhuyi

地方民族主义

Diqing Zangzu zizhizhou

迪庆藏族自治州

dixia dang zuzhi

dizhu

地下党组织

地主

Feilaisi

飞来寺

funong

富农

fushe li

Ganden Phodrang

辐射力

Gelukpa

Dga'ldan pho brang

Gönpo Tsering

Dge lugs pa

(Tib.) Mgon po tshe ring, (Ch.) Gongbu Zeren 恭布泽仁 / Hai Zhengtao 海正 涛 / Hai siling 海司令

gongchan 共产

Gongling

贡岭

guanguang

观光

Gyelthang

(Tib.) Rgyal thang, (Ch.) Da Zhongdian 大中甸

Hai Zhengtao

海正涛

He Long

贺龙

He Qichang

何其昌

He Rongguang

何荣光

heping jiefang

和平解放

hulu dui

护路队

Jiangbian

江边 
Jingkou

Judian

Kanading

Kangnan lianhe panluan

Kangren zhi Kang

kangtsen

Kelzang Tsering

Kenading

Ketsak

Liao Yunzhou

Lijiang zhuanqu lianhe zhengfu weiyuan

Li Liesan

Lithang

Liu En

Liu Hanxun

Lobsang Nyima

Lobsang Wangdü

Long Yun

Luo Shuchang

mabang

minbing

minzhu gaige

Ngawang Kesang

Ngawang Lobzang Tendzin

nongnu

nongnuzhu

nuli

nulizhu

Nyetsang Tsering Püntsok

Nyishar
菁口

巨甸

卡那顶

康南联合叛乱

康人治康

(Tib.) khang tshan

(Tib.) Bskal bzang tshe ring, (Ch.)

Gesang Zeren 格桑泽仁

克那顶

(Tib.) Skad tshag, (Ch.) Geza 格咱

廖云周

丽江专区联合政府委员

李烈三

(Tib.) Li thang, (Ch.) Litang 理塘

刘恩

刘汉勋

(Tib.) Blo bzang nyi ma, (Ch.) Lurong Nima 鲁茸尼玛

(Tib.) Blo bzang dbang 'dus, (Ch.)

Lurong Wangdui 鲁茸汪堆

龙云

罗树昌

马帮

民兵

民主改革

(Tib.) Ngag dbang Skal bzang, (Ch.) Angwang Gesang 昂旺格桑 / Liu Shaoyu 刘绍禹

(Tib.) Ngag dbang Blo bzang Bstan 'dzin, (Ch.) Songmou Angwang Luosang Danzeng Jiacuo 松谋.昂汪洛桑 丹增嘉措

农奴

农奴主

奴隶

奴隶主

(Ch.) Niancang Zeren Pingcuo 念仓 泽仁平措 / Qi Yaozu 七耀祖

(Ch.) Nixi 尼西 


\begin{tabular}{|c|c|}
\hline pinnong & 贫农 \\
\hline qianzong & 千总 \\
\hline Qingming jie & 清明节 \\
\hline Ren Naiqiang & 任乃强 \\
\hline Sanba & 三坝 \\
\hline sengsu tuanwu zhihui & 僧俗团务指挥 \\
\hline Shengping zhen & 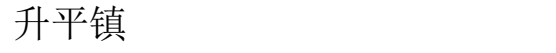 \\
\hline shenyog & (Tib.) bran gyog \\
\hline sixiang gongzuo & 思想工作 \\
\hline suku & 诉苦 \\
\hline Sun Zhihe & 孙致和 \\
\hline Termarong & $\begin{array}{l}\text { (Tib.) Gter ma rong, (Ch.) Dongwang } \\
\text { 东旺 }\end{array}$ \\
\hline tiaotian yizu, jiefang nuli & 调田议租, 解放奴隶 \\
\hline tuanfang & 团防 \\
\hline tubazong & 土把总 \\
\hline tudigaige & 土地改革 \\
\hline tuqianzong & 土千总 \\
\hline tusi & 土司 \\
\hline Uncle Wangchuk Tempa & $\begin{array}{l}\text { (Tib.) Dbang phyug Bstan-pa akhu, } \\
\text { (Ch.) Wang Xueding Agou 汪学鼎阿沟 }\end{array}$ \\
\hline Wang Qupi & $\begin{array}{l}\text { 汪曲批 / Wang Chuipi汪吹匹 / Wang } \\
\text { Xuepi 汪学批 }\end{array}$ \\
\hline Wangchuk Tempa & (Tib.) Dbang phyug Bstan-pa, (Ch.) \\
\hline & $\begin{array}{l}\text { Wang Xueding 汪学鼎/ Wang Xued- } \\
\text { ingba 汪学鼎巴 }\end{array}$ \\
\hline Wangchuk Tempa Lemar & $\begin{array}{l}\text { (Ch.) Wang Xueding Liemu 汪学鼎 } \\
\text { 列木 }\end{array}$ \\
\hline Xianggelila xian & 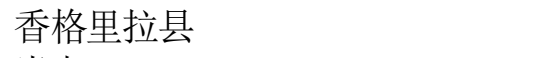 \\
\hline Xiao Ke & 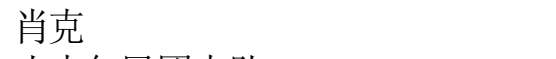 \\
\hline Xiao Zhongdian mintuan dadui & 小中甸民团大队 \\
\hline Xinlian xingzhengcun & 新联行政村 \\
\hline Xueshanshe & 雪山社 \\
\hline Yading & 亚丁 \\
\hline Yangthang & $\begin{array}{l}\text { (Tib.) Yang thang, (Ch.) Xiao Zhong- } \\
\text { dian 小中甸 }\end{array}$ \\
\hline yi siyang si & 以寺养寺 \\
\hline Yunnan & 云南 \\
\hline Yunniang cun & 酝酿村 \\
\hline Zhalujiangzhong Wang Xueding cun & 扎路江仲汪学顶村 \\
\hline
\end{tabular}


Zhao Baohe

zhengzhi shuifugongzuo

zhengzhixieshang huiyi

Zhongdian

Zhongdian mintuan

Zhongguo gongnong hong jun

zhongnong

Zhongxin zhen

ziwei duiyuan

赵宝鹤
政治说服工作
政治协商会议
中甸
中甸民团
中国工农红军
中农
中心镇
自卫队员

赵宝鹤

政治说服工作

政治协商会议

中甸

中触勾

中国工农红军

中农

自卫队员

\section{References}

Anagnost, Ann. 1997. National Past-Times: Narrative, Representation and Power in China. Durham: Duke University Press.

Andrugtsang, Gompo Tashi. 1973. Four Rivers, Six Ranges: Reminiscences of the Resistance Movement in Tibet. Dharamsala, India: Information and Publicity Office of H.H. The Dalai Lama.

Barnett, Robert. 2006. 'Beyond the Collaborator-Martyr Model: Strategies of Compliance, Opportunism, and Opposition within Tibet'. In Contemporary Tibet: Politics, Development, and Society in a Disputed Region, edited by Barry Sautman and June Teufel Dreyer, 25-66. Armonk, N.Y.: M.E. Sharpe.

Barnett, Robert. 2014. 'Introduction: A Note on Context and Significance'. In My Tibetan Childhood: When Ice Shattered Stone, written by Naktsang Nulo and translated by Angus Cargill and Sonam Lhamo, xv-li. Durham: Duke University Press.

Bstan-pa-rgyal-mtshan. 1985. Rgyal than் yul lun dgon gnas dan் bcas pa'i byun ba mdo tsam brjod pa blo gsal mgul pa mdzes pa'i rgyan (A History of the Gyelthang Gompa Monastic Complex and its Environs). Dharamsala, H.P., India: Rgyal-than Bya-'thab, Ṅag-dban் Thabs-mkhas.

Bulag, Uradyn. 2010. Collaborative Nationalism: The Politics of Friendship on China's Mongolian Frontier. Lanham: Rowman \& Littlefield.

Bulag, Uradyn. 2012. 'Seeing Like a Minority: Political Tourism and the Struggle for Recognition in China'. Journal of Current Chinese Affairs 41 (4): 133-158.

Bulag, Uradyn. 2012a. 'Good Han, Bad Han: The Moral Parameters of Ethnopolitics in China'. In Critical Han Studies: The History, Representation, and Identity of China's Majority, edited by Thomas Mullaney, James Leibold, Stéphane Gros, and Eric Vanden Bussche, 92-109. Berkeley: University of California Press.

Deng, Xiaoping 邓小平. 1957. 'On Minorities'. In Report on the Rectification Campaign, 41. Beijing: Foreign Languages Press. 
Deqin xian zhi bianzuan weiyuanhui 德钦县志编纂委员会 (Deqin County Gazetteer Compilation Committee), ed. 1997. Deqin xian zhi 德钦县志 (Deqin County Gazetteer). Kunming: Yunnan minzu chubanshe.

Diqing zangzu zizhizhou gaikuang bianxiezu 迪庆藏族自治州概况编写组 (Diqing Tibetan Autonomous Prefecture Survey Composition Group), ed. 1960. Yunnan Sheng Diqing Zangzu Zizhizhou Gaikuang 云南省迪庆藏族自 治州概况 (A Survey of Diqing Tibetan Autonomous Prefecture in Yunnan Province). Lijiang.

Diqing zangzu zizhizhou minzu zongjiao shiwu weiyuanhui 迪庆藏族自治州 民族宗教事务委员会 (Diqing Tibetan Autonomous Prefecture Nationalities Religious Affairs Committee), ed. 2001. Diqing Zangzu zizhizhou minzu zhi 迪 庆藏族自治州民族志 (Diqing Tibetan Autonomous Prefecture Nationalities Gazetteer). Kunming: Shenzhen huiyuan caise yinshua youxian gongsi.

Diqing zhouzhi bianzuan weiyuanhui迪庆州志编纂委员会 (Diqing Prefecture Gazetteer Compilation Committee), ed. 2003. Diqing zangzu zizhizhouzhi迪 庆藏族自治州志 (Diqing Tibetan Autonomous Prefecture Gazetteer), 2 vols. Kunming: Yunnan minzu chubanshe.

Dreyfus, Georges. 2003. The Sound of Two Hands Clapping: The Education of a Tibetan Buddhist Monk. Berkeley: University of California Press.

Epstein, Lawrence. 2002. 'Introduction'. In Khams pa Histories: Visions of People, Place, and Authority, edited by Lawrence Epstein, 1-5. Leiden: Brill.

Faure, David and Ho Ts'ui-P'ing, eds. 2013. Chieftains into Ancestors: Imperial Expansion and Indigenous Society in Southwest China. Vancouver: University of British Columbia Press.

Feng, Ruzhang 冯如璋. 2013. Feng Ruzhang wenji 冯如璋文集 (An Anthology of Feng Ruzhang's Scholarship). Beijing: Zhongguo minzu sheying yishu chubanshe. Fromm, Martin. 2019. Borderland Memories: Searching for Historical Identity in Post-Mao China. Cambridge: Cambridge University Press.

Gesang, Qiren 格桑棋仁. 2010. ‘Wang Xueding qi ren qi shi 汪学鼎其人其事’ (A Biographical Sketch of Wangchuk Tempa). In Diqing wenshiziliao, diba ji 迪庆 文史资料, 第八辑 (Cultural and Historical Materials from Diqing), vol. 8, edited by Diqing zangzu zizhizhou zhengxie wenshi ziliao weiyuanhui 迪庆藏族自 治州政协文史资料委员会 (The Cultural and Historical Materials Committee of the Chinese People's Political Consultative Conference of Diqing Tibetan Autonomous Prefecture), 423-446. Kunming: Yunnan minzu yinshuachang.

Goldstein, Melvyn. 1986. 'Reexamining Choice, Dependency and Command in the Tibetan Social System: “Tax Appendages” and Other Landless Serfs'. The Tibet Journal 11 (4): 79-112.

Goldstein, Melvyn. 1988. 'On the Nature of Tibetan Peasantry: A Rejoinder'. The Tibet Journal 13 (1): 61-65. 
Goldstein, Melyvn. 2014. A History of Modern Tibet, vol. 3: The Storm Clouds Descend, 1955-1957. Berkeley: University of California Press.

Goldstein, Melvyn, William Siebenschuh, and Tashi Tsering. 1997. The Struggle for Modern Tibet: The Autobiography of Tashi Tsering. Armonk, New York: M. E. Sharpe.

Goldstein, Melyvn, Dawei Sherap, and William Siebenschuh. 2004. A Tibetan Revolutionary: The Political Life and Times of Bapa Phüntso Wangye. Berkeley: University of California Press.

Goullart, Peter. 1955. Forgotten Kingdom. London: John Murray.

Gros, Stéphane. 2016. 'Tricks of the Trade: Debt and Imposed Sovereignty in Southernmost Kham in the Nineteenth to Twentieth Centuries'. Cross-Currents: East Asian History and Culture Review 5 (2): 378-407.

Harrell, Stevan. 2007. 'L'état, c'est nous, or We Have Met the Oppressor and He Is Us: The Predicament of Minority Cadres in the PRC'. In The Chinese State at the Borders, edited by Diana Lary, 221-239. Vancouver: University of British Columbia Press.

Herman, John. 1993. National Integration and Regional Hegemony: The Political and Cultural Dynamics of Qing State Expansion, 1650-1750. PhD Dissertation, University of Washington.

Herman, John. 1997. 'Empire in the Southwest: Early Qing reforms to the Native Chieftain System'. The Journal of Asian Studies 56 (1): 47-74.

Hershatter, Gail. 2011. The Gender of Memory: Rural Women and China's Collective Past. Berkeley: University of California Press.

Holmes-Tagchungdarpa, Amy. 2015. 'Depicting Life in the Twentieth-Century Sino-Tibetan Borderlands: Local Histories and Modernities in the Career and Photography of Zhuang Xueben (1909-1984)'. In China's Encounters on the South and Southwest: Reforging the Fiery Frontier over Two Millennia, edited by James Anderson and John Whitmore, 339-369. Leiden: Brill.

Huang He 黄河. 1998. 'Zhongdian xian de minzhu gaige 中甸县的民主改革' (Democratic Reforms in Zhongdian County). In Diqing zhou wenshiziliao xuanji, di liu ji 迪庆州文史资料选辑, 第六辑 (An Anthology of Cultural and Historical Materials from Diqing Prefecture), vol. 6, edited by Diqing zangzu zizhizhou zhengxie wenshi ziliao weiyuanhui 迪庆藏族自治州政协文史资料委员会 (The Chinese People's Political Consultative Committee of Diqing Tibetan Autonomous Prefecture, The Cultural and Historical Materials Committee), 34-42. Kunming: Xizhan caiyinchang.

Huber, Toni. 2011. 'Pushing South: Tibetan Economic and Political Activities in the Far Eastern Himalaya, ca. 1900-1950'. In Buddhist Himalaya: Studies in Religion, History and Culture. Proceedings of the Golden Jubilee Conference of the Namgyal Institute of Tibetology, Gangtok, 2008, vol. 1: Tibet and the Himalaya, edited by 
Alex McKay and Anna Balikci-Denjongpa, 259-276. Gangtok: Namgyal Institute of Tibetology.

Kingdon Ward, Francis. 1923. Mystery Rivers of Tibet. London: Seeley Service \& Company.

Kolås, Åshild. 2008. Tourism and Tibetan Culture in Transition: A Place Called Shangrila. New York: Routledge.

Lawson, Joseph. 2013. 'Warlord Colonialism: State Fragmentation and Chinese Rule in Kham, 1911-1949'. The Journal of Asian Studies 72 (2): 299-318.

Le'an Wangdui 勒安旺堆. 2003. Maoniu suiyue 牦牛岁月 (The Yak Years). Kunming: Yunnan renmin chubanshe.

Le'an Wangdui 勒安旺堆. 2009. Dangdai Yunnan zangzujianshi 当代云南藏族简 史 (A Concise Contemporary History of Tibetans in Yunnan). Kunming: Yunnan renmin chubanshe.

Leibold, James. 2005. 'Un-Mapping Republican China's Tibetan Frontier: Politics, Warlordism and Ethnicity along the Kham/Xikang Borderland'. The Chinese Historical Review 12 (2): 167-201.

Liao Yunzhou 廖运周. 1987. 'Zai Zhongdian xian de rizi 在中甸县的日子' (My Days in Zhongdian County). In Diqing zhou wenshi ziliao xuanji, diyiji 迪庆 州文史资料选辑. 第一辑 (An Anthology of Cultural and Historical Materials from Diqing Prefecture), vol. 1, edited by Zhongguo renmin zhengzhi xieshang huiyi, Yunnan sheng Diqing zangzu zizhizhou weiyuanhui, wenshi ziliao yanjiu weiyuanhui 中国人民政治协商会议, 云南省迪庆藏族自治州委员会, 文史资料研究委员会 (Chinese People's Political Consultative Committee, The Committee of Diqing Precture in Yunnan Province, The Cultural and Historical Materials Research Committee), 9-16. Kunming: Yunnan minzu yinshua chang.

Lin, Hsiao-Ting. 2006. Tibet and Nationalist China's Frontier: Intrigues and Ethnopolitics, 1928-49. Vancouver: University of British Columbia Press.

Liu, Xiaoyuan. 2004. Frontier Passages: Ethnopolitics and the Rise ofChinese Communism, 1921-1945. Stanford: Stanford University Press.

Lobsang, Gyaltsen. 1971. 'Ba' kyi lo rgyus (History of Kham Ba-pa). Dehra Dun: Nyingmapa Lamah Press.

Makley, Charlene. 2005. “Speaking Bitterness": Autobiography, History, and Mnemonic Politics on the Sino-Tibetan Frontier'. Comparative Studies in Society and History 47 (1): 40-78.

Makley, Charlene. 2008. 'The Politics of Memory: Gender, Autobiography and Maoist Violence in Amdo'. In Conflict and Social Order in Tibet and Inner Asia, edited by Fernandia Pirie and Tony Huber, 113-133. Leiden: Brill.

Manning, Kimberley. 2007. 'Communes, Canteens, and Crèches: The Gendered Politics of Remembering the Great Leap Forward'. In Re-envisioning the Chinese 
Revolution: The Politics and Poetics of Collective Memories in Reform China, edited by Ching Kwan Lee and Guobin Yang, 93-118. Stanford: Stanford University Press. Mao, Zedong. 1977. 'On the Cooperative Transformation of Agriculture'. In Selected Works of Mao Tsetung, vol. 5, 184-207. Beijing: Foreign Languages Press.

McGranahan, Carole. 2010. Arrested Histories: Tibet, the CIA, and Memories of a Forgotten War. Durham: Duke University Press.

Miller, Beatrice. 1987. 'A Response to Goldstein's “Reexamining Choice, Dependency and Command in the Tibetan Social System"'. The Tibet Journal 12 (2): 65-67.

Mortensen, Dáša Pejchar. 2017. 'Wenshi Ziliao Narratives of Anti-Communist Resistance in Northwest Yunnan'. Unpublished paper presented at the Association for Asian Studies Conference.

Mueggler, Erik. 2001. The Age of Wild Ghosts: Memory, Violence, and Place in Southwest China. Berkeley: University of California Press.

Mullaney, Thomas. 2010. Coming to Terms with the Nation: Ethnic Classification in Modern China. Berkeley: University of California Press.

Norbu, Jamyang. 2009. 'March Winds'. URL: http://www.jamyangnorbu.com/ blog/2009/03/o6/march-winds/. (Accessed on 3 March 2014)

Peng, Wenbin. 2002. 'Frontier Process, Provincial Politics and Movements for Khampa Autonomy during the Republican Period'. In Khams pa Histories: Visions of People, Place and Authority, edited by Lawrence Epstein, 57-84. Leiden: Brill.

Pirie, Fernanda and Toni Huber, eds. 2008. Conflict and Social Order in Tibet and Inner Asia. Leiden: Brill.

Qi Jiguang 祁继光. 1993. 'Diqing tuisi shihua 迪庆土司史话' (The History of Tusi in Diqing). In Fengjian nongnu zhidu zai diqing de fumie 封建农奴制度在迪 庆的覆灭 (The Destruction of the Feudal Slave System in Diqing), edited by Zhonggong Diqing zhouwei dangshi zhengji yanjiu shibian 中共迪庆州委党 史征集研究室编 (The C.C.P. Diqing Prefecture Committee on Party History Research Group), 198-206. Dali: Dali zhou dianzi yinshuachang.

Qi Yaozu 七耀祖 and Xiluo Jiachu 西洛嘉初. 1990. 'Zhongdian Gadan Songzanlin (Guihuasi) Zhilüe 中甸嘎丹松赞林 (归化寺) 志略' (Historical Synopsis of Zhongdian's Ganden Sumtseling (Guihua) Monastery). In Diqing zhou wenshi ziliao xuanji, di san ji 迪庆州文史资料选辑. 第三辑 (An Anthology of Cultural and Historical Materials from Diqing Prefecture), vol. 3, edited by Zhongguo renmin zhengzhi xieshang huiyi, Yunnan sheng Diqing zangzu zizhizhou weiyuanhui, wenshi ziliao yanjiu weiyuanhui 中国人民政治协商会议, 云南省迪庆藏族自治 州委员会, 文史资料研究委员会 (Chinese People's Political Consultative Committee, The Committee of Diqing Precture in Yunnan Province, The Cultural and Historical Materials Research Committee), 17-56. Kunming:Xizhan caiyinchang. Ren Naiqiang 任乃强. 1934. Xikang tujing: minsu pian 西康图经: 民俗篇 (Illustrated Record of Xikang: Volume of Folklore). Nanjing: Xin yaxiya xuehui. 
Reylea, Scott. 2010. Gazing at the Tibetan Plateau: Sovereignty and Chinese State Expansion in the Early Twentieth Century. PhD Dissertation, University of Chicago. Rock, Joseph. 1925. 'The Land of the Yellow Lama'. The National Geographic Magazine 47 (4): 447-491.

Rock, Joseph. 1947. The Ancient Na-khi Kingdom, vol. 1. Cambridge: Harvard University Press.

Sangye Yeshi (Ch. Sangji Yuexi 桑吉悦希 / Tian Bao 天宝). 1968 'Plant Red Flags in Every Corner of the Tibetan and Yi Regions of Szechuan'. (6 September 1958. In Minzu Tuanjie 民族团结 [Nationalities Unite] 9). Reprinted in Tibet 1950-1967, edited by Nai-min Ling, 321-324. Hong Kong: Union Research Institute.

Schwieger, Peter. 2011. 'The Long Arm of the Fifth Dalai Lama: Influence and Power of the Fifth Dalai Lama in Southeast Tibet'. In Buddhist Himalaya: Studies in Religion, History and Culture. Proceedings of the Golden Jubilee Conference of the Namgyal Institute of Tibetology, Gangtok, 2008, vol. 1: Tibet and the Himalaya, edited by Alex McKay and Anna Balikci-Denjongpa, 239-257. Gangtok: Namgyal Institute of Tibetology.

Schwieger, Peter. 2015. The Dalai Lama and the Emperor of China: A Political History of the Tibetan Institution of Reincarnation. New York: Columbia University Press.

Shakya, Tsering. 1999. The Dragon in the Land of Snows: A History of Modern Tibet since 1947. London: Pimlico.

'Sheng minwei fuzhuren Wang Xueding xiansheng bingshi 省民委副主任汪学鼎 先生病逝' (Wang Xueding, Vice Chair of the Provincial People's Committee, Dies from Illness). Yunnan Ribao 云南日报 (Yunnan Daily). 9 July 1961.

Smith, Warren. 1994. 'The Nationalities Policy of the Chinese Communist Party and the Socialist Transformation of Tibet'. In Resistance and Reform in Tibet, edited by Robert Barnett, 51-75. Bloomington: Indiana University Press.

Song Guozhu 松国柱 (interviewee) and Tao Yuhua 陶玉华 (transcriber). 1992a. 'Jingkou shijian fasheng qianhou 菁口事件发生前后' (The Occurrence of the Jingkou Incident). In Zhongdian wenshi ziliao xuanji 中甸文史资料选辑 (An Anthology of Literary and Historical Materials from Zhongdian), edited by Zhongguo renmin zhengzhi xieshang huiyi, Yunnan sheng Zhongdian xian weiyuanhui wenshi ziliao weiyuanhui 中国人民政治协商会议, 云南省中 甸县委员会, 文史资料委员会 (China People's Political Conference, Yunnan Province Zhongdian County Committee, Literary and Historical Materials Committee), 39-42 (unpublished internally-circulated volume).

Song Guozhu 松国柱 (interviewee) and Tao Yuhua 陶玉华 (transcriber). 1992b. 'Shuofu Wang Xueding xia shan touxiang de jingguo 说服汪学鼎下山投降的 经过' (The Process of Persuading Wangchuk Tempa to Come Down from the Mountains and Surrender). In Zhongdian wenshiziliao xuanji 中甸文史资料选 辑 (An Anthology of Literary and Historical Materials from Zhongdian), edited 
by Zhongguo renmin zhengzhi xieshang huiyi, Yunnan sheng Zhongdian xian weiyuanhui wenshi ziliao weiyuanhui 中国人民政治协商会议, 云南省中甸县 委员会, 文史资料委员会 (China People's Political Conference, Yunnan Province Zhongdian County Committee, Literary and Historical Materials Committee), 83-88 (unpublished internally-circulated volume).

Sperling, Elliot. 1976. 'The Chinese Venture in K'am, 1904-1911, and the Role of Chao Erh-feng'. The Tibet Journal 1 (2): 10-36.

Sperling, Elliot. 1976a. 'Red Army's First Encounters with Tibet: Experiences on the Long March'. Tibetan Review 11 (10): 11-18.

Sulang Jiachu 苏朗甲楚. 1990. 'Wang Xueding Zhuanji 汪学鼎传记' (A Biography of Wang Xueding). In Diqing zhou wenshiziliao xuanji, disan ji 迪庆州文史资料 选辑. 第三辑 (An Anthology of Cultural and Historical Materials from Diqing Prefecture), vol. 3, edited by Zhongguo renmin zhengzhi xieshang huiyi, Yunnan sheng Diqing zangzu zizhizhou weiyuanhui, wenshi ziliao yanjiu weiyuanhui 中 国人民政治协商会议, 云南省迪庆藏族自治州委员会, 文史资料研究委员会 (Chinese People's Political Consultative Committee, The Committee of Diqing Precture in Yunnan Province, The Cultural and Historical Materials Research Committee), 105-114. Kunming: Xizhan caiyinchang.

Sulang Jiachu 苏朗甲楚. 2007. SulangJiachu Zangxue wenji 苏朗甲楚藏学文集 (An Anthology of Sulang Jiachu's Tibetan Studies Scholarship). Kunming: Yunnan minzu chubanshe.

Sun, Bintao 孙涁涛. 2011. 'Diqing difang dang shi zhuyao licheng 迪庆地方党史 主要历程' (The Principal Course of Party History in Diqing). Xianggelilawang, 21 June. URL: http://www.xgll.com.cn/xwzx/2011-06/21/content_51608_3.htm. (Accessed on 5 February 2018)

Sun, Feiyu. 2013. Social Suffering and Political Confession: Suku in Modern China. London: World Scientific Publishing Company.

Sun, Zhihe 孙致和. 1987. 'Heping jiefang Zhongdian jingguo: huiyi 1950 nian 和平解 放中甸经过: 回忆一九五O年' (The Process of Peacefully Liberating Zhongdian: Recalling 1950). In Diqing zhou wenshi ziliao xuanji, di yi ji 迪庆州文史资料选 辑. 第一辑 (An Anthology of Cultural and Historical Materials from Diqing Prefecture), vol. 1, edited by Zhongguo renmin zhengzhi xieshang huiyi, Yunnan sheng Diqing zangzu zizhizhou weiyuanhui, wenshi ziliao yanjiu weiyuanhui 中 国人民政治协商会议, 云南省迪庆藏族自治州委员会, 文史资料研究委员会 (Chinese People's Political Consultative Committee, The Committee of Diqing Tibetan Autonomous Prefecture in Yunnan Province, The Cultural and Historical Materials Research Committee), 25-34. Kunming: Yunnan minzu yinshua chang. Thondup, Kargyal. 1992. Mdo khams cha phreng kyi lo rgyus gser gyi snye ma (The Golden Grain of Dokham Chaktreng's History). Dharmasala: Library of Tibetan Works and Archives. 
Took, Jennifer. 2005. A Native Chieftaincy in Southwest China: Franchising a Tai Chieftaincy under the Tusi System of Late Imperial China. Leiden: Brill.

Tsomu, Yudru. 2006. Local Aspirations and National Constraints: A Case Study of Nyarong Gonpo Namgyel and His Rise to Power in Kham (1836-1865). PhD Dissertation, Harvard University.

Tsomu, Yudru. 2013. 'Taming the Khampas: The Republican Construction of Eastern Tibet'. Modern China 39 (3): 319-344.

Tsomu, Yudru. 2015. The Rise of Gönpo Namgyel in Kham: The Blind Warrior of Nyarong. Lanham, MD: Lexington Books.

Tuttle, Gray. 2005. Tibetan Buddhists in the Making of Modern China. New York: Columbia University Press.

Unger, Jonathan. 1993. 'Introduction'. In Using the Past to Serve the Present: Historiography and Politics in Contemporary China, edited by Jonathan Unger, 1-8. Armonk: M. E. Sharpe.

Van Spengen, Wim. 2002. 'Frontier History of Southern Kham: Banditry and War in the Multi-Ethnic Fringe Lands of Chatring, Mili, and Gyethang, 1890-1940'. In Khams pa Histories: Visions of People, Place and Authority, edited by Lawrence Epstein, 7-29. Leiden: Brill.

Wang Hengjie 王恒杰. 1995. Diqing Zangzu shehui shi 迪庆藏族社会史 (The History of Tibetan Society in Diqing). Beijing: Zhongguo zangxue chubanshe. Wang Lianfang 王连芳. 1987. 'Zhongyang fangwentuan dao Zhongdian fangwen de nanwang huiyi 中央访问团到中甸访问的难忘回忆' (The Unforgettable Memory of the Central Visitation Team's Visit to Zhongdian). In Diqing zhou wenshiziliao xuanji, di yi ji 迪庆州文史资料选辑, 第一辑 (An Anthology of Cultural and Historical Materials from Diqing Prefecture), vol. 1, edited by Zhongguo renmin zhengzhi xieshang huiyi, Yunnan sheng Diqing zangzu zizhizhou weiyuanhui, wenshi ziliao yanjiu weiyuanhui中国人民政治协商会议, 云南省迪庆藏族自 治州委员会, 文史资料研究委员会 (Chinese People's Political Consultative Committee, The Committee of Diqing Tibetan Autonomous Prefecture in Yunnan Province, The Cultural and Historical Materials Research Committee), 17-24. Kunming: Yunnan minzu yinshua chang.

Wang Xueding 汪学鼎. 1989. 'Wang Xueding xuexi zongjie (jiechao) 汪学鼎学习总结 (节抄)' (A Summary of Wangchuk Tempa's Lessons [condensed transcription]). In Zhongguo gongchandang Dian xigongwei Dian xibei diwei shiliao xuanbian 中 国共产党滇西工委滇西北地委史料选编 (An Anthology of Historical Materials from the Chinese Communist Party's West Yunnan Working Committee and Northwest Yunnan Prefectural Party Committee), edited by Zhonggong Dali Lijiang Baoshan Nujiang Diqing Dehong dizhouwei dangshi bangongshi 中 共大理丽江保山怒江迪庆德宏地州委党史办公室 (The C.C.P. Dali, Lijiang, 
Baoshan, Nujiang, Diqing, and Dehong Districts' and Prefectures' Committee, The C.C.P. Party History Office), 615-616. Dehong: Dehong minzu chubanshe. Wang Xueding 汪学鼎. 1994. 'Wang Xueding xie gei Liao shizhang de xin 汪学 鼎写给廖师长的信’ (The Letter that Wangchuk Tempa wrote General Liao). In Diqing zhou wenshi ziliao xuanji, diwu ji 迪庆州文史资料选辑. 第五辑 (An Anthology of Cultural and Historical Materials from Diqing Prefecture), vol. 5, edited by Zhongguo renmin zhengzhi xieshang huiyi, Yunnan sheng Diqing zangzu zizhizhou weiyuanhui, wenshi ziliao yanjiu weiyuanhui 中国 人民政治协商会议, 云南省迪庆藏族自治州委员会, 文史资料研究委员会 (Chinese People's Political Consultative Committee, The Committee of Diqing Tibetan Autonomous Prefecture in Yunnan Province, The Cultural and Historical Materials Research Committee), 166-167. Dali zhou: dianzi yinshua chang. Wangyal, Baba Phuntsok. 2007. Witness to Tibet's History. Translated by Tenzin Losel, Jane Perkins, Bhuchung Sonam, and Tenzin Tsundue. New Delhi: Paljor Publications.

Weiner, Benno. 2012. The Chinese Revolution on the Tibetan Frontier: State Building, National Integration and Socialist Transformation, Zeku (Tsékhok) County, 19531958. PhD Dissertation, Columbia University.

Weiner, Benno. 2015. 'A Last Hurrah for the United Front: Pastoral Collectivization, Retrenchment and Rebellion on the Amdo (Qinghai) Grasslands, 19561958'. Unpublished paper presented at the Association for Asian Studies Conference.

White, Sydney. 2002. 'Town and Village Naxi Identities in the Lijiang Basin'. In China offCenter: Mapping the Margins of the Middle Kingdom, edited by Susan Blum and Lionel Jensen, 131-147. Honolulu: University of Hawai'i Press.

Wong, How Man. 2002a. 'A Teacher in Bandit Country'. China Explorers 4 (3): 17-19. Wong, How Man. 2002b. 'Treachery with Honour'. China Explorers 4 (3): 10-11.

Yang, Fuquan. 2013. 'The Ancient Tea and Horse Caravan Road: The "Silk Road" of Southwest China'. The Silk Road Foundation Newsletter. URL: http://www. silkroadfoundation.org/newsletter/2004vol2num1/tea.htm. (Accessed on 31 March, 2019).

Yunnan sheng bianji zu 云南省编辑组 (The Editing Division of Yunnan Province), ed. 1986. Zhongyang fangwen tuan di er fentuan Yunnan minzu qingkuang huiji 中央访问团第二分团云南民族情况汇集 (上) (The Report of the Second Central Visiting Delegation to Investigate the Conditions of the Ethnic Minorities in Yunnan Province), vol. 1. Kunming: Yunnan minzu chubanshe.

Yunnan sheng difangzhi bianzuan weiyuanhui 云南省地方志编纂委员会(Yunnan Province Gazetteer Compilation Committee). 2002. 'Wang Xueding 汪学鼎'. In Yunnan sheng zhi 云南省志 (Yunnan Province Gazetteer), edited by Yunnan 
sheng difangzhi bianzuan weiyuanhui 云南省地方志编纂委员会 (Yunnan Province Gazetteer Compilation Committee), 452-454. Kunming: Yunnan renmin chubanshe.

Zhongdian xian zhi bianzuan weiyuanhui 中甸县志编纂委员会 (Zhongdian County Gazetteer Compilation Committee), ed. 1997. Zhongdian xian zhi 中 甸县志 (Zhongdian County Gazetteer). Kunming: Yunnan minzu chubanshe.

'Zhongguo gongnong hongjun er fangmian jun zhengzhi bu guanyu er liu juntuan changzheng de zhengzhi gongzuo zongjie baogao (zhailu) 中国工农红军二方 面军政治部关于二六军团长征的整治工作总结报告(摘录)' (Final Report by the Political Department of the Second Front Army of the Chinese Workers' and Peasants Red Army on the Second and Sixth Army Groups' Political Work During the Long March, 19 December 1936 [Excerpts])'. 1991. In Minzu Wenti Wenxian Huibian 民族问题文献汇编 (Collection of Documents on the Nationality Question), edited by Zhongguo gongchandang zhongyang tongyizhan gongzuo bu 中国共产党中央统一战工作部 (United Front Department of the Central Committee of the Chinese Communist Party), 436-440. Beijing: Zhonggong Zhongyang Dangxiao Chubanshe.

Zhongguo renmin zhengzhi xieshang huiyi, Yunnan sheng Diqing zangzu zizhizhou weiyuanhui, wenshi ziliao yanjiu weiyuanhui 中国人民政治协商会议, 云南 省迪庆藏族自治州委员会, 文史资料研究委员会 (Chinese People's Political Consultative Committee, The Committee of Diqing Tibetan Autonomous Prefecturein Yunnan Province, The Cultural and Historical Data Research Committee), ed. 2005. Diqing zhou wenshiziliao xuanji, di qi ji 迪庆州文史资料选辑, 第七辑 (An Anthology of Cultural and Historical Materials from Diqing Prefecture), vol. 7. Kunming: Yunnan yafeng san he yinwu jingmao you xian gongsi.

Zhongguo renmin zhengzhi xieshang huiyi, Yunnan sheng Zhongdian xian weiyuanhui 中国人民政治协商会议,云南省中甸县委员会 (The Chinese People's Political Consultative Conference, Yunnan Province Zhongdian County Committee), ed. 2003. Zhongdian xian zhengxiezhi 中甸县政协志 (The Gazetteer of the Chinese People's Political Consultative Conference of Zhongdian County). Dali: Yunnan sheng Diqing zhou wenhua xinwen chuban zhunyin zheng.

Zhongguo renmin zhengzhi xieshang huiyi, Yunnan sheng Zhongdian xian weiyuanhui wenshi ziliao weiyuanhui 中国人民政治协商会议, 云南省中 甸县委员会, 文史资料委员会 (The Chinese People's Political Consultative Conference, Yunnan Province Zhongdian County Committee, Literary and Historical Materials Committee), ed. 1992. Zhongdian wenshi ziliao xuanji 中 甸文史资料选辑 (An Anthology of Literary and Historical Materials from Zhongdian) (unpublished internally-circulated volume).

Zhuoma Qinglin 卓玛青林. 2015. 'Yeye de gushi 爷爷的故事' (Grandfather's Story). Diqing Ribao 迪庆日报 (The Diqing Daily). 2 February: 4. 
About the Author

DÁša PejChar Mortensen is Assistant Professor of History at Davidson College, U.S.A. Her research focuses on ethnic politics, memory, tourism, and the construction of historical narratives in Kham under Chinese Communist rule. She is currently writing a book on the history of Gyelthang in the Mao and post-Mao periods. 


\title{
13 Return of the Good King
}

\author{
Kingship and Identity among Yushu Tibetans since $195^{1}$
}

\author{
Maria Turek
}

\begin{abstract}
This chapter focuses on history writing about the Eastern Tibetan kingdom of Nangchen based on newly published local chronicles that legitimize Nangchen as an autonomous power centre, opposing official state views on its peripherality. These historical narratives centre on an idealized concept of kingship deeply rooted in the Tibetan Buddhist orthodoxy, myth, and ritual. The contemporary remembering of the legitimate Nangchen kings' lineage transcends a revival of traditional historiography or nostalgia, and has the capacity to repair the broken connection with local tradition and to re-emphasize the value of the landscape as its container. The narrative return of the good kings becomes an important factor in the reconstruction of local identity.
\end{abstract}

Keywords: Nangchen, Qinghai, historiography, kingship, identity, revival

\section{Introduction}

The Eastern Tibetan kingdom of Nangchen, whose location today roughly corresponds to Yushu Tibetan Autonomous Prefecture (T.A.P.), Qinghai Province, remains one of the least studied Tibetan polities so far. This chapter is one of the very first attempts to draw up an ethnohistory of Nangchen by taking into consideration newly composed or republished local material.

The sources that reconstruct local history represent Nangchen as a self-referential sphere with a flourishing religious life and as being of great influence over religious culture throughout Eastern Tibet (Kham). These historiographic projects centred on 'place memory' (Casey 1987), in this example understood as a combination of local identity and a

Gros, Stéphane (ed.), Frontier Tibet: Patterns of Change in the Sino-Tibetan Borderlands. Amsterdam, Amsterdam University Press 2019

DOI: 10.5117/9789463728713_CH13 
mnemonic process, take manifold forms and may at times challenge each other. However, at the heart of a great many of these narratives lies the idealized concept of kingship, recounted through written practices that transcend factualist historiography. In post-Mao Yushu T.A.P. and for many exiled Nangchenmi ('people of Nangchen'), as the locals refer to themselves, remembering Nangchen kings re-positions the kingdom from the periphery of China or Tibet to an autonomous centre. Through and in the local narratives themselves, kingship also becomes an argument in the reconstruction of identity, which has the capacity to heal the broken connection with local tradition and, since Tibetan memory practices often evolve around specific places, to re-emphasize the value of the landscape as the container of traditional narratives. The kingship narrative proves useful in the reconstruction of identity because it re-engages with local self-description in terms of subjecthood to the Nangchen kings. A similar phenomenon has been described for another kingdom located in Kham, that of Gyelrong (Ch. Jiarong) (Prins 2007). In this contribution, I would like to draw attention to the fact that in Tibetan societies, subjecthood to a king implies belonging to a larger constellation of social and religious-mythical meanings of both pre-Buddhist and Indic Buddhist origins. These meanings provide a comprehensive explanation about the origins of and dynamics between human and non-human actors. These meanings are contained in the native place, which is very much emphasized in Tibetan culture in general. Therefore, because the cosmology of kingship is linked to the landscape and to places, the literature which resurrects this cosmology may have a profound effect on Nangchenmi in Yushu T.A.P. and in exile, and can assist them in reaffirming the ties to their homeland. The power of the kingship narrative to reconstruct local identity is especially visible in cases like Nangchen, where the king wielded little or no real political authority. The power was divided among a network of hereditary headmen with the king as primus inter pares. Above this on-the-ground structure was the sovereignty of the Qing (since at least 1725) and later, of Republican China and Qinghai warlords. However, as a sacred form of rule, the local institution of kingship was probably the most pervasive, yet symbolic, force, which determined the moral unity and local identity in the land. Parallel to several other Khampa kingdoms like Dergé and Trokyap described in this volume, kingship in Nangchen was crucial to defining its own centrality and cultural specificity. In Nangchen, this perceived autonomy was re-produced simultaneously with its marginalization by external power centres. However, these 'outer' forces were also internalized in the local kingship and power structures. This non-linear although historically consistent process is representative 
of the production of place in Kham, discussed throughout this volume, which emerges in a relational manner and which argues for a 'processual geography' of the region (Gros, this volume).

\section{Authority of the Local Narrative, Authority of the King}

As has been observed by Stevan Harrell (1995), China's government's 'civilizing project' targeted at minorities with the premise that they are in need of assistance in order to become truly civilized and fully integrated in the nation-state can lead to a reinforcement of or a focusing of ethnic identity (Harrell 1995, 27). Previous writings have also situated the memory practices of China's minorities in the context of Deng's reforms and the subsequent awakening of ethnic pride (Litzinger 1998; Harrell and Li 2003). The Tibetan minority is also engaged in negotiating their origins and pasts based on their new historiographies. The renewed interest and pride in local history can be observed throughout Kham, and the Nangchen materials discussed here should be seen against the background of this larger process.

Historians, whose work has informed this contribution, are descendants and revivers of the traditional historiographic discourse deeply rooted in Tibetan Buddhist orthodoxy and historical imagination. These native scholars therefore often position themselves differently from those who write the history of the neighbouring Dergé kingdom. Authors of the history of Dergé are employed at large Chinese universities and/ or represent an active local government and Party leadership. Their schooling has enabled them to also quote excerpts from Chinese sources on the history of Dergé. Unlike these Tibetan intellectuals, Nangchen historians are all monks, save one, Denma Jamyang Tsultrim (b. 1943). However, even the aforementioned author was trained in a traditional monastic environment. Traditional training has influenced the way these authors recollect and re-codify the past as history. This calls upon a world view dominated by religion. Perhaps as a parallel to medieval European chroniclers, who 'believed in God as being the cause of all historical processes' (Misztal 2003, 33), the Buddhist experience of history, associated with circular epochs of the rise and decline of Buddhist teachings, meant that the past and memory 'were not seen as models for understanding the present or the future but as sources of evidence of divine intervention in history' (Tosh 1991, 11-12 in Misztal 2003, 33). The opening pages of one of our Nangchen sources illustrates this orthodox view: the book begins with an image of Avalokiteśvara, the protective-deity of the Land of Snows, followed by the three dharma-kings of Tibet, then by 
images of protective deities associated with the author's clan, and finally local places said to be the abodes of those deities (Gedrong Logyü, 2-4). At the same time, we learn what constitutes an authority on this historical narrative: first, non-human beings ranked in a classic order from totally enlightened to locally bound deities and suprahuman forces associated with the local landscape. Next are photographs of an archive record and two edicts which are said to be one of the sources for the current chronicle, and lastly, a full-page photograph of the last ruling Nangchen monarch, King (gyelpo) Trashi Tséwang Dorjé (1910-1961) with the caption: 'Dharmaking Tashi Tséwang Dorjé, the sixty-seventh generation of Dru lords, and twenty-fifth in the line of kings: Photograph taken in 1950' (Gedrong Logyü, 7). The strategic position of the king directly after the divine, non-human actors and the authoritative archive materials (which include a certificate of award granted by one of the earlier kings) highlights the central theme of kingship in contemporary writings about Nangchen history. Since the revival of local and ethnic identity is simultaneous 'with the emergence of religion' (Sørensen 2015, 155) in these traditional narratives, kingship itself is viewed from a Buddhist perspective. That the genealogy of the kings is frequently recounted in the opening chapter of the local chronicles resonates with the traditional Tibetan idea about how these types of narratives serve as the universally sanctioned representation of history (Sørensen 2015, 159).

How is the revival of traditional historiography positioned within Chinese state-endorsed historical scholarship? On the one hand, China is engaged in its project of civilizing Tibetans and in writing their official historiography, for which I provide examples below. On the other hand, some Tibetan writers are in the process of negotiating this viewpoint by using practices that I will describe. However, the accounts of Tibetan history that contest the state narrative were published in the People's Republic of China (P.R.C.) by large official publishing houses. The fact that the state would endorse, or at the very least, tolerate this kind of literary production testifies to the complex relations that exist between the government's stance on history writing and the Tibetans themselves as one of China's minorities. Although these links should not be viewed in black and white, it is indeed a fact that any official scholarship about Tibetan history is expected to reflect Tibetan societies' long-standing dependency on China and on the Han as China's most advanced group. The narratives described in this chapter need to be seen against a backdrop of practices of historical appropriation, such as the notification in English, Chinese, and Tibetan that Kham's most beloved legendary hero, King Gesar of Ling and his epic story, originated 'in the highlands of Qinghai, Yushu Tibetan Autonomous Prefecture', as seen on a 
Figure 13.1 The last ruling Nangchen king, Trashi Tséwang (Topgyel) Dorjé (19101961)

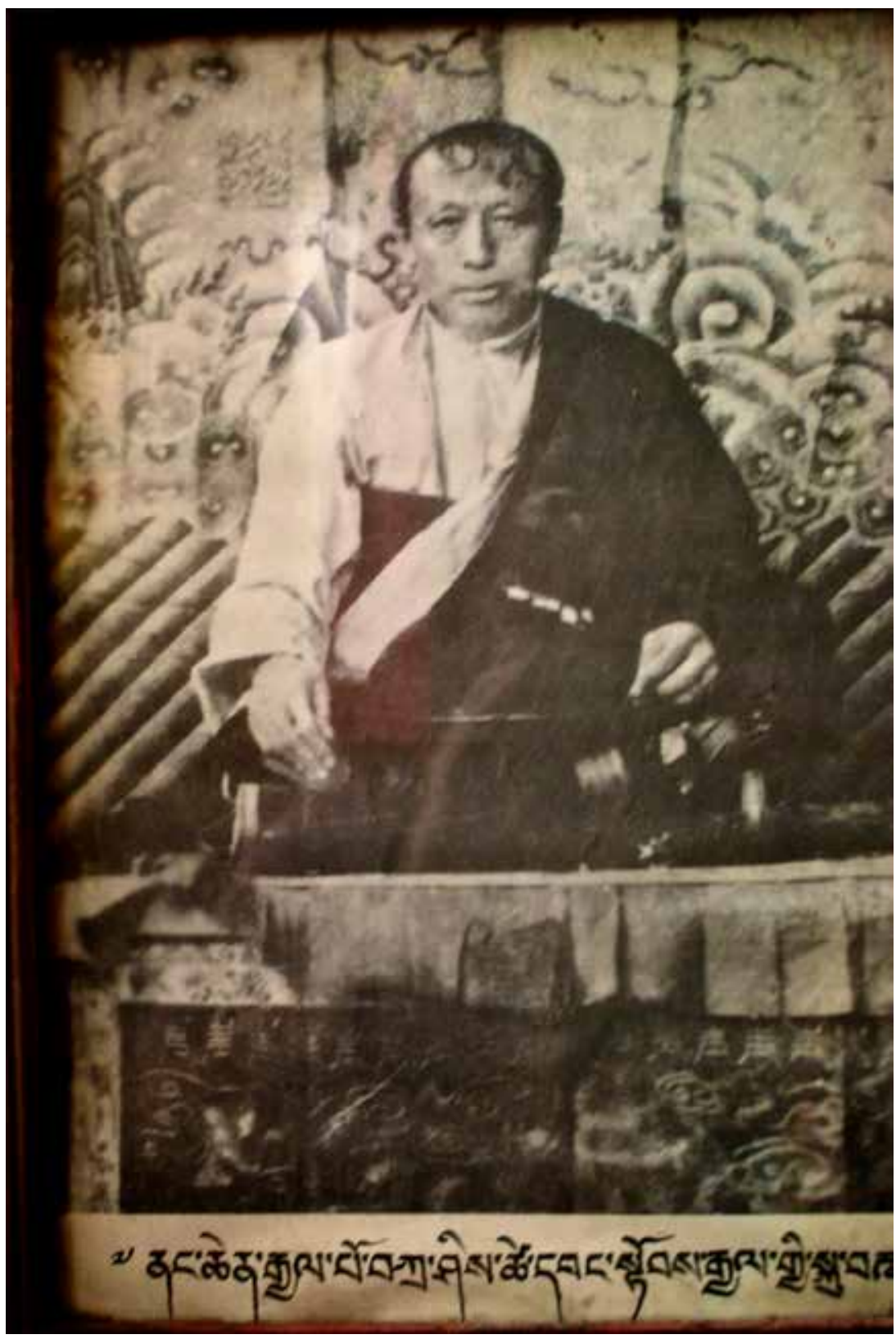

Anonymous photographer 
signpost at the recently erected Gesar monument in Jyekundo on the former territory of the Nangchen king. Khampa kingship narratives have not only been the object of appropriation but also of denigration, as evidenced by the English and Chinese renderings of the term chögyel (dharma-king) into 'headman' and 'tusi', with reference to the 42nd Dergé king, Tenpa Tsering, and inscribed on entrance tickets to the famous Dergé Printing House. Despite these examples of politics of historical representation, we might perceive the traditional Nangchen historian as engaging in the reconstruction of an alternative history in a creative effort to renegotiate their understanding of the local past with the dominant, communist and Han-centric narrative (compare Harrell and Li 2003).

KhamtöLogyü (History of Upper Kham), one of the main sources used here, opens with a black-and-white photograph of the royal family that was taken in 1951. It portrays the last, newly deposed, Nangchen king, Trashi Tséwang Dorjé with his spouse, the Dergé princess Yudrön, and their offspring in the role of envoys of the new communist regime under the watchful eye of a People's Liberation Army officer. Dressed in traditional Tibetan clothing, the king and his family are seated on a row of chairs in the centre of the photograph. The soldier is carrying a long rifle, and the sign on the concrete gate, high above their heads, reads: 'People's Government of Qinghai Province, Yushu Tibetan Autonomous Prefecture' (Khamtö Logyü II, n.pag.). Although the last ruler was granted the position of leader of the new local regime, the king was more a captive than a collaborator, and he died a decade later under house arrest. Unlike other Khampa leaders from the neighbouring Dergé: the queen regent (his own sister) and the strongman Jagö, the Nangchen king was much less proactive in the reception of the communist forces. The king's chaplain Adé Rinpoche remembers that the gyelpo initially contemplated flight into exile, but eventually settled on staying and adopted a passive attitude towards the new regime (Adeu 2011, 90).

A glance at this particular photograph reveals the stark contrast between traditional expressions of local leadership, especially in such a symbol-laden form as kingship, and the brave new order imposed from outside. This raises a number of questions about the recent local past and about how it has affected present-day ideas about belonging and identity. It also prompts the reader to think about history and its writing. When the last Nangchen gyelpo was coerced into representing the new communist power structures and, especially later, when he was not only stripped of his authority but also of his highly revered status and held in confinement, history too, in the words of Carole McGranahan (2010), was arrested. Modern Tibetan historiographies, such as Khamtö Logyü, have attempted to reverse this 
process, or at least to compensate for the crisis that arose with the abrupt rupture in the continuity of the local socio-political structure and with the erasure of its authority. By recounting Nangchen's kingship narrative, Tibetan authors from Yushu or those in exile aim to restore the kings' elevated status and fundamental role in the history of Nangchen. However, to over-write the official view of local histories that portray Eastern Tibet as backward and relevant only in its capacity as tributary to regimes ruling from China, Nangchen historians first had to reinstate the authority of the local historical narrative as a valid mode of remembering the past and thus regain control of their own history and territory.

The authors address their histories to the local elite and those exiled Nangchen Tibetans, who take interest in their past. In the new Nangchen chronicles, the power of the kings is constantly recalled, born in the reader's mind and engages with the present in ways which do not threaten the coherence of the official state narrative which presents Nangchen Tibetans as one of China's minorities. Many Tibetan authors publishing their works in China might find such an agenda too politically sensitive to express their opinion openly; but this subtle critique is reminiscent of what James Scott (1990) has called the 'hidden transcripts' practised by people of subaltern status, voicing their claims in ways that go unnoticed by power-holders.

Reviving the memory of legitimate kingship, as reflected in publications produced today in Yushu T.A.P. and among Nangchen Tibetans living abroad, compensates not only for the loss of royal authority but for what is more disruptive to local identity: the loss of recollection of this authority. Recounting elements of legitimacy formation therefore means 're-membering the dismembered' as David Germano (1998) aptly described post-Mao Tibetan revivalist practices. In the process of this revival, narratives and especially those involving secular and religious power play a vital role in effectively re-codifying local identity. The image that is recreated when Nangchen is remembered as a self-referential sphere under the revered lineage of Tibetan monarchs comprises several elements: proto-Tibetan myths and legends, the foreign mandate, and Buddhist elements such as the MahāyanāDharmaraja/Cakravartin ideal and, more specifically, the ritual power of Tantric hermitism.

\section{The Kingdom of Nangchen: A Brief History}

The territory of the historical kingdom of Nangchen was made up of a largely pastoral area surrounding the upper reaches of the Dzachu (Mekong) and 
Drichu (Yangtze) rivers. Prior to the thirteenth century Nangchen had been incorporated into the territory of the Tibetan Yarlung Empire (seventh-ninth centuries A.D.). Sometime in the mid-twelfth century the Dru clan, which claimed direct descent from one of the six ancient proto-Tibetan families, settled in Ga in what was later to become northeastern Nangchen and developed its influence over most of the Jyekundo (Yushu) area (Nangchen Gyelrap [The Royal Nangchen Chronicle], 20-21 and 32; Khamtö Logyü, 38 ). It was this very clan whose descendant would be enthroned as the first Nangchen king almost two centuries later.

By way of introducing the origins of the Dru lineage, Nangchen Gyelrap quotes the story of the matrix egg, a widespread Tibetan cosmogonic myth. It narrates how the six classes of beings hatched from the egg and then gave birth to all forms of life from which the six human clans came forth. The clans were divided into eighteen branches. Sixteen of these branches scattered in all directions. One of them was said to be the Dru. Another wellestablished mythical account in Nangchen Gyelrap, and which is repeated after Mani Kabum and other Tibetan classics, tells the story of an ogress (an emanation of Tārā) who had six children with the Monkey Meditator (who in reality was Avalokiteśvara). Their six children were the progenitors of the six clans, including the Dru (Nangchen Gyelrap, 20-22). This source also mentions specific legends involving the Dru in particular, one of which portrays early clan patriarchs as culture heroes, a cross between Yarlung emperors, a divinity and the legendary master Padmasambhava who brought Tantric Buddhism to Tibet:

Lord Dru, a divine prince with a white turban slaughtered a black, rapacious human demon, [...] and a hoard of demons headed by crab-sprits with eyes on their shoulders [...]. Lord Dru stole [from them] a bleating, conch-coloured lamb, a talking turquoise-coloured parrot and eighteen of the demon's yak bulls. In the course of a fierce battle he was the opponent of the vicious Viṣnu [...]. (Nangchen Gyelrap, 21).

Not unlike chronicles from Central Tibet, where myths and legends are intertwined with historical facts, which is particularly obvious in accounts dating back to the time of the Tibetan emperor Songtsen Gampo (seventh century), Nangchen Gyelrap (22) also describes how the Dru were of 'divine lineage'. These literary borrowings feed on a sense of timelessness and other mythic elements, a skilful technique for reconstructing both the history of the kings and also the cosmology of kingship - a necessary strategy for the successful negotiation of identity in the present revival. 
Furthermore, we learn that one of the early Dru patriarchs by the name of Kyehu Khorlo Zangpo was minister (Tib. nanglun) to an emperor, supposedly from the Tibetan Yarlung dynasty (Barom Namthar, 260-261). Nangchen Gyelrap (23-24) refers to Kyehu Khorlo Zangpo as a great (Tib. che) man. The combination of the two syllables nang and che led him to be known by the name Nangchenpa (and later prompted the name 'Nangchen' for the kingdom). As Amy Holmes-Tagchungdarpa observed in her work on another Khampa kingdom, Lhatok, historiographic techniques such as the appropriation of authority from broader Tibetan cultural narratives can highlight the autonomy and the distinctiveness of the local process, while at the same time emphasizing the sense of belonging to a larger Tibetan constellation of polities. In the case of the Nangchen royal genealogy, we find a similar process by which the format of the royal genealogy 'presents an alternative way to write and understand history as a political tool to create physical and imaginative boundaries around a place' (Holmes-Tagchungdarpa 2010, 19). In this way the narrative itself acquires historical legitimacy since it is based on another account which is seen locally as authoritative. Consequently, a narrative that has been renegotiated as history can be used as a proclamation of political power.

The following passages briefly recount the local story of state formation, governance, and the situation inside the kingdom. They are useful in our discussion about remembering kingship in Nangchen because they allow us to appreciate the complexity of the canvas onto which local historians placed kingship as a social practice.

Making reference to former places of power can be a way of capitalizing on knowledge about the landscape in order to reassert local identity and to position the native place vis-à-vis practices of peripheralization. Our sources frequently recall the earliest power centre in what was to become Nangchen - the Barom Kagyüpa monastery of Kumbum, known as 'Barom root'. Kumbum was founded by the Tangut master Repa Karpo (1198-1262), a disciple of the Tibetan imperial preceptor at the Tangut court, Tishi Repa Sherap Senggé (1164-1236). Around 1240, a few years after Tishi Repa's death, during a reconnaissance expedition under commander Doorda that Gengghis Khan's grandson Godan Khan had dispatched to conquer Tibetan areas, Kumbum became the scene of an encounter between the Mongols and the local authorities. Consequently, parallel to developments at Sakya in Central Tibet, Repa Karpo was established as the main religious authority along with a Dru lord, a layman called Driwo Awu, who was tasked with overseeing secular matters (Khamtö Logyü II, 39-41, 50; Barom Namthar [Life Stories of the Barompas] 220, 235). The Mongols therefore introduced 
an administrative structure which guaranteed their control of Nangchen, and Kumbum monastery started to develop into a local power centre with authority to rule over twelve myriarchies (Barom Namthar, 234-236). To lend weight to this, Repa Karpo further extended the Kumbum complex with Nangso Chenmo - an impressive palace including a remarkable temple and a monastic compound. It was probably during this period, with the advent of Mongol administrative divisions, that Nangchen was organized into 25 pastoral clans and eighteen monastic districts (Khamtö Logyü II, 40, 79-87; Tsomu 2006, 37). These religious units, each governed by a main monastery, are all said to have originally been of the Barom Kagyü denomination, perhaps owing to early Barom supremacy in the region. Thereupon Nangchen grew to become a Kagyü stronghold and the Barom tradition, which was to undergo a substantial decline in later times, became the principal religious and political force in the kingdom in the initial stages of its existence. In fact, the rise, decline, and successive revivals of Barom Kagyü were inextricably bound to the secular history of Nangchen.

Consolidation of the religious and secular dominance of the Barom school in Nangchen as well as the centralization of power took place during the reign of Tsangsar Lümé Dorjé (1226-1292), Repa Karpo's principal heir. After Repa Karpo's demise, Chögyel Pakpa (1235-1280), whose success at the court of Kublai Khan and the resulting supremacy over Ütsang and other Tibetan areas are well documented, sanctioned Lümé Dorjé to exert both religious and temporal rule over upper-central Nangchen. This no doubt transpired in 1274 when Pakpa was passing through Nangchen (Khamtö Logyü II, 164). However, it must be emphasized that Lümé Dorjé originated from a local clan and rival to the Dru - the Tsangsar - and in the early phases of Nangchen's development, the Dru had yet to emerge as the lineage of Nangchen kings (Depter Mukpo [The Maroon Annals], 321-322).

The subsequent Barompa ruler in the Tsangsar lineage was Jangchup Zhönnu (1254-1323), Lümé Dorjé's nephew. It would seem that Jangchup Zhönnu's early reign marked the last period of political and religious unity in the realm. During this overlord's lifetime, preparations were being made to establish a Dru son as a rival ruler. It was a clan matter - the Tsangsar had been in power for two generations now, and the Dru had been waiting anxiously for the opportunity to seize power again and had been preparing to gradually settle Dru Chökyi Gyeltsen on the throne. Sources report that Dru Chökyi Gyeltsen was first proclaimed abbot of Kumbum by the Yuan emperor Temür Khagan (ruled 1294-1307) and that a little later, Sakya Khön issued a decree addressed at the monastic communities in Nangchen and in the Dru homeland of Trirapkha, which stated that the throne in Nangchen 
should be occupied by someone with the title of chögyel, dharmarāja, which refers to the pan-Tibetan and Indic idea of an ideal sovereign who rules in accordance with Buddhist teachings (Barom Namthar, 262-263). Alternatively, Khamtö Logyü (II, 165) recounts that in 1294, a high-ranking official in the Sakya-Yuan hierarchy and a disciple of the influential Sakya master Ga Anyen Dampa (1230-1303), who went by the name of Sangha, issued an edict and seal that exempted Chökyi Gyeltsen from paying taxes (Khamtö Logyü II, 165). It is possible that the strong ties between the Dru clan and the Sakya rulers dated back to the time when Chögyel Pakpa visited Kumbum. However, some sources claim that the 1294 edict had in fact been issued even earlier and that it also granted Dru Chökyi Gyeltsen the right to rule over both Nangchen and his native Trirapkha (Gedrong Logyü [Chronicle of the Good Drongpa Clan], 99; Barom Namthar, 262-263). Other authors attribute the edict to Chögyel Pakpa himself (Khamtö Logyü II, 166).

Nonetheless, all local chronicles are unanimous: Dru Chökyi Gyeltsen ascended the Nangchen throne as chögyel in 1300 . He received the right to collect tribute and corvée in the territory comprising Trirapkha and up to and excluding Kumbum. This local power centre was handed down to Jangchup Zhönnu and his transmission holders (Khamtö Logyü II, 165; Nangchen Gyelrap, 28). Given this state of affairs, Jangchup Zhönnu had no other choice but to build another castle to centralize the power he still exercised. Consequently, in 1302 the Tsangsar stronghold was built and Jangchup Zhönnu moved into the compound, which in 1323 was most probably where he died (Nangchen GönkhakJungwa [Origins of Nangchen's Monasteries], 332).

Chökyi Gyeltsen had influential relatives: his maternal uncle, Be Jangchub Gönpo, and cousin, Yonten Pal, were both high-ranking officials at the grand temple of Nangso Chenmo (Barom Namthar, 262; Khamtö Logyü I, 39). During Jangchup Zhönnu's lifetime the uncle had already intervened at the Sakya court in what I assume was a power struggle, and obtained an edict which proclaimed Yonten Pal, Chökyi Gyeltsen's maternal cousin, the rightful heir to Tsangsar castle. The Barom Namthar (262-263) implies that this occurred in 1324. As a result, the realm was separated into two domains of equal status according to the Sakya-Mongol legal system: one territory under Dru Chökyi Gyeltsen, the Nangchen gyelpo, and another under his maternal cousin who governed from Tsangsar (Khamtö Logyü II, 166; Nangchen GönkhakJungwa, 332). To further emphasize the split in power, all the Barompa relics, precious objects as well as ritual implements, were relocated from Kumbum to Tsangsar (Barom Namthar, 233, Khamtö Logyü II, 48-49). This division was accompanied by a further fragmentation 
of the Barom transmission of doctrines and rituals, which I have described elsewhere (Turek 2018).

Local sources recall in some detail these numerous factions, all bearing foreign edicts, and locate the power struggle in and among the three local centres of power: Kumbum, Nangso Chenmo, and Tsangsar. These monasticpolitical institutions would at times have one overall steward, such as Chökyi Gyeltsen at Nangso Chenmo, and at other times two persons in charge, one to oversee the monastic and another to supervise secular affairs. Abbots, monastic administrators, and lay officials were all strongly bound by kinship ties and religious allegiances. This created a complex, shifting landscape of clan loyalties, marriage alliances, and religious fidelities, which provided an opportunity for outside authorities to issue mandates that were expected to solve inner conflicts of power. All this led to the formation of Nangchen as a polity and the emergence of Dru Chökyi Gyeltsen as the first king. But how do our sources represent the very first ruler as chögyel? Dru Chökyi Gyeltsen is described as being accomplished and learned in both secular and religious matters; he is also presented as someone who was a figure of authority respected by both lay and monastic leaders (Khamtö Logyü II, 62-64, 165; Barom Namthar, 262-263). A ritual virtuoso and a well-read monk, who, like many luminaries at that time, had received his training at the Sakya capital in Central Tibet, Chökyi Gyeltsen became the transmission holder of the previous Barompa patriarch and ruler, Lümé Dorjé (Khamtö Logyü II, Barom Namthar, 262-263, Nangchen Gyelrap, 27).

The Dru, which was Chökyi Gyeltsen's paternal clan, had already set a precedent for local power. Chökyi Gyeltsen's father was the aforementioned $\mathrm{Awu}$, who had acted earlier on as the secular myriarch in the local government under the auspices of Goden Khan. Although there were several clans that competed for power at that critical time of Nangchen's formation, in contemporary historical accounts, only the Dru are portrayed as the glorious bloodline endowed with a divine origin (Nangchen Gyelrap, 20-22, Dge 'brong lo rgyus, 42). The same passages also describe the Dru as arriving in Nangchen from outside.

To some extent, this theme of the external origin of the ruler is reminiscent of Marshall Sahlin's $(1985,2008)$ interpretation of the 'stranger-king' concept that he originally developed about Indonesia and Oceania, and which could also be applied to describe the Central Tibetan Yarlung emperors. However, 'the potency of alterity' (Sahlins 2008, 192) would mean that kings were the real power holders, when in practice, as some of Sahlin's critics have observed, kings often enjoyed great prestige but little real authority (Oosten 1988, 269). Even though the Dru dynasty had been attributed an exalted rank, 
it was not the only contender for power. While their moral superiority and their claim to royal status were never challenged, over time their political authority waned.

During the Ming era in China (1368-1644) the king and local aristocratic estates remained independent of any foreign regimes, as Barom Namthar (256) mentions in passing. No further mention is made about the state of affairs in Nangchen during that period in any of the chronicles. The omission of facts has been linked to the empowerment of subalterns by overlooking inconvenient truths (Rowland 1993), but I strongly suspect that our sources did not find sufficient or adequate historical references, given a certain vagueness surrounding the same period in Central Tibet.

Local sources leap from the Mongol period to the year 1634 which saw the ultimate destruction of Kumbum when the Eastern Tibetan prince of Beri, eager to extend his scope of authority and to win territory for the Bön, invaded Nangchen (Nangchen Gyelrap, 38; Khamtö Logyü II, 3, 171). The aggressor was defeated by Quoxot forces in 1640, but the 'Barom root' and at the same time the royal seat and capital of the realm, was never rebuilt. The king managed to escape, but the utter destruction of Kumbum had a devastating effect on the development of the Barom school (Turek 2018).

The memory of Kumbum monastery is celebrated in all contemporary Nangchen chronicles as a basis for the organization of power which would eventually lead to the creation of a polity and territorial identity. In local writings, both the emergence of Kumbum and the rise of gyelpo, as the process of centralizing authority, are linked to Mongol supremacy over Tibet and vast areas of Asia in the thirteenth and fourteenth centuries. It is possible that it was necessary for an external force from outside Nangchen to sanction the rise of a new local regime at that particular moment in time. However, the use of the Sakya-Mongol mandate in the narratives could further capitalize on a certain aspect of pan-Tibetan historical identity. In the self-image practised by many traditionally trained scholars and authors, the thirteenth-fourteenth centuries are known as the era when Mongol emperors revered and exalted their Tibetan preceptors. Reference to the Sakya-Yuan diarchy in local narratives has the effect of sanctioning the Nangchen state formation in the wider, Tibetan collective memory. This mnemonic technique also validates the legitimacy of local kingship by borrowing from a larger Tibetan cultural narrative.

Let us now return to our local history. Prior to the destruction of Kumbum, the Nangchen king waged war on the Beri armies and appealed to both the Fifth Dalai Lama (1617-1682) and Gushri Khan (1582-1655) for support. Subsequently, like most of the Tibetan world, Nangchen was included in 
the greater Tibetan territories ruled from Lhasa by the Central Tibetan Ganden Phodrang government. In the early stages of his rule over Nangchen, Gushri Khan issued an edict confirming the validity of the kingdom's previous administrative division (Khamtö Logyü II, 171). In the 1640s, the Fifth Dalai Lama upheld the king's right to rule over monastic and lay estates in Nangchen (Nangchen Gyelrap, 39). Tribute to Lhasa was enforced and introduced by means of a census. Later in history, the conversion of monasteries into Gelukpa provided the opportunity for Ganden Phodrang to encroach on Nangchen when it had become independent from Central Tibet (Turek, forthcoming a).

In 1724 royal authority was channelled into a new semi-mobile residence, the 'Nangchen Encampment' (Khamtö Logyü II, 3). A year later the kingdom was placed under the administration of a Qing amban who governed from Xining (Tuttle 2015), although the king remained directly responsible for political affairs and some religious matters in his realm. Here lies a major theme which is subsequently found again and again in all the sources mentioned herein. During the reign of the Yongzheng emperor, the Yunnan governor, Hao Yuling, summoned several representatives of Khampa kingdoms to Chamdo. An envoy of the eighteenth Nangchen king, Dorjé Tséwang (r. 1680-1734), also attended. On this occasion, the Nangchen king received the hereditary title of chanhu (Ch. qianhu, chiliarch, commander of a thousand men); lower-ranking officials obtained the title of behu (Ch. baihu, commander of a hundred men) and bechang (Ch. baizong, commander of fifty men). These titles were originally military decimal units in the Jurchen Jin state (1115-1234) and had continually been used along with the tusi system by China's dynastic regimes since the Yuan era to exercise nominal or real power in borderland areas. Leaders of several Eastern Tibetan groups or polities, such as Choné, Hor, Golok and Repkong, had received the qianhu title during the Ming period (Tuttle 2015; Weiner 2012, 69). For the Manchu dynasty, the ranks of qianhu, baihu, and baizong became a way of integrating pastoral societies like Nangchen in the Qing empire - while among agricultural populations, such as Dergé, native authorities often received the rank of tusi. For the Nangchen king and his subjects, these new ranks merely endorsed the validity of the earlier local administration; an additional edict was issued to confirm the king's right to rule over his realm (Barom Namthar, 275). Although in theory the ranks implied the right to enforce levies on a specific number of families, the structure merely reflected an administrative hierarchy rather than provide precise information about taxation.

To give one example of how the new titles were a means of maintaining the status quo rather than reorganizing the kingdom, the Nangchen king's 
qianhu title meant that he had the right to tax 1000 families, while in fact he received tribute from 700 households. These obligations were divided according to the binary system of 'monastic taxes' (sertrel) and 'lay taxes' (kyatrel). All subjects, regardless of their rank or position (Khamtö Logyü II, 81, 86; Nangchen GönkhakJungwa, 410-411) were expected to pay these levies. However, there is some evidence to support the theory that by the nineteenth-twentieth centuries the king only taxed dependants who lived on his estates and that he lacked the leverage to make decisions concerning land use in his realm or even to negotiate during disputes over land. According to Yudru Tsomu (2006, 37), the Nangchen ruler had the right to allot land, but 'he did not enjoy the real power to administrate [these lands]'. Still, some monarchs are remembered for having issued edicts that relieved certain monasteries of fiscal duties. For instance, on one occasion, a royal prince was recognized as a reincarnation of an abbot; for this reason, the king granted his monastery tax exemptions (Nangchen GönkhakJungwa, 410-411).

In our sources, it is obvious that the Qing qianhu rank became a vital part of the local process of legitimating the monarch in the eyes of historiographers. No author forgets to mention the title, and it is frequently used throughout the texts much the same as the title chögyel. Further on in this chapter I will elaborate on how the concept of chögyel was implemented in Nangchen, but here I wish to briefly discuss how the rank of qianhu is used in contemporary negotiations of the local past. Nangchen qianhu-kings were deliberately forgotten when history was 'arrested' during the Maoist era, when only one version of the past was authorized; all Tibetan matters had to be subordinate to China, hence the Nangchen king was relegated to the role of qianhu, which reflected the position of his realm as a dependent periphery of the Qing Empire. Such a one-sided presentation is a gross distortion of the local perception of the title. For the authors of contemporary chronicles, the rank of qianhu attests to recognition of the gyelpo and to his elevation above all other members of the local elite through the official approval by a foreign and much more powerful sovereign, even if we assume that the title merely connoted a peripheral or obsolete function in the complex imperial hierarchies. That the king may also have enjoyed special royal esteem even among Han and Hui traders passing through Nangchen is reflected through anecdotal evidence provided by the German traveller Albert Tafel, who passed through Nangchen at the beginning of the twentieth century. His travelogue relates the many difficulties he faced while traversing Nangchen without the king's knowledge and permission. He also reports (Tafel 1914, 145) that Han merchants used the term wang (king) - a Chinese equivalent of the Tibetan title gyelpo - to refer to the Nangchen ruler. 
In other words, it is significant that local authors commemorate and celebrate in their writings the fact that the king was granted the rank of qianhu by China's Manchu dynasty. Similarly, Nangchen historians highlight the role the Sakya-Mongol edict played in the enthronement of the first gyelpo and in the confirmation of his rights by the Fifth Dalai Lama's regime in recollection of the foreign endorsement of the Nangchen kings. Ironically, since these very components also consigned the kingdom to larger political structures which, thanks to their historiography and cartography, appropriated the gyelpo's territories with great skill and eloquence, they also became the primary reasons for Nangchen's provincialization in the sense of its position on the periphery of Lhasa-centric and Sino-centric narratives. Today these memories of the foreign mandate play an important part in politics of representation designed to negotiate the past as a testimony to local power.

It is also important to understand that the local meaning of the Qing titles and insignia bestowed on the Nangchen elite typifies the encounters between inside and outside in the 'matrix' of the Sino-Tibetan borderlands, as Gros describes in his introductory chapter to this volume. The local reception of the qianhu rank, whether seen as hybridity or acculturation, constituted an internalization of an 'external' sign of inclusion. It was one of the many phenomena that made Nangchen and Kham an ambiguous, inconsistent space. Regardless of contemporary recollections of the king's position in the local hierarchy, Nangchen rulers may have been granted legitimacy to be kings, but their rights to actually govern were either never universally recognized or short-lived. Nineteenth-century travellers inform us that the king had limited influence over secular and monastic districts: the power of the king was only effective in the immediate vicinity of the capital (Grenard 1904, 366), meaning the four districts around the capital represented by four baihu.

By the nineteenth century the gyelpo presided over 33 'inner' administrative districts, while the 25 headmen of 'outer' districts of Gapa were, it seems, self-governed from Jyekundo. The king's four ministers (baihu selected from a larger number of officials referred to by the same title) presided over the fiscal-administrative units that were characterized by varying levels of independence from the ruler. A Chinese survey carried out during the hegemony of Ma Bufang in Qinghai, and therefore also in the Jyekundo area, as quoted by Sperling $(2003,13-35)$, speaks of 175 local headmen who were linked to the king in different ways. Nangchen lacked both a political force that would dominate this intricate network and a coherent economic superstructure that could accommodate all local influences. For this reason, 
I concur with Gruschke (2004, 105-108) and Yudru Tsomu $(2006,37)$ when they say that Nangchen was more of a federation of clans united under the royal banner than a centralized polity, and that loyalty to the king was borne out of a sentiment for him as 'a moral and social institution' (Gruschke 2004, 108) rather than because he was recognized as a de facto leader.

A closer look at the socio-political structure of Nangchen reveals that its ideology of political power was borrowed from Indic mythology as was the case of many historical Hindu and Buddhist states of Southeast Asia. Stanley J. Tambiah explains that they were organized according to cosmological principles and based on the assumed correspondence between the superhuman macrocosm and the human microcosm:

The kingdom was a miniature representation of the cosmos, with the palace at the center being iconic of Mount Meru, the pillar of the universe, and the king, his princes, and ruling chiefs representing the hierarchy in Tavatimsa heaven [...]. (Tambiah 1976, 109).

Nangchen Gar, which served as the capital from the early eighteenth century onwards, was topographically structured after the cosmological construct of the mandala, with the king at its centre as both the ideal Buddhist ruler, cakravartin, and simultaneously cosmocrator, the ruler of the world. The mandala model of four cardinal points placed around a focal point was mapped onto the ground plan of the capital and at the same time onto the structure of political functionaries and ministers. As mentioned above, the king had four ministers, whose land surrounded Nangchen Gar. Moreover, it is no coincidence that the 33 officials and their districts, who were directly subordinate to the chögyel, correspond to the 33-unit configuration typical of Hindu and Buddhist cosmologies and religious-political compositions, which in the different variations on the model reflected the hierarchy in the divine realm of Trāyastrimśa (lit. 'thirty-three'): Indra, the four guardians of cardinal directions (lokapāla), and 28 subordinate gods. ${ }^{1}$ This Indic blueprint proved successful in distant Buddhist kingdoms, such as Java, Thailand or Burma, partly because it elevated the monarch to the holder of the sacred

1 It is interesting to note that, as shown by Yudru Tsomu, the kingdom of Dergé had a similar structure (Tsomu, in this volume). There is no doubt that aside from the regular political alliances, there were many continuities in the organization of the two kingdoms and their topographies. If my assumption that the broader Asian cosmological paradigm found its way to Kham is correct, the question remains how that came about and if the regional source of its reproduction was Dergé, which had the reputation of the cultural center of Kham. 
teachings of the Buddha, a cosmocrator, and an intermediary between the realms of the divine and of humans (Tambiah 1976, 108-109).

The Indic cosmological model for organizing society and for the topographic layout of the capital illustrates the idea of 'galactic polity', a galaxy-like constellation of entities that are autonomous yet centred (around the figure of the king) and fixed in their trajectory (predetermined social order) (Tambiah 1976, 113). This concept has already been applied to describe Khampa principalities (Samuel 1995, 61-63) and, though the application of Tambiah's model onto Kham has met with some criticism (Holmes-Tagchungdarpa 2010, 10-11; Tsomu 2006, 28), the critiques are based on historical examples of Lhatok and Nyarong, two Eastern Tibetan polities that were not organized around the principle of kingship. The case of Nangchen, as presented in modern chronicles, was unquestionably different and therefore offers a vivid example of Tambiah's concept. Although the cosmocratic influence of its monarchs was greater than their political control, their exalted status and symbolic capital 'extended beyond their ability to enforce it - thereby creating a far-reaching cultural subordination among hinterland peoples without the benefit of real-political coercion' (Sahlins and Graeber 2017, 335).

The mnemonic practice of describing the political organization in Nangchen in ways which correspond to the concept of a galactic polity can also convey contemporary agendas, such as legitimizing the kingdom as a power centre in its own right, and assist in the reconstruction of local identity. Although decentralized in terms of their jurisdiction, the Indic cosmological components employed in Nangchen's socio-political structure emphasized the focus on the king as the centre of the mandala. Therefore, although the official state discourse locates the former kingdom in a peripheral, 'borderland' position, recollection of the moral and symbolic centrality of kingship lays emphasis on autonomy and self-referentiality, and shifts local awareness from the margins to its own centre. Given that cosmologies are narratives that focus on a sense of belonging, remembering the local past in terms of subjecthood to the Nangchen king could become an effective way of reconstructing local identity.

It was common for many Tibetan and Asian societies on the whole to identify kingship with the rule of law, which was associated with the Buddhist doctrine in particular. In a recent piece of work, Charles Ramble $(2008,313-314,325-326)$ states that this principle, according to which the monarch had to be associated with religion, was typically applied across Tibetan societies. A monarch protected his subjects with the authority of Buddha's teachings which portrayed him as a true chögyel. It was, among 
other elements, this image of pious fairness that elevated him above other lower-ranking leaders.

Throughout local histories, the Nangchen king is presented as the one who protected his realm and defended the faith; mention is often made of the idea that he ruled according to the law. Even if we have no evidence about the right of the gyelpo to exercise his rule over (or as it is phrased in our chronicles, 'to protect') a specific territory, territorial awareness did develop in Nangchen, as attested to by our sources (Turek, forthcoming a). The idea of a king as the protector of his realm is manifest in Nangchen Gyelrap (80) which reproduces a map based on a land record made by one of the gyelpo.

The map locates Nangchen inside Kham and next to Central Tibet and Amdo. Although geographically imprecise, it represents the major points inside the kingdom such as the royal capital, the trading town of Jyekundo and the four main rivers running through the kingdom (Drichu, Dzachu, Machu, and Chichu). The smaller, striped map at the bottom with the word 'Tibet' written in Latin alphabet represents the location and perceived size of Nangchen in relation to Central Tibet and the Himalayan kingdoms of Nepal, Sikkim, and Bhutan.

A Buddhist king who rules according to Buddha's sacred teachings will typically also be known for protecting animals from hunters. Consequently, local histories relate how the Nangchen ruler passed laws to preserve wildlife (Barom Namthar, 280; Nangchen Gyelrap, 22, 75). Today, recalling the strictness of the king's law might be a way of attesting to the fact that, as a chögyel, the king met his people's expectations by protecting his realm and defending the moral principles codified by Buddhism:

The king's law [concerning] secular (srid phyogs) matters was very strict. If a man was slain, the perpetrator had to have his one eyeball gouged out, his one ear shorn off and one foot chopped off. If a yak was stolen, [the thief] paid nine measures [of barley, which] in reality amounted to ten. If a wild animal was slain on the holy Nyenpo mountain, the hunter's right index finger was cut off (Nangchen Gyelrap, 74-75; Gedrong Logyü, 92).

Another way in which religious themes are used to sustain or to add to the idea of Dru patriarchs being elevated beings worthy of royal status was based on the long-standing reputation of Nangchen as a 'nest of the cotton-clad yogins, region of meditators' (retsang gomdé). Throughout the history of contemplative lineages (drupgyü), Nangchen was famous not only for its number of convents, hermitages, and monastics but perhaps most 
Figure 13.2 Sketch map of Nangchen based on a narrative land record composed by one of the gyelpo

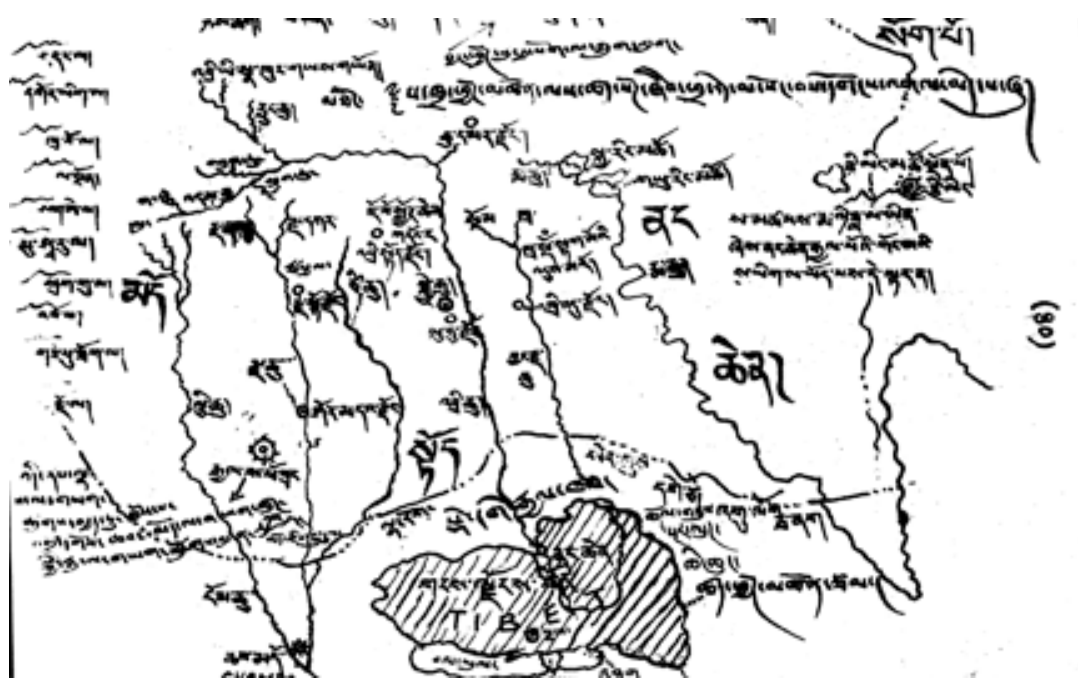

Source: Nangchen Gyelrap, 80

of all for the many exceptional masters of meditation who originated from or had been educated in the pastoral kingdom. In oral lore and in modern chronicles we still come across songs extolling Nangchen as the perfect environment for Tantric practices which even extended to the laity: 'all men were meditators, all women were meditators' (Khamtö Logyü II, 2-3). In keeping with the contemplative reputation of their realm, it is said that several notable members of the Dru dynasty became deeply involved not only in the royal business of founding and maintaining religious centres, but also in the pursuit of a personal, spiritual vocation. During the first few generations, Nangchen kings are remembered as ordained monastics. Later the dynasty became secularized and passed down royal authority from father to eldest son; they also lost their exclusive interest in the Barom school and embraced the doctrines and rituals of various schools and lineages.

Returning to the self-ascription of 'Nangchen the region of meditators' (nangchen gomdé) briefly introduced above, the second part of the abbreviation-compound gomdé is worth some elaboration in the context of Kham as a heterotopic space in which multiple, contradictory or even mutually exclusive places coexist and compete throughout time (see Gros, this volume). The meaning of dé ('region, district, section, faction, group, department') relates to a regional entity which is both a social collective and a part of a larger body. The communal aspect of the designation dé 
may relate to the egalitarian style of Nangchen lamas, who, according to legend, famously imparted the most advanced teachings on meditation and mystic experience to anyone and everyone. But how can we understand the connotation of dé as a 'region' (or in terms of any other equivalent of the word dé which relates to a part of a larger whole) in reference to the Buddhist 'kingdom of Nangchen' (nangchen gyelkhap)? For anyone eager to categorize Nangchen as either an autonomous or a tributary realm, this emic inconsistency irritatingly complexifies the local claims to territory and the reverence towards their native tradition of kingship. In a study of regionalism quoted in the current volume, Vicente Rafael problematizes the 'region' as a place of otherness that destabilizes and complicates the claims of powerful centres (Rafael 1999). Kingship and local identity in Nangchen were not formulated as political claims challenging larger powers dominating the region from the outside. Judging by the behaviour of several kings and other members of the local elite, they were rather pragmatist and opportunistic when it came to dealing with Quoxot warlords, the Qing, Ma Bufang, or the Ganden Phodrang. In an event of an interference or an invasion, the Nangchen ruling elite frequently bet on the winning horse, similarly to the Dergé strongman Jagö Topden. So, perhaps - precisely because they saw the precariousness of their own geopolitical position - by reiterating their self-chosen epithet 'region of meditators', the people of Nangchen realistically acknowledged that they were merely a 'region'? However, they were no ordinary region, but one that united Tantric meditators. Thus, the proliferation of the legend of Nangchen gomdé could generate a utopian response to the dystopian visions of war or exploitative overtaxation. By proposing this interpretation, I am by no means claiming that Nangchen was a 'kingdom' for the insiders and a 'region' for the outsiders. As discussed throughout this volume, in Kham, the notions of inside and outside were notoriously interwoven and convoluted in space and time. A good example of this is the Nangchen gyelpo's title of qianhu, an object of great local pride, but which placed the king among several other rank holders positioned on the margins of the Qing territories. ${ }^{2}$ However, the local esteem of the qianhu title was so great that it survived the empire well into the 1940 .

Even if the locally/regionally relevant discourses of power in Nangchen often took the form of a religious orientation of kingship and society, the

2 Compare also the case of Ming dynasty titles bestowed on members of the Central Tibetan elite in the period between fourteenth-fifteenth centuries. Although they were not titles of political recognition, they were used for competition among Tibetans themselves; see Schwieger (2009-2010). 
complexity of these discourses did not exclude regional politics. Thus, the presentation of Nangchen as a Buddhist society develops a horizontal and a vertical significance as the notion of the 'region' discussed by Vicente Rafael (1999). The image of Nangchen as an especially pious region seen from a lateral perspective could have been a way to highlight their special status among other Eastern Tibetan polities ('regions') subordinate to the same power. Thinking vertically, the 'regional' positioning of Buddhist kingship and society could have been a local strategy of injecting meaning into relations with a higher political power flowing from 'outside'. The 'region of meditators' is thus rendered as a site and source of ritual power for the distant emperors or foreign rulers. Multiple historical precedencies for this type of thinking can be found in the histories from Central Tibet, in which the politics of the Mongol/ Manchu-Tibetan relations were sometimes imagined through the lens of the 'priest-and-benefactor' (chöyön) concept. According to this idea, various Tibetan hierarchs such as the Dalai Lamas embodied the ritual authority of the Tantric guru and of religion, more broadly, as towering over the worldly and as such, transient, rule of the khan or emperor they had links with. If the relations meant in practice that the Tibetan ecclesiastic was a local representative of the Qing and that Central Tibet was an extension of the Qing empire, changing the discourse from that of political subordination to ritual and religious supremacy meant asserting ownership of the discourse. I would like to propose the same type of Buddhist imagination working for the image of Nangchen as 'region of meditators'. As one local chronicler describes Kyodrak, one of the most powerful monasteries in the realm, founded in fourteenth century with a donation of the last Yüan emperor:

Kyodrak monastery became the crown ornament among the sublime objects of veneration for the Hor, Lijang, Minyak kingdoms, and so on, as well as for the Chinese, Tibetans and Mongolians. (Kyodrak Shedra: 28 )

The moral authority of the Nangchen king was linked to his commitment to support religious institutions in his realm. This translated into the physical realm when Tsechu monastery was erected next to the royal palace, calling to mind the tradition of the local religious-secular power centres of Kumbum, Nangso Chenmo, or Tsangsar (Nangchen GönkhakJungwa, 486-494). Perhaps the king also wished to style his capital on Dergé, where the royal palace was situated next to Gönchen monastery. Neighbouring Dergé was seen as the cultural heart of Kham, with which Nangchen enjoyed close yet constantly shifting relations, expressed through marriage alliances, wars, and unions. 
Today, both Tsechu and Gönchen monasteries have been rebuilt, while their secular counterparts, the royal palaces of Dergé and Nangchen, lie in ruins that have either been intentionally concealed or rebuilt in form of a tiny temple. In the ethnic Tibetan areas of contemporary China, monuments to secular power can be reassembled through mnemonic practices such as narrative accounts that focus on 'place memory', and although Nangchen palace is mentioned in all local sources, only the one published in exile gives a description of it (Depter Mukpo, 125-128).

Elsewhere I mention (Turek, forthcoming a) how the chronicles describe a specific category of rituals dedicated to the Nangchen ruler's longevity and which was called kurim; this was an obligation that certain monasteries, hermitages and lamas had to fulfil. The mutual benefit resulting from the ritual was meant to legitimize and in a way sanctify the king, while bestowing privileges on the institutions involved. Accordingly, kurim monasteries received the status of quasi-independent territories governing whole districts, including a large number of dependants. There may have been various reasons for elevating these particular monasteries, but the choice of different monastic schools once again styled Nangchen after Dergé where royal patronage over monasteries of various denominations had been the preferred line of action since at least the nineteenth century.

One particularly ceremonial type of kurim devoted to the long life of the Nangchen monarch is described as follows:

Annually, during the kurim ceremony, the precious Kangyur was completely read aloud for the king and a retinue of his subjects, who would travel to where the ritual was held. The monasteries were obliged to take turns [to carry out the ritual], and when theirs arrived, [the ceremony was performed by] around fifteen lamas and monks. There was a custom: on the way, while travelling, the lamas responsible for kurim would lead the king's mules, laden with his belongings, [while] it was required that the lamas' caravan would be led by the chant master [of Tsechu monastery?] (Khamtö Logyü II, 85).

As longevity rituals are evoked in contemporary local history writing, their mnemonic potential can be harnessed as we follow the trail left by the pan-Tibetan heritage of the Yarlung Empire. In ancient Tibet, kurim rituals were carried out to protect the emperor's divine body which served as a metaphor for his realm (Walter 2009, 166-174). As the ritual later spread throughout the Plateau, it was also performed in villages for the collective good of the community (Childs 2005). In Nangchen 
the ceremony depicted the local political cosmology in which the body of the sovereign represented the land and the territorial identity of his subjects. That is why remembering this category of rituals today may be a way of contributing to local identity reconstruction. If we also agree with Samten Karmay $(1998,245)$ and Margaret Prins $(2007,194)$ that Tibetan rituals are reenactments of mythical narratives, then, by recalling rituals associated with kingship, the entire local tapestry of symbolic meanings and practices is recreated, which can be used for the reconstitution of place memory.

The social nature of kurim brings us to the major aspect of these kingshiprelated rituals. Rituals in general and kingship-related rituals have a strong performative element which is often communicated to the audience through insignia of power. Contemporary local sources emphasize the special headgear worn by the monarch; a top hat decorated with red coral presented by a Xining amban. This was a sign of a qianhu, and lower-ranking members of the Nangchen ruling elite who enjoyed the rank of baihu also received buttons made of semi-precious stones, though coral was reserved for the qianhu. Together with the qianhu title, the hat was bestowed on native leaders on the periphery of the Qing Empire as a sign of their assimilation into the administration, but in the Nangchen narratives, the insignia marks the prestige of the one and only legitimate ruler.

According to our genealogies of kings, the monarch was at the centre of several rituals whose effectiveness relied on their power-oriented symbolism and theatricality. In addition to kurim - one example of a religious ceremony in the service of the king - secular rites and festivals took place in the royal palace grounds. Annual horse races and the protocol governing welcoming ceremonies for the monarch are particularly good examples of how vividly local chronicles recollect the performances of local identity and its political cosmology:

When the king returned home on horseback, four grey silk banners had to be raised before him one by one. [There were officials] equipped with staffs, monastic robes and clay drums. Furthermore, twenty-five bechang, [representatives of] kurim monasteries, some fifteen monks of the Tsechu convent presided by the four chamberlains and the behu all gathered at this place, [as well as] lay people and monks. Peacock canopies were raised for both Adé Rinpoche and for the king. On their both sides walked four lay people, bearing leopard-skin banners and two monks bearing canes. Behind, members of the court had to line up along with [them]. (Nangchen Gyelrap, 74-75, Gedrong Logyü, 92) 
Performances such as the one described above, which include symbolic implements of authority, have the capacity to linger in visual memory as de facto mnemonic devices that are effective in the restoration of what kingship looks and feels like and which can be used in the wider context of identity reconstruction.

To get back to the subject of the performativity of rituals dedicated to the king's long life, as described above, a kurim ceremony included the recitation of the Kangyur, the canonical collection of scriptures believed to be the words of Buddha. Performed by alternating monasteries, the ritual emphasized the interdependence of prestige, moral obligation, and merit which is important for Tibetan societies and many Buddhist states across Asia. There were uniquely Tantric types of kurim in Nangchen and several reincarnated lamas or yogins, who were believed to be particularly powerful yogins, were paid from the king's treasury to perform longevity practices for the king in ritual seclusion (Tulku Urgyen 2005, 171, 177). The fact that not only merit but also Tantric power was collected and utilized to sustain the monarch was a special feature of kingship in keeping with Nangchen's reputation as 'the realm of meditators'.

The king is said to have been personally highly involved in religious life. Oral tradition has recorded how some monarchs dwelt in meditative seclusion and, in order to fully embrace the life of a renunciate, passed on their function of chögyel to their eldest son. In other narrated scenes, subjects plead with the king, who is practising Tantric meditation in ritual seclusion, to resume his royal obligations for the sake of all the people in his realm. The king returns reluctantly - yet another element adding to the specifically Tibetan image of an ideal monarch (Ramble 2008, 325-326).

A story that is still recounted again and again today in Yushu T.A.P. tells how the last king, Trashi Tséwang Dorjé, died while meditating in retreat in the vicinity of the Gyanak Mani pilgrimage site outside Jyekundo (another version of the same event, which comes from Nangchenmi in exile, stresses that the king's isolation was not of a voluntary nature and that he had been sentenced to home arrest). Of course, remembering that the king's virtues were in keeping with Buddhist teachings is important for reviving the specific Tibetan identity of his former realm and for reconstructing the interdependent identities of former subjects. In addition to this, I would like to highlight how the Nangchen kingship narrative, especially elements concerning the legitimacy of Dru kings, is enhanced by an association of kingship with Tantric meditation in seclusion and the ritual power believed to be collected through these practices. Emphasis on Tantric mastery as part of the Nangchenmi's mnemonic process serves to reconstruct the traditional mythical-religious make-up in the realm in the current process of identity revival. 
The Nangchen kings enhanced the charisma of kingship with the charisma of meditation and mysticism. However, in twentieth century Kham the charisma of royalty itself was apparently important to the reputation of leadership, as we learn from Yudru Tsomu's chapter in this volume. The Derge strongman Jagö Topden, while challenging the traditional model of hereditary kingship, also appropriated some of its charisma through adopting the title of the 'hundred-year-king' (gyalo gyelpo). It is interesting to note that the leader of the opposing faction which represented the traditional model of leadership and was intent on defending it, was the Nangchen king Trashi Tséwang Dorjé's own sister.

\section{The Demise of the Kingdom: Legitimacy and Conquest}

From the beginning of the twentieth century onwards, Kham became an area of increasing tension and unrest. In 1911, during the reign of king Wangdrak Tsering Lhagyel, Nangchen fell under the authority of the Hui Ma clan which ruled from Xining. This barely changed the actual status quo on the ground, with the king presiding over baihu and baizong as well as over the semi-independent monastic estates; this might be one of the reasons why the legacy of the most famous Ma warlord, Ma Bufang (1903-1975), was largely 'forgotten' in the Nangchen chronicles. Accounts of Ma Bufang's much-feared punitive campaigns against monasteries or families with overdue fiscal payments are mostly oral.

During the reign of the last monarch, a new power emerged in China communist forces defeated Ma Bufang and Xining fell in September 1949 (Marshall and Cooke 1997, 1593). The early presence of Chinese communists is mentioned in our sources but, as we shall see, depending on whether the material was printed in the P.R.C. or in exile, it is represented in different ways.

In June $195^{\circ}$ Chinese troops spread further south and took over Jyekundo, where they established their temporary headquarters as a necessary base for the subsequent invasion of Central Tibet (Nangchen Gyelrap, 49). From Melvyn Goldstein's interviews with Tibetan informants we learn that Lhasa failed to conspire with both the Dergé queen and the Nangchen king to join forces to drive away P.L.A. troops. After 5 October, Nangchen became the corridor through which the $154^{\text {th }}$ Regiment of the People's Liberation Army transited to Riwoche and further on to the strategically important town of Chamdo (Goldstein 1991, 681-682). After the fall of Chamdo, the P.L.A. were able to proceed to Lhasa which they conquered without much resistance. 
In another paper I pointed out how certain contemporary Tibetan authors use myths in representing facts from recent Sino-Tibetan history to portray Chinese communist democratic reforms and their aftermath as an ideological and cosmological conflict rather than a political or ethnic one (Turek, forthcoming b). Nangchen Gyelrap accordingly credits the last king with a clairvoyant vision of the communist takeover, portraying him as a sage endowed with exceptional powers that emerge with the performance of prolonged and ritually efficacious Tantric meditation in seclusion. At the same time, the passage from Nangchen Gyelrap presents the author's interpretation of local history between 1950-1959:

What concerns oppression by the communist Chinese, the venerable king had a prophetic vision of the future and described them as enemies of the teaching and samaya-violators; [he saw how] three faces of the communist Chinese, drunk with three kinds of poison, would manifest three expressions:

First, there would be a time for [showing] a face of ignorance [wearing] a fake smile: they would call everyone 'brothers and sisters', paid one silver piece for a mere cup of cold water, would not collect the customary taxes and corveé labour. They would be very peaceful and gentle.

In the meantime, there would be a time for [showing] a red face of greed, beaming with delight: the Chinese would buy land at strategic points piece by piece and for surprisingly [high] prices, where they built roads and military barracks. They would be very cunning: under the disguise of opera shows, performances and pretending to have a friendly attitude, they performed medical experiments on humans and livestock, examined the amount of rainfall on wet fields. Suspicions clearly emerged [in the vision]. Because they enticed individuals to conflict, endless family fights broke out. They said that the oppression of the people was [now] eradicated and that weapon-making blacksmiths were no longer needed. The families who had swords were summoned and the weapons taken away.

Finally, there would be a time for [showing] a black face of anger, frowning terribly: land, possessions and cattle were collectivized. Several local lay people and members of the clergy were [invited for] inspection visits [to factories, etc.], [ideology] classes, and meetings. [But in reality,] district [authorities] tortured them [and they] died horrible deaths; the government eliminated them. On the other hand, people were [also] killed through heavy military action. In short, these techniques of deception, trickery and cunning [which took place] between 1950-1959 became clearly apparent [in the king's vision]. [...] (Nangchen Gyelrap, 51-53) 
The three phases of local history that are referred to in this fragment are in fact a fairly adequate representation of what transpired in the 1950 s as we know it from Western scholarship on Central Tibet and parts of Amdo and Kham. The period in question has been the object of intense negotiations between publications sanctioned by the Chinese state and works published in exile. The above extract is taken from a source published in India, whereas for instance Khamtö Logyü (II, 211), produced in China, mentions the Nangchen king's cooperation and his plans to re-establish the realm as part of new communist China. This contrasts with testimonies of Tibetan authors based in exile, who recount the armed struggles and atrocities committed in this first phase of the P.R.C.'s expansion into Nangchen. Thus, in 1950, according to Nangchen Gyelrap, after failed diplomatic attempts on the part of the king's father, Wangdrak Tsering Lhagyel, struggles are reported to have broken out throughout the realm. Many desperate people were driven to commit suicide, the queen was captured, and the king forced to comply with the new government (Nangchen Gyelrap, 52-53).

The year 1951 saw the establishment of the '[Local] Government of the Tibetan People's Autonomous District of Yushu or Upper Kham' (Tib. Khams stod dam yu shul bod rigs sa khongs rang skyong mi dmangs srid gzhung, Ch. Qinghai sheng Yushu Zangzu Zizhi qu renmin zhengfu) with king Trashi Tsewang Dorjé as its nominal head (Khamtö Logyü II, 211). In the newly created Yushu Prefecture, the years 1950-1958 saw further preparations for socialist reforms envisioned by Mao. Along with lower-ranking Tibetan cadres, the Nangchen elite had to undergo compulsory training, which, as the central government in Beijing hoped, would reform their thinking. We do not learn this only from the excerpt above but also from photographs reproduced in Nangchen Gyelrap (81-82) and dated 1950, showing king Trashi Tsewang Dorjé with his ministers on 'an invited sightseeing tour' through the factories and monuments of China (see also Dáša Mortensen, this volume). The Year of the Earth Dog (1958) marked the final demise of what constituted the kingdom of Nangchen: the royal authority of the Dru dynasty that had been ruling since the beginning of the fourteenth century and the prestige of the eighteen monastic districts, which contained the realm's rich religious culture. In all the recent histories of Nangchen, 1958 is remembered as a major traumatic milestone that brought about an irreversible change of society.

Since then, modern maps of the People's Republic of China delineate a small fraction of the former Nangchen kingdom, which they call Nangqian County (Ch. Nangqian xian) within Yushu Tibetan Autonomous Prefecture. The former centre of the galactic polity, Nangchen Gar, lies far off the beaten 
track and consists of the reconstructed Tsechu monastery and a minute temple where the royal palace once stood. Today, the centre of Yushu Prefecture is Jyekundo, which was elevated to this position following the devastating earthquake in 2010 . The need for a total reconstruction of the town after this disaster has provided the government with the opportunity of creating a new Shangri-La, a colonialist, urban fantasy about Khampa culture and history.

\section{Conclusion}

This contribution presents an overview of the revival of traditional history writing about the Eastern Tibetan kingdom of Nangchen, with special focus on the kingship narrative to which these new Tibetan-language histories give prominence. My understanding of the construction of the Nangchen kingship narrative is that the mnemonic process initiated to recollect the royal genealogy, legitimacy of rule and the socio-political organization in the kingdom draws on broader pan-Tibetan and Asian kingship narratives and cosmologies. These conceptions of kingship offer a tradition-sanctioned explanation of the structure, nature, meaning, and interdependence of the universe, society, history, place, state, and ruler. Indeed, the sudden suppression of the kingship narrative in Yushu T.A.P. in the 1950s destroyed the local sense of belonging, and the perception of tradition and of Nangchen Gar as a place where the authority of that tradition should be centred. Crediting kings once again with a divine status through historiographic practice has, at least in literature, the capacity to reverse or to stop the irreversible shifts that took place in Nangchen society.

Firstly, as Amy Holmes-Tagchungdarpa (2010) noted regarding Lhatok, royal genealogies have the potential to transfer local self-perception from a periphery of an external power centre to its own autonomous centre, and to represent this practice as a historical, and therefore authoritative process of renegotiation of the local past.

Secondly, I argue that remembering the Nangchen gyelpo in a close conversation with widespread Tibetan and Asian ideas of kingship - as the centre of a universe filled with complex meanings and tropes - contributes to the reconstruction of local identity. This mnemonic practice can restore the identity of the Nangchenmi as subjects to their legitimate king. Through its cosmological aspect, the literary return of good kings also shows the potential to re-establish the broken connection with local tradition and to re-emphasize the value of the landscape as its container. 
Kingship can also potentially serve as an axis for an imagined pan-Tibetan community. That the kingship narrative is in great demand on both sides of the China-India border can be illustrated by an anecdote I heard in Jyekundo in the spring of 2015 - about a man who went to various Tibetan communities in India, introducing himself as 'the king of Nangchen' not without some success, even though he had no credentials to prove his claim.

\section{Glossary of Tibetan and Chinese Terms}

Adé Rinpoche

Barom Kagyüpa

Be Jangchub Gönpo

bechang

behu

Bön

Chamdo

Chichu

Choné

chögyel

Chögyel Pakpa

Chökyi Gyeltsen

chöyön

dé

Denma Jamyang Tsultrim

Dergé

Dorjé Tsewang

Drichu

Driwo Alu

Dru

drupgyü

Dzachu

Ga

Ga Anyen Dampa

Gesar

Golok

gyalo gyelpo

Gyelrong

Gyanak Maṇi

gyelkhap
A lde'u rin po che

'Ba' rom bka' brgyud pa

'Be byang chub mgon po

be chang, (Ch.) baizong 百总

be hu, (Ch.) baihu 百户

Bon

Chab mdo

Lci chu

Co ne

chos rgyal

Chos rgyal 'phags pa

Chos kyi rgyal mtshan

chosyon

sde

Ldan ma 'jam dbyangs tshul "khrims

Sde dge

Rdo rje tshe dbang

'Bri chu

Tre bo a'u

'Bru

sgrub brgyud

Rdza chu

Sga

Sga a nyan dam pa

Ge sar

Mgo log

rgyal lo rgyal po

Rgyal rong (Ch.) Jiarong 嘉线

Rgya nag maNi

rgyal khab 
gyelpo

Gönchen

Hor

Jagö Topden

Jangchup Zhönnu

Jyekundo

Kangyur

Khampa

Kumbum

kurim

kyatrel

Kyodrak

Kyehu Khorlo Zangpo

Lhatok

Lümé Dorjé

Machu

Maṇi kabum

Minyak

Nangchen

Nangchenmi

nanglun

Nangso Chenmo

Nyenpo

qianhu

Repkong

retsang gomdé

Riwoche

Repa Karpo

Sakya Khön

sertrel

Songtsen Gampo

Tenpa Tsering

Tishi Repa Sherap Senggé

Trashi Tsewang (Topgyel) Dorjé

Trirapkha

Trokyap

Tsangsar

Tsechu

Ütsang

Wangdrak Tsering Lhagyel rgyal po

Dgon chen

Hor

Bya rgod stobs ldan

Byang chub gzhon nu

Skye dgu mdo

Bka' 'gyur

Khams pa

Sku 'bum

sku rim

skya khral

Skyo brag

Kye hu 'khor lo bzang po

Lha tog

Lus med rdo rje

Rma chu

Mani bka' 'bum

Mi nyag

Nang chen

Nang chen mi

nang blon

Nang so chen mo

Gnyen po

(Tib.) chan hu, (Ch.) 千户

Reb khong

ras tshang sgom sde

Ri bo che

Ras pa dkar po

Sa skya khon

gser khral

Srong btsan sgam po

Bstan pa tshe ring

Ti shri ras pa shes rab seng ge

Bkra shis tshe dbang rdo rje

Tre rab kha

Khro skyabs

Tshangs gsar

Tshe chu

Dbus tsang

Dbang drag tshe ring lha rgyal 
Yarlung

Yonten Pal

Yudröng
Yar klung

Yon tan dpal

Yu sgron

\section{Appendix: List of rulers mentioned}

Dru Driwo Awu (dates unknown) ruling with Répa Karpo (1198-1262)

Tsangsar Lümé Dorjé (1226-1292)

Tsangsar Jangchup Zhönnu (1254-1323)

Dru Chökyi Gyeltsen (r. 1300) - first in the line of kings

Dorjé Tsewang (r. 1680-1734)

Wangdrak Tsering Lhagyel (dates unknown)

Trashi Tsewang Dorjé (1910-1961)

\section{References}

\section{Tibetan sources}

\section{Barom Namthar}

Tshangs gsar blo gros rin chen. 2005. dPal ldan 'ba' rom bka' brgyud kyi rnam thar chos 'byung mdor bsdus gsal byed sgron me (Brief Religious History and Life Stories of the Glorious Barom Kagyüpas; an Illuminating Lamp). Zi ling: Mtsho sngon mi rigs dpe skrun khang.

\section{Depter Mukpo}

'Brong pa rgyal po. 2003. Bod ljongs mdo khams nang chen spyidang bye brag gi byung ba brjod pa ldong 'brong pa'i deb gter smug po (The General and Specific History and Presentation of the Tibetan Khampa Nangchen Kingdom; the Maroon Annals of the Dong Drong Clan). Dharamsala: Amnye Machen Institute.

\section{Gedrong Logyü}

Lho bstan 'dzin nyi ma. 2012. mDo khams dge 'brong lo rgyus deb ther lci zla'i zegs ma (Chronicle and Annals of the Good Khampa Drongpa Clan; Droplets of the Chichu and Dachu Rivers). Gan su: Gan su mi rigs dpe skrun khang.

\section{Gyelrap Ngotrö}

Ba ri zla ba tshe ring. 2005. Nang chen nyer lnga'i rgyal rabs ngo sprod dang lo rgyus rgyu cha'dems bsgrigs (Introduction to the Royal Chronicle of 
Nangchen and its Twenty-five Clans and their History; a Compilation of Selected Materials). Dharamsala, Nang chen nyer lnga'i mthun tshogs.

\section{Khamtö Logyü}

'Jam dbyangs tshul khrims. 1995-1997. Khams stod kyi lo rgyus thor bsdus su bkod pa gangs phrug bsu ba'i shing rta. The Brief History of Upper Kham, Eastern Tibet (Brief Registry of the History of Upper Kham; Chariot Welcoming Children of the Snowland). 2 Vols. Zi ling: Kan su'u mi rigs dpe skrun khang.

\section{Kyodrak Shedra}

sKyo brag bshad grwa. N.d. Chos rje skyo brag pa'i gnas dang bla ma rten gyi rnam thar mdor bsdus skal bzang dwangs pa'i dpal gter rin chen gser gyi phreng ba (The Abbreviated Hagiographic Account of How the Dharma Lord Chodrakpa Relied on His Practice Venue and His Teachers, the Splendid Treasury of the Pure and Fortunate Age, the Golden Jewelled Garland). sKyo brag bshad grwa karma legs bshad chos gling.

\section{Nangchen Gyelrap}

Karma phrin las. 1965. Gangs ljongs mdo stod nang chen rgyal rabs dang 'brel ba'i lo rgyus phyogs bsdudya rabs rna rgyan (The Summary of Histories Related to the Royal Chronicle of Nangchen in Upper Kham, Land of Snows; the Noble Ear Ornament). n.l.: Lama Wangchen.

\section{Nangchen GönkhakJungwa}

sGa Karma don grub phun tshogs, ed. 1999. Khams sgom sde nang chen pa'i dgon khag rnams kyi byung ba phyogs bsgrigs rin chen sgrom brgya 'byed pa'i deb ther gser gyi lde mig (Collection on the Origins of Monasteries in Kham Nangchen, Realm of Meditators; the Chronicle Unlocking One Hundred Trunks Like a Golden Key). Skye dgu mdo: Nang chen rdzong srid gros rig gnas lo rgyus gzhung don khang.

\section{Western sources}

Adeu Rinpoche. 2011. Freedom in Bondage: The Life and Teachings of Adeu Rinpoche. Berkeley, CA: North Atlantic Books.

Beckwith, Christopher I. 1993. The Tibetan Empire in Central Asia: A History of the Struggle for Great Power among Tibetans, Turks, Arabs, and Chinese during the Early Middle Ages. Princeton, NY: Princeton University Press.

Casey, Edward S. 1987. Remembering: A Phenomenological Study. Bloomington, IN: Indiana University Press. 
Childs, Geoff. 2005. 'How to Fund a Ritual: Notes on the Social Usage of the Kanjur (bKa' 'gyur) in a Tibetan Village'. Tibet Journal 30 (2): 41-48.

Debreczeny, Karl. 2014. 'Imperial Interest Made Manifest: sGa A gnyan dam pa's Mahākāla Protector Chapel of the Tre-shod Maṇạala Plain'. In Trails of the Tibetan Tradition: Papers for Elliot Sperling, edited by Roberto Vitali, 129-166. Dharamsala: Amnye Machen Institute.

Germano, David. 1998. 'Re-membering the Dismembered Body of Tibet: Contemporary Tibetan Visionary Movements in the People's Republic of China'. In Buddhism in Contemporary Tibet: Religious Revival and Cultural Identity, edited by Melvyn C. Goldstein and Matthew Kapstein, 53-94. Berkeley: University of California Press.

Goldstein, Melvyn C. 1991. A History of Modern Tibet, 1913-1951: The Demise of the Lamaist State. Berkeley: University of California Press.

Grenard, Fernand. 1904. Tibet: The Country and Its Inhabitants. Translated by A. Teixeira de Mattos. London: Hutchinson \& Co.

Gruschke, Andreas. 2004. The Cultural Monuments of Tibet's Outer Provinces: Kham. Vol. 2. The Qinghai Part of Kham. Bangkok: White Lotus.

Harrell, Stevan, and Li Yongxiang. 2003. 'The History of the History of the Yi, Part II'. Modern China 29 (3): 362-396.

Holmes-Tagchungdarpa, Amy. 2010. 'Defining Peripheral Power: Writing the History of the Kingdom of Lhathog, Eastern Tibet'. In New Views of Tibetan Culture, edited by David Templeman, 7-19. Caulfield, Australia: Monash University Press.

Litzinger, Ralph A. 1998. 'Memory Work: Reconstituting the Ethnic in Post-Mao China'. Cultural Anthropology 13 (2): 224-255.

Marshall, Steven D., and Susette Ternent Cooke. 1997. Tibet Outside the TAR: Control, Exploitation and Assimilation: Development with Chinese Characteristics. Washington, DC: Alliance for Research in Tibet.

McGranahan, Carole. 2010. Arrested Histories: Tibet, the CIA, and Memories of a Forgotten War. Durham, NC: Duke University Press.

Oosten, Jarich G. 1988. 'The Stranger-King. A Problem of Comparison'. In Time Past, Time Present, Time Future: Perspectives on Indonesian Culture: Essays in Honour of Professor PE de Josselin de Jong, edited by Henri J.M. Claessen and David S. Moyer, 259-275. Dordrech: Foris Publications (Verhandelingen van het Koninklijk Instituut voor taal. Landen Volkenkunde, 131).

Petech, Luciano. 2003. 'The Establishment of the Yuan-Sa-skya Partnership'. In The History of Tibet, edited by Alex McKay. London: Routledge Curzon.

Prins, Marielle. 2007. 'The Rgyalrong New Year: A Case History of Changing Identity'. Zentralasiatische Studien 36: 189-216.

Rafael, Vicente L. 1999. 'Regionalism, Area Studies, and the Accidents of Agency'. American Historical Review 104 (4): 1208-1220. 
Ramble, Charles. 2008. The Navel of the Demoness: Tibetan Buddhism and Civil Religion in Highland Nepal. New York: Oxford University Press.

Rowlands, Michael. 1993. 'The Role of Memory in the Transmission of Culture'. World Archaeology 25 (2): 141-151.

Sahlins, Marshall. 2008. 'The Stranger-King or, Elementary Forms of the Politics of Life'. Indonesia and the Malay World 36 (105): 177-199.

Sahlins, Marshall and David Graeber. 2017. On Kings. Chicago: Hau Books.

Scott, James C. 1990. Domination and the Arts of Resistance: Hidden Transcripts. New Haven, CT: Yale University Press.

Schwieger, Peter. 2009-2010. 'Significance of Ming Titles Conferred upon the Phag mo gru Rulers: A Reevaluation of Chinese-Tibetan Relations during the Ming Dynasty'. The Tibet Journal 34/35 (3/2): 313-328.

Shakabpa, Tsepon Wangchuk Deden. 2010. One Hundred Thousand Moons: An Advanced Political History of Tibet. Vol. 1. Translated by Derek F. Maher. Leiden: Brill.

Sørensen, Per K. 2015. 'The Development and Formation of religious Historiography in Tibet'. In History and Religion. Narrating a Historical Past. Religionsgeschichtliche Versuche und Vorarbeiten, edited by Otto Bernd-Christian, Suanne Rau and Jörg Rüpke, 151-164. Berlin: De Gruyter.

Sperling, Elliot. 2003. 'Introduction' to Bod ljongs mdo khams nang chen spyi dang bye brag gi byung ba brjod pa ldong 'brong pa'i deb gter smug po, by 'Brong pa rgyal po, 7-37. Dharamsala: LTWA.

Tafel, Albert. 1914. Meine Tibetreise: Eine Studienfahrt durch das Nordwestliche China und durch die Innere Mongolei in das Östliche Tibet. Vol. 2, Stuttgart: Union Deutsche Verlagsgesellschaft.

Tambiah, Stanley J. 1976. World Renouncer and World Conqueror. A Study of Buddhism and Polity in Thailand against a Historical Background. Cambridge: Cambridge University Press.

Tsomu, Yudru. 2006. Local Aspirations and National Constraints: A Case Study of Nyarong Gonpo Namgyel and His Rise to Power in Kham (1836-1865). Unpublished PhD dissertation, Harvard University.

Tulku Urgyen. 2005. Blazing Splendor: The Memoirs of the Dzogchen Yogi Tulku Urgyen Rinpoche, as Told to Erik Pema Kunsang \& Marcia Binder Schmidt. Translated by Erik Hein Schmidt and Marcia Binder Schmidt. Kathmandu, Nepal: Rangjung Yeshe Publications.

Turek, Magdalena Maria. 2018. 'The Contemporary Revival of the Barom Kagyü School in Kham'. In The Hybridity of Buddhism: Contemporary Encounters between Tibetan and Chinese Traditions in Taiwan and the Mainland, edited by Fabienne Jagou, 133-158. Paris: École française d'Extrême-Orient.

Turek, Magdalena Maria. Forthcoming a. 'Monastic Obligations, Hat Change and Lhasa Encroachment: Notes on the Economic System in the Historical Kingdom 
of Nang-chen'. In When the Taxman Cometh: Tax, Corvée and Community Obligations in Tibetan Societies, edited by Charles Ramble, Peter Schwieger, and Alice Travers. Leiden: Brill.

Turek, Magdalena Maria. Forthcoming b. 'Milarepa in a People's Commune: Myth and Charisma in Contemporary Tibetan Hagiography and Society'. In Re-remembering Early Contact between Tibetans and the Chinese Communist Party in the post-Mao Period, edited by Robert Barnett, Françoise Robin, and Benno Weiner. Leiden: Brill.

Tuttle, Gray. 2015. 'An Overview of Amdo (Northeastern Tibet) Historical Polities'. The Tibetan and Himalayan Library Online. http://www.thlib.org/reference/ dictionaries/tibetan-dictionary/about/wiki/an\%2ooverview\%20of\%20amdo20. Accessed 15 October 2015 .

Vitali, Roberto. 1990. Early Temples of Central Tibet. London: Serindia Publications. Walter, Michael L. 2009. Buddhism and Empire: The Political and Religious Culture of Early Tibet. Leiden: Brill.

Weiner, Benno Ryan. 2012. The Chinese Revolution on the Tibetan Frontier: State Building, National Integration and Socialist Transformation, Zeku (Tsékhok) County, 1953-1958. Unpublished PhD dissertation, Columbia University.

\section{About the Author}

M. MARIA TuREK received her PhD in Tibetan Studies at the Humboldt University of Berlin in 2013. Her work centres on the practice of Tantric Buddhism among Tibetans living in the People's Republic of China and on sacred kingship in Eastern Tibet as represented in the contemporary historiographies published within China and in the Tibetan diaspora. She is currently affiliated with the Robert H.N. Ho Centre for Buddhist Studies at the University of Toronto, where she teaches courses on global Buddhism. Her current project is a book entitled Sainthood and Asceticism in an Eastern Tibetan Hermitage. It is an ethnographic study of ascetics devoted to traditional Tantric meditation practices in ritual seclusion revived within China today. 


\title{
14 Yachen as Process
}

\author{
Encampments, Nuns, and Spatial Politics in Post-Mao Kham \\ Yasmin Cho
}

\begin{abstract}
This chapter examines a distinctive form of Buddhist space, called an 'encampment' (gar), that is being built by Tibetan Buddhist nuns in Yachen. By ethnographically focusing on the nuns' material engagements, I show how the inherent incompleteness and inclusiveness of an encampment provide a space for the nuns to flourish in a politically restrictive situation. I also explore the spatial politics occurring between the nuns and the Chinese state in and through Kham in the post-Mao era. I argue that Yachen is continually being made and transformed by various actants, including the nuns and their material activities, within the unique geopolitical malleability of Kham, and that the emergence of this encampment allows us to see Yachen as an unfolding process.
\end{abstract}

Keywords: encampment (gar), spatial politics, nuns, Tibetan Buddhist revival, Yachen Gar

\section{Introduction}

Few people visiting the eastern Tibetan plateau would fail to notice the ubiquitous presence of the massive grasslands where herds of yak graze freely, each animal maintaining a good distance from the others and from the herders' tents that are scattered sparsely across the steppe. It is within this kind of nomadic landscape, deep within Kham, that Yachen Gar, a mega-sized Tibetan Buddhist encampment, can be found. More specifically, the encampment ( $g a r$ ) is located in the northwestern part of Sichuan province, not far from the provincial border of the Tibet Autonomous Region (T.A.R.). 'Yachen' is the name that nomadic people used to refer to this area

Gros, Stéphane (ed.), Frontier Tibet: Patterns of Change in the Sino-Tibetan Borderlands. Amsterdam, Amsterdam University Press 2019

DOI: 10.5117/9789463728713_CH14 
before the encampment was established. From a nearby hilltop in Yachen Gar, one can see a large residential area in the valley below with several thousand individual shacks built by Tibetan nuns. ${ }^{1}$ The zone filled with these rough-hewn quarters is partially hemmed in by a river that makes the entire area resemble an island (see Figure 14.1). Many who visit Yachen for the first time do not expect a Buddhist 'monastery' to possess such a large shantytown within it and are often awestruck by this scene; this is why the nuns' quarters have been a popular subject for photography.

Yet beyond its photogenic appeal, what makes this 'island' zone, and all of Yachen, truly astonishing is the way in which this enormous, if squalid, Buddhist enclave and the grand natural vistas that surround it invoke a sense of triumphant Buddhist spirituality in its earthly form. Among visitors and practitioners (both Tibetans and non-Tibetans), the challenging living conditions of the enclave are easily read as proof of the nuns' firm devotion toward their practices and their nunships; and the wild natural environment is often perceived as a necessary condition for containing and transmitting spiritual purity and sacredness. Even at a sensorial level, the devotees whom I encountered often told me that they felt a sense of spiritual and bodily purification just by walking around Yachen, eating and drinking there, and breathing its air (not to mention meditating or receiving teachings in Yachen). However, this fascination with Yachen does not arise only from such a heated religious ethos; in fact, in part, it arises from and is strengthened by a submerged, secular 'mystery' about how such a gigantic ethnic-religious community could emerge in a region of China where ongoing political (spatial) restrictions are the norm.

Securing firm and stable territorial boundaries is one of the quintessential components of the modern nation-state, and territorial sovereignty has been a ceaseless source of wars, disputes, and tensions. This issue is bound to be particularly acute for the People's Republic of China (P.R.C.) since its massive border regions are occupied largely by ethnic minorities, many of whom may not entirely agree with their incorporation into the spatial and cultural project of Zhonghua, the Chinese nation. In particular, since their land was taken over by the Chinese army in 1951, Tibetans have continued to express their dissatisfaction with the state-led myth of a homogenous Chinese nation. (This dissatisfaction was expressed most recently in the protest in Lhasa in 2008 and the wave of self-immolations that followed

1 In 2017, the number of nuns in Yachen exceeded 10,000. A smaller number of monks (no more than 200o) were settled on the upper side of the encampment. The monks also build their own huts, which are more spacious and made of much higher quality materials. 
Figure 14.1 The nuns' residential sector in Yachen

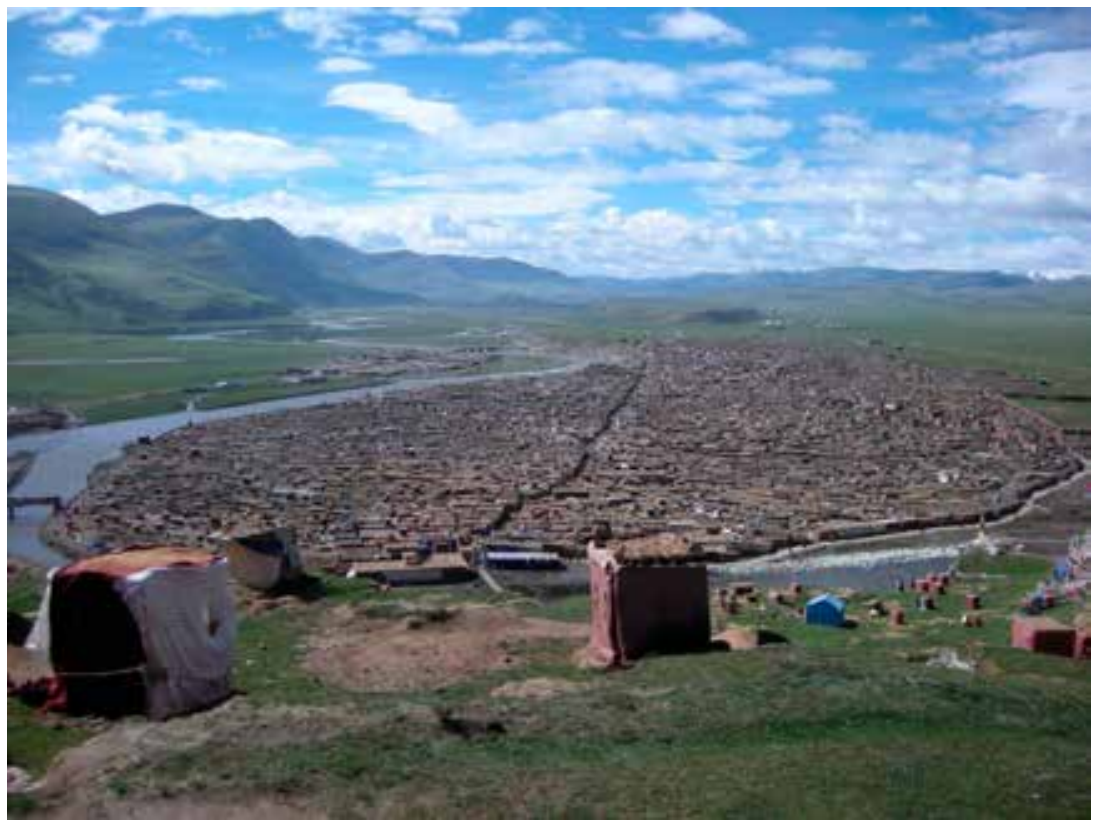

Photograph by Yasmin Cho 2010

after. $\left.^{2}\right)$ Given the fact that Tibetan-populated regions in China constitute almost one fourth of the entire national territory of China, it is crucial for the Chinese state to secure a sense of territorial belonging from Tibetans, in other words, to achieve the 'territorialization' (Yeh 2013) of Tibetans to the motherland of China. For this reason, the Chinese state's ethnic policies have been geared toward soliciting ethnic minorities' recognition and submission of their ethnic territories as firmly bounded under the P.R.C.'s sovereignty.

Within this particular geopolitical context, the emergence of Yachen Gar can be seen as an unusual instance of spatial dominance, or deterritorialization, exercised by Tibetans. By saying this, I do not mean that Yachen is a 'successful' deviation from the Chinese control scheme or that it has achieved a static, independent position once and for all. The stories about Yachen that I will present in this chapter are much more complex. Since its inception and by its nature, Yachen has been undergoing a constant process of formation and transformation through the interventions of various actors, or 'actants' 
(Latour 1999): Tibetan lamas, monastics, Chinese lay disciples, the state's policies, Buddhist devotion, the landscape, building activities, and so on. The structurally embedded uncertainty, openness, and unexpectedness of the landscape and the politics in Kham have crucially defined the present form of the encampment. This chapter is dedicated to showing ethnographically how the encampment is being formed and deformed through the Tibetan nuns' material engagements - their hut building and migratory practices in particular - within the specific spatial and temporal process that is 'Kham'.

Looking at the changing physical and residential (especially architectural) properties of the encampment of Yachen is useful for properly understanding 'Kham as a process' (see Gros, in the Introduction). The studies discussed in this volume all point out, with different emphases and approaches, that Kham is not simply a background or a container of actions and histories that have unfolded; instead, Kham, with its own contested and elastic geopolitical and historical vectors, plays the role of an active medium through which various participants seek to confront, challenge, and negotiate with one another. Yachen's emergence and expansion, at least before the infrastructural and biopolitical interventions ${ }^{3}$ that the Chinese state has gradually made in recent years, owe a great deal to 'the malleability of Kham' as represented in the trope of 'the Möbius strip' that Gros aptly elaborates in the Introduction. More specifically, in the emergence of Yachen, an extensive political and gendered repression, occurring both within Tibet and in relation to the Chinese state, is one of the fundamental conditions for so many Tibetan girls who migrate to this remote region of Kham. In other words, Tibet's internal dynamics, tensions, and uncertainties as well as the external pressures and changing politics on the plateau play essential roles in the making of an active and unbounded Buddhist space (in de Certeau's sense) ${ }^{4}$ at the outer rim of Tibet, and these complex entanglements return to and enhance the already conflated nature of Kham. I believe the notion of Kham-as-a-process, rather than simply Kham as the name of a region, has profound analytical value for helping us to likewise understand 'Yachen as a process'. Only when we can see Yachen as a changing phenomenon or movement - and not as a bounded place, monastery, or religious site - will we be able to recognize and

3 The Chinese authorities have initiated a large-scale demolition and rearrangement of the nuns' quarters under the pretext of infrastructural and hygienic improvements for the residents. These include expanding the number of streets, dismantling huts, and removing the wild dogs that roamed the encampment.

4 Michel de Certeau argues that space involves mobile elements and variables: things occurring, the organizing of movements, not simply being-there (place). Therefore, to de Certeau, 'space is a practiced place' $(1984,117)$. 
see the nature of the encampment and what it entails: the specific forms of political tension and negotiation in its emergence and expansion, and, most important of all, the Tibetan nuns' unique contributions to each of these.

After all, Yachen's 'island' zone is spectacular not only because it is large and densely crowded, but also because it conveys a sense of infinite potentiality in movement and growth. The zone literally merges with the vista of endless grasslands and by doing so, it can also embrace a sense of unbounded Buddhist spirituality. Borrowing from Tim Ingold's contrasting juxtaposition of 'line and blob' (2015), the 'island' zone, at first glance, resembles a blob consisting of mass, materials, and forms; yet in fact, the real spectacle of the zone lies in its unbridled - thus almost illegible and unexpected - paths, threads, and traces that produce many 'lines' (Ingold 2007, 2015); for example, the routes of individual nuns' migrations from their hometowns to Yachen, the life paths they choose and negotiate, the traces of the religious desires they follow, and the limitless material extensions (huts, roads, halls, etc.) they add to the encampment while living in Yachen. By using an ethnographic vantage point, in the first part of this chapter, I will detail the spatial effect of the nuns' ongoing hut construction in shaping Yachen. To this end, the particular manner and politics in which the huts are built will be examined; and also, equally important, I will focus on how hut construction creates unruly pathways and routes across the encampment that make it harder for the Chinese authorities to read and control the space, as well as how the Chinese state has responded to this spreading illegibility of Yachen in recent years. In the rest of the chapter, I will address the spatial challenges the Tibetan nuns face when they exercise their mobilities.

The term 'encampment' (gar) suggests so much more than its functional proximity to a traditional monastery; it represents the movement, change, and unruliness that Yachen uniquely stands for and is based upon. Ultimately, I show how it has been possible in this environmentally challenging and politically conflicted region for the nuns' 'encamping' to evade the P.R.C.'s sovereign mapping; and how Kham is a good-to-think-with category for recognizing a new kind of engagement with Sino-Tibetan spatial politics that has been initiated and continued by ordinary Tibetan nuns.

\section{Encampment and Its Unruly Presence}

What does it mean to have total physical control over one's residential structure? What if one could be the designer, builder, and resident of a built-form all at the same time? It is quite unusual in modern urban settings 
for an ordinary citizen to assume all three of these roles, yet it is often the norm in a religious encampment like Yachen. Beginning in the 1980 s, over 10,000 Tibetan nuns have migrated to this remote region of Kham and have remained there by building their own huts. The conditions for hut building have been challenging; construction materials are not easy to come by - one must either rely on limited market supplies or collect natural resources such as mud and gravel - and, until recently, few modern amenities, such as electricity, were available to make the construction process more efficient (for example, some nuns now use electric-powered saws). Nevertheless, the nuns' migration to Yachen has not been stopped and their building activities have increased; this is constantly redefining the spatial limits of the encampment.

When I first met Drölma in 2012, she had been in Yachen for almost fifteen years. She and two other nuns had built their huts close together and later enclosed them using several large pieces of plywood to make a small communal yard for themselves. Since coming to Yachen, Drölma, like other fellow nuns, has ceaselessly repaired, remodelled, and rebuilt pieces of her hut and yard by utilizing all the available materials, tools, and skills at her disposal. The three nuns are very collegial, all are from the same village in Kham, and they share the same religious path and the hope of spending their entire lives practicing in Yachen. Despite such closeness and similar life experiences, however, they strictly respect each other's individual spaces and rhythms. Nuns in Yachen usually do not share or merge their kitchen areas, not even for the sake of convenience. They prefer to set up small stoves and a few bowls and plates at the feet of their beds and to have their own spaces for cooking and eating, rather than creating a more properly sized kitchen and sharing meals. The fact that Yachen has over 10,000 small huts means that it has almost the same number of 'mini-kitchens'. 5 This is one reason why small-scale constructions by the nuns go on ceaselessly and are of such importance in Yachen.

Over the years of visiting Drölma's hut, I noticed that she was constantly, albeit slightly, changing the structure of her room. On one occasion, she had moved the dividing wall between the room and the kitchen, sacrificing space in the kitchen area to create more space in her main room. Drölma

5 One person per hut is preferable because of the nature of the practices that Yachen promotes. These practices focus on solitary meditation for extended hours. Cooking and eating together might disturb the meditative flows of individual practitioners. Yet as the quarters-shortage issue in Yachen has grown in recent years, more nuns are compelled to share their spaces with other nuns (usually siblings and relatives), but this measure is usually considered a temporary one and each nun seeks to procure her own space. 
used the same wallpaper and fabric to match the existing patterns of the interior of the room. She did such a good job that I could not locate even a trace of the original wall. It is obvious that tasks like moving a wall are simple enough for Drölma to accomplish, and her experience of over fifteen years of residence in Yachen gives her relative expertise in dealing with various construction matters. Many Tibetan nuns with whom I talked would frequently share their upcoming plans for transforming their huts and, in most instances, they succeeded in making these happen. Over their years of living in Yachen, they learn, share, and transmit the knowledge of hut-building to one another; and in doing so, they are equipping themselves with total physical control over their material environment.

When I visited Drölma's hut again at a later time, I found a new construction project being undertaken right next to her yard. This was a common scene given that the nuns were, almost by default, continually engaged in building or repairing their huts. Drölma told me that a Chinese nun would be moving in soon. Unlike Tibetan nuns, Chinese nuns usually hire carpenters from outside if they build a hut (they usually rent one). This is mostly because their numbers are not large enough to mobilize a group to do construction work, and they have little experience and few skills for building huts. ${ }^{6}$ As I passed two male carpenters working on the hut that day, I noticed that the construction site seemed too small for a residential hut. But the new hut had an innovative design that maximized the utility of the tiny piece of land it was built upon. The Chinese nun designed her hut to be a double-decker space (see Figure 14.2); she asked the carpenters to build a kitchen on the first floor and an attic-style bedroom on the second floor. Interestingly, around the same time, I also found that in other sections of the nuns' residential area, Tibetan nuns were increasingly adopting this double-decker system to deal with the hut-shortage issue.

The double-decker system is one good example of how the nuns have direct physical control over their residential structures and do not seek official approval or wait for the intervention of the authorities. Furthermore, this innovation reflects the unique ways that the residential environment is arranged in Yachen by the nuns themselves, and how they exercise and authorize spatial and architectural freedom - that is, the freedom, within the

6 Some of the Tibetan nuns who can speak Chinese have good relationships with Chinese nuns. It was extremely rare to see any Chinese nuns speaking Tibetan or interacting with Tibetan nuns in Tibetan in Yachen. The number of Chinese nuns in Yachen is at most only a few hundred, and the kinds of activities and classes that these two groups participate in are largely separate; therefore, their daily interactions are usually limited, even though they live side by side. 
Figure 14.2 The hut construction next door to Drölma's hut

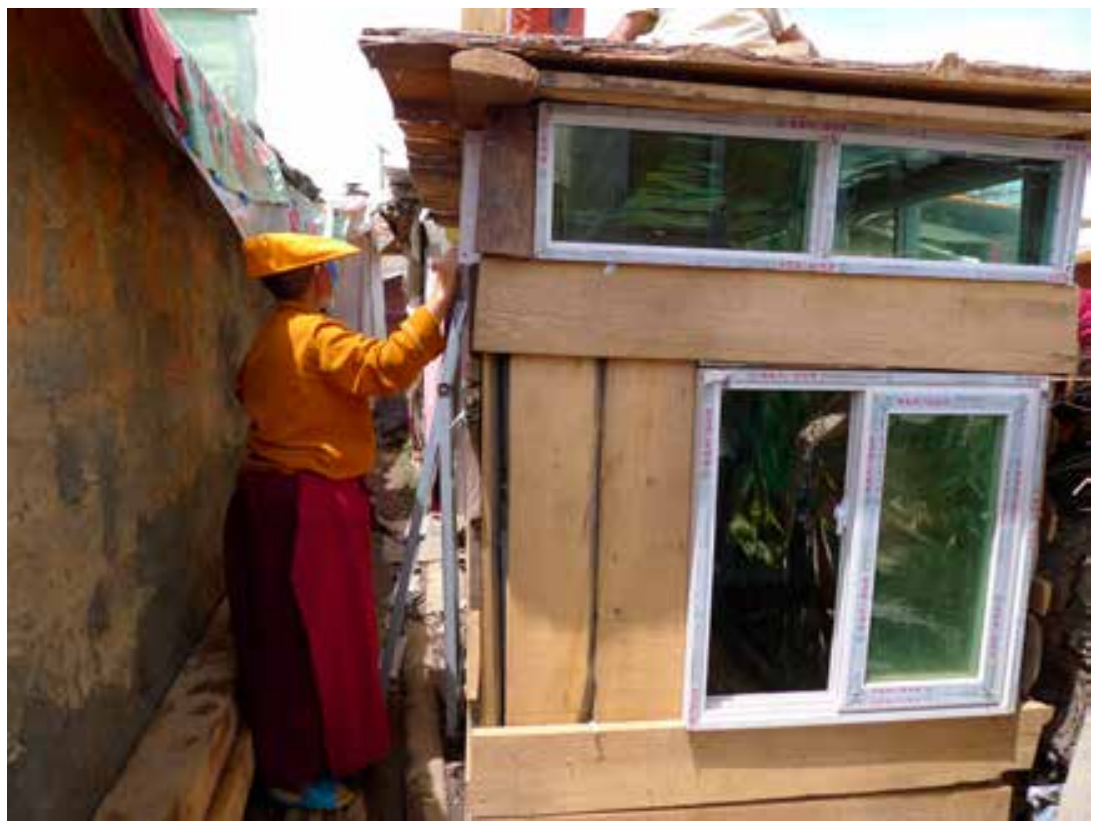

Photograph by Yasmin Cho 2015

given circumstances, to design their own structures and to transform their physical living conditions as they choose. This does not mean that Yachen is a restraint-free space or a space in which anyone can exercise a right to build. In fact, the Chinese authorities have always expressed concern about Yachen's rapid expansion and, as one of their control measures, they have encircled the nuns' residential area with a cement ring road to mark the boundary of the community (see Figure 14.1). Any hut-building activities outside of this ring road have practically been prohibited (although as we will see below, the state itself is now expanding and rearranging the nuns' community in the prohibited zone.) In addition to double-deckers, whenever the level of the state's surveillance becomes loosened, the nuns also frequently seek out opportunities to secretly build other kinds of residential structures (tents, for example) in the supposedly prohibited zone. Both in and outside the ring road, the nuns continually design ways to maintain their nunships in Yachen.

The hut that was being built next to Drölma's was near a narrow, winding passage that would not normally be suitable for a residential structure. But this unfavourable location turned out to be a lucky factor in its smooth completion. The site was too deep in the maze of huts for the Chinese 
authorities to be able to spot it and to immediately exert control over it. ${ }^{7}$ Tibetan nuns usually take on the risk of building a hut by quickly mobilizing more than ten nuns at a time and finishing the hut within a day or two. As a result of their nimble execution that eludes the Chinese authorities, the nuns literally and repeatedly make new passages, routes, and pathways, along with huts in new shapes and sizes, within their already intricate surroundings (see Figure 14.3); they are continually overlaying the old maze with a new one. If a cartographer were to try to map out the nuns' residential area, she would have to redraw it every month, if not every week, and to accept that it will always be incomplete. What also stands out here is that the nuns' hut-building in Yachen is an outcome of a collection of under-analysed and ignored forces, such as the nuns' material and spatial needs, their construction techniques, their collaborative mindsets, and the micro-spatial politics between them and the Chinese authorities.

The encampment itself, in its inherent incompleteness, is therefore the outcome of these complex and ongoing entanglements around the nuns' hut-building activities. In Yachen, nuns may need to wait before finding open spots in which to build new huts (as the Chinese nun did in Drölma's neighbourhood), but they do not wait for the head office to allocate residential cells to them, or for the government to send them permit papers as a precondition for admittance to the community. Upon their arrivals, with the help of fellow nuns, the nuns exercise direct control over their residential spaces; and this is significantly different from the spatial and bureaucratic thresholds typically imposed for initial admission to monastic communities in the more formal monasteries in the T.A.R. and elsewhere. Yachen's distinctive spatial arrangement, with its self-organizing and improvisational nature, thus serves as extraordinary testimony to what an encampment can achieve that formal monasteries, which are structurally and politically associated with the characteristics of fixity, finality, and completeness, typically cannot.

Encampments and mountain hermitages have long existed as alternatives or complements to formal monasteries and have served to enrich Tibetans' religious lives. Religious encampments (chögar) appeared in the fourteenth century in the Kagyu school (Terrone 2008), yet it seems that there are

7 In many Tibetan monastic communities, there is a governing unit called the Work Team (Ch. gongzuo zu) that has been dispatched by the government. Its aim is to exert control over any issues that disturb the general social harmony. One of the Work Team's main tasks in Yachen is to monitor new hut-building activities in the nuns' area. Given the tension around the community at that time, the Chinese nun's hut building might have been stopped and the hut destroyed if it had been caught by the Work Team. 
forms of outdoor teaching communities in remote regions that have an even older history than this. ${ }^{8}$ In many places in Tibet now, 'encampment' and 'monastery' interchangeably refer to spaces where Buddhist teachers and practitioners live and practice together, and share the same rhythms and practices provided by the community. Thus, it is not entirely productive to scrutinize the similarities and differences of these two forms of community in Tibet since, regardless of what Yachen is called - a monastery (Ch. si, usually by Chinese disciples), a 'quasi-monastery' (Terrone 2009), or an encampment - it plays a role in the fullest sense of transmitting Buddhist teachings and knowledge to wider audiences.

However, we should be cautious about an insidious effect that is produced when one uncritically applies the term 'monastery' in the case of Yachen. When Yachen is understood as a (traditional) Tibetan Buddhist monastery, the focus rests on the founder's or the authorities' will and power, and on the symbolic representation of the community as a completed form with a fixed role, rather than on the various processes, movements, and activities occurring in and around the community. In this regard, within a monastery framework, Yachen is tacitly presented as an already-planned structure that was foreseen centuries ago in the vision of its founding lama and is now fully instantiated in its final and static form (See Treasure movement). ${ }^{9}$ Transformations, disorderly arrangements, and the explosive migration of nuns and the roles they play in Yachen are neither recognizable nor important in that framework. When Yachen is conceived as a crystalized, abstract, and conceptual edifice - as it is in the sacred prophecies recorded in the biographies of lamas in Yachen, the soaring number of nuns and their activities goes unmentioned; we fail to raise - not to mention fail to recognize - questions about why and how so many Tibetan female practitioners have gathered there and why and how Yachen continues to change.

8 Based on a lecture given by Khenpo Tsultrim Lodro, entitled 'The History, Role, and Reemergence of Tibetan Buddhist Encampments', on 14 August 2017, at Columbia University, the beginning of encampments and outdoor teachings and practices nearly coincides with the beginning of monasteries.

9 The claim is made that Yachen is linked directly to the ancient master Padmasambhava's or Guru Rinpoche's prophecy. Guru Rinpoche's prominent methods in transmitting Buddhist teachings in the purest form are known as the Treasure (Tib. terma) tradition, according to which teachings (written scriptures) and other sacred objects were hidden by Guru Rinpoche and are to be found by the right figures in more peaceful times. In this way, Buddhism can once again be resuscitated in Tibet. Yachen's founder, Achuk lama, was known to be one of the revealers (Tib. tertön) of the treasures; and Yachen's spiritual basis therefore lies in the undisturbed, direct teachings from Guru Rinpoche in these revealed teachings. For more information about the Treasure movement in Kham, see Doctor (2005), Gyatso (1998), Germano $(1998,2002)$ 
In other words, the problem of seeing Yachen through the perspective of architectural finality is that it prescribes to its members only fixed roles that do not deviate from a high religious purpose. This perspective automatically and conveniently dismisses the enormous number of physical activities that make possible and maintain the system of religious practices and the continuation of the sacred legacies. As one would expect, the nuns in Yachen engage in various religious practices and follow the teachings and instructions given by teachers - they pray, chant, and meditate. And yet, quite unexpectedly, they also engage in a significant amount of physical labour throughout the encampment, from building and repairing their own huts to working on large communal projects such as stupas, halls, and roads. ${ }^{10}$ As Drölma and other nuns show, they constantly build and alter their rooms, cells, and pathways, thereby remodelling the physical shape of Yachen; creating new spaces from non-spaces; embracing new members despite the government's controls; and in doing so, generate new spatial possibilities. These unexpected and piecemeal transformations that the nuns make on a daily basis have a direct impact on the unusual expansion of the encampment under repressive political conditions.

Michel Foucault (1977) discusses how regulatory power in modern society is deployed through the meticulous spatial layouts of buildings (schools, hospitals, prisons, etc.). He notes that 'stones can make people docile and knowable' (1977, 172); in other words, buildings, with their distinctive materiality, operate as an invisible mechanism for directing and regulating individual behaviours and minds. Yet, from the perspective of the nuns who directly create the spatial and material transformation of their huts, power is deployed in favour of the nuns in a way that makes them less docile and less predictable and thus less susceptible to the government's controlling grip. In Yachen, how many small residential huts will end up being built, dismantled, and remodelled by the nuns through their circumvention of the Chinese officials' patrols and surveillance; how many more nuns will be moving in or moving out of Drölma's neighbourhood; and what portions of Yachen are reconfigured and reshaped will therefore always remain open and undecided. ${ }^{11}$ The architectural properties of the encampment must be taken seriously not only because they allow the nuns to manoeuvre relatively

10 The monks in Yachen are usually exempt from communal physical work.

11 By saying this, I do not mean to dismiss the essential vulnerability of ethnic religious communities under the P.R.C.'s regime. But given that the Chinese state may exercise a Machiavellian sovereign power over its subjects, it is all the more interesting to examine how Yachen has sustained and expanded itself. The undecidability and openness-to-transformation of the encampment have had a significant effect thus far. 
Figure 14.3 The maze-like pathways in the nuns' residential sector

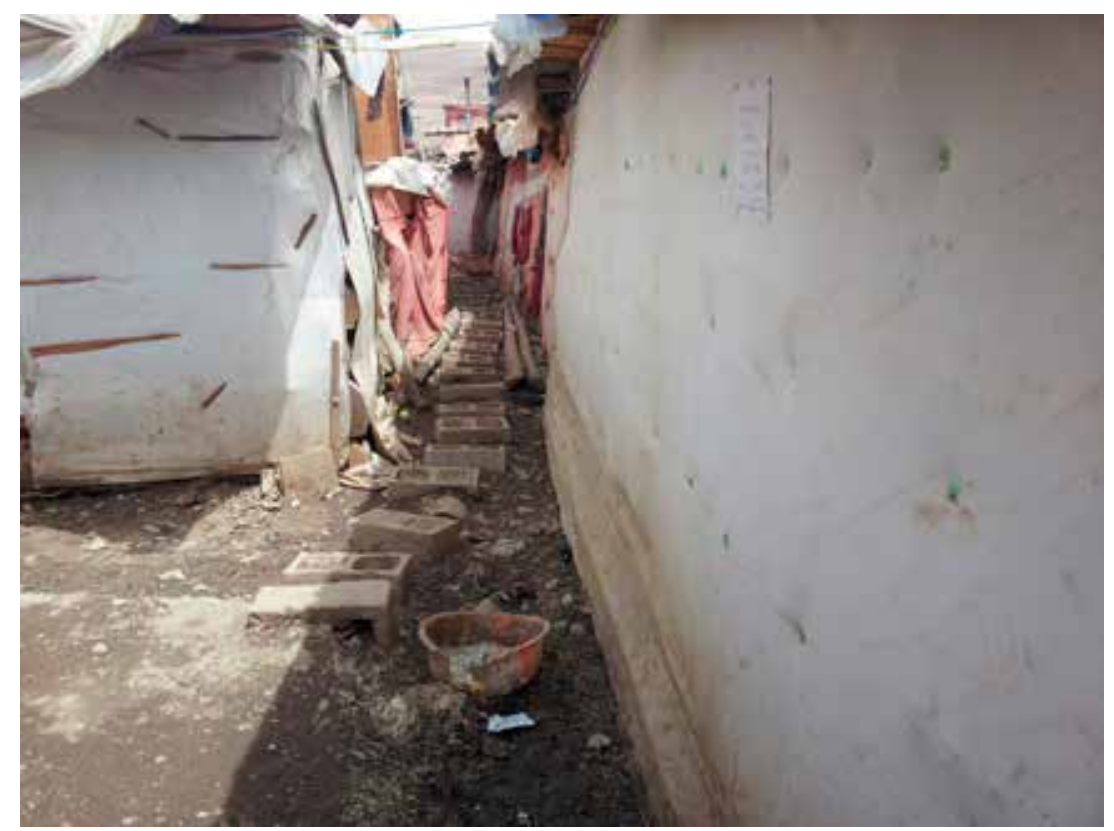

Photograph by Yasmin Cho 2013

freely in their spaces, and to create, dissect, and merge these spaces based on their needs, but also because the encampment is a distinctive kind of arrangement that disturbs, in a subtle and insidious manner, the spatial control of the Chinese authorities.

What has been clear so far is that Yachen is a space that 'occurs', is 'found', or 'produced' (Lefebvre 1991) through the active material engagements of the Tibetan nuns who have sought out alternative paths in and through Kham. The existence of Yachen as a space is indebted, in part, to Kham-as-a-process.

\section{Tibetan Nuns and Spatial (Im)Possibility}

How does one join a monastic community in contemporary Tibet? How does one become a Buddhist nun in a Tibetan context? Given that Buddhism is so deeply integrated into Tibetan life, and given that monastics occupy a concrete social position that is very well recognized and respected in Tibet, it may at first seem absurd to pose such questions as these. In general, it appears that monastics, as well as nuns-to-be and monks-to-be, have more 
or less full material and psychological support from their families and society; and therefore, for Tibetans, the process for joining a monastery is supposedly fairly straightforward. However, this general understanding of Tibetan monastics often obscures what typically happens when ordinary Tibetan women attempt to join a nunnery. Historical records regarding Tibetan female monastics and practitioners are rare when compared to the number of texts that exist about their male counterparts; but even among the handful of materials about women that are available, the focus is usually on figures who have demonstrated extraordinary achievements or had unusual social and familial backgrounds. ${ }^{12}$ Therefore, the glimpses we have of the lives of ordinary Tibetan nuns are limited to understandings that are, at best, based on inferences and conjectures extracted from accounts of a few exceptional female figures, the lives of monks, or from the words of male teachers. Now, however, with the emergence of Yachen, an encampment with an unprecedentedly large number of ordinary nuns, we have a crucial opportunity to acquire a better understanding of the hitherto ignored processes by which ordinary Tibetan females join monastic communities. Looking at Yachen from the nuns' perspectives will provide insights into the lives of Tibetan nuns themselves and into the specific kind of space they are making, both of which have left a significant mark on the Tibetan Buddhist revival occurring in Kham over the past few decades.

Tibetan nuns in Yachen hail from all over the Tibetan plateau. Many are from remote regions in Kham while, at the same time and rather unexpectedly, nuns from Lhasa and its near vicinity are also frequently seen in Yachen. ${ }^{13}$ Given the general respect that Tibetans have for Lhasa, in particular the life-time desire popularly expressed by Tibetans living outside

12 A few works, based on limited written records, about extraordinary female practitioners are available. For monographs focusing on a single figure, see, for example, Allione (2000), Bessenger (2016), Diemberger (2007), Jacoby (2014), Schaeffer (2004); see also several articles by Hofer, Jacoby, Robin, and Schneider in a special issue edited by Schrempf and Schneider (2015). There are some ethnographic accounts of ordinary Tibetan monastics; see, for example, Grimshaw (1994), Gutschow (2004), Havnevik (1989), Makley (2005), and Shneiderman (2006). But these works, except for Makley, focus on female practitioners in the Himalayan region; there are very few studies in the English language on Tibetan nuns living in contemporary Tibet.

13 Although the record is rather outdated, Padma'tsho (2014) provided a survey, based on a governmental report produced in 2007, of the origins of the nuns in Yachen. In this report, 1711 out of a total of 5070 nuns (at the time of her research) were from the T.A.R. It must be noted that it is tricky to track down precise population statistics for Yachen because of the dynamic daily movements of practitioners in and out of the community. In addition, the political pressure to limit the number of new admissions in Yachen often means that the real number of practitioners may not be disclosed by Yachen's head office. Through various informal sources and my own estimates, I can say that the number of nuns was well over 10,000 as of 2017. 
Lhasa to visit and to spend time there, it comes as a surprise at first that some nuns give up the opportunity to remain in Lhasa and instead relocate themselves to a marginal region. ${ }^{14}$ Before going into detail about why these nuns do so, it is worth addressing some of the widespread experiences of Tibetan women when they attempt to join monastic communities. Among the various obstacles women face in becoming nuns, a particular kind of story repeatedly stood out over the years of my field research. Most of the nuns with whom I talked in Yachen told me that, at the beginning, they did not receive full support from their families. Based on my numerous interviews with nuns and the parents of nuns, I have come to see that familial disagreement originates largely from a deeply embedded misogynous belief in Tibetan society about females' indeterminate minds and their lack of the spiritual capacity needed to carry out a lifelong religious commitment. In the dominant narratives in Tibetan Buddhism, the ideal form of the body for making a serious religious commitment is the male body. Those with female bodies, which are considered an insufficient tool for achieving a lifelong commitment, may try to maintain such a commitment, but the effort will be longer and more arduous. In addition, the constant demand for female labour around the home is often a crucial factor in the initial familial rejection. Some girls, in responding to this domestic call, decide to remain at home as semi- or informal nuns who maintain celibacy while continuing to help in the household. ${ }^{15}$

Considering this unfavourable situation that is widely experienced by Tibetan nuns across regions, I would like to focus on the specific structural (political) conditions that the nuns from Lhasa, or the T.A.R. generally, face when they join Yachen, and look at how those conditions force or allow them to seek out this alternative spatial possibility. The permanent relocation from Lhasa to a nomadic region in Kham to fulfil one's religious desire has not been a widely chosen path among Tibetans until recently. Yet the prolonged and intensified spatial and political repression in the T.A.R. by the Chinese state has given the malleability of Kham more visibility - this is particularly true for those Tibetans who are more vulnerable and more deprived of their space due to the recent political restrictions. Tibetan nuns

14 See Katia Buffetrille's discussion in this volume.

15 There are very limited accounts of the existence of this type of 'household nuns' - those women who maintain celibacy (either previously married or not), keep some basic vows, and remain at home to help with house chores for their entire lives. By accumulating merits in this way, they hope to gain a better rebirth and to join monasteries in their next lives. Ethnographers working in Tibet, including myself, recognize the presence of such female semi-monastics, with variances, across Tibetan villages. See Grimshaw (1994) and Makley (2005). 
in Lhasa are among those who have been active in seeking out an alternative space and opportunity for themselves in and through Kham. Chenco is one of the many nuns from nearby Lhasa whom I met in Yachen. ${ }^{16} \mathrm{Her}$ initial goal was to join a nunnery in Lhasa, as other young nuns-to-be in her town often wish to do. Maintaining a short distance between the nunnery and one's hometown is common in her village. ${ }^{17}$ However, when Chenco applied to join a nunnery in Lhasa, she learned that she would have to wait for several years before she could obtain a permit that would allow her to be a nun there. 'I was told that there is a long waiting list of girls who want to be nuns, and I worried that I wouldn't be able to obtain a permit for the next few years', she told me.

The permit system, one of the many control policies imposed by the Chinese state on Tibetan Buddhism, was put into place when the monasteries in the T.A.R. were allowed to revive themselves after the devastating era of the Cultural Revolution (Goldstein 1998). Historically and symbolically important monasteries in the T.A.R., such as Drepung, are the primary targets of the system, and other monastic institutions in the T.A.R. are quickly affected as well. These monasteries have been assigned quotas for the number of members they are permitted, which results in communities that are significantly smaller than they used to be. Allowing the monasteries to 'revive', yet at the same time limiting the number of admissions, demonstrates both the dilemma and the tactic of the Chinese state when dealing with Tibetan Buddhism in the post-Mao era. The Chinese state fundamentally fears allowing the important monastic centres to recuperate themselves and serve as main spaces for aggregating Tibetan dissent toward Chinese rule. But it is also unwise to entirely prohibit Buddhist activities in Tibet given that the state has decided to move away from a focus on ethnic political struggles and to concentrate instead on economic development. The state's message is that monasteries can exist in the T.A.R., but they must show restraint in their role of providing religious, or other, inspiration.

16 The nuns' names used in this chapter are pseudonyms. In addition, the names of the natal towns of the nuns discussed here are not revealed.

17 In my research, Tibetan nuns and monks usually continue to maintain close relationships with their families after they join monasteries; they and their families support each other through ongoing spiritual and economic exchanges. Due to the lack of any support mechanisms other than their families, nuns usually rely on their families more than monks do. Also, in the case of smaller and more marginalized nunneries, the nuns are often mobilized for various labour needs in both their families and their monastic communities; therefore, the proximity between hometowns and monastic communities is preferable in many ways. See Kim Gutschow's work (2004) on Tibetan Buddhist nuns in northern India where she argues that the nuns are trafficked between homes and monasteries. 
The state prefers that they serve as inert religious centres and lively tourist attractions.

In the case of nunneries in Tibet, the situation is worse. Since nunneries are in general much smaller and, compared to monasteries, less connected to lay communities, the revival processes have been slower and more onerous due to the difficulties of raising donations, patrons, and other forms of social support that are needed to resuscitate these ruined communities. Girls who wish to be nuns in Lhasa end up having longer waiting times and thus face more uncertainty about their futures as nuns. Some of the girls who are on waiting lists live together temporarily in low-priced housing in the city until they can obtain permits. The idea is that girls who have the same goal can rely on one another to overcome the difficult and uncertain waiting period. But these self-organized living arrangements often extend for several years, and the combination of prolonged waiting and the low odds of success in obtaining a permit, not to mention the financial burden of living in this way, cause many girls to look for other options. Chenco told me that, during this time, some girls are forced to abandon their initial decisions to become nuns, often due in part to growing pressure from their families about marriage and other obligations at home.

But while the Chinese state's fixed quotas for monastic admission surely have a dampening effect on the girls who wish to join nunneries, the extended waiting period is ultimately not the only or even the most important reason that pushes Chenco and other girls to leave Lhasa. Chenco and other nuns say that the real issues these days are the serious doubts that practitioners themselves hold about the efficacy and true benefits of practicing Buddhism in Lhasa. The Chinese government not only regulates the size of the monastic communities in the T.A.R., it also controls the types and levels of religious activities - including rituals, initiations, and lamas' lectures - that originally fell under monastic authority. Chenco perceives this situation to be much worse in the case of nunneries: 'In Lhasa, there are many restrictions on what the lamas can lecture about and what teachings they can transmit in monasteries. The teachers cannot teach what they want. They are monitored. In the case of nunneries, it's worse. Even fewer lamas wish to serve at nunneries and fewer religious activities are undertaken.' She simply could not see any hope of freely and rigorously practicing Buddhism in the current religious environment in Lhasa.

Chenco's statement touches on an old issue that nuns face in Tibetan Buddhism: a lack of spaces for practicing Buddhism and a lack of proper and durable social support. The lack of spaces, teachers, and mental and material supports for nuns is simultaneously both the outcome and the 
cause of a deeply rooted misogynistic attitude, if not in principle then in practice, toward women in Buddhism. Kim Gutschow (2004) shows how the status of Tibetan nuns is considered lower than monks almost by default, and how this status operates and is constantly reproduced in Tibetan society through the unquestioned monastic order and tradition, as well as the nuns' own acceptance of their lower status (see also Schaeffer 2004). Charlene Makley (2005) also argues that 'monkhood', the ultimate ideal of monastic embodiment, serves as a third gender in the gender-sex system in Tibetan society. Buddhism, in principle, liberates sentient beings from fundamental hierarchies; but as several studies show, in practice, it acquiesces to, if not actively promotes, gender asymmetries that are exercised in both monastic and lay lives. ${ }^{18}$ To state this more directly, the general lack of resources, and thus respect, for nuns has been taken for granted as a social fact in Tibet, so that the response given to me by most nuns and monks (and lamas) in answer to my simple question about the reason for such a lack usually went like this: 'This is the way it has always been'.

Therefore, many nuns in Tibet have ended up walling themselves up in small, isolated, rundown nunneries - if and when they are admitted to one - with little support from outside other than from their kin groups. There are few active teaching and practice systems available, few donations made, and virtually no invitations given to nuns to perform rituals in villages. Performing various rituals in villages is a respectful way to generate income for seasoned monks. They can showcase their specialities and knowledge by serving the public in unique ways; and by doing so, they gain a warm reception, esteem, and material compensation. But villagers almost never invite nuns to do rituals because of the inferior capacity and education that the nuns usually possess, which is deemed to make them unqualified for doing such tasks. And the nuns themselves, even those who are properly educated and receive good teachings, have also been inculcated in the belief that the task of performing public rituals rightfully belongs to the monks. For many ordinary Tibetans, a self-evident question is: 'Why invite nuns when there are so many monks are around?'

Given this situation, Chenco's choice (and that of many other girls like her) to travel outside of the T.A.R. no longer appears odd. It has become obvious to Chenco that because of the long-standing repressive religious policies imposed by the Chinese government, Lhasa and the T.A.R. in general are no longer active religious centres for Tibetan Buddhist education in the same way that they used to be. And this especially affects the nuns and 
nuns-to-be in the T.A.R. Chenco had heard of a new place called Yachen that had no such quotas or waiting lists, and where several renowned lamas offered teachings to nuns and monks equally. She and many girls from the T.A.R. have thus turned their attention toward a place they once thought of as belonging to the margin, but which is now a place where they can find a large gathering of nuns, illustrious teachers, and the systematic support they have never had, nor even imagined (for a discussion of the larger context of this, see also Buffetrille, this volume).

Chenco's story tells us that many of the nuns who join Yachen have experienced, all along, forms of gender discrimination that are structurally and culturally embedded in Tibetan society. Whether they conceive of this as unfair gender bias or as the outcome of unwholesome karma linked to female bodies, they hope to overcome these predicaments by seeking to find in Yachen the superior teachings and practices that have rarely been available to them. Contrary to what the existing literature implies, I do not view this unprecedented opportunity for the nuns as something simply provided by lamas or the Chinese government's somewhat less restrictive policies in the 1980s. What makes this exceptional opportunity a viable one is, in significant part, the inherent inclusiveness and incompleteness of Yachen's material status, i.e. encampment, and how the nuns utilize this for their own purposes. What Yachen most crucially offers to the nuns is therefore a spatial possibility (with its accompanying educational chances and other opportunities) that is brutally disappearing in the nunneries in Lhasa.

Yachen's open-ended nomadic environment signals a virtually unlimited space for determined practitioners. As the number of nuns has continued to increase, the priority of the head office has slowly begun shifting to focus on the nuns' education and their welfare. Yachen was not initially designed specifically to improve the nuns' welfare and education, but the ever-increasing population of nuns has made this a greater priority. ${ }^{19}$ This unruly space that the nuns are making and remaking in Kham has the effect of attracting a large number of socially disadvantaged people, because the form of encampment places few, if any, obstacles to entry into the community. In this space, the nuns have become an overwhelming majority, and they have acquired equal footing with monks in terms of education

19 Some might say that 'letting the nuns stay' should be considered as an unusually gracious action by the previous head lama. However, even in the biographies about the lama that are produced by Yachen's head office, the large number of nuns that have gathered is not recognized as a great feat or a compassionate action by him. Accounts usually treat the massive number of followers as androgynous, classless, and ethnicity-free anonymous bodies. 
and access to high-ranking teachers. In turn, such opportunities, which are rarely available elsewhere, have been a major source of attraction bringing even more girls to Yachen.

\section{Emerging Geometrical Control}

The spatial unruliness of Yachen serves as a way for the nuns to stealthily venture out and extend their presence both deep inside the encampment and at times even into the unbounded nomadic grassland beyond the 'island' zone - for a few years, a growing number of nuns living in tents outside the ring zone formed a tent city. ${ }^{20}$ But for the Chinese authorities, such unruliness invites confusions and illegibilities that require an alternative (and equally spatial) response. Recently, Yachen's form has been substantially altered, not by the small, daily material engagements of the nuns, but by large-scale infrastructural constructions authorized by the Chinese government. The extensive street repairs in both the nuns' and the monks' residential areas are the most noticeable of these. ${ }^{21}$ At a superficial level, one might see this positively, as a sign that Yachen is modernizing and the standard of living is rising. In fact, the head office has been promoting these street constructions for years by saying that, with paved roads, practitioners will no longer become mired in the streets when it rains or snows. Most of the nuns with whom I have spoken seem to welcome the idea of having the main streets cleaned up and paved because this would no doubt make their mundane chores less exhausting. On the other hand, however, the construction processes have entirely upset the residential environment of some of the nuns. Those who lived in huts bordering the main streets were ordered to move out; their huts had to be removed because the newly constructed streets are twice as wide as the original dirt-filled streets. The new streets are wide and straight enough to accommodate two lanes of minivans (see Figure 14.4 and compare it to Figure 14.1 taken in 2010).

20 The Chinese state allowed the tent city to grow for years because it did not see the tents as solid residential structures that fell under the category of surveillance. The new metal hut complex eventually absorbed the tent city, and the nuns who used to live in the tents moved into the complex. But for a time, the growth of the tent city literally redrew the legal boundaries of Yachen.

21 In the summer of 2019, as this chapter is going to press, there are new reports of demolitions in the nuns' quarters by the Chinese authorities. The size of the demolitions needs to be confirmed, but it appears that the government's infrastructural rearrangements have been extended to the nuns' residential area. 
Figure 14.4 The nuns' residential sector in Yachen in 2016

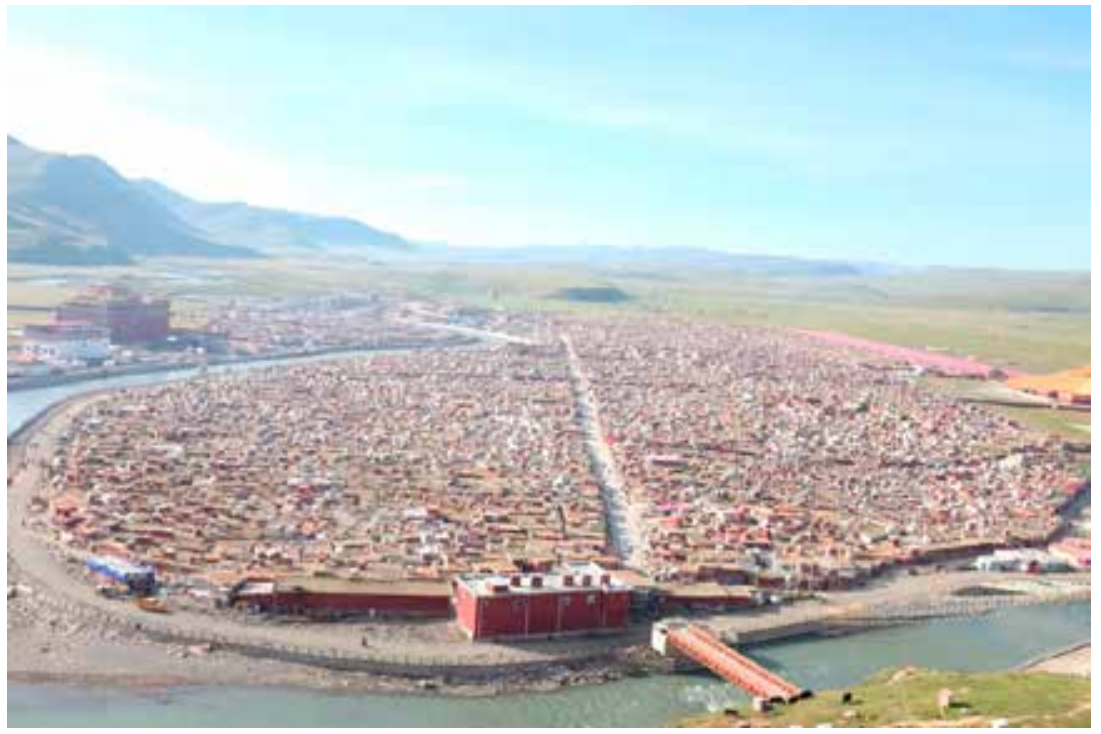

Photograph by Yasmin Cho 2016

Here, a return to our focus on encampment points to an alternative perspective from which to understand these recent infrastructural constructions taking place in Yachen. If we set aside for a moment the discussion of whether or how the streets improve the nuns' daily lives as these straight, aligned streets appear in the middle of the nuns' residential areas, the essential character of the encampment as a space, with its meandering pathways and routes created by the nuns, is slowly disappearing. What makes an encampment an encampment - that is, a distinctive Buddhist space in contemporary Kham - is lost as the maze-like routes and paths, the freely erected huts and cells, and the surprises and unknowns built into this ever-changing space are gradually incorporated into the realm of the visible and the knowable. We are now beginning to see geometrical street grids that run across the middle of the nuns' residential area.

After years of negotiation between Yachen's head office and the Chinese authorities, the nuns who had been displaced ended up moving to a complex of metal shacks located on the outskirts of the encampment where it had long been forbidden to build huts. The Chinese authorities brought in makeshift, rectangular, prefabricated metal quarters for the nuns who had lost their quarters because of the road construction. In addition to the displaced nuns, newly arrived nuns and those who had no space of their own and were 
Figure 14.5 The complex of prefabricated metal quarters

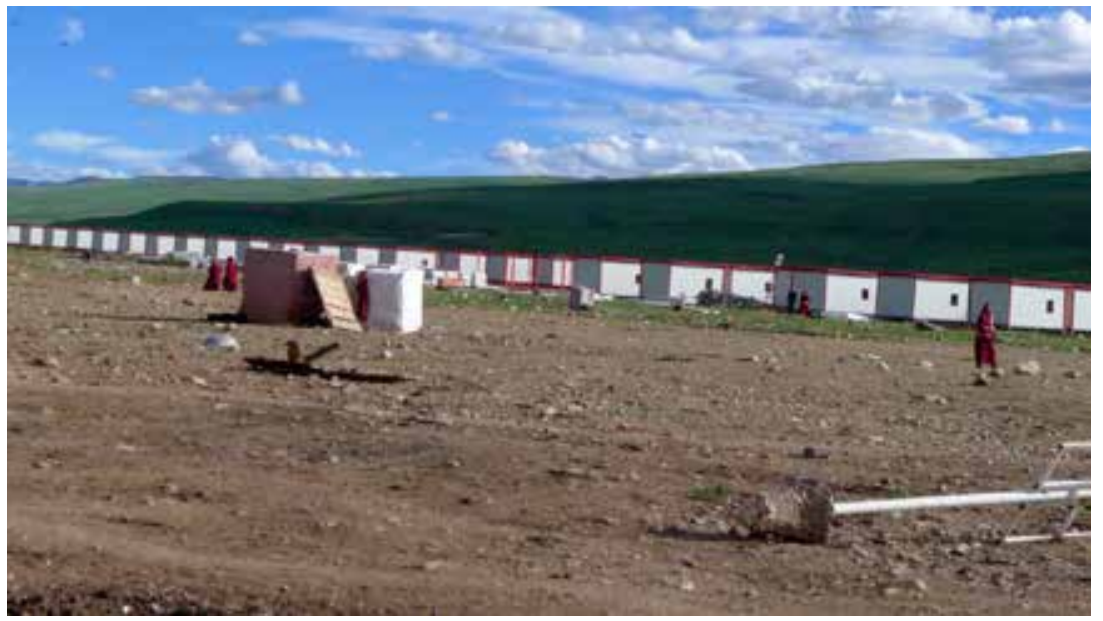

Photograph by Yasmin Cho 2015

staying with other nuns were also moving into metal shacks. Facing the endlessly growing number of nuns and their never-ending secret hut-building activities, the Chinese state seemed to be responding by making the nuns' residential arrangements more open and visible, even if this meant forgoing the original spatial prohibitions on hut-building.

These prefab metal units are arrayed in straight lines like an army complex; each has an identical layout, divided inside into a room and a kitchen (see Figure 14.5). The nuns' reactions are mixed. With the exception of their distance from the main halls and the main market areas, these quarters are considered by some nuns to be as good as, or even better than, the huts the nuns themselves build. The rooms are spacious, the ceilings are high, and the quarters mostly come with front yards. Some (young) nuns even intentionally gave up their existing lumber- and mud-built huts and moved into these metal quarters. Other nuns hold the opposite view; they dislike these metal quarters because metal transmits both heat and cold too quickly into their indoor spaces, making it especially difficult to endure the highland's cruel winter season. ${ }^{22}$

22 When a nun voluntarily decides to move into a prefab unit, she either rents out her original hut or sells it. (All hut-related transactions are strictly monitored by the head office, and the prices are decided by the office as well). The head office requires the nuns to pay half of the price of the unit (about 10,000 RMB) when they move in. They can stay there without making further instalment payments as long as they maintain their nunship in Yachen. But if the nun decides to leave Yachen, she must pay the rest of house's price to the head office. 
At the time of my first visit to Yachen in the summer of 2010, there were no prefab metal quarters, no wood-and-mud quarters built in lines and rows, and the streets were serpentine, dirt-filled, organically created routes. I used to find the locations of the huts of nuns with whom I was acquainted by memorizing the detailed architectural traits of their quarters and the material environments of their neighbourhoods: the shapes of doors, the types of materials and fabrics used for the exteriors of the huts, the number and forms of cells on the roofs or yards, the patterns of the pathways that linked their huts, and so on. Since each hut had its own distinctive individual features that had grown out of numerous repair and rebuilding activities, this was almost the only possible way to recognize them. Yet, locating huts in this way remained challenging. No matter how carefully I inscribed the peculiar features of the huts into my brain, I often failed to find the one I was looking for because of the nuns' constant rebuilding and repairing activities. I would find myself drifting along the streets or wandering in the wrong area and being chased by the wild dogs that were guarding the area from strangers. The nuns' residential zone was a maze with few signposts or markers.

In the areas of Yachen that one was most familiar with, even a small task like fetching water required multi-sided and multisensory attentiveness. When fetching water in Yachen, even though the route from my hut to the well was relatively fixed and known, I had to meticulously check various things on the way: I needed to examine the conditions of the streets on that particular day to avoid stepping into water holes, mud holes, and dog stools; take care not to hit my head on the untrimmed construction materials jutting out from huts and walls; and avoid other new obstacles. Walking through Yachen to do chores and to visit friends or lamas resembled the experience of wayfaring in a new place without having a map or reliable information in hand. Michel de Certeau reminds us of the embodied role of walkers in cities: 'They are walkers [...] whose bodies follow the thicks and thins of an urban "text" they write without being able to read it' $(1984,93)$. These walkers claim new spaces and terrains that are not shown on the maps and itineraries; their unexpected and unplanned bodily presences, equipped with cautions and curiosities, produce new texts and new stories for urban spaces. In 2010, at least, before the new streets and metal quarters, before the governmental spatial controls were established, the nuns and visitors in Yachen were like the walkers in de Certeau's description.

In 2016 then, when I visited an old friend of mine in Yachen and attempted to locate her hut by recalling my memories of the physical traits of the hut and its surroundings, I realized there was no longer a need to memorize 
every detail in order to find what I was looking for. After the new streets were completed, I did not need to pay attention to the changing curves of the ground or the routes that I used to use. When I visited a nun living in the metal quarters' area, I found myself checking the house number that marked each living quarter instead of memorizing specific features as I used to do. The metal quarters are virtually identical, with few visibly distinctive traits and few indications that transformations are occurring. The distinctive physical features of individual huts have been replaced with lifeless numbers, lines, and markers. In the complex of metal quarters, the flow of the nuns' movements is visible and predictable. There is no need for multisensory attentiveness when passing through the complex. The routes are fixed and unmovable, the concrete streets require little attention from those who walk along them; there are few water holes, mud holes, or animal excreta. ${ }^{23}$

Since the completion of the new streets and the complex of metal huts, the geometry of the nuns' residential area is slowly transforming into a more legible form, in echo of James Scott's (1998) analysis of the technologies of 'simplification' deployed by the state to tame a space and ensure spatial control. The flows of the nuns' daily movements are more regulated and arranged than before. Less time is spent on the streets, and chores can be done more efficiently. Some might say that the overall environment for practicing Buddhism in Yachen is much improved because the nuns can now spend more time focusing on their practices instead of dealing with daily chores. The stories and reactions among the practitioners about the new streets and the metal quarters are complex and segmented, and are currently still unfolding and evolving. What is certain is that now there is less space left in Yachen for the nuns to freely reconfigure their own living structures, and more space that forces the nuns to move along fixed and planned routes. There is now less space for the nuns to 'write' their own texts and stories, and more space for the authorities to 'read' the nuns. The sheer physicality of the nuns' hut-building is reduced, and Yachen is now becoming more of a static and abstract 'monastery' with less texture or movement involved. Yet, interestingly, Yachen's monasticization this time

23 Almost all the wild dogs have been removed from Yachen under an order given by the Chinese authorities in 2016. The local governments in Tibetan regions have begun slaughtering a massive number of wild dogs over the past few years under the pretext of improving the level of hygiene in local communities. The order was made in 2016 that all dogs in Yachen, which had numbered three to four thousand, must be slaughtered. As a Buddhist community, Yachen could not allow such massive killings to take place on their watch. In the end, the head office negotiated with the government not to slaughter the dogs but to send them away. 
is being executed by the state's specific projection of geometrical control onto the community, rather than through the high-ranking lamas' visions and prophecies.

\section{Conclusion}

I have argued that an encampment is a space that is being made - in response to the nuns' needs (both religious and secular) and through their active material engagements - in ways that are not easily recognizable, legible, or predictable to the authorities. The dominant approach to perceiving Yachen has not been conducive to properly assessing the nature of 'encampment' as a crucial architectural feature that makes possible Yachen in its current form. The intense focus on a handful of celebrated male lamas and their spiritual capacities, including their extraordinary prescience and political sensibilities, has overwhelmingly determined the ways in which the Tibetan Buddhist revival, as well as an encampment like Yachen, are typically understood. As a result, not only the vital activities of the nuns that shape the encampment but also the malleable politics of Kham that crucially facilitate Yachen's emergence are dismissed.

I have shown that the large number of Tibetan nuns in Yachen is neither accidental nor incidental; the unusually active level of female involvement is closely related to the emergence of this particular form of Buddhist space in and through Kham. In other words, the encampment in contemporary Kham is not a mere backdrop to stories about Yachen, but is the principal mechanism that allows this Buddhist space to grow through architectural freedom and material manoeuvrability, despite the unstable political environment.

Focusing on the nature of encampment also enables us to develop an alternative perspective for understanding the kind of political control executed by the Chinese state. From this perspective, the tensions that exist between Yachen and the Chinese state can be seen as fundamentally spatial in nature. The Chinese authorities continue to make efforts to 'read' their subjects through spatial control by imposing upon the encampment a geometrically measurable order; while the nuns constantly endeavour to escape this spatial control by creating new huts, pathways, and routes that undermine it. In Yachen, seemingly simple spatial rearrangements, whether created by the nuns or by the state, are, after all, a reflection of the political tensions and asymmetrical confrontations between the nuns and the Chinese government out of which Yachen continues to arise and evolve. 


\section{Glossary of Tibetan and Chinese Terms}

$\begin{array}{ll}\text { Achuk Lama } & \text { a khyug blama } \\ \text { chögar } & \text { chos sgar } \\ \text { Drölma } & \text { Sgrol ma } \\ \text { gar } & \text { sgar } \\ \text { gongzuo zu } & \text { 工作组 } \\ \text { Khenpo Tsultrim Lodro } & \text { mkhan po Tshul khrims Blo gros } \\ \text { terma } & \text { gter ma } \\ \text { tertön } & \text { gter ston } \\ \text { si } & \text { 寺 } \\ \text { Yachen Gar } & \text { (Tib.) Ya chen sgar, (Ch.) Yaqing si 亚青寺 } \\ \text { Zhonghua } & \text { 中华 }\end{array}$

\section{References}

Allione, Tsultrim. 2000. Women of Wisdom. Ithaca, New York: Snow Lion Publications.

Bessenger, Suzanne M. 2016. Echoes of Enlightenment: The Life and Legacy of the Tibetan Saint Sèonam Peldren. New York: Oxford University Press.

De Certeau, Michel. 1984. The Practice of Everyday Life. Berkeley: University of California Press.

Diemberger, Hildegard. 2007. When a Woman Becomes a Religious Dynasty: The Samding Dorje Phagmo of Tibet. New York: Columbia University Press.

Doctor, Andreas. 2005. Tibetan Treasure Literature: Revelation, Tradition, and Accomplishment in Visionary Buddhism. Ithaca, New York and Boulder, Colorado: Snow Lion Publications.

Foucault, Michel. 1977. Discipline and Punish: The Birth of the Prison. New York: Pantheon Books.

Germano, David. 1998. 'Re-Membering the Dismembered Body of Tibet: Contemporary Tibetan Visionary Movements in the People's Republic of China'. In Buddhism in Contemporary Tibet: Religious Revival and Cultural Identity, edited by Melvyn C. Goldstein and Matthew T. Kapstein, 53-94. Berkeley and Los Angeles: University of California Press.

—. 2002. 'History and Nature of The Collected Tantras of the Ancients'. The Tibetan \& Himalayan Library. 25 March 2002. http://www.thlib.org/encyclopedias/ literary/wiki/history\%2oof\%2ongb.html. (Accessed22 March 2019)

Goldstein, Melvyn C. 1998. 'The Revival of Monastic Life in Drepung Monastery'. In Buddhism in Contemporary Tibet: Religious Revival and Cultural Identity, edited 
by Melvyn C. Goldstein and Matthew T. Kapstein, 15-52. Berkeley: University of California Press.

Grimshaw, Anna. 1994. Servants of the Buddha: Winter in a Himalayan Convent. Cleveland, Ohio: The Pilgrim Press.

Gutschow, Kim. 2004. Being a Buddhist Nun: The Struggle for Enlightenment in the Himalayas. Cambridge, Massachusetts; London, England: Harvard University Press.

Gyatso, Janet. 1998. Apparitions of the Self: The Secret Autobiographies of a Tibetan Visionary. Princeton, New Jersey: Princeton University Press.

Havnevik, Hanna. 1989. Tibetan Buddhist Nuns: History, Cultural Norms, and Social Reality. Oslo: Norwegian University Press.

- 1994. 'The Role of Nuns in Contemporary Tibet'. In Resistance and Reform in Tibet, edited by Robert Barnett and Shrin Akiner, 259-266. Bloomington and Indianapolis: Indiana University Press.

Ingold, Tim. 2007. Lines: A Brief History. New York: Routledge.

-. 2015. The Life of Lines. London and New York: Routledge.

Jacoby, Sarah H. 2014. Love and Liberation: Autobiographical Writings of the Tibetan Buddhist Visionary Sera Khandro. New York: Columbia University Press.

Latour, Bruno. 1999. Pandora's Hope: Essays on the Reality of Science Studies. Cambridge, Mass: Harvard University Press.

Lefebvre, Henri. 1991. The Production of Space. Oxford: Blackwell.

Makley, Charlene E. 2005. 'The Body of a Nun: Nunhood and Gender in Contemporary Amdo'. In Women in Tibet, edited by Janet Gyatso and Hanna Havnevik, 259-284. New York: Columbia University Press.

McGranahan, Carole, and Ralph Litzinger. 2012. 'Self-Immolation as Protest in Tibet'. Hot Spots, Fieldsights, 9 April. https://culanth.org/fieldsights/series/ self-immolation-as-protest-in-tibet. Accessed 7 June 2019.

Padma'tsho. 2014. 'Courage as Eminence: Tibetan Nuns at Yarchen Monastery in Kham'. In Eminent Buddhist Women, edited by Karma Lekshe Tsomo, 185-194. Albany, New York: State University of New York Press.

Schaeffer, Kurtis R. 2004. Himalayan Hermitess: The Life of a Tibetan Buddhist Nun. Oxford: Oxford University Press.

Schrempf, Mona, and Nicola Schneider, eds. 2015. 'Women as Visionaries, Healers and Agents of Social Transformation in the Himalayas, Tibet and Mongolia'. Revue d'Etudes Tibétaines, no. 34 (Special Issue).

Scott, James C. 1998. Seeing like a State: How Certain Schemes to Improve the Human Condition Have Failed. New Haven [Conn.]: Yale University Press.

Shneiderman, Sara. 20o6. 'Living Practical Dharma: A Tribute to Chomo Khandru and the Bonpo Women of Lubra Village, Mustang, Nepal'. In Women's Renunciation in South Asia:Nuns, Yoginis, Saints, and Singers, edited by Meena 
Khandelwal, Sondra L. Hausner, and Ann Grodzins Gold, 69-94. New York: Palgrave Macmillan.

Terrone, Antonio. 2008. 'Tibetan Buddhism beyond the Monastery: Revelation and Identity in rNying Ma Communities of Present-Day Kham'. In Images of Tibet in the 19th and 2oth Centuries, edited by Monica Esposito, 2:747-779. Paris, France: École française d'Extrême-Orient.

-. 2009. 'Householders and Monks: A Study of Treasure Revealers and Their Role in Religious Revival in Contemporary Eastern Tibet'. In Buddhism Beyond the Monastery: Tantric Practices and Their Performers in Tibet and the Himalayas, edited by Sarah Jacoby and Antonio Terrone, 73-110. Leiden and Boston: Brill. Willis, Janice Dean, ed. 1989. Feminine Ground: Essays on Women and Tibet. Ithaca, N.Y: Snow Lion Publications.

Yeh, Emily T. 2013. Taming Tibet: Landscape Transformation and the Gift of Chinese Development. Ithaca and London: Cornell University Press.

\section{About the Author}

YASMIN CHo is a postdoctoral research scholar in the Department of Anthropology, Columbia University, U.S.A. She is currently completing a book manuscript that addresses the political subjectivity and the mode of life led by young Tibetan Buddhist nuns in the mega-sized Buddhist encampment of Yachen Gar in northwestern Sichuan province. 



\title{
Afterword
}

Chinese Settler Colonialism: Empire and Life in the Tibetan Borderlands

\section{Carole McGranahan}

\begin{abstract}
What does Chinese settler colonialism look like? More precisely, what does Chinese communist settler colonialism look like? In this essay, I consider contemporary Chinese empire in Tibet as a structure of both dispossession and domination, including the loss of state sovereignty. As in situations of empire elsewhere, Tibetan responses to colonization range from consent to new hegemonic politics to outright refusal of them. Given structural limits for cultural and political expression in China, consent, resistance, and refusal necessarily coexist. While this may be true for peoples throughout the People's Republic of China, the burden of empire places additional forms of oppression on Tibetans. Identifying these forms of oppression as imperial, rather than simply those of a multi-ethnic state, enables a historical precision commensurate with peoples' experiences of empire under socialism.
\end{abstract}

Keywords: Kham, settler solonialism, empire, frontiers, self-immolation

The Chinese are like kind parents The silver dollars rain down upon us - Local saying

One person's frontier is the centre of another person's world. Kham is such a place. It is the eastern territory of Tibet, one of the country's three historical regions - Amdo, Kham, and Ü-Tsang. Kham is both centre and frontier, and for many people it is a homeland that precedes and thus transgresses borders and the nations and empires that define them. Kham

Gros, Stéphane (ed.), Frontier Tibet: Patterns of Change in the Sino-Tibetan Borderlands. Amsterdam, Amsterdam University Press 2019

DOI: $10.5117 / 9789463728713$ AFTER 
is a place of diversity and contrast, and like all places, of contradictions. In the current political period, Kham's contradictions are especially relevant for they illuminate Chinese and Tibetan histories in important, overlooked ways.

In the 1950s, in an imperial move of aggression led by Mao Zedong, the People's Republic of China (P.R.C.) invaded and took over Tibet. In eastern Tibet, the Chinese soldiers were initially kind, offering ordinary Tibetans so many silver coins that these actions were memorialized in the above ditty that older Tibetans still remember today. The government of Tibet, including its leader the Fourteenth Dalai Lama, protested, but to no avail. Although a sovereign state, Tibet was not a member of the United Nations, and thus no country substantively came to Tibet's defence. These events unfolded during the era of the Cold War and of European decolonization. As countries around the world demanded and gained independence, Tibet ironically lost its independence and became a colony of the communist P.R.C. In Tibet, including Kham, a key aspect of Chinese communist empire is settler colonialism.

What is settler colonialism? Imperial territorial acquisition followed by ongoing dispossession and oppression through colonial administration and settlement. Canadian Indigenous political scientist Glen Coulthard defines settler colonialism as follows: 'A settler-colonial relationship is one characterized by a particular form of domination; that is, it is a relationship where power - in this case, interrelated discursive and nondiscursive facets of economic, gendered, racial, and state power - has been structured into a relatively secure or sedimented set of hierarchical social relations that continue to facilitate the dispossession of Indigenous peoples of their lands and self-determining authority' (2014, 6-7, emphasis in the original). To settle includes to dispossess others of their land and autonomy. As explained by U.S.A.-based Mohawk anthropologist Audra Simpson (2014, 2018), it is more than other people settling on native land, but also the unsettling of native practices and beliefs. It is to attempt to unmake existing worlds and replace them with imperial ones. In the case of Tibet, it is to replace Tibetan worlds with Chinese ones. In Tibet, Chinese colonial goals include economic and resource extraction, political administration, settlement incentives, the renaming and dividing of lands, cultural assimilation, and (thus far unsuccessful) efforts to eliminate religion in favour of an idealized atheistic socialism.

Imperial formations know no boundaries. They are not limited to certain parts of the world or time periods or types of polities. Thinking of empires as always in formation rather than as steady or coherent states enables 
needed comparisons across cases in addition to appreciation of their specificities (Stoler 2006; Stoler and McGranahan 2007). Acknowledging that an imperial formation is as likely to be Chinese, communist, and of the twentieth or twenty-first centuries as it is to be English, capitalist, and of the eighteenth or nineteenth centuries is both a historic reality and an analytic argument (McGranahan 2007). It is also a political claim. Claiming the People's Republic of China to be an imperial polity rather than (only) a multi-ethnic one is to assert an anti-imperial politics and to centre a colonized perspective. Given Tibet and China's long tenure as neighbouring polities, their shared political history ranges wildly. It has not always been a story of colonialism. Telling the story of Chinese colonialism in Tibet requires assessment of how empire is not only implemented but also how it is lived. Even in the most authoritarian of periods, people rarely respond to or experience colonialism in a singular way. As a structure rather than an event (Wolfe 1999), settler colonialism has shared features but not total coherence across Tibetan areas. Tibetans are colonized by China, but this structural reality has discrete geographic, historic, and political components to it.

Tibet's imperial realities are multiple. For the twentieth century alone, they are quadruple, including imperial relationships with British India, Qing China, the P.R.C., and the U.S.A. Going further back, they include the period when Tibet itself was an empire during the seventh through the ninth centuries, ruling over many of its neighbours, including portions of China, as well as territories further afield (Beckwith 1993). A genealogy of imperial formations related to Tibet over the last millennia thus includes a range of polities, including Tibet itself. The eighth-century arrival of Buddhism in Tibet effectively ended Tibet's imperial structure and activity. Governance, including relations with neighbours, was recalibrated within Buddhist frameworks. Across a vast territory that Tibetans often speak of as historically stretching from Ladakh in the west to Dartsedo in the east, Tibet was a patchwork of social, political, and religious institutions. Such variation was the norm. For example, depending on the village or town in which one lived in Kham, one could be under the administration of a monastic leader, a chiefly family, or a royal family. People living in border areas were sometimes under the influence or even direct rule of neighbouring non-Tibetan rulers and vice versa. Local power relations existed alongside other relations of trade, sociality, and religion. The latter was key for Tibet: Buddhist religious ties bound peoples through practices of patronage, pilgrimage, and devotion. Religious institutions and figures were omnipresent in Tibetan economic, social, and political domains. Indeed, 
the common term for Tibetan systems of governance was chösi, or 'religion (and) politics'. This combination of religion and politics is a continuing and constant tension for Chinese empire today.

Studying Chinese colonialism in Kham is to ask questions about frontiers, empire, and sovereignty. As Stéphane Gros argues, the eastern Tibetan region of Kham presents a 'categorical challenge' to what we think we know about both China and Tibet (this volume, Introduction). Analysing Chinese colonialism in Kham challenges denials that the P.R.C. is an imperial polity. Instead, it insists on categorizing current Tibetan relationships to China as colonized, and asks what changes when we do so. Borderlands, for example, have never been neutral political sites of cultural and economic exchange, but are instead areas of political possibility distinct from metropole locations. In this sense, Kham has long been a site for Chinese workings out of imperial policy (Coleman 2002; Frank, this volume; Giersch, this volume; Jagou 2009; Lawson 2013; Lin 2006; Relyea, this volume, 2015; Sperling 1976, 1998; Tsomu 2013, 2014; Tuttle 2005; Wang 2011). For Tibet, centring history and society in Kham is to de-centre Lhasa, Tibet's capital. Challenging the idea of Lhasa as national centre forces attention to the historical place of regions such as Kham, Amdo, Ngari, or more provocatively perhaps, areas such as Bhutan (druk yül), in relation to central Tibet. It also forces a conversation on sovereignty.

Tibetan claims to state sovereignty, and thus to Chinese imperialism in Tibet, can be as productively grounded in Kham as in Lhasa (McGranahan 2003a, 2003b). Kham is a region long associated with a fierce sense of independence, and people there have continued that tradition in response to the P.R.C. Since the 1950s, a consistent Tibetan response to Chinese political change has been resistance. As with colonized peoples elsewhere, Tibetan responses to empire exist along a spectrum from consent to refusal, including periods of more active or more passive reactions. Reconfigurations of everyday life under colonialism include consenting to new hegemonic policies and expectations to outright refusal of them (Simpson 2014). Given structural limits for cultural and political expression in China, consent, resistance, and refusal necessarily coexist. While this may be true for peoples throughout the P.R.C., the burden of empire places additional forms of oppression on Tibetans as well as Uyghurs and other colonized peoples (Bovingdon 2002, 2003; Byler 2019; Cliff 2016; Hillman and Tuttle 2016). For some individuals and communities, consent and refusal might be simultaneous, if contradictory practices of survival. This is part of the story of the contemporary Tibetan borderlands in Kham. 


\section{Settler Colonialism with Chinese Communist Characteristics}

Empires take many forms. Settler colonialism is one form, elastic rather than rigid across cultural and historic contexts (Veracini 2013). It consists of the settling of others' land by the colonizer with the intention of displacing, replacing, or otherwise eliminating the natives of the colonized territory (Wolfe 1999). Classic examples of settler colonialism are Australia, Canada, and the United States of America. In each instance, there exist drastic policies of both assimilation and destruction, including of native peoples as well as of their historical beliefs, practices, and claims to land. Settler colonialism may be one of several strategies or forms an empire takes. While it is often linked to European colonialism and also white supremacy, it - like empire in general - is not solely a European or white phenomenon. Settler colonialism is a possible feature of all imperial formations, including that of China.

Is China an empire? If many China Studies scholars have been hesitant to call the P.R.C. an empire, Tibetan Studies scholars have not hesitated to do so. From political science and international relations (e.g., Anand 2019; D. Norbu 1985; Smith 1996, 2008) to anthropology, geography, and history (e.g., Carrico 2018, Hansen 2003, Lokyitsang 2017; McGranahan 1995, 2007; Yeh 2013), many Tibetan Studies scholars portray Tibet's relationship with the P.R.C. as imperial. However, not all scholars do. Some prefer the term 'occupied', a term that calls attention to the problematic and violent nature of Tibet's relationship with the P.R.C. but that falls short of the term 'colonized'. This dilemma of naming the socialist state an empire is not limited to China, but also exists within Soviet Studies. Given the development of colonial and later postcolonial studies from within Marxist frameworks, non-capitalist empires such as the P.R.C. and U.S.S.R. did not fit scholarly imperial models (Annus 2012; Chari and Verdery 2008; McGranahan 2007; Stoler and McGranahan 2007; Verdery 2002). While there are similarities in the two cases, the scholarly literatures on these two socialist empires has unfolded differently.

In much of China Studies empire is past-tense, with important studies focused on the Qing or further back (e.g., Crossley 1999; Hostetler 2005; Leibold 2007; Perdue 2007, 2009). Why is this? Avoiding labelling China as imperial draws on a range of possible reasons, including the following: 1) scholarly fears of criticizing the government, and thus potential persecution or loss of research access (Makley 2009; Milward 2011); 2) Marxist 'radical reductionism' or ideological affiliation with or apology for the Chinese communist government (Yeh 2009); 3) a myopic focus on European empire 
(Stoler, McGranahan, and Purdue 2007); and, 4) pervasive 'discourse[s] of Chinese victimhood at the hands of Western empires' (Shih 2011, 709). Within China Studies, one important recalibration of the study of empire is through Sinophone Studies (Shih 2011, 2012; Shih, Tsai, and Bernards 2013) or the domination of the Chinese language.

Sinophone communities are one way to recognize Chinese empire. Literary scholar Shu-mei Shih identifies three historical processes of imperial consolidation: 'the continental colonialism of Manchu and Han Chinese empires that produced internal colonies in today's China; Han settler colonialism in select places such as Taiwan, Singapore and colonial Malaya; and (im)migration out of China that produced minoritized Sinophone communities in different parts of the world such as Australia, Europe, and the Americas' (2012, 5; on Taiwan, see also Chen 2010; Hirano, Veracini and Roy 2018; Sugimoto 2018). In this formulation, language is central. This holds true in some but not all ways for Tibetan colonial experiences in the P.R.C. A focus on language misses important historical and theoretical conversations about sovereignty that necessarily ground discussions and experiences of empire in Tibet. In the Tibetan language, the conceptual and imperial Other is China (gyanak) and the Chinese (gyemi), not the Chinese language nor the 'Han' Chinese. Thus, in addition to a genealogical connection to an imperial formation grounded around language, i.e. the Sinophone, in the case of Tibet, we also need a Tibetan-centred historical and political perspective.

Following World War II, China and the U.S.A. both used anti-imperial Cold War rhetoric to reframe empire as something else; for example, to posit imperialism as development or as the liberating spread of either socialism or democracy (McGranahan 2007, 2018). In the case of China, the consolidation of the People's Republic of China as socialist empire used and also retuned longstanding Chinese tropes of barbarians outside the gates of civilized society as well as new political strategies for and justifications of empire. When the People's Liberation Army invaded Tibet, the initial justification was the need for socialist liberation from feudalism and religion. Later the Chinese Communist Party added a historical justification to the earlier ideological one: the claim that Tibet was always a part of China. Ironically, this historical argument is itself only several decades old. For Xinjiang in addition to Tibet, anthropologist Kevin Carrico argues that such rhetorical shifts over time maintain the colonial project: 'the ideological application of the euphemism of development is particularly pressing in the current western areas of China, where from the Maoist rhetoric of "liberation" to the post-Maoist rhetoric of "development" a process of unrelenting Han Chinese 
colonization has been insistently represented as anything but colonization' (2018, 640; see also Fischer 2013; Yeh and Wharton 2016). Whom does a denial of colonialism serve? Mostly, but not only, those in power.

Under socialism, the Chinese civilizing project has been one of forging national unity and ethnic harmony (Harrell 1995). In Tibet, one example of this is the ongoing Education Aid for Tibet project where Chinese citizens travel to Tibetan areas to work as teachers. This labour is seen as moral and part of a civilizing saviour complex familiar to colonial situations elsewhere (Yang 2019). Moral justifications for the programme rest on stereotypical narratives such as 'the Han [i.e., Chinese] are superior, central, civilized, and safe and the ethnic minorities [i.e., the Tibetans] are inferior, peripheral, barbaric, and unsafe' (Yang 2019, 5; see also Carrico 2017). In her ethnographic research with teachers in the programme, scholar Miaoyan Yang (2019) found they understood their participation to be not so much about education for its own sake, as education in the service of ethnic unity, national stability, and national integration. Underlying this discourse is the argument that Tibetans are not integrated into the Chinese state, and that this is a problem to be fixed. Instead of unity and harmony, Tibetans thus potentially present problems of 'separatism' and 'splittism' to a benevolent imperial state.

Tibet is not an internal colony of China. To call it an 'internal colony' would support the fiction that Tibet was historically part of China. An internal colony is a territory inside a state which is administered in a colonial fashion, or for which there exists massive economic inequality between it and the state centre (Hechter 1975). In the P.R.C., there are places and peoples whose relation to the state is that of an internal colony (Gladney 1998; Oakes 1995). These are mostly non-Han ethnic areas and groups, but not necessarily ones that had a sovereign state as did Tibet. All non-Han peoples are nonetheless grouped into one ethno-political category, that of 'minority nationalities' or minzu, in a way that defines this grouping as natural or inevitable, that is such that 'these peoples are officially described as always already a part of China, as if they somehow naturally belonged on this map and did not end up as part of China by being conquered' (Fiskesjö 2017, 7). Anthropologist of China Magnus Fiskesjö argues that this historical revisionism has stark political repercussions: 'One formidable effect of this formulation is that it equalizes all the minorities and thereby erases the differences between those who built their own states and empires in the past, such as Tibet, which could easily, like Mongolia, fulfill the criteria for being recognized by the modern world as independent states with their own seat in the United Nations and on the other hand, those minority peoples who never engaged in any such state-building in the past' (Fiskesjö 2017, 7). 
Tibet's eighteenth-nineteenth-century imperial relations were with the Qing (Manchu) empire, which was a non-Han empire of China. Buddhism bound the Qing emperor and Tibetan Dalai Lama together in a 'patronpriest' relationship that Tibetans understood as a relation of equals, not one of subordination (Jagou 2009; Schwieger 2015). Being in an imperial relationship was not the same as being in a colonial one. During the same period, for example, British India also considered Tibet to be in its imperial interest; however, these Great Game politics were not an indicator of loss of sovereignty. In 1913, following the fall of the Qing empire and efforts of the new Republican government in China to assert claims to Tibet, the Thirteenth Dalai Lama proclaimed Tibet's independence. Tibet never came under the imperial or colonial administration of the Republican government of China. What then does current Chinese settler colonialism look like?

Instructions on how to be civilized. Exclusions from certain programmes and possibilities. Inclusions in other programmes and possibilities. Requirements to perform gratitude, to embrace aspects of socialism, to reject local beliefs and practices, including religious ones - Buddhism in Tibet and Islam in Xinjiang. A visible security presence, and invisible but known surveillance methods. State policies based on misunderstandings of native peoples, such as nomadic pastoralists (Tan, this volume). Alongside these, however, is everyday life. People find ways to live in empire, to live alongside colonizers, to survive and even thrive within limits. Strategies for doing so are multiple.

Within the P.R.C., at times Tibetans creatively push back on their state ethnic (minzu) categorization, and other times they operate within proscribed limits (Germano 1998; Grant 2017, 2018; Hillman and Henfry 2006; Jinba 2013; Keogh 2015; Makley 2007; Smyer Yü 2103; Yeh 2007). Poetry, literature, art, and song are all important genres for Tibetan cultural and political expression, often with risks of imprisonment and abuse for artists, intellectuals, and even community members (Buffetrille, this volume; Gayley 2016; Jabb 2013, 2019; Morcom 2015; Thurston 2017; Warner 2013). Changes in government policies for nomads, farmers, and urban residents have created new forms of inequality and struggle between Tibetans (Bum 2018; Gyal 2019; Sulek 2019; Yeh and Makley 2019; Zhaxi 2019). Tibetan experiences of nationalist modernity within China are shared across regions. For example, short stories written in Amdo are read by people in Kham. Songs performed by Khampas are beloved by people in Amdo. Poems composed in honour of historical events in Lhasa circulate among Tibetans in all provinces via social media (Jabb 2019). In the digital era, people have new ways to connect and communicate, including to 'undermine political authoritarianism' (Jabb 2019, 51). 
Tibetan experiences with Chinese neighbours long precede contemporary empire. Traders, intellectuals, monks, and others regularly travelled to China and other neighbouring countries such as India and Nepal, and resided there sometimes by choice and other times as forced exile (Jagou 2013; McGranahan 2017; Stoddard 1985; Yongdan 2019). The city of Chengdu in Sichuan, for example, has long had Tibetan residents, and is currently being reimagined anew as a Tibetan place within China ( $\mathrm{Xu}, \mathrm{Kou}$, and Wall 2018). While Kham and other Tibetan regions each have historical and administrative specificities, shared cultural sensibilities and forms have new uses under colonial rule. Understanding Kham thus requires understanding Tibet and vice versa.

\section{Kham: Borderlands, Centre, Home}

Where is Kham? It is north of Arunachal Pradesh and Burma and Yunnan, south of Amdo, east of Lhasa, and west of Sichuan and China. For Khampa Tibetans in exile, Kham is where they are not. Kham is a dreamt-of homeland, a place kept alive through memory and WeChat. Borders of Kham are not just with China; this is not simply 'the Sino-Tibetan borderlands'. Instead, borders of Kham and Tibet are also with a range of other peoples (Atwill 2014; Bhutia and Holmes-Tagchungdarpa 2019; Gros 2016b; Guyot-Réchard 2017; Roche 2016). An orientation toward China is only one way to situate Kham, albeit a very potent way given the current geopolitical situation. However, borders are not only geographic, they are also conceptual and cultural. For example, religious borders in the form of different Buddhist sects stratify much of Tibet and provide impetus to overcome the limits of single sectarian approaches or dominance (Gardner 2009). Environmental borders of rivers, passes, elevation, and so on challenge and shape human possibility, as do linguistic borders. Kham is an area of religious, environmental, and linguistic diversity, and histories plural that match this diversity. Just as Tibet is not a singular cultural field, neither is Kham. The southern district of Gyelthang is an excellent example of this in terms of a distinct, and even at times indifferent, relation to Kham (E. Mortensen, this volume). When and how people identify as Khampa is situational and strategic. Nonetheless, in times of loss and change, geopolitical singularities can possess new meanings for people. The current moment is one such time.

A list of possible identities for any individual is always graduated. For an individual in Kham, geopolitical identities are layered and split. One has Tibetan geopolitical identities and now also Chinese administrative 
ones. Historically, Kham was one of the chölkha (regions) of Tibet, and was comprised of many phayül (fatherlands) or districts. Each phayül had a central town and many villages and monasteries within its domain. Different Tibetan dialects and even languages are spoken throughout the region, some mutually unintelligible. Under Chinese rule, Tibetan terms were replaced with Chinese administrative units of prefectures, counties, cities, and townships. Nyarong is now Xinlong. Chaktreng is Xiangchen. Gyelthang is Shangri-La or Xianggelila (Hillman 2003). The names shift as the language does, the places reassemble with new boundaries and sensibilities. For some people, the two naming systems co-exist; for others, one fades in the face of the other. If your phayül is Nyarong and chölkha is Kham, your county is now Xinlong in the Chinese-established Ganzi Tibetan Autonomous Prefecture in Sichuan Province. Colonizing a place, settling a territory, includes renaming and reshaping its land. This is not a neutral act. The Tibetan and Chinese languages are not related. They jointly head the Sino-Tibetan language family, but Chinese is the current language of empire (Shakya 1994). Resistance to this is ongoing.

Insistence on the use of Tibetan languages is one nationalist form of resistance. We see this in numerous projects and forms of activism in the eastern Tibet regions, from the building of schools and creation of language programmes to the Lhakar ('White Wednesday') movement's pledge to speak only Tibetan on Wednesdays. Such actions are considered counterrevolutionary by the Chinese government. In May 2018, three years after appearing in a New York Times video discussing his work to support the teaching and preservation of the Tibetan language, Tashi Wangchuk was sentenced to five years in prison for 'incitement to separatism'. His story dissolves important borders: he is from Jyekundo in the historic Tibetan region of Amdo, now known by its Chinese name of Yushu in the province of Qinghai. But his story of linguistic activism and of the state violence that accompanies it could be that of someone in Kham or central Tibet. Becoming visible to the state for advocating for things Tibetan - language, dress, religion, rights - is to take a risk. Even ostensibly safe ways to publicly present and perform Tibetan identities through, for example, 'ethnic' song and dance, always include such dangers. Negotiating the risks of state violence is something required under settler colonialism, even for things that on the surface seem apolitical.

How can one be unknowable to the state? At Yachen Gar, a religious community of nuns in Kham, women seek ways to be unknowable to, and thus uncontrollable by the state (Cho, this volume). This is a project in constant motion, as the nuns build huts in manners and formations designed 
to deter, confuse, and refuse state mandates to be knowable. Remembering past resistance efforts against the state is also a political project. In exile as in the P.R.C., there are prohibitions against narrating histories of the Kham-centred citizen Chushi Gangdrug army that fought against the P.L.A. for almost two decades (McGranahan 2005, 2010). Also discouraged are histories that challenge either Chinese or Tibetan ideas of Kham or even of specific phayül as marginal places, rather than centres of their own (Turek, this volume). The historiography and scholarship produced under such conditions is partial and also political.

Histories written in service to the state, or as a form of international relations, flatten the complexities of actual people and the often complicated lives they live. For example, the experiences of an individual such as Khampa Tibetan communist Baba Püntsok Wangyal cannot be reduced to his relationship to socialism or Buddhism or with Mao or the Dalai Lama (Goldstein et al. 2004; Stoddard 1986; Takla 1969; Wangyal 2007). Some beliefs are held constant across a lifetime and others necessarily change over time. Acknowledging the range of subject positions of an individual such as Wangchuk Tempa - monk, bandit, strongman, resistance fighter, communist party member, and Tibetan trying to navigate a Chinese political world - enables a fuller portrait of life in the borderlands, including the sometimes oppositional array of life choices available to individuals (D.P. Mortensen, this volume). In the twentieth century alone, numerous Khampa Tibetans participated in national political projects, from locations both inside and outside of Kham. Some families and individuals gained power through religious rank and accomplishment, others through trade success, and still others through education and literacy (in both Chinese and/or Lhasa Tibetan) which enabled access to and affiliation with new ideological worlds of democracy, nationalism, and/or socialism.

Political possibility in the borderlands has long been strategic rather than stable. Relations with Lhasa, with Amdo, with China, changed over the centuries and also varied across different places and for peoples of Kham. There was no one Khampa perspective or experience. At times, individuals and groups actively worked to effect political change. They agitated to change relations with neighbouring districts or phayül. They agitated for respect and power in relations with others deemed senior to them in terms of either religious or secular authority. Boundaries between districts could be fiercely defended by one generation, and productively blurred by the next. One area could declare its autonomy from any overlord, accept being under another polity, or reject external claims of subordination and instead proffer its own geopolitical preferences. The latter is the case of the kingdom of 
Trokyap, which in the 1930s-1940s rejected new Chinese and Kham political affiliations in favour of maintaining an older political bond with the state of Sichuan (Jagou, this volume). In this same period, others organized to forge a pan-Kham polity with strategic links to existing Tibetan and Chinese powerholders (Peng 2002; Tsomu, this volume). These efforts were predated by those of Nyarong chief Gönpo Namgyel, about whom stories are still told in exile as well as in Kham. A figure who commanded both fear and respect, Gönpo Namgyel successfully conquered neighbouring districts and almost created a politically united Kham (Tsering 1985; Tsomu 2014). Writing histories of the present as well as of these often confusing pasts is also a matter of sources and accessibility.

Writing a history of Kham as a borderlands is to posit multiple centres elsewhere. These centres - be they Tibetan, Chinese, Indian, or otherwise - tell different stories of their margins. Some are familiar. The Tibetan state considered its borderlands as places to be both defended and civilized (Buffetrille, this volume). This language is echoed in Chinese colonial language found in contemporary education and development projects (Yang 2019; Yeh 2013) as well as in both European and Asian Christian missionary discourse in Tibet from the nineteenth century through to the present-day (Bray, 1991, this volume; Galipeau 2018; Gros 1996; Horlemann 2013; King and Klassen 2015; Zenz 2014). Sources for imperial histories of Kham exist in multiple languages and archives with varying degrees of access throughout the world. Sources for Kham-centred histories exist wherever Khampas are in the world. They are orally narrated, and written and published by Khampa individuals and communities inside Tibet and also in exile. From hagiographies and local histories to diaries and political testimonies and more (e.g., Galli, this volume; Hartley 2013; McGranahan 2017; J. Norbu 1986; Pemba 2017; Schwieger 2002; Thargyal 2007; Wangmo 2017), available sources are not always accessible inside Tibet. Many documents were destroyed during the $1950 \mathrm{~s}-1960 \mathrm{~s}$. Access to Tibetan archives is controlled by the Chinese government, as is permission for field research. Access to non-archival sources is limited by fear of imprisonment and abuse for the researcher, the individual speaking and writing, or both. This is a reality of research in a settler colonial region.

Scholarly studies of Kham fall under both Tibetan and Chinese Studies. As such, they may have different orientations, research questions, and understandings of Kham in relation to both Tibet and China rather than to only one of the two polities (Epstein 2002; Gros 2016a; Van Spengen and Jabb 2009). Over the centuries, Kham's relations to Tibet and China were not commensurate. Kham was not a part of China. It was a part of Tibet. This 
is a cultural, religious, and historical claim. Prior to the twentieth-century rise of the nation-state around the world, most peoples expressed and recognized identities in locally meaningful ways. People in Kham and throughout Tibet - all regions, not just the Chinese-designated Tibetan Autonomous Region - considered themselves connected to each other through religion and other cultural markers. They were nang pa (insiders), meaning practitioners of Tibetan Buddhism. This term exceeded politics, as did another one still in use today: tsampa eaters, people who eat roasted barley flour. As historian Tsering Shakya explains, 'If Buddhism provided the atom of Tibetanness, then tsampa provided the sub-particles of Tibetanness. The use of tsampa transcended dialect, sect, gender, and regionalism' (1993). Kham is home to tsampa eaters. Yet, as scholar Katia Buffetrille asks about Kham (this volume), what happens to the periphery when the centre is gone? For if all Tibetans were tsampa eaters, the heart of the Tibetan world in recent times was Lhasa and the Dalai Lama. One answer to her question is that in the periphery, people have created new practices to re-centre what has been lost.

\section{Bodies and Borders: A Conclusion}

Tibetan brothers and sisters unite. Independence for Tibet. Long life to the Dalai Lama. Dalai Lama return to Tibet. Each of these statements is one made by a Tibetan self-immolator, and repeated again and again by others who have self-immolated. As of July 2019, 164 Tibetans have self-immolated. One person self-immolated in China, three in Nepal, and seven people have self-immolated in India; the rest have done so inside Tibet. 164 individuals have chosen to end their lives by pouring petrol over their bodies, or into their bodies, and lighting a match. They have done so consistently as a form of protest against Chinese rule in Tibet. We know this because of the oral and written testimonies they prepared before the act, as well as by the things they say while they are burning. Of the 153 Tibetans who have self-immolated in Tibet since February 2009, the great majority have done so in 'the Sino-Tibetan borderlands'. Six self-immolations have taken place in Central Tibet. In contrast, 147 self-immolations or 96 per cent of the total inside Tibet have been in eastern and northeastern Tibet, in the historic regions of Amdo and Kham, and the current Chinese provinces of Gansu, Qinghai, and Sichuan. Among this group, the majority of the self-immolators are doing so at the borders of Kham and Amdo, near Kirti Monastery in Ngaba, Sichuan. In Ngaba alone there have been 39 self-immolations, or 25 
per cent of all self-immolations inside Tibet. At this Tibetan border, at a monastery where monks come from different areas of Tibet, a new practice of resistance and offering is centred.

Self-immolation is a twentieth-century form of political protest. It does not have a history in Tibet until now (Buffetrille and Robin et al. 2012; Dorjee 2019; McGranahan and Litzinger 2012; Woeser 2016). It is now a method - a drastic, bold method - used by Tibetans to speak in a new way to a situation they find untenable. To self-immolate is to kill oneself, but Tibetans widely consider these deaths to be sacrifices rather than suicides. New terminology had to be invented for the act of self-immolation. It is referred to as selfburning in fire (ranglü mesek), self-offering (ranglü chöbül), self-offering in fire (ranglü mechö), or self-giving and burning (ranglü jingsek). Acts of self-immolation are framed as religious offerings in the historic sense of fire offerings, of the flame that is always lit on family and monastic altars. They are pleas to the Tibetan community to remain united to defend country and religion, and use the same language to make these pleas that resistance fighters used in the 1950s. And, they are protests against the ongoing oppression and violence of Chinese colonialism.

Chinese governmental reactions are predictable. They blame selfimmolations on the Dalai Lama and the exile community. They claim the self-immolators are disturbed individuals. They deny they happened at all. They arrest self-immolators (those who did not die during their attempt) and sometimes also arrest their families. They create policies against self-immolation and launch anti-immolation programmes. According to a 2013 report in the Gansu Daily, the messages of anti-immolation re-education campaigns are that 'Tibet is an inalienable part of China' and that Tibetan citizens must 'uphold the leadership of the Communist Party of China and protect social stability and economic development' (TCHRD 2013). At the same time, other forms of protest continue. Detentions continue for all sorts of activism including linguistic activism, environmental activism, for displaying the Tibetan flag or possessing a photo of the Dalai Lama, for circulating certain songs or for writing them, or for offering condolences to the family of a self-immolator. However, amidst the imperial logics of surveillance and detention, life continues in Kham and throughout Tibet, including at its borders. Sometimes too, when the Chinese government permits, research also takes place.

Academic questions of empire and borderlands are lived by actual peoples. They are not abstractions. Borders and borderlands are thought to be places of possibility, where mixture is possible but where centres and claims to purity are also most strongly defended or illuminated at times (Stoler 1991, 2002). Historically, political practices and possibilities in Kham were not the same 
as in Central Tibet, just as political practices and possibilities in Tibet were not the same as those of China. Today, these Khampa and Tibetan practices and possibilities continue to pose challenges. They challenge specific ideas of nation and empire; they challenge specific structures of power and the people who implement them. In contemporary Tibet, these challenges unfold in a 'settler-colonial present', a 'deeply unequal scene of articulation' in which people must both live their lives and structure their resistance while also insisting on and acting from another possible understanding of the political (Simpson 2016). In other words, there is a constant tension between consent and refusal (Simpson 2013, 2016). In Tibet, current Chinese rule is imperial. Self-immolation is one response to imperial rule. It is a refusal to live life in a certain way, a commitment to Tibetan ideas of life plural, and a reminder to all of the impermanence of things including, eventually, empire.

\section{Glossary of Tibetan and Chinese terms}

$\begin{array}{ll}\text { chölkha } & \text { cholkha } \\ \text { chösi } & \text { chos srid } \\ \text { drukyül } & \text { 'drugyul } \\ \text { gyanak } & \text { gyanag } \\ \text { gyemi } & \text { gyemi } \\ \text { minzu } & \text { 民族 } \\ \text { phayül } & \text { phayul } \\ \text { ranglü mesek } & \text { rang lus me bsregs } \\ \text { ranglü chöbül } & \text { rang lus mchod'bul } \\ \text { ranglü mechö } & \text { rang lus me mchod } \\ \text { ranglüjingsek } & \text { rang lus sbying bsregs }\end{array}$

\section{Acknowledgments}

My sincere thanks to Stéphane Gros for the invitation to write this essay, and for his generous intellectual engagement with my argument as well as the ethnographic, historical, and political details. Thank you also to Christophe Besuchet for his precise, compassionate database of Tibetan self-immolators. My gratitude also to those mentors, colleagues, and students who have taught me so much over the years, especially the late Fernando Coronil, Nicholas Dirks, the late Lodi Gyari Rinpoche, Dawa Lokyitsang, Jamyang Norbu, Audra Simpson, Warren Smith, the late Elliot Sperling, 
Heather Stoddard, Ann Laura Stoler, Tashi Tsering, and individuals inside Tibet who cannot be named.

\section{References}

Anand, Dibyesh. 2019. 'Colonization with Chinese Characteristics: Politics of (In) Security in Xinjiang and Tibet'. Central Asian Survey 38(1): 129-147.

Annus, Epps. 2012. 'The Problem of Soviet Colonialism in the Baltics'. Journal of Baltic Studies 43(1): 21-45.

Atwill, David G. 2014. 'A Tibetan by Any Other Name: The Case of Muslim Tibetans and Ambiguous Ethno-religious Identities'. Cahiers d'Extrême-Asie 23: 33-61.

Beckwith, Christopher. 1993. The Tibetan Empire in Central Asia. Princeton, NJ: Princeton University Press.

Bhutia, Kalzang and Amy Holmes-Tagchungdarpa. 2019. 'A Spot of Enlightenment: Tea as Fuel for Connectivity in Tibetan Buddhist Cultures'. In Objects and Frontiers in Modern Asia:Between the Mekong and the Indus, edited by Lipokmar Dzüvichü and Manjeet Baruah, 157-173. London: Routledge.

Bray, John. 1991. 'Language, Tradition, and the Tibetan Bible'. The Tibet Journal 16(4): 28-58.

Buffetrille, Katia and Françoise Robin, eds. 2012. 'Tibet is Burning. Self-Immolation: Ritual or Political Protest'. Special issue of Revue d'Etudes Tibétaines 25.

Bum, Tsering. 2018. 'Translocating Ecological Migration Policy: A Conjunctural Analysis of Tibetan Pastoralist Resettlement in China'. Critical Asian Studies 58(4): 518-536.

Byler, Darren. 2018. 'Native Rhythms in the City: Embodied Refusal among Uyghur Male Migrants in Ürümchi'. Central Asian Survey 37(2): 191-207.

Carrico, Kevin. 2017. The Great Han: Race, Nationalism, and Tradition in China Today. Berkeley: University of California Press.

Carrico, Kevin. 2018. 'A Colony by Any Other Name: The Cultural Politics of Development in Tibet'. Critical Asian Studies 50(4): 639-647.

Chari, Sharad and Katherine Verdery. 2008. 'Thinking between the Posts: Postcolonialism, Postsocialism, and Ethnography After the Cold War'. Comparative Studies in Society and History 51(1): 6-34.

Chen, Kuan-Hsing. 2010. Asia as Method: Toward Deimperialization. Durham, NC: Duke University Press.

Cliff, Tom. 2016. Oil and Water: Being Han in Xinjiang. Chicago: University of Chicago Press.

Coleman, William M., IV. 2002. 'The Uprising at Batang: Khams and its Significance in Chinese and Tibetan History'. In Khams Pa Histories: Visions of People, Place and Authority, edited by Lawrence Epstein, 31-56. Leiden: Brill. 
Coulthard, Glen Sean. 2014. Red Skin White Masks: Rejecting the Colonial Politics of Recognition. Minneapolis, MN: University of Minnesota Press.

Crossley, Pamela. 1999. A Translucent Mirror: History and Identity in Qing Imperial Ideology. Berkeley: University of California Press.

Dorjee, Tenzin. 2019. 'Foreign Policy and Religion: Tibetan Independence Movement'. Oxford Research Encyclopedia, Politics, 26 June. uRL: https://oxfordre.com/politics/view/10.1093/acrefore/9780190228637.001.0001/acrefore-9780190228637-e-837 (Accessed 11 July 2019)

Fischer, Andrew. 2013. The Disempowered Development of Tibet in China:A Study in the Economics of Marginalization. Lanham, MD: Lexington Books.

Fiskesjö, Magnus. 2017. 'The Legacy of the Chinese Empires: Beyond "the West and the Rest"'. Education About Asia 22(1): 6-10.

Frank, Mark. [this volume]. 'Wheat Dreams: High-Altitude Farm Stations and Chinese Micro-Order in Kham, 1937-1949'. In Frontier Tibet: Patterns of Change in the Sino-Tibetan Borderlands, edited by Stéphane Gros. Amsterdam: Amsterdam University Press.

Galipeau, Brendan A. 2018. 'A Tibetan Catholic Christmas in China: Ethnic Identity and Encounters with Ritual and Revitalization'. Asian Ethnology 77(1\&2):353-370.

Gardner, Alexander. 2009. 'The Twenty-five Great Sites of Khams: A Narrative Map of an Imperiled Place'. In Studies in the History of Eastern Tibet, edited by Wim van Spengen and Lama Jabb, 97-132. Halle: International Institute for Tibetan and Buddhist Studies.

Gayley, Holly. 2016. 'T-Pop and the Lama: Buddhist "Rites Out of Place” in TibetanMonastery Produced VCDs'. In Religion and Modernity in the Himalaya, edited by Megan Adamson Sijapati and Jessica Vantine Birkenholtz, 63-82. London and New York: Routledge.

Germano, David. 1998. 'Re-membering the Dismembered Body of Tibet: Contemporary Tibetan Visionary Movements in the People's Republic of China'. In Buddhism in Contemporary Tibet: Religious Revival and Cultural Identity, edited by Melvyn C. Goldstein and Matthew T. Kapstein, 53-94. Berkeley: University of California Press.

Giersch, C. Patterson. [this volume]. 'The Origins of Disempowered Development in the Tibetan Borderlands'. In Frontier Tibet: Patterns of Change in the Sino-Tibetan Borderlands, edited by Stéphane Gros. Amsterdam: Amsterdam University Press.

Gladney, Dru C. 1998. 'Internal Colonialism and the Uyghur Nationality: Chinese Nationalism and Its Subaltern Subjects'. Cahiers d'Etudes sur la Méditerranée Orientale et le monde Turco-Iranien 25: 47-63.

Goldstein, Melvyn C., Dawei Sherap, and William R. Siebenschuh. 2004. A Tibetan Revolutionary: The Political Life and Times of Bapa Phüntso Wangye. Berkeley: University of California Press. 
Grant, Andrew. 2017. “Don't Discriminate Against Minority Nationalities”: Practicing Tibetan Ethnicity on Social Media'. Asian Ethnicity 18(3): 371-386.

Grant, Andrew. 2018. 'Hyperbuilding the Civilized City: Ethnicity and Marginalization in Eastern Tibet'. Critical Asian Studies 50(4): 537-555.

Gros, Stéphane. [this volume]. 'Frontier of Experience: An Introduction'. In Frontier Tibet: Patterns of Change in the Sino-Tibetan Borderlands, edited by Stéphane Gros. Amsterdam: Amsterdam University Press.

Gros, Stéphane. 2016a. 'Introduction to "Frontier Tibet: Trade and Boundaries of Authority in Kham"'. Cross-Currents: East Asian History and Culture Review 5(2): 209-238.

Gros, Stéphane. 2016b. 'Tricks of the Trade: Debt and Imposed Sovereignty in Southernmost Kham in the Nineteenth to Twentieth Centuries'. Cross-Currents: East Asian History and Culture Review 5(2): 378-407.

Gros, Stéphane. 1996. 'Terres de Confins, Terres de Colonisation: Essai sur les Marches Sino-Tibétaines du Yunnan à Travers l'Implantation de la Mission du Tibet'. Péninsule 33(2): 147-210.

Guyot-Réchard, Bérénice. 2017. Shadow States: India, China and the Himalayas, 1910-1962. Cambridge: Cambridge University Press.

Gyal, Huatse. 2019. "I am concerned with the future of my children": The Project Economy and Shifting Views of Education in a Tibetan Pastoral Community'. Critical Asian Studies 51(1): 12-30.

Hansen, Peter. 2003. 'Why Is There No Subaltern Studies for Tibet?' The Tibet Journal 28(4): 7-22.

Harrell, Stevan, ed. 1995. Cultural Encounters on China's Ethnic Frontiers. Seattle, WA: University of Washington Press.

Hartley, Lauran. 2013. 'The Kingdom of Dergé'. In The Tibetan History Reader, edited by Gray Tuttle and Kurtis R. Schaeffer, 525-548. New York: Columbia University Press.

Hechter, Michael. 1975. Internal Colonialism: The Celtic Fringe in British National Development, 1536-1966. London: Routledge and Kegan Paul.

Hillman, Ben and Gray Tuttle, eds. 2016. Ethnic Conflict and Protest in Tibet and Xinjiang: Unrest in China's West. New York: Columbia University Press.

Hillman, Ben and Lee-Anne Henfry. 20o6. 'Macho Minority: Masculinity and Ethnicity on the Edge of Tibet'. Modern China 32(2): 251-272.

Hillman, Ben. 2003. 'Paradise Under Construction: Minorities, Myths, and Modernity in Northwestern Yunnan'. Asian Ethnicity 4(2): 175-188.

Hirano, Katsuya, Lorenzo Veracini, and Toulouse-Antonin Roy. 2018. 'Vanishing Natives and Taiwan's Settler-Colonial Unconsciousness'. Critical Asian Studies 50(2):196-218. Horlemann, Bianca. 2013. 'Christian Missionaries in Qinghai and Gansu: Sources for Tibetan and Mongol Studies'. Monumenta Serica 18: 294-313. 
Hostetler, Laura. 2005. Qing Colonial Enterprise: Ethnography and Cartography in Early Modern China. Chicago: University of Chicago Press.

Jabb, Lama. 2011. 'Singing the Nation: Modern Tibetan Music and National Identity'. Revue d'Etudes Tibétaines 21: 1-29.

Jabb, Lama. 2015. Oral and Literary Continuities in Modern Tibetan Literature: The Inescapable Nation. Lanham, MD: Lexington Books.

Jabb, Lama. 2019. 'The Mingled Melody: Remembering the Tibetan March $10^{\text {th }}$ Uprising'. Revue d'Etudes Tibétaines 48: 50-98.

Jagou, Fabienne. 2009. 'The Thirteenth Dalai Lama's Visit to Beijing in 1908: In Search of a New Kind of Chaplain-Donor Relationship'. In Buddhism Between Tibet and China, edited by Matthew Kapstein, 349-378. Boston: Wisdom Publications.

Jagou, Fabienne. 2009. 'Liu Manqing: A Sino-Tibetan Adventurer and the Origin of a New Sino-Tibetan Dialogue in the 1930s'. Revue d'Etudes Tibétaines 17: 5-20. Jagou, Fabienne. 2013. 'In Search of the Tibetan Translators within the Manchu Empire: An Attempt to Go from the Global to the Local'. In Tibetans who Escaped the Historian's Net: Studies in the Social History of Tibetan Societies, edited by Charles Ramble, Peter Schwieger, and Alice Travers, 41-52. Kathmandu: Vajra Books.

Jinba, Tenzin. 2013. In the Land of the Eastern Queendom: The Politics of Gender and Ethnicity on the Sino-Tibetan Border. Seattle: University of Washington Press.

Keogh, Tricia. 2015. 'I Am Tibetan? An Exploration of Online Identity Constructions Among Tibetans in China'. Asian Ethnicity 16: 314-333.

King, Matthew W. and Pamela E. Klassen. 2015. 'Suppressing the Mad Elephant: Missionaries, Lamas, and the Mediation of Sacred Historiographies in the Tibetan Borderlands'. History and Anthropology 26(5): 529-552.

Lawson, Joseph D. 2013. 'Warlord Colonialism: State Fragmentation and Chinese Rule in Kham, 1911-1949'. The Journal of Asian Studies 72(2): 299-318.

Leibold, James. 2007. Reconfiguring Chinese Nationalism: How the Qing Frontier and its Indigenes Became Chinese. New York: Palgrave MacMillan.

Lin, Hsiao-ting. 2006. Tibet and Nationalist China's Frontier: Intrigues and Ethnopolitics, 1928-1949. Vancouver: University of British Columbia Press.

Lokyitsang, Dawa. 2017. 'Are Tibetans Indigenous?' Lhakar Diaries, 27 December. URL: https://hakardiaries.com/2017/12/27/are-tibetans-indigenous/ (Accessed 7 July 2019)

Makley, Charlene. 2007. The Violence of Liberation: Gender and Tibetan Buddhist Revival in Post-Mao China. Berkeley: University of California Press.

Makley, Charlene. 2009. 'Anthropology and the Anaconda: China Post-2008'. Anthropology News, April.

Makley, Charlene. 2018. The Battle for Fortune: State-Led Development, Personhood, and Power Among Tibetans in China. Ithaca, NY: Cornell University Press. 
McGranahan, Carole and Ralph Litzinger, eds. 2012. Self-Immolation in Tibet. Special online issue of Cultural Anthropology, 8 April 2012. https://culanth. org/fieldsights/series/self-immolation-as-protest-in-tibet (Accessed 7 July 2019) McGranahan, Carole. 2003a. 'From Simla to Rongbatsa: The British and the "Modern" Boundaries of Tibet'. The Tibet Journal 28(4): 39-6o.

McGranahan, Carole. 2003b. 'Empire and the Status of Tibet: British, Chinese, and Tibetan Negotiations, 1913-1934'. In The History of Tibet, Volume 3: The Tibetan Encounter with Modernity, edited by Alex McKay, 267-295. Richmond, Surrey: Curzon Press.

McGranahan, Carole. 2005. 'Truth, Fear, and Lies: Exile Politics and Arrested Histories of the Tibetan Resistance'. Cultural Anthropology 20(4): 570-6oo.

McGranahan, Carole. 2007. 'Empire Out-of-Bounds: Tibet in the Era of Decolonization'. In Imperial Formations, edited by Ann Laura Stoler, Carole McGranahan, and Peter C. Perdue, 173-209. Santa Fe, NM: SAR Press.

McGranahan, Carole. 2017. 'Imperial but Not Colonial: British India, Archival Truths, and the Case of the "Naughty" Tibetans'. Comparative Studies in Society and History 59(1): 68-95.

McGranahan, Carole. 2018. 'Love and Empire: The CIA, Tibet, and Covert Humanitarianism'. In Ethnographies of U.S. Empire, edited by Carole McGranahan and John F. Collins, 333-349. Durham, NC: Duke University Press.

Milward, James A. 2011. 'Being Blacklisted by China and What Can Be Learned from It'. The China Beat Blog Archive 2008-2012. 683. https://digitalcommons. unl.edu/cgi/viewcontent.cgi?article $=1683 \&$ context $=$ chinabeatarchive (Accessed 6 June 2019)

Morcom, Anna. 2015. 'Landscape, Urbanization, and Capitalist Modernity: Exploring the "Great Transformation" of Tibet through Its Songs'. Yearbook for Traditional Music 47:161-189.

Norbu, Dawa. 1985. 'An Analysis of Sino-Tibetan Relationships, 1245-1911: Imperial Power, Non-Coercive Regime, and Military Dependency'. In Soundings in Tibetan Civilization, edited by Barbara Nimri Aziz and Matthew Kapstein, 176-195. Delhi: Manohar.

Norbu, Dawa. 2001. China's Tibet Policy. Richmond: Curzon Press.

Norbu, Jamyang. 1986. Warriors of Tibet: The Story of Aten, and the Khampa's Fight for the Freedom of their Country. London: Wisdom Publications.

Oakes, Timothy S. 1995. 'Tourism in Guizhou: The Legacy of Internal Colonialism'. In Tourism in China: Geographic, Political and Economic Perspectives, edited by Alan A. Lew and Lawrence Yu, 203-222. Boulder, CO: Westview.

Pemba, Tsewang Yishey. 2017. White Crane, Lend Me Your Wings. Delhi: Niyogi Books. Peng, Wenbin. 2002. 'Frontier Process, Provincial Politics and Movements for Khampa Autonomy During the Republican Period'. In Khams Pa Histories: 
Visions of People, Place and Authority, edited by Lawrence Epstein, 57-84. Leiden: Brill.

Perdue, Peter C. 2007. 'Erasing the Empire, Re-Racing the Nation: Racialism and Culturalism in Imperial China'. In Imperial Formations, edited by Ann Laura Stoler, Carole McGranahan, and Peter C. Perdue, 141-169. Santa Fe, NM: SAR Press. Perdue, Peter C. 2009. China Marches West: The Qing Conquest of Central Eurasia. Cambridge: Harvard University Press.

Relyea, Scott. [this volume]. 'Settling Authority: Sichuanese Farmers in Early $20^{\text {th }}$ Century Eastern Tibet'. In Frontier Tibet:Patterns of Change in the Sino-Tibetan Borderlands, edited by Stéphane Gros. Amsterdam: Amsterdam University Press. Relyea, Scott. 2015. 'Yokes of Gold and Threads of Silk: Sino-Tibetan Competition for Authority in Early Twentieth Century Kham'. Modern Asian Studies 49(4): 963-10o9.

Roche, Gerald. 2016. 'The Tibetanization of Henan's Mongols: Ethnicity and Assimilation on the Sino-Tibetan Frontier'. Asian Ethnicity 17(1): 128-149.

Schwieger, Peter. 2002. 'History as Oral Tradition: The Construction of Collective Identity in Brag G.yab (Khams)'. In Khams Pa Histories: Visions of People, Place and Authority, edited by Lawrence Epstein, 127-154. Leiden: Brill.

Schwieger, Peter. 2015. The Dalai Lama and the Emperor of China: A Political History of the Tibetan Institution of Reincarnation. New York: Columbia University Press. Shakya, Tsering. 1993. 'Whither the Tsampa Eaters?' Himal South Asian: A Review Magazine of Politics and Culture. September 1993.

Shakya, Tsering. 1994. 'Politicization and the Tibetan Language'. In Resistance and Reform in Tibet, edited by Robert Barnett and Shirin Akiner, 157-165. London: C. Hurst \& Co.

Shih, Shu-mei, Chien-hsin Tsai, and Brian Bernards, eds. 2013. Sinophone Studies: A Critical Reader. New York: Columbia University Press.

Shih, Shu-mei. 2011. 'The Concept of the Sinophone'. PMLA 126(3): 709-718.

Shih, Shu-mei. 2012. 'Foreword: The Sinophone as History and the Sinophone as Theory'. Journal of Chinese Cinemas 6(2): 5-7.

Simpson, Audra. 2014. Mohawk Interruptus: Political Life Across the Borders of Settler States. Durham, NC: Duke University Press.

Simpson, Audra. 2016. 'Consent's Revenge'. Cultural Anthropology 31(3): 326-333. Simpson, Audra. 2018. 'Sovereignty, Sympathy, and Indigeneity'. In Ethnographies of U.S. Empire, edited by Carole McGranahan and John F. Collins, 72-89. Durham, NC: Duke University Press.

Smith, Warren W., Jr. 1996. Tibetan Nation: A History of Tibetan Nationalism and Sino-Tibetan Relations. Boulder: Westview Press.

Smith, Warren W., Jr. 2008. China's Tibet?: Autonomy or Assimilation. Lanham, MD: Rowman and Littlefield Publishers. 
Smyer Yü, Dan. 2013. 'Subaltern Placiality in Modern Tibet: Critical Discourses in the Work of Shogdong'. China Information 27(2):155-172.

Sperling, Elliot. 1976. 'The Chinese Venture in K'am, 1904-1911, and the Role of Chao Erh-feng'. The Tibet Journal 1(2): 10-36.

Sperling, Elliot. 1998. 'Awe and Submission: A Tibetan Aristocrat at the Court of Qianlong'. The International History Review 2o(2): 325-335.

Stoddard, Heather. 1985. Le Mendiant d'Amdo. Paris: Societe d'Ethnographie Paris.

Stoddard, Heather. 1986. 'Tibet from Buddhism to Communism'. Government and Opposition 21(1): $76-95$.

Stoler, Ann Laura and Carole McGranahan. 2007. 'Introduction: Refiguring Imperial Terrain'. In Imperial Formations, edited by Ann Laura Stoler, Carole McGranahan, and Peter C. Perdue, 3-42. Santa Fe, NM: SAR Press.

Stoler, Ann Laura, Carole McGranahan, and Peter C. Perdue, eds. 2007. Imperial Formations. Santa Fe, NM: SAR Press.

Stoler, Ann Laura. 1991. 'Carnal Knowledge and Imperial Power: Gender, Race, and Morality in Colonial Asia'. In Gender at the Crossroads of Knowledge: Feminist Anthropology in the Postmodern Era, edited by Micaela di Leonardo, 51-101. Berkeley: University of California Press.

Stoler, Ann Laura. 2002. Carnal Knowledge and Imperial Power: Race and the Intimate in Colonial Rule. Berkeley: University of California Press.

Stoler, Ann Laura. 2006. 'On Degrees of Imperial Sovereignty'. Public Culture 18(1): $125^{-146 .}$

Sugimoto, Tomonori. 2018. 'Settler Colonial Incorporation and Inheritance: Historical Sciences, Indigeneity, and Settler Narratives in Post-WWII Taiwan'. Settler Colonial Studies 8(3): 283-297.

Sulek, Emilia Roza. 2019. Trading Caterpillar Fungus in Tibet: When Economic Boom Hits Rural Area. Amsterdam: Amsterdam University Press.

Takla, T.N. 1969. 'Notes on Some Early Tibetan Communists'. Tibetan Review 2(17): 7-10. Thargyal, Rinzin. 2007. Nomads of Eastern Tibet: Social Organization and Economy of a Pastoral Estate in the Kingdom of Derge. Leiden: Brill.

Thurston, Timothy. 2017. 'On Artistic and Cultural Generations in Northeastern Tibet'. Asian Ethnicity 19(2): 143-162.

Tibetan Centre for Human Rights and Democracy (TCHRD). 2013. 'China Uses Religious Propaganda to Counter Tibetan Self-Immolations'. Tibetan Centre for Human Rights and Democracy website, 20 March 2013.URL: http://tchrd. org/china-uses-religious-propaganda-to-counter-tibetan-self-immolations/ (Accessed 22 June 2019)

Tsering, Tashi. 1985. 'Nag-ron mGon-po rNam-rgyal: A $19^{\text {th }}$ Century Khams-pa Warrior'. In Soundings in Tibetan Civilization, edited by Barbara Nimri Aziz and Matthew Kapstein, 196-214. Delhi: Manohar. 
Tsomu, Yudru. 2013. 'Taming the Khampas: The Republican Construction of Eastern Tibet'. Modern China 39(3): 319-344.

Tsomu, Yudru. 2014. The Rise of Gönpo Namgyel in Kham: The Blind Warrior in Nyarong. Lanham, MD: Lexington Books.

Tuttle, Gray. 2005. Tibetan Buddhists in the Making of Modern China. New York: Columbia University Press.

Van Spengen, Wim and Lama Jabb, eds. 2009. Studies in the History of Eastern Tibet. Halle: International Institute for Tibetan and Buddhist Studies.

Veracini, Lorenzo. 2013. “Settler Colonialism”: Career of a Concept'. The Journal of Imperial and Commonwealth History 41(2): 313-333.

Verdery, Katherine. 2002. 'Whither Postsocialism?'. In Postsocialism: Ideals, Ideologies, and Practices in Eurasia, edited by Chris Hann, 15-28. London: Routledge.

Wang, Xiuyu. 2011. China's Last Imperial Frontier: Late Qing Expansion in Sichuan's Tibetan Borderlands. Lanham, MD: Lexington Books.

Wangmo, Sonam. 2017. 'A Study of Oral and Written Narratives in Lhagang, Eastern Tibet'. Revue d'Etudes Tibétaines 45: 69-88.

Wangyal, Baba Phuntsok. 2007. Witness to Tibet's History. Translated by Tenzin Losel, Jane Perkins, Bhuchung D. Sonam, and Tenzin Tsundue. New Delhi: Paljor Publications.

Warner, Cameron. 2013. 'Hope and Sorrow: Uncivil Religion, Tibetan Music Videos, and YouTube'. Ethnos 78(4): 543-568.

Woeser, Tsering. 2016. Tibet on Fire: Self-Immolations Against Chinese Rule. Kevin Carrico, tr. London: Verso Books.

Wolfe, Patrick. 1999. Settler Colonialism and the Transformation of Anthropology: The Politics and Poetics of an Ethnographic Event. London and New York: Cassell. $\mathrm{Xu}$, Honggang, Lirong Kou, and Geoffrey Wall. 2018. 'Retired Tibetan Migrants' Adaptation Experiences in Chengdu, China'. Asian Ethnicity 19(3): 319-343.

Yang, Miaoyan. 2017. Learning to Be Tibetan: The Construction of Ethnic Identity at Minzu University of China. Lanham, MD: Lexington Books.

Yang, Miaoyan. 2019. 'Moralities and Contradictories in the Educational Aid for Tibet: Contesting the Multi-Layered Saviour Complex'. Journal of Multilingual and Multicultural Development. Dor: https://doi.org/10.108o/01434632.2019.162 3225 (Accessed 7 July 2019)

Yeh, Emily T. 2007. 'Tibetan Indigeneity: Translations, Resemblances, and Uptake'. In Indigenous Experience Today, edited by M. de la Cadena and O. Sarn, 69-97. Oxford: Berg.

Yeh, Emily T. 2009. 'Tibet and the Problem of Radical Reductionism'. Antipode 41(5): 983-1010.

Yeh, Emily T. 2013. Taming Tibet: Landscape Transformation and the Gift of Chinese Development. Ithaca, NY: Cornell University Press. 
Yeh, Emily T. and Charlene Makley. 2019. 'Urbanization, Education, and the Politics of Space on the Tibetan Plateau'. Critical Asian Studies 51(1): 1-11.

Yeh, Emily T. and Elizabeth Wharton. 2016. 'Going West and Going Out: Discourses, Migrants, and Models in Chinese Development'. Eurasian Geography and Economics 57(3): 286-315.

Yongdan, Lobsang. 2019. 'The Invention of a Tibetan Lama General: A Biographical Account of Bla ma dkar po (1835-1895)'. Revue d'Etudes Tibétaines 49:67-92.

Zenz, Adrian. 2014. 'Tibetanness' Under Threat?: Neo-Integrationism, Minority Education, and Career Strategies in Qinghai, P.R. China. Leiden: Brill.

Zhaxi, Duojie. 2019. 'Housing Subsidy Projects in Amdo: Modernity, Governmentality, and Income Inequality in Tibetan Areas of China'. Critical Asian Studies 51(1): 31-50.

\section{About the Author}

Carole McGranahan is Professor of Anthropology at the University of Colorado. She is the author of Arrested Histories: Tibet, the CIA, and Memories of a Forgotten War (Duke University Press, 2010), and co-editor of the volumes Imperial Formations (with Ann Laura Stoler and Peter C. Purdue, SAR Press, 2007), and Ethnographies of U.S. Empire (with John F. Collins, Duke University Press, 2018). Her research focuses on twentieth and twenty-first century Tibet and the Himalayas, and on issues of history, memory, empire, and gender, including ongoing projects on social death and impermanence, and on political asylum and refugee citizenship in the Tibetan diaspora. 


\section{Index}

\section{Page numbers in italic refer to figures, maps, and tables. Italicized page numbers followed by an ' $\mathrm{f}$ ' refer to figures. Thus $67 \mathrm{f} 1.1$ refers to figure $1.1 \mathrm{on}$ page 67. Italicized page numbers followed by 'map' refer to maps; italicized page numbers followed by ' $\mathrm{t}$ ' refer to tables.}

Agnew, John 69

Amdo 18 map1

repression of rebellion in $\left(195^{8}\right) \quad 30,31,94 \mathrm{n} 27$ resistance army organized in 94 ; see also Qinghai; Xining

— cultural sphere

revival of religion and traditional practices in $94-98$

Kalacakra and Lamrim Chenmo teachings by the Fourteenth Dalai Lama in 325 writers and filmmakers of 101-102

Amdowa identity 128 and Lhasa and Central Tibet $\quad 87,90-93$ and the threat of Sinicization $\quad 98-99,104-105$ and vegetarianism $97,292-293$

Anderson, Benedict $\quad 55,221$

Andrutsang (A 'brug tshang) family and Khampa trading communities in Central Tibet 319 see also Andrutsang Gönpo Tashi

Andrutsang, Gönpo Tashi (also Gompo Tashi Andrugtsang)

on C.C.P. implemented reforms in Gyelthang $430 n 38$ and the 'Four Rivers, Six Ranges' (Chushi Gangdruk) resistance army 94,324 , 325n19, 328

and resistance to the Chinese control over the Tibetan plateau $\quad 325-326$

Aris, Michael 86,328

Assam

British authority in 202-203

British impact on the musk trade in 157 murder of British Capt. Noel

Williamson 203

and Zhao Erfeng's settlements in

Dzayül 199

Atup chief Wangga (Dbang dga'a) 385

Atup Lakartsang family (A thub l'a dkar tshang), and Jagö Topden $\quad 378 n_{34}$

Atup Ripuk (A thub ri phug), and Jagö Topden's camp at $38 \ln _{3} 8$

Ba Chöde monastery (T. 'Ba chos sde gling; Ch. Dingning si 丁宁寺)

and the Khampa Rebellions (1955) 431-432 and persecution of M.E.P. missionar-

ies 170,173

as a regional landowner $\quad 164,192$
Bailey, Lt.-Col. F. M. 202-203

Bapa Püntsok Wangyel ('Ba' pa Phun tshogs

Dbang rgyal or Pünwang)

and the Eastern Tibetan People's

Autonomous Alliance $30,310,417$

and the idea of pan-Tibetan

nationality 91

and Jagö Topden $\quad 384-385$

Barom Kagyü ('Ba' rom bka' brgyud) school fragmentation of 463-464 monasteries see Kumbum and Nangchen $\quad 461-462,472$

Barth, Fredrik $\quad 51$

Bathang (T. 'Ba'thang; Ch. Batang 巴塘) depas (governors) from the Tibetan government appointment by the Fifth Dalai Lama (1648) 163

Lhasa's sending of (1703) 22

and the persecution of M.E.P.'s 173

and the Qing's collapse (1912) 365n 5

and Fengquan as Assistant Amban to

Tibet $25-26,192,192$ nn10-11

Han settlements in 191-192

and Kelzang Tsering

and the emergent elite in

Bathang 364,364nn2-3

launching of 'Khampa rule of Kham' in $338-339 n 1,415-416$

location of $18 \mathrm{map} 1,43$ map1.1

in the early twentieth century $\quad 171 \mathrm{f} 4.3$

at the time of Jagö Topden 369 map11.1

and the long-distance tea trade from

Dartsedo to Lhasa 155

M.E.P. outposts in 163-165, 164 map4.1

as one of the four big indigenous chieftains (sida tusi) $5^{2}$

Zhao Erfeng's campaign against 25 see also Ba Chöde monastery; Bapa Püntsok Wangyel

Baud, Michel, and Willem van Schendel $\quad$ 48-49

beyül (T. sbas yül, valleys hidden by Padmasambhava) 97-98, 311

biopolitics

and Chinese mining operations 122,127 , $131,237,263,271-272$

and state control 147,492 and the marginalization of pastoralism $148-149,285^{-2} 86$ 
and state imposition of geometrical control on Yachen Gar 507-512, 509f14.5

Bishop, Peter 67

Booz, Patrick 169, 263, 266, 271

borderlands

five-stage life-cycle of $\quad 48-49$

and liminality $10-11,59,127$

parallel and often overlapping authorities

$$
\text { in } 153-154,163,308-309
$$

and topographical boundaries $\quad 5^{0-51}$

and Zomia $\quad 53-54,70$

see also centre and periphery relations; frontiers; regions

— as a term

and elements of change $87,105,314$

and Kham-as-a-process $53-54,68$, 492-493, 500

and the term "Sino-Tibetan border-

lands" 44, 116-117, 525

'Tibetan-Yi corridor' (Ch. Zang-Yi zoulang) coined by Fei Xiaotong 62 and vernacular Tibetan

terminology $87-89$

Borges, Jorge Luis $\quad 133^{-134}, 135$

Buddhism

and China's transition to a nation-state $\quad 56 \mathrm{n} 11$

circumambulation of Mount Kawakarpo $\quad 98,99 f 2.2$

and Dorje Shugden see Dorje Shugden and identity

and the image of Nangchen as region of meditators (retsang gomdé) $\quad 472^{-}$ $474,477-478$

and Indic cosmological constructs and ideas of an ideal sovereign 459, $463,469-471$

and Milarepa 95

incorporation of territorial gods $(y \ddot{u} l$ lha) 98

rituals - kurim (sku rim)

ceremony $475-477$

schools of Tibetan Buddhism see Geluk;

Karma Kagyü; Nyingma; Sakya

see also monastic communities;

Padmasambhava; religion - revival of

religion and traditional practices

Bulag, Uradyn $\quad 425-426$

Bumla (Ningjing shan 寧静山) stele marking

the border between China and Tibet

erection of (1727) 20,23, 48, 181, 182map5.1

and the McMahon Line 205

bureaucratization (gaitu guiliu, 'substituting chieftains with state-appointed civilian officials')

implementation in Dergé $\quad 185,367,373$

implementation in Gyelrong 20

implementation issues in Trokyap 348 ,

350-352
Lu Chuanlin's implementation of 146 , 185-187

Qing policy established (1792) 23, 186-187

and schools in the Sichuan

borderlands $364 \mathrm{n} 2$

Zhao Erfeng's implementation of 199 , $35^{0-}-35^{2}$

Cartier, Carolyn $\quad 65$

cartography

and knowledge

Borges's parable about the perfectly congruent map 133-135

and J.Z. Smith on maps and territory $118,128-135$

place identification authority in Gyelthang 123, 125, 128-134

and the maze of Yachen 497

narrative maps $\quad 56,288-289$

and the provincialization of Nangchen $\quad 468$

Qiu Zhijie's 'Map of the World' series 65-

$66,67 \mathrm{f} 1.2$

centre and periphery relations

and the continuum of boundary dynam-

ics $\quad 60-61,67$ f1.1

and forms of illegibility and partial

belonging $283,287,294,296-299$

Kham as both centre and frontier 56 ,

104-105, 517-520

and the agency of local inhabitants in processes of change 60

and the need to re-centre $94,520,529$

and the maintenance of state control in the

borderland $143-147,284,315-316,438$

and Nangchen's provincialization 468

and refusing to be knowable to the

state $499,505,5^{26-527}$

and terminology used to define the

borderlands $\quad 51,86-89$

and the topological reconfiguration of the

Sino/Tibetan binary $44,54,69-72$,

$71 \mathrm{f} 1.3,132,314$

and $\ddot{U}$ (Central Tibet) in relation to the

borderlands $86-87,89-93$

see also frontiers; Kham - territorialization

Chakla (T. Lcags la) kingdom 60

capital of see Dartsedo

and the eighteen kingdoms of

Gyelmorong 339n2

as one of the four big indigenous chieftains

(sida tusi) $5^{2}$

Chamdo (T. Chab mdo; Ch. 昌都)

and Central Tibet's military intervention in

Kham (1918) 28, 375

and the Lhasa government $\quad 28-29$

localization of $18 \mathrm{map} 1,43 \mathrm{mi} 1$

at the time of Jagö Topden $\quad 369$ map11.1

M.E.P. missionaries in $\quad 152$

and tourism $\quad 66$ map1.4, 103 
Chen, Zhihong $\quad$ 62-63n17, $63 n 18$

Chichu (Lci chu), and the kingdom of

Nangchen $471,472 \mathrm{f}_{13} .2$

Chinese Communist Party (C.C.P.) control in Gyelthang $\quad 411-438$ passim and the disempowerment of Tibetan locals $\quad 257-260$ and political persuasion work (zhengzhi shuifu gongzuo) $\quad 310,412,427,436-438$ 'speak bitterness' (suku) meetings 433, 437 United Front policy of incorporating local ethnic leaders $\quad 420-427,437-438$ see also Cultural Revolution; Eastern Tibetan People's Autonomous Alliance; Long March; Mao Zedong

Choktsé (T. Cog Tse), and the eighteen kingdoms of Gyelmorong 339n2

Chophel, Gedun $\quad 45 \mathrm{n} 2,88$

Chuchen (southeast of Dzamtang ['Dzam thang]), and the eighteen kingdoms of Gyelmorong 339n2

Chushi Gangdruk (Chu bzhi gangs drug, 'Four Rivers, Six Ranges) resistance army and Gönpo Tashi Andrutsang 94, 324, 325n19, 328

colonialism

and field research $\quad 62-63 n 17$

Qing expansion into Kham 142-149 agricultural colonization effort launched by Fengquan 192, 192nn10-11 and Euro-American models of colonialism $\quad 262$ settler colonialism defined $\quad 518$

- Chinese colonialism in Tibetan areas and imperial expansion $\quad$ 517-519 Lu Chuanlin's proposals for the borderlands $146,185^{-186,188-189}$ Republican-era agricultural colonization in Kham 221

self-immolation as a response 33,100 , 10onn37-39, 490-491, 529-531 see also bureaucratization

Coulthard, Glen Sean $\quad 518$

Cultural Revolution (1966-1976) 32 and the destruction of religious and cultural heritage 94-95 and Sumtseling monastery 123

Dadu River (T. Ngülchu [Rngul chu]; Ch. Daduhe 大渡河) $46 \mathrm{n} 3$

Dajianlu see Dartsedo

Dalai Lamas

Altan Khan's conferral of the title on Sönam Gyatso (1578) 21

decree warning about Christian missionaries 162

possession of photos of $53^{\circ}$ and the power of monk regents supported by Manchu emperors 24 rule of Central Tibet $\quad 19-20,337-338$

— Fifth Dalai Lama, Ngawan Lobzang Gyatso

beginning of the rule of 21

unification of Tibet 19

the Nangchen king's rule supported by $465-466$

two depas of Bathang appointed by 163

control over Gyelthang 21-22, 412-413

construction of Ganden Sumtseling $\quad 22$ suppression of the Karmapa and

Nyingmapa 21-22, 412-413

his death and its concealment by Regent

Sanggyé Gyatso 22

- Thirteenth Dalai Lama, Tupten Gyatso birth of $(1876) \quad 26$

assumption of his role as head of state (1895) 26

flight to Mongolia (1904) 26

imperial audience in Beijing (1908) 27

return to Tibet (1909) 27,374

Tibet's independence proclaimed by 28 , 524

Tsewang Düdül chosen to accede to the Dergé throne by $376 \mathrm{n} 28$

death of (1933) 29, 344

and the Jagö family $\quad 374-375$

and Ngawang Jampel Rinchen $\quad 372-375$, $375 \mathrm{n} 27$

— Fourteenth Dalai Lama, Tenzin Gyatso

his discovery by a search party (1937) 30

enthronement of (1940) 30

assumption of his role as head of state (1950) 30

travels with the Panchen Lama to meet Mao Zedong (1955) 31

travels with the Panchen Lama to India (1956) 31

golden throne offering to (1957) 94, 325-326

Kalacakra and Lamrim Chenmo teachings bestowed on traders in Kham and Amdo 325

flight to India (1959) 19, 32, 328

dismissal of Dorje Shugden from the Geluk pantheon 123

protest of the incorporation of Kham into the P.R.C. 518

Dartsedo (T. Dar rtse mdo; Ch. Dajianlu 打箭炉 now Kangding 康定)

administrative status of a sub-prefecture accorded by the Qing (1729) 20, 23

as the capital of Xikang 7

French Catholic mission in $\quad 25,171-172,234$ as the gateway to Tibet from China proper 46

localization of $18 \mathrm{map} 1$ at the time of Jagö Topden $\quad 369$ mapis.1

Tibetan Inn $\quad 167 \mathrm{f}_{4.2}$

and tourism 103-104 
Dartsedo (T. Dar rtse mdo; Ch. Dajianlu 打箭炉 now Kangding 康定) - trade and commerce and Han Chinese merchants 263-264, 271-272

long-distance tea trade via Lithang and Bathang to Lhasa $155,156 \mathrm{f}_{4.1}$ and shifting political alignments 308 Sino-Tibetan trade in the late 1940s 322 Yunnanese merchants involved in longdistance trade $\quad 264,267,270-271$

Das, Veena, and Deborah Poole 286n6, 287, 297,300

Dechen (T. Bde chen, Ch. Adunzi 阿墩子/Deqin 德钦) $18 \mathrm{map} 1$

and Jol 121-122n11

and Kham exports by Hengshenggong $\quad 267$ location outside of Gyelthang $18 \mathrm{map} 1$, 118-119

Qing garrisons stationed in 413 revival of local culture by the Kawakarpo Institute 103

Tibetan Communist activities in $\quad 417-418$ and Wangchuk Tempa's political and military clout $415-416,420$

Denkhok ('Dan khog), and Tsewang Düdül $377^{\mathrm{n}} 31$

Dergé (T. Sde dge; Ch. Dege 德格) and Central Tibet's military intervention in Kham (1918) $367,373-376$

Gönpo Namgyel's occupation of 371

implementation of gaitu guiliu in $\quad 185$, 367,373

and the Lhasa government after the failure of the Simla Convention $\quad 28-29$

localization of $18 \mathrm{map} 1,43$ map1.1 at the time of Jagö Topden 369 map11.1 as one of the four big indigenous chieftains (sidatusi) $5^{2}$ pastoralists of the estate of Zilphukhog 296 and the rise of Jagö Topden 363-394 passim and Sino-Tibetan trade in the late 1940s $\quad 322$

- Royal family decline of its power and authority $\quad 367$ and feuding between two brothers $\quad 185$ as hostages of Gönpo Namgyel 371n19, $374 n 25$

Jagö faction's power and authority compared with 388

and the Lhundrupteng monastery (Dergé Gönchen) $\quad 370$

Tenpa Tsering (Bstan pa Tshe ring) 23, $45^{8}$

Tsewang Düdül (Tshe dbang Bdud 'dul) death of 385

enthroning of $376,376 \mathrm{n} 28$

and Jagö Topden $\quad 377,377 n_{31}, 386 \mathrm{n} 48$ marriage to Jamyang Pelmo (daughter of the Nangchen king) 377n31

Urgyenkyap (O rgyan skyabs, aka Wuga [O dga']) $\quad 385$
Desgodins, Auguste $\quad$ 155, 165-166, 168-169

Döndrupling (T. Don grub gling, Ch. Dongzhulin si 东竹林寺)

construction in Gyelthang (1667) 21

and Renou 159

and Shugden practice 124

Dongwang (Termarong [Gter ma rong])

Gyelthang distinguished from $117-118 \mathrm{n}_{5}$, 118-119, 119-120n8, 120map3.1

and the Shugden issue 123-124

and Wangchuk Tembu 412n2, 413-415, 414n6

Dorje Shugden (T. Rdo rje Shug ldan) dismissal from the Geluk pantheon by the Fourteenth Dalai Lama 123 and Tibetans in Gyelthang $\quad$ 123-124

Drakteng (Brag steng) cycles of poverty and disempowerment exemplified by Khampa farmer Peldengyel 255-257, 260-261, 269, 271-272

and the eighteen kingdoms of Gyelmorong 339n2

Han migrant population in $\quad 260-261,268$, 272

Drango (T. Brag mgo; Ch. Zhanggu 章

谷), localization at the time of Jagö

Topden 369map11.1

Drebö (Bre 'bod) family

dispute with families in Menshö $\quad 387$

Drebö Lhagyel's assassination $\quad 386-387$, $386 n 49$

Dreyfus, Georges $\quad 94,96$

Drichu River (T. 'Bri chu; Ch. Jinsha 金沙 [upper Yangtze])

as the border between Central Tibet and China proper (1727) 20

as the border between the T.A.R. and Sichuan (1955) 29

as the border marking Central Tibet's control in Kham (1918) 28, 92, 375-376 and the kingdom of Nangchen $459-460$, $471,472 \mathrm{f} 13.2$

Dzachu (T. Rdza chu; Mekong River) as the border between Central Tibet and China proper (1727) 20 and the kingdom of Nangchen $459-460$, $471,472 \mathrm{f}_{13} .2$

Dzayül (Rdza yül) and British incursions 204, 207 and the musk trade 157 and Zhao Erfeng's settlements 199-203

Dzigak (T. Rdzi 'gag), and the eighteen kingdoms of Gyelmorong 339n2

Eastern Tibetan People's Autonomous Alliance (T. Böshar gyümi mang rang kyong na tün; Ch. Dongzang renmin zizhi hui 东藏人民自 治会), establishment of 310,417 economic inequality $255^{-2} 74$ passim 
and C.C.P. implemented reforms targeting ethnic minority areas $\quad 420-421,424$ and land reform in Gyelthang $\quad 426$ 430,43 on $38,435,435 \mathrm{n} 46$ and political tourism $\quad 425-427,436-437$ and the rise of the developmentalist state $147-149,244-245,257,260-265$, 271-274

Ekvall, Robert 291

elites

and political persuasion exerted on

Khampa leaders $\quad 310,412,427,436-438$ see also Jagö Topden; tusi 土司 (native

office system); Wangchuk Tempa

Elliot, Mark C. $\quad 5^{1 \mathrm{n}} 7$

encampments (chögar [chos sgar])

and the revitalization of Buddhism in

contemporary Tibet 96,512

and the case of nunneries $501-504,512$

environment

adaptation to ecological conditions in

Songpan (northern Sichuan) 6o, 144, 147,316

and the 'Great rivers project' led by The

Nature Conservancy (T.N.C) 65

and toponyms $45^{-47}$

see also biopolitics; topography

Epstein, Lawrence $\quad 5^{2,217}$

ethnicity

'ethnographic Tibet' as a term $\quad 45,5^{8}$

and the fixing of boundaries by institution-

al and state power structures 121n10, $430 n 38$

and the idea of pan-Tibetan nationality 91

and identity dynamics $10,51,86,128$

and inequality $147-148,244-245,257$,

260-262, 271-274, 420-421

romanticization of $\quad 64-66$

and special ethnic zones (S.E.Z.) 65

see also Khampa rule of Kham; identity

farming

and agrarian nationalism $\quad 221,223,225$, $227,232,245$

agricultural colonization effort launched

by Fengquan during the Qing 192, 192nn10-11

agricultural production

and the C.C.P.'s first Five Year Plan 429

and cycles of poverty $196-197,256-260$

scientific analyses of Kham's growing

conditions 226

experimental stations run by the

B.A.I. see under Simaqiao; Taining

and Han dynasty yimin shibian 移民

實邊 ('settle people to support the

border') 187-188

and improvements promised by the Khampa

rule of Kham movement $\quad 379,417$ trade as a supplement to $155,256-257$

Zhang Yunping's 'Tunken Recommendations' 222-223, 225, 230-231, 237, 283

Zhao Erfeng's settlement endeavour in

Kham 199-202, 20omap5.2, 204

Fischer, Andrew $\quad 258-259,261$

Foreign Missions Society of Paris see

Missions Étrangères de Paris (M.E.P)

Foucault, Michel

notion of heterotopia $\quad 66-67$

on the regulatory power 147,499

four big indigenous chieftains (si da tusi 四大 土司)

allegiance to the Qing emperor $\quad 52,289$

see also Bathang; Chakla; Dergé; Lithang

'Four Rivers, Six Ranges' (Chushi Gangdruk)

resistance army $94,324,325 \mathrm{n} 19,328,527$

frontiers

and borderlands: the complex cultural

'matrix' of the Sino-Tibetan border-

lands $52-53,61,61$ f1.1, 70, 314

'frontier service' 63,220

and historiography $\quad 62-63$

and indigenous narratives of

place-making $\quad 59-62$

and Kham as a zone of contact $39,43-44$,

$5^{2}, 68-71,307$

and nation building in the republican

period 63-64

vernacular terms for 88

gaitu guiliu see bureaucratization

Ganden Sumtseling (Dga'ldan sum rtsen gling) as a centre of identity-gravity in the region of Gyelthang 117,117nn3-4

construction of (1679) 22

and the Khampa Rebellions 431, 433-434

Wangchuk Tempa's as the leader of its bandit defense force 414

Ganden Sumtseling (Dga'ldan sum rtsen gling) - kangtsen (monastic colleges) 117, 117-118n 5

and the 'Shugden issue' 123-124

and territorial boundaries $124,128,130$

Gansu 甘肅

and the administrative divisions of the eastern borderlands of the Tibetan plateau 42

and the inclusion of the Kham frontier into

Chinese national space $58 \mathrm{n} 13,346,392$ and self-immolation by Tibetans 530 trade between Golok pastoralists and Muslims in 296 and tunken-style development $\quad 222 \mathrm{n} 6$

Gardner, Alexander $\quad 56,289 n 9,289 n 11$

Garjé region (Sgar rje), localization at the time of Jagö Topden 369 map11.1

Geluk (Dge lugs)

conversion of monasteries $\quad 21,466$ 
and influence in Gyelthang $\quad 413$

exclusion from Jamgon Kongtrul's intrasectarian map of Kham 56, $289 n 9$ monasteries see Ba Chöde; Döndrupling; Ganden Sumtseling and the rimé movement $\quad 327$ see also Dalai Lamas; Panchen Lamas

Germano, David, on post-Mao Tibetan revivalist practices $\quad 459$

Gesar tradition historical appropriation of $45^{6,45^{8}}$ revitalization of $101,102 \mathrm{f} 2.3$

Géshitsa (Dge shis tsa), and the eighteen kingdoms of Gyelmorong 339n2

Geza 格咱 (T. Ketsak [Skad tshag]) 418n16 anti-Shugden areas of 124 and Chinese mining operations $\quad 127,131$ and local identity $\quad 130-131$ and Buddhism 131-132 and Wangchuk Tembu $412 \mathrm{n} 2$

Giersch, C. Patterson $\quad 60,316$

Goldstein, Melvyn C., peaceful democratic reforms distinguished from land reforms in China 429n37

Golok ('Go Log or Mgo log) drokpa (pastoralists): self-identification of 291-292, 296-297 Lung Ngön monastery (Lung sngon dgon pa) $95-96,97$ song recorded by Namkhai Norbu 91

Gomé (Mgo smad), and the eighteen kingdoms of Gyelmorong 339n2

Gönpo Namgyel (Mgon po Rnam rgyal) and Dergé $\quad 371,371 n 19$ Jagö Topden compared with $\quad 309,366$ regions south of his control 121 rise of $24-26,56,290,5^{28}$

Gotang (Mgo 'thang), and the eighteen kingdoms of Gyelmorong 339n2

Gotö (Mgo stod [east of Dartsedo]), and the eighteen kingdoms of Gyelmorong 339n2

Great Western Development Strategy (Go West) (xibu dakaifa 西部大开发) 148, 286, 286t8.1

Gruschke, Andreas $\quad 469$

Gushri Khan Khan (1582-1655) 21, 465-466

Gutschow, Kim 505

Guyot-Réchard, Bérénice 307

Gyelkha (Rgyal mkha), and the eighteen kingdoms of Gyelmorong 339n2

Gyelmorong (T. Shargyelmo Tsawarong [Shar rgyal mo tsha ba rong])

communist presence from 1935 to 1936 in 344

eighteen kingdoms of $339 n 2$

and the establishment of Xikang province $354 \mathrm{n}_{3} 6$ see also Chakla; Drakteng; Trokyap

Gyelrong (T. Rgyal rong; Ch. Jiarong 嘉线)
Jinchuan campaigns in (1747-1749 and 1771-1776) 20, 23

military agricultural colonies established by Lu Chuanlin in $\quad 186-187$

Gyelthang (T. Rgyal thang; Ch. Da Zhongdian 大中甸)

Communist Party Rule in $\quad 411-438$ passim

and C.C.P. implemented reforms targeting ethnic minority areas $\quad 426-430,430 n 38$

Dongwang (Termarong [Gter ma rong]) distinguished from $117-118 \mathrm{n}_{5}, 118-119$, 119-120n8, 123

and Dorje Shugden practice $\quad$ 122-123

Fifth Dalai Lama's control over 21-22, 412-413

and Khampa identity $\quad 116-117,125-128$

localization of 43 map1.1

monasteries in see Ganden Sumtseling

rebellion against taxes imposed by the

Chinese Nationalist army $\quad 414-415$

and the Red Army $\quad 416,416-417 n 14$

Tenth Karmapa's flight to (1647) 21

as a territory $\quad 118-122,118 \mathrm{n}_{7}, 120$ map3.1 and Shangri-La County (Ch. Xianggelila xian) $64-67,116,119,122$

and tourism $\quad 64-65,103-104$ see also Geza; Sanba; Wangchuk Tempa

Hämäläinen, Pekka, and Samuel Truett 68

Hansen, Thomas Blom, and Finn Stepputat 59

Harrell, Stevan 122n12, 284n4, 436, 455

Hayes, Jack P. 6o, 144, 147, 316

historiography

alternatives to histories found in official records 12

and kingship narratives and cosmologies $310,454-460,481$

and frontier studies $\quad 50 n 6,62-63$

official and unofficial middle ground distinguished 60

terminology vernacular terminology used to define the borderlands $\quad 51,87-89$

Western terminology used to discuss political formations $\quad 58-59$ see also middle ground

Holmes-Tagchungdarpa, Amy $56,461,481$

Huber, Toni 86

identity

and the advent of the nation-state in the early twentieth century $27-28,529$ and the concept of Sino-Tibetan 'borderland' 62, 68-69, 116-117 and homeland (phayül [phayul]) 45-46, 127-128

and 'true Tibet' found in a body of religious and cultural practice $69 \mathrm{n} 22$ 
and nangpa (Tibetan Buddhist insiders) vs. chipa (non-Buddhists) 94

and the reconstruct the traditional mythical-religious elements $45^{8}$, $477-478$

and the revitalization of the Gesar tradition $101,102 \mathrm{f} 2.3$

and the revival of Tibetan scripture in the Dechen region 103

and the term Ü-pas 90

see also Khampa identity; ethnicity

- and mnemonic practices $453-454,465$,

$475-476$

and cults to local territorial deities $\quad 57-58$

and kingship and local identity in

Nangchen $\quad 465-473$

and the successive revivals of Barom Kagyü and Kumbum 461-465

imperialism

and the British

East India Company rule in India $\quad 23$ 25,320

and Great Game politics $\quad 188,524$

Tibet invaded by $\quad 24-26$

see also bureaucratization; colonialism

Jagö (Bya rgod) family

benefits granted by the Thirteenth Dalai

Lama to $374-375$

Drebö family suppported by 386

Jagö Topden (Bya rgod Stobs ldan)

account of the rise of 363-394 passim

and Atup chief Wangga's (Dbang dga'a)

assassination $\quad 385-386$

Miser Gyelkhap (T. Mi ser rgyal mkha, The People's Nation) proposed by 387 power and authority of the Dergé royal family compared with $\quad 387-388$ support for the Communist Party and the Chinese central government 389 and the title of the 'hundred-year-king' (gyalo gyelpo) $\quad 387,478$

Jamyang Pelmo ('Jam dyangs dpal mo) and Jagö Topden $\quad 386,388-389,389 n_{57}$ marriage to Tsewang Düdul $377 \mathrm{n} 31$ political appointments in Xikang and Kangding 389-39o,39on 58 as regent Urgyenkyap (heir to the Dergé throne) $\quad 385-386$ support for the Communist Party and the Chinese central government 389

Jigme Püntsok ('Jigs med phun tshogs) 96

Jinchuan 金川, Qing military campaigns in (1747-1749 and 1771-1776) 20, 23, 186, $35^{1}$

Jomda ('Jo mda')

localization at the time of Jagö

Topden 369map11.1 occupation by Lhasa troops $\quad 375-376$ Jyekundo (T. Skye dgu mdo) (Yushu) and the Dru clan 460

Gesar monument in $45^{8}$

localization of 18 map1, 43 map1.1 and Sino-Tibetan trade in the late

$1940 \mathrm{~s} \quad 322$

and tourism 103-104

see also Nangchen

Kangding 康定 see Dartsedo (T. Dar rtse mdo)

kangtsen (khang tshan) monastic colleges and Dongwang 117-118n5,119-120n8

Wangchuk Tempa's study at Sera 414 see also Ganden Sumtseling (Dga'ldan sum rtsen gling) - kangtsen (monastic colleges)

Karma Kagyü (Kar ma bka' brgyud) encampments (chögar) associated with 96

the Fifth Dalai Lama's suppression of 413 and Zhongdian county $123 n 14$ see also Barom Kagyü

Karmay, Samten $\quad 89 n 12,476$

Kelzang Tsering (T. Bskal bzang tshe ring; Ch. Gesang Zeren 格格桑泽仁) and the emergent elite in Batang 364 , $364 n 3,391$

Khampa rule of Kham launched by (1932) 29, 379, 415-416

Xikang ambitions of $\quad 338-339 n 1$

Ketsak (T. Skad tshag) see Geza

Kham (Khams)

celebrity of Khampa singers $\quad 102$

four big indigenous chieftains (si da tusi) see Bathang; Chakla; Dergé; Lithang

'four rivers, six ranges' (chushigangdruk) as a designation $46,281 \mathrm{n} 1$ rivers of see Chichu; Drichu; Dzachu; Machu

'Four Rivers, Six Ranges' (Chushi Gangdruk) resistance army set up by Gönpo Tashi Andrutsang $31,56,94,324,325$ n19, 328,527

size and demographics of $\quad 42,43$ map1.1 see also Gyelmorong; Gyelrong; Gyelthang; Nangchen

- territorialization $18 \mathrm{map} 1$

deterritorialization of the exiled community in Kham 44-45, 525, 528-529 as a discontinuous landscape of kingdomcentred realms $\quad 338-339$

incorporation into the P.R.C. $\quad 5^{18}$ and its spatio-temporal variation as a place surrounded by two power centres 20 , 37-39, 47-52, 307, 517-520

'Chinese Tibet' distinguished from 'Tibet proper' by the Vicariate of Tibet 153 
and the local institution of kingship $454^{-}$ 455,461

see also Bumla (Ningjing shan) stele marking the border between China and Tibet; Xikang Province

Khampa identity

Böpas (Tibetans from Central Tibet) distinguished from $\quad 91-92$

and the creation of the resistance army in 195894

geopolitical layers of $\quad 5^{25} 5^{-529}$

and Lhasa and Central Tibet $87,91-93$

and Minyak Drokpa $\quad 282-283,287-289$, 291-292, 297-300

and the threat of Sinicization $\quad 98-99,104-105$

and the Tibetans of Gyelthang 116-117, 125-128

and vegetarianism $\quad 97,292-293$

Khampa rule of Kham (T. Kangpé rangsi rangkyong or Kangpé rangdé rangpön; $\mathrm{Ch}$. Kangren zhi Kang 康人治康)

Jagö Topden's changing allegiance towards it $378-380$

and the idea of Miser Gyelkhap (T. Mi ser rgyal mkha, The People's Nation) $\quad 387$

Kelzang Tsering's launching of (1932) 29, $379,415-416$

and Kham's discontinuous landscape 338

and the logic of national autonomy 309 , $364 n 3,366-367$

and the ninth Panchen Lama $379-380$

second movement launched by Gara Lama

(Nörla Hutuktu) (1935) 29, 324

Khampa traders

political and economic power of $313-329$ passim

see also Andrutsang (A 'brug tshang)

family; Khatag Dzamyag; Pangdatsang

(Spang mda' tshang) family; Sandutsang (Sa 'du tshang) family

Khatag Dzamyag (Kha stag 'Dzamyag), title tsongpön (chief-merchant) $317 \mathrm{n} 6$

kingship

and the authority of Buddha's teach-

ings $459,463,470-471,477$

as an axis for an imagined pan-Tibetan

community 482

and the charisma of royalty 478

and the designation dé (sde, region) $\quad 472-474$

and the production of place in

Kham 454-455

and the production of place in Lhatok 461 , 470

see also Dergé (T. Sde dge; Ch. Dege 德

格) - Royal family; Nangchen (T. Nang chen) - kingship

Kumbum (Sku 'bum)

as a local religious-secular power

center $462,464,474$ destruction of 465

founding by Repa Karpo $\quad 461-462$

Kyodrak (Skyo brag) monastery 474

Larung Gar (Bla rung gar)

demolition of monastic dwellings in $96 \mathrm{n} 32,311$

and Jigme Püntsok 96

and vegetarianism $\quad 292-293$

Lattimore, Owen $\quad 49,58-59,296$

Lawson, Joseph D. 148, 225

Leach, Edmund $\quad 58$

Leibold, James $\quad 63 n 18,349,438$

Lewis, Martin W. and Kären E. Wigen $\quad 78$

Li Anzhai 62-63

Lijiang 丽江 18 map1

bandit raids in $415,415 \mathrm{ng}$

and the Great Shangri-La Eco-Tourism

Zone 66mapi.4

Jang kingship defeated by the

Mongols 290

and long-distance trade in Kham $\quad$ 266-267

Tenth Karmapa's flight to 21

Lithang (T. Li thang; Ch. Litang 理塘)

Jamchen Chokholing's economic dominance $\quad 272-273$

localization of $18 \mathrm{map} 1$ at the time of Jagö Topden $\quad 369$ map11.1 as one of the four big indigenous chieftains (sidatusi) $5^{2}$

Zhao Erfeng and Ma Weiqi's campaign against $\quad 265$

Long March

in the Kham region $29,343,380,416 \mathrm{n} 12$, 417

and Wangchuk Tempa 416

in Yunnan 416n12, 424

Lu Chuanlin 146, 183-186, 188-189

Lung Ngön monastery (Lung sngon dgon pa) $95-96,97$

Lungu (T. Lungdgu; Ch. Wenchuan 汶 川), and the eighteen kingdoms of Gyelmorong 339n2

Macdonald, Alexander $\quad 57 \mathrm{n} 12$

McGranahan, Carole $\quad 57,143,45^{8}$

Machu (Rma chu), and the kingdom of Nangchen $471,472 \mathrm{f}_{13} .2$

Maconi, Lara 65

Makley, Charlene E. $\quad 55,64,505$

Mao Zedong

and the C.C.P.'s first Five Year Plan 429

meeting with the Fourteenth Dalai Lama (1955) 31

margins

and forms of illegibility and partial

belonging $283,287,297-299$

see also borderlands; centre and periphery relations; frontiers 
Markham (Smar khams) localization of $18 \mathrm{map} 1$ at the time of Jagö Topden 369 map11.1 Pangdatsang family in 319,364

Renou's travels in 158,160

Merkel-Hess, Kate 222

Michaud, Jean 53

middle ground

and adaptation to ecological conditions 60 borderlands as 315

and models proposed by Mark Lewis and

Kären Wigen $\quad 52-53,70$

between the nomadic and the industrial in Zhang Yunping's agrarianism 223 'official' and an 'unofficial' middle ground distinguished 60 and Richard White's scholarship

Minyak (Mi nyag) region

and Kyodrak monastery 474

pastoralism in 281-300 passim

and the six highland ranges in the designation 'four rivers, six ranges' (chushi gangdruk) 46n3, 281n1

missions and missionaries

and access to Tibet $\quad 25$

the Dalai Lama's decree against Christian missionaries 162

French Catholic mission in Tibetan Kham

areas 145-146, 234

mission in Dartsedo $\quad 25,171-172,234$

J.H. Edgar 196

Johan Lossing Buck 219

and Kham-centered histories $\quad 528$

see also Desgodins, Auguste; Missions

Étrangères de Paris; Renou, Charles

Missions Étrangères de Paris (M.E.P., Foreign

Missions Society of Paris)

and French diplomacy 154

missions in the Sino-Tibetan border-

lands $163-165,164$ map4.1

and violent rioting in Bathang 25

and Qing protection based on the Treaty of

Tianjin 161-163

and smallpox vaccination in Tibetan areas 172

and trade $145,151-175$ passim

see also Desgodins, Auguste; Renou, Charles

monastic communities

administrators of 464

and contestations for power and authority

in Kham 364

and Work Teams (Ch. gongzuo

zu) $\quad 497 \mathrm{n} 7$

and gender asymmetries $\quad 505$

and monastic taxes (sertrel) $\quad 467$

nuns

lower status of $\quad 505$

relationships with their families 503n17 see also Ba Chöde; encampments; Ganden Sumtseling; Kumbum; Lung Ngön monastery; Yachen Gar

Mongols and Mongolia

Altan Khan confers the title of Dalai Lama on Sönam Gyatso 21

and the Fifth Dalai Lama's unification of Tibet 19

Gushri Khan's support of Nangchen's war on the Beri armies $\quad 465-466$

Jang kingship in Lijiang defeated by 290

Mongolian People's Republic founded (1924) 28

Nangchen's implementation of Mongol administration 462

Quoxot Mongols see Qoshot (Qoshot Khanate or Quoxot Mongols)

Zunghars see Zunghar Mongols

Muchi (T. Mu phyi), and the eighteen kingdoms of Gyelmorong 339n2

Mueggler, Erik $122 \mathrm{n} 12$

Nangchen (T. Nang chen)

localization of $18 \mathrm{map} 1$

at the time of Jagö Topden 369 map11.1

Nangchen (T. Nang chen) - kingship

chanhu title bestowed on see qianhu千户

and historiographic practice $455-459$, 481

and the Hui Ma clan 478

and identity $310,453-482$ passim

kurim (sku rim) ceremony $475-477$

and the production of place 454-455, 460-464

reign of Wangdrak Tsering Lhagyel (Dbang drag Tshe ring Lha rgyal) $\quad 478,480$ see also Trashi Tsewang

Nangchen (T. Nang chen) - socio-political

structure

and the Barom Kagyü $\quad 462-463$

and the Indic cosmological model of organizing society $\quad 469-470$

and Mongol administrative structure $\quad 461-462$

as a region of meditators (retsang gomdé [rastshang sgom sde]) 471-473

nationalism

'agrarian nationalism' 221, 283

and the idea of pan-Tibetan national-

ity $91,94,125$

and the role of Buddhism $\quad 5^{6 \mathrm{n} 11}$

and the 'self-rule' movements of the 1930s $\quad 5^{6-57}$ and Western terminology $\quad$ 58-59 see also sovereignty

Naxi and Naxi regions and C.C.P. implemented reforms in Gyelthang 121n10, 430n38 see also Sanba 三坝 
Ngor E wam chöden, Khatag Dzamyag as a trade agent for a labrang of $317 \mathrm{n} 6,320-321,321 \mathrm{n} 12$

Norbu, Jamyang, on laudatory and mythic terms for Wangchuk Tempa $\quad 412 \mathrm{n} 2$

Nulo, Naktsang 93

Nyarong (Nyag rong)

implementation of gaitu guiliu in $\quad \mathbf{1 8 5}$

localization of $18 \mathrm{map} 1$

at the time of Jagö Topden 369 map11.1 see also Gönpo Namgyel (Mgon po Rnam rgyal)

Nyingma (Rnying ma) school

in Dongwang $117 \mathrm{n}_{5}, 119 \mathrm{n} 8$

forced conversion of adherents to the Gelukpa school 21

Oakes, Timothy S. $\quad 44,65^{-66}$

Okzhi ('Og gzhi), and the eighteen kingdoms of Gyelmorong 339n2

Oppenheim, Robert 66

Outer Mongolia, and tunken-style development $222 n 6$

Paasi, Ansi and Jonathan Metzger $\quad 71$

Padmasambhava 95

beyül (T. sbas yül) valleys hidden by $97^{-}$ 98,311

and the Dru 460

and Yachen 498ng

Panchen Lamas - ninth Panchen Lama and armed clashes with Liu Wenhui in Kandzé 380

Central Tibet's reach into Kham resisted by 338

exile in China (1924) $\quad 28$

and Khampa rule of Kham $\quad 379-380$

Panchen Lamas - tenth Panchen Lama travels with the Dalai Lama to meet Mao Zedong (1954) 31 travels with the Dalai Lama to India (1956) 31

death of (1989) $3^{2}$

Panchen Lamas - eleventh Panchen Lama, dispute over the choice of (1995) 33

Pangda Topgyé (Spang mda' Stobs rgyas/Spom mda' Stobs rgyas)

and Jagö Topden $\quad 384,389$

and the 'Khampa rule of Kham' movement 324, 379

Pangdatsang (Spang mda' tshang) family active involvement in Sino-Tibetan relations $\quad 364-365$

and Khampa trading communities in Central Tibet 319

official positions in the Lhasa government held by 324

Pangdatsang Nyigyel's economic pragmatism toward monastic institutions $\quad 327$

Rapga Pangdtsang $\quad 328$
Parker, Bradley $\quad 44,60-61,61 f 1.1$

pastoralism

and Chinese state policies $\quad 148,286 \mathrm{t} 8.1$

in Golok 291, 296

and the grassland ecology of Kham $\quad 240,245$

and mumin (herder) as a category $\quad 284$ -

$287,294-295,299$

pastoral movements $\quad 291-292,291 \mathrm{t} 8.2$

in Qinghai $\quad 296$

regional trade as a supplement to 155

pathways

and efforts by nuns at Yachen to escape spatial control $487-500,512$

and imperial governance 144

and trade networks along Khams 'four rivers, six ranges' (chushigangdruk) $\quad 46$

Pawang (Dpa'dbang), and the eighteen

kingdoms of Gyelmorong 339n2

Pelyül (Dpal yül)

localization at the time of Jagö

Topden 36gmap11.1

occupation by Lhasa troops $\quad 375-376$

Perdue, Peter C. $\quad 5^{1}$

place-making

and the 'idea' of Gyelthang $119,124-128$

and process-oriented spatial forma-

tion $41-42,68-72,314,454-455$

and toponyms 47

see also centre and periphery relations; frontiers; identity - and mnemonic practices; Kham - territorialization; territorialization

political tourism see under tourism

Pommaret, Françoise 86

Prins, Marielle $\quad 476$

Püntsok, Tubten $376 \mathrm{n} 28$

qianhu 千户 (Tib. chan hu, chiliarch, com-

mander of a thousand men)

as a Manchu title 466

and Nangchen contemporary negotiations

of the local past $\quad 467$

and Nangchen Dorjé Tséwang (r. 1680-1734) 466-468

and Nangchen kings during the Maoist error 467

Qinghai 青海

and the administrative divisions of the eastern borderlands of the Tibetan plateau 42

discovery of the Fourteenth Dalai Lama in (1937) 30

Golmud-Lhasa railroad constructed in 33

Guomindang's establishment of (1928) 29 and the inclusion of the Kham frontier into Chinese national space $47,49-5^{\circ}$, $58 n 13,346,392$

nomadic pastoralism in 296

self-immolations in $\quad 529$ 
tea trade networks $\quad 264,316$ and tunken-style development $\quad 222 \mathrm{n} 6$ see also Jyekundo (Yushu); Nangchen

Qoshot (Qoshot Khanate or Quoxot Mongols) and the Fifth Dalai Lama's control over

$$
\text { Gyelthang 21-22 }
$$

Lhazang Khan as the chief of 22

and the Nangchen 465,473

rule over most of Amdo (1636-1724) 21

Rafael, Vicente L. $\quad 473-474$

Ramble, Charles $\quad 470$ regions

and dé (sde, region) in the ascription of

'Nangchen the region of meditators'

(nangchen gomdé) 471-474

'four rivers, six ranges' (chushigangdruk) as a designation $\quad 46,281 n 1$

and heterotopic space $\quad 65,472$

and identity $127-128$

Kham as regional category $\quad 54,71-72,315$

and the spatialization of sovereignty 54

'three regions of Tibet' (chölkha sum) 45, 57

Tibet as a macro-regional category 45

and Zomia as a heuristic $\quad 53-54,70$

religion

and Jamgon Kongtrul's intra-sectarian map of Kham 55-56, 288-289, 289ng

local religious-secular power centers 462 , 464,474

religion - revival of religion and traditional

practices

in Amdo 94-98

emergence of treasure-revealers (ter-

tön) $96,311,498$ ng, 498

encampments 96,311

and local dynamics in Kham 11

and re-codifying local identity 103,459 , $477-478$

and rimé (ris med) values $\quad 96,327,327 \mathrm{n} 22$

Ren Naiqiang

on the French Catholic mission in Tibetan

Kham areas 145,234

on Jagö Topden $\quad 386-387$

Khampa stereotypes of 64

'sightseeing' (guanguang 观光): and political tourism proposed by $425-426$

on Zhao Erfeng 220-221

Renou, Charles

death of 162

on long-distance trade

in Tibetan areas $\quad 155$

in Yunnan 158

purchase and conversion of child slaves proposed by 159

and smallpox vaccination efforts in Tibetan areas $172 n 37$ on taxes and corvée labour burdens 154

'trade' by

in Chamdo $151^{-152,157-158}$

in Yunnan $\quad 158-159$

Tsarong land acquired and developed by $160-162,174$

Rock, Joseph $\quad 86,415$ n9

Rodman, Margaret C. 52

Rodseth, Lars 44

Rongpatsa (Rong pa tsha) $\quad 28$

Sahlins, Marshall 464

Sakya (Sa skya) school

and the Dergé royal family $\quad 370,371 n 17$

and the Sakya-Yuan hierarchy $463-465$, 468

Salzman, Philip C. $\quad$ 295n12, 296

Samuel, Geoffrey 57

Sanba 三坝

Dorje Shugden practice 124

location in Gyelthang 12omap3.1, 121

rebellion in 423

Sandutsang (Sa 'du tshang) family

and Khampa trading communities in

Central Tibet 319

and Khatag Dzamyag $\quad 318-323$

Lo Gendun Sandutsang $\quad 328$

official positions in the Lhasa government held by 324

Rinchen Dorje as an agent of 321

wool exports to the United States and England 322

Scott, James C. $\quad 53,232,284-285,459,511$

self-immolations $33,100,100 n n 37-39,490-491$, 529-531

'Seventeen-Point Agreement'

the Dalai Lama's denouncement of (1959) 32

and the incorporation of Central Tibet into the People's Republic of China (1951) 31

and Khampa Rebellions of

1955-1957 431-432

Shakya, Tsering $90,435^{n} 46,529$

Shangri-La

and the Great Shangri-La Eco-Tourism

Zone 66mapi.4

as heterotopia $\quad 66-67$

and Qiu Zhijie's 'Map of the World' series $\quad 65^{-66}, 67 \mathrm{f}_{1.2}$

and Shangri-La County (Ch. Xianggelila xian) $64-67,116,119,122$

Shen Congwen 沈從文 64,66

Shneiderman, Sara 86

Sichuan see also Dartsedo

Sichuan Frontier Special Administrative

Region (Chuanbian tebie xingzhengqu,

S.A.R)

establishment of (1914) 28, 205-206 
renaming as Xikang Special Administrative

Region 28, 206n22, 341

Simaqiao 馮馬 橋

experimental station in $\quad 233-237,233$ map6.1

Taining station compared with $238-240$, 242

southeast Kham the focus of 242

and the Xikang Provincial B.A.I. $\quad 231$

Simla Convention (1913-1914) 28, 48-49

failure of $28-29,205-206,341$

and the McMahon Line 32

and the labels 'Outer Tibet' and 'Inner

Tibet' 49, 49map1.2, 92, 205

and R.O.C. territorial claims $183,184,199$, 207-208

slavery $154,159,187-188,416 \mathrm{n} 14$

slave as a class label $\quad 429-430$

Smith, Jonathan Z. 118, 128-135

sovereignty

Indian Buddhist ideas of an ideal sovereign $\quad 459,463,469-471$

regions as the spatialization of 54

and territorial distinction between China and Tibet 48

and the Treaty of Westphalia (1648) 21, $27-28,55 \mathrm{n} 10,146$

zones of mutual interest $\quad 5^{8-59}$

see also 'Seventeen-Point Agreement'; Simla Convention

space

the borderlands as a process-oriented spatial formation $\quad 314-315$

and legibility 48

and state imposition of geometrical

control on Yachen Gar 507-512, $509 f_{14.5}$

and the maze of Yachen Gar $\quad 487-500$, 500 f 14.3

and regulatory power in modern society $147,499,511$

and sovereignty

and mapping $\quad$ 128-129

and narrative maps $\quad 56,288-289$

and territorial integrity $\quad 54-55$

see also borderlands; frontiers; margins; middle ground; pathways; placemaking; regions

stele (1727) see Bumla (Ningjing shan 寧静山) stele marking the border between China and Tibet

Stoler, Ann 143

Sulang Jiachu 432

Sumtseling see Ganden Sumtseling

Sun Yat-sen

and autonomy status granted to border areas 356

Republic proclaimed by 341,347

Three Principles of the People 417
Tafel, Albert $\quad 467$

Taining 泰寧

experimental station in 233map6.1

and the Xikang Provincial B.A.I. 231-232, 237-243

Tambiah, Stanley J. $\quad 469-470$

Teichman, Eric $\quad 28,289,289 n 11$

Tenpa (T. Bstan pa), and the eighteen kingdoms of Gyelmorong 339n2

Termarong see Dongwang

territorialization

and boundary-making in the Sino-Tibetan borderlands $37-38,55-57$

and the disputed frontier zone of NorthEast India 202-205, 307

and dynamic and heterogeneous processes of intervention $\quad 68-72$

of Kham see Kham - territorialization see also centre and periphery relations; frontiers

Tibetan Communist Party see Eastern Tibetan People's Autonomous Alliance topography and boundaries $\quad 47,5^{0-51,70}$ republican period surveys of the frontier 63 topology and the Möbius strip $\quad 70-71,71 \mathrm{f1} \cdot 3,492$ reconfiguration of the Sino/Tibetan binary $44,54,69-72,71 \mathrm{f} 1.3,132,314$

toponyms

borderlands as places to be defended or to be made civilized $\quad 51,89,181$

Dokham used for the Sino-Tibetan borderlands 45

and the expression khamkyi gyeltren (khams kyirgyal phran), 'the small principality on the border' 88

'four rivers, six ranges' (chushigangdruk) as a designation for Kham $46,281 \mathrm{n} 1$

and identity $\quad 46-47$

and the invention of Zomia $\quad 53-54,70$

tourism - political tourism

the creation of special ethnic zones 65 , $65 \mathrm{n} 20$

and economic inequality $\quad 425-427,436-437$ use with 'political persuasion work' to control Gyelthang 412, 436-437

and efforts to win over and transform ethnic minority leaders $\quad 424-426$ and the Great Shangri-La Eco-Tourism Zone 64-66, 66map1.4 and Ren Naiqiang's civilizing logic $\quad 425-426$ trade

and bachong 壩充 facilitators $\quad 268-270$

British military expedition into Lhasa forces a trading agreement (1903-1904) 24, 26

local networks: and resistance to interventionist policies $144,261,271-273$ 
long-distance trade in Kham and Lijiang $\quad 266-267$

see also Dartsedo - trade and commerce in

Ma Bufang's embargo on pastoral products from Golok 296

and medicinal materials $\quad 256,262$, 267-272, 296

and musk (shexian 摩香) $157,172,256$, 262, 268-269, 272, 296

regional trade as a supplement to agriculture and pastoralism 155

and the M.E.P.'s engagement with

Tibet $153-157,167-168$

re-emergence of networks 148

salt exchanges $155,165,263,272$

tea-trade 266

and British Indian trade with

Tibet $\quad 166-169$

networks in Qinghai $\quad 264,316$

transformative power of traders $\quad 316-317$, 320-323, 328-329

see also Khampa traders

Trashi Tsewang (Topgyel) Dorjé (Bkra shis Tshe dbang Rdo rje) $\quad 457 f_{13} .1$ and the communist takeover of Nangchen $\quad 458-459,478-480$

death of 477

as the nominal head of the Tibetan People's

Autonomous District of Yushu or Upper

Kham 480

Travers, Alice 319

Trokyap (T. Khro skyabs; Ch. Chuosi jiabu 绰斯 甲布) kingdom

and the authority dispute between Sichuan and Xikang (1930s-1940s) 309, 337-356 and the eighteen kingdoms of

Gyelmorong 339n2

localization of 345 mapio.1

submission to the Qing (1700) 22

Tsenla (Tib. Btsan lha; Ch. Xiaojin 小

金), and the eighteen kingdoms of

Gyelmorong 339n2

Tsewang (Tshe dbang, wealthy person in the Tsarong district) $\quad 160-162$

Tsewang Düdül see under Dergé (T. Sde dge; Ch. Dege 德格) - Royal family

Tsomu, Yudru $60,64,105,157,414 \mathrm{n} 7,426 \mathrm{n} 13$, 467,469

Turek, Maria M.

on Nangchen as a self-referential sphere $\quad 315$

on rimé masters $\quad 327$

Turner, Frederick J. $\quad 51 \mathrm{n} 7$

tusi 土司 (native office system)

the C.C.P.'s suspicion of 421,427

and the denigration of Khampa kingship narratives $45^{8}$ dismantling of 435

and 'hereditary officials' 289n11

and indirect rule of the borderlands by the

Qing 143-144

Jagö Topden's opposition to 387

see also four big indigenous chieftains (si da tusi)

Tuttle, Gray $\quad 56 n 11$

Van Schendel, Willem 53

Van Spengen, Wim 414n8

Vasantkumar, Chris $69 n 22$

vegetarianism 97, 292-293

Wang Chuan 244

Wangchuk Tempa

and the consolidation of C.C.P.'s rule in

Gylethang $\quad 411-438$ passim

early life of 413-414

Jagö Topden compared with 394

militia of

establishment of $\quad 415-416$

and the Red Army $\quad 416-417,422 n 26$

and the peaceful liberation of

Gyelthang 421-424

political persuasion exerted on 412,427 , $436-438$

Wangdrak Tsering Lhagyel (Dbang drag Tshe ring Lha rgyal) 478,480

Wang Xiuyu 146, 225

Wu Wenzao 62

Xianggelila xian 香格里拉县 (Shangri-La) see Gyelthang

Xikang Province (Xikang xian 西康

县) 233 map6.1

as a term for Kham before its official

establishment $415^{\mathrm{n} 10}$

borders in 1933 and $1939 \quad$ 5omap1.3

dismantling of (1955) 29, 31

establishment of (1939) 29-30

and the 'frontier reconstruction' spirit $\quad 63-64$

Kham region incorporated into it $\mathbf{2 2 0}$ tunken development in 222n6, 224-227 see also Simaqiao; Taining; Trokyap

Xikang Special Administrative Region (Xikang tebie xingzheng qu) 28,206n22,341 see also Sichuan Frontier Special Administrative Region

Xining

and the Hui Ma clan $\quad 478$

tunken development in $222 n 6$

Xinjiang

as a region run by State Owned

Enterprises 259

and tunken-style development $\quad 180,198$, $222 n 6$ 
Yachen Gar (T. Ya chen sgar; Ch. Yaqing si 亚 青寺)

spatial arrangement of

perpetually incomplete maze of $\quad 487$ $500,500 f 14.3$

state imposition of geometrical control on $\quad 5^{07-512,509 f 14.5}$

and the Treasure (T. terma) tradition 311, 498ng

Yeh, Emily T. $\quad$ 46, 257-258, 261, 285, 309

Yunnan

expansion of Yunnan tea firms into Kham 265-267

Renou on long-distance trade in $15^{8}$

Renou's missionary 'trade' in $\quad$ 158-159

Second Red Army's Long March

through 416n12, 424

silver shortage in 161,264

see also Dechen; Gyelthang; Lijiang; Naxi
Zartman, William I. 87,105

Zhang Yunping's 'Tunken Recommendations' 222-223, 225, 230-231, 237, 283

Zhao Erfeng 趙爾豐

campaign against Bathang $\quad 25,195,265$

Dergé royal family led by Tsewang Drölma defeated by (1909) 374

execution by Sichuanese revolutionaries 265

settlement of Sichuan farmers in Kham 188, 195-202, 200map5.2, 204 as the Sichuan-Yunnan Frontier Commissioner (duban Chuan Dian bianwu dachen) 25, 27, 146, 183, 193, 264

Zhongdian 中甸 see Gyelthang

Zinda, John Aloyysius 65

Zomia concept $53-54,70$

Zunghar Mongols invasion and occupation of Lhasa (17171720) 20,22

rule over much of central Eurasia (1630s-1756) 21 